Conference Proceedings

DOKBAT

12th Annual International Bata Conference

for Ph.D. Students and Young Researchers

Conference venue

Tomas Bata University in Zlín

Faculty of Management and Economics

Mostní 5139 - Zlín, 76001

Czech Republic 
Copyright (C) 2016 by authors. All rights reserved.

The publication was released within the DOKBAT conference, supported by the IGA project. No reproduction, copies or transmissions may be made without written permission from the individual authors.

Many thanks to the reviewers who helped ensure the quality of the papers.

Edited by: Ing. Lukáš Danko, Ing. Markéta Slováková

ISBN: 978-80-7454-592-4

DOI: $10.7441 /$ dokbat.2016 
Expert guarantor of the conference:

Ing. Jana Matošková, Ph.D.

Manager and coordinator of the conference:

Ing. Filip Kučera

Members of the organizing team:

Ing. Zuzana Crhová

Ing. Lukáš Danko

Ing. Martin Horák

Ing. Tomáš Janů

Ing. Viera Pechancová

Ing. Markéta Slováková

Ing. Blanka Vytrhlíková 


\section{CONTENT}

DOES THE INTRODUCTION OF THE BOND MARKET REDUCE THE INTEREST RATE ON KOSOVO BANKING INDUSTRY?

FLORIN ALIU, ORKHAN NADIROV, DAWUDA ALHASSAN

THE ANALYSIS OF MANAGEMENT SYSTEM OF ECONOMIC DEVELOPMENT OF SUGHD REGION OF TAJIK REPUBLIC

Avezov Azizullo Khabibovich, Azimova Mashokhida Azalovna, Přemysl PÁlKa

GOVERNMENT DEBT MANAGEMENT, STRUCTURE AND ECONOMIC GROWTH:

INVESTIGATION OF THE VISEGRAD FOUR

PETER BAĎO.

THE ROLE OF CUSTOMER JOURNEY IN B2B CONTENT MARKETING

ELINA BAKHTIEVA

SOLVING BUSINESS DECISION-MAKING PROBLEMS WITH AN IMPLEMENTATION OF AZURE MACHINE LEARNING

Luis ANTONio Beltran PRieto And RavindRa Hewa KurupPuge 43

Perception of Risk and Managing Flood Disaster: a Case study of Rural Community in Czech REPUBLIC

MOHAN KUMAR BERA AND PETR DANĚK

FUNCTION OF INTEGRATED MARKETING COMMUNICATION AND ITS IMPACT ON CONSUMER BEHAVIOUR

VERONIKA BRACINÍKOVÁ

CHANGES IN COMPETITIVENESS OF THE CZECH REPUBLIC WITHIN PREVIOUS EU FINANCIAL FRAMEWORK

KRISTÝNA BRZÁKOVÁ

THE EFFECT OF CAPITAL STRUCTURE ON FINANCIAL PERFORMANCE

ALI IBRAHIM DASUKI

THE DETERMINANTS IMPACT ON CASH HOLDING: EVIDENCE FROM THE VIETNAMESE STOCK MARKET

DO THI THANH NHAN

BUDGETING PROCESS IN THE BUSINESS ENVIRONMENT

JIŘí DOKULIL

ETHICAL ASPECTS OF NEUROMARKETING

JANA DURĎÁKOVÁ

LINKING COMPONENTS OF THE SERVICE SYSTEM AND PERFORMANCE MANAGEMENT SYSTEM

FABIANOVÁ ZUZANA.

AGENT-PRINCIPAL PROBLEM, STEWARDSHIP THEORY AND BEHAVIOURAL AGENCY MODEL IN THE EXPLANATION OF FAMILY BUSINESS PERFORMANCE

GERGELY FARKAS

HUMANS IN THE FOCUS FOR OUTSTANDING INNOVATION

MARKUS H. GERICKE

BANK CAPITAL LEVERAGE: A SCHOLARLY LITERATURE REVIEW 
CLUSTER POLICIES AND INITIATIVES WITHIN THE SERVICE SECTOR - GOOD PRACTICES FROM EU COUNTRIES AND RECOMMENDATION FOR THE CZECH CLUSTER POLICY

MARTIN HORÁK

CRM SYSTEM IN SMALL AND MEDIUM-SIZED ENTERPRISES

ADÉLA CHROMČÁKOVÁ

POSITION OF LOGISTICS IN ORGANIZATIONAL STRUCTURES - TRENDS

JAN JAKEŠ 185

ENERGY FROM BIO-WASTE IN SLOVAKIA

JURAJ JAŠKA, NADEŽDA JANKELOVÁ 196

THE APPLICATION OF EXPECTATION MAXIMIZATION TO MANAGE MISSING DATA, BIASES VALUE-AT-RISK AND VOLATILITY MODELS IN FINANCIAL TIME SERIES?

GÁBOR DÁVID KISS, MARIANNA SÁVAI.

CREATING SHARED VALUE: OPPORTUNITY FOR DESTINATION MANAGEMENT IN THE CZECH REPUBLIC?

MAREK KOŇAŘíK

EU COHESION POLICY AS AN INSTRUMENT FOR THE DEVELOPMENT OF THE SMART CITY CONCEPT

FILIP KUČERA

EXPLORING REASONS OF PROJECT PROPOSAL REJECTION

ALOK KUMAR

THE IMPACT OF EARNINGS ANNOUNCEMENT ON CONSERVATISM IN VIETNAMESE FINANCIAL STATEMENTS

LE TUAN BACH

REGULATION, PRICING OF DRUGS AND PARALLEL TRADE IN CZECH REPUBLIC

TEREZA LUKÁŠOVÁ.

CONSUMER BEHAVIOR IN THE CONTEXT OF WINE TOURISM

LENA MALAČKA, JITKA VESELÁ

STATE HOUSING POLICY IN SLOVAK REPUBLIC AS THE MEAN OF STIMULATING DEMAND IN THE REAL ESTATE MARKET

DANIELA NEMCOVA

THE DETERMINANTS OF SATISFACTION WITH ONLINE GROUP-BUYING PURCHASES: AN EXTENDED PERSPECTIVE OF DELONE \& MCLEAN IS SUCCESS MODEL AND TRUST

PAVLÍNA PAWLASOVÁ

BEHAVIORAL ASPECTS IN RESIDENTIAL ENERGY USE

VIERA PECHANCOVÁ

CZECH MISSION STATEMENTS IN THE LIGHT OF 21ST CENTURY

PERNICA KAREL., TYLL LADISLAV...

INVESTMENT EFFICIENCY OF INVESTMENT INCENTIVES IN THE CZECH REPUBLIC

ŠÁRKA PINDOROVÁ.

STRUCTURE CREATION OF VALUE MANAGEMENT MAKING PROVISION FOR STAKEHOLDERS IN BUSINESS PRACTICE

TATIANA POTKANOVÁ, MÁRIA ĎURIŠOVÁ. 


\section{TALENT MANAGEMENT IN AN ORGANIZATION}

VĚRA RUBÁKOVÁ

USE OF CORPORATE SOCIAL RESPONSIBILITY FOR THE SUSTAINABLE DEVELOPMENT OF ORGANIZATION

ANUSUA SAHA

HOW CAN BE THE HOLISTIC MANAGEMENT USED IN THE CLUSTER ORGANISATION?

MARKÉTA SLOVÁKOVÁ

VALIDITY AND RELIABILITY OF PERSONALITY TESTS

BERNHARD STOCKER

MONEY ILLUSION AND THE EURO: DOES THE SINGLE CURRENCY LEAD TO SUB-OPTIMAL ECONOMIC CHOICES?

IVO STREJČEK

BASIC FINANCIAL LITERACY OVER DEMOGRAPHIC CHARACTERISTICS: A STUDY COMMERCIAL BANKS' CUSTOMERS IN VIETNAM

THI ANH NHU NGUYEN

THE USAGE OF SELECTED MODELS PREDICTING THE FINANCIAL CONDITIONS OF FIRMS: CASE FROM SLOVAKIA

MiLOŠ TUMPACH, AdRIANA STANKOVÁ

LEAN HEALTHCARE: RESULTS OF MULTICENTER SURVEY OF CZECH MEDICAL STAFF

VERONIKA VAVRUŠOVÁ, EDITA VITÁSKOVÁ.

TECHNICAL EFFICIENCY OF FDI FIRMS IN THE VIETNAMESE MANUFACTURING SECTOR

Vu HOANG DUONG

THE RELATIONSHIPS BETWEEN SERVICE QUALITY, CUSTOMER SATISFACTION AND CUSTOMER LOYALTY: AN INVESTIGATION IN VIETNAMESE RETAIL BANKING SECTOR

Vu MiNH NGO

CROSS-CULTURE STUDY FOCUSING ON ARGENTINE, CZECH AND AMERICAN BUSINESS PRACTICES

WHAT DIFFERENT MANAGERIAL SKILL-SETS TEACH US 


\title{
DOES THE INTRODUCTION OF THE BOND MARKET REDUCE THE INTEREST RATE ON KOSOVO BANKING INDUSTRY?
}

\author{
Florin Aliu, Orkhan Nadirov, Dawuda Alhassan
}

\begin{abstract}
Kosovo does not have a bond market which would enable companies, people and other economic agents to have access to it, that would have been a substitute for the companies to get other sources of funds beside banking sector. The Kosovo economy has only one source of institutional money injected into the economy and that is the banking industry. Bringing back the money of Kosovo Pension and Saving Trust (KPST) to Kosovo would have been a huge injection for the economy to raise GDP and lower unemployment. Since the companies in Kosovo contain a lot of asymmetric information within their financial statements, clearing the way for KPST how to allocate their investments in Kosovo would be through alleviating asymmetric information. The paper stands on the general concepts of the asymmetric information and how to alleviate it within the financial market and particularly within the bond market. The other part of the paper concentrates on theoretical framework how to eliminate asymmetric information for the companies who want to get funding from KPST. Therefore, it is necessary to have healthy banks and better environment to have a sound bond market. On the other hand, bond market may increase the health of banks by enhancing market competition.
\end{abstract}

Keywords: asymmetric information, Market competition, Kosovo Pension Fund, Interest Rate, bond market

\section{INTRODUCTION}

Competition is proven throughout theoretical paradigms and also tested with empirical results that it is the key driver of productivity, innovation and growth acceleration. Since the banking industry in Kosovo is the key institutional money injection into Kosovo economy, there is a huge concern if the interest rates in the Kosovo economy is set up from the competition among the banks or it is driven up by the banks throughout their market power (banks set up interest rates on their own). According to Aliu (2015), the banking industry in Kosovo has higher interest rates on lending activities than regional countries, while all risks are lower, such as public debt, non-performing loans (NPL), exchange rate risk, economic growth and etc. In this paper we built our research questions based on paradox that the risks are lower in Kosovo than regional countries while interest rates spread is higher. In our paper, we will try to find out the answers to these questions: Do the interest rates in the Kosovo banking industry reflect the risks that the industry is opposed to? Does the establishment of the bond market create pressure for the banking industry in Kosovo to lower the interest rates on lending activities while raising the interest rates on deposits? These questions have been intensively debated throughout the paper.

The view that the interest rates spread lies on general microeconomic principles of price signals and market competition has been attracted for many years by scholars in emerging countries to attain research on bond market. The main reasons for starting a bond market in emerging countries were to fund fiscal deficit and sterilise large capital inflows (Turner, 2002). According to Yoshitomi and Shirai (2001) and Shirai (2001), banking markets should be developed before bond market established and they suggested several reasons for this. First, households have a greater preference for liquid short-term bank deposits; second, institutional investors are immatur ; third, very few large companies are enable to issue 
bonds; and last main problem is that the legal and judicial infrastructure is not in place. But, some economists believe the health of banks in emerging countries can be increased after developing bond market. For instance, Greenspan (2000) provided that bond markets can act like 'spare tire', they can substitute as a source of finance when banks' balance sheets are frail and banks are rationing credit. Greenspan (2000) stated that in the moment when there is a "loss of confidence" in the economy than the bond market will be a substitute for the banks. But in contrast to Greenspan (2000), Hawkins (2002) considers that in times when banks lose the confidence within the economy, bond market will not be an efficient substitute. Further he comments that asymmetric information is even deeper, because bondholders have even less information for the bond issuers than banks have for their clients. Moreover, previous work of Hanson and Roca (1986) is inventive study on the determinant factors affecting the interest rate spread. Their study contained a sample of 29 countries for a period of eight years where factors such as financial costs, recession, competition and inflation were statistically significant. Our research differentiates itself from the prior studies concerning the banking industry in Kosovo in the following aspects: 1) It gives a clear picture how to bring back to Kosovo allocated investments of the Kosovo Pension and Saving Trust (KPST) as a key ingredient for establishing bond market . 2) It shows clear outlook how to eliminate asymmetric information during the listing process, which would enable all companies in Kosovo to have access in the bond market. 3) It gives practical overview how to ensure competition within the overall financial system.

The paper is constructed under two objectives. First tries to find out the impact of introducing the bond market on the interest rates in the banking industry of Kosovo. The second objective is trying to give theoretical construction how to eliminate asymmetric information during the process of listing companies in the bond market. To this end, we use theoretical justification standing on the microeconomic concepts of market competition, asymmetric information and price elasticity through graphical illustration. The main contribution of our paper lies in practical forms how to ensure a competitive environment within the financial system (reach financial market equilibrium) through the bond market where the banking industry is not the only institutional money injected into the economy.

The remaining structure of this study is as follows: First part encompasses introduction and briefly reviews related literature. The second part contains theoretical background. Used methodology is presented within the third section. Graphical explanation is presented within the fourth section. Authors present overall evaluation and giving conclusion in the last section.

\section{THEORITICAL BACKGROUND}

According to the general microeconomic principles competition is a key driver of innovation and productivity, also competition among the entrepreneurs and economic agents drives prices down in the industry where the companies are operating $(\mathrm{P}=\mathrm{MC})$, so it means in a perfect market competition companies are operating with profits close to zero. Basically, economic agents will end up in a price war, which will drive prices down. In perfect competitive environment players do not have a market power to determine the prices compared to monopoly and monopolistic competition where players have some market power. The market consists of many buyers and any single buyer has a small fraction within the market. Since the buyers is a price taker in his purchase, they do not have any impact on determining the price within the market. The market contains many sellers and any single seller has an insignificant impact on the market to affect the prices, so in this case the seller operates as a price taker. Since he operates as a price taker, he only chooses the level of production that maximizes his profit. Firms that sell in the market are free to enter and exit. 
The goods sold by the sellers in the market are homogenous. Buyers and sellers in the market are assumed to have perfect information. Both buyers and sellers know the prices driven by the market. The demand side of the market contains all potential buyers, and each of the buyers which compound the demand side have their own preferences, consumption and level of income (Jehle and Reny, 2011).

$$
q^{d}(p)=\sum_{i \in I} q^{i}\left(p, P, y^{i}\right)
$$

In our case the demand $\left(q^{d}\right)$ would contain all people, economic agents, government etc., that are looking for recourses to finance their daily activities or their daily needs (Jehle and Reny, 2011). The supply side contains all providers of the products or services (q) in a particular market, which non of them has a market power to determine the prices. In a short run, number of players within the market is limited, profit incentives push other players to join the market and drive prices and profits of existing players in the market. On the supply side the equation contains these elements:

$$
q^{s}(p)=\sum_{j \in S} q^{j}(p, W)
$$

Market demand together with the market supply determine the price and the quantity traded on the market. Market equilibrium is achieved at a price (p) when $q^{\wedge} d(p)=q^{\wedge} s(p)$. So basically under these circumstances, no economic agent in the market is interested to change his behavior (Jehle and Reny, 2011). In order to ensure competition within particular market there are assumptions that should be accomplished which are depicted below:

Assumption 1-Homogenous product: money is homogeous in each bank, moreover the products that banks are offering are almost the same.

Assumption 2- Low transaction costs: For economic agents, is quite easy to have access to the prices delivered from the banking sector through internet accesses or through getting the information directly from the bank. Establishing the bond market would be also under low transaction cost to get the information on the bond prices, interest rates and their denomination, since all the necessary information will be accessible online. Assymetric information is linked with the concept when one party has less information than the other party involved in the transaction (buyers or sellers). Pionering work of Akerlof, Spence and Stiglitz (2001) on market with lack of information shed light on the concept of market disequilibrium, where one part of the market has more information than the other part of the markets. Borrowers know more than the lenders cocnerning their ability to repay their debts, managers are more aware for the compay then shareholders. All these problems involved within the markets lead to disequilibrium and also to speculation concerning particular prices. Moreover, Liu and Wang (2016) concluded that due to market power, information asymmetry may decrease welfare loss.

Assumption 3- Free entry and exist in short run: stands on the general concept of matured industries, if there is a profit realized on particular industry new entries will occur and drive profits down to the level of price equals marginal costs (P=MC). This condition in the banking industry of Kosovo is hardly achieved since establishing new bank requires certain rules and regulation that new potential bank should fulfil. 


\section{METOHODOLOGY}

There are multiple forms how you can make pressure on the banks to lower interest rates. One is through laws and regulation in force on purpose, of reaching market competition in the industry if they are speculating on the risks. The other is naturally making pressure on them through capital market where money will move toward those segments that return signals offer better prospect.

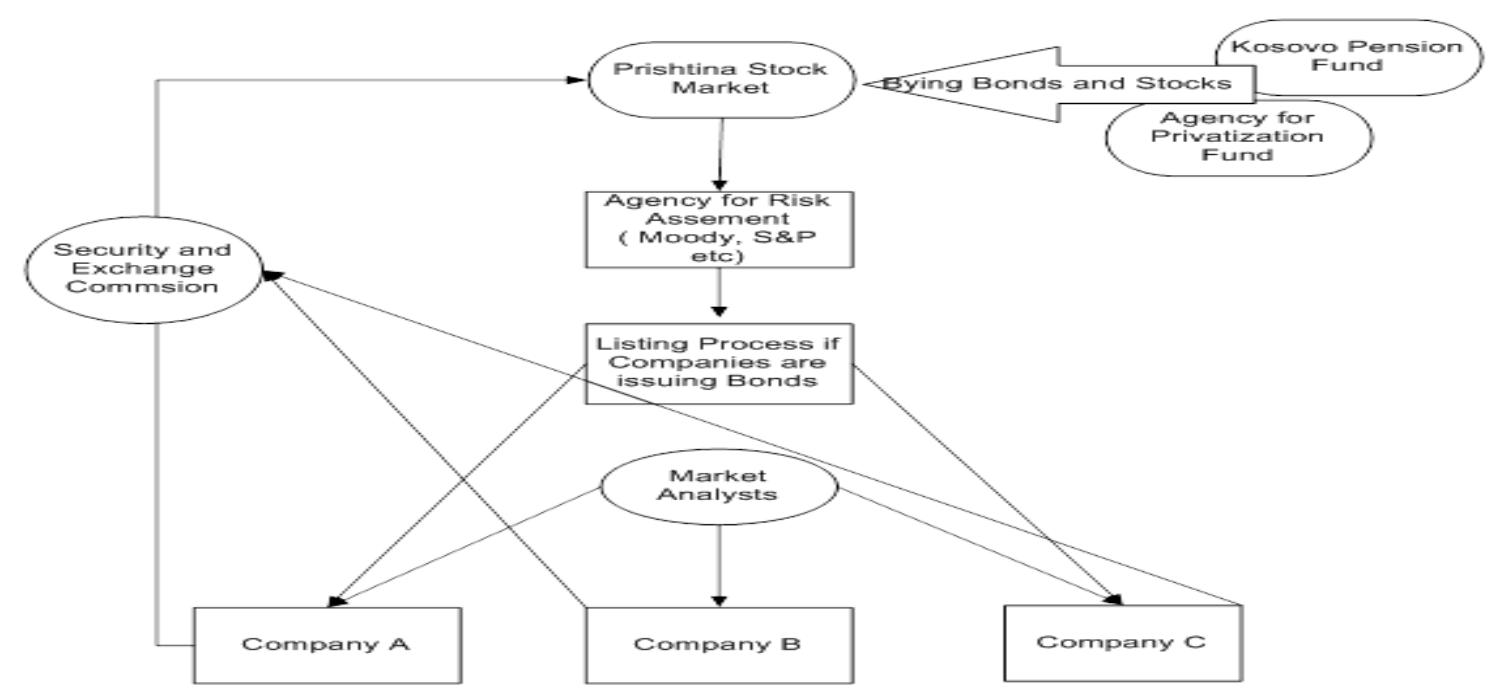

Figure 1 - Investing in Prishtina Bond and Stock Market. Source: Authors own model

Fig. 1 explains one of the forms to bring back allocated investments of the Kosovo Pension Fund, as far as the law constraints investments only on financial assets because of liquidity concerns (KPST, 2004). Kosovo should create Prishtina Stock and Bond Market in order to enable for domestic companies to get listed in it. The efficiency of the stock market is depended on multivariable factors such as volume of trading, information asymmetry, regulatory framework, judicial system, political will and etc. Companies which issue bonds will go through the agency which we have named as 'Debt Assessment Agency or Rating Agency'. Bond has its price and annual payments reflected by the interest rates. Those companies that are audited from big five worldknown audited companies will not contain asymmetric information on their financial statements, they will be only appraised on the ability to pay back the debts on the time, and consequently they will be appraised on ratios such as performance, liquidity, debt and so forth. Those companies who are not audited from the big five, for them the "Debt Assessment Agency" will decline their interest rate and also will reduce their bond price, which is common law how debt markets operate. For instance, if interest rates on the Prishtina Bond Market are in the range of $8 \%$ we will see huge movements from banking deposits toward Prishtina Bond Market. Here, 8\% means interest payments for the company that is issuing that bond, and on the other side that is income for a person, company or government who is buying the bond. Equally the issuer and buyer of the bond will be happy to generate that transaction (as far as for the issuer is more profitable to issue that bond than to get credit from the banks, the buyer will earn higher returns than depositing money in the banks) and we will see huge capital movements from the banking industry toward stock market as a result this will make pressure on the banking industry to lower interest rates to the level of $8 \%$ or even lower in order to attract their depositors to keep their money in the banking industry. 


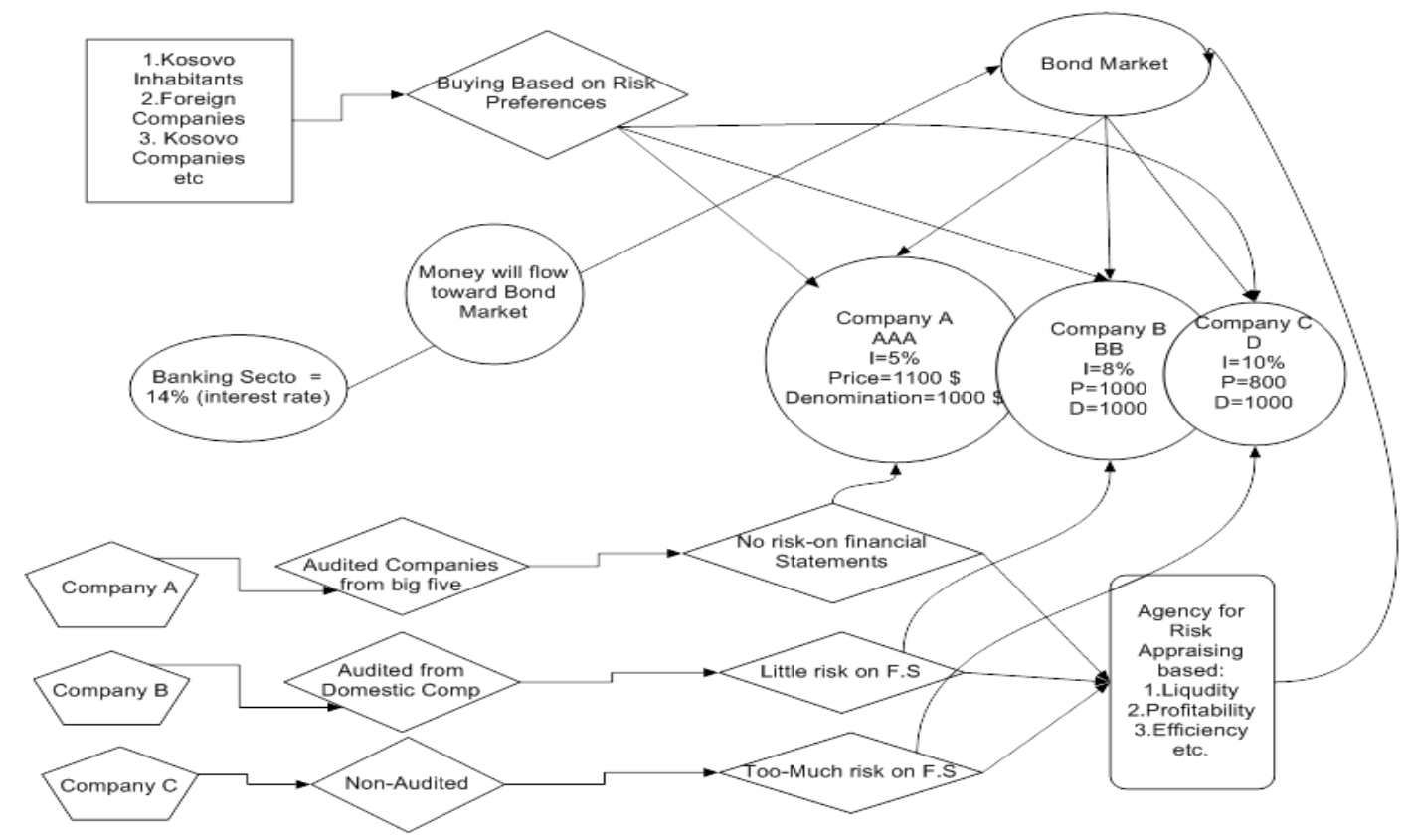

Figure 2 - Process of Risk Appraising. Source: Authors own model

Fig. 2 shows that investments will be allocated on three types of companies based on risk preferences, some people are risk averse and allocate their money in company A, some are risk neutral and they are not concerned at the risk level they just want a certain amount of expected return for a given level of risk and the others are risk lovers which invest in Company C. Money will flow en route on those sectors and industries where prices and profits are increasing. This scheme will push companies toward formalization in order to keep their financial statements not fraud, as far as for them is less costly to obtain credits from bond market if their financial statements are audited. As an outcome banks will feel the pressure of capital flight from their balance sheets on the way to bond market, they will lower interest rates on lending activities and raise interest rates on deposits. It will be more profitable for citizens to invest in bonds than keeping their money on bank deposit which does not cover even the inflation level (CBK, 2013). Kosovo Inhabitants, Foreign Companies and Domestic Companies can buy bonds on the bond market based on their risk preferences. The model is built under the assumption that three companies have strong ability to pay their debts (all the ratios are the same) on time but they are audited from different companies. We are using these assumptions to simplify explanation.

Company A: Is audited from big 5 worldknown audited companies which eliminates the risk on financial statements (so if financial statements are fraud the responsibility drops on audited companies), and according to the "Agency for Risk Assessment" the company's ability to pay their debts on time is high and therefore it is rated AAA. So, the price of the bond has gone up and its coupon down.

Company B: Contains more risk for the reason that its financial statements are audited from domestic companies, because of that its coupon rate has gone up while its price has dropped down and is rated BB. Denomination value is all the same for three companies.

Company $\mathrm{C}$ : which is not audited by any domestic or international audit company, it contains a lot of risk that its financial statements might be fraud. Therefore, its coupon rate is higher 
compared to Company A and Company B, as well bond price has dropped down in a much superior range than the other two companies.

\section{RESULTS}

Explanation driven from the (Fig.1) shows how Kosovo Pension and Saving Trust and Privatization Agency of Kosovo could bring back to Kosovo investments that they have allocated outside Kosovo. This will be realized through establishment of the Agency for Risk Assessment and also establishment of the Prishtina Stock Market. Moreover (Fig. 2) which enables creation of the competition within the financial system and in particular pressuring banks to lower interest rates on lending activities and raise interest rates on deposits, shows how the asymmetric information will be alleviated via audited companies and through agency for risk assessment. The other part of the diagram demonstrates how companies, government of Kosovo, Kosovo Pension and Saving Trust, Kosovo Privatization Agency via participating in the bond market will be a significant player to reach equilibrium in the overall financial system (general theory of market competition).

\section{CONCLUSION}

The banking industry is a crucial element of the inclusive economic growth of Kosovo due to the fact that is the fundamental component of funding business ideas and their daily operations. Therefore ensuring competition within the banking industry is decisive for delivering better products, lower prices and higher efficiency. Ensuring competition within banking industry is in line with the laws established from the parliament of Kosovo on competition issues (KCA, 2016). Kosovo have not been able to establish the stock and bond market during the transformation of the real economy in comparison to some countries of exSoviet Union such as Czech Republic, Poland, Slovakia, Hungary, Romania etc. Kosovo financial system in order to add one additional source of funding within itself, it is suggested to bring back in Kosovo allocated investments of KPST and Privatization Agency which would create supplementary competition toward the banking industry. Kosovo Pension and Saving Trust (KPST) has allocated investments abroad around more than 1 billion euro (KPST, 2013), bringing back those monies in Kosovo would contribute on raising whole liquidity of the economy, GDP acceleration, lower unemployment. Allocated investments of KPST would generate extra competition within all financial systems (in particular on the banking industry) through lowering interest rates on lending activities and raising interest rates on deposits. Theoretical concepts expressed on (Fig.1 and Fig. 2) shows overview map on how companies can emit bonds and have access to funding, while standing on these statements economic agents will buy bond based on their risk preferences. KPST would have been a one of the key engines on ensuring competition within the financial system.

\section{References}

Akerlof, G., Spence, M., \& Stiglitz, J. (2001). Markets with Asymmetric information. Committee, Nobel Prize.

Aliu, F. (2015). Understanding the current state of the financial system in Kosovo and its implications for human security. Center for research documentation and publication, Policy Brief. [Online]. Available at: http://cn4hs.org/wpcontent/uploads/2015/12/FINAL-POLICY-BRIEF-ENGLISH-DEC.18-2015.pdf

CBK. (2013). Central Bank of Kosovo, Annual reports.[online]. Available at: http://bqkkos.org/index.php? $\mathrm{m}=\mathrm{t} \& \mathrm{id}=57$ 
Greenspan, A. (2000). Global challenges. In remarks at the Financial Crisis Conference, Council on Foreign Relations, New York.

Hanson, J. A., \& de Rezende Rocha, R. (1986). High interest rates, spreads, and the costs of intermediation: Two studies (Vol. 18). World Bank.

Hawkins, J. (2002). Bond markets and banks in emerging economies. BIS papers, (11), 42-48.

Jehle, G. A., \& Reny, P. J. (2011). Advanced Microeconomic Theory, Harlow: Financial Times.

KCA. (2010). Kosovo Competition Authority. Law on Protection of Competition.[online]. Available at: https://ak.rks-gov.net/?cid $=2 \% 2 \mathrm{C} 1$

KPST. (2004). Kosovo Pension and Saving Trust Law on Kosovo Pension Fund.[online].Available

at: http://www.kuvendikosoves.org/common/docs/ligjet/Law\%20on\%20Pension\%20Fund s\%20of\%20Kosovo.pdf

Liu, H., \& Wang, Y. (2016). Market making with asymmetric information and inventory risk. Journal of Economic Theory. https://doi.org/10.1016/j.jet.2016.01.005

Shirai, S. (2001). Searching for new regulatory frameworks for the intermediate financial market structure in post-crisis Asia.

Turner, P. (2002). Bond markets in emerging economies: an overview of policy issues. BIS papers, 11, 1-12.

Yoshitomi, M., \& Shirai, S. (2001). Designing a financial market structure in post-crisis Asia: how to develop corporate bond markets (No. 15). ADBI Research Paper Series.

\section{Contact information}

Florin Aliu

Faculty of Management and Economics, Tomas Bata University, T.G Masaryka 5555, 760 01, Zlin - Czech Republic

Telephone number +420 774864451

E-mail florinaliu88@hotmail.com

orcid.org/0000-0002-4782-8820

DOI: https://www.doi.org/10.7441/dokbat.2016.01 


\title{
THE ANALYSIS OF MANAGEMENT SYSTEM OF ECONOMIC DEVELOPMENT OF SUGHD REGION OF TAJIK REPUBLIC
}

\author{
Avezov Azizullo Khabibovich, Azimova Mashokhida Azalovna, Přemysl Pálka
}

\begin{abstract}
The paper analyses economic indicators of Sughd region in 2010-2014, reveals tendencies and problematic issues of regional modern economic development and considers the economic development management system of executive authority. As a conclusion we suggested the implementation of unified regional pilot business support portal, which also might be approbated at the national level after successful results.
\end{abstract}

Keywords: Sughd region, Tajikistan, economic development, management system, business, portal.

\section{INTRODUCTION}

Since the Independence the Republic of Tajikistan has declared the course towards ensuring sustainable development of national economy, increasing living standards based on development of mechanisms of market economy, providing national security, unity of nation, preservation and development of cultural traditions.

Considerable changes of its spatial structure of economy became one of consequences of acquisition of the state independence by the Republic of Tajikistan. Specific economic problems that caused deterioration of national economy were designated in each region of the country. Differences of economic and geographical conditions justify the existence of specific regional problems that should be noted.

According to Constitutional Law of "On Procedure of Determination of Administrative Territorial System of the Republic of Tajikistan" (Constitutional Law № 958, 2013) the current administrative division of the Republic of Tajikistan is following:

- South - Khatlon region.

- North - Sughd region.

- East - Gorno-Badakhshan Autonomous Region.

- West - Districts of Republican Subordination (including the capital - Dushanbe).

The condition of economic development of all four regions allows to refer them to problematic group, however some of them can be referred to developing category by particular indicators. Each of regions has the resource potential (natural, scientific and technical, labor, production) the effective use of which is important for both, development of the region, and for national economy in general.

In conditions of modern economic model of Tajikistan the development level of region`s economy is based more on concentration in their territories of the most favorable types of economic activity than by the technical level of production.

Differentiation of conditions for conducting economic activity and unequal distribution of objects of energy industry, the industry and other production branches on the regional level requires concentration of research on economy of Tajikistan, in particular, of the Sughd region as an important region. 
The Sughd region has great economic potential, that depends on effective management system, taking into account features of social and economic processes, which will lead to increase of competitiveness of the region. The importance of the Sughd region in the economy of the Republic of Tajikistan and it's potential predetermine actuality of our research.

Based on actuality of the research the purpose of this paper is to analyse the existing economic development management system of the region and to arrive at recommendations for perfection.

\section{METHODOLOGY}

There are several approaches, containing a simplified solution to the problem of effective management nowadays (Andronnnikova and et.al., 2002; Larina \& Kisel'nikov, 1998; Afanas'ev et.al., 2001; Smirnov, 2007; L'vov \& Granberg, 2004).

Firstly, proposed to evaluate the effectiveness of management by indicators of economic development and economic activities (production, national income, productivity, etc.).

Second, the management costs are equated to the administrative costs, which allow to determine the costs for the "production" of the administrative act, law, regulation, decision, etc.

According to Smirnov (2007) "It is required to develop the methods of effective management of social-economic development of the region in context of "region-system", i.e. evaluation of the effectiveness of management decisions requires to reveal all essential relationships and to establish its influence in view of these relationships on the behavior of the whole system, not just to part of it.

The management system of economic development of the region is rather complicated subject of research as in terms of analysis and in forecasting its development as well. It is necessary to consider a set of various factors that impact on regional development.

The main methodological approaches to the analysis of management system of economic development of the region allow to use them in an assessment of the social and economic processes happening in the region, to estimate consequences of political decisions on enterprise activity of formation of investment climate, etc.

Thus, formation of a management system of social and economic development of the region is too complicated because formalization of external and internal processes is almost impossible. Herewith the modern scientific approaches to the formation of regional management system solve the management tasks only within the required parameters. Generally, these parameters define a common vector of development of socio-economic system.

\section{RESULTS}

Economic globalisation, political processes, the accelerated technical development, acceleration of welfare requires attention to regional development.

Strategy on the sustainable economic development of the Republic of Tajikistan, increase of public administration efficiency, creation of favourable investment climate is reflected in "National Strategy of Development of the Republic of Tajikistan for the period of 2015" (National Development Strategy of the Republic of Tajikistan for the period to 2015, 2015). The matters of economic development have been specified in "The Program of Economic Development of the Republic of Tajikistan for the period of 2015" (The legislation of the CIS 
(Commonwealth of Independent States) countries, 2015), the Republic of Tajikistan developed according to the Government resolution of June 21, 2001, No. 316 (Ministry of Justice of the Republic of Tajikistan, 2001).

Sughd region is among the most developed regions of the Republic of Tajikistan and has an important role in an economic complex of the country. Nowadays more than 100 various branches and types of production are located in that particular region. Sughd industry includes nearly 750 industrial enterprises from which more than 250 are small and large companies. The sustainable development of Sughd region has an important role in strengthening the economy of Tajikistan (Mirsaidov, 2015).

The main spheres of production are the food industry which is based on development of agricultural production (first of all, vegetable growing) and a light industry which is connected with a full cycle of processing cotton.

Sughd region attracts not only the companies but also individual foreign investors. The enterprises located in the region are engaged in international trade with 64 countries of the world (9 CIS countries and 55 foreign countries). Free economic zone "Sughd" is successfully functioning in the region (Executive authority of the Sughd region, 2014).

The President of the Republic of Tajikistan Emomali Rahmon noted at the ceremony of laying foundation of the metallurgical plant in Istiqlol city on April, 2014: "Sughd region has huge industrial potential, and we comprehensively support the initiative of responsible persons and experts of the industrial sphere in transformation from the agrarian and industrial region in the nearest future to the industrial and agrarian region" (Official website of the President of the Republic of Tajikistan, 2014).

The growth rate of the Sughd region's Gross Regional Product (GRP) reflects positive dynamics as state economy during the period of 2010-2014 (fig. 1). The volume indices of GRP in 2014 has reached 11 billion somonis which is $28 \%$ of GDP, the revenues of the regional budget reached 103,1\%, 1 billion 143,9 million somonis have come to the budget of the area, this number exceeds the planned indicator for 34,2 million somonis. The volume of industrial production output has reached 3,8 billion somonis in 2014 which exceeds the indicator of 2013 for 846 million somonis.

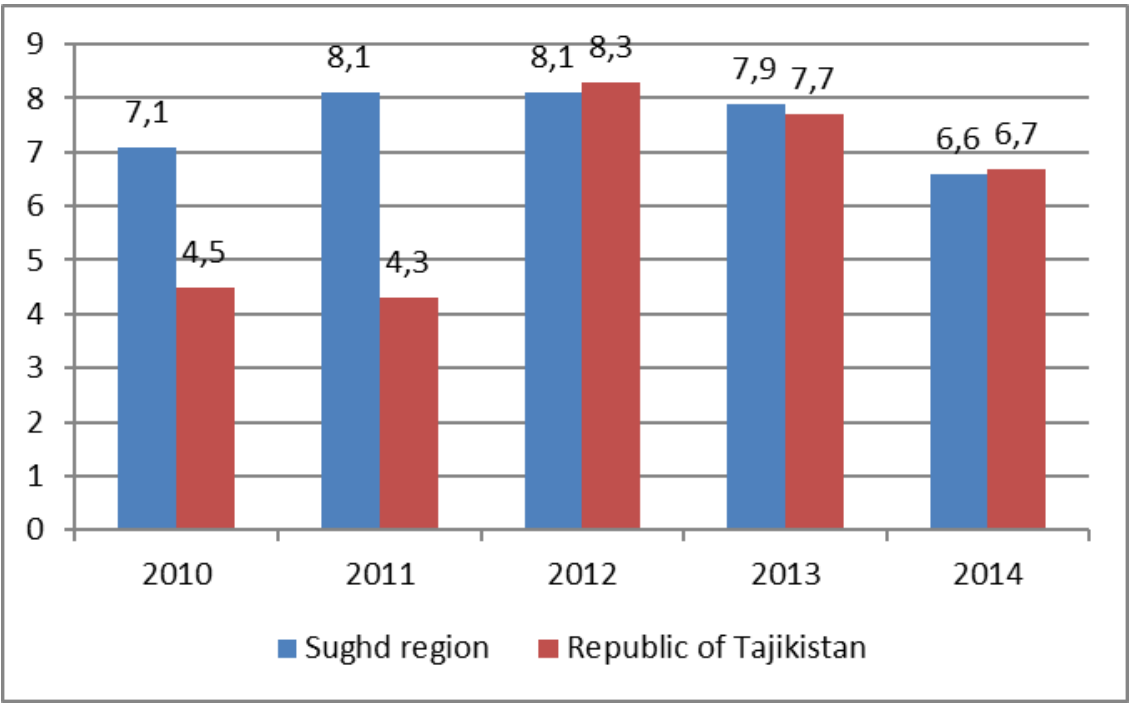

Figure 1 - Dynamics of GRP of Sughd region and the Republic of Tajikistan in 2010-2014, \%. Source: Executive authority of the Sughd region, 2014; Rafieva, 2015.

The growth of agricultural production output in comparison with 2013 was 30,4\%. Foreign direct investment inflow to economy of the region increased by $80 \%$ in 2014 and reached 
$\$ 242,3 \mathrm{mln}$. The cooperation with Commonwealth of Independent States countries is also developing in Sughd region on the basis of bilateral agreements. However, indicators of 2014 also reflect some negative tendencies:

- the decrease in growth rate of GRP;

- 121 industrial enterprises showed a decrease in production, and 34 didn't function at all (Executive authority of the Sughd region, 2014)

- nonfulfillment of tax revenue planning in Kanibadam, Zafarabad, Pendzhikent districts.

Table 1 Tax revenues of the region and cities in 2013. Source: (Avezov, 2015)

\begin{tabular}{|l|c|c|c|c|}
\hline $\begin{array}{l}\text { Total, thousand. } \\
\text { Som }\end{array}$ & Khujand & Kanibadam & Penjikent & Sughd region \\
\hline at \% & 100 & 58988,8 & 159609,4 & 1369740,1 \\
\hline Including, \% & 100 & 100 & 100 \\
\hline Industry & 12,9 & 5,5 & 61,8 & 24,7 \\
\hline Agriculture & 0 & 21,0 & 2,5 & 30,8 \\
\hline Construction & 6,8 & 0,3 & 0,9 & 2,1 \\
\hline $\begin{array}{l}\text { Transport and } \\
\text { communications }\end{array}$ & 15,2 & 3,5 & 0,4 & 7,1 \\
\hline Trade & 4,0 & 1,9 & 0,4 & 1,5 \\
\hline Services & 18,7 & 5,7 & 0,3 & 18,2 \\
\hline Other & 42,5 & 62,1 & 33,7 & 15,6 \\
\hline
\end{tabular}

Analysis of the data in table 1 shows that in Khujand budgeting income is mainly due to industry $-12.9 \%$, transport and communications $-15.2 \%$, services $-18.7 \%$ and other sectors of the economy - $42.5 \%$; The main sources for Kanibadam only two: agriculture $-21 \%$, and other sectors of the economy. As for Penjikent $61.8 \%$ revenue it provides the industry, the foundation of which is the single largest mining and processing enterprise.

It should be noted that the budget, the revenue of which is diversified, more resistant to the negative factors of the economy, in contrast to the budget, the revenue of which is not diversified.

Stability of the regional economy particularly depends on the timely formation of the budget revenues. Industries, which tax revenues form the main part of the income of the budget should be under deep control by the management system of the region.

In this situation, we suggest the analysis of management system of economic development of Sughd region of the Republic of Tajikistan. Structural divisions of Sughd executive authority directly or indirectly participates in the economic development and have an important influence on the economic development of the region. They are:

- department of investments and state property;

- the finance department of the area;

- department of public service on supervision in the sphere of work, employment and social protection of the population in the region;

- department of justice; 
- department of environmental protection (The official website of the Executive authority of Sughd region, 2016).

Besides, the activities of the regional coordination centre of the Ministry of Industry of Tajikistan is very important, as well as structural units of the Chairman unit areas, such as:

- department of energy and industries;

- department of contacts and decisions;

- construction sector;

- department of transport and communications;

- control department.

The significant role for an economic development of the region and application of private initiative plays the activity of regional Chamber of Commerce and Industry (CCI). Effective interaction of independent, non-state, non-profit organization as the Chamber of Commerce and Industry with regional authoritative institutes assists for the development of regional economy, formation of modern industrial and financial infrastructure, creating favorable conditions for business, for development and establishment of trade and economic relations with foreign partners (Website of the Chamber of Commerce of the Sughd region of Tajikistan, 2015).

There is a need for improvement of Sughd management system of economic development, in modern conditions, a decrease of economic indicators and negative tendencies, despite the existing management system of economic development of the region. It is important to note that various researchers earlier offered and offer now various options of measures of improvement of economic development of the region.

Issues of regional economic development, support of small business, joint business are reflected in researches of I.P. Rakhimov, Yu.N. Alimova, A.A. Kayumov (Rakhimov, 2002; Alimov, 2006; Kayumov, 2007). A.A. Baymatov points out the importance of a sustainable development of regional economy and problems of perspective development of Sughd region (Baymatov, 2015). The necessity of formation of strategic reference points of a sustainable development of the region is indicated by A.H. Avezov (Avezov, 2015). The importance of development of joint ventures for the economy of Sughd region is emphasized by M. M. Kayumov (Kayumov, 2007).

In our opinion, without denying importance of the mentioned aspects, today in the conditions of information society formation, creation of the unified portal for business support (including innovative) at the regional level is vital, on which actual information on support of medium and small businesses would be posted and from which transition to the official websites of various public organizations (website of the president of the Republic of Tajikistan, regional executive authority, tax authorities, customs department, etc.) would be possible. Except undoubted advantages to businessmen on this website, it would be also possible to fulfill a number of national objectives. So, within the specified Internet resource by the authorities of the Sughd region could be organized cooperation on development of mechanisms of monitoring and an assessment of results of programs of the state support of business, and also use of results of an assessment when planning new initiatives, including the following:

- the system of monitoring including indicators of expenses to support enterprise projects and creation of innovative products (services) which would be estimated during a certain period of time (annually, half-annually, monthly); 
- the mechanism of a usual assessment of all business support programs activities which considers peculiarities of state intervention in enterprise projects and precludes the exclusion of project risk by use of portfolio approach;

- participation in estimation process of the independent external experts applying modern techniques in their work;

- Integration of regional information for completeness of general situation description and simplification of comparisons.

The specified actions would promote economic development not only in the Sughd region but also in all country and could play an important role in information exchange between authorities and enterprises.

At the same time, we recognize that expansion of information exchange process and support of business is important factor improving the productivity of social and economic activities, especially at the existing level of technological development in the Republic of Tajikistan. At the same time, there is a certain problem with the distribution of economic or technological experience in other branches of economy, and it fully concerns opening of the new companies.

New initiatives of strengthening ties between small and medium-sized companies and large state or private companies are being developed in Tajikistan. However, the interrelation of participants of enterprise projects in the national economic system in general remains weak, in our opinion, it has to be the object of constant attention from the state side. Therefore, such initiative as creation of a regional unified portal of business support has to be realized in the nearest future. This portal could become the pilot project and tested on the experience of Sughd region as one of the economically developed regions of the country. Further practice of regional portal functioning could be the basis for the activity of the unified state portal of business support on the scale of the Republic of Tajikistan.

\section{CONCLUSIONS}

According to our research results we developed following conclusions for the development of the management system of economic development of the Sughd region of the Republic of Tajikistan.

The necessary structure of institutions of governance and support for economic activity is already formed in Sughd region which is reflected in the various executive authorities at the regional level. At the same time, there is no regional state Internet resource that fully provide business representatives with necessary information and support. Information on state support measures of business, the existing programs and realized projects in this sphere is dispersed on various Internet resources.

Further development of economic activities and business in Sughd region demand creation of the unified (single) portal of business support. It would be possible to fulfill a number of national objectives, except undoubted advantages to businessmen by means of creation of this website. So, within the specified Internet resource might be organized monitoring and an assessment work on the development of mechanisms and results of business state support programs and use of assessment results when planning new initiatives by the authorities. This portal could become the pilot project and tested on the experience of Sughd region as one of the economically developed regions of the country.

Further practice of regional portal functioning could be the basis for the activity of the unified (single) state business support portal within the Republic of Tajikistan. Change of approaches 
to the organization of information exchange between regional government institutions and business community on the basis of unified (single) business support portal creation will intensify the development of business and private initiatives that fully correspond to modern and perspective requirements of economic promotion in Sughd region and the Republic of Tajikistan itself.

\section{References}

Afanas'ev, V. Ja., Bystrjakov, I. K., \& Vidjapin, V. I. (2001). Priorities for management of regional development.

Alimov Yu.N. (2006). Improving organizational structures of management of small businesses: the case of the Sughd province of Tajikistan (dissertation thesis). Khudjand.

Andronnnikova, N. G., Burkov, V. N., \& Leontyev, S. V. (2002). Complex estimation in problems of regional management. M.: ITTU Russian Academy of Science.

Avezov, A. H. (2015). Strategic guidelines for sustainable development in the region: An analysis of the situation and the formation of a system of indicators. Scientifictheoretical journal "Bulletin of TSULBP" Series of Social Sciences, (1), 18-29.

Baymatov, A. A. (2015). The stability of the regional economy and the problems of perspective development of the Sughd region. Scientific-theoretical journal "Bulletin of TSULBP”, Series of Social Sciences, (2), 31-39.

Constitutional Law (2013). On Procedure of Determination of Administrative Territorial System of the Republic of Tajikistan, no 958

Retrieved from: http://mmk.tj/ru/library/+o_poryadke_resheniya_voprosov_adm.terr._ustroistva_rt.doc

National Development Strategy of the Republic of Tajikistan for the period to 2015 (2015). Retrieved from from http://www.carecprogram.org/uploads/docs/TAJ-NationalDevelopment-Strategy-ru.pdf

Executive authority of the Sughd region (2014). Review of economic sector. Retrieved from http://sughd.tj/index.php/ru/statistika/econom-sektor/1713-econom-sektor.

Kayumov, A.A. (2007) The development of joint business in the Republic of Tajikistan: the example of the Sughd region (dissertation thesis). Dushanbe.

Kayumov, M. (2013). The role and place of joint ventures in the Sughd region's economy. Scientific-theoretical journal "Bulletin of TSULBP", Series of Social Sciences, 53(1), 106-112.

Larina, N. I., \& Kisel'nikov, A. A. (1998). Regional policy in the market economy countries. M.: Ekonomika.

L'vov, D. S., \& Granberg, A. G. (2004). Strategic management: region, city, enterprise, 605.

Ministry of Justice of the Republic of Tajikistan (2001). Resolution of the Government of Tajikistan from 21.06.2001, no 316 "About the development of the program of economic development of the Republic of Tajikistan for the period until 2015". Retrieved from http://www.adlia.tj/show_doc.fwx?rgn=3561.

Mirsaidov, N. (2015). Sustainable development of Sughd region strengthens the economy of Tajikistan. Retrieved from http://inozpress.kg/news/view/id/44007

Muhetdinova, N. M. Regional economic policy. // Problems of regional and municipal management. Conference proceedings, - M.: "Security Business Consulting". Retrieved from: http://sbcinfo.ru.

Official website of the President of the Republic of Tajikistan (2014). Official speech at the ceremony of laying foundation stone of the metallurgical company in Istiklol. Retrieved from http://www.prezident.tj/ru/node/6486. 
Rafieva, M. (2015). Sughd summed up the socio-economic development of the region. Retrieved from http://news.tj/ru/news/v-sogde-podveli-itogi-sotsialnoekonomicheskogo-razvitiya-oblasti.

Rakhimov, I.P. (2002). Status and development of the industry in the transition to a market economy: the case of the Sughd region of Tajikistan (dissertation thesis). Dushanbe.

Smirnov, V. V. (2007). Features of effective management development region: methodologies, strategies, mechanisms, organization. Audit i finansoviy analiz, (6), 393-403.

Smirnov, V. V. (2007). Increasing effectiveness of social-economic development of the region: methodologies, evaluation, effectiveness. Audit i finansoviy analiz, (6).

The legislation of the CIS countries (2015). Resolution of the Government of Tajikistan from 01.03.2004, № 86 "Program of economic development of the Republic of Tajikistan for the period till 2015". Retrieved from http://base.spinform.ru/show_doc.fwx?rgn=11074.

The official website of the Executive authority of Sughd region (2016) Structural division of the authority. Retrieved from http://sughd.tj.

Website of the Chamber of Commerce of the Sughd region of Tajikistan (2015). Abou the Chamber of Commerce. Retrieved from http://www.tppsughd.tj/index.php?page=about.

Contact information

Avezov Azizullo Khabibovich

Khujand Polytechnic Institute of Tajik Technical University named after academician M.

Osimi, Dr. of Economy, Professor of Department Economic theory and Management,

Khujand, Tajikistan

azizullo@businessconsulting.tj

Azimova Mashokhida

Department of Finance and Accounting, Faculty of Management and Economics, Tomas Bata University in Zlin, Zlin, Czech Republic

Khujand Polytechnic Institute of Tajik Technical University named after academician M. Osimi, Department of Finance and Credit,

Khujand, Tajikistan

mashokhon@mail.ru

Přemysl Pálka

Department of Finance and Accounting, Faculty of Management and Economics,

Tomas Bata University in Zlin,

Zlin, Czech Republic

ppalka@fame.utb.cz

orcid.org/0000-0002-9506-4861

DOI: https://www.doi.org/10.7441/dokbat.2016.02 


\title{
GOVERNMENT DEBT MANAGEMENT, STRUCTURE AND ECONOMIC GROWTH: INVESTIGATION OF THE VISEGRAD FOUR Peter Bad'o
}

\begin{abstract}
This contribution investigates the relationship between government debt and economic growth in four similar and linked countries. Visegrad Four. The emphasis is also put on the structure of the government debt and how the debt was created. Through the history, there are many different ways of how the debt can be accumulated. It is important for the government to know this, so they can use the correct debt management policies. This paper focuses at four economies belonging to the Visegrad Four and it is using data from the last two decades to investigate evidence of these debt management policies and changes in debt structure.
\end{abstract}

Keywords: debt, sustainability, economic growth, debt structure

\section{INTRODUCTION}

In the last two decades several developed countries have experienced significant budget deficits, while the ability of government to cope with fiscal deficits has been receiving increasing attention from economists. This is an important topic both in terms of economics and public policy. This issue is also an important for a newly formed euro area and this is one of the motivations for this paper. Furthermore, the Treaties governing the European Union impose the practical necessity of sustainable public finance and also avoid excessive deficits, keeping the debt levels below the 60 percent of GDP.

The paper is organized as follows. The next section - Literature overview, discusses the issue of sustainability of government debt and several different concept of it. Section three reviews methods and data, which were used in this research. Following section discusses the results of empirical analysis and compares the results of economies in the Visegrad Four. Finally, the last section provides conclusion.

\section{LITERATURE ANALYSIS}

In the scientific literature are several approaches to how we can estimate the sustainability of the government debt. One of the most used and know approach to the government debt is to take it as a whole sum of unpaid government debts, most often specified as the amount of money, or more accurate as a ratio to the GDP. Next approach is to consider the solvency of the government, and if the government is solvent, then the sustainability of the debt is solvent as well. Problem with this approach is that it is quite abstract and hard to express, mainly because methods used to evaluate the solvency and the reasoning behind it are complicated on its own. Also it requires fairly extensive analysis to back up the results. Another concept is evaluation of the debt burden. Sustainability of government debt is based on non-increasing debt, which would be induced by the debt burden. In this case however the evaluation methods are fairly specific and also as in the previous concept only a long run time period should be considered to gain significant results. The next approach is using budget limitations. The debt is sustainable if the amount of borrowing and obligations does not exceeds the increase of the economy. Finally, the last concept is about the effectiveness of the borrowed funds. This effectiveness can be measured by several different indicators, but the reasoning behind these indicators must be concrete. 
In the paper from Reinhart and Rogoff (2010) is made research of data of 44 countries, where the relationship between indebtedness, economic growth and inflation is investigated. They do not looks at hidden causes, which had created the debt, but they are taking the debt and his structure as given. Interesting is the results of their research, where they claim that every financial crisis will results in increase of government debt by 86 percent in the following 3 years. Several authors tried to replicate their research like Wray (2010) or Herndon, Ash and Pollin (2013), but both papers came to different results and pointing out number of irregularities. In the first part, they came to almost identical results that the GDP is growing more or less steadily by 3-4 percent per annum in developed economies up to the limit of 90 percent of debt to GDP ratio. But in this part the differences occurred. Reinhart and Rogoff argue that at this time, the real average economic growth is slowing to the rate of 0.1 percent per annum. Herndon, Ash and Polling estimated this growth to be 2.2 percent per annum. Also the limit of public debt of $0-30$ percent in current economic situation is pointless.

On the other hand, the how and when the debt is created is important. Several authors stated out that it matters how the debt is accumulated, if it is in times of peace and prosperity, when behind the creating of the debt may lays several hidden political issues, which has tendencies to persist during long time period, or it is created during times of war, which tend to lower when the conflicts ends. As stated in Cukierman and Melzer (1989) that debt obtained during times of war, has a much smaller impact on economic growth and inflation.

Rose of government debt was not only observed after recent financial crisis, but also during several last decades. As described in Tanzi and Schuknecht (1997) this is the case of increasing size of government. As shown in their research average debt increased from 12 percent in 1913 to 43 percent of GDP in 1990. At the end of the time period average debt to GDP ratio was 79 percent for big governments, 60 percent for medium sized governments and 53 percent for small governments.

Interesting research is made by Bolton and Jeanne (2011), which describe the links between financially integrated economies. They mainly deal with individual banks holding of debt in Eurozone as well as with portfolio of sovereign debt.

Lejour, Lukkenzen and Veenendaal (2010) address the problems of debt sustainability in the euro area in the selected countries after the financial crisis. Concretely, which countries are at risk of not being able to maintain or procure their debt? The results of their research shows that the most stable country is the Belgium and that was only in cases which did not included the possibility of an aging population, so all of the monitored countries are in need of convert protective measures until the end of decade.

Some economic literature assumes that debt management should hold principles of sound finance management. According to Matthews and Colander (2004) principles of this theory could be understood as balanced budget approach. On the other hand, Forstater (1999) and Aspromourgos (2014) reject traditional doctrines of sound finance. According to them the only reason to lower or even extinguish debt is to achieve better rate of interest which result in increased investments and output. More on this topic is explained in Bad'o and Komínek (2015).

\section{METHODS AND DATA}

In this section are described data and methods used in this research. Various methods were used for different part of the research, but holistic approach was used to ensure the consistency of the entire research. To analyze the scientific literature, the methods of generalization and systematization was used to identify the different methods 
and techniques used in debt sustainability by governments. These methods were also used to identify particularities used for different debt stabilizations tools and management. Qualitative analysis of the primary and the secondary data is made.

\subsection{DATA}

This research is applied to study four different economies belonging to the Visegrad Four, concretely Czech Republic, Hungary, Poland and Slovakia. Annual data from 1995 - 2014 are used. The choice of this sample is based on high quality data. The data set used in the analysis consist of annual data. Data of Poland (currency and deposits, debt securities and loans) are only from year 2000. The main source of these data is the Eurostat database. All of the figures have time on $\mathrm{X}$-axis and on $\mathrm{Y}$-axis is measured debt level in millions of euro or in percent for better comparison.

\section{RESULTS}

In the following section are the results of the conducted research. The results of the research are based on the outcome of the research, which was performed accordingly with the mentioned methods and limitations.

In the first figure (1), we can observe the evolution of the GDP in the economies of the Visegrad Four between years of 1995 - 2014. Until the year 2008, the year of the financial crisis, we can see the growing trend of GDP of all four observed economies. From the year 2008, economies of Czech Republic, Hungary and Slovakia show almost no change in economic growth. Only Poland after the recession has returned to the growth state of the economy. It is also a noticeable, that the GDP of Slovakia, has suffered a lesser impact of the financial crisis as other 3 observed economies. This is most likely caused by acceptance of euro as national currency at 1.1.2009.

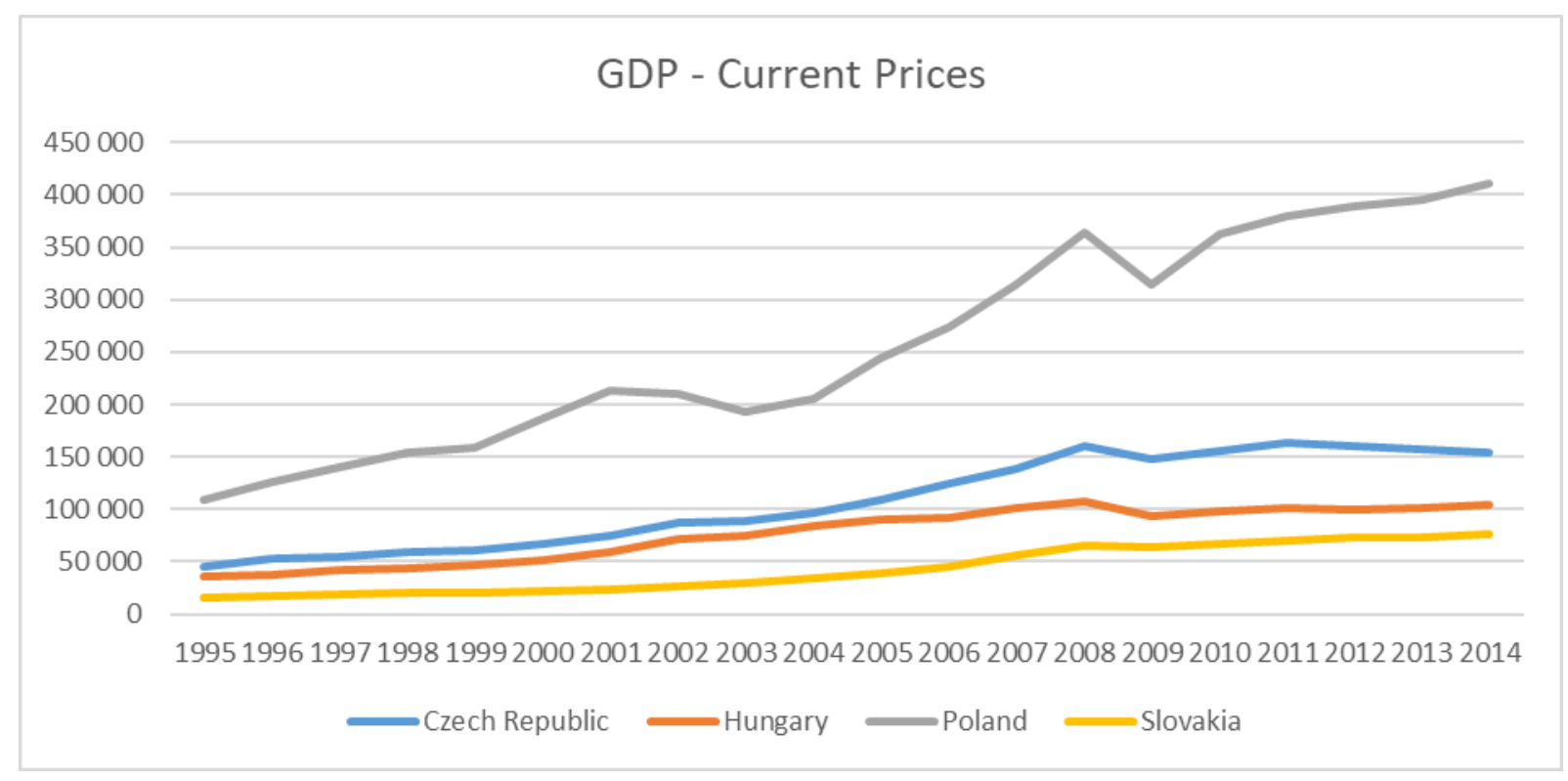

Figure 1 GDP in Millions of Euro (data source - Eurostat)

In the following figure (2) is the government consolidated gross debt. From the figure it is obvious, that for almost entire time period the debt was increasing steadily. After the financial crisis, when various problems of European countries have surfaced, individual states began to pursue a policy to reduce their debts. Hungary and Slovakia were able to stop the growing trend of government debt. Furthermore Czech Republic and Poland were even able to begin reducing its obligations. 


\section{Government Consolidated Gross Debt}

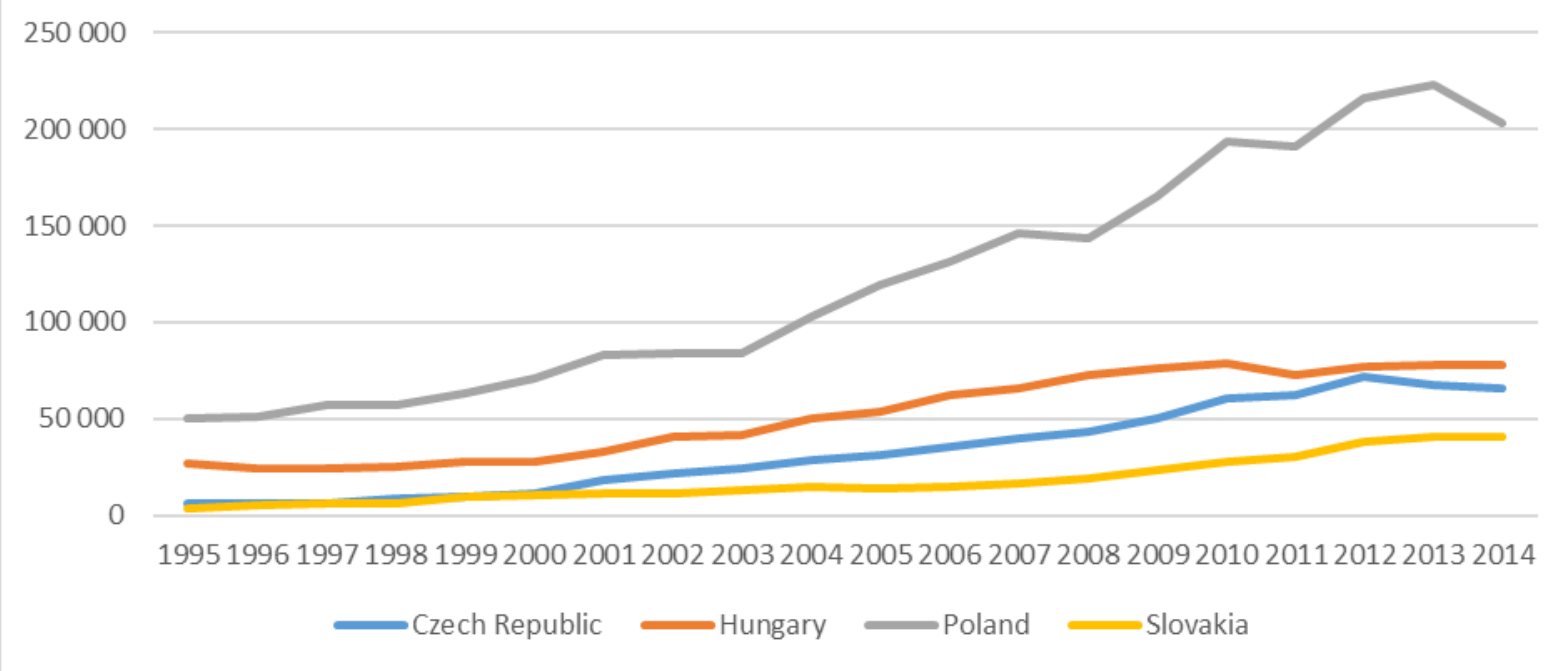

Figure 2 Government Consolidated Gross Debt in Millions of Euro (data source - Eurostat)

By combining constants from figure 1 and 2, we get the debt to GDP ratio, which changes are represented in figure (3). During years 1995 - 2000, we can observe very slow increase in Czech Republic, but in years 1997 and 2002, when the country was affected by large floods, we can also notice an increase in debt, mostly in short term debt securities and in currency and deposits (figures 4 and 5). Also in this time period, Hungary was showing a decrease of debt to GDP ratio. We can also noticed, that all countries of Visegrad Four, are trying to stabilize their measures as a react to Maastricht criteria, which were needed for admission to the European Union. If we look, at the last two years of these three figures, we can see even that the GDP is non-increasing (except of Poland), but the government debt is decreasing, we can also see a decrease in debt to GDP ratio.

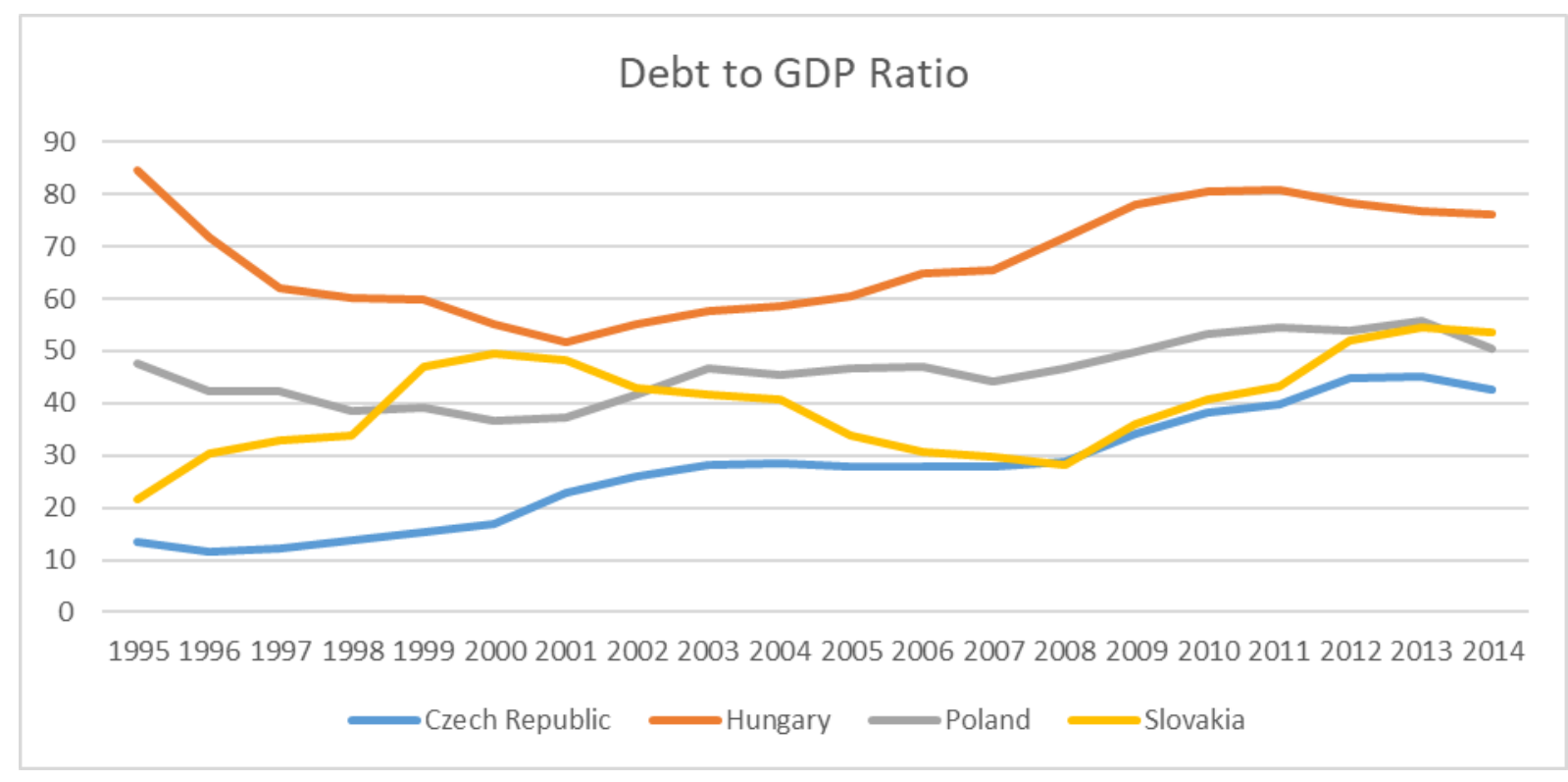

Figure 3 Debt to GDP Ratio in Percent (data source - Eurostat)

This figure (4) is showing one part of government debt - currency and deposits. At the first look, we can see, that currency and deposits create only a fraction of whole debt. Approximately 1 percent. For almost first 10 year of the sample, there was almost no change 
in this sample, with exception of Czech Republic, which were affected by large floods in these years. Poland manage to decrease their currency and deposits debt to 0 in year 2007 and it has not increased since that.

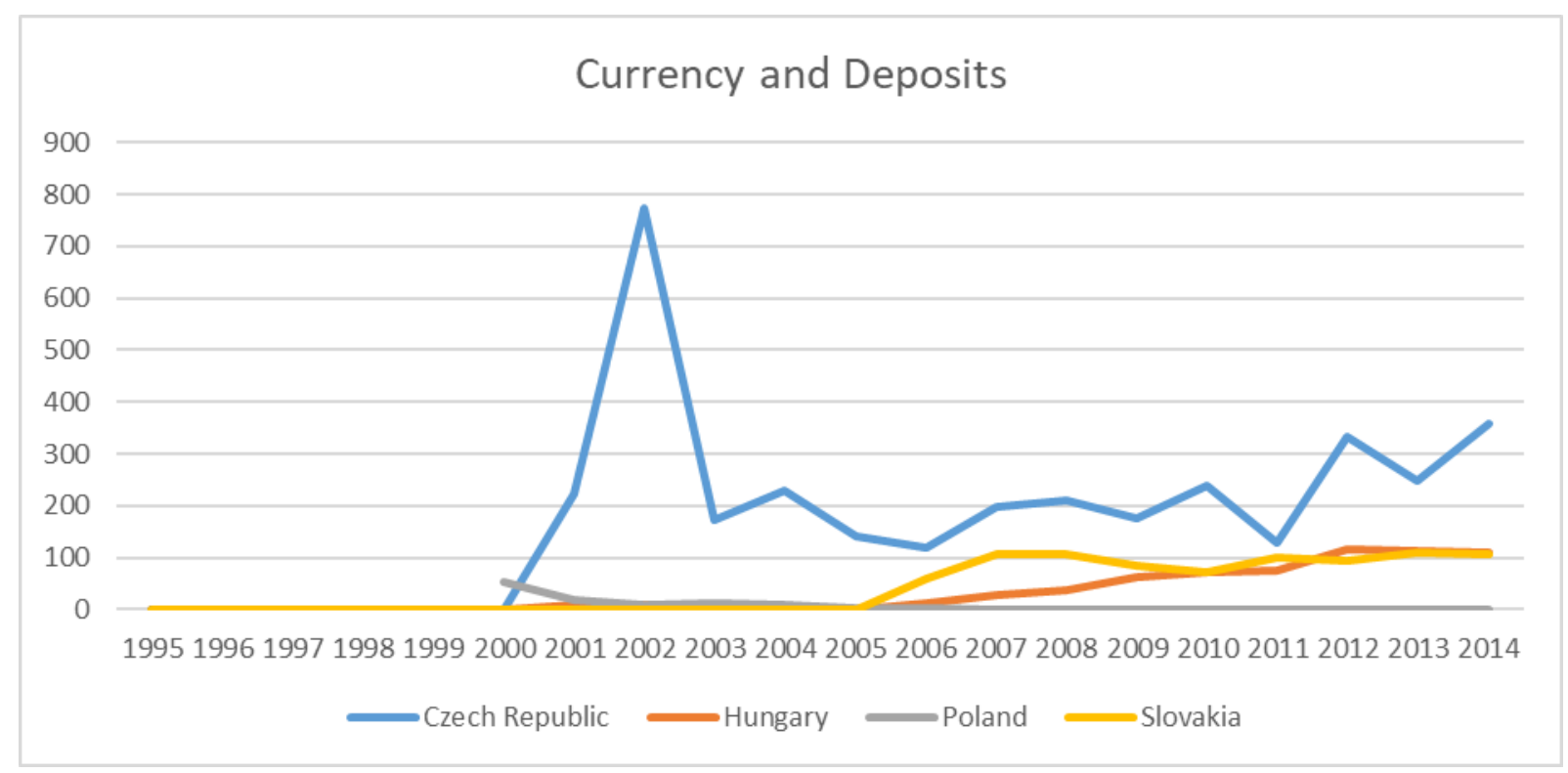

Figure 4 Currency and Deposits in Millions of Euro (data source - Eurostat)

On the other hand, debt securities shown in the next figure (5), create the largest portion of the government debt in every observed country. There is a steady increase in all 4 countries of the Visegrad Four. Interesting is the year 2009, when in the Hungary and Poland was decline in the issuance of debt securities. If we divide the debt securities to short term and long term, we would have seen, that the short term debt securities after the year 2003 are showing decreasing trend opposite to the long term debt securities. Short term debt securities are creating in average less than 2 percent of the debt in all 4 countries.

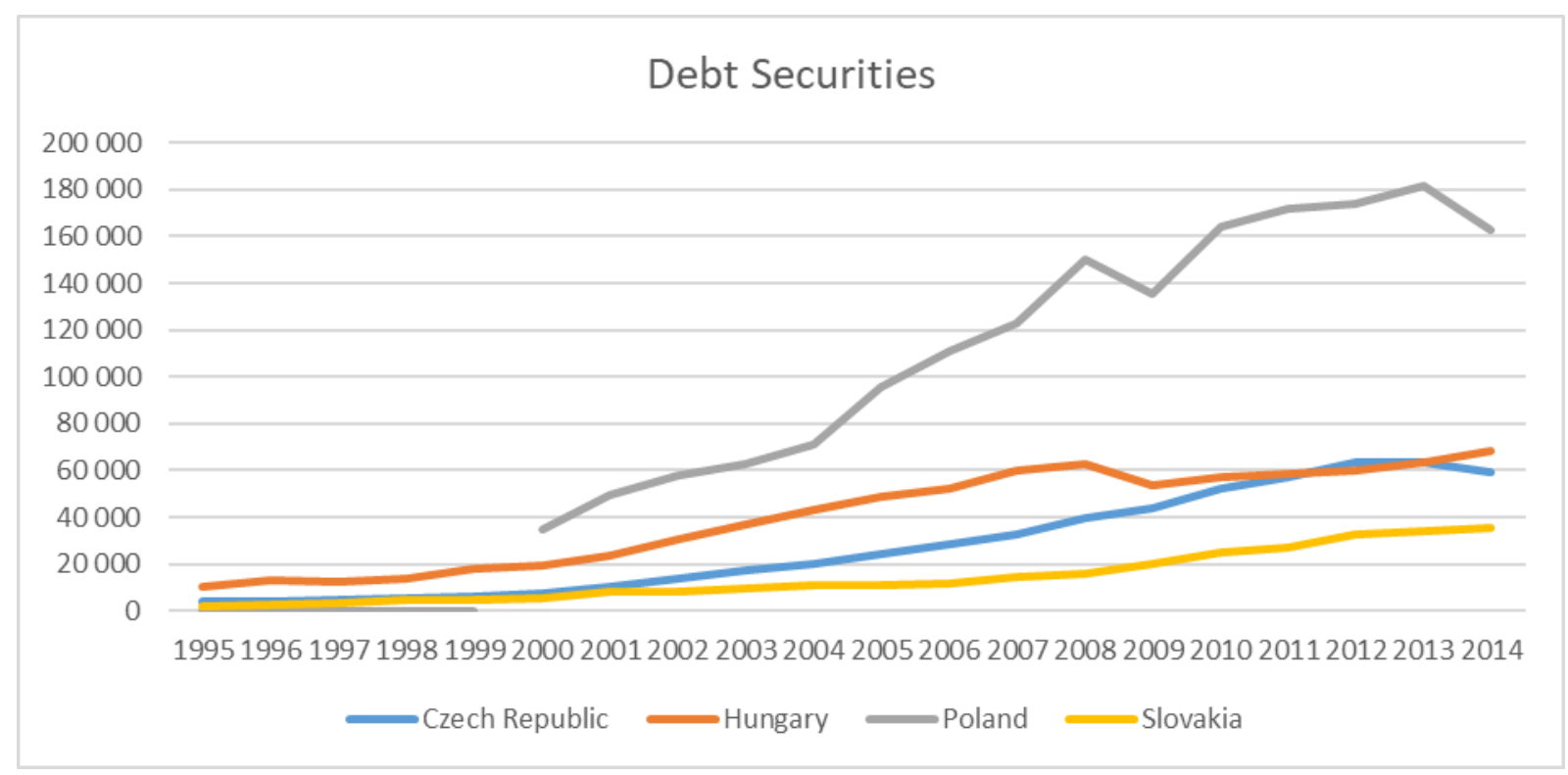

Figure 5 Debt Securities in Millions of Euro (data source - Eurostat)

In the last figure (6), are the loans, which are composed of short term and long term loans. Again similar to the currency and deposits, loans compose a much smaller part of the debt 
than the debt securities and short term loans are almost insignificant to the amount of the long-term loans ( $0-6$ percent of all loans, this is the reason, only combined loans are used in the figure), it is obvious that the states are using mostly different economic instruments to cover increased government spending, for example the debt securities.

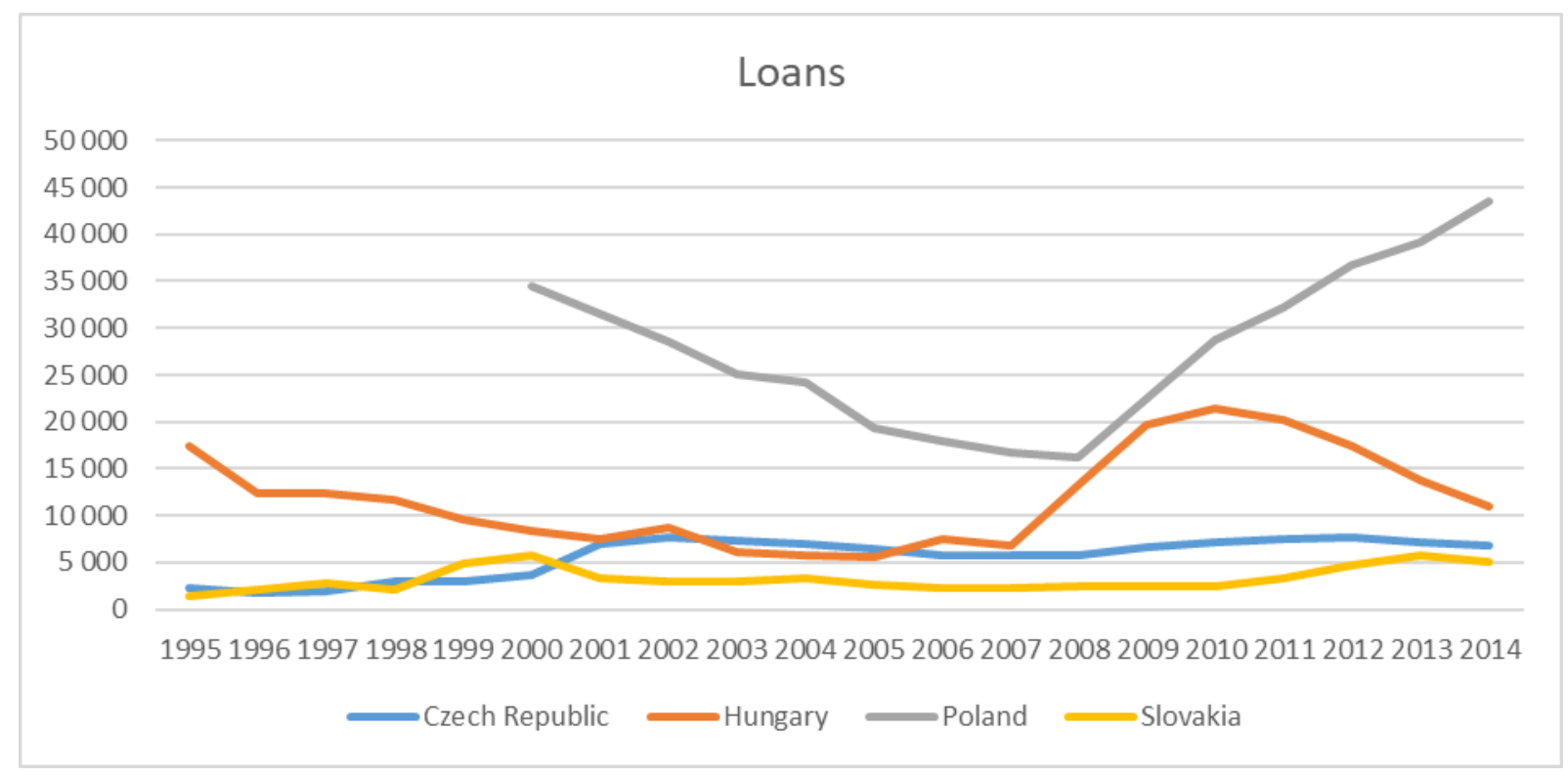

Figure 6 Loans in Millions of Euro (data source - Eurostat)

\section{CONCLUSION}

In comparison with other authors, previous result and own expectations, the results are satisfactory. This paper followed a previous research and will work as a base for a further research of government debt and relationship with economic growth.

In this paper are analyzed several different concepts of debt sustainability and reasons behind creation of government's debt. Results of the literature analysis showed that small open economies should put their focus on prevention against long term violation of balanced budget. Also it is known, that the debt could arise even during times of economic prosperity or with increasing size of government, not only during time of conflict or economic recession.

As it can be seen, from the analysis of the data of economies belonging to the Visegrad Four, all four countries need to overcome increasing size of government's debt, also the level of public debt is far from balanced growth path. It is good to see, that each country has already accepted strategy to lower their existing debt. On the other hand, it would be good to implemented those tools and strategies sooner and not after it caused problems in several countries and after the pressure from public.

\section{Acknowledgement}

This paper was created within a specific research Macroeconomic analysis of the behaviour of the economy and economic policy using quantitative methods marked MUNI/A/1049/2015.

\section{References}

Aspromourgos, T. (2014). Keynes, Lerner and the Question of Public Debt: History of political economy. Duke Univ. Press, 46, 409-433 https://doi.org/10.1215/001827022796209 
Bad'o, P and Komínek O. (2015). Government Debt Management and Policy. Tomas Bata University in Zlín, Vol. 1.

Bordo, M.D.,et al (2010). Foreign currency debt, financial crises and economic growth: A long-run view, Journal of international Money and Finance, 29, 642-665 https://doi.org/10.1016/j.jimonfin.2010.01.002

Cukierman, A. \& Meltzer. A. H. (1989). A political theory of government debt and deficits in a Neo-Ricardian framework. The American Economic Review, 79(4).

Chen, S.-W. (2011).Current account deficits and sustainability: Evidence from the OECD countries.

Economic

modelling,

28 ,

$1455-1464$ https://doi.org/10.1016/j.econmod.2011.01.011

Checherita, C. and Rother, P. (2010). The impact of high and growing government debt on economic growth: An empirical investigation for the euro area, European Central Bank: Working Paper Series No. 1237

Forstater, M. (1999). Functional Finance and Full Employment: Lessons from Lerner for Today, The Jerome Levy Economics Institute, Working Paper No. 272

Lejour. \& Lukkenzen. \& Veenedaal. (2010). Sustainability of government debt in the EU. Netherlands Bureau for Economic Policy Analysis

Liliko, A. Holmse, E., and Sameen, (2009). Controlling Spending and Government Deficits: Lessons from History and International Experience. Policy Exchange

Reinhart, C. R., \& Rogoff, K. S. (2009). Growth in a time of debt. National Bureau of Economic Research: Working Paper Series [online]. No. 15639

Teica, R. A. (2012). Analysis of the public debt sustainability in the Economic and Monetary Union, International conference about emerging markets queries in finance and business, 3, 1081-1087

Data source: Eurostat, http://ec.europa.eu/eurostat/data/database downloaded 2.3. 2016 


\section{Contact information}

Peter Bad'o

Masaryk University, Faculty of Economics and Administration, Lipová 507/41a, 60200 Brno Czech Republic

Telefone number: +420774978166

Email:pbado@mail.muni.cz

DOI: https://www.doi.org/10.7441/dokbat.2016.03 


\title{
THE ROLE OF CUSTOMER JOURNEY IN B2B CONTENT MARKETING
}

\author{
Elina Bakhtieva
}

\begin{abstract}
Constantly developing technologies and marketing methods increase the importance of content marketing as one of the main communication channels. Content marketing is a new division of digital marketing. It has a revolutionary nature, and has changed the way of communication with customers, from a one-way, broadcasting, approach to a customercentric. Due to the development of social media and user generated marketing, modern companies are learning to consider customer journey in their digital marketing strategy. Content marketing plays an important role for business-to-business (B2B) companies due to the higher (than for business-to-customers (B2C) companies) dependence on customers. The latter could be explained by longer purchase decision time, smaller amount of customers and longer business relationships. It is often believed that large global companies disseminate best practices due to high level of available resources, process optimisation and the effectiveness level. The aim of the current research is to identify by means of a content analysis whether the largest global B2B companies listed in Global 500 make use of the concept of the customer journey in their digital marketing strategy. The provided analysis helps to identify a link between content types and customer journey steps.
\end{abstract}

Keywords: B2B marketing, customer journey, content maturity, website content analysis

\section{INTRODUCTION}

Website development undergoes constant changes. Development of digital marketing has changed the nature of websites by positioning customers and their needs in the centre of digital concept. In order to be successful in digital marketing, companies have to change their thinking from a broadcasting approach to customer-centric, and try to help customers to make their life easier (Holliman \& Rowley, 2014). In order to do so companies have to take into account the steps of the customer journey. This is especially important in the B2B sector due to its specifics, characterised by a lower number of customers and longer relationships than in the $\mathrm{B} 2 \mathrm{C}$ sector.

Many companies consider the experience of the best-performing companies in choosing their marketing strategies. Worldwide known international companies are often seen as a sample for the best practices. The purpose of the current paper is to analyse the websites of the leading global B2B industrial companies and find out the role of the customer journey in their content strategy.

\section{BACKGROUND}

The main characteristic of content marketing is its revolutionary nature, which requires the transition of communication style from one-directional, broadcasting, to bi-directional (Holliman \& Rowley, 2014; Wymbs, 2011). Moreover B2B companies have to change their attitude to the relationships with customers and start to interact with customers instead of trying to sell their products or services (Holliman \& Rowley, 2014).

The main differences of $\mathrm{B} 2 \mathrm{~B}$ sectors from $\mathrm{B} 2 \mathrm{C}$ sector are longer purchase decision time, smaller amount of customers, fewer transactions than for B2C companies (Järvinen, Tollinen, 
Karjaluoto, \& Jayawardhena, 2012). Furthermore, values not emotions, play the main role in a decision process (Gillin \& Schwartzman, 2011).

Due to changes in the decision process many companies pay additional attention to the

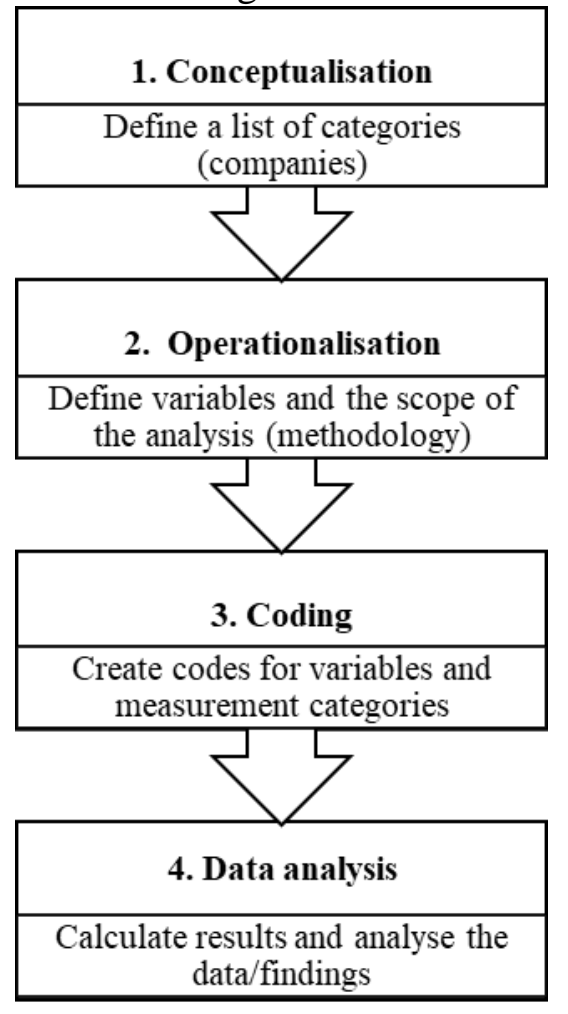
customer journey. It is important to know what path the customers use before they take a purchase decision, and if he or she will stay with the company in the future. Experts distinguish four stages of the customer journey, or customer lifecycle, which are called evaluation, purchase, and postpurchase experience (Vázquez et al., 2014). The first, awareness, stage reflects the ways of a customer gets information about a product and a brand. During the second, evaluation, stage a customer analyses the received information and provides (sometimes unconsciously) a benchmarking. A purchase stage is responsible for taking a purchase decision. On the last stage, the post-purchase experience, a customer evaluates the purchase and decides whether he or she will stay with a company or a product in the future (Edelman, 2010; Vázquez et al., 2014). In this paper I will use different names for the steps of the customer journey, which reflect the customer journey from the point of view of a company, not a customer. These stages are Entertain, Inspire, Convince and Engage.

A website content featuring customer journey could considerably influence the actions of a customer. Content analysis could help to evaluate the status quo of the strategy used at every stage of customer journey.

Weber (1990) defines content analyses as a research method of making valid inferences from

Fig. 1 - A flowchart for content analysis of a website, adapted from by Parveen, Jaafar, \& Ainin (2013) and Neuendorf (2002). Source: author the text (Weber, 1990). Riffe, Lacy and Fico (1997) explain content analysis as a research technique of replicable examining of the symbols of communication (Riffe, Lacy, \& Fico, 1997). Krippendorf (2004) defines content analysis as a research technique of evaluating a meaningful matter of the content, whether this matter is presented in the form of text, images or voices (Krippendorf, 2004). In the current paper I will understand under content analysis a research technique for systematic inference from communication data/symbols presented in a form of texts, images or voices.

Content analysis as a research method could be used in both qualitative and quantities research (Kim \& Kuljis, 2010). Researchers distinguish certain advantages of the content analysis, including its unobtrusiveness, capability to deal with large quantity of data, focus on artefacts of communication instead of individuals, relative low bias, simplicity and cost effectiveness (Kim \& Kuljis, 2010; Krippendorff, 1980). On the other hand, content analysis as a research technology has several limitations. For instance, some researchers mention a lack of theoretical basis of content analysis and problems with data interpretation (Kim \& Kuljis, 2010).

Previous research on content analysis was mainly focused on the content analysis of social media (Parveen, Jaafar, \& Ainin, 2013). Analysis of websites was focused on a textual analysis (Beninger, Parent, Pitt, \& Chan, 2014; Kohli, Kaur, \& Singh, 2012). Moreover many studies have examined cross-cultural differences in the content (e.g. (Calabrese, Capece, Di Pillo, \& Martino, 2014; Huertas-Garcia, Casas-Romeo, \& Subira, 2013; Nacar \& Burnaz, 2011). 


\section{METHODOLOGY}

The purpose of the current paper was to analyse a content of the websites of the leading B2B industrial companies and to find out whether they consider the customer journey in their content marketing strategy.

The methodology was based on the models of content analysis suggested by Parveen at el (2013) and Neuendorf (2002). The already existing methodology was modified because of two reasons. First, Parveen, Jaafar, \& Ainin, (2013) were examining social media presence, whereby the current research was focusing only on website content analysis. Second, the methodology suggested by Neuendorf (2002) was applicable mostly to offline non-changing content. Chyba! Nenalezen zdroj odkazů. illustrates the process of the content analysis of a website, which has been used in the current research.

\section{Step 1: Conceptualisation}

The first step involved gathering a list of companies. A list of companies of Global 500 for 2015 was used. Global 500 represents a list of top 500 global corporations. It is often believed that the largest global companies could disseminate best practices, because they have enough resources available and possess synergy of the processes. The initial list of 500 companies was reduced to the companies representing B2B sector. After that the working list included 76 companies from the following sectors: Chemicals, Construction \& materials, Electronic \& electrical equipment, General industrials, Industrial engineering, Industrial transportation, Oil equipment \& services and Support services. Such sectors as Oil equipment \& services and Support services were excluded from the analysis due to difference in the nature of the business compared to the other sectors. In order to increase reliability of the research it was decided to concentrate on industrial manufacturing B2B companies. Therefore such sectors as Industrial engineering and Industrial transportation were also excluded from the list. After these manipulations the working list of companies represented 41 global companies from four industries: Chemicals, Construction \& materials, Electronic \& electrical equipment, General industrials.

To facilitate the analysis a spreadsheet in MS Excel was created. A list of companies was complemented by the websites of each company analysed. It is important to note here that only global (in one case, European) websites were taken into consideration in order to avoid the influence of national and cultural characteristics on the content.

After the screening out irrelevant companies three companies were excluded from the list. The first company was focused mostly on B2C sector. The second did not have a global website and led customers directly to a local website depending on the user location. The third company led to a website, which was already included in the list. Both companies represented the same business group. Upon completion of the categorisation process 38 companies were left in the list.

\section{Step 2: Operationalisation}

After obtaining the list of companies and screening their websites, the second step was to identify the types of content the companies use on their websites.

At every stage of the customer journey content has to fulfil a certain function. At the stage of awareness it has to entertain and evoke emotions. At the stage of evaluation the content has to inspire. At the stage of purchase it should convince. At the stage of the post-purchase experience by means of educational and engaging content it should help customers in their possible problems and build loyalty. 
The list of content types was based on Content Marketing Mix (2016), suggested on the portal Smart Insights. The pre-screening of the websites let me to identify some other content types. Finally I have maintained a list of 39 content types that I have divided into four groups concerning the objectives of the content types and the steps of the customer journey. The table in the working spreadsheet had the following headings according to four groups of content types (For the purpose of easiness and simplification I have named the content included in the group "Entertain" as Entertain-content. The other content groups have been respectively named Inspire-content, Convince-content and Engage-content.

Table 2).

For the purpose of easiness and simplification I have named the content included in the group "Entertain" as Entertain-content. The other content groups have been respectively named Inspire-content, Convince-content and Engage-content.

Table 2 - Variables identified for the content analysis of the websites. Source: author

\begin{tabular}{llll} 
Entertain & Inspire & Convince & Engage \\
\hline Corporate brochure & "About"\& facts & Price lists & $\begin{array}{l}\text { Speeches and } \\
\text { presentations* }\end{array}$ \\
Games & Reviews & Data sheets & White papers \& studies \\
Corporate Videos & Forums & Case studies \& references & Guidelines \\
Quizzes & Events & Webinars & Blogs \\
Virals & Celebrity/Experts & Checklists & Product Videos \\
& endorsement & & \\
Brand images & Ratings \& awards & Interactive demos & E-books \\
News \& press releases & & Product features & Trend reports \\
Expert interviews & & Reports & Research magazine \\
Widgets & & Newsletter subscription & Inforgraphics \\
& & Supporting docs (CAD- & Product related \\
& & files, visuals, etc) & background information \\
& & FAQ & Trend / Industry Videos \\
& & Annual reports & \\
\hline
\end{tabular}

*not related to an Annual General Meeting

On this step it is important to choose the scope of the analysis: weather to analyse the whole website or focus only on home or landing page. It was decided to focus mainly on home and landing pages. However as in many cases not much content was available on a home or landing page, it was decided to check websites to the third level. The third level was chosen based on the information that the levels one to three include the main information of a website (Jano et al., 2015), which has been proved during the pre-screening. Each time a specific content type was found on a website, it was included in the working table. The analysis was taken between the $22^{\text {nd }}$ of February and the $6^{\text {th }}$ of March 2016.

\section{Step 3: Coding}

The next step considered a coding of the identified categories. Information about a content type was entered in the table depending if a company obtained certain content type or not. Every positive entry was coded as 1 otherwise as 0 .

The final step included data analysis. 
Table 3 - Reflection of the customer journey in content marketing by industrial B2B companies listed in Global 500. Source: author

\begin{tabular}{|c|c|c|c|c|c|c|c|}
\hline Entertain & $\%$ & Inspire & $\%$ & Convince & $\%$ & Engage & $\%$ \\
\hline Corporate brochure & $47 \%$ & "About" \& facts & $97 \%$ & Price lists & $0 \%$ & Speeches and presentations* & $45 \%$ \\
\hline Games & $0 \%$ & Reviews & $24 \%$ & Data sheets & $65 \%$ & White papers \& studies & $45 \%$ \\
\hline Corporate Videos & $74 \%$ & Forums & $3 \%$ & Case studies \& references & $58 \%$ & Guidelines & $58 \%$ \\
\hline Quizzes & $0 \%$ & Events & $79 \%$ & Webinars & $37 \%$ & Blogs & $21 \%$ \\
\hline Virals & $0 \%$ & $\begin{array}{l}\text { Celebrity/Experts } \\
\text { endorsement }\end{array}$ & $8 \%$ & Checklists & $21 \%$ & Product Videos & $68 \%$ \\
\hline Brand images & $34 \%$ & Ratings \& awards & $39 \%$ & Interactive demos & $58 \%$ & E-books & $3 \%$ \\
\hline News \& press releases & $97 \%$ & & & Product features & $87 \%$ & Trend reports & $45 \%$ \\
\hline Expert interviews & $26 \%$ & & & Reports & $47 \%$ & Research magazine & $34 \%$ \\
\hline \multirow[t]{5}{*}{ Widgets } & $13 \%$ & & & Newsletter subscription & $61 \%$ & Inforgraphics & $26 \%$ \\
\hline & & & & $\begin{array}{l}\text { Supporting docs } \\
\text { (CAD-files, visuals, etc) }\end{array}$ & $26 \%$ & $\begin{array}{l}\text { Product related background } \\
\text { information }\end{array}$ & $74 \%$ \\
\hline & & & & FAQ & $63 \%$ & Trend / Industry Videos & $45 \%$ \\
\hline & & & & Annual reports & $100 \%$ & & \\
\hline & & & & Ask an expert & $39 \%$ & & \\
\hline Statistic Entertain & & Statistic Inspire & & Statistic Convince & & Statistic Engage & \\
\hline Mean Entertain & $32 \%$ & Mean Inspire & $42 \%$ & Mean Convince & $51 \%$ & Mean Engage & $42 \%$ \\
\hline Median Entertain & $26 \%$ & Median Inspire & $32 \%$ & Median Convince & $58 \%$ & Median Engage & $45 \%$ \\
\hline Mode Entertain & $0 \%$ & Mode Inspire & $\mathrm{kA}$ & Mode Convince & $58 \%$ & Mode Engage & $45 \%$ \\
\hline Standard Deviation & $35 \%$ & Standard Deviation & $39 \%$ & Standard Deviation & $27 \%$ & Standard Deviation & $21 \%$ \\
\hline
\end{tabular}

*not related to a Annual General Meeting 


\section{Step 4: Results and Discussion}

After obtaining a list of companies, screening their websites and entering the data on the content type they use, a deep analysis of the results was provided. I calculated a percentage of positive entries ("1") in a total number of entries for every content type. The results are presented in Table 3.

The analysis has shown that not all content types were used by the companies. In terms of entertaining, almost every company regularly published news and press releases. Over $70 \%$ of the analysed companies posted corporate video on their website. Some mentioned continent types as virals, games and quizzes were not used at all. This probably could be explained by the specifics of B2B business, when the decisions are made not based on emotions but the facts. Concerning the Inspire-content, almost every company had a section, related to the facts and history of a company. About $80 \%$ of the companies published upcoming events on their websites.

In terms of convincing customers to take a purchase decision, companies were very effective. They used all content types, which were identified earlier, except the price lists. This could be reasoned by the fact, that the global websites, which were analysed in the current paper, were not willing to confuse customers from different geographical locations, because prices could differ from country to country. Because every company analysed was a public company, every website included an annual or a quarterly report. Furthermore, the majority of companies explained in detail the specifics of their products - by means of publishing data sheets $(65 \%)$ or product features $(87 \%)$. Over $60 \%$ of the companies introduced FAQ and offered a newsletter subscription. These two activities could display a wish to closely interact with the customers. More than one third of the analysed companies went even further and suggested direct communication, providing webinars or a service "Ask an expert" that allows customers to address their specific questions to a responsible department.

In terms of customer engagement, the analysed companies actively used almost every content type, suggested earlier. One exception has concerned e-books. This fact could be explained by the necessity to apply high efforts in creating of an e-book. Moreover some other more simple alternatives, as white papers and research magazines existed. These alternatives were used by $45 \%$ and $34 \%$ of the companies respectively.

Secondly, the results have shown that companies focused on visual content types, as pictures and videos. The share of videos in the whole content was very high $-68 \%$ of the companies published product videos, $74 \%$ - corporate videos and $45 \%$ - industry related videos. It is interesting to note that despite the suggestions of the majority of marketing experts to build bidirectional and direct communication with customers, the leading companies have not done this. So, the share of companies using blogs was only about $21 \%$, those who had a forum - only $3 \%$.

To sum up it should be mentioned that the communication by means of a website keeps being broadcasting and one-directional. The companies tried to entertain customers by adding a lot of visual material, instead of focusing on customers' feedback. Maybe this could be explained by the fact that the analysed companies wanted to separate website and social media, where communication is a priori bi-directional. However, as the current research did not include social media content in the analysis, this could not be proved.

The content analysis results have shown that the analysed companies used less than $70 \%$ (see the data from Bayer from Table 4) of the content available on the market. The minimum share of the 
content used by a company was for China Communications Construction, which used only $13 \%$ of the available content types. The results representing the share of every content group representing customer lifecycle in total amount of content types identified earlier is presented in Table 4.

Table 4 - Distribution of a website content among the content groups reflecting the customer journey. Source: author

\begin{tabular}{|c|c|c|c|c|c|c|}
\hline Sector & Company & $\begin{array}{l}\text { The share of } \\
\text { "Entertain"- } \\
\text { content in } \\
\text { all content }\end{array}$ & $\begin{array}{l}\text { The share of } \\
\text { "Inspire"- } \\
\text { content in } \\
\text { all content }\end{array}$ & $\begin{array}{l}\text { The share of } \\
\text { "Convince"- } \\
\text { content in } \\
\text { all content }\end{array}$ & $\begin{array}{l}\text { The share of } \\
\text { "Engage"- } \\
\text { content in } \\
\text { all e content }\end{array}$ & $\begin{array}{l}\text { The share of } \\
\text { used content } \\
\text { in all } \\
\text { content }\end{array}$ \\
\hline \multirow{15}{*}{ 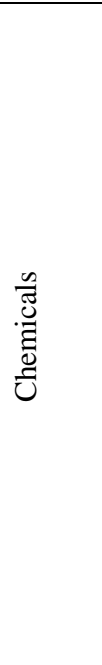 } & Bayer & $13 \%$ & $8 \%$ & $23 \%$ & $26 \%$ & $69 \%$ \\
\hline & Basf & $10 \%$ & $10 \%$ & $18 \%$ & $23 \%$ & $62 \%$ \\
\hline & EI Du Pont de Nemours & $10 \%$ & $8 \%$ & $26 \%$ & $23 \%$ & $67 \%$ \\
\hline & Saudi Basic Industries & $8 \%$ & $3 \%$ & $8 \%$ & $3 \%$ & $21 \%$ \\
\hline & Dow Chemical & $8 \%$ & $5 \%$ & $18 \%$ & $13 \%$ & $44 \%$ \\
\hline & Air Liquide & $10 \%$ & $5 \%$ & $13 \%$ & $18 \%$ & $46 \%$ \\
\hline & LyondellBasell Industries & $10 \%$ & $5 \%$ & $21 \%$ & $8 \%$ & $44 \%$ \\
\hline & Linde & $10 \%$ & $5 \%$ & $18 \%$ & $13 \%$ & $46 \%$ \\
\hline & Praxair & $8 \%$ & $10 \%$ & $18 \%$ & $15 \%$ & $51 \%$ \\
\hline & Ecolab & $8 \%$ & $8 \%$ & $28 \%$ & $23 \%$ & $67 \%$ \\
\hline & Air Products \& Chemicals & $15 \%$ & $5 \%$ & $18 \%$ & $8 \%$ & $46 \%$ \\
\hline & Syngenta & $8 \%$ & $5 \%$ & $15 \%$ & $13 \%$ & $41 \%$ \\
\hline & PPG Industries & $10 \%$ & $10 \%$ & $23 \%$ & $15 \%$ & $59 \%$ \\
\hline & Shin-Etsu Chemical & $5 \%$ & $8 \%$ & $15 \%$ & $13 \%$ & $41 \%$ \\
\hline & $\begin{array}{l}\text { Potash Corporation of } \\
\text { Saskatchewan }\end{array}$ & $10 \%$ & $5 \%$ & $23 \%$ & $13 \%$ & $51 \%$ \\
\hline \multirow{7}{*}{ 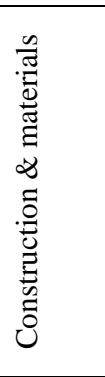 } & $\begin{array}{l}\text { China Communications } \\
\text { Construction }\end{array}$ & $3 \%$ & $5 \%$ & $5 \%$ & $0 \%$ & $13 \%$ \\
\hline & China Railway Group & $3 \%$ & $8 \%$ & $10 \%$ & $0 \%$ & $21 \%$ \\
\hline & $\begin{array}{l}\text { China State Construction } \\
\text { Engineering }\end{array}$ & $3 \%$ & $5 \%$ & $5 \%$ & $3 \%$ & $15 \%$ \\
\hline & China Railway Construction & $5 \%$ & $8 \%$ & $5 \%$ & $3 \%$ & $21 \%$ \\
\hline & Vinci & $13 \%$ & $10 \%$ & $10 \%$ & $15 \%$ & $49 \%$ \\
\hline & Sherwin-Williams & $13 \%$ & $3 \%$ & $21 \%$ & $15 \%$ & $51 \%$ \\
\hline & Larsen \& Toubro & $5 \%$ & $5 \%$ & $13 \%$ & $3 \%$ & $26 \%$ \\
\hline \multirow{7}{*}{ 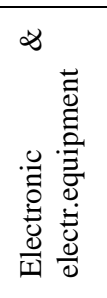 } & Schneider Electric & $5 \%$ & $5 \%$ & $26 \%$ & $18 \%$ & $54 \%$ \\
\hline & Hon Hai Precision Industry & $5 \%$ & $3 \%$ & $18 \%$ & $3 \%$ & $28 \%$ \\
\hline & Emerson Electric & $8 \%$ & $8 \%$ & $26 \%$ & $21 \%$ & $62 \%$ \\
\hline & Keyence & $5 \%$ & $8 \%$ & $26 \%$ & $18 \%$ & $56 \%$ \\
\hline & Hitachi & $5 \%$ & $10 \%$ & $21 \%$ & $21 \%$ & $56 \%$ \\
\hline & Murata Manufacturing & $8 \%$ & $5 \%$ & $21 \%$ & $10 \%$ & $44 \%$ \\
\hline & TE Connectivity & $8 \%$ & $5 \%$ & $18 \%$ & $10 \%$ & $41 \%$ \\
\hline \multirow{9}{*}{ 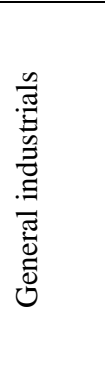 } & General Electric & $11 \%$ & $8 \%$ & $16 \%$ & $11 \%$ & $45 \%$ \\
\hline & $3 \mathrm{M}$ & $8 \%$ & $5 \%$ & $23 \%$ & $18 \%$ & $54 \%$ \\
\hline & Siemens & $10 \%$ & $5 \%$ & $26 \%$ & $26 \%$ & $67 \%$ \\
\hline & Honeywell International & $8 \%$ & $8 \%$ & $28 \%$ & $13 \%$ & $56 \%$ \\
\hline & Danaher & $3 \%$ & $5 \%$ & $13 \%$ & $0 \%$ & $21 \%$ \\
\hline & Hutchison Whampoa & $5 \%$ & $5 \%$ & $5 \%$ & $3 \%$ & $18 \%$ \\
\hline & Jardine Matheson & $5 \%$ & $8 \%$ & $3 \%$ & $3 \%$ & $18 \%$ \\
\hline & Citic & $3 \%$ & $5 \%$ & $5 \%$ & $0 \%$ & $13 \%$ \\
\hline & Eaton & $3 \%$ & $8 \%$ & $18 \%$ & $15 \%$ & $44 \%$ \\
\hline
\end{tabular}


In order to get full picture regarding the content variation used by the analysed companies, it was decided to provide a correlation analysis of the variables. The results have shown a high correlation between a Convince-content and an Engage-content. In other words, the more companies focus on convincing customers to take a purchase decision the more they invest in keeping them engaged after the purchase.

Table 5 - Correlation analysis. Source: author

\begin{tabular}{|l|r|r|r|r|}
\hline Correlation & Entertain & Inspire & Convince & Engage \\
\hline Entertain & 1 & & & \\
\hline Inspire & 0,435 & 1 & & \\
\hline Convince & 0,450 & 0,259 & 1 & \\
\hline Engage & 0,529 & 0,464 & 0,794 & 1 \\
\hline
\end{tabular}

\section{Content Maturity}

The next phase of the research was the identification of a maturity level of content marketing for the analysed companies. The levels of the maturity were identified based on the share of the content variation used by a company at every stage of customer journey. For instance, Eaton used only $11 \%$ of the available Entertain-content variation, $50 \%$ of the Inspire-Content, 54\% of the Convince-Content and 55\% of Engage-Content, which according to Table 6 refers to Level 1 in Entertain-Content, Level 2 in Inspire-Content and Level 3 in both Convince and EngageContent.

Table 6-Content maturity levels. Source: author

\begin{tabular}{|l|l|}
\hline Maturity level & \% \\
\hline Level 1 & $1-25 \%$ \\
\hline Level 2 & $26-50 \%$ \\
\hline Level 3 & $51-75 \%$ \\
\hline Level 4 & $76-100 \%$ \\
\hline
\end{tabular}

The results representing maturity levels for every company analysed are presented in Table 7.

As it could be seen from the results, the companies had different levels of content maturity. Even the leading companies, e.g. Bayer, have not achieved the highest level of maturity at every stage of customer journey. This could be explained by the specifics of B2B sector. As it was mentioned above, the purchase decisions in B2B sector are often made based on facts and not emotions. Therefore the Entertain- and the Inspire-content does not play such important role as in B2C sector. Furthermore the current research has shown positive correlation between the Convince- and the Engage-content.

Table 7 - Maturity level of the content at every stage of customer journey. Source: author

\begin{tabular}{|c|c|c|c|c|c|c|c|c|}
\hline Company & $\begin{array}{c}\text { Share of } \\
\text { used } \\
\text { Entertain- } \\
\text { Content } \\
\text { variation }\end{array}$ & $\begin{array}{c}\text { Share of } \\
\text { used } \\
\text { Inspire- } \\
\text { Content } \\
\text { variation }\end{array}$ & $\begin{array}{c}\text { Share of } \\
\text { used } \\
\text { Convince- } \\
\text { Content } \\
\text { variation }\end{array}$ & $\begin{array}{c}\text { Share of } \\
\text { used } \\
\text { Engage- } \\
\text { Content } \\
\text { variation }\end{array}$ & $\begin{array}{l}\text { Maturit } \\
\text { y of the } \\
\text { Entertai } \\
\text { n- } \\
\text { Content }\end{array}$ & $\begin{array}{l}\text { Maturit } \\
\text { y of the } \\
\text { Inspire- } \\
\text { Content }\end{array}$ & $\begin{array}{c}\text { Maturit } \\
\text { y of the } \\
\text { Convin } \\
\text { ce- } \\
\text { Content }\end{array}$ & $\begin{array}{l}\text { Maturit } \\
\text { y of the } \\
\text { Engage } \\
- \\
\text { Content }\end{array}$ \\
\hline Bayer & $56 \%$ & $50 \%$ & $69 \%$ & $91 \%$ & Level 3 & Level 2 & Level 3 & Level 4 \\
\hline
\end{tabular}




\begin{tabular}{|c|c|c|c|c|c|c|c|c|}
\hline Basf & $44 \%$ & $67 \%$ & $54 \%$ & $82 \%$ & Level 2 & Level 3 & Level 3 & Level 4 \\
\hline EI Du Pont de Nemours & $44 \%$ & $50 \%$ & $77 \%$ & $82 \%$ & Level 2 & Level 2 & Level 4 & Level 4 \\
\hline Saudi Basic Industries & $33 \%$ & $17 \%$ & $23 \%$ & $9 \%$ & Level 2 & Level 1 & Level 1 & Level 1 \\
\hline Dow Chemical & $33 \%$ & $33 \%$ & $54 \%$ & $45 \%$ & Level 2 & Level 2 & Level 3 & Level 2 \\
\hline Air Liquide & $44 \%$ & $33 \%$ & $38 \%$ & $64 \%$ & Level 2 & Level 2 & Level 2 & Level 3 \\
\hline Lyondell Basell Industries & $44 \%$ & $33 \%$ & $62 \%$ & $27 \%$ & Level 2 & Level 2 & Level 3 & Level 2 \\
\hline Linde & $44 \%$ & $33 \%$ & $54 \%$ & $45 \%$ & Level 2 & Level 2 & Level 3 & Level 2 \\
\hline Praxair & $33 \%$ & $67 \%$ & $54 \%$ & $55 \%$ & Level 2 & Level 3 & Level 3 & Level 3 \\
\hline Ecolab & $33 \%$ & $50 \%$ & $85 \%$ & $82 \%$ & Level 2 & Level 2 & Level 4 & Level 4 \\
\hline Air Products \& Chemicals & $67 \%$ & $33 \%$ & $54 \%$ & $27 \%$ & Level 3 & Level 2 & Level 3 & Level 2 \\
\hline Syngenta & $33 \%$ & $33 \%$ & $46 \%$ & $45 \%$ & Level 2 & Level 2 & Level 2 & Level 2 \\
\hline PPG Industries & $44 \%$ & $67 \%$ & $69 \%$ & $55 \%$ & Level 2 & Level 3 & Level 3 & Level 3 \\
\hline Shin-Etsu Chemical & $22 \%$ & $50 \%$ & $46 \%$ & $45 \%$ & Level 1 & Level 2 & Level 2 & Level 2 \\
\hline PCS* & $44 \%$ & $33 \%$ & $69 \%$ & $45 \%$ & Level 2 & Level 2 & Level 3 & Level 2 \\
\hline $\mathrm{CCC}^{* *}$ & $11 \%$ & $33 \%$ & $15 \%$ & $0 \%$ & Level 1 & Level 2 & Level 1 & Level 1 \\
\hline China Railway Group & $11 \%$ & $50 \%$ & $31 \%$ & $0 \%$ & Level 1 & Level 2 & Level 2 & Level 1 \\
\hline $\operatorname{CSCE}^{* * *}$ & $11 \%$ & $33 \%$ & $15 \%$ & $9 \%$ & Level 1 & Level 2 & Level 1 & Level 1 \\
\hline China Railway Construction & $22 \%$ & $50 \%$ & $15 \%$ & $9 \%$ & Level 1 & Level 2 & Level 1 & Level 1 \\
\hline Vinci & $56 \%$ & $67 \%$ & $31 \%$ & $55 \%$ & Level 3 & Level 3 & Level 2 & Level 3 \\
\hline Sherwin-Williams & $56 \%$ & $17 \%$ & $62 \%$ & $55 \%$ & Level 3 & Level 1 & Level 3 & Level 3 \\
\hline Larsen \& Toubro & $22 \%$ & $33 \%$ & $38 \%$ & $9 \%$ & Level 1 & Level 2 & Level 2 & Level 1 \\
\hline Schneider Electric & $22 \%$ & $33 \%$ & $77 \%$ & $64 \%$ & Level 1 & Level 2 & Level 4 & Level 3 \\
\hline Hon Hai Precision Industry & $22 \%$ & $17 \%$ & $54 \%$ & $9 \%$ & Level 1 & Level 1 & Level 3 & Level 1 \\
\hline Emerson Electric & $33 \%$ & $50 \%$ & $77 \%$ & $73 \%$ & Level 2 & Level 2 & Level 4 & Level 3 \\
\hline Keyence & $22 \%$ & $50 \%$ & $77 \%$ & $64 \%$ & Level 1 & Level 2 & Level 4 & Level 3 \\
\hline Hitachi & $22 \%$ & $67 \%$ & $62 \%$ & $73 \%$ & Level 1 & Level 3 & Level 3 & Level 3 \\
\hline Murata Manufacturing & $33 \%$ & $33 \%$ & $62 \%$ & $36 \%$ & Level 2 & Level 2 & Level 3 & Level 2 \\
\hline TE Connectivity & $33 \%$ & $33 \%$ & $54 \%$ & $36 \%$ & Level 2 & Level 2 & Level 3 & Level 2 \\
\hline General Electric & $44 \%$ & $50 \%$ & $50 \%$ & $36 \%$ & Level 2 & Level 2 & Level 2 & Level 2 \\
\hline $3 \mathrm{M}$ & $33 \%$ & $33 \%$ & $69 \%$ & $64 \%$ & Level 2 & Level 2 & Level 3 & Level 3 \\
\hline Siemens & $44 \%$ & $33 \%$ & $77 \%$ & $91 \%$ & Level 2 & Level 2 & Level 4 & Level 4 \\
\hline Honeywell International & $33 \%$ & $50 \%$ & $85 \%$ & $45 \%$ & Level 2 & Level 2 & Level 4 & Level 2 \\
\hline Danaher & $11 \%$ & $33 \%$ & $38 \%$ & $0 \%$ & Level 1 & Level 2 & Level 2 & Level 1 \\
\hline Hutchison Whampoa & $22 \%$ & $33 \%$ & $15 \%$ & $9 \%$ & Level 1 & Level 2 & Level 1 & Level 1 \\
\hline Jardine Matheson & $22 \%$ & $50 \%$ & $8 \%$ & $9 \%$ & Level 1 & Level 2 & Level 1 & Level 1 \\
\hline Citic & $11 \%$ & $33 \%$ & $15 \%$ & $0 \%$ & Level 1 & Level 2 & Level 1 & Level 1 \\
\hline Eaton & $11 \%$ & $50 \%$ & $54 \%$ & $55 \%$ & Level 1 & Level 2 & Level 3 & Level 3 \\
\hline
\end{tabular}

* Potash Corporation of Saskatchewan; ** China Communications Construction;*** China State Construction Engineering

\section{CONCLUSION}

Not many studies have been conducted on the analysis of content maturity. The current study had an aim to provide a framework for content analysis of the websites based on the example of the leading global B2B industrial companies. 39 types of contents were identifies for the purpose of analysis. They were divided into four groups that reflect four stages of customer journey. The 
results have shown that the companies have not used all available content types. Moreover they have not always concentrated on achieving the best results in content variations. If to look at the maturity levels for every step of the customer journey one can see that the majority of the companies achieved the second level of maturity for the Entertainment- and the Inspire-content. This could be reasoned by the specifics of B2B sector, when emotions do not play such important role as in $\mathrm{B} 2 \mathrm{C}$ sector. In general, the analysis has shown high percentage of visual content, especially videos. However, contrary to the opinion of many marketing experts, the communication with customers keeps being one-directional, although some changes have been maintained.

The current research is beset with some limitations. The paper considers only website content. As it has been already mentioned by Kim and Kuljiis (2010) websites are characterised with always changing content, which makes the analysis rather difficult. Second, I did not analyse the whole site, only a home page or a landing page, or the main menu until the third level. An alternative to my method would be downloading the whole website, as it was suggested in some other studies (e.g. (Beninger et al., 2014; Kim \& Kuljis, 2010)). However, this could lead to some legal and copyright issues. This limitation could lead to the fact that some content types could be looked and therefore not included in the analysis. Third, it was decided that if a certain type of content appear at least once, it should be included in the list. However because no other researchers clearly describe the analysis of a website, it was decided to keep this rule. Forth, the number of the companies was limited. It is suggested to provide similar research with a bigger sample set. Finally, the current research does not examine deeply the content maturity, suggesting four levels based on the percentage share. The mentioned above gaps in the research could be used for the future research.

The current paper could be beneficial for science, practitioners and academic research. There is a lack of scientific research on digital maturity models. The current paper on content maturity could be seen as an attempt to develop this area. The paper could be used as a base for the future research. From the practical point of view, this research could be interesting for B2B industrial companies, because it provides the analysis of the content of the leading global companies representing the best practices. The results of the analysis could be used with the purpose to develop and amend a company content strategy. The current research could be interesting for academician, because provide a knowledge base for further development of the topic.

\section{References}

Beninger, S., Parent, M., Pitt, L., \& Chan, A. (2014). A content analysis of influential wine blogs. International Journal of Wine Business Research, 26(3), 168-187. https://doi.org/10.1108/IJWBR-09-2013-0036

Calabrese, A., Capece, G., Di Pillo, F., \& Martino, F. (2014). Cultural adaptation of web design services as critical success factor for business excellence. Cross Cultural Management: An International Journal, 21(2), 172-190. https://doi.org/10.1108/CCM-09-2012-0070

Edelman, D. C. (2010). Branding in the digital age: You're spending your money in all the wrong places. Harvard Business Review, 88(12), 39-65. https://doi.org/10.1002/cmr.a

Gillin, P., \& Schwartzman, E. (2011). Social Marketing to the Business Customer: Listen to Your B2B Market, Generate Major Account Leads, and Build Client Relationships. Journal of Chemical Information and Modeling , 53. 
Holliman, G., \& Rowley, J. (2014). Business to business digital content marketing: marketers' perceptions of best practice. Journal of Research in Interactive Marketing, 8(4), 269-293. https://doi.org/10.1108/JRIM-02-2014-0013

Huertas-Garcia, R., Casas-Romeo, A., \& Subira, E. (2013). Cross-cultural differences in the content and presentation of web sites. Kybernetes, 42(5), 766-784. https://doi.org10.1108/K-03-2013-0061

Jano, Z., Noor, S. M., Ahmad, R., Md Saad, M. S., Saadan, R., Bokhari, M., \& Abdullah, A. N. (2015). Website usability and cultural dimensions in Malaysian and Australian universities. Asian Social Science, 11(9), 1-10. https://doi.org/10.5539/ass.v11n9p1

Järvinen, J. ., Tollinen, A. ., Karjaluoto, H. ., \& Jayawardhena, C. (2012). Digital and Social Media Marketing Usage in B2B Industrial Section. Marketing Management Journal, 22(2), 102-117.

Kim, I., \& Kuljis, J. (2010). Applying content analysis to web based content. Journal of Computing and Information Technology, 18(4), 369-375. https://doi.org/10.2498/cit.1001924 369

Kohli, S., Kaur, S., \& Singh, G. (2012). A website content analysis approach based on keyword similarity analysis. In Web Intelligence and Intelligent Agent Technology (WI-IAT), 2012 IEEE/WIC/ACM International Conferences on, 1, 254-257). https://doi.org/10.1109/WIIAT.2012.212

Krippendorf, K. (2004). Reliability in content analysis: Some common misconceptions and recommendations. Human Communication Research, 30, 411-433. https://doi.org10.1111/j.1468-2958.2004.tb00738.x

Krippendorff, K. (1980). Content Analysis: An Introduction to Its Methodology. Sage, London. https://doi.org/10.2307/2288384

The Content Marketing Matrix. (2016, February 23). Retrieved March 30, 2016, from http://www.smartinsights.com/content-management/content-marketing-strategy/thecontent-marketing-matrix-new-infographic

Nacar, R., \& Burnaz, S. (2011). A cultural content analysis of multinational companies' web sites. Qualitative Market Research: An International Journal, 14(3), 274-288. https://doi.org/10.1108/13522751111137505

Neuendorf, K. A. (2011). The content analysis guidebook (2nd ed.). Thousand Oaks, CA: Sage.

Parveen, F., Jaafar, N. I., \& Ainin, S. (2013). Social Media Usage Among Businesses: A Website Content Analysis. Asian Journal of Information Technology, 12(10), 342-348. https://doi.org/10.3923/ajit.2013.342.348

Riffe, D., Lacy, S., \& Fico, F. G. (1997). Analyzing Media Messages: Using Quantitative Content Analysis in Research. College Composition and Communication (Vol. 48). https://doi.org/10.2307/358412

Vázquez, S., Muñoz-García, Ó., Campanella, I., Poch, M., Fisas, B., Bel, N., \& Andreu, G. (2014). A classification of user-generated content into consumer decision journey stages.

Neural Networks, 58, 68-81. https://doi.org/10.1016/j.neunet.2014.05.026

Weber, P. (1990). Basic content analysis (2nd ed.). Newbury Park, CA: Sage Publications.

Wymbs, C. (2011). Digital Marketing: The Time for a New “Academic Major" Has Arrived. Journal of Marketing Education, 33(1), 93-106. https://doi.org/10.1177/0273475310392544

Contact information 
Elina Bakhtieva

Department of marketing

Faculty of Management and Economics

Tomas Bata University in Zlín

Mostní 5139 - Zlín (U2 Building) - Czech Republic

+4367657068 80

bakhtieva@fame.utb.cz

orcid.org/0000-0002-8176-2319

DOI: https://www.doi.org/10.7441/dokbat.2016.04 


\title{
SOLVING BUSINESS DECISION-MAKING PROBLEMS WITH AN IMPLEMENTATION OF AZURE MACHINE LEARNING
}

\author{
Luis Antonio Beltran Prieto and Ravindra Hewa Kuruppuge
}

\begin{abstract}
Business decision making is always risky and critical. The optimization of profit or cost is not guaranteed unless decisions are taken in the right time and the right way. Therefore, business decision-making is mostly supported by mathematical or statistical techniques. With the development of the technology, some business decisions-making models are developed to facilitate managers to take their decisions. The aim of this paper is to introduce a decision tree regression model built on the Azure Machine Learning platform and use it to predict and compare the performance of telecommunication industry between Mexico and Sri Lanka. Data related to telecommunication industry from both countries were collected from various reliable secondary sources. Data analysis was carried out in Azure Machine Learning. Results of the model indicated the ability of the model in terms of forecasting information, in this case, mobile cellphone subscriptions, which can be used by companies or the government to develop new technologies, offer new services or plan budgets. Results further reflected that managers of any business field can make predictions based on these models to make their decisions effectively at very high accuracy levels. However, other kind of projects can also be identified in order to test and apply these techniques in the solution of real-life problems, including those from the noncomputer related fields of study.
\end{abstract}

Keywords: Decision making, business models, Azure Machine Learning, Artificial Intelligence Algorithms, Mexico and Sri Lanka

\section{INTRODUCTION}

Business decisions are taken in various ways. The optimal decision is mostly supported by mathematical or statistical techniques. Rust \& Huang (2014) mentioned that models and data are having a huge role to play in efficient and effective organizational decision making. Yet, selecting appropriate model to get effective decisions is important as there are many business supporting models, such as regression, correlation, transportation, liner programming, time series, waiting line and game theory, which are popular among practitioners and scholars.

In top of all, regression models are tools used for analysis of the relationships between a dependent variable and a set of independent variables. The aim of regression analysis is to estimate an output value based on the strength of relationship between the dependent variable with the rest of the features. Thus, the decision-making process can benefit from a regression model that analyses data and predicts an outcome. This is an important task in different fields of study. For instance, data-adaptive regression was used to diagnosis a medical score that is developed to estimate the probability of mortality among stroke victims (Birkner et al, 2007); moreover, a multivariable linear regression model contributed to predict the daily mean cooling load of buildings by considering features such as temperature and building materials (Qiang, Zhe, Yan \& Neng, 2015); a cross-sectional regression model predicted the credit spread among firms, as indicated by (Yu, 2005). 
On the other hand, decision trees are well-known predictive algorithms often used for tasks such as classification, regression, and survival analysis (Rokach, 2016). A decision forest is an ensemble of decision trees which are improved by the recursive training of multiple trees. A decision forest algorithm starts by setting parameters, such as resampling method, number of decision trees and their depth, among others. Data are splitted in two partitions thereafter: the training set and the test set. The training partition is used by the algorithm to deploy a series of trees, determine the rules contained in the decision trees and build the model. Finally, this proposed model is evaluated against the test partition.

In this paper, we use a decision forest regression model on Azure Machine Learning platform in order to predict and compare the performance of telecommunication industry between Mexico and Sri Lanka. The structure of the paper is as follows. First, the importance of telecommunication industry nowadays is provided. Then, a general background of both countries in terms of this technology is presented, followed by a description of the decision forest regression model. The next section describes how the specific data was integrated in the model, including how the parameters were set. Results, their evaluation and comments are presented thereafter. The final part of the paper includes the conclusion and future work related with the current paper.

\section{METHODS AND METHODOLOGY}

Methods and methodology of this article can be split into two parts. First, an overview of the model and its background information are given. The model developed through software is simple and user friendly. The model can be upgraded with the requirement of the objectives of the analysis. Even a person who has a basic computer literacy can upgrade the software in line with the requirement. In this paper, a decision forest regression model is used on Azure Machine Learning in order to predict and compare the performance of telecommunication industry between Mexico and Sri Lanka.

Regression algorithms are generally supervised techniques, i.e. they learn through known data, in order to forecast new values. These algorithms use data features in order to build accurate predictions by determining the contribution of each characteristic to the regression model in the process. The learning phase is also known as the training phase.

A Decision Tree is a predictive model which forecasts values by creating sets of rules based on the data features and a calculated value. A rule can be as simple as "For this data row, is the value of feature $X$ greater than $Y$ ", where $\mathrm{X}$ is a specific attribute from the data set and $\mathrm{Y}$ is a value calculated by the algorithm. Different rules are applied after, whether the condition is met or not. In 2-class models, the rule has only two possible answers, such as true/false, or yes/no. However, in multiclass models, there are more than two choices, such as easy/hard/medium, $A / B / C$, etc. A node can be either a rule (non-leaf node) or a final value (leaf node). The maximum number of nodes until a leaf-node is reached (counting from the very first rule) is known as the depth of the tree. A decision tree can be either a classification tree or a regression tree, depending on the leaf-node value. For instance, a classification tree generates class values, such as hot, cold, survived, died, will churn, will not churn, etc. while a regression tree generates numeric values, such as the price of a car, the number of days that a customer will stay with a company, or the cost of a strategy. 
Decision trees test data rows and data features building binary trees of rules, i.e. trees with two nodes only until a leaf node is reached, as depicted on Figure 01. During training and prediction, they are efficient in resource usage. Moreover, they perform a feature selection process in the training phase, meaning that non-relevant characteristics of data are discarded or assigned a small weight value.

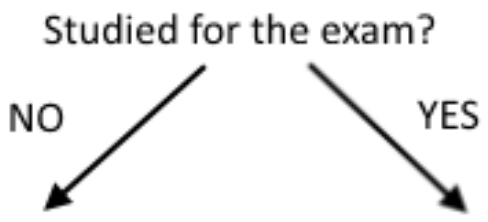

\section{Submitted all homework? Attended the guest lecture?}

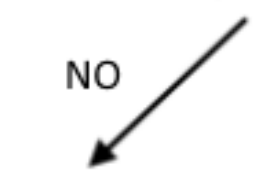

Not pass

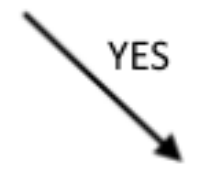

Pass

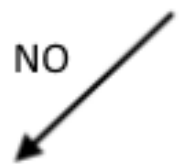

Not pass

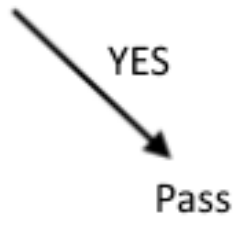

Figure 1 - A Classification Decision Tree example. Source: Authors' impression

When several decision trees are generated, a forest is created. Each decision tree contains its own set of rules, nodes, and values, as shown in Figure 02. A predicted new value is generated after the evaluation of each tree according to the feature values of the data row.
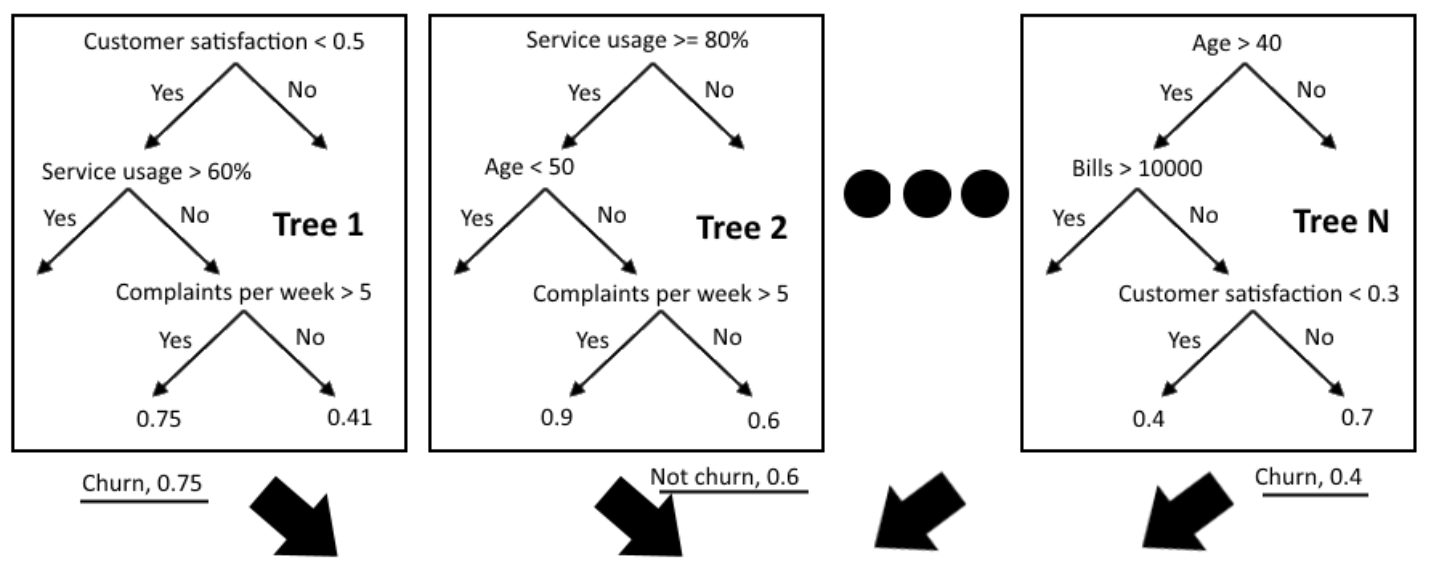

Mode for classification $=$ Churn

Average for regression $=0.7$

Figure 2 - A Decision Forest Model Example. Source: Authors' impression

Decision Trees and Forests have been widely used in research to solve problems, such as building recommendation systems (Zhang \& Min, 2016), improving the performance of a heuristic classifier known as Ant Colony (Kozak \& Boryczka, 2015), and modelling of water quality (Everaert, Bennetsen, and Goethals, 2016). Predicting outcomes is one of their applications, so they can be integrated into regression problems. In this case, a decision forest regression algorithm starts by setting several parameters, including the number of decision trees, the maximum depth of each tree and the splits per node, among others. Then it works as a supervised learning method, which means that it requires previously known data in order to 
predict future values. These data are splitted in two partitions thereafter: the training set and the test set. The training partition is used by the algorithm to deploy a series of layers, determine the weight of input units and build the model. Finally, this proposed model is evaluated against the test partition.

\subsection{Azure Machine Learning}

Azure Machine Learning (AML) is a managed cloud service that can be applied to build and deploy predictive analytic solutions. It can be used either by scientists who want to apply machine learning algorithms or by developers who want to integrate data science into their projects. Both basic machine learning tasks, such as classification, regression, clustering, and anomaly detection, and advanced machine learning capabilities including text analytics and computer vision are possible to use in this cloud service.

Regression algorithms, which are used to predict a value based on different features by determining the contribution of each feature to a function, are included in AML in different flavors. For instance, Bayesian Linear Regression, Poisson Regression, Neural Network Regression, and Decision Forest Regression, among others. For this study, we have chosen the latter one. Moreover, Decision Forest Regression in AML can be customized by setting several properties, namely the resampling method -to specify how the trees are created-, number of decision trees -to determine the size of the forest-, maximum depth of the decision trees -a value that defines the highest possible number of nodes of any decision tree-, and the number of random splits per node - a value that partitions the features of the data-. Each property will be described in the Data Analysis and Discussion section.

Data are uploaded to the model. This study is based on secondary data reported over the last five years from both countries, Mexico and Sri Lanka. Secondary data of some of macro variables, such as GDP per capita, inflation, education level of both counties is used to perform the data analysis. The whole analyses will be done by the model. The impact on some of macro variables on number of telephone subscribers in each country will be measured by the model. The model is shown by figure 03 .

\section{STUDY CONTEXTS}

Communication is considered as one of the prime human and social requirements. Communication is simply defined by Derek Tannis and August (2010) as a common way of speaking, talking, writing to sending a massage to another person or group of people. Accordingly, communication has become the most valued media in the case of business and individual purposes of exchanging ideas, opinions and information. With this human requirement, telecommunication has become mostly a profitable industry in service sector. Especially, GSM and CDMA technologies have tremendously impacted on mobile communication development in the world. As a result, several developing countries, including Sri Lanka and Mexico, have experienced a rapid development in mobile telecommunication. There are five main service providers in Sri Lanka, namely Bharti Airtel Lanka (Pvt) Ltd, Dialog Telecom Ltd, Hutchison Telecommunications Lanka (Pvt) Ltd, Mobitel (Pvt) Ltd and Etisalat (Pvt) Ltd which are dominating the mobile telecommunication market. Mexico, on its part, considers Telcel (67.8\%), Telefonica (21.9\%), Iusacell-Unefon (4.8\%), Nextel (4.8\%), and OMV 
$(0.7 \%)$ as its lead mobile-communications service providers (Instituto Federal de Telecomunicaciones, 2015).

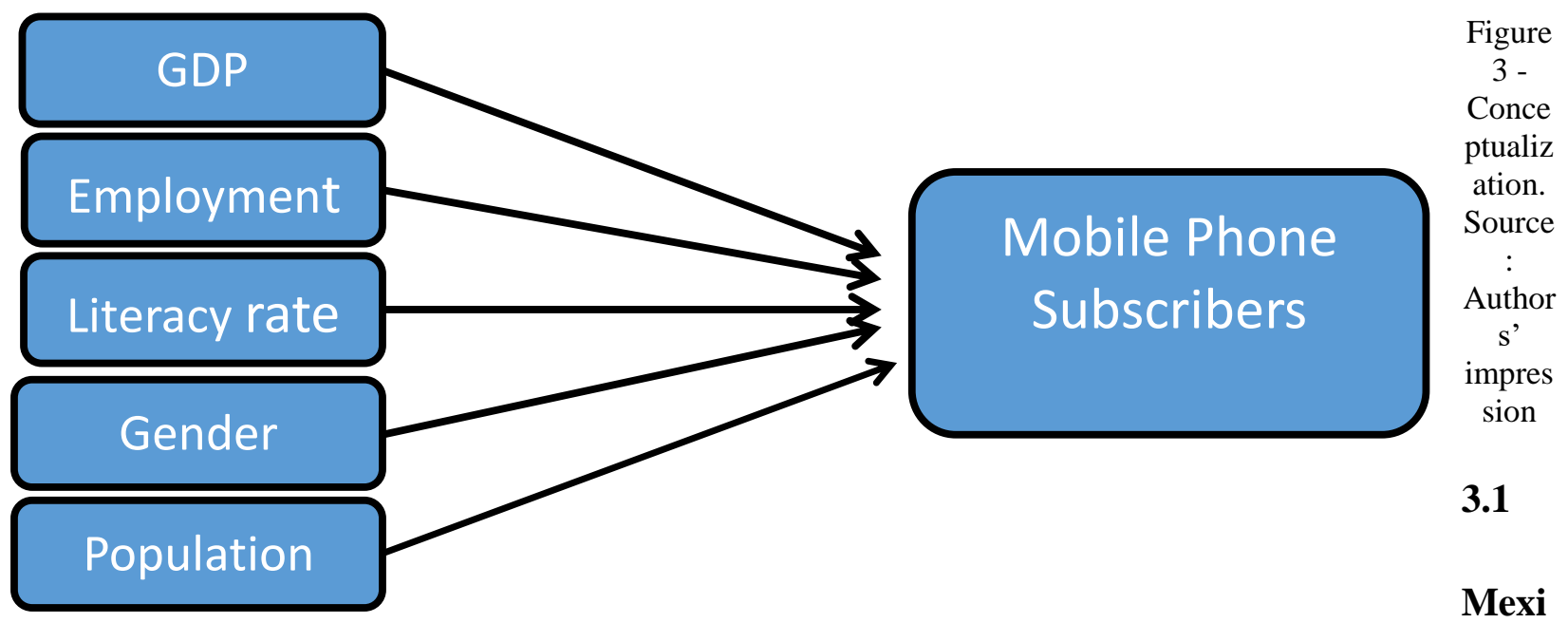

co

Mexico is a country located in North America and the 14th largest country of the world, covering approximately 1, 960, 000 square kilometers of land (INEGI, 2015). Mexico is the 11th most populated country of the world, with more than 119 million habitants, being the State of Mexico and Mexico City the two most populated federal entities of the country, covering $21 \%$ of the population. The country is a federation comprising thirty-two states. The literacy rate of the country is around 93.62\%. Mexico accounts for an estimated USD 2.2 trillion GDP in 2015 (IMF, 2015; CIA, 2015) and has been categorized as an emerging market with an expected 2.6 and 2.9 projection growth rate in 2016 and 2017, respectively. The services sector has been pointed out as the main economic activity of the country, accounting $62.4 \%$ of the country's GDP while industry makes a significant $34.1 \%$ contribution to the country's economy. Mexico has become the United States' second-largest destination of exports and the third-largest imports market.

According to (Ordóñez, Bouchaín, Schinca, 2013), the country's smartphone adoption is increasing, even though it hasn't reached a 100\% mobile connection penetration. 59.8\% of all mobile connections in Mexico are now linked to smartphones. Samsung (24\%), Apple (15\%), LG (14.7\%), Motorola (11.7\%), and Nokia (9.5\%) control the mobile phone manufacturers' market share in the country (Alamilla \& Camargo, 2015). Still, the biggest challenge to achieve more subscriber penetration in the country is to bring access in rural areas to telecommunications. In 2013, a Telecommunications and Broadcasting Reform in Mexico was signed into law in order to guarantee economic competition and encourage access to Internet, digital television and other new technologies, bringing benefits to users in the mobile sector, such as lower charges and market competition (Diario Oficial de la Federación de Mexico, 2013). Thus, Mexico is considered to be experiencing a new, modern era in the telecommunications sector, relying on it to increase productivity, education level, and the people's quality life. 


\subsection{Sri Lanka}

Sri Lanka is an island located in the Indian Ocean occupying approximately $65,600 \mathrm{Km}^{2}$. The country's population accounts for approximately 21 million and around $80 \%$ of them are living in rural areas. The literacy rate of the country is around $92 \%$. Sri Lanka's $\$ 64$ billion economy is poised for a steady economic rebound in the next three to five years. According to the International Monetary Fund (IMF), the economy expanded 6.4\% in 2012 and is forecast to grow by $6.3 \%$ and $6.7 \%$ in 2013 and 2014 respectively. The service sector accounts for almost $60 \%$ of the economy, while agriculture and manufacturing also make significant contributions. There is a strong push to develop ICT capabilities through investment in infrastructure and ICT education in order to position Sri Lanka as a knowledge and outsourcing hub in order to bring in foreign revenue.

Sri Lankan government investments for Information Technology are having an increasing trend. The latest governments in charge have attempted to provide the infrastructure for ICT industry. Interestingly, around 50\% of the population in Sri Lanka have mobile phones. Yet, there is still headroom for subscriber penetration in the country. On the face of it, the bulk of this growth would come from closing the urban-rural division -current mobile ownership is around 53\% in urban cities compared to $42 \%$ in rural areas. Given that the majority (85\%) of the population resides outside of cities, even if rural ownership plateaued at 50\%, this still implies an incremental rise of 1.2 million people based on the current levels. While coverage non-spots and digital literacy are barriers to this, we believe that affordability, particularly in rural areas, also presents a considerable challenge. Rural households have fewer income earners (1.7 versus 1.9 in cities) while household incomes are $25 \%$ lower than those in urban areas.

\section{DATA ANALYSIS AND DISCUSSION}

Data was analysed using Azure Machine Learning Studio. The datasource includes secondary data of both countries. For this analysis, we considered population percentage, literacy rate, employment rate, and GDP per capita as the independent variables, while the dependent variable for prediction tasks was mobile cellphone subscriptions number.

First, Mexico's data analysis was performed. Figure 04 depicts the elements involved in the design of the model. To begin with the design, the aforementioned information of the country, such as literacy rate and employment rate among others, for each of the thirty-two states of the country is submitted into the tool in a Comma-Separated-Values (CSV) format, representing the data source of the analysis. Right after, a Split Data module is incorporated in order to separate data into two halves, each containing the statistics from a different year. The first part consisted of data from 2010, while the second one comprised information from 2015. A Decision-Forest Regression model was considered for this analysis. Parameters were set as shown in Table 01 for the training phase. 


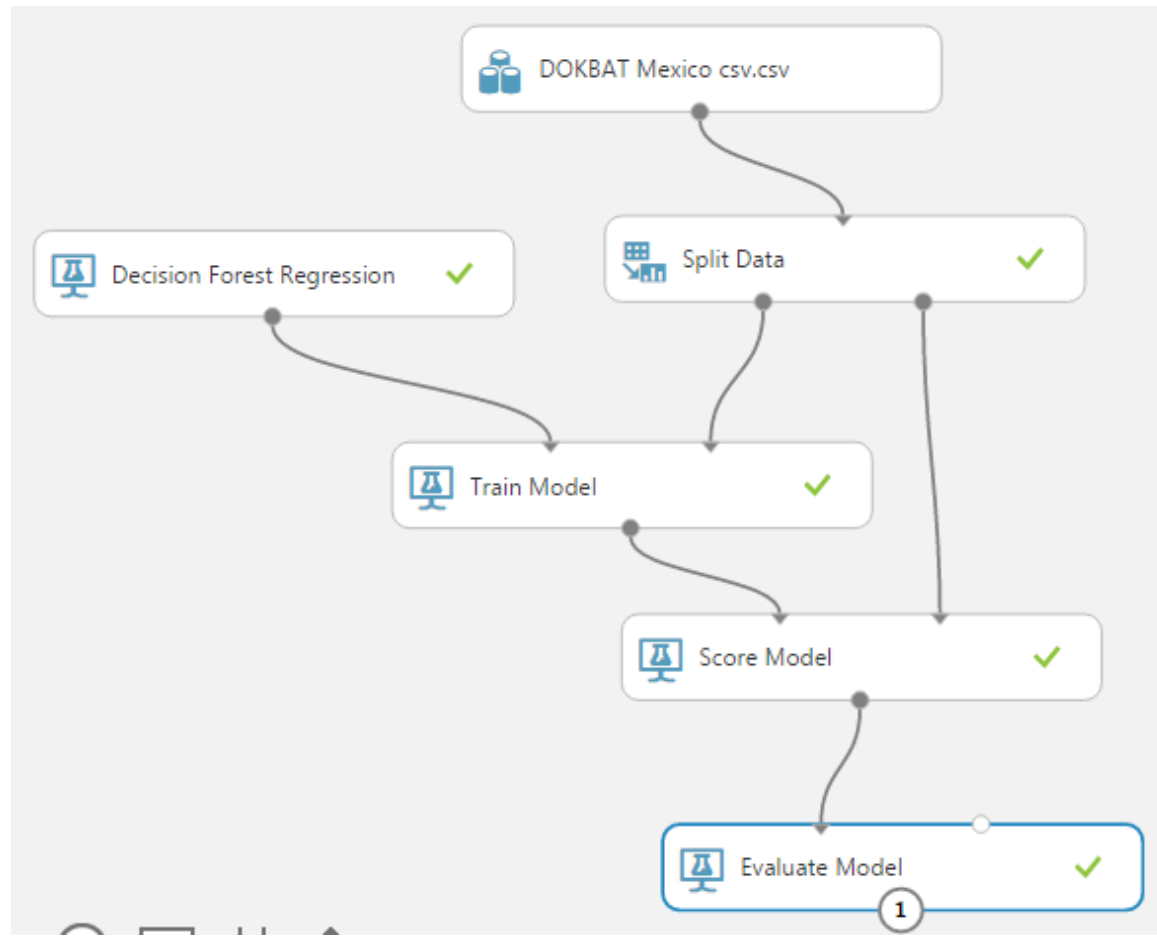

Figure 4 - Components for Mexico's data analysis. Source: Authors' analysis in Azure Machine Learning Studio

Table 1 - Parameters and values used for Mexico's data analysis

\section{Parameter}

Resampling method

Trainer mode creation

Number of decision trees

Maximum depth of the decision trees

Number of random splits per node

Minimum number of samples per leaf node

Allow unknown values for categorical features
Value

Bagging

Single parameter

8

32

128

1

Yes

Resampling refers to the way that Decision Forest algorithm creates the individual trees. In this case, we chose the Bagging method, also known as Bootstrap aggregating, in which each tree generates a Gaussian distribution for prediction purposes. As for Trainer mode creation, a Single-parameter option was selected in order to allow us to configure the rest of the numeric parameters. On the one hand, the number of decision trees that are generated affects both training time and effectivity. While an increased number provides better results, it also makes the learning phase to take more time. On the other hand, the depth of the decision trees influences precision, overfitting risk, and training time. Overfitting refers to a random error which can be generated when a model's complexity is raised up. The number of random splits when building each node of the tree means that attributes from the data source are randomly selected in each level of the node. Finally, the number of cases required to create any leaf in a tree is determined by the number of samples per leaf node parameter. Due to the fact that there are no unknown 
values in our data source, the setting that allows unknown values for categorical features is irrelevant.

As previously stated, data was split into two parts. On the one hand, the section which covers Mexico's 2010 data was used to train the Decision Forest model. Machine learning algorithms discover patterns and trends through training phases in order to forecast behaviours and predict new values. On the other hand, the remaining data include Mexico's 2015 information and were used for testing purposes, i.e. scoring and evaluating the designed model. After a model is developed with the provided data source, the chosen algorithm and the specified configuration, it is first scored against known data, which in this case means that it will make predictions of the mobile cellphone subscription number from the 2015 data. This can be seen in Figure 05, where the column labelled "Mobile cellphones subscriptions" refers to the real values for Mexico during 2015 while the data below "Scored Label Mean" indicate the estimation obtained by the proposed model. Right after, the forecasted values are compared against the real ones by using the Evaluation module in order to test the model's accuracy.

\begin{tabular}{|c|c|c|c|c|c|c|c|c|c|}
\hline ge & $\begin{array}{l}\text { Literacy } \\
\text { rate }\end{array}$ & $\begin{array}{l}\text { Male } \\
\text { literacy }\end{array}$ & $\begin{array}{l}\text { Female } \\
\text { literacy }\end{array}$ & $\begin{array}{l}\text { Employment } \\
\text { rate }\end{array}$ & $\begin{array}{l}\text { Male } \\
\text { employment }\end{array}$ & $\begin{array}{l}\text { Female } \\
\text { employment }\end{array}$ & $\begin{array}{l}\text { PIB per capita } \\
\text { (USD) }\end{array}$ & $\begin{array}{l}\text { Mobile } \\
\text { cellphones } \\
\text { subscriptions }\end{array}$ & $\begin{array}{l}\text { Scored Label } \\
\text { Mean }\end{array}$ \\
\hline & 1. |n|l|| & IIllihn. & 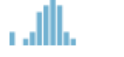 & 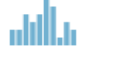 & Inll|l. . & In.|.|.|. & |l|l|r. & & ||..1 . . \\
\hline 7 & 97.03229 & 48.12882 & 51.87118 & 53.71 & 70.38 & 38.18 & 10912.76875 & 1027421 & 1001054.635417 \\
\hline 9 & 97.57875 & 49.622441 & 50.377559 & 55.98 & 70.42 & 41.79 & 10194.59803 & 2878600 & 2808454.322917 \\
\hline 4 & 96.78992 & 50.797669 & 49.202331 & 58.31 & 73.16 & 43.07 & 9653.910976 & 862681 & 972478.25 \\
\hline 4 & 92.876582 & 49.13007 & 50.86993 & 51.69 & 71.61 & 32.78 & 11561.78695 & 799052 & 856966.0625 \\
\hline 9 & 84.198297 & 49.917016 & 50.082984 & 44.48 & 69.1 & 21.81 & 3177.151228 & 3081874 & 3005699.416667 \\
\hline 8 & 94.986468 & 48.746976 & 51.253024 & 51.68 & 67.47 & 36.6 & 11835.84159 & 2983750 & 3111565.835417 \\
\hline & 97.098022 & 49.001915 & 50.998085 & 51.43 & 69.26 & 34.23 & 12123.77473 & 2891947 & 2930557.397917 \\
\hline
\end{tabular}

Figure 5 - Partial visualization of the results obtained by the model. Source: Authors' anaylsis in Azure Machine Learning Studio

As shown in Figure 06, our proposed model obtained a $72.27 \%$ coefficient-of-determination value, which is considered as a standard way of measuring how well the model predicts the data.

\begin{tabular}{llll|l}
$\begin{array}{l}\text { Mean Absolute } \\
\text { Error }\end{array}$ & $\begin{array}{l}\text { Root Mean Squared } \\
\text { Error }\end{array}$ & $\begin{array}{l}\text { Relative Absolute } \\
\text { Error }\end{array}$ & $\begin{array}{l}\text { Relative Squared } \\
\text { Error }\end{array}$ & $\begin{array}{l}\text { Coefficient of } \\
\text { Determination }\end{array}$ \\
\hline 1 & & & & \\
1061002.417513 & 2090896.969137 & 0.511222 & 0.277256 & 0.722744
\end{tabular}

Figure 6 - Evaluation of the accuracy of the model. Source: Authors' analysis in Azure Machine Learning Studio

After the model has been trained, a forest is generated. In this case, the analysis generated 8 trees, as set in the configuration parameters. Figure 07 depicts one of the generated trees. Each node of the tree represents a rule, i.e. a decision, which is compared against a generated value, creating a path with two possibilities in the process. For instance, the first rule of the tree is "Is the female percentage value of a state less than or equal to 51.64"? If true, then the left path will be followed. Otherwise, the right path is evaluated. It is worth mentioning that both the feature (female percentage) and the value (51.64) were decided by the decision tree algorithm by using a 
heuristic function which determines the minimal tree after evaluating several combinations of rules and values. In other words, the algorithm analyses other features from the data set so it can build and combine rules until an optimal leaf node is reached.

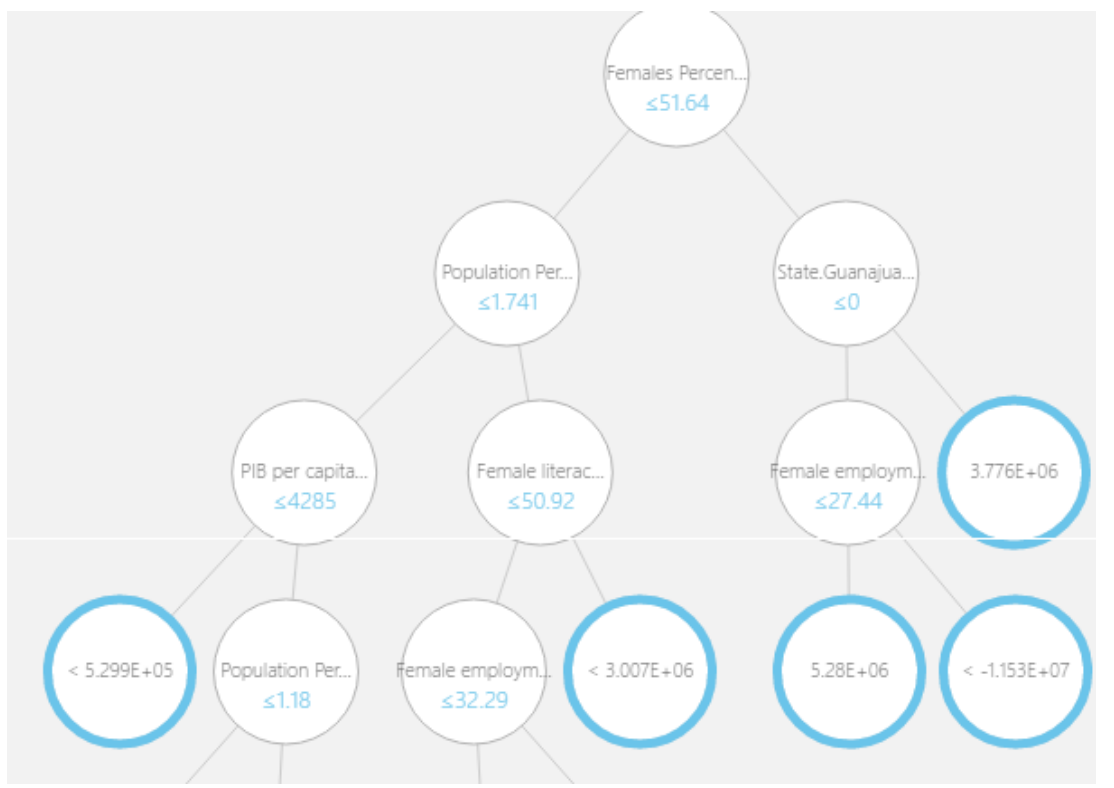

Figure 7 - A fragment of a decision tree generated during the training phase. Source: Authors' analysis in Azure Machine Learning Studio

The second part of the analysis considered Sri Lanka's secondary data for 2012 and 2014. Figure 08 shows the elements involved in the design of the model. For this analysis, Sri Lanka's 2012 information was considered for the training of the Decision Forest model while the remaining data, i.e. Sri Lanka's 2014 facts, were used for both the scoring and evaluation of the designed model. A Decision-Forest Regression model was considered again. Table 02 describes the configuration used (parameters and their values) for this evaluation. Due to the fact that in the experiment there are less data rows in Sri Lanka (9 provinces) than in Mexico (32 states), parameters had to be tuned accordingly. For instance, the number of decision trees and both their maximum depth and their number of splits were increased in order to generate a better accuracy, although this modification incremented the analysis time as well. 


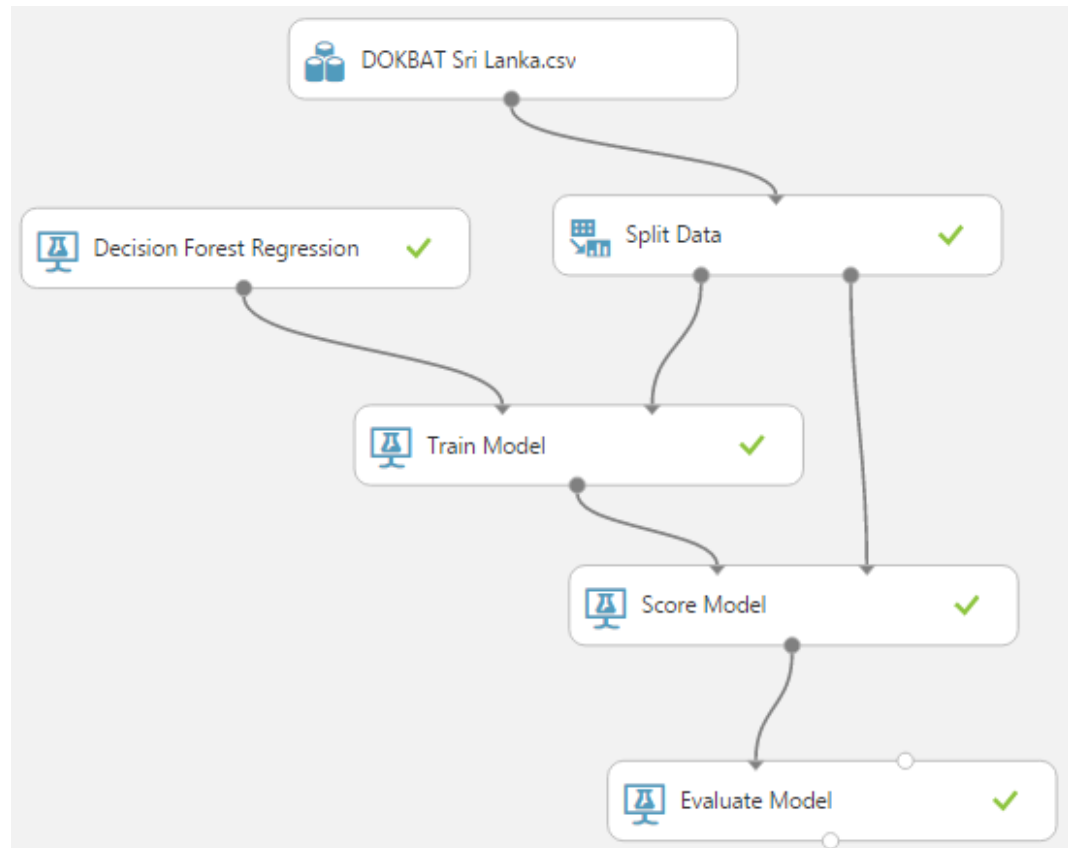

Figure 8 - Components for Sri Lanka's data analysis. Source: Authors' analysis in Azure Machine Learning Studio

Table 2- Parameters and values used for Sri Lanka's data analysis

\section{Parameter}

Resampling method

Trainer mode creation

Number of decision trees

Maximum depth of the decision trees

Number of random splits per node

Minimum number of samples per leaf node

Allow unknown values for categorical features
Value

Bagging

Single parameter

23

116

162

1

Yes

As can be seen in Figure 09, the column labelled "Mobile cellphones subscriptions" refers to the real value for Sri Lanka during 2014 while the details below "Scored Label Mean" indicate the estimation obtained by the proposed model. Similarly to Mexico's data analysis, the predicted values are compared against the real ones in order to test the model's accuracy. As shown in Figure 10, our proposed model obtained a $60.65 \%$ coefficient-of-determination value after the evaluation. The forest generated is composed of 23 decision trees, with Figure 11 showing one of them and the rules involved in it. 


\begin{tabular}{|c|c|c|c|c|c|c|c|c|}
\hline $\begin{array}{l}\text { Literacy } \\
\text { rate }\end{array}$ & $\begin{array}{l}\text { Male } \\
\text { literacy }\end{array}$ & $\begin{array}{l}\text { Female } \\
\text { literacy }\end{array}$ & $\begin{array}{l}\text { Employment } \\
\text { rate }\end{array}$ & $\begin{array}{l}\text { Male } \\
\text { employment }\end{array}$ & $\begin{array}{l}\text { Female } \\
\text { employment }\end{array}$ & $\begin{array}{l}\text { GDP per } \\
\text { capita }\end{array}$ & $\begin{array}{l}\text { Mobile } \\
\text { cellphones } \\
\text { subscriptions }\end{array}$ & $\begin{array}{l}\text { Scored Label } \\
\text { Mean }\end{array}$ \\
\hline | || | | & . I I & |ll| || & II I I & || & | || & | & || & | |1 | \\
\hline 98.1 & 98.7 & 97.9 & 51.8 & 69.1 & 30.9 & 3858307 & 9070430 & 5091842.460145 \\
\hline 94.1 & 96.5 & 93.3 & 62.1 & 66 & 34 & 884257 & 2455653 & 3772324.286232 \\
\hline 95.4 & 96.8 & 95 & 51.1 & 69 & 31 & 1017951 & 2499899 & 3538008.333333 \\
\hline 98 & 98.4 & 97.5 & 45.6 & 77.7 & 22.3 & 362973 & 663690 & 1371138.351449 \\
\hline 92.4 & 94.2 & 92 & 47.4 & 78.2 & 21.8 & 559866 & 884920 & 1604717.92029 \\
\hline 96.3 & 97 & 95.7 & 51.7 & 71.1 & 28.9 & 863632 & 1991070 & 2813263.731884 \\
\hline 95.9 & 96.8 & 94.3 & 54.9 & 71.5 & 28.5 & 429823 & 1327380 & 1363406.376812 \\
\hline 92.9 & 94.7 & 93 & 55.8 & 67.5 & 32.5 & 397000 & 1548610 & 1583436.630435 \\
\hline
\end{tabular}

Figure 9 - Partial visualization of the results obtained by the model. Source: Authors' analysis in Azure Machine Learning Studio

\begin{tabular}{lllll}
$\begin{array}{l}\text { Mean Absolute } \\
\text { Error }\end{array}$ & $\begin{array}{l}\text { Root Mean Squared } \\
\text { Error }\end{array}$ & $\begin{array}{l}\text { Relative Absolute } \\
\text { Error }\end{array}$ & $\begin{array}{l}\text { Relative Squared } \\
\text { Error }\end{array}$ & $\begin{array}{l}\text { Coefficient of } \\
\text { Determination }\end{array}$ \\
\hline & & & &
\end{tabular}

Figure 10 - Evaluation of the accuracy of the model. Source: Authors' analysis in Azure Machine Learning Studio

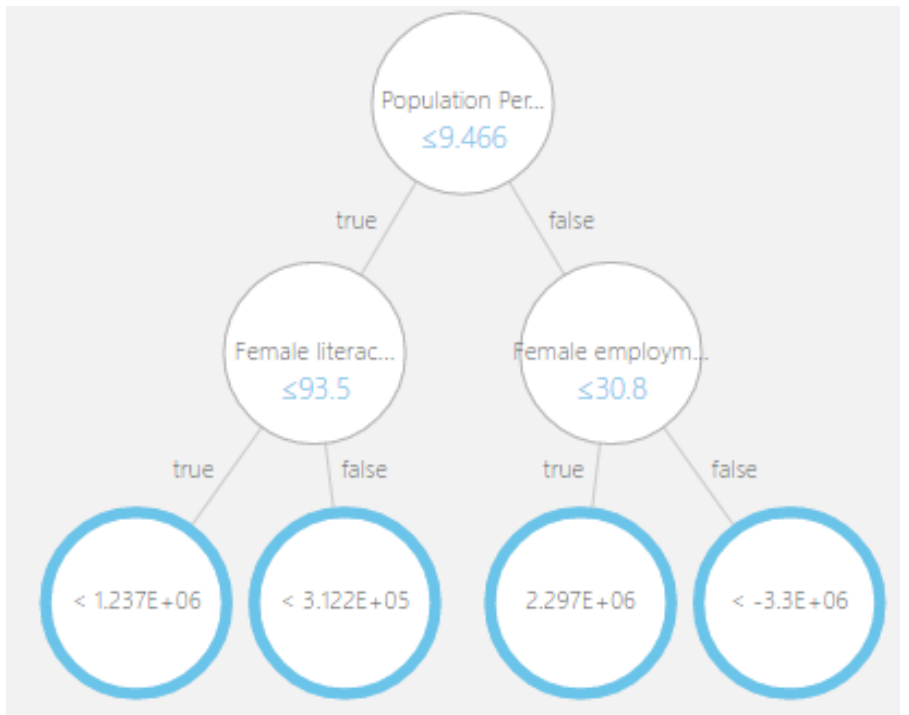

Figure 11 - A decision tree generated during the Training phase. Source: Authors' analysis in Azure Machine Learning Studio 


\section{CONCLUSION}

The analysis of this study indicated that a decision forest regression model on Azure Machine Learning can be used to predict and compare the performance of telecommunication industry between Mexico and Sri Lanka. The main purpose of the paper and the analysis is to show the features of the model and its ability to use it in business matters. Yet, the relationship of mobile subscribers and other relevant macroeconomic data of both countries were considered to run the model as an example.

The analysis shows the ability of the model in terms of forecasting information, in this case, mobile cellphone subscriptions, which can be used by companies or the government to develop new technologies, offer new services or plan budgets. Managers of any business field can make predictions based on this model to make their business a success. At the same time, both models can predict information with relative accuracy (70\% and 60\%). If more data were available, then a more robust model can be developed with a more complex analysis. Furthermore, similar models would include many variables as well as data to reflect another feature(s).

Finally, new Artificial Intelligence algorithms based on evolutionary algorithms and heuristic techniques which perform accurately and effectively in terms of time and computational resources usage are being developed to classify and predict data. Future research can be conducted to test and apply these techniques in the solution of real-life problems, including those from the non-computer related fields of study.

\section{Acknowledgement}

Authors of this article are thankful to the Internal Grant Agency of projects IGA/CebiaTech/2016/007: Hybridization of Computational Intelligence Techniques with Applications and FaME TBU No. IGA/FaME/2016/001: Enhancing Business Performance through Employees' Knowledge Sharing, for financial support to carry out this research.

\section{References}

Alamilla, R. and Camargo, R. (2015). Radiography of Smartphones Market in the Second Quarter of 2015. The Competitive Intelligence Unit Press Release. Mexico. 2015. Retrieved from http://www.the-ciu.net/nwsltr/419_2Distro.html on March 10, 2016

Birkner, M. D., et al. (2007). Creating diagnostic scores using data-adaptive regression: An application to prediction of 30-day mortality among stroke victims in a rural hospital in India. Therapeutics and Clinical Risk Management, 3(3), 475-484.

Central Intelligence Agency. (2015). Mexico, In The World Factbook. Retrieved from https://www.cia.gov/library/publications/the-world-factbook/geos/mx.html on March 10, 2016.

Department of Census and Statistics of Sri Lanka. Sri Lanka Census of Population and Housing, (2012). Sri Lanka. Retrieved fromhttp://www.statistics.gov.lk/PopHouSat/CPH2011/index.php?fileName=Activities/T entativelistofPublications on March 19, 2016.

Diario Oficial de la Federación de Mexico (2013). Reforma 208: Reforma de Telecomunicaciones y Radiodifusión [Telecommunications and Broadcasting Reform]. 
Mexico City, Mexico. 2013, June 11. Retrieved from http://reformas.gob.mx/reforma-enmateria-de-telecomunicaciones/reformas-y-leyes on March 10, 2016.

Everaert, G, E. Bennetsen, \& P.L.M. Goethals, (2016). An applicability index for reliable and applicable decision trees in water quality modelling, Ecological Informatics, 32, 1-6, ISSN 1574-9541, https://doi.org10.1016/j.ecoinf.2015.12.004.

Government of Sri Lanka. ICT Infrastructure Report (2012). Sri Lanka. Retrieved from http://www.labour.gov.lk/web/index.php?option=com_content\&view=article\&id=2 95\&Itemid=274\&lang=en on March 17, 2016.

Heng-Ru Zhang, Fan Min (2016). Three-way recommender systems based on random forests, Knowledge-Based Systems, 91, 275-286, ISSN 0950-7051, https://doi.org10.1016/j.knosys.2015.06.019.

Instituto Federal de Telecomunicaciones. Sistema de Informacion Estadistica de Mercados de Telecomunicaciones (SIEMT) - Estadisticas. Mexico City. (2012). Retrieved from http://siemt.ift.org.mx/home.php on March 19, 2016.

Instituto Federal de Telecomunicaciones. Third Quarterly Statistics Report (2015). Mexico City. 2016. Retrieved from http://cgpe.ift.org.mx/3ite15/ on March 10, 2016. Instituto Nacional de Geografía y Estadística. Statistical and Geographical yearbook of the United Mexican States (2015). Mexico. Retrieved from http://www3.inegi.org.mx/sistemas/biblioteca/ficha.aspx?upc=702825077280 on March $10,2016$.

International Monetary Fund. (2015). Mexico. In the Article IV Executive Board Consultation. Retrieved from http://www.imf.org/external/country/MEX/ on March 10, 2016.

Kozak, J., \& Boryczka, U. (2015). Multiple Boosting in the Ant Colony Decision Forest metaclassifier, Knowledge-Based Systems, Volume 75, Pages 141-151, ISSN 0950-7051, https://doi.org10.1016/j.knosys.2014.11.027.

Lior Rokach, Decision forest: Twenty years of research, Information Fusion, (2016). Volume 27, Pages 111-125, ISSN 1566-2535, https://doi.org10.1016/j.inffus.2015.06.005.

Qiang, G., Zhe, T., Yan, D., Neng, Z. (2015). An improved office building cooling load prediction model based on multivariable linear regression, Energy and Buildings, Volume 107, Pages 445-455, ISSN 0378-7788, https://doi.org10.1016/j.enbuild.2015.08.041

Rust, R. T., \& Huang, M.-H. (2014). The service revolution and the transformation of marketing science. Marketing Science, 33(2), 206-221.

Sergio Ordóñez, Rafael Bouchaín, Gustavo Schinca, (2013). México en el mundo de las telecomunicaciones: más allá de Slim y la ocde, Economía UNAM, Volume 10, Issue 29, Pages 74-91, ISSN 1665-952X, https://doi.org10.1016/S1665-952X(13)72196-0.

Telecommunications Regulatory Commision of Sri Lanka. Statistics. Sri Lanka (2015). Retrieved from http://www.trc.gov.lk/2014-05-13-03-56-46/statistics.html on March 17, 2016.

$\mathrm{Yu}, \mathrm{F}$, (2005). Accounting transparency and the term structure of credit spreads, Journal of Financial Economics, Volume 75, Issue 1, Pages 53-84, ISSN 0304-405X, https://doi.org10.1016/j.jfineco.2004.07.002. 


\section{Contact Information}

Luis Antonio Beltran Prieto

Tomas Bata University in Zlin, Faculty of Applied Informatics

Mostni 4511,76005 Zlin, Czech Republic

Email: luis.beltran@itcelaya.edu.mx

orcid.org/0000-0002-8208-4206

R H Kuruppuge

Tomas Bata University in Zlin, Faculty of Management and Economics

Mostni 5139,76001 Zlin, Czech Republic

Email: kuruppuge@yahoo.com

orcid.org/0000-0002-9456-4071

DOI: https://www.doi.org/10.7441/dokbat.2016.05 


\title{
PERCEPTION OF RISK AND MANAGING FLOOD DISASTER: A CASE STUDY OF RURAL COMMUNITY IN CZECH REPUBLIC
}

\author{
Mohan Kumar Bera and Petr Daněk
}

\begin{abstract}
Risk is a combined outcome of hazard and vulnerability. Level of perception of risk varies with changing nature of hazards and vulnerability and impacts of risk. Perception also varies with individual/community awareness, preparedness and coping capacity with risk. Therefore needs of every individual/community for risk reduction are different with context, time and space. There are certain factors that influence people to involve in dealing with uncertainty and unfamiliar future. People in the Czech Republic become survivor of frequent flood disasters in last couple of decades. There is a relationship between increasing frequency of floods and climatic variations which has been widely experienced in Central European countries. As a result, conventional top-down approach of the government is slowly accepting the importance of communities and community based institutions in disaster risk reduction. Rural areas in Czech Republic are economically backward and villagers mainly depend on farming, tourism, wood processing, and food processing industries. Increasing frequency of flood disasters in last couple of decades has damaged properties and loss of lives that directly affected people living near the rivers and streams. The Research has been exploring the people perception of risk and adaptation with the changing governance system to cope with increasing frequency of flood disasters in Czech Republic.
\end{abstract}

Key Words: Floods; Risk Perception; Disaster Management; Dyje River; Czech Republic

\section{INTRODUCTION}

Frequent floods damage huge amount of properties and cause loss of lives. However, most of the flood disasters are reported in developing and underdeveloped countries, people in the central and western European countries become survivor of floods in last couple of decades. Researchers find the relationship between increasing frequency of floods and climatic variations which has been widely experienced in central European countries (Brázdil et al. 2006; Mudelsee et al. 2003; Duží et al. 2014). Changing governance system in Central and Eastern Europe also has influenced on the perception of disaster risks of communities and government. Conventional topdown approach of the government is slowly accepting the importance of communities and community based institutions in disaster risk reduction (Dostál 2015). Czech Republic has adopted all hazards management approach. Since democratic transition in Czech Republic in 1989, floods created 'Crisis Situation' in 1997, 2002, 2006, 2007 and 2013. Crisis situation is managed through three main agencies: fire fighter, health emergency service and police. The crisis management works at municipality; regional and state levels. Local government (i.e., municipality) in Czech Republic is largely responsible to manage the crisis situation at grassroots level. Municipalities are depending on different government and non government agencies and volunteers to reduce the impacts of huge damages and losses due to frequent natural hazards. However there is a limited flow of information, all the agencies and civil society organisations cooperate and work together to manage the situation (Dostál 2014). People consider frequent floods as natural hazards and believe on its technological solution in Czech Republic (Brázdil 
2005a; Potluka and Slavíková 2010; ICPDR, 2009). The damages and losses due to flood events and lack of adequate supports from insurance companies influence people to adopt strategies to cope with disasters (Duží et al. 2014). However coping mechanisms depend on the perceptions of disaster risk, people participate and cooperate with the local government to reduce the impacts of natural hazards. The research understands the perceptions of people about the flood disaster and resilience to cope with increasing natural hazards. How risk perception and traditional understanding influence people to work collaboratively in disaster risk reduction. And how does the culture of dependency on the government in risk reduction influence the risk perception and cooperation with the government?

\section{FLOOD DISASTERS IN CZECH REPUBLIC}

Floods are the most destructive natural hazards in Czech Republic. Most of the floods had been experienced in $16^{\text {th }}$ century, $19^{\text {th }}$ century and $20^{\text {th }}$ century. Frequency of floods decreased in second half of $20^{\text {th }}$ century (Vávra et al. 2015). The seasonal variation of flood disasters in Czech Republic varies with geographical location, precipitation, sudden increasing temperature during winter and wind direction. Winter and spring floods caused of snow melting and rain that is usually experienced in under mountain areas. Summer flood is caused by cloudburst and heavy rainfall with high intensity storm that covers small areas. Winter flood is caused by sudden increasing temperature during winter (ICPDR 2009). Most of floods occur between February to August but March and June is also important for flood disaster in Czech Republic (Brázdil et al. 2011:479). The research in post 1997 flood in Czech Republic has found that changing climate is not only the factor but changing landuse pattern, channel modification, building dam and reservoirs, population pressure and developmental work on flood plain has important role in for frequent floods (Brázdil et al. 2011:480).

The data since 1995 to 2015 show that 12 out of 27 major disasters in Czech Republic are floods. Flood disasters affected 1622347 people and caused property damages worth of US\$ 5964112 (EM-DAT, 2015). Most of these floods are riverine flood and flash floods. Most frequent floods have been experienced between 1995 to 2002 that affected 302171 people and cost of damage US\$4418000. A flash flood is also recorded in 2010 that affected 200 people and total loss was US $\$ 157560$ (EM-DAT, 2015). Analysis of pre-instrumental data shows that there were 102 flood disasters had occurred between 1671 to 1870 and instrumental data show 95 floods had been observed between 1871 to 2009 (Brázdil et al. 2005a).

Total 588 reservoirs including 123 large dams are built in Czech Republic from 1900 to 1997. 13 large dams are built before 1900, 103 dam are built from 1900 to 1989, 7 are built from 1989 to 1997. No dams are built after 1997 (Vávra et al. 2015; Ministry of Agriculture and Ministry of the Environment 2006; Czech Technical University in Prague 2012). The main purposes of these reservoirs are supplying drinking water, irrigation, power generation, development of tourism and flood protection. The short term success of construction of dam decreased the number of flood event during mid 20th century. 'Dam' enhances confidence among people to avoid flood permanently, but it is a 'false security' in flood prone areas (Tobin 1995; Vávra et al. 2015).

After WWII intensive agriculture has been promoted by socialist collective farming that destroyed grassland and forest and changed the landuse pattern. Modification of river bed, shortening of river, coniferous monoculture, increasing arable land and extensive economic activities in flood plains affects on natural water retention. Inappropriate landuse pattern is 
considered as an important factor of major floods in South-Eastern part of Czech Republic (Vávra et al. 2015: 3; Brázdil et al. 2011:480). Most of the studies on flood in Czech Republic focus on hydro-meteorological measurement, flood plain, characteristics of river course and channel, geomorphologic and physical aspects of disaster (Brázdil et al. 2011). The 1997 flood in Morava River basin was so destructive that has influenced to change the nature of floods management in Czech Republic (Brázdil et al. 2011; Dostál 2015; Duží et al. 2014; Potluka and Slavíková 2010).

\section{STRATEGIES OF FLOOD RISK MANAGEMENT IN CZECH REPUBLIC}

As a part of long term joint Action Program for Sustainable Flood Action Prevention in the Danube River Basin, Morava River becomes important to reduce the impacts of floods (ICPDR 2000). The program includes increasing flood awareness, improvement in flood forecasting, preparedness, prevention and mitigation of water pollution due to floods and technical flood defences. The framework for flood protection/management strategies in Czech Republic is prepared based on experiences of previous floods in country and neighbouring countries. The strategy includes providing flood forecasting and warning; flood control measures; reduction of risks to people and reduce damages and protection properties (MAME 2000). The strategy is done through River Basin Board lead by Ministry of Agriculture and Environment.

Flood disaster in Czech Republic is managed through Integrated Rescue System (IRS). IRS is not an institution or legal entity. It is a 'system of coordination and cooperation using model process, contracts and rules, and it is also part of national part the national system for internal security' (Dostál 2015). It has been operationalised through the Government of Czech Republic legislation in June 2000 (Law no. 239/2000 on IRS). IRS has coordination with state government departments including Ministry of Interior, Ministry of Defence, Water Resource Management, Ministry for Development and Planning and Ministry of Finance.

IRS has been formed to coordinate activities of rescuers in emergency management to save lives and properties even before emergency (Dostál 2015; Law no. 239/2000 on IRS). The main components of the IRS are the Police of the Czech Republic, Medical Rescue Service, and Fire Rescue Service (FRS) including volunteer fire fighters. The other components of the IRS are military forces, public health authorities, NGOs and voluntary organisations (Ministry of Interior of the Czech Republic 2015). The importance of the IRS is to communicate and share information among government departments such as Fire Rescue Service, public administrations and voluntary organisations. But inadequate cooperation with NGOs caused duplication of emergency management strategies by different departments (Dostál 2015:204).

It is a legal responsibility in Czech Republic that the flood risk management is shared by national government (state), local governments (regional and municipal level) and citizen. The national government has responsibility in crisis/emergency management and also risk management. Local government and citizens are an integral part of crisis management but most of supports and subsidies are provided by the national government. There is also a gap between the strong legal position and weak involvement of citizen and local government in different phases of flood disaster risk reduction (Potluka and Slavíková 2010).

Czech Republic has developed the early warning system for flood disaster that connects state, regional administration and municipalities through the Water Act (Act No. 254/ 2001 coll.). 
Flood warning is managed through Czech Hydrometeorological Institute in coordination with River Basin Board, regional and local administrations. The Czech Hydrometeorological Institute runs national monitoring network that provides information regarding rising water level and heavy rainfall to the mayor at river basin. The warning is disseminated by the Fire and Rescue Service (FRS). There is also a system of flood commission at state, regional and municipality level for managing emergency (CHMI 2005). Mayor is the key person to adopt strategies and taking decision in risk reduction at municipality. Mayor activates the flood committee at the municipality after receiving warning from the Czech Hydrometeorological Institute. The flood committee consists of advisory group of technical, water and rescue experts. The mayor and flood committee evaluate the flood situation and announce three types of flood risks: watchfulness, alert and threat. People are expected to follow certain standardised actions on each degree of flood alert. These actions include evacuation, monitoring river and streams and construction of flood protection wall. All the flood committees are integrated into territorial flood crisis bodies. If mayor finds the incapability to manage flood risk at municipality level, neighbouring municipality as well as regional administrations are requested for support. Most of the cases multiple municipalities are affected by flood in a region. Therefore, affected municipalities are unable to help each other. The efforts taken by municipality are supported by the IRS that operates at regional level. The central office of public administration involves in disaster management if disaster exceeds regional territory or beyond the capability of regional administration. If the flood situation goes beyond the control of central level public administration, the parliament or the national government announces as 'Crisis Situation'. The centralised system of emergency management is activated to manage the 'Crisis Situation' under the command of Ministry of Interior.

Municipality engages in long term planning in reduction of flood risk through organising training for flood committee, improving warning system, educating inhabitants, purchasing equipment for flood protection (Potluka and Slavíková 2010). As per Act Nr. 254/2001 Coll. Section 86, municipalities are can adopt measures to protect villages from flood. Regional and central government provides financial support to these municipalities for flood protection activities. But in reality municipalities do take any technical measures or flood reduction project due to financial constraints (Potluka and Slavíková 2010). According to Act Nr. 254/2001 Coll. Municipalities prohibit villagers to use flood plain for developmental works and indentify as 'Territory in Risk'. Municipalities also take decision to strict conservation measures in flood plain. They do not allow construction works and potential developmental zone into park land. But the strategy has not succeeded because private land owner do not accept the restriction (Potluka and Slavíková 2010).

NGOs and voluntary organisations are the most important component in disaster management in Czech Republic. Dostál (2015) argues that Czech Republic Military can not deal with major natural disaster alone. There are 375000 volunteer fire fighters who have been engaging in emergency management and contributed during floods in 1997, 2002 and 2013 (Fire Rescue Service 2002, 2013; Dostál 2015: 206). They helped in evacuation and providing humanitarian aids to affected people. However government has lack of trust towards NGOs, they have cooperation for sharing information, effective rescues and recovery activities at state, regional and municipality level (Dostál 2015: 204). The state government also relies on the NGOs planning in disaster reduction and largely depends on volunteers fire fighters. Local government in Czech Republic is largely responsible to manage flood disaster risk. Particularly municipality representatives directly engage in disaster management and adopt steps to rescue people at safer 
place and protect properties, save lives and prevent loss and damages in future (Potluka and Slavíková 2010). However there is systematic monitoring on the activities and performance of municipalities during emergency, long term performances are not monitored (Potluka and Slavíková 2010; cf. Čamrová and Viktorová 2006).

\section{UNDERSTANDING OF PERCEPTION OF DISASTER RISK}

Risk is judgemental rather than fact. It is a way of expressing uncertainty and collection of perceptions about the natural hazards. Perception is a process of understanding about a risk phenomenon and consequences (Raaijmakers et al. 2008:308). Risk perception is a process of collecting, selecting, interpreting signals about uncertain natural hazards and activities (Wachinger et al. 2013:1049; cf Slovic 1987). These signals can be achieved through direct individual experiences and experiences from indirect sources (i.e., mass media experts and shared individual experiences). Risk perception is an image of real phenomenon to be happened. The image has been developed through direct and indirect sources of information (Wachinger et al. 2013:1049). The image also has been modified and changed by socio-economic-cultural environment, media and individual experiences of natural hazards. Perception of risk is characterised as an intuitive judgement of individuals or groups about risk in the context of limited and uncertain information (Raaijmakers et al. 2008:308). Risk perceptions are based on risk characteristics which are result of voluntariness, dread and knowledge of risk. In natural hazards 'dread' is worry, 'knowledge of risk is awareness' and 'degree to control over risk' is preparedness (Slovic 2000). So, it is the relationship among worry, awareness and preparedness. Characteristics of risk perception (i.e., worry, awareness and preparedness) determine societal preferences in reducing risk or conserving benefits.

Awareness is the knowledge and consciousness about the natural hazards. Awareness is developed through individual experiences and external awareness programme. Worry or fear depends on awareness about the disaster risk and impacts. More people worry about the risk, more demands of people to be safe. Sevage (1993) argues that if people are worry about the natural hazards, there will be 'willingness-to-pay' to reduce the risk. Awareness leads higher or lower level of worry that helps in higher or lower degree of preparedness. Awareness and preparedness are also influenced by public policy that helps to educate and enhance the preparedness measures. However level of worry is not influenced by public policy, it influences awareness and preparedness measures of people (Raaijmakers et al. 2008: 313). Risk can be reduced if individuals are prepared to reduce the risk. When preparedness increases, individuals

and groups are more capable to reduce the negative consequences of natural hazards. But preparedness needs awareness and readiness to deal with the natural hazards (Kron 2002). A better prepared society is less worry about the risk (Raaijmakers et al. 2008: 312). But the capability of disaster preparedness also depends on social, technical, economic and institutional dimensions in the state and community. There are literatures that claim that higher level of perception of risk leads higher degree of attitude to reduce the risk (Raaijmakers et al. 2008; Kraus and Slovic 1988). Perception of risks is influenced by a set of choices. Choices become larger if there are alternatives and similarities in perceived benefits. People have three choices by examining the risk and perceived benefits of natural hazards: acceptance of risk; reduce the risk and avoid the risk all together. The choices are based on 'trade-off' of perceived risk and benefit and risk characteristics (Raaijmakers et al. 2008; Fischhoff et al. 1978). 
It is not only the public policy that influences risk perception but people perception on construction measures and trust on technocratic solution of disaster influences on risk perception. Higher level of structural measures and no personal experience of floods lead to low perception of risk in Netherland (Terpstra 2011:1658). Personal experiences and experiences shared by friends, neighbours make people aware about the risk but it depend on interpretation of risk. Keller et al. ( 2006) found that emotions developed through direct or indirect experience encourages to decide positive or negative decision in risk reduction. But the negative experiences also help in positive decisions that enhance ability to reduce the risk in future. Survisours of tsunami in Thailand and refugees in El Salvador believe that they got positive knowledge to cope with uncertainty in future (Terpstra 2011:1659).

Risk perception mainly influenced by types of risk, context of risk, individual characteristics and socio-economic and cultural background of an individual. The knowledge, ability of thinking, experiences and awareness, attitudes and emotions judges the acceptability and seriousness of risk that changes the risk perception. Perception motivates people to ignore or avoid the risk and also helps to judge, decide and adopt strategies to reduce the impacts of natural hazards. But the implementation of strategies depends on awareness of risk and willingness and engagement on risk reduction measures (Wachinger et al. 2013:1050).

People live at disaster prone areas have developed coping mechanisms that come through long experiences and inherent abilities to deal with the situation. It is also argued that people have some benefit to live at risk (Valente et al. 2008; Alexander 1993). Perception of risk depends on individual characteristics of people (i.e., age, gender, socio-economic condition, cultural and religious values), familiarity of sources of risks, knowledge about hazards, trust on authorities and physical constructional measures (Valente et al. 2008).

Most of the research in risk management focuses on responsibility of people to participate in risk reduction. The perception of the government authorities is equally important to adopt strategies in risk reduction. Government authorities even at grassroots level protect wet lands and regulate land use pattern in flood that contributes in natural water retention in river basin (Vávra et al. 2015). However researchers primarily focus on people's perception to live at flood plain, political behaviours and strategies to risk management in Czech Republic (Vávra et al. 2015; Duží et al. 2014; Dostál 2015; Klemešová and Andráško 2015), activities of government authorities in the context of changing paradigm of disaster risk management is hardly highlighted. The main gap in literatures is the lack of combined understanding of perception of risk between government and residents to reduce flood risks. Ultimately, citizens are the key component in risk reduction and implementing new approach of flood management.

\section{RESEARCH METHODOLOGY}

People in large part of Czech Republic believe that floods are not purely natural hazards. It is the governance system that can manage the flood disasters (Vávra et al. 2015). In 1980s and 1990s, dams were considered as an important flood protection measures, but people are shifting attention towards non-structural measures. There is also a general insight about connection between increasing flood hazards and climate change. It is realised that structural measures are 
inadequate to reduce damages in future. It becomes necessary for the government and people in frequent flood affected areas to cope with the changing strategies in flood risk management incorporating with local perception and knowledge (Vávra et al. 2015). In the context of changing paradigm of flood management, perception of people and the representatives of government are not discovered. It becomes important to see the responses of people in the post socialist governance system and participation and activities to manage floods.

A village in Morava region has been selected where people flood have been experiencing after 2000. Prior to select the village, an interview has been conducted with an expert from the Czech Meteorological institute and NGO activists in Czech Republic. Thaya or Dyje River basin has been repeatedly referred because of damages due to recent floods. Grecmanova (2011:105) also has mentioned higher level of potential flood in the Dyje river basin. However Dyje catchment was not flooded in 1997, it was in was in 2002 and 2006 (ICPDR, 2009). A large number of floods have been experienced in the Dyje River during 1711-1730; 1741-1750; 1811-1870; and 1891-1900 (ibid: 479). There was no flood till end of $20^{\text {th }}$ century after 1909 flood in Dyje catchment. Heavy rainfall from 6-15 ${ }^{\text {th }}$ August, 2002 in western and south Bohemia caused flood at lower course of Dyje River. Sudden rising temperature and heavy rainfall in March, 2006 caused flood in Dyje catchment. Another devastating flood was experienced in Dyje catchment on $30^{\text {th }}$ July, 2006 when municipality Podhradi nad Dyje was affected (ICPDR 2009).

Podhradi nad Dyji village of Okres Znojmo district of Jihomoravský region of South Morava region has been selected for study. The Podhradi nad Dyji is located at the bank of Thaya or Dyje river. The village has two parts: Podhradí nad Dyjí and Podhradí nad Dyjí-chatová oblast. Most of the villagers live at Podhradí nad Dyjí. The village was not affected by flood in 1997 in South Morava but it was affected by flood on $30^{\text {th }}$ July 2006 . Flood also had been experienced in the village in 1935, 1941, 1947, 1948, 1951, 2002 and 2006 (CHMI 2016). These floods had been experienced from late February to late June. There are many dams and reservoirs are built on the Dyje River. Grecmanova (2011:105) has shown that the village Podhradi nad Dyji has higher level of flood risk mainly during the spring and summer. A case study has been conducted in the village Podhradi nad Dyji. The study has been exploring the risk perception and strategies of citizens and government at municipality level. Different cases have been indentified based on specific criterion. Total population of the village is 48 (Czech Statistical Office 2013). There are 74 family houses and 87 flats in the village but only 26 houses are occupied. A good number of citizen travel everyday in cities for searching livelihood. There are few villagers also engage in service sector and tourism industry in village.

It is presume that villagers who live near the river bank in the village Podhradi nad Dyji will be affected due to potential floods. However, impact will be different because of risk characteristics and component of risk. Therefore, research has included all the households in the village for collecting data. But the main criteria of selecting households are permanent residentship and ownership of properties in the village. However, all the households have been selected for interview, every household do not willing to cooperate in interview (Duží et al. 2014:4). The household heads have been requested for interview. The village temporarily migrate to cities in search of job, therefore senior members are requested to participate in interview. There are thirty questionnaires have been asked and expected for in-depth answer. The study follows the open ended in-depth interview among the villagers. The respondents have been divided into three categories: (a) respondents engage with municipal administration (Mayor, deputy mayor; and Councillor); (b) respondents engage with the IRS (fire fighter; voluntary fire fighter; police and 
health service provider) and (c) respondents those who do not engage with municipality and the IRS. The interview has been conducted in English language by the help of Czech language interpreter.

Table1 - Research Method for Required Data

\begin{tabular}{|l|l|l|l|}
\hline Research question & Required information & $\begin{array}{l}\text { Indentified } \\
\text { Respondent }\end{array}$ & Strategies \\
\hline $\begin{array}{l}\text { Is the risk perception } \\
\text { only factor that influence } \\
\text { people and local } \\
\text { institution collaborates in } \\
\text { flood risk reduction? }\end{array}$ & $\begin{array}{l}\text { Influencing factors of } \\
\text { risk; }\end{array}$ & $\begin{array}{l}\text { Government } \\
\text { representative; } \\
\text { villagers and IRS; } \\
\text { Experts }\end{array}$ & $\begin{array}{l}\text { In-depth } \\
\text { interview; } \\
\text { Reviewing } \\
\text { existing literatures }\end{array}$ \\
\hline $\begin{array}{l}\text { In what way the } \\
\text { conventional approach of } \\
\text { flood disaster } \\
\text { management influences } \\
\text { community and local } \\
\text { government to decide } \\
\text { strategies in flood risk } \\
\text { reduction? }\end{array}$ & $\begin{array}{l}\text { Perception about } \\
\text { structural measures; } \\
\text { aboust dependency on } \\
\text { and present governance } \\
\text { system in flood } \\
\text { management }\end{array}$ & $\begin{array}{l}\text { Government } \\
\text { representative; } \\
\text { villagers and IRS }\end{array}$ & $\begin{array}{l}\text { In-depth } \\
\text { interview; } \\
\text { Government } \\
\text { reports; }\end{array}$ \\
\hline $\begin{array}{l}\text { How does the culture of } \\
\text { dependency on the } \\
\text { government in risk } \\
\text { reduction influence the } \\
\text { risk perception and } \\
\text { cooperation with the } \\
\text { government? }\end{array}$ & $\begin{array}{l}\text { Disaster management } \\
\text { strategies; government } \\
\text { legislative Act; } \\
\text { changing activities of } \\
\text { the municipalities and } \\
\text { citizens }\end{array}$ & $\begin{array}{l}\text { Government } \\
\text { representatives in } \\
\text { the municipality; } \\
\text { experts }\end{array}$ & $\begin{array}{l}\text { Reviewing the } \\
\text { government } \\
\text { reports; } \\
\text { In-depth Interview } \\
\text { with personnel in } \\
\text { municipality and } \\
\text { experts }\end{array}$ \\
\hline
\end{tabular}

\section{RISK PERCEPTION OF FLOODS IN CZECH VILLAGE}

Risk reduction strategies vary with type of hazard, geographical location, culture, affordability of people, livelihood dependency, rules and regulation, media and local governance, influence of relatives and neighbours, male female ratio in family, age, ownership of house and properties and prior experiences and awareness of disaster risk (Duží et al. 2014). 'Culture' is considered as an important factor that influences people to decide during the crisis (Macours and Swinnen 2005; Hoffman and Oliver-Smith 2002; Krüger et al. 2015). A large number of affected people migrate to cope with crisis of livelihood during post disaster phase. But permanent migration is the last option because are connected with home and place of birth, availability of livelihood and dependency on locally available sources of income. In Czech Republic, flood insurance becomes a factor to decide strategies in risk reduction. It is started after destructive floods in 1997 when insurance companies increase the price of flood insurance and denied to provide insurance. Companies also do not sell flood insurance to people those who live at highly risk areas. As a result many people are not eligible to buy flood insurance and many people are not able to pay higher price (Duží et al., 2014:5). Willingness of people is also another factor that derives from 
financial capability and attitude towards contribution of time and resources in risk reduction. People having flood insurance in Moravia river basin are not willing to contribute resource and time and less interested to adopt strategies in risk reduction (Duží et al. 2014:10). It is also the fact that villagers having experiences of flood and live at river bank buy the flood insurance however it depends on economic background and awareness about floods.

Risk perceptions towards ability or inability of people or institutions help to decide possible measures to reduce the impacts of hazards. Local people judge the risk based on individual or community experiences and knowledge of the hazards. Local people develop risk map based on their knowledge and experiences. Therefore, risk map developed by the formal institutions are different from people's map (Siegrist and Gutscher 2006). Many villagers are not aware about the risk map from formal institutions. Sometimes, perception of risk in Czech Republic is quire higher than reality because of previous experiences and flow of information regarding the hazards (Duží et al. 2014). People live at highly risky location do not take the risk seriously. Living at risk location becomes a part of daily activities. The supports from families, friends and neighbours and high dependency on insurance help them to decreases the risk perception. The experiences are overlapped by experience of similar natural hazards for long time and people do not take the hazards seriously. Municipalities in Czech Republic have details data about the landuse and flood risks in a village. It needs awareness and flow of information through multisectoral communication and suggestions from experts and sharing the outcome of research report to decide possible strategies in risk reduction.

Villagers living at risk zone in Czech Republic experienced multiple floods. There are many research works mainly focus on 1997 flood to analyse the probability floods and status of risk in villages in south Morava region. After 1997 floods, affected villagers take flood seriously and change the housing structure. But risk perception of floods has decreased over the period if villagers do not experience flood long period. It shows that risk perception is higher during the post flood situation. At the same time, risk perceptions are overlapped by many small flood incidents in villages of Czech Republic. When flood do not occur in the village, villagers hardly take the level of water seriously. However flood risk of a place may or may not be the risk in non-affected areas. There are two incidents happen: people forget the flood incident because of lack of experience for long time at the same time overlapped minor experiences can not considered as a risk.

However, villagers in Podhradi nad Dyje experienced three major floods in since 2002, they have not increased the height of ground floor. On the other hand researchers worked on flood affected villages in 1997 found the changing strategies in construction measures of house (Duží et al. 2014). The guest house and hotels at river bank have not changed in the construction. Increasing height of ground flood requires higher investment to construct the house. But the main question is the increased height of ground floor a result of higher risk perception or trend in village? However flood affected villagers in Bangladesh and Fiji islands construct house above the average floods level and change the construction materials. Higher level of consciousness and risk perception of floods help to adopt strategies to cope with floods. Villagers have adopted different measures to protect the house from floods in future (Stojanov et al. 2015). Changing measures in construction of house directly affects people's savings. A large number of villagers depend on non-agricultural activities and therefore, loss of agricultural product has very less impacts on village life. Changing measures to protect houses are visible if villagers are worry 
about the loss and damage due to floods. Villagers directly invest money to build the house and therefore they have tendency to adopt different strategies to avoid the loss and damage.

The strategies represent the individual/family subjective experiences with intensity and frequency, consequences of flood risks (Stojanov et al. 2015); ability or inability to pay for flood insurance, educational level; physical ability; socio-economic and cultural background of villagers, geographical location of village and efforts/supports from the governments. There is a relationship between strategies adopted by the villagers and experienced of floods risk. The risk perception is also varies with location of house and economic activities. Villagers live at high risk zone having multiple strategies to cope with risk. But the perception varies with income generation activities and awareness about the risk. In villages of Czech Republic nature of employment is also another factor to perceive the risk. A large number of villagers commute everyday for jobs in cities or towns near the village. Therefore perception of risk varies from villagers who live permanently in village than commuting villagers.

People live at high risk zone of the village, having higher level of risk perception and different strategies. However it varies with awareness and experiences of floods. Villagers do not consider flood as a disaster unless it affects their livelihood. The villagers live at low risk zone have high perception of risk but adopt less strategies. They are confidence to deal with floods because of geographical location of house. At the same time they are worried about the increasing height of flood water level which has been experienced in last one decade. It is found that people live at safer location hardly bother about floods. Usually they go to risk areas during flood either to take photo of the river or help to affected villagers. They adopt strategies if resources and properties are near to high risk areas. But the adopted strategies are dependent on economic condition of the family and available choices of people.

Villagers are not much aware about the flood risk zoning. They see the flood risk though experiences over the period. The marking of flood level and volume of water reminds them about the risk. They mentions about the common marking points like badly damaged houses, discolour marking of houses. The height of flood level increases over the last two decades, flood affected areas become larger. The villagers having good economic background and other place to move do not bother about the increasing frequency of floods. They do not have plan leave the village. The source of income based on tourism and non-farming activities, they hardly concentrate on the limited loss after receiving support from insurance. They invest to build protection near to the river and use fine pebble sand on the ground near the house.

\section{CONCLUSION}

It is not only the risk perception but consciousness of self responsibility towards society and government's rule regulations that influence people to engage in disaster risk reduction. The topdown governance system hardly allows villagers in Czech Republic to engage in government activities. However, villagers help each other, help government personnel and work collectively during emergency, the trend of collectivities becomes very less. Villagers live at high risk areas are worry about safety of individual family and neighbours due to increasing level of floods. But, social networks among friends, neighbours and trust on government supports help to deal with emergency. The sense of collectivities during emergency is very strong within the social networks. The social network of a household helps during and post emergency but none of the family expect money support. The emotional support becomes from the social network become 
most important during emergency. However, disaster management mechanisms of the government are centrally controlled, villagers blindly trust councillors, mayors in disaster reduction. There is also high dependency on government in short and long term risk reduction activities. Disaster management programmes in villages is largely dependent on funding from European Union. It is found that centrally controlled mechanisms are not adequate to deal with frequent floods. High dependency on government and insurance companies reduces coping mechanisms that create extra burden with changing rules and regulations of insurance and governance system.

\section{References}

Act No. 239/2000 Coll. On IRS

Act No. 254/ 2001 coll. (Water Act) http://eagri.cz/public/web/file/10629/The_Water_Act.pdf Alexander, D. (1993). Natural Disasters. UCL Press, London, U.K.

Annual Report of the Fire Rescue Service, Prague. (2002). Available from: http://www.hzscr.cz/soubor/rocenka-2002-pdf.aspx.

Annual Report of the Fire Rescue Service, Prague. (2013). Available from: http://www.hzscr.cz/soubor/rocenka-2013-pdf.aspx.

Brázdil, R., et al. (2006). Historical and recent floods in the Czech Republic: causes, seasonality, trends, impacts. In Flood Risk Management: Hazards, Vulnerability and Mitigation Measures. 1. vyd. Dordrecht: Springer, 247-259, 13 s. NATO Science Series. 67. https://doi.org/10.1007/978-1-4020-4598-1_20

Brázdil, R. and Kirchner, K. (eds). (2007). Vybrané p̌rírodní extrémy a jejich dopady na Morav'e a ve Slezsku (Selected natural extremes and their impacts in Moravia and Silesia, in Czech). Brno, Praha, Ostrava: Masarykova univerzita, C` eský hydrometeorologický ústav, Ústav geoniky Akademie ve`d C` eské republiky, v.v.i.

Brázdil, R., et al. (2005a). Historical and Recent Floods in the Czech Republic. Masaryk University and Czech Hydrometeorological Institute, Brno, Prague. 370.

Brázdil, R., et al.(2011). Fluctuations of floods of the River Morava (Czech Republic) in the 1691-2009 period: interactions of natural and anthropogenic factors. Hydrological Sciences Journal. 56(3), 468-485, DOI: 10.1080/02626667.2011.564175

Čamrová, L.; Viktorová, D. (2006). Policy-Making Decisions under the Thumb of Disasters - A Case of the Floods in the Czech Republic. Current Politics and Economics of Russia, Eastern and Central Europe. 21(3), 203-204.

CHMI. National Report of the Czech Republic towards the WCDR in Kobe 2005

Czech Technical University in Prague. (2012). Soupis pr`ehrad $C^{`} R$. Available at http://www.prehrady.cz [

Dostál. J. (2015). Lessons of cooperation between government and non-governmental organizations in emergency management in the Czech Republic. International Journal of safety and security eng. 5(3), 203-221. https://doi.org/10.2495/SAFE-V5-N3-203-221

Dunwoody S, and Peters HP. (1992). Mass media coverage of technological and environmental risks: A survey of research in the United States and Germany. Public Understanding of Science. 1(2), 199-230. https://doi.org/10.1088/0963-6625/1/2/004

Duží, B. D., et al. (2014). Household measures for river flood risk reduction in the Czech Republic. Journal of Flood Risk Management. DOI: 10.1111/jfr3.12132

EM-DAT 2015 
European Commission. (2007). Communication from the Commission to the European Parliament and the Council - addressing the challenge of water scarcity and droughts in the European Union. Impact assessment. Brussels: European Commission. Available at http://ec.europa.eu/environment/water/quantity/pdf/comm_droughts/impact_assessment.p df

European Union. (2007). Directive 2007/60/EC on the assessment and management of flood risks. Official J Eur Union 6 (11). http://eur-lex.europa.eu/legalcontent/EN/TXT/PDF/?uri=CELEX:32007L0060\&from=EN

Fischhoff, B., et al. (1978). How safe is safe enough? A psychometric study towards technological risks and benefits. Policy Sci. 9, 127-152 https://doi.org/10.1007/BF00143739

Government of the Czech Republic. (2000). Strategie ochrany pr`ed povodne mi pro území $C^{\vee}$ eské republiky schválená usnesením vlády $C^{\iota} R$ z 19. dubna $2000 c^{2}$. 382. Available at http://www.mzp.cz/cz/strategie_ochrany_povodne [accessed on 6 March 2016].

Hoffman S.M. and Oliver-Smith A., (eds). (2002). Catastrophe and culture: the anthropology of disaster. Santa Fe/Oxford: School of American Research Press/James Currey.

Keller C, Siegrist M, Gutscher H. (2006). The role of the affect and availability heuristics in risk communication. Risk Analysis. 26(3), 631-639. https://doi.org/10.1111/j.15396924.2006.00773.x

Klemešová and Andráško. (2015). Perception of floods - towards more effective flood management in the Czech Republic. Carpathian Journal of Earth and Environmental Sciences. 10(2), $199-208$.

Kraus NN and Slovic P. (1988). Taxonomic analysis of perceived risk: modeling individual and group perceptions within homogenous hazard domains. Risk Anal. 8, 435-455 https://doi.org/10.1111/j.1539-6924.1988.tb00508.x

Kron, W. (2002). Flood risk exposure vulnerability. In: Wu B, Huang Z, Wang G, Huang G, Fang H, Huang J (eds) Flood defence 2002: proceedings of the second international conference on flood defence, Beijing. Tsinghua University, Science Press New York Ltd. 82-97

Krüger F., et al. (2015). Cultures and disasters: understanding cultural framings in disaster risk reduction. Abingdon: Routledge.

Law no. 239/2000 on Integrated Rescue System. http://www.ifrc.org/Docs/idr1/343EN.pdf

Macours K. and Swinnen J.F.M. (2005). Agricultural labor adjustments in transition countries: the role of migration and impact on poverty. App Econ Persp Pol. 27(3), 405-441. https://doi.org/10.1111/j.1467-9353.2005.00236.x

Ministry of Agriculture and Ministry of the Environment. (2006). Plán hlavních povodí C eské $\begin{array}{llllll}\text { republiky } & - & 2 & \text { pracovni Available at }\end{array}$ http://eagri.cz/public/web/mze/voda/planovaniv-oblasti-vod/plany-povodi-pro-1obdobi/plan-hlavnichpovodi-cr/x2-pracovni-verze-planu-hlavnich-povodi.html

Ministry of Agriculture and Ministry of the Environment. (2010). Koncepce rešeni problematiky ochrany pr`ed povodne ‘mi v Ceské republice s využitím technických a pr írode` blizkých opatr ení schválená usnesením vlády $C^{\vee} R$ ze dne 10. listopadu $2010 c^{`}$. 799. Available at http://eagri.cz/public/web/file/100217/Koncepce_PPO_uv101110._0799.pdf [accessed 25 February 2016]

Ministry of Agriculture and Ministry of Environment (MAME). (2000). Strategy for protection against floods in the czech republic. (approved by Resolution of the Czech Government 
No. 382 of 19 April 2000). Prepared under the co-operation of Ministry of Agriculture and Ministry of Environment. Prague Czech Republic April, 2000

Ministry of Agriculture. (2007). Plán hlavnich povodí $C^{`}$ eské republiky schválený usnesením vlády $C^{`} R$ ze dne 23. kve tna $2007 c^{2} .562$

Ministry of Interior of the Czech Republic. (2015). In Case of Danger - Citizens' Handbook. Available from: http://www.mvcr.cz/mvcren/article/in-case-of-danger-citizens-handbook590735.aspx.

Ministry of the Environment. (2012). Pr`edbe žné vyhodnocení povodn`ových rizik v $C^{2}$ eské republice 2011. Implementace sme rnice Evropského Parlamentu a Rady 2007/60/ES ovyhodnocování a zvládání povodn`ových rizik (verze 5.0). Available at http://www.povis.cz/mzp/smernice/2011/CZ_zprava_PFRA_APSFR.pdf

Mudelsee M., Borngen M., Tetzlaff G. and Grunewald U. (2003) No upward trends in the occurrence of extreme floods in central Europe. Nature. 425, 166-169. https://doi.org/10.1038/nature01928

Potluka, O., and Slavíková, L. (2010). Impact of Floods on Local Political Representation. Acta Politologica. 2(1), 1-17.

Raaijmakers, R., Krywkow, J., and van der Veen, A. (2008). Flood risk perceptions and spatial multi-criteria analysis: an exploratory research for hazard mitigation. Nat Hazards. 46, 307-322. DOI 10.1007/s11069-007-9189-z https://doi.org/10.1007/s11069-007-9189-z

Siegrist M. and Gutscher H. (2006). Flooding risks: a comparison of lay people's perceptions and expert's assessments in Switzerland. Risk Anal. 26 (4), 971-979. /https://doi.org/10.1111/j.1539-6924.2006.00792.x

Slovic, P. (2000). The perception of risk. Earthscan publications Ltd., London.

Slovic P. (1987). Perception of risk. Science. 236, 280-285. /https://doi.org/10.1126/science.3563507

Slovic, P., H. Kunreuther, and G. F. White. (1974). Decision processes, rationality and adjustment to natural hazards, edited by G. F. White, Natural hazards, local, national, and global, New York, Oxford University Press. 187-205.

Stojanov, R, et al. (2015). Adaptation to the Impacts of Climate Extremes in Central Europe: A Case Study in a Rural Area in the Czech Republic. Sustainability. 7, 12758-12786. doi:10.3390/su70912758

Terpstra, Teun. (2011). Emotions, Trust, and Perceived Risk: Affective and Cognitive Routes to Flood Preparedness Behavior. Risk Analysis. 31(10). https://doi.org/10.1111/j.15396924.2011.01616.x

The ICPDR Flood Action Programme. (2009). Flood Action Plan in the Morava River Basin. Prepared by Austria Federal Ministry of Agriculture, Forestry, Environment and Water Management Freiland Umweltconsulting ZT GmbH REVITAL Ziviltechniker GmbH Czech Republic Czech Hydrometeorological Institute Ministry of Environment Morava River Board, s.e. Slovak Republic Ministry of Environment Slovak Hydrometeorological Institute Slovak Water Management Enterprise, s.e. Water Research Institute. Version: Final Date: November 2009.

Tobin G.A. (1995). The levee love affair: a stormy relationship? Water Resour Bull. 31 (3), 359367. https://doi.org/10.1111/j.1752-1688.1995.tb04025.x

Valente, S.; Coelho, C.; Figueiredo, E.; Pinho, L. (2008). What do we think about floods? Social perception on flood risk in Águeda municipality, Portugal. Conference: Freude am Fluss Final Conference: Space for the river, space for people? Center for Sustainable 
Management of Resources, Radboud University, Nijmegen, The Netherlands. Cd-Rom., At Nijmegen, The Netherlands.

Vávra, J. M. Lapka, E. Cudlínová and Z. Dvor áková-Líšková. (2015). Local perception of floods in the Czech Republic and recent changes in state flood management strategies. J Flood Risk Management. 1-15.

Wachinger, G., et al. (2013). The Risk Perception Paradox - Implications for Governance and Communication of Natural Hazards. Risk Analysis. 33(6). https://doi.org/10.1111/j.15396924.2012.01942.x

\section{Contact Information}

Mohan Kumar Bera

Department of Geography

Faculty of Science, Masaryk University

Kotlářská 2, 61137 Brno, Czech Republic

+420773914349

Email: mohan.bera@gmail.com

orcid.org/0000-0001-8641-2177

DOI: https://www.doi.org/10.7441/dokbat.2016.06 


\title{
FUNCTION OF INTEGRATED MARKETING COMMUNICATION AND ITS IMPACT ON CONSUMER BEHAVIOUR
}

\author{
Veronika Braciniková
}

\begin{abstract}
One of the most disputed areas of research is with no doubt Integrated Marketing Communication. Concept of Integrated Marketing Communication has been evolving from the modest using of promotional instruments to the convoluted strategic system. Marketing Communication holds the significant function in communicating with the consumers by applying its offline or online implements to deliver the messages. It can be appointed that the principal aim of Integrated Marketing Communication is to influence the consumer behaviour and its structural processes as attitude, motivation and perception. That is why this system has become the main manner of accomplishment of the targets of companies, because identifying of opportunities for increasing impact on consumer behaviour helps to achieve the objectives of the enterprises. Therefore, this paper focuses on distinguishing ways in which Integrated Marketing Communication might affect behaviour of consumers materialized in the process of their decision-making.
\end{abstract}

Keywords: integrated marketing communication, consumer behaviour

\section{INTRODUCTION}

Survival and growth of businesses in today's economic system is largely depended on the acquisition and the existence of precise and detailed information of buyers. Such information means information about the customer's needs, his attitudes, personal reaction, acts or decisions. Just modern marketing concept is based on the need to have such knowledge. It is now widely accepted idea that the main objective of marketing is not finding and persuading customers to buy the product of some company, but to meet the needs of the consumers, which is the foundation of customer orientation. Continuous searching and developing of methods and procedures which will effectively meet the needs of buyers, is the main task of marketing communications.

Identifying communication channels and links which is the behaviour of consumers influenced by, is a major activity of marketing communication. The ultimate goal is not just creating good marketing message, but also the choice of the most appropriate channel for reaching target groups of customers.

Marketing communication is not only one of the elements of the marketing mix, but the overall approach, which use of its other tools to reach customers, create and strengthen relationships with them. Therefore, the aim of this paper is to focus on clarifying aspects of Integrated Marketing Communication (IMC) mechanism affecting consumer behaviour, which is reflected in their decision-making process of buying the product. 


\section{INTEGRATED MARKETING COMMUNICATION AND ITS FUNCTION IN THE ENTERPRISE}

The role of communication in the business activities of the company may be regarded from different perspectives, because through communication the company does not just create awareness of its brand among customers, but also used a communication as the tool for building a strong brand image. To produce products or provide services is not enough for the sellers. The communication has the paramount importance for the future achievement of the objectives of businesses in the market. It follows that for the sellers it is of course important to aware their current and potential customers of their brand and then keep it in the minds of these consumers (Okyere \& Agyapong Nyarko, 2011).

Therefore, marketing is much more than a simple sale of what the company possesses or promotion of what the company produces. It is more about deciding what to produce and to who the product offers to. In practice, the marketing strategy should be the leader of business strategy and keep it in the development of such product that can be sold rather than selling such product, which can be produced (Grasby et al., 2004).

Marketing communication began to gain in importance over the last decade of the twentieth century, which was the result of remarkable development of marketing in this period. Although consensus of specialists in terms of content is still missing, the consensus of specialists in the role and importance of marketing communication does not. There is a very dynamic market in the global way in which is the strong competition in marketing communication (Mihart, 2012). Companies are constantly trying to develop more efficient ways of delivering news and information to customers for easily understanding the benefits that they can gain through consumption or use of their goods and services (Clow \& Baack, 2010). Marketing communication has become the most important aspect of marketing and business vision, as all businesses use its various forms in order to offer their products to market and achieve not only financial objectives but also non-financial interests (Shimpo, 2003).

Marketing communications is a mixture of methods though the enterprises deliver messages to diverse audiences. However, besides this mixture there are a number of subcategories. Advertising, direct marketing, personal selling, customer relations, sales promotion - all of these tools can be rightly described as components of marketing communication and each one has its own unique significance and is particularly important in an integrated marketing plan of businesses (Belch \& Belch, 2008).

An approach that maintains and is based on the fact that communication is included in all four means of marketing mix which are product, price, distribution and marketing communication, is called integrated marketing communications. The effectiveness of this approach is based on market segmentation. This means that the product is designed to meet and stimulate the needs of well-defined segment of consumers, then the products are marketed with a price, they are distributed through appropriate distribution channels and not least with the help of appropriate components of marketing communication that adapt to these needs of the target group of customers. The instruments that promote and organize activities of IMC, is an integrated communication strategy and integrated communication plan. An integrated communication strategy is reflected in the market position based on the objectives, which are set by the communication line. Integrated communication plan is aimed to the selection of specific 
components with regard to their effective correlation in terms of cost optimization (Mihart, 2012).

IMC is aimed at building and strengthening consumers' interests and relationships. By focusing on relationships IMC combines marketing and Customer Relationship Management (CRM). It is a challenge for managers to deal with integration, interface, measurement and responsibilities of both, it means the traditional approach of marketing and new interactive marketing approaches (Baker \& Mitchell, 2000).

With the further spread of the concept of communication focused on customer, managers must recognize that IMC provides above-average advantage over the competition to the company, which is an excellent opportunity to become a leader in the market (Porcu, García \& Kitchen, 2012).

\subsection{Performance and Outputs of Integrated Marketing Communication in the Enterprise Activities}

One of the main problems associated with the proceedings taken in the field of marketing are the marketing inputs. IMC as a discipline is regarded as an investment in communication, but accountants consider it as an expense. This leads to problems in the recognition of financial incomes. And thus apparently satisfactory interventions of ICM become useless when they are thoroughly investigated for accounting purposes. In spite of there are no clear answers, the company must seek to improve the situation through measures of marketing communication (Ambler et al., 2002).

Given the fact that today the brands become the main competitors in the market and one of the focal areas of marketing communication is to build and strengthen brand, the opinions of many experts converge to the idea that marketing communication is the only way to create and maintain competitive advantage. Successful completion of marketing goals and objectives of the organization is provide from majority by marketing communication, so it is essential to identify ways to further strengthen its impacts. This objective can be achieved by integrating all specific components into a coherent, integrated system. IMC has become very controversial subject. There is a theory that represents the most significant development of marketing communication (Kitchen \& De Pelsmacker, 2004), but also opinions that this is just a collection of traditional marketing specific terms presented in new forms (Spotts, Lambert \& Joyce, 1998).

Brands and communication are the links between businesses and customers because communication distinguishes one brand from another. The companies are constantly seeking new perspectives in terms of individuals, households, and organizations of which may subsequently become customers. Whereby the customer / consumer is the person who really buys. Consumers are members of the market in which they consume goods and services. Thus, the seller should focus on factors that influence buyers the most. The key to success for businesses is to look at everything from the perspective of the customer. This means that marketing takes into account what customers want and need; how to decide about meeting their needs and, based on that knowledge they develop an approach with which they come in front of the clients. An example would be creating a cordless phone depending on the fact that people have a need to communicate with each other even when they are on the road (Okyere, \& Agyapong Nyarko, 2011). 
In the view of Keller and Lehmann (2003) there is a productivity system of IMC that combines efficiency in the management of marketing communication and campaigns with customers and brand value. Rust et al. (2004) developed in the paper about measuring marketing productivity the chain that brings together marketing strategy and tactics with the consumer, market and financial benefits for businesses. At the same time they identify the impact of marketing strategies and tactics (involving marketing communication) on consumer attitudes, his loyalty and satisfaction. These preliminary interpretations of power can be aggregated to the level of marketing assets and measured using metrics related to brand value and customer value. Such conduct has the effect on the financial impact (ROI, EVA) as measured according to financial situation (including earnings and cash flow). The net result of such a chain of events is not only an increased market value of the organization, but also the value of the company as a whole.

Reid, Luxton and Mavondo (2005) suggest ways of measuring the performance of the brand across two levels comprising operating performance of marketing communication and brand performance. Table 1 shows a number of possible measures which may be used in order to measure this performance.

Table 1 - Outputs of Integrated Marketing Communication. Source: (Reid, Luxton \& Mavondo, 2005).

\begin{tabular}{|c|l|}
\hline \multicolumn{1}{|c|}{$\begin{array}{l}\text { MEASURING THE OUTPUTS OF IMC } \\
\text { THE DEGREE OF } \\
\text { REALIZATION IMC }\end{array}$} & \multicolumn{1}{c|}{ PERFORMANCE / OUTPUTS } \\
\hline \multicolumn{1}{|c|}{$\begin{array}{l}\text { Performance of marketing communication } \\
\text { Premises }\end{array}$} & $\begin{array}{l}\text { Reduced incidence of conflicts, lower transaction costs through } \\
\text { cooperation, reduced duplication of effort, reduced duplication } \\
\text { communication strategies, clearly defined brand positioning, } \\
\text { one vote - one view. }\end{array}$ \\
\hline $\begin{array}{l}\text { Campaign } \\
\text { Impact on customers and benefits }\end{array}$ & $\begin{array}{l}\text { The synergy between the communication mix, recorded success in } \\
\text { indirect campaign goals relative to competitors, economic return on } \\
\text { transient changes in customer awareness, customer associations, } \\
\text { attitudes customer, the customer's affection, experience and return on } \\
\text { investment. }\end{array}$ \\
\hline
\end{tabular}




\begin{tabular}{|l|l|}
\hline $\begin{array}{l}\text { Impact on the market } \\
\text { and the relative position }\end{array}$ & $\begin{array}{l}\text { Lower price elasticity of customers, reducing sales and service costs, } \\
\text { strengthening market position, growth in sales and revenue. }\end{array}$ \\
\hline $\begin{array}{l}\text { The financial impact and } \\
\text { the impact on company } \\
\text { value }\end{array}$ & $\begin{array}{l}\text { Profit growth, EBIT (earnings before tax), stability and growth in } \\
\text { cash flow, ROI (return on investment) / ROBI (return on investment } \\
\text { in the brand - present and future), EVA (economic value added), } \\
\text { MVA (market value added), the share price, market capitalization. }\end{array}$ \\
\hline
\end{tabular}

In general, marketing communication includes measures related to internal metrics and represents a return on effort invested in the campaign, and in this model the power of brand has a direct impact on customers, the market and also profit and cash flow metrics. Given the lack of empirical research on the relationship among the IMC and various performance results, it is too difficult to determine the exact relationship among them (Reid, Luxton \& Mavondo, 2005).

However, according to Cornelissen and Locke (2000) operationally IMC provides benefits and advantages to businesses by coordinating the various activities and marketing communication across the different functions involved in the implementation of marketing campaigns. And these benefits are subsequently characterized as psychosocial manifested by reduction of conflicts and reducing transaction costs. Other resources that used to cost savings in companies are related to the organizational structures, in which the means of cooperation between departments of the company avoid unnecessary duplication of communication strategies, thereby improving the operating efficiency and compactness of messages (Pickton \& Hartley, 1999).

In terms of campaigns, one would expect that companies that implement successful IMC, should achieve improvements in the outcomes of these campaigns. Cornelissen and Lock (2000) call these results functional and by Linton and Morley (1995) include things like the interaction between the elements of the communication mix campaign. While increasing the ability to use a wider and more appropriate range of communication tools, especially resulting from the application of the principles of planning from scratch (Duncan \& Moriarty, 1997). The success of the campaign can be measured through economic analysis return on investment with the help of direct behavioural objectives and subjective views of managers about the success of the campaign compared with those of competitors. Rossiter and Bellman (2005) argue that a company applying IMC should be better able to achieve the objectives of direct and indirect campaigns including brand awareness, positive attitude and brand preference, brand action intentions and facilitate the purchase. The successful achievement of these goals of each campaign should be reflected over time in increasing the value of the company and brand for customers who are subsequently measured through related indicators. This increase would be reflected, among other factors in achieving higher price premiums and reduction of price elasticity, as well as an enlargement of the share itself on the market and increase its profitability (Keller \& Lehmann, 2003). In general it can be stated that one of the most desired outcomes of effective IMC is more differentiation leading to monopolistic brands, making firms with such brand less vulnerable in relation to competing enterprises (Rust et al., 2004). 


\section{IMPACT OF INTEGRATED MARKETING COMMUNICATION ON CONSUMER BEHAVIOUR}

In order to assess the impact of IMC on consumer behaviour, it is necessary to monitor the response of consumers to a single message sent by all components of IMC. The obstacle in linking the purchase with the action of this communication could be that the other elements of the marketing mix can improve or worsen the chance of a positive response of customers (Duncan, 2004). For example, the price can be at odds with the quality perceived by customers. IMC as a complex system, which affects consumer response using communication potential of the elements of the marketing mix, solves the problem of noticeable difference between information of marketing communication and information associated with price, packaging, brand or distribution channel. Consumer feedback can be explored through a variety of models of effects that help companies to establish marketing plans, structure of objectives and help to analyse the impact of the message as a series of steps called the model hierarchy reactions. Belch and Belch (2008) explain that these models have been developed to portray the stages which consumers can move from a state that is not aware of a particular product or brand to the actual purchase behaviour. They could be used in a broader context for the examination of the impact of IMC on consumer behaviour.

Model hierarchy reactions can be divided into two main categories - traditional models and alternative models. Among traditional models it includes AIDA model which characterizes the four steps that the consumers should go through in each marketing message - absorb attention (A), generate interest (I), evoke desire (D) and get to action of buying (A). Another model is the Dagmar - defining advertising goals for measured advertising results. This model thus begins with the awareness, understanding and passes through belief and ends with action. An alternative model is the processing of information developed in 1973, which identifies three alternative positions based on the perception of product differentiation and product involvement (Belch \& Belch, 2008).

Processes of consumer behaviour are influenced by marketing communication, which is created and based on the results of marketing research and market segmentation. Other elements of the marketing mix discover the power of communication to work with the strategy and plan of marketing communication. There are many ways that could be influenced by the consumer's perception of a product, service, or even a business entity. One of the methods is the characteristic of the product. The results indicate that the changes to the consumer perception of the product may be caused by changing the physical characteristics of the product or the packaging. For this reason, marketing communication is associated with the perception of the customer as a result of brand image and its differentiation. Another component of IMC is the price. It also has an impact on consumer perception of the product. On average, consumer's preferences and choices are based on the quantification of quality or benefits that may be obtained from the product compared to the price, which has to be paid. This means that the customer's perceived value is associated with the quality and benefits of the product and their willingness to pay for these benefits. The distribution is the other component, which acts on consumer behaviour. The distribution includes material equipment of shop, location, product configuration (Hun \& Yazdanifard, 2014). Although IMC globally influences motivation primarily through marketing communication, it represents a complex process of motivation, which has the power to stimulate consumer behaviour (Hawkins \& Mothersbaugh, 2010). 
The amount of researches regarding with consumer behaviour are associated with high engaged in marketing communication. Effective marketing communication must be consistent in the delivery of information in order to build positive awareness and confidence in the target segments (Kitchen \& Schultz, 2003). Marketing communication becomes effective especially in the consumer segment, Generation $\mathrm{Y}$ when used to deliver a clear and specific message broadcast media such as television or radio. Advertising through newspapers, magazines, billboards, radio and television is the emotional connection with customers in order to stimulate their requirements and needs on the basis that online communication channels are the easiest and the fastest way to get more information about goods and services for customers. When consumers are interested in certain products and are excited about them, they are looking for other information on the Internet and spread this information further by word of mouth among friends and relatives. It is a functioning offline word of mouth. Mostly Generation Y has benefited from such a combination of online and offline marketing communication. The same is true for some consumers of Generation X. It is therefore essential that the company used both online and offline marketing channels of communication in order to meet and stimulate the needs of all categories of consumers (Hun \& Yazdanifard, 2014).

\subsection{Consumer Segmentation in Marketing Communication}

Procedures for the allocation of individual customers in larger groups based on specific characteristics, which may be as age, gender, interest, habits, is known as segmentation of consumers. This allows companies to efficiently allocate marketing resources among these specific groups of consumers (Hun \& Yazdanifard, 2014).

There are four commonly used types of customer segmentation, which are geographical segmentation, psychographic, behavioural and demographic segmentation. The geographical segmentation means that the market is broken down into different geographical units such as countries, towns, villages, while psychographic segmentation means that the consumers are distributed on the basis of their personal traits, lifestyle and nature. Behavioural segmentation of consumers based on criteria such as brand loyalty, brand awareness, attitude to products and services, and the rate of use. In demographic segmentation comes to creating groups based on age, sex, education, occupation or income (Sun, 2009).

Companies for the purpose of efficiency often use segmentation in marketing communication for example in ads that target specific consumers. Generational segmentation is considered as the most basic and provides many benefits. However, the relevant research has to be implemented correctly and then carefully applied. Different generations have different experiences, values, beliefs, attitudes, preferences, ideas, opinions and feelings (Hun \& Yazdanifard, 2014). Understanding the differences between Generations X, Y and Baby Boomers enable companies to use the most effective and best marketing strategies to communicate with these different generations of consumers (Solomon, 2011). The Baby Boomers generation is before the age of retirement or is already retired. This means that nostalgically conceived ads, or ads that appeal to health, can be successful in this generation. Generation $\mathrm{X}$ is more family orientated and focuses on casual lifestyle. These consumers, if they have more time, they carry a variety of leisure time activities. Given that they are currently in the middle of their careers, balance and perspective in their life is important to them. Advertising and products aimed at family values are more likely to be able to take this generation of consumers (Hun \& Yazdanifard, 2014). Generation Y is three times larger than the Generation $X$ and tends to spend more money than the other two 
generations. Research has shown that Generation $\mathrm{Y}$ is more focused on brand and was exposed to a wider range of advertising media such as television, radio, internet and technological development, when they were children. Generation Y tends more to fashion, technology and music. Therefore, using actors from the same generation in advertising packed with fashion and music, it may be efficient and correct advertising for this generation (Bennett, Sagas \& Dees, 2006).

\subsection{The influence of Integrated Marketing Communication on Consumer Decision-Making Process}

To facilitate purposeful comparisons between different companies, time etc. is important to model the research of IMC influence on consumer behaviour. For creating such a research model (Figure 1) it is necessary to test several variables as regards matching model components and its functional relationship with theoretical precepts which are accepted as defining IMC (Mihart, 2012).

Block A - Integrated marketing communication - ways in which communication is found in all four elements of marketing mix. Such impact must be founded on market research that supports appropriate market segmentation. It means the product is made and designed to meet the needs of specific group of consumers, it is fetched out to market at a certain price through the adequate distribution channels and the structure of marketing communications is made in a particular way, which is tailored to the characteristics of the target segment. The instruments which support and organize the IMC activities are integrated communication strategy and integrated communication plan (Mihart, 2012).

Block B - Consumer behaviour - is composed of five dimensions through which specialists define this process, on the conceptual. The five basic components which are the perception, information / learning, attitude, motivation and actual behaviour used to be taken into account in the design and implementation of many forms of behavioural studies (Mihart, 2012).

Block C - Consumer decision-making process - obtains the stages which the consumers go through when they are deciding to purchase goods and services which are generally accepted by experts in the field of marketing: need recognition, information research, evaluation of alternatives, evaluation result and when buying, post-purchase evaluation. Apparently, the stages of buying decision are determined by product specific, consumer target segment and the particularities of the five processes which composed the consumer behaviour (Mihart, 2012).

The relations of the model are divided in three categories - main functional relations which describe the essential relations between blocks and they are illustrated in the model by the horizontal block arrows; secondary relations which describe structural links among components of the same block or of different block and they are illustrated by lines; feedback lines (Mihart, 2012). 


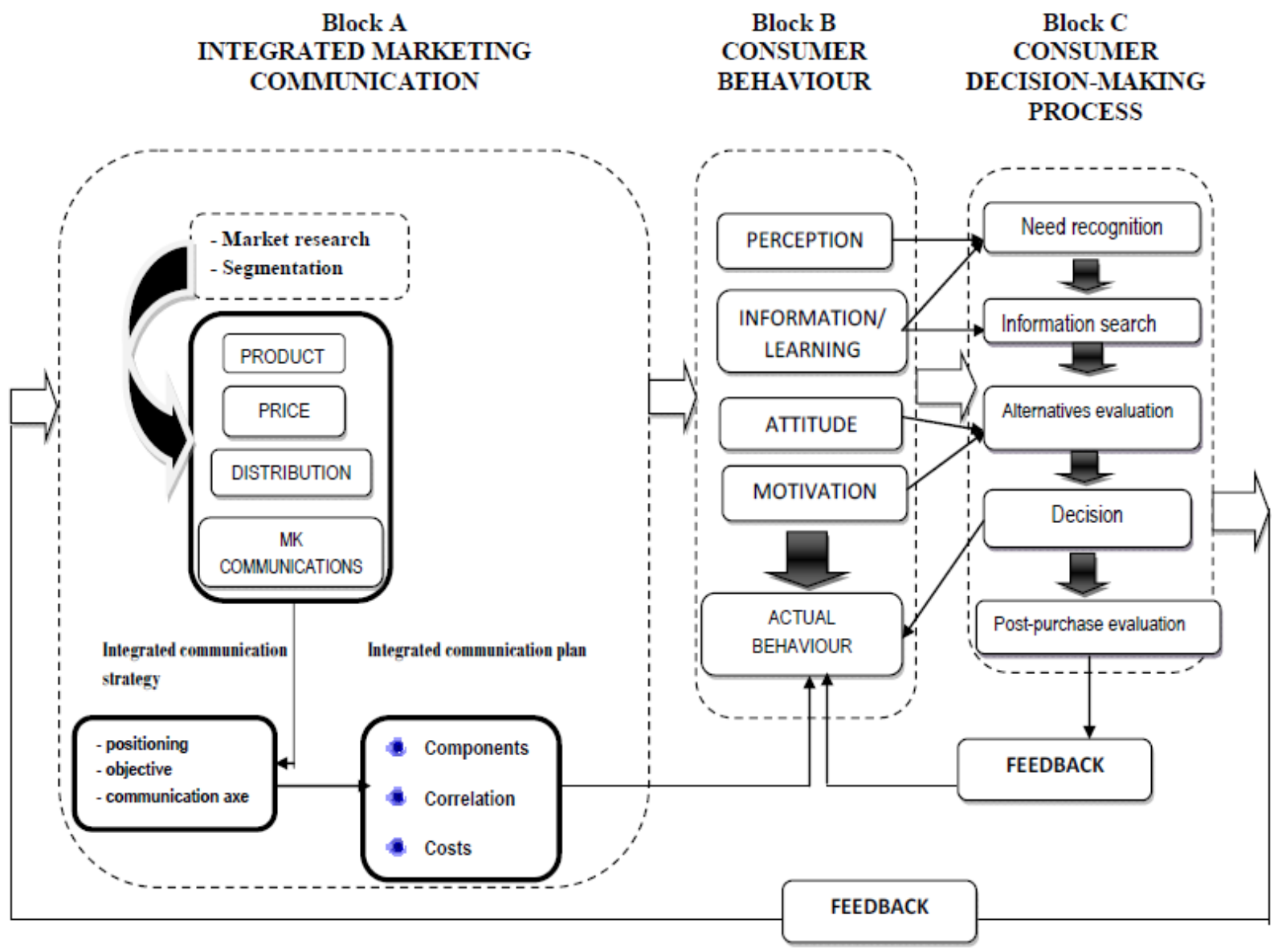

Figure 1 - Model of the IMC influence on the consumer decision-making process. Source: (Mihart, 2012).

Block A $\longrightarrow$ Block B - IMC (Block A) influence on consumer behaviour processes, based on results of market research and market segmentation, is propagated by each component of marketing mix (product, price, distribution and marketing communication), exploring its communicational potential and it is reflected in integrated communication strategy and in integrated communication plan. There are many ways in which product characteristics and attributes affect the perception of consumer. The perception of product is influenced by its physical characteristics. The price has also direct implications on the perception. Consumer perception is also related to the distribution. All IMC elements transmit to the consumers various information, and due to the support of the learning process they acquire the purchase and consumption knowledge. Forming or changing attitude is one of the most important goals of IMC, which is not influenced just by components of marketing mix, but also it is result of experience that an individual has with the attitude object. IMC could globally influence motivation, especially through marketing communications component (Mihart, 2012).

Block B $\longrightarrow$ Block C - The processes that the Consumer Behaviour (Block B) are influenced, each one, in various proportions and combinations by the components of marketing mix belonging to Block $\mathrm{A}$ and by the operational tools. Block B has a main resultant which reflects the differentiated and particular impact of the behavioural processes on the stages of consumer decision-making process. The first stage - need recognition - all the components of IMC have to be tailored for solving consumer recognized problem. IMC strategy must take into account the 
type of consumer identified problem. In case of an active one (consumer is aware of it), it has to focus on convincing a consumer that a specific product is the best solution. If there is an inactive problem, the strategy aims to determine consumer to recognize a problem and then offer a possibility to solve it. The second stage - information search is based on learning process according to which consumer has usually a previous knowledge and an experience related to a product. The third stage - evaluation of alternatives is conditioned by the type of consumer's choice. The evaluation process is closely related to learning, motivation and attitudes. IMC could affect this stage by coordinating the appropriate marketing communications tools to highlight positive feelings which are resulted from product using. IMC could have a contribution on attitude forming. Decision stage is a resultant of the previous stages and it is materialized in consumer's actual behaviour. Consumer decision-making process is completed with the postpurchase evaluation, in which consumer compares the product real performance with his expectations. This evaluation generates feedback which increases the experience level and is included further in learning process, influencing future related decisions (Mihart, 2012).

Block $\mathrm{C} \longrightarrow$ Block $\mathrm{A}$ - The relationship between consumer-making decision and IMC is materialized in feedback. All the IMC components could be revised and improved by taking into account the main aspects resulted from feedback of consumers (Mihart, 2012).

\section{CONCLUSION}

In the current consumer society full of visible consumption, organizations should understand what for, why, where and when consumers decide to spend. Companies must have the detailed information about the behaviour of consumers to select the appropriate communication channel in order to its effective functioning. This means that when these companies have this expertise and knowledge, allowing them to within its business operations and activities in the market to apply the most effective marketing communication tools at this difficult time consumption.

Marketing communication represents a personal connection between consumer and product. The company, which uses tools and components of marketing communication wisely and effectively, can successfully influence consumer behaviour and build the brand so that consumers deem credible. It follows that the proper application of these communication mix elements often not only creates, but also enhances the long-term customer loyalty.

But the election of the proper communication mean is not preceded just by obtaining detailed information about customers, but also it is necessary for the organization needs to accomplish market segmentation. Given that the different generations have different needs when buying a product, also the demands on the communication channel are different. It is therefore necessary to segment consumers and choose for different target groups the most appropriate means of communication according to their preferences. Following the development of an adequate advertising campaign of a particular product, the consumer demand for the goods will increase, because it brings more utility.

\section{References}

Ambler, T., Bhattacharya, C. B., Edell, J., Keller, K. L., Lemon, K. N., \& Mittal, V. (2002). Relating Brandand Customer Perspectives on Marketing Management. Journal of Service Research, 5(1), 13-25. https://doi.org/10.1177/1094670502005001003 
Baker, S., \& Mitchell, H. (2000). Integrated Marketing Communication: Implications for Managers. European Society of Opinion and Marketing Research, 42(5), 53-62.

Belch, G., \& Belch, M. (2008). Advertising and Promotion: An Integrated Marketing Communications Perspective. (8th ed., p. 864). NY: McGraw-Hill. ISBN 978-007338109-1.

Bennett, G., Sagas, M., \& Dees, W. (2006). Media preferences of action sports consumers: differences between generation X and Y. Sport Marketing Quarterly, 15(1), 40-49.

Clow, K. E., \& Baack, D. (2010). Integrated Advertising, Promotion, and Marketing Communications (4th ed., p. 515). Upper Saddle River: Prentice Hall. ISBN 978-013607-942-3.

Cornelissen, J. P., \& Lock, A. R. (2000). Theoretical Concept or Management Fashion? Examining the Significance of IMC. Journal of Advertising Research, 40(5), 7-15. https://doi.org/10.2501/JAR-40-5-7-15

Dubrin, A. J. (1997). Fundamentals of Organizational Behavior: An Applied Approach (1st ed., p. 300). Cincinnati: South-Western College Publishing. ISBN 978-05-3885-776-5.

Duncan, T. (2004). Principles of Advertising and IMC (2nd ed., p. 800). Boston: McGraw-Hill. ISBN 978-00-7253-774-1.

Duncan, T. R., \& Moriarty, S. (1997). Driving Brand Value (1st ed., p. 284). New York: McGraw Hill. ISBN 978-07-8630-822-4.

Grasby, E., Crossan, M., Frost, A., Haywood-Farmer, J., Pearce, M., \& Purdy, L. (2004). Business Decision Making: Text and cases, (7th ed., p. 786). Mishawaka: Nelson College Indigenous. ISBN 978-01-7622-458-5.

Hartlez, B., \& Pickton, D. (1999). Integrated Marketing Communications Requires a New Way of Thinking. Journal of Marketing Communications, 5(2), 97-106. https://doi.org/10.1080/135272699345699

Hawkins, D., \& Mothersbaugh, D. (2010). Consumer Behavior: Building Marketing Strategy (11th ed., p. 778). Boston: McGraw-Hill. ISBN 978-00-7128-841-5.

Hun, T. K., \& Yazdanifard, R. (2014). The Impact of Proper Marketing Communication Channels on Consumer's Behavior and Segmentation Consumers. Asian Journal of Business and Management, 2(2), 155-159.

Keller, K. L., \& Lehmann, D. R. (2003). How Do Brands Create Value? Marketing Management. 12(3), 26-32.

Kitchen, P. J., \& De Pelsmacker, P. (2004). Integrated Marketing Communication: A Primer (1st ed., p. 193). London: Routledge. ISBN 978-04-1531-421-3.

Kitchen, P., \& Schultz, D. (2003). Integrated corporate and product brand communication. Advances in Competitiveness Research, 11(1), 66-86.

Linton, I., \& Morley, K. (1995). Integrated Marketing Communications (1st ed., p. 135). Oxford: Butterworth Heinemann. ISBN 978-07-5061-938-7.

Mihart, C. (2012). Impact of integrated marketing communication on consumer behavior: effects on consumer decision - making process. International Journal of Marketing Studies, 4(2), 121-129. https://doi.org/10.5539/ijms.v4n2p121

Okyere, N. D., Agyapong, G. K., \& Kwamena, M. N. (2011). The Effect of Marketing Communications on the Sales Performance of Ghana Telecom. International Journal of Marketing Studies, 3(4), 50-62. https://doi.org/10.5539/ijms.v3n4p50 
Porcu, L., García, S. B., \& Kitchen, P. J. (2012). How Integrated Marketing Communications (IMC) works? A theoretical review and an analysis of its main drivers and effects. Researchgate, 25(1), 313-348.

Reid, M., Luxton, S., \& Mavondo, F. (2005). The Relationship between Integrated Marketing Communication, Market Orientation, and Brand Orientation. Journal of Advertising, 34(4), 11-23. https://doi.org/10.1080/00913367.2005.10639210

Rossiter, J. R., \& Bellman, S. (2005). Marketing Communication: Theory and Applications . Sydney: Pearson Education. ISBN 978-17-4103-269-7.

Rust, R. T., Ambler, T., Carpenter, G. S., Kumar, V., \& Srivastava, R. K. (2004). Measuring Marketing Productivity: Current Knowledge and Future Directions. Journal of Marketing, 68(4), 76-89. https://doi.org/10.1509/jmkg.68.4.76.42721

Shrimp, T. A. (2003). Advertising, Promotion: Supplemental Aspects of Integrated Marketing Communication. Mason: Thomson South-Western. ISBN 978-00-3035-271-3.

Solomon, M. R. (2011). Consumer behavior: buying, having, and being. Pennsylvania: Prentice Hall. 978-03-3611-092-7.

Spotts, H. E., Lambert, D. R., \& Joyce, M. L. (1998). Marketing Déjà Vu: The Discovery of Integrated Marketing Communications. Journal of Marketing Education, 20(3), 210-219. https://doi.org/10.1177/027347539802000304

Sun, S. (2009). An analysis on the conditions and methods of market segmentation. International Journal of Business and Management, 4(2), 63-70. https://doi.org/10.5539/ijbm.v4n2p63

\section{Contact information}

Veronika Braciníková

Silesian University in Opava

School of Business Administration in Karviná

Univerzitní náměstí 1934/3

Karviná, Czech Republic

Telephone number: +421908702930

bracinikova@opf.slu.cz

DOI: https://www.doi.org/10.7441/dokbat.2016.07 


\title{
CHANGES IN COMPETITIVENESS OF THE CZECH REPUBLIC WITHIN PREVIOUS EU FINANCIAL FRAMEWORK
}

\author{
Kristýna Brzáková
}

\begin{abstract}
Objective of the paper are to bring up a comparative measurement of competitiveness of country and to show changes in competitiveness of the Czech Republic in previous financial framework of EU. Further hypothesis suggested eventual correlation between competitiveness of the country and allocated subsidies via EU funds. There are explained definition of subsidy and its theoretical effects on the economy and practical use by EU. There are specified approaches of the term of competitiveness and explained Porter's diamond model in international perspective. Measures are based on both qualitative and quantitative data and the Porter's diamond for the Czech Republic in each year of financial framework are calculated and evaluated.
\end{abstract}

Keywords: competitiveness, Porter diamond, EU funds

\section{INTRODUCTION}

In the 2013, EU foreign direct investments exceed $2.6 \%$ of GDP within EU28 (EUROSTAT, 2015). Within the previous financial framework EU allocated EUR 201,000 mil from European regional development fund to its member states. Namely, the Czech Republic had available amount of EUR 13,933 mil to enhance regional development (EC, 2015).

Have the allocated money help to enhance competitiveness of the Czech Republic? Have the competitiveness changed positively in the Czech Republic within this time period? The aim of this article is to show change of competitiveness position of the Czech Republic within time period 2007-2013 by means of Porter's diamond model. There will be analysed EU strategies aiming on competitiveness, and competitiveness factors focusing on improvement of the competitiveness position. The evaluation is based on data analysis; situation before subsidies and after subsidies. Analysis will be carried out on selected national indicators of the Czech Republic by means of the Porter's diamond model.

There is quite a big amount of money that is transferred to the European budget and people might not know where the money goes. It tends to be in our great interest to know where the taxed part of our salary goes. For certain purposes are high percentage of the state budget paid to European budget (EC, 2012). The purpose of this money can be found in the European strategy documentation and regulations. There are not many possibilities to influence the directions of the strategy for each individual in EU. Nevertheless there is importance to query and this should interest each person whether the big amount of money from the European budget is used as it is set up in the regulations and weather turns profit in the form of its objectives. These results should be obvious in the granted projects, the granted companies and also in the economy of the country at the end.

Budget money is allocated through the different European funds that in its regulations define what can be supported and what not. It also establishes the main goal and key objectives for the funds (EC, 2006). After the submission of the long run European budget framework the process 
turns attention to national strategy documentation. For the previous financial framework (i.e. 2007-2013), the Czech republic must have the National Strategic Reference Framework that determines global and national strategy, main goals and targets, procedure of implementation, evaluation and analysis of allocated subsidies (Strukturální Fondy, 2007).

The assessment and evaluation at the national level is taken in the form of monitoring indicators that are mostly related to the specific activity of each operational program, such as kilometres of highway newly built, number of graduates of courses etc. Programs have established so-called contextual (core) indicators, which are to some extent the same for all EU members for the purpose of comparison. These indicators include e.g. unemployment rate or GDP. However, the EU does not provide a comprehensive assessment model to evaluate its members' economic situation and further more EU does not evaluate the competitiveness of each member state or region and its change.

One of the main processed strategies and trends of the EU is to promote enhancement of the competitiveness of EU Member States, its regions and companies operating within the EU. E. M. Porter considers the competitiveness as a competitive advantage and specifies a definition of the competitive advantage factors using his Diamond model (Porter, 2004). Porter's model is used in this paper to analyse competitive position change of the selected regions in the EU, particularly in the Czech Republic.

Research question will be answered by means of the Porter's model. Data are analysed within the previous financial framework, i.e. period 2007-2013. Evaluation carried out within on selected national indicators in the Czech Republic. Results show slight change of competitiveness in the positive way. But not every pillar of the Porter's diamond in this case is improving.

The paper is structured as follows. Firstly theoretical background is introduced, after that, methods of research are constituted, than results are presented. The paper concludes with summarized conclusion with data presented in Appendix.

\section{THEORY REVIEW ON COMPETITIVENESS AND SUBSIDIES}

The theory section explains what is subsidy, put the subsidies into context of competitiveness and explains several definitions of competitiveness.

Firstly, it is necessary to provide a definition of subsidy. According to the analysis carried out by L. Rubini the definition of "subsidy" is not fully covered in the European Commission's regulations. The definition is contained only in the EC Regulation, Article 87 (1). The European Commission defines subsidy as "any aid granted by the State or through State resources in any form" (Rubini, 2010). From this point of view subsidy might be almost everything what flows as state money. For more precise definition it is necessary to interpret what the subsidy comes from and for what reason.

So, there are main important definitions provided in the paper accordingly the definition of subsidy can be generalised and posted. Regarding the intention of this paper on the EU subsidy, particularly, this paper will consider subsidy more precise. On the basis of contracts, other regulations of the European Union and above definitions subsidy can be defined as a financial support from one of the EU funds, which will contribute to economic and social development of member countries and thereby will reduce the significant regional differences between 
prosperous and lagging regions. Subsidy according its aim should enhance competitiveness of supported state or region.

Where is the theoretical background for subsidies? The core reason for subsidies is to support the economic growth and economic development in particular localities. There are many different theories explaining fundamental principles of state subventions and subsidies. One of the reasonable is endogenous growth theory that is based on neo-classical economic theory. Origins of the endogenous growth theory come from Romer (1986) and Lukas (1988). This theory explains economic development as a result of increasing capital in economy. They consider capital in general as a human and physical capital. They also assume that the technology is not a public good and the technological change is determined by the aiming action of the economy actors. Their approach shows that returns from capital do not tend to decline in the economic growth because it provides enforcement of positive externalities from human capital and diffusion of technological knowledge among producers. Lucas (2009) farther claims positive effect from diffusion of ideas among people and companies on economic growth. This results show importance of support of production, innovation and clusters in context of EU in order to ensure economic development. Institutional theory sees the core importance in support of suitable innovative environment to enhance innovation process by the suitable economic regional policy. This theory claims that innovative process do not take place only among regional actors but on the global level too (Bathelt \& Malmberg \& Maskell, 2004). From that it can be assumed that subsidy is reasonable and should help to economic development in the international context in way of support increasing of productivity and innovative process. Many other theories such as origin economic theory from Keynes provide evidence based on theoretical and empirical data analysis about positive effects of state aid into economy on economic growth.

Next step is to define the term competitiveness. The term of competitiveness is a worldwide phenomenon. Policy makers, politicians and others often use it. Many academic researchers doubt about the term itself e.g. Krugman (1994). In this paper we do not discuss whether the term should be used or not. The major problem is in ambiguous definition of competitiveness in the literature (Bontho, 1995). There are quite many definitions and following section provides some core. According The Global Consulting Group, P. Forth (2015): "The definition of competitive advantage will be the relative speed and ability of companies to change." According to M. E. Porter (2012): "The United States is competitive location to extent that companies operating in the U.S. are able to compete successfully in the global economy while supporting high and rising living standards for the average American." Porter also says that competitive local conditions produce prosperity for companies and as well for citizens. Competitiveness of nations lays on long-run productivity and it requires business environment which support continued innovation of process, products and management. Main objective of policy should be long-term orientation (e.g. sustainable employment). Porter et al. in their new working paper define the term competitiveness through global investment attractiveness. Attractiveness of location is given by low costs of factor. Further, locations with higher attractiveness have higher potential to growth faster and the international investments and trade is influenced by global investment attractiveness (Delgado \& Ketels \& Porter \& Stern, 2012).

As previously stated competitiveness lays on interdependence of complex features of state, region or company. According to definitions competitiveness depends on dynamics of action, long-run productivity, innovation process, and policy environment to attract companies in global perspective. The competitiveness can be therefore measured by well-known approach of Porter's 
diamond (Porter, 1990). Furthermore double diamond (Cho \& Moon, 2000) is even more necessary because it considers international characteristics that are very important for small "catching-up" economies like Czech Republic relying on export. According to Porter's concept, the competitiveness of the economy is determined by interdependent factors at the microeconomic level which include: factor conditions, demand conditions, rivalry among the companies, and the existence of supporting industries. Relations and interactions among the elements create network of the diamond shape and contributes to business development.

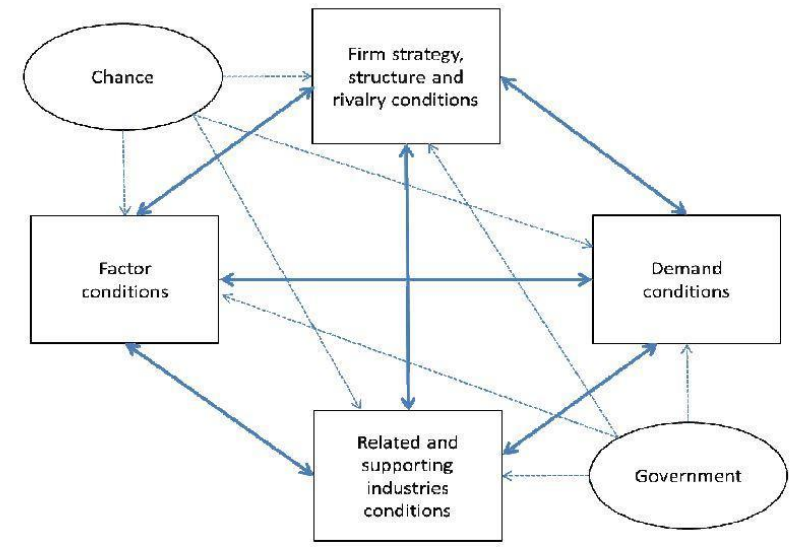

Figure 1 - Porter's diamond of competitive advantage. Source: Porter. (1990).

To summarize according the previously stated theory approaches there should be assumption about the positive effect of subsidy on the competitiveness of company, region and state. All three levels of competitiveness are interdependent therefore subsidy should influence all of them. In the concrete, subsidy supports innovative process in companies, investments into $R \& D$, help to reduce costs of innovations, employees etc. Overall, according to the above it is clear that the European Union aims at ensuring long-term sustainability in terms of competitiveness within EU markets. However, this condition is preceded by achievement the same economic level of the EU Member States. From this can be deduced that EU subsidies should lead to improve the competitiveness of EU members, both among themselves and globally.

\section{METHODS}

Generalized double diamond model is a background of empirical analysis. The concept of the generalized double diamond is put forward by Moon's et al. paper where the authors define competitiveness as: "the capability of firms engaged in value added activities in a specific industry in a particular country to sustain this value added over long periods of time in spite of international competition" (Moon \& Rugman \& Verbeke, 2000). It goes with accordance with above suggested definition therefore Moon's generalized double diamond can be used in this situation. The indicators of the diamond are adjusted to small "catching-up" country relying on export trade. The analysis is based on the double diamond perspective including domestic and international competitiveness, so the indicators are divided into 2 sections (domestic and international) and 4 pillars (factor of production, demand conditions, rivalry among the companies, and supporting industries). The analysis presented in this paper is based on the proxies suggested by Moon of the original generalized double diamond model. Each pillar of the 
diamond includes several indicators shown in the table below. The indicators were inspired with research paper by authors Molendowski \& Žmuda (2013) but not all of them were used in this research, as there are no data available. Therefore in this Porter model analysis are fewer indicators then in paper by Moledowski \& Žmuda.

Table 1: Indicators (unit, source) used in Porter's diamond model. Source: Molendowski \& Žmuda (2013). Own preparation.

\begin{tabular}{|c|c|c|c|}
\hline \multicolumn{4}{|c|}{ Domestic indicators } \\
\hline Factors of production & Demand conditions & Rivalry among companies & Supporting industries \\
\hline $\begin{array}{l}\text { Activity rate }(\% \text { of the } \\
\text { population aged } 15- \\
64 \text {, Eurostat) }\end{array}$ & $\begin{array}{l}\text { GDP per capita (in market } \\
\text { prices, EURO, Eurostat) }\end{array}$ & $\begin{array}{l}\text { Intensity of local competition } \\
\text { (GCR) }\end{array}$ & Local supplier quantity (GCR) \\
\hline $\begin{array}{l}\text { Labour productivity (based on } \\
\text { PPS per employed person, } \% \text { of } \\
\text { EU28, Eurostat) }\end{array}$ & $\begin{array}{l}\text { Tertiary education level ( } \% \text { of } \\
\text { population aged } 30-34 \text {, Eurostat) }\end{array}$ & Value chain breadth (GCR) & $\begin{array}{l}\text { Internet availability (\% of } \\
\text { population who have used a } \\
\text { search engine to find } \\
\text { information, Eurostat) }\end{array}$ \\
\hline $\begin{array}{l}\text { Average wage (monthly, CZE, } \\
\text { CSO) }\end{array}$ & Buyer sophistication (GCR) & & \\
\hline \multicolumn{4}{|l|}{$\begin{array}{l}\text { Number of employees in R\&D } \\
\text { scientist and engineer aged } 25- \\
64 \text { ( } \% \text { of total employment, } \\
\text { Eurostat) }\end{array}$} \\
\hline \multicolumn{4}{|l|}{$\begin{array}{l}\text { R\&D expenditure level ( } \% \text { of } \\
\text { GDP, Eurostat) }\end{array}$} \\
\hline \multicolumn{4}{|l|}{ Capacity of innovation (GCR) } \\
\hline \multicolumn{4}{|c|}{ International indicators } \\
\hline Factors of production & Demand conditions & Rivalry among companies & Supporting industries \\
\hline $\begin{array}{l}\text { Value of exports (millions of } \\
\text { EURO, Eurostat) }\end{array}$ & $\begin{array}{l}\text { Value of exports (thousands of } \\
\text { EURO, CSO) }\end{array}$ & $\begin{array}{l}\text { Business impact of rules on FDI } \\
\text { (GCR) }\end{array}$ & $\begin{array}{l}\text { Control of international } \\
\text { distribution }(\mathrm{GCR})\end{array}$ \\
\hline $\begin{array}{l}\text { FDI inflows (foreign direct } \\
\text { investment, USD, The World } \\
\text { Bank) }\end{array}$ & & $\begin{array}{l}\text { Prevalence of foreign ownership } \\
\text { (GCR) }\end{array}$ & $\begin{array}{l}\text { Air-transport infrastructure } \\
\text { (number of travellers serving } \\
\text { yearly in Prague Airport, } \\
\text { Websites of Prague Airport) }\end{array}$ \\
\hline $\begin{array}{l}\text { Technology transfer via FDI } \\
\text { (GCR) }\end{array}$ & & $\begin{array}{l}\text { Prevalence of trade barriers } \\
\text { (GCR) }\end{array}$ & \\
\hline
\end{tabular}

All the above indicators were chosen regarding the theory and research results mentioned above and so they affect the competitive position of the country significantly. The factors of production reflect the position of "catching-up" country and constitute the source of innovation, 
driving force of technological process, long-run development, and achievement of long-run sustainable competitive advantage. In the international perspective, there is emphasis on the inbound foreign direct investment as a stimulation of the competitiveness of economy. The high technology and innovations are direct or indirect transferred to the country through the inflows investments. The demand conditions lay on its size and growth rate, and efficiency of companies. For the small country is very important ability of access foreign markets. Next, demanding and sophisticated customers force companies to innovate and its purchase decision depends more on non-price factors. Therefore level of education is important too. Rivalry among companies is based on firm strategy, structure of organization and executive skills. These are fundamental elements that determine the level of the competitiveness of a sector. Presence of international corporations in a local market motivates local companies to be more efficient and productive and so it helps to achieve better competitiveness in the global market. Supporting industries is a crucial element of the companies' success within an international competition. Informal relationships facilitate exchange of ideas in field of $\mathrm{R} \& \mathrm{D}$. Besides, quality of transport and Internet communication infrastructure are of a great importance. Even an effective integration and linkages are important in a globalized production and in internationalization supply chain. Those indicators are even more important for the companies in a small and export oriented countries as they can have easy contact to the international partners in the globalized world.

Procedure of the analysis is based on these steps:

1. Determined the maximum value within given years of each indicator.

2. Transmitted to percentage where maximum value equals $100 \%$ and all values accounted in this way.

3. All indicators in each pillar were averaged for each year and the diamond was created for each year.

4. Accounted a breadth of each diamond in the given years.

5. Correlated calculated data of competitiveness and number of allocated subsidies to beneficiaries using statistic correlation.

Next section follows with Data presentation.

\section{DATA}

The empirical analysis was conducted within the time period 2007-2013. The reason is that the EU for the financial framework of the European funds sets up exact time. In 2007 the ERDF started allocating the subsidies into state members and its regions. The budget of the European structural funds is planned for this time framework. Within this time framework plus 2 more years has to be all submitted projects finished. Some effects of the subsidies might be already obvious in the economic development and on competitiveness. Used data were collected from the Eurostat database, The World Bank, The Economic Forum - Global Competitiveness Reports (GCR), the Czech Statistics Office database (CSO) and web sites of Prague International Airport. Each indicator is tagged with unit and source in the brackets in the Table above. All these hard data are collected by author's procedure from mentioned online sources. Data are presented within the years 2007 - 2013 and the change of competitiveness is pointed out using Porter's diamond model.

The difficulties of model application are related with problem of selection suitable proxies in order to precise assessment of the diamond. Therefore, it is used some indicators based on 
qualitative survey conducted by The Economic Forum and the data are taken from several editions of The Global Competitiveness Report (GCR). These indicators were measured by specific question. The detailed description of such each indicator is available in the Appendix 1 of this paper. In the table above, indicators taken from The Global Competitiveness Report are tagged by GCR in brackets.

Collection of indicators and values of empirical data are presented in the Appendix 2. Explanation of the results is provided in the next section.

\section{RESULTS}

After the mentioned procedure of analysis results are presented in this section. There is assumption in previous parts that one of the purposes of the European subsidies is to help to enhance competitiveness of member states. The provided grants should help to increase economic development of lagging countries and regions in the EU. This chapter presents results of change of competitiveness within time period 2007-2013 allocated to the Czech Republic.

Figure 2 presents Porter's diamond using empirical data within the time framework 2007-2013. Diamond has 4 specific pillars; different indicators mentioned above in the Table 1 calculate the value of each pillar. Overview of the collected empirical data is presented in the Appendix 2. Figure 2 presents situations of competitiveness of the Czech Republic in each year of the period. There is lack of data for year 2012 therefore the diamond for this year is missing. Starting value of the analysis is the year 2007 and so the following indicators are compared to it. Value of change of competitiveness is calculated as a distinction between starting year and each year of the period. Value of competitiveness in the starting year has been set up as 100\% and the change is calculated as decrease or increase in percentage. Table 2 shows the comparative distinction of each pillar separately.

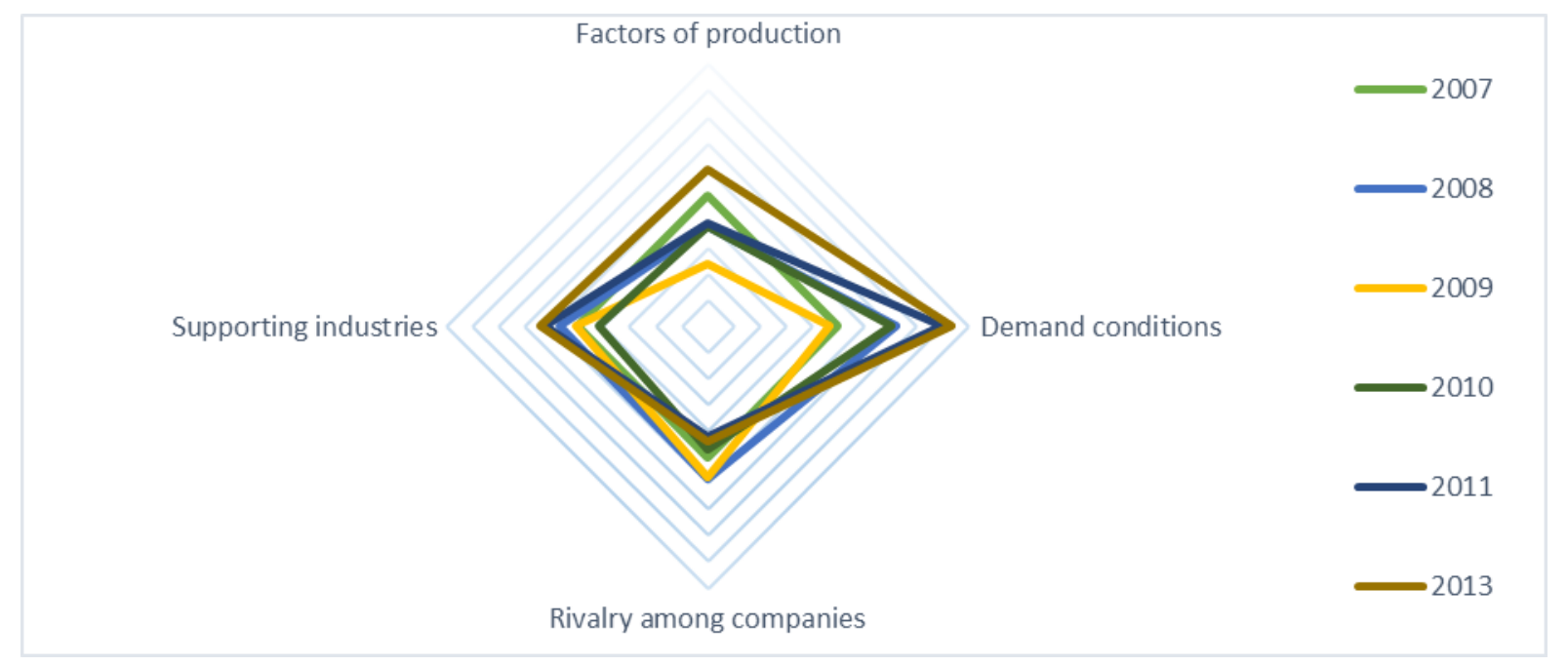

Figure 2: Porter's diamond of competitiveness in the Czech Republic within 2007-2013. Source: own preparation.

Factors of production: From the first year the pillar has been continuously decreasing when it reached the bottom in 2009. After this year the pillar goes up and final position is even higher than in the starting year. Overall increase illustrates $4.91 \%$. This improvement is caused mainly by increase of number of employee in R\&D sector where the percentage increased from 3.8 up to 
$6 \%$ of total employment. Slight increase recorded average wage and expenditure level in R\&D. From the international perspective of competitiveness, value of exports increased its value; otherwise indicators stagnated or even decreased.

Demand conditions: After several fluctuations in that period there is finally big increase of the pillar. Overall increase illustrates $21.55 \%$ comparing 2007 and 2013. Increase of GDP and big growth of exports evoke such increase of the pillar. Mainly, improvement of exports recorded twice bigger value of the primary value in 2007.

Rivalry among companies: From the starting year 2007 the pillar increases after it reaches the top in 2008 , than it decreases down to 2013. All over decrease is $3.13 \%$ from the 2007. Mainly two indicators influenced the rapid decrease of the pillar. Prevalence of trade barriers decreased, which says imported goods face bigger barriers to compete local goods in the country so there are larger barriers for international companies to launch and continue in the Czech market. Second, the decrease of business impact of rules on FDI, which means the rules governing FDI discourage international companies to use the FDI.

Supporting industries: There is obvious big fluctuation of value of the pillar. At the end of the time framework the value of pillar increases of $7.19 \%$ of the primary value in 2007. Internet availability played a crucial role from the all indicators in terms of overall increase. Its value grown twice than it was the primary value in 2007. Other indicators slightly declined.

Overall from four pillars there are three that recorded increase and one decrease in the time period; the competitiveness of the Czech Republic slightly improved despite of world economic crises. There are obvious tendencies in the year 2008 and 2009 of declining of almost all evaluated indicators. The assumption may conclude by important role of European subsidies that help to support economy in the years of crises and it also help to faster return of economic growth in the Czech Republic. There is no significant evidence of increase of competitiveness due to European subsidies. On the other side there is no rejection of influence of European subsidies on the competitiveness.

Table 2: Calculated distinction of each pillar within time framework 2007-2013 (\%). Source: own preparation.

\begin{tabular}{lcrrrrrr} 
& \multicolumn{1}{c}{2007} & \multicolumn{1}{c}{2008} & \multicolumn{1}{c}{2009} & \multicolumn{1}{c}{2010} & \multicolumn{1}{c}{2011} & \multicolumn{1}{c}{2012} & \multicolumn{1}{l}{2013} \\
Factors of production & 100,00 & 94,28 & 86,89 & 94,08 & 94,74 & 84,67 & 104,91 \\
Demand conditions & 100,00 & 111,08 & 98,42 & 110,19 & 119,70 & 108,82 & 121,55 \\
Rivalry among companies & 100,00 & 104,01 & 103,77 & 98,49 & 95,87 & - & 96,87 \\
Supporting industries & 100,00 & 103,49 & 100,13 & 96,05 & 106,13 & 115,41 & 107,19
\end{tabular}

Table 3 shows results of calculated breadth of each diamond in the given years. There is no result for 2012 because of lack of data. Third row presents annual change of the breadth (2008/2007), only year 2013 is calculated as a distinction of 2013/2011. Last row presents overall change in the time framework 2007-2013 totally. 
Table 3: Calculated breadth of Porter's diamond in each year in the Czech Republic. Source: own preparation.

$\begin{array}{lcccccc} & 2007 & 2008 & 2009 & 2010 & 2011 & 2013 \\ \text { Breadth } & 15598 & 17046 & 15304 & 15776 & 15891 & 16792 \\ \text { Annual Change } & - & 109 \% & 90 \% & 103 \% & 101 \% & 106 \% \\ \text { Change 2013/2007 } & 0 & 2200 & 102024 & 1028,65 \% & 106135 & 97608\end{array}$

It the first part of time period it is seen rapid declining of 10\% between years 2008-2009 caused probably by world economic crises. After this bottom there is slight continuous growth of breadth of diamond in each year. The competitiveness measured by Porter's diamond increases very slowly. In 2013 the value of competitiveness did not reach the same value as before crises in 2008. According to calculation of the selected indicators there is evidence of improvement of the Czech Republic competitiveness in this time period.

Table 4: Pearson correlation coefficient of allocated subsidies and breadth of competitiveness diamond. Source: own preparation

$\begin{array}{llllll}\text { Pearson correlation coeficient } & \mathrm{Sr} & \mathrm{t} & \text { Level od importance } & \text { Test criterion } & \text { Resulst of correlation } \\ -0,2662 & 0,4310 & -0,6177 & 5 \% & 2,571 & \text { NO } \\ & & & 1 \% & 4,032 & \text { NO }\end{array}$

Last analysis was not conducted to any valuable results. Using statistic correlation method to the data set did not bring any visible relationship and correlation between value of competitiveness (calculated breadth) and number of allocated subsidies (CZK) in each year to the Czech Republic. Pearson correlation coefficient came up by negative and it demonstrates "cannot reject independence" but there are too lack of data to conclude with any tangible results in this final analysis. In case of complexity of data set there might be result significantly different.

\section{CONCLUSION}

Objective of the paper are to bring up a comparative measurement of competitiveness of the country and to show change of competitiveness of the Czech Republic in previous financial framework of EU. For the analysis is used Porter's diamond model specified to double diamond model.

To conclude with, according to used indicators in Porter's diamond the competitiveness of the Czech Republic has been improved in the time period 2007-2013. The increase of the value of competitiveness is slight; the change from year 2007 to 2013 was only $7.65 \%$. One from the important reasons that influenced the competitiveness growth is rapid increase in number of employees in the sector R\&D. R\&D sector and its size has a significant share on enhancing competitiveness. R\&D brings up to the market updated inventions and development of ideas and shift the level of productivity further. This means good beginning step to the better competitiveness of the Czech Republic. In long-term perspective increase of R\&D employees 
should contribute to faster change of economic structure and the effect of economic development occurs later.

There are several indicia that demonstrate continuing support to export-oriented economy. Firstly, value of export grown up and secondly barriers for international trade in form of a bigger competition between local and foreign products increased. This signal shows significant role of export for competitiveness improvement for small economy like the Czech Republic.

Further hypothesis suggested eventual correlation between competitiveness of the country and allocated subsidies via EU funds. This paper assumed that subsidy is a financial support from one of the EU funds, which will contribute to economic and social development of member countries and thereby will reduce the significant regional differences between prosperous and lagging regions. Subsidy according its aim should enhance competitiveness of supported state or region. Both, in theoretically and practically usage are subsidies used as an investment into economy in form of financial support of human and physical capital. It also supports faster diffusion of technological knowledge and change of ideas among people. Importance of support to production, innovation and clusters in context of EU is crucial in order to ensure economic development. From that it can be assumed that subsidy is reasonable and should help to economic development in the international context in way of support increase of productivity and innovative process.

All the aid that the EU provides is core attributes of competitiveness of the country. As previously stated competitiveness lays on interdependence of complex features of state, region and company. Competitiveness depends on dynamics of action, long-run productivity, innovation process, and policy environment to attract companies in global perspective.

To conclude with, the result shows that interrelations among foreign economies might have greater influence on the competitiveness of the Czech Republic than European subsidies. International business relationships and stability of world economy influence small economies very rapid. Allocated subsidies might also express its effects in long-term perspective and so the repeating of evaluation after several years will show more details of the effects.

\section{References}

Bathelt, H., Malmberg, A. \& Maskell, P. (2004). Clusters and knowledge: local buzz, global pipelines and the process of knowledge creation. Progress in Human Geography, 28(1), 31-56. https://doi.org/10.1191/0309132504ph469oa

Bontho, A. (1995). The Assessment: International Competitiveness. Oxford Review of Economic Policy, 12(3), 1-16.

Cho, D. \& Moon, H. (2000). From Adam Smith to Michael Porter: Evolution of competitiveness theory. Asia-Pacific Business Series, 2(1). https://doi.org/10.1142/4531

Czech Statistics Officer Database. (2015). Available at: https://www.czso.cz

Delgado. M., Ketels. C., Porter. M. E. \& Stern. S. (2012). The Determinants of National Competitiveness. NBER Working Paper No. 18249. https://doi.org/10.3386/w18249

European Commission. (2015). Regional Policy. Available at: https://cohesiondata.ec.europa.eu/

European Commission. (2012). REGULATION (EC) No 1080/2006 of the European Parliament and of the Council of 5 July 2006 on the European Regional Development Fund and 
repealing Regulation (EC) No 1783/1999 Available at: http://eur-lex.europa.eu/legalcontent/EN/TXT/PDF/?uri=CELEX:32006R1080\&from=CS

Economic Forum: Global competitiveness reports 2007, 2008, 2009, 2010, 2011, and 2013

Eurostat. (2015). Available at: http://ec.europa.eu/eurostat/web/balance-of-payments/data/maintables

Eurostat Database. (2015). Available at: http://ec.europa.eu/eurostat

Forth, P. The Global Consulting Group. Available at: https://imagestore.slidesharecdn.com/86eb743e-0827-4717-a7d7-05e77afc7036-original.jpeg

Krugman, P. (1994). Competitiveness: A Dangerous Obsession. Foreign Affairs, 73(2), 28-44. https://doi.org/10.2307/20045917

Lucas, R. (2009). Ideas and Growth. Economica, 76(301), 1-19. https://doi.org/10.1111/j.14680335.2008.00748.x

Lucas, R. (1988). On the Mechanics of Economic Development. Journal of Monetary Economics, 22(1), 3-42. https://doi.org/10.1016/0304-3932(88)90168-7

Molendowski, E. \& Źmuda. M. (2013). Changes In Competitiveness Among The Visegrad Countries After Accession To The European Union: A Comparative Analysis Based On A Generalized Double Diamond Model. Versita 16(4), 121-153.

Moon. H. \& Rugman. A. \& Verbeke. A. (2000). Extended Model: The Generalized Double Diamond Model. [in:] Cho. D. \& Moon. H. (ed.) From Adam Smith to Michael Porter. Asia-Pacific Business Series 2(1).

Porter, M. E. \& Rivkin. J. W. (2012). The looming challenge to U. S. competitiveness. Harvard Business Review 90(3), 54-62.

Porter. E. M. (2004). Competitive Advantage: Creating and sustaining superior performance. Detroit: Free Press.

Porter. M. E. (1990). The Competitive Advantage of Nations. New York: Macmillan Press. https://doi.org/10.1007/978-1-349-11336-1

Prague International Airport. (2015). Availabe at: http://www.prg.aero/cs/

Romer, P. (1986). Increasing Returns and Long-Run Growth. Journal of Political Economy, 94(5), 1002-1037. https://doi.org/10.1086/261420

Rubini. L. (2010). The Definition of Subsidy and State Aid: WTO and EC in comparative perspective. Oxford: Oxford University Press.

Strukturální Fondy. (2007). National Strategic Reference Framework. Available at: http://www.strukturalni-fondy.cz/getmedia/c81992d9-a5a7-4382-a859a7ec13e9d654/Narodni-strategicky-referencni-ramec-CJ-cervenec

World Bank Database. (2015). Available at: http://data.worldbank.org

\section{Contact information}

Kristýna Brzáková

Technical University of Liberec, Faculty of economics

Studentská 1402/2, 46117 Liberec

+420 485352406

kristyna.brzakova@tul.cz

orcid.org/0000-0002-7510-3480

DOI: https://www.doi.org/10.7441/dokbat.2016.08 


\section{Appendix 1: Explanation of the indicators taken from The Global Competitiveness Report}

- Business impact of rules on FDI: To what extent do rules governing foreign direct investment encourage or discourage it? (1=strongly discourage FDI; 7=strongly encourage FDI).

- Buyer sophistication: In your country, how do buyers make purchasing decisions? ( $1=$ based solely on the lowest possible price; $7=$ based on a sophisticated analysis of performance attributes)

- Control of international distribution: To what extent is international distribution and marketing in your country owned or controlled by domestic companies? $(1=$ not at all, they take place through foreign companies; $7=$ extensively, they are the primarily owned and controlled by domestic companies).

- Domestic market size index: Sum of gross domestic product plus value of imports of goods and services, minus value of exports of goods and services, normalized on 1-7 (best) scale (GCR hard data).

- Extent of technology transfer via FDI: To what extent does FDI bring new technologies into your country? ( $1=$ not at all, $7=$ FDI is a key source of new technology).

- Foreign market size index: Value of exports of goods and services, normalized on 1-7 (best) scale (GCR hard data)

- Intensity of local competition: How would you assess the intensity of competition in the local markets in your country? (1=limited in most industries; $7=$ intense in most industries).

- International value breadth: Domestic companies ( $1=$ are mainly engaged in raw material processing and production; 7= not only produce but also take part in the research, marketing, logistics and customer service).

- Local capacity of innovation: In your country, how do companies obtain technology? ( $1=$ exclusively through licenses or imitating foreign companies; $7=$ by conducting formal research and pioneering own products).

- Local supplier quantity: How numerous are local suppliers in your country? (1=largely non-existent; $7=$ very numerous)

- Prevalence of foreign ownership: How prevalent is foreign ownership of companies in your country? (1=rare; $7=$ prevalent).

- Prevalence of trade barriers: In your country, to what extent do tariff and non-tariff barriers limit the ability of imported goods to compete in the domestic market? (1=strongly limit; $7=$ do not limit).

- State of cluster development: In your country's economy, how prevalent are welldeveloped and deep clusters? (1=non-existent; 7=widespread in many fields) 


\section{Appendix 2: Collection of empirical data}

\begin{tabular}{|c|c|c|c|c|c|c|c|}
\hline \multicolumn{8}{|l|}{$\begin{array}{l}\text { Factors of production } \\
\text { Domestic indicators }\end{array}$} \\
\hline activity rate $15-64(\%)$ eurostat & 69,8 & 69,4 & 69,6 & 69,8 & 70,1 & 70,7 & 72,3 \\
\hline $\begin{array}{l}\text { labour productivity based on } \\
\text { PPS per employed person (\% } \\
\text { of EU28 total) eurostat }\end{array}$ & 76,3 & 74,1 & 75,9 & 74.3 & 74.6 & 73.9 & 72.0 \\
\hline $\begin{array}{l}\text { average wage monthly (CZE) } \\
\text { CSU }\end{array}$ & 20927 & 22653 & 23425 & 22748 & 23144 & 24126 & 24061 \\
\hline $\begin{array}{l}\text { number of employees in R\&D } \\
\text { scientist and engeneers } 25-64 \\
\text { (\% od total employment) } \\
\text { eurostat }\end{array}$ & 3,8 & 3,7 & 4,3 & 3,9 & 4,9 & 5,4 & 6,0 \\
\hline $\begin{array}{l}\text { R\&D expenditure level (\% of } \\
\text { GDP) eurostat }\end{array}$ & 1,3 & 1,2 & 1,3 & 1,3 & 1,6 & 1,8 & 1,9 \\
\hline capacity of innovaiton /GCR & 4,3 & 4,2 & 4,2 & 4,1 & 4,0 & & 4,3 \\
\hline \multicolumn{8}{|l|}{ International indicators } \\
\hline $\begin{array}{l}\text { value of export (milion EURO) } \\
\text { eurostat }\end{array}$ & 89382 & 99809 & 80983 & 100311 & 117054 & 122230 & 121588 \\
\hline $\begin{array}{l}\text { FDI inflow (foreign direct } \\
\text { investment, US \$) the world } \\
\text { bank }\end{array}$ & 10606063122 & 6572516198 & 2868837937 & 6119064334 & 2248932510 & 7975891701 & 5006911507 \\
\hline $\begin{array}{l}\text { technology transfer via FDI } \\
\text { /GCR }\end{array}$ & 5,8 & 5,5 & 5,4 & 5,3 & 5,3 & & 5,1 \\
\hline \multicolumn{8}{|l|}{$\begin{array}{l}\text { Demand conditions } \\
\text { Domestic indicators }\end{array}$} \\
\hline $\begin{array}{l}\text { GDP per capita in market } \\
\text { prices (EURO) eurostat }\end{array}$ & 12800 & 14800 & 13600 & 14300 & 14800 & 14600 & 14200 \\
\hline $\begin{array}{l}\text { Teriary education level (\% from } \\
30-34 \text { age) }\end{array}$ & 80,6 & 78,3 & 78,1 & 77,7 & 77,0 & 76,4 & 78,4 \\
\hline Buyer sophistication /GCR & 4,4 & 4,1 & 4,1 & 3,9 & 3,6 & & 3,4 \\
\hline \multicolumn{8}{|l|}{ International indicators } \\
\hline $\begin{array}{l}\text { Value of export (tousands } \\
\text { EURO) CSU }\end{array}$ & 82587376 & 99246955 & 80992054 & 100318540 & 117056930 & 122244052 & 122185683 \\
\hline \multirow{2}{*}{\multicolumn{8}{|c|}{$\begin{array}{l}\text { Rivalry among companies } \\
\text { Domestic indicators }\end{array}$}} \\
\hline \multicolumn{7}{|l|}{ Domestic indicators } & \\
\hline $\begin{array}{l}\text { Intensity of local competition } \\
\text { (GCR) }\end{array}$ & 5,5 & 5,8 & 5,8 & 5,7 & 5,6 & & 5,8 \\
\hline Value chain breadth (GCR) & 4,8 & 4,8 & 4,7 & 4,3 & 4,3 & & 4,6 \\
\hline \multicolumn{8}{|l|}{ Interantional indicatiors } \\
\hline $\begin{array}{l}\text { Business impact of rules on } \\
\text { FDI (GCR) }\end{array}$ & 5,9 & 5,7 & 5,8 & 5,4 & 5,2 & & 4,7 \\
\hline $\begin{array}{l}\text { Prevalence of foreign ownership } \\
\text { (GCR) }\end{array}$ & 5,0 & 5,5 & 5,5 & 5,2 & 5,0 & & 6,0 \\
\hline $\begin{array}{l}\text { Prevalence of trade barriers } \\
\text { (GCR) }\end{array}$ & 5,4 & 5,9 & 5,9 & 5,7 & 5,4 & & 4,3 \\
\hline \multicolumn{8}{|l|}{ Supporting industries } \\
\hline \multicolumn{8}{|l|}{ Domestic indicators } \\
\hline Local supplier quantity (GCR) & 5,5 & 5,7 & 5,7 & 5,4 & 5,3 & & 5,2 \\
\hline $\begin{array}{l}\text { Internet availability (\% of } \\
\text { Individuals who have used a } \\
\text { search engine to find } \\
\text { information) eurostat }\end{array}$ & 50,0 & & & & 68.0 & 72,0 & 76.0 \\
\hline International indicators & & & & & & & \\
\hline $\begin{array}{l}\text { Control of international } \\
\text { distribution (GCR) }\end{array}$ & 3,7 & 3,9 & 3,7 & 3,5 & 3,6 & & 3,5 \\
\hline $\begin{array}{l}\text { Accessibility of air-transport } \\
\text { infrastructure }\end{array}$ & 12,4 & 12,6 & 11,6 & 11,6 & 11,8 & 10,8 & 10,9 \\
\hline
\end{tabular}




\title{
THE EFFECT OF CAPITAL STRUCTURE ON FINANCIAL PERFORMANCE
}

\author{
Ali Ibrahim Dasuki
}

\begin{abstract}
The aim of this study is to investigate the impact of capital structure on financial performance of firms. For this purpose180 manufacturing companies listed on Borsa Stock Exchange Istanbul Turkey over the period 2004 to 2013 were examined. Return on Assets (ROA) and Return on Equity (ROE) are the two performance indicators. Total Debt to Total Assets (TDTA) and Long term Debt to Total Assets (LDTA) were introduced as the capital structure of firms while size, sale growth, tangibility, intangibility and risk where included in the model as control variables. The first result obtained confirm that long term debt and total debt have a negative significant effect on the financial performance of the firm measured by ROA, While the second confirm that long term debt and total debt have no significant effect on the financial performance of the firm measured by ROE.
\end{abstract}

Keywords: capital structure, firm performance, return on equity, return on assets, Borsa Stock Exchange, emerging economy

\section{INTRODUCTION}

Capital structure decision is one of the most important decisions to be taken by any business in order to maximize the shareholders' wealth and maintain the company's growth. Capital structure choices play a significant part in maximising performance of a company. Capital structure comprises the choice about the mixture of the different source of fund in its capital investment and finances its operation. Basically, there are two ways: the first one is debt financing which comprises of both long term debt and short term debt and the second is equity financing which consists of common stock and preferred stock. Modigliani and Miller (1958) presented a capital structure theory and its relationship with performance and companies' value. They argued assumptions that capital structure choices is insignificant in deciding firm value under the assumptions that economy is free of tax, no transaction cost, no bankruptcy costs, no agency cost and information is asymmetries. Modigliani and Miller (1963) argued that cost of capital influences capital structure this implies that there is a relation between method of financing; that is, capital structure and company value, taking tax into consideration. This means that borrowing gives tax advantage in such a way that when interest was deducted from the tax it will result in tax shields which will lead to reduction in cost of borrowing and maximise the firm performance.

There are numerous studies that examine the relationship between capital structure and firm performance over the last forty years. Though, empirical research evidence concerning the relationship between capital structure and firm performance is inconsistent and mixed. Some studies such as Gleason, Mathur, and Mathur (2000), Frank and Goyal (2009) and Hadlock and James (2002) argued that there is positive relation between capital structure and firm performance, while studies such as El-Sayed Ebaid (2009), Chakraborty (2010) and Karadeniz, Kandir, Balcilar, and Onal (2009) document a negative relationship between capital structure and firm performance. This research was enlightened by the fact that the effect of capital 
structure decisions on firm performance is well documented in developed markets such as USA and Europe, little is known about other parts of the world particularly emerging economies such as Turkey as argued by Eldomiaty (2008) that capital market in emerging economy is ineffective, imperfect and is hurt by higher level of information asymmetry than in capital markets of developed economy.

The aim of this study is to investigate the impact of capital structure on financial performance of firms in an emerging country, Turkey. The paper examines this impact by a sample of 180 manufacturing companies listed on Borsa Stock Exchange Istanbul Turkey over the period 2004 to 2013. Panel data analysis techniques are used for data analysis. Return on Assets (ROA) and Return on Equity (ROE) are the two performance indicators of the model, Total Debt to Total Assets (TDTA) and Long term Debt to Total Assets (LDTA) introduced as the explanatory variables while size, sale growth, tangibility, intangibility and risk were included in the model as control variables. The rest of this paper is organized as follows: Section two examine the relevant literature which offers the literature on capital structure and firm performance. Section three discusses data and variables for the analysis. Section four consists of the empirical results and discussion. Lastly, section five concludes the research.

Actual text of the contribution (including introduction and conclusion).

Maximum size of the manuscript is 15 pages (format A4).

The actual text of the contribution should be divided into chapters where possible. Headings can be maximum in two levels and numbered (e.g. 1 TITLE OF CHAPTER, 1.1 Title of sub-chapter.

\section{LITERATURE REVIEW}

The relationship between capital structure choices with the firm performance was informed by numerous theories that consist of static trade-off theory, agency theory and pecking order theory. Static trade-off theory acknowledges a positive relation between the firm's capital structure and its performance; agency cost theory admits that the higher firm's level debt, in the context of lower agency costs, decreases inefficiency and thus leads to improved firm performance; pecking order theory acknowledges a negative correlation between the company capital structure and its performance. See Tudose (2012) and Meero (2015)

The seminar conducted by (Modigliani and Miller (1958) marked the beginning of the theory of capital structure and its relationship with performance and companies' value and has been a baffling topic in both accounting and finance literature. Modigliani and Miller (1958) argued that capital structure choices is insignificant in deciding firm value under the assumptions that economy is free of tax, no transaction cost, no bankruptcy costs, no agency cost and information is asymmetries. According to Khan (2012) looking at the above proposition it implies that firm's value is determined by its real assets not by the combination of securities. El-Sayed Ebaid (2009) argued that as a result of MM proposition, an investor may end up buying undervalued share of a company and sell overvalued share of a company since equivalent income stream are achieved. He further argued that as stockholders exploit these arbitrage opportunities, the overvalued shares price will fall while the price undervalued shares will fall the price of overvalued shares will fall and that of the undervalued shares will rise up until when both prices are equal.

However, the impossibility of Modigliani and Miller assumptions to be possible in the real world, lead to many studies by numerous researchers to come up with further justification for 
underlying assumptions signifying that capital structure affects performance and firm's value, especially Jensen and Meckling (1976) argued that high leverage or a low equity to asset ratio reduces the agency costs of outside equity and increases firm value by encouraging managers to act more in the interests of shareholders and it can change manager's actions and operating decisions. This indicate that capital structure affects performance see Brav, Graham, Harvey, and Michaely (2005).

Consequently, the researchers examine the relationship between capital structure theory and its relationship with performance and companies' value through new theory which is called the agency theory. Agency theory advocates that capital structure choice may assist in reducing the agency costs. The first advocate of this theory was Jensen and Meckling (1976) argued that high leverage or a low equity to asset ratio reduces the agency costs of outside equity and increases firm value by encouraging managers to act more in the interests of shareholders. The theory also reveals a possible dispute between shareholders and managers and also on the other hand a possible dispute between shareholders. The potential dispute between shareholders and managers can arise when the shareholders appoint the manager as an agent to manage their company for wealth maximization, but the managers focus more profitable and risky investments so that they to achieve their interests at first which is incentives and rewards, while putting shareholder objective coming second Jensen and Meckling (1976) and Myer (2001).

\section{Relationship between Capital Structure and Firm Performance}

El-Sayed Ebaid (2009) examines the impact of capital structure choice on performance of 64 listed companies in Egyptian Capital Market from 1997 to 2005. He studied three dependent variables including Return on Assets (ROA), Return on Equity (ROE) and gross profit margin (GPM), he concluded that the impact of capital structure choices on performance is, generally, weak. He concluded that short term, long term and total debt to total assets which are the explanatory variables has insignificant relationship with performance measured by Return on Equity (ROE), whereas, the relation of short term debt and total debt to total assets is negative and statistically significant with the Return on Asset (ROA) while when Return on Asset (ROA) measure with long term is negative and statistically insignificant.

King and Santor (2008) studied the linkage between family ownership, firm performance and capital structure on Canadian firms. They studied Tobin's ratios and Return on Assets (ROA) as dependent variable. The result indicates that self- supporting family who owned company with a single share class have the same market performance when compared to other companies, while when measured with ROA self- supporting family who owned company with a single share class have superior accounting performance when compared to other companies and higher financial leverage based on debt- to- total Assets. Gleason et al. (2000) examines interrelationship between culture, capital structure, and performancein Europe. They study Return on Assets (ROA) and profit margin (PM) as his dependent variable and he found that there is a negative and significant relation between capital structure and firm performance when measured by both ROA and PM.

San and Heng (2011) examines the relationship between capital structure and firm performance of construction industries in Malaysia after the financial meltdown of 2007-08 that severely affected most of both emerging markets and developed market around the world including Malaysia. Their result shows that as a result of large scale of construction work in the country financial crises do not show any major impact on performance of Malaysian construction 
industries. They also found that there is a relationship that exists between leverage and performance measured by ROA, ROE and profitability in the Malaysian construction companies. Onaolapo and Kajola (2010) in their research on the non-financial listed companies in Nigerian stock exchange found that there is a significantly negative relation between leverage performances in Nigerian companies. This is as a result of potential conflict between agency and various stakeholders. Bokpin, Aboagye, and Osei (2010) in their research on the companies in Ghana stock exchange, a developing market, they found that level of debt differ among industries. Companies use high debt levels in their capital structure and favour the use of short term debts to equity to finance its operations.

Mohammad, Farzad, Reza, and Ghorban (2013) examines the effect of capital structure on firm performance base on the sample of 85 companies listed in Tehran Stock Exchange from 2006 to 2011. They used accounting measures and market measure, these include ROE (return on equity), ROA (return on assets), MBVR (market value of equity to the book value of equity) and Tobin's Q. the result indicate that there is positive relationship between ROE,MBVR and Tobin's Q with capital structure while the relationship between ROA and capital is significant and negative. Saedi and Mahmoodi (2011) examines the impact of capital structure and firm performance of 320 listed companies in Tehran Stock Exchange Market from 2002 to 2009. They studied the relation between performance variables including Return on Assets (ROA), Return on Equity (ROE), Earning per Share (EPS) and Tobin's Q, and three capital structures including long term debt short - term debt and total debt ratio. They concluded that firm performances which are measured by EPS and Tobin's Q, have positive and significant relationship with capital structure, on the other hand ROA has negative relation with capital structure while ROE has no significant relationship with Capital structure.

\section{DATA}

The purpose of this research is to identify the impact of capital structure on financial performance, the sample consist of 180 Turkish manufacturing firms listed on Borsa Stock Exchange Istanbul. The data covers the period of 10 years from 2004 to 2013. The firms were selected on the basis of availability of records. Data collected was tabulated, analysed, and interpreted.

\section{Firm Performance variables}

There are different numbers of firm's performance measurement used in the literature, these measures are based on accounting measures calculated from financial statement of the company which include ROE, ROA and G Abor (2005). This research uses two of common accountingbased performance measures to assess the firm's performance. These measures are: ROA and ROE.

ROA; the return on assets: is calculated by dividing operating income with total assets

ROE; return on equity: is calculated by dividing net income with equity

ROA and ROE were selected since they are the most significant accounting-based ratio that they are generally recognised as measures of financial performance. ROA can also be seen as a "measure of management's efficiency in utilizing all the assets under its control, regardless of source of financing" as argued by Zeitun and Tian (2007). 


\section{Capital Structure variables}

There are different ways of measuring capital structure Abor (2005); El-Sayed Ebaid (2009) consider short term, long term and total debt to total assets ratio as measures of financial leverage. In this research Total Debt divided by the Total Assets of the firm (TDTA) ratio and Long Term Debt divided by the Total Assests of the firm (LDTA) was used.

\section{Control Variable}

Literature shows a number of researches firm specific factors are important in influencing the performance. (Margaritis \& Psillaki, 2007, 2010) identify four firm-specific explanatory variables in their study. These include size (SIZE), profitability (INTANG), growth (GROWTH), and tangibility (TANG). Booth et al., (2001) add volatility or business risk (RISK) to this list. In this research, the above five firm-specific variables were used as control variable.

Size: Firm size is defined as the natural logarithm of total sales.

Growth: Growth opportunity is defined as percentage change in sales

Tangibility: Tangibility is defined as net fixed assets over total assets.

Intangibility: Intangibility is defined as intangible fixed asset over firm equity

Risk: Business risk is defined as the standard deviation of operating income over total assets during the sample period.

The author used the panel data model with random effects. ROA and ROE are the dependent variable of the model, TDTA introduced as the explanatory variables while size, sale growth, tangibility, intangibility and risk were included in the model as control variable

\section{Model}

$\begin{array}{lll}\text { ROA }=\beta_{0}+\beta_{1} \text { TDTA }_{i t}+\beta_{2} \text { INTANG }_{i t}+\beta_{3} \mathrm{GROWTH}_{i t}+\beta_{4} \mathrm{TANG}_{i t}+\beta_{5} \mathrm{RISK}_{i t}+\beta_{6} \mathrm{SIZE}_{i t}+U_{\text {it }} & \text { (1a) } \\ \text { ROA }=\beta_{0}+\beta_{1} \mathrm{LDTA}_{i t}+\beta_{2} \mathrm{INTANG}_{i t}+\beta_{3} \mathrm{GROWTH}_{i t}+\beta_{4} \mathrm{TANG}_{i t}+\beta_{5} \mathrm{RISK}_{i t}+\beta_{6} \mathrm{SIZE}_{i t}+U_{\mathrm{it}} & \text { (1b } \\ \text { ROE }=\alpha_{0}+\alpha_{1} \mathrm{TDTA}_{i t}+\alpha_{2} \mathrm{INTANG}_{i t}+\alpha_{3} \mathrm{GROWTH}_{i t}+\alpha_{4} \mathrm{TANG}_{i t}+\alpha_{5} \mathrm{RISK}_{i t}+\alpha_{6} \mathrm{SIZE}_{i t}+U_{\text {it }} & \text { (2a) } \\ \text { ROE }=\alpha_{0}+\alpha_{1} \mathrm{LDTA}_{i t}+\alpha_{2} \mathrm{INTANG}_{i t}+\alpha_{3} \mathrm{GROWTH}_{i t}+\alpha_{4} \mathrm{TANG}_{i t}+\alpha_{5} \mathrm{RISK}_{i t}+\alpha_{6} \mathrm{SIZE}_{i t}+U_{\text {it }} & \text { (2b) }\end{array}$

Where:

ROAit $=$ Return on assets for firm $i$ in year $t$.

ROEit $=$ Return on equity for firm $\mathrm{i}$ in year $\mathrm{t}$.

TDTAit $=$ Total debt to total assets for firm $\mathrm{i}$ at year $\mathrm{t}$.

LDTAit $=$ Long term debt to total assets for firm $\mathrm{i}$ at year $\mathrm{t}$

INTANGit $=$ Intangible assets for firm $\mathrm{i}$ at year $\mathrm{t}$.

GROWTHit $=$ Growth of the firm $i$ at year $\mathrm{t}$.

TANGit $=$ Tangible assets for firm $\mathrm{i}$ at year $\mathrm{t}$.

RISKit $=$ operating income over total assets for firm $\mathrm{i}$ at year $\mathrm{t}$.

SIZEit $=$ Size of the firm $\mathrm{i}$ at year $\mathrm{t}$.

$\mathrm{U}=$ is a stochastic error 


\section{ANALYSIS AND RESULTS}

Table 1 - Statistic.

\begin{tabular}{ccccccc} 
Table 1 & \multicolumn{1}{c}{ Distribution } \\
\hline \hline \multirow{2}{*}{ VARIABLES } & \multirow{2}{*}{$\mathrm{N}$} & \multirow{2}{*}{ Mean } & SD & \multicolumn{3}{c}{} \\
\cline { 5 - 7 } & & & & 0.00 th & 50 th & 90 th \\
\hline ROA & 1650 & 0.0536792 & 0.2389921 & -0.0694765 & 0.0506373 & 0.171914 \\
ROE & 1650 & 0.061221 & 1.91844 & -0.2505541 & 0.0591438 & 0.2536473 \\
TDTA & 1650 & 0.5048254 & 0.4959155 & 0.1552066 & 0.4384672 & 0.7835189 \\
SIZE & 1646 & 18.80401 & 1.716105 & 16.7552 & 18.7194 & 20.95762 \\
TANGIBILITY & 1650 & 0.375382 & 0.1799465 & 0.1396037 & 0.3764827 & 0.6106259 \\
INTANGBILITY & 1650 & 0.0399755 & 0.138447 & 0.0000973 & 0.0038528 & 0.0762877 \\
RISK & 1290 & 0.0634551 & 0.1637807 & 0.0133898 & 0.04076 & 0.1081013 \\
SALESGROWTH & 1466 & 0.1395843 & 0.5773874 & -0.1771319 & 0.0903311 & 0.4194899 \\
\hline \hline
\end{tabular}

The results of descriptive statistics indicate that mean of total debt to assets for Turkish manufacturing companies listed on Borsa Stock Exchange Istanbul during 2004-2013 is 50.48\%. It shows that about $50.48 \%$ percent of total assets of Turkish manufacturing companies are financed by debt. Further the table shows that mean of ROA, ROE, Size, Tangibility, Intangibility, Risk and Sales Growth are 5.36\%, 6.12\%, 37.53\%, 39.97\%, 6.34\% and 13.95\% respectively.

\section{RESULTS}

Random effect regression method was used to find the relationship of capital structure with performance of the firm. The regression equations were run to study the relationship between each of the capital structure measures and the firm's financial performance called ROA and ROE. Further, in the regression equation, the control variables were added to check their effects on firm's financial performance.

Table 2 - Capital Structure and Firm Performance measured by ROA

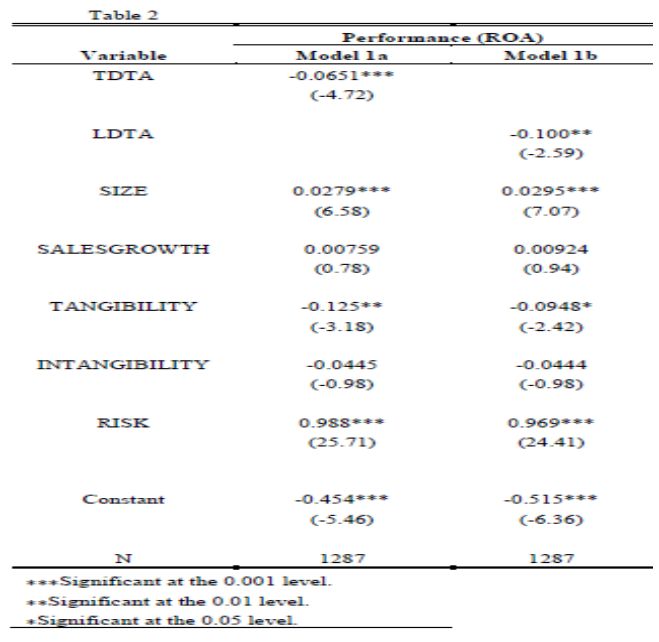


Table 2 shows long term debt and total debt have a negative significant effect on the financial performance of the firm measured by ROA. On the other hand the two out five control variables, size of the firm and risk affect performance of the firm measured by ROA is positive and significant, there is significant negative relationship between tangibility and ROA while sales growth and intangibility have insignificant relationship with the performance of the firm measured by ROA. This negative relationship is in consistent with finding of (Bokpin et al., 2010); El-Sayed Ebaid (2009); Khan (2012)Sheikh and Wang, 2011

Table 3 - Capital Structure and Firm Performance measured by ROE

\begin{tabular}{|c|c|c|}
\hline \multirow[b]{2}{*}{ Variable } & \multicolumn{2}{|c|}{ Performance (ROE) } \\
\hline & Model 2a & Model 2b \\
\hline TDTA & $\begin{array}{l}0.0750 \\
(0.63)\end{array}$ & \\
\hline LDTA & & $\begin{array}{l}-0.181 \\
(-0.51)\end{array}$ \\
\hline SIZE & $\begin{array}{l}0.0349 \\
(1.00)\end{array}$ & $\begin{array}{l}0.0354 \\
(1.01)\end{array}$ \\
\hline SALESGROWTH & $\begin{array}{l}0.0567 \\
(0.57)\end{array}$ & $\begin{array}{l}0.0520 \\
(0.53)\end{array}$ \\
\hline TANGIBILITY & $\begin{array}{l}-0.0462 \\
(-0.14)\end{array}$ & $\begin{array}{c}-0.0404 \\
(-0.12)\end{array}$ \\
\hline INT ANGIBILITY & $\begin{array}{c}-1.497 * * * \\
(-3.61)\end{array}$ & $\begin{array}{c}-1.455 * * * \\
(-3.48)\end{array}$ \\
\hline RISK & $\begin{array}{l}0.0657 \\
(0.17)\end{array}$ & $\begin{array}{l}0.219 \\
(0.56)\end{array}$ \\
\hline Constant & $\begin{array}{l}-0.539 \\
(-0.78)\end{array}$ & $\begin{array}{l}-0.499 \\
(-0.73)\end{array}$ \\
\hline $\mathrm{N}$ & 1287 & 1287 \\
\hline
\end{tabular}

Table 3 shows long term debt and total debt have no significant effect on the financial performance of the firm measured by ROE. This result is consistent with Zeitun and Tian (2007) and Ebaid (2009). On the other hand only intangibility out five control variables that has negative significant effect on performance of the firm when measured by ROE, while the remaining four control variable have no any significant effect on the financial performance of the firm measured by ROE.

\section{CONCLUSION}

The aim of this study is to investigate the impact of capital structure on financial performance of firms in Turkey. The paper examines the impact of capital structure on financial performance of 180 manufacturing companies listed on Borsa Stock Exchange Istanbul Turkey over the period 2004 to 2013. Panel cross- sectional time series techniques are used for data analysis. Return on Assets (ROA) and Return on Equity (ROE) are the two dependent variables of the model, Total Debt to Total Assets (TDTA) and Long term Debt to Total Assets (LDTA) introduced as the explanatory variables while size, sale growth, tangibility, intangibility and risk were included in the model as control variables.

The first result obtain confirm that long term debt and total debt have a negative significant effect on the financial performance of the firm measured by ROA. This negative relationship is consistent with finding of Bokpin et al. (2010); El-Sayed Ebaid (2009); Khan (2012); Sheikh and 
Wang, (2011), Rajan and Zingales (1995) and Zeitun and Tian (2007). The first finding shows that Turkish manufacturing sector have adopted capital structure on the pecking order hypothesis. As a result of undersized debt market and less efficient equity market, the main source of finance for Turkish manufacturing companies is short term debt. Banks are the main source of finance in Turkey and as a result of volatility in earning, information asymmetry finances are protected with stringent covenants which can force the companies to borrow less while Long term finances is costly. On the other the find does not support both Agency theory and static trade off theory when measuring long term debt and total debt with ROA in Turkish manufacturing companies.

While the second confirm that long term debt and total debt have no significantly effect on the financial performance of the firm measured by ROE. This result is consistent with Zeitun and Tian (2007) and Ebaid (2009). This implies that this finding does not support Pecking order theory, Agency theory or static trade off theory when measuring long term debt and total debt with ROE in Turkish manufacturing companies. There is need for further study that should consist of all companies list on Borsa Stock Exchange both financial and non-financial manufacturing and non-manufacturing industries. Introduction of additional national variable such as ownership concentration macroeconomic factors would be important to consider in further studies.

\section{References}

Abor, J. (2005). The effect of capital structure on profitability: an empirical analysis of listed firms in Ghana. The Journal of Risk Finance, 6(5), 438-445. https://doi.org/10.1108/15265940510633505

Bokpin, G. A., Aboagye, A. Q. Q., \& Osei, K. A. (2010). Risk exposure and corporate financial policy on the Ghana Stock Exchange. The Journal of Risk Finance, 11(3), 323-332. https://doi.org/10.1108/15265941011043684

Brav, A., Graham, J. R., Harvey, C. R., \& Michaely, R. (2005). Payout policy in the 21st century. Journal of Financial Economics, 77(3), 483-527. https://doi.org/10.1016/j.jfineco.2004.07.004

Chakraborty, I. (2010). Capital structure in an emerging stock market: The case of India. Research in International Business and Finance, 24(3), 295-314. https://doi.org/10.1016/j.ribaf.2010.02.001

El-Sayed Ebaid, I. (2009). The impact of capital-structure choice on firm performance: empirical evidence from Egypt. The Journal of Risk Finance, 10(5), 477-487. https://doi.org/10.1108/15265940911001385

Eldomiaty, T. I. (2008). Determinants of corporate capital structure: evidence from an emerging economy. International Journal of Commerce and Management, 17(1/2), 25-43. https://doi.org/10.1108/10569210710774730

Frank, M. Z., \& Goyal, V. K. (2009). Capital Structure Decisions: Which Factors Are Reliably Important ? Financial Management, 38(1), 1-37. https://doi.org/10.1111/j.1755053X.2009.01026.X

Gleason, K. C., Mathur, L. K., \& Mathur, I. (2000). The interrelationship between culture, capital structure, and performance: Evidence from European retailers. Journal of Business Research, 50(2), 185-191. https://doi.org/10.1016/S0148-2963(99)00031-4 
Hadlock, C. J., \& James, C. M. (2002). Do Banks Provide Financial Slack? The Journal of Finance, 57(3), 1383-1419. https://doi.org/10.1111/1540-6261.00464

Jensen, M. C., \& Meckling, W. H. (1976). Theory of the firm: Managerial behavior, agency costs and ownership structure. Journal of Financial Economics, 3(4), 305-360. doi:https://doi.org10.1016/0304-405X(76)90026-X

Karadeniz, E., Kandir, S. Y., Balcilar, M., \& Onal, Y. B. (2009). Determinants of capital structure: evidence from Turkish lodging companies. International Journal of Contemporary Hospitality Management, 21(5), 594-609. https://doi.org/10.1016/0304405X(76)90026-X

Khan, A. G. (2012). The relationship of capital structure decisions with firm performance: A study of the engineering sector of Pakistan. International Journal of Accounting and Financial Reporting, 2(1). https://doi.org/10.5296/ijafr.v2i1.1825

King, M. R., \& Santor, E. (2008). Family values: Ownership structure, performance and capital structure of Canadian firms. Journal of Banking \& Finance, 32(11), 2423-2432. https://doi.org/10.1016/j.jbankfin.2008.02.002

Margaritis, D., \& Psillaki, M. (2007). Capital Structure and Firm Efficiency. Journal of Business Finance \& Accounting, 0(0), 070905001421001-??? https://doi.org/10.1111/j.14685957.2007.02056.x

Margaritis, D., \& Psillaki, M. (2010). Capital structure, equity ownership and firm performance. Journal of Banking \& Finance, 34(3), 621-632. https://doi.org/10.1016/j.jbankfin.2009.08.023

Meero, A. A. (2015). The Relationship between Capital Structure and Performance in Gulf Countries Banks: A Comparative Study between Islamic Banks and Conventional Banks. International Journal of Economics and Finance, 7(12), 140. https://doi.org/10.5539/ijef.v7n12p140

Mohammad, R. E., Farzad, E., Reza, S. B., \& Ghorban, S. (2013). The Impact of Capital Structure on Firm Performance: Evidence from Tehran Stock Exchange. Australian Journal of Basic and Applied Sciences, 7(4), 1-8.

Rajan, R. G., \& Zingales, L. (1995). What Do We Know About Capital Structure - Some Evidence from International Data. Journal of Finance, 50(5), 1421-1460. https://doi.org/10.2307/2329322

Tudose, M. B. (2012). Capital Structure and Firm Performance. Economy Transdisciplinarity Cognition, 15(2), 76-82.

Zeitun, R., \& Tian, G. G. (2007). Does ownership affect a firm's performance and default risk in Jordan? Corporate Governance: The international journal of business in society, 7(1), 6682. https://doi.org/10.1108/14720700710727122

\section{Contact information}

Ali Ibrahim Dasuki

Faculty of Economics and Management

Fatih University Istanbul, Turkey

DOI: https://www.doi.org/10.7441/dokbat.2016.09 


\title{
THE DETERMINANTS IMPACT ON CASH HOLDING: EVIDENCE FROM THE VIETNAMESE STOCK MARKET
}

\author{
Do Thi Thanh Nhan
}

\begin{abstract}
Using a sample of 650 listed firms on the Vietnamese stock exchange over the period 2008 to 2015, we examine the factors affect the cash holding. The results find out leverage, cash flow and bank to debt ratio has a negative impact on cash holding while growth, profitability and size influence positive on cash holding. The findings have implications of cash management in the firms.
\end{abstract}

Keywords: Firm Value, cash holding, cash management

\section{INTRODUCTION}

Recently, finding the amount of cash holding is an important decision for the managers because cash is using for operating all activities in the corporations. Managing cash has many challenges for all kind of businesses due to the fact that the free cash should be invested to earn more profit while the firms must ensure the appropriate liquidity to meet the demand in future. Most empirical studies have used three theoretical models to explain the reasons for the level of cash holding and the determinants which impact on the cash reserves: Tradeoff Model (Myers, 1977), the Pecking Order Theory (Myers and Maljuf, 1984) and Free Cash Flow Theory (Jensen, 1986).

Some of papers investigated the determinants influence on the firm value which have the negative or positive relationship between cash holding and firm size such as net working capital, leverage, inventories, growth opportunities, financial distress, cash flow, dividend payment, bank to debt ratio and profitability elements. Contrary to previous studies, this paper examines the cash holding issue in listed firms in Vietnam which is one of emerging market in Asia. The paper sought to discover the factors affect cash holding on the listed firms.

The rest of the paper is arranged by defining the model specifications to address the relevant empirical studies, generating the results based on the model using Stata, analyzing the empirical results and deriving a conclusion based on the findings.

\section{REVIEW OF RELEVANT EMPIRICAL STUDIES}

This section discusses the specific characteristic influence the cash holding which were enquired in previous papers from different countries such as growth, cash flow, size, leverage, profitability, bank to debt ratio.

\subsection{Growth}

The companies are growing prefer using the internal capital than external because of the cost for raising the capital according to the asymmetric information (Myers and Majluf, 1984) and during the growing period the firms may have more investment opportunities. For all these motivations, the firms choose to hold more liquidity assets as increasing cash holding level (Haris and Raviv, 
1991; Shleifer and Vishny, 1992). In addition, Ferreira and Vilela (2004) indicate that the growth opportunities will lose when the firm is a lack of sources or in financial distress. According to the pecking order theory, the demand for cash will rise if the companies get profitable investment chances (Ozkan and Ozkan, 2004). Some previous papers account for the positive relationship between cash holding and growth of the firms (Hardin et al., 2009; Megginson and Wei, 2010; Uyara A. and C. Kuzeya, 2014).

\subsection{Cash flow}

Based on the trade-off theory, the negative correlation between cash flow and cash holding is supported by Kim et al. (2011). On the other hand, the firms should keep higher amount of cash during the difficult time and the majority of studies found a negative relationship between two variables (Ferreira and Vilela, 2004; Rizwan and Javed, 2011; Uyara A. and C. Kuzeya, 2014; Ogundipe et al., 2012; Bigelli and Sanchez-Vidal, 2012). For the above result, the high cash flow is higher cash level which is consistent with the pecking order theory.

\subsection{Size}

Asymmetric information often occurs for small companies; thus the cost of raising capital is costly in comparison with larger firms. However, the bigger corporations have more advantages in getting the information as well as more flexibility in fiscal policy. Therefore, the smaller firms have higher cash level which is in the line with the trade-off theory (Ferreira and Vilela, 2004; Saddour, 2006; Megginson and Wei, 2010; Uyara A. and C. Kuzeya, 2014). Likewise, the younger and smaller firms will hold more cash in order to decrease the cost of raising external capital.

\section{$2.4 \quad$ Leverage}

Whenever the cash deficit, the companies may borrow funds by issuing debts or the banks. Pecking order theory and free cash flow theory suggest a negative correlation between cash and leverage (Ferreira and Vilela, 2004; Hardin and et al., 2009; Rizwan and Javed, 2011; Uyara A. and C. Kuzeya, 2014; Sungsin Kim, 2014). In addition, Martinez-Sola et al. (2008) indicated that the cash holding level is higher to avoid the financial problems.

\subsection{Profitability}

If the company gets more profit from operating activities which create large cash flow, so the firms can reduce the cash reserve (Kim et al, 1998). And the company decreases to mobilize capital when they have higher profit (Opler et al, 1999; Ferreira and Vilela, 2004). Nevertheless, some companies intend to keep more cash as they can get more profit in growing periods. (Megginson and Wei, 2010; Ogundipe et al., 2012).

\subsection{Bankd}

Bankd is the bank to total debt which is one of important factors to decide the level of cash because the firms are easier to get finance from external sources when the capital structure has debt from the bank (Uyar A. and Kuzey C., 2014). Likewise, previous studies also confirmed the negative correlation between cash and bank debt. (Ozkan and Ozkan, 2004; Ferreira and Vilela, 2004; Martinez-Sola,2007). 


\section{METHODOLOGY AND MODEL:}

This paper extracted data from financial statements from the databases of the two largest stock exchange companies in Vietnam, Ho Chi Minh City Stock Exchange (HOSE) and Hanoi City Stock Exchange (HASTC). The paper used the industrial firms listed on Vietnam stock exchange for the period 2008 to 2015. The data has 3973 firm-year observations with 650 listed firms from the Vietnam Stock Exchange which excludes financial institutions. The data was preprocessed by removing missing values, correcting accounting errors, and removing repetitions. Companies were selected based on the possessing of all data for the time period used. The observations were financially calculated into user variables in testing the models to respond to the three main objectives for this paper.

The model will evaluate the association between cash holding and other determinants in listed firm in the model. Tong (2008) posited that cash holding below or above optimal cash holding has a direct effect on firms. Tong's assertion was corroborated by Ferreira \& Vilela, (2004), Han \& Qiu, (2007), Ozkan \& Ozkan, (2004) among others. In this model, some variables are used to determine cash and evaluated to ascertain whether these determinants have a negative or positive effect on cash in relation to the firm. The model in equation 1 has been substantiated by previous works in determining cash (García-Teruel \& Martínez-Solano, 2008; Kim et al., 2011; Pinkowitz \& Williamson, 2001; Ferreira \& Vilela, 2004; among others).

$$
\begin{aligned}
\text { Cash }_{i t}=\beta_{0} & +\beta_{1}\left(\text { Size }_{i t}\right)+\beta_{2}\left(\text { CF F }_{i t}\right)+\beta_{3}\left(\text { Prof }_{i t}\right)+\beta_{4}\left(\text { Growth }_{i t}\right)+\beta_{5}\left(\text { Lev }_{i t}\right)+\beta_{6}\left(\text { Bankd }_{i t}\right) \\
& +\lambda_{i t}+\varepsilon_{i t}
\end{aligned}
$$

where $\mathrm{i}$ is the accumulation of firms; $\mathrm{t}$ is time; Cash $\mathrm{it}_{\mathrm{i}}$ is cash holding equal cash plus cash equivalent divided by total asset; $\mathrm{CF}_{\text {it }}$ is net profit plus depreciation divided by gross sales; Growth $_{\text {it }}$ is natural logarithm of growth of total assets; Prof $\mathrm{it}_{\mathrm{it}}$ is profitability is net profit plus depreciation divided by total assets; Bankd $_{i t}$ is the ratios of bank to total debt; Size $_{i t}$ is natural logarithm of total assets; $\operatorname{Lev}_{\text {it }}$ is total debt divided by total assets; $\chi_{\text {it }}$ are dummy variables and equal for all firms used; Eit is the error term; B0 to $\beta i$ are coefficients of the explanatory variables.

The paper used the Stata data analysis tool to analyze the data extracted from the databases. The correlation analysis and the linear regression modeling techniques were employed in producing the coefficients of the explanatory variables to analyze the model in response to the objectives of the study.

\section{EMPIRICAL RESULTS}

Table 1 represents the summary statistics for all variables used in the paper. As can be seen from the table, the average cash holding is $8.9 \%$ out of total asset which is higher than some markets. Likewise, this rate is higher in comparison with others such as Garcia Teruel and Martinez Solano (2008) indicate that the average cash holding is $6.57 \%$ in Spain; Cristina MartinezSolano, Pedro J. and Pedro M. (2010) in United State, 7.9\%; Gill. A and Shah (2012) in Canada, 3.87\%; Ogundipe L., Ogundipe S. and Ajao (2012) in Nigeria, 7.18\%. 
Table 1-Descriptive Statistic. Source: Vietnam stock exchange

\begin{tabular}{cccccc}
\hline Variables & Obs & Mean & Std. Dev. & Min & Max \\
\hline cash & 3973 & 0.097844 & 0.10649 & 0.0007 & 0.5053 \\
lev & 3973 & 1.669701 & 1.70997 & 0.002 & 9.4741 \\
growth & 3973 & 0.12214 & 0.240467 & -0.4239 & 1.0626 \\
prof & 3973 & 0.089076 & 0.083949 & -0.1432 & 0.3731 \\
CF & 3973 & .1100166 & .1968234 & -.8461 & .9255 \\
size & 3973 & 12.7649 & 1.710408 & 0 & 16.47347 \\
Bankd & 3973 & .4186654 & .2878403 & 0 & .92541 \\
\hline
\end{tabular}

Note: Growth $=$ Ln ( Total assets/Total assets $t-1)$;

Prof $=($ Net profit + depreciation $) /$ Total assets; Size $=$

Ln (total assets); Lev= Total debt/total assets;;

Cash $=($ cash + cash equivalent $) /$ total asset; $C F=$

earnings after tax + depreciation/ gross sales; ; Bankd=

bank / total debt.

The table 2 shows the results for dependent variable CASH with other independent variables. Furthermore, all the variables are significant at the $10 \%$ level. It indicates the positive correlation between cash and growth, size and profitability. In contrast, cash flow, leverage and bankd variables are a negative relation.

\begin{tabular}{r|rrrrrr} 
cash & Coef. & Std. Err. & $z$ & P $>|z|$ & [95\% Conf. Interval] \\
\hline cash & & & & & \\
L1. & .2890399 & .0565422 & 5.11 & 0.000 & .1782193 & .3998605 \\
cflow & -.026745 & .0086625 & -3.09 & 0.002 & -.0437232 & -.0097667 \\
lev & -.0058095 & .0023888 & -2.43 & 0.015 & -.0104914 & -.0011276 \\
size & .0034102 & .0017528 & 1.95 & 0.052 & -.0000252 & .0068456 \\
bankd & -.0376113 & .016708 & -2.25 & 0.024 & -.0703583 & -.0048643 \\
prof & .1609923 & .0482537 & 3.34 & 0.001 & .0664169 & .2555678 \\
growth & .0491749 & .009127 & 5.39 & 0.000 & .0312863 & .0670635 \\
cons & .034298 & .023654 & 1.45 & 0.147 & -.012063 & .080659
\end{tabular}

Note: Growth $=$ Ln ( Total assets/Total assets $t-1) ;$ Prof $=($ Net profit + depreciation)/Total assets; Size = Ln (total assets); Lev= Total debt/total assets; $;$ Cash $=($ cash + cash equivalent $) /$ total asset $; C F=$ earnings after tax + depreciation/gross sales; ; Bankd= bank/total debt.

The experimental results provide the cash flow, growth, leverage, profitability, bank to debt and firm size are the factors to determine the cash holding level. In more details, leverage, bankd and cash flow negatively impacts cash holding which is similar with the outcomes from pecking order and free cash flow theory; Ferreira and Vilela (2004); Hardin and et al (2009); Rizwan and Javed (2011); Uyara A. and C. Kuzeya (2014); Sungsin Kim (2014). Besides, the listed corporation in Vietnam tends to keep more cash in order to avoid the high cost of external financing which is in the line with the finding from Ferreira, 2004 and Paskelian et al. (2010). 
On the other hand, growth, size and profitability have opposite effect on the stockpiling cash. Similar to the trade-off theory, Haris and Raviv (1991), Shleifer and Vishny (1992), the company in Vietnam should keep enough cash to take all opportunities in the growing period. Moreover, the firms are a bigger size which should keep more cash in order to obtain the opportunities while the smaller size should keep more cash to reduce the cost of raising external source. (Megginson and Wei, 2010; Sungsin Kim, 2014; Lawrencia and et al, 2014).

\section{CONCLUSION}

The paper investigates impact factors to the cash holdings of a business include leverage, cash flow, and bank to debt ratio which has a contradictory influence on the cash holding. However, growth, size, profitability impact positively on the cash reserve. Basically, these results provide the elements impact the cash holding and the listed companies can adjust the cash level in the corporation in order to prevent the shortage of finance.

\section{References}

Bigelli M. and Sanchez-Vidal (2012). Cash holding in private firms, Journal of Banking and Finance, 36, 26-35. https://doi.org/10.1016/j.jbankfin.2011.06.004

Blundell R. and S. Bond (1998). Initial conditions and moment restrictions in dynamic panel data models, Journal of Econometrics, 87(1), 115-143. https://doi.org/10.1016/S03044076(98)00009-8

Bolton P., H. Chen and N. Wang (2011). Unified Theory of Tobin's q, Corporate Investment, Financing, and Risk Management, The journal of Finance, 66(5), 1545-1578. https://doi.org/10.1111/j.1540-6261.2011.01681.x

Dahya J., Dimitrov O. and J. Mc Connell (2008). Dominant shareholders, corporate boards, and corporate value: A cross-country analysis. Journal of Financial Economics, 87(1), 73100. /https://doi.org/10.1016/j.jfineco.2006.10.005

Derek, K. O. and P. P. Marc (2014). Implications of Insufficient and Excess Cash for Future Performance, Contemporary Accounting Research ,31, 253-283. https://doi.org/10.1111/1911-3846.12012

Economics, Management and Financial Markets, 6(1), 344-358.

Erickson T. and T. M. White (2012). Treating Measurement Error in Tobin's q, The review of Financial Studies, 25(4), 1286-1329. https://doi.org/10.1093/rfs/hhr120

Ferreira, M.A and A.S Vilela (2004). Why do firms hold cash? Evidence from EMU Countries, European Financial Management, 10, 295-319. https://doi.org/10.1111/j.13547798.2004.00251.x

Gill A. and C. Shah (2012). Determinants of Corporate Cash Holdings: Evidence from Canada, International Journal of Economics and Finance, 4(1), 70-79.

Hafzalla, N., R. Lundholm, and E. M. VanWinkle (2011). Percent accruals, The Accounting Review,86 (1), 209-236. https://doi.org/10.2308/accr.00000011

Harford, J. (1999), "Corporate cash reserves and acquisitions". Journal of Finance,54, 19691997. https://doi.org/10.1111/0022-1082.00179

Jensen M.C. and W.H. Meckling (1976). Theory of the firm: managerial behaviour, agency costs and ownership structure, Journal of Financial Economics, 3, 305-360. https://doi.org/10.1016/0304-405X(76)90026-X 
Jensen, M. (1986). Agency costs of free cash flow, corporate finance and takeovers, American Economics Review, 76, 323-329.

Keynes M J.(1936). The General Theory of Employment Interest and Money, The Quarterly Journal of Economics, 51(1), 147-167.

Kusnadi Y and K.C. John Wei (2011). The determinants of corporate cash management policies: Evidence from around the world, Journal of Corporate Finance, 17(3), 725-740. https://doi.org/10.1016/j.jcorpfin.2010.12.002

Lawrencia, O, L.O. Ogundipe, S.E. Ogundipe, and S.K. Ajao (2012). Cash holdings and firm characteristics: Evidence from Nigerian Emerging Market, Journal of Business, Economics and Finance, 1, 45-58.

Martinez-Solano C., J. Pedro and M. Pedro (2013). Corporate cash holdings and firm value, Applied Economics, 45 (2), 161-170. https://doi.org/10.1080/00036846.2011.595696

Megginson L.W., B. Ullah and Z. Wei (2014). State ownership, soft-budget constraints, and cash holdings: Evidence from China's privatized firms, Journal of Banking and Finance, 48, 276-291. https://doi.org/10.1016/j.jbankfin.2014.06.011

Megginson L.W., R.C. Nash and M. Van Randenborgh (1994). The financial and operating performance of newly privatized firms: an international empirical analysis, The Journal of Finance, 49, 403-452. https://doi.org/10.1111/j.1540-6261.1994.tb05147.x

Myers, S.C and N. Majluf (1984). Corporate financing and investment decisions when firm have information that investors do not have, Journal of Financial Economics, 12, 187-221. https://doi.org/10.1016/0304-405X(84)90023-0

Myers, S.C. (1977). Determinants of Corporate Borrowing, Journal of Financial Economics, 5, 147-175 https://doi.org/10.1016/0304-405X(77)90015-0

Opler T., L. Pinkowitz, R. Stulz and R.Williamson (1999). The determinants and implications of corporate cash holdings, Journal of Financial Economics, 52, 3-46. https://doi.org/10.1016/S0304-405X(99)00003-3

Ozkan, A. and N. Ozkan (2004). Corporate cash holdings: an empirical investigation of UK companies, Journal of Banking and Finance, 28, 2013-2134. https://doi.org/10.1016/j.jbankfin.2003.08.003

Rizwan, M.F., \& Javed, T. (2011). Determinants of corporate cash holdings: Evidence from Pakistani public sector.

Uyara A. and C. Kuzeya (2014). Determinants of corporate cash holdings: evidence from the emerging market of Turkey, Applied Economics, 46(9), 1035-1048 https://doi.org/10.1080/00036846.2013.866203

\section{Contact information}

Do Thi Thanh Nhan

Tomas Bata University

Faculty of Management and Economics

Mostní 5139, 76001 Zlín

orcid.org/0000-0002-2505-1715

DOI: https://www.doi.org/10.7441/dokbat.2016.10 


\title{
BUDGETING PROCESS IN THE BUSINESS ENVIRONMENT
}

\author{
Jiř́ Dokulil
}

\begin{abstract}
Budgeting is a managerial accounting tool which primarily focuses on the future. Traditional budgeting methods are widely used across many different businesses, however they remain the subject of much discussion among managers, economists and academics alike. Over the last few decades a growing scepticism can be observed with regards to the efficacy and poor adaptability of budgeting in the current business environment. The criticisms centre around the annual basis of budgets and the preference to use budgeting as a control tool.

The introduction to this paper presents an overview of the trends within the discipline of budgeting on the basis of a literature review of publications and information garnered from scientific databases. The main part of the study presents the results of a survey focused on the budgeting process in the business environment. The sample consists of medium-sized and large Czech companies. The main objective of the survey was to assess the predictability of selected factors in the business environment through the budgeting process and to assess how effectively budgeting can adapt to market changes.
\end{abstract}

Keywords: Budgeting, planning, business environment, Czech Republic.

\section{INTRODUCTION}

Budgeting is a traditional managerial tool of which the theoretical basis has been defined in the monographs of many well-known authors (Drury, 2000; Garrison, Noreen \& Brewer, 2014; Horngren, 2009, etc.). Hilton and Platt (2013) state that budgeting is the most common method by which to facilitate planning and control. According to Popesko (2009) it is one of the basic activities of employees in Finance Departments.

Budgeting is often connected with the planning process (Ostergren \& Stensaker, 2011). Many authors consider budgets to be detailed forms of business plans (Drury, 2000), or as plans transformed into currency units (Král, 2010). Hänninen states (2013) that in budgets strategic ideas are transformed into operative activities. Companies use budgets for various purposes, for example for the allocation of resources and the coordination of individual activities and are widely connected with measureable performance (Blocher et al., 2002). According to surveys by Banovic (2005) and Pietrzak (2013), almost 90\% of firms use budgeting for either planning purposes, the coordination of activities, or for the motivation and evaluation of staff.

However, traditional budgeting systems have been the object of criticism for several decades. Drury (2000) highlights the conflicting roles budgets play in terms of, for example, motivation and planning. Lidia (2014) states that budgets are in practice the most controversial managerial tool in existence today. A summary of the greatest criticisms drawn from various sources are given below (Hansen, Otley and Van der Stede, 2003; Neely, Bourne, Adams, 2003; Popesko, 2009):

1) Lack of adaptability to unexpected changes in circumstances (budgets are outdated shortly after their approval because the real progression of the monitored variables is different than planned). 
2) Traditional budgets support outdated stereotypes of thinking and organization. This may be a barrier to change within a company.

3) Plans and budgets are focused on results, not on causes.

4) Budgeting is often annually based and more often than not directly linked to the financial reporting calendar. In today's business environment, which is subject to constant change, this cycle is no longer appropriate.

5) Budgets are not linked. Within companies there are various types of plans and budgets relating to differing periods of time.

A detailed analysis of the criticisms of budgeting appear in the publication of Neely, Sutcliffe and Heyns (2001). They compiled a comprehensive inventory of the twelve most cited weaknesses of budgeting. Hope and Fraser (2003) put forward a much stronger opinion by claiming that budgeting is non-functional in a dynamic environment and should therefore be cancelled. Other authors complement (Hänninen, 2013; Libby \& Murray, 2007) this argument by stating that traditional budgeting is a relic of the past and cannot possibly be useful in an age in which the business environment is subject to constant changes.

Budgets are also highly criticized for being time consuming (Libby and Lindsay, 2010). Neely et al. (2003) established through their research that the budgeting process consumes more than $20 \%$ of all managerial time. One of the most discussed limitations of traditional annual budgets is the inflexibility of the fixed budgets to changes in the business environment. Hope and Fraser (2003) state that the current business environment is characterized by unpredictability, whereby prices and margins are constantly under pressure and product life cycles are shorter.

The question is how to remove the limitations of budgeting and effectively utilize the potential of this managerial tool. In more recent publications emphasis is placed on defining what is understood under traditional and alternative budgeting methods. Alternative methods include Activity-Based Budgeting, Beyond Budgeting, Zero-Based Budgeting and Rolling Budgets. The impact of these methods is based on their focus on the accuracy of budget outputs (ActivityBased Budgeting), improvements in the accuracy of forecasts (Rolling Budgets), and the radical abandonment of old practices and ideas (Beyond Budgeting, Zero-Based Budgeting) (Needles, 2014; Popesko, 2009; Cardos, 2014; Henttu-Aho a Järvinen, 2013).

Cardos (2014) believes that the discipline of budgeting stands at a crossroads. It is not a simple choice to choose between traditional or alternative budgeting methods because each way produces its own direct or indirect effects throughout the organization. It generates a large number of interactions and non-intuitive outcomes.

This study shows the results of a questionnaire survey conducted among medium-sized and large Czech enterprises. The outputs are subsequently compared with the main findings from the literature review.

\section{METHODS}

This article is based on a questionnaire survey conducted among a selected sample of Czech enterprises. The main objective of the study was to assess the predictability of selected factors in the business environment through the budgeting process and to assess how effectively budgeting can adapt to market changes. 
The Albertina database was used as a source of contact information to individuals who are employed in financial management in small and medium-sized companies. It included positions such as Financial Director, Economic Director or Head of Controlling Department. The first step of the research was to contact these managers and ask them to participate in the survey. In total, 1375 medium-sized and large companies that were approached, 618 agreed to participate in the survey, of which 177 returned completed questionnaires.

Table 1. Structure of respondents by sectors

$\begin{array}{ccc}\text { Sector } & \text { Frequency } & \text { Percentage } \\ \text { Manufacturing } & 78 & 44.1 \% \\ \text { Automotive } & 12 & 6.8 \% \\ \text { Construction } & 15 & 8.5 \% \\ \text { Engineering } & 16 & 9 \% \\ \text { Agriculture } & 15 & 8.5 \% \\ \text { Other } & 41 & 23.2 \% \\ \text { Number of respondents } & 177 & 100 \%\end{array}$

Source: author

As can be seen in Table 1, the sectors with the largest sample of companies were Manufacturing (44.1\%), Engineering (9\%), Construction (8.5\%) and Agricultural (8.5\%).

The questionnaire was divided into several sections e.g. functions of budgets, added value of budgeting, time spent on budgeting, etc. The main findings with regards to the section on the business environment are presented in this article.

\section{RESULTS}

The research, in combination with the literature review, was focused on the predictability of selected factors in the business environment, the role of budgets within a company and the effectiveness of budgeting in predicting market changes.

Respondents were firstly asked to identify how predictable the marketing activities of their main competitors were as a result of their budgeting processes. The results are given in Table 2 below.

Table 2. Predictability of business environment through budgeting process

How predictable are the marketing activities of your main competitors (price strategy, launching new products, Frequency Percentage marketing activities) through budgeting? 


$$
\begin{array}{ccc}
1 \text { - easy to predict } & 9 & 5.26 \% \\
2-\text { mostly predictable } & 51 & 29.82 \% \\
3 \text { - sometimes predictable } & 41 & 23.98 \% \\
4-\text { relatively difficult to predict } & 35 & 20.47 \% \\
5-\text { difficult to predict } & 21 & 12.28 \% \\
6 \text { - unpredictable } & 14 & 8.19 \%
\end{array}
$$

\section{Source: author}

The responses are relatively well balanced which suggests that there is no general trend in this field. For further analysis, the results needed to be evaluated by sector. The predictability of the marketing activities of competitors was assessed as high by the majority of firms in the Automotive (58.33\%) sector, and to a lesser degree in the Engineering (31.25\%) and Manufacturing (24.36\%) sectors. This result is connected with the fact that the key players in the Czech automotive industry have not changed since 2006 (Škoda Auto, TPC Automobile, Hyundai Motor Manufacturing Czech). This illustrates the stability of the competitive environment in this industry.

Respondents were subsequently asked to identify whether their companies relied on budgeting as a tool with which to adapt to change.

Table 3. Reliance on budgeting to adapt to change (Part 1)

How heavily does your company rely on

budgeting as a tool with which to adapt to changes in market conditions?

\begin{tabular}{cc} 
Frequency & Percentage \\
\hline 26 & $14.69 \%$ \\
31 & $17.51 \%$ \\
90 & $50.85 \%$ \\
30 & $16.95 \%$ \\
\hline
\end{tabular}

\section{Source: author}

The majority of respondents stated that their reliance on budgeting as a tool for change was at a medium level. The industrial sectors with the highest response rates at this level were Manufacturing (46.15\%), Engineering (43.75\%) and Automotive (33.33\%).

In contrast, almost $15 \%$ of respondents stated that they did not rely on budgeting as a tool for change. The industrial sectors with the greatest scepticism towards budgeting were Construction (40\%), Manufacturing (12.82\%) and Engineering (6.25\%). 
The third question addressed the effectiveness of budgeting when adapting to change. The results are presented in Table 4 below.

Table 4. Effectiveness of budgeting when adapting to change (Part 2)

How effective is the budgeting process when adapting to changes in market conditions?

Frequency Percentage

$\begin{array}{ccc}-3=\text { strictly ineffective } & 4 & 0.56 \% \\ -2=\text { ineffective } & 25 & 6.78 \% \\ -1=\text { rather ineffective } & 37 & 15.25 \% \\ 0=\text { neutral } & 71 & 40.11 \% \\ +1=\text { rather effective } & 27 & 20.90 \% \\ +2=\text { effective } & 12 & 14.12 \% \\ +3=\text { highly effective } & 1 & 2.26 \%\end{array}$

Source: author

As is evident from the results in Table 4, budgeting is a neutral managerial tool for almost half of the respondents. Viewed by sector, only in the Automotive industry did more than $50 \%$ of the respondents evaluate the effectiveness of budgeting on a scale of between +1 and +3 (in total $58.33 \%$ ). Negative responses on the scale of between -3 and -1 were mostly given by companies in the Engineering (31.25\%), Manufacturing (21.80\%) and Construction (20\%) sectors.

\section{CONCLUSION}

As presented in the literature review, traditional budgeting has come in for some strong criticism in the last few decades. The main reasons for the criticisms by experts and academics are based on the lack of adaptability to unexpected changes in market conditions and the annual nature of the reporting period which does not reflect the realities of the current business environment which is subject to constant change.

The results of the survey were compared to these statements. The research data was collected through a web-based questionnaire. In total, 177 of the companies approached completed the questionnaire. The sample set consisted of medium-sized and large companies from the Manufacturing, Automotive, Construction, Engineering and other sectors. Three research questions were posed with a focus on the predictability of selected factors in the business environment, the role of budgets in a company and the effectiveness of budgeting when adapting to changes in market conditions. 
In summary, the results displayed some trends. The reliance of companies on budgeting was considered to be at a medium level. Significant reliance was identified by Manufacturing companies $(46.15 \%)$. The greatest scepticism towards budgeting was shown by Construction companies $(40 \%)$. This scepticism most probably relates to the fact that an initial budget usually has to be submitted for every construction project and that changes thereto during the actual construction are very limited.

From the answers of the respondents we can conclude that the effectiveness of budgeting when adapting to changes in market conditions is neutral. The Automotive industry was the exception, with more than $50 \%$ of respondents evaluating the effectiveness of budgeting as rather effective or effective. The majority of negative responses (budget is rather ineffective, ineffective or strictly ineffective) came from companies operating in the Engineering (31.25\%) sector.

This survey must be considered as the first stage of ongoing research. Questions for follow-up research need to focus on the connection between budgeting and the implementation of strategy and manager's expectations of budgeting.

\section{Acknowledgement}

This work was supported by the Internal Grant Agency of Tomas Bata University in Zlin under project number IGA/FaME/2016/005.

\section{References}

Banovic, D., (2005). Evolution and Critical Evaluation of Current Budgeting Practices. University of Ljubljana.

Blocher, E. J., Chen, K. H., Li, T. W. (2002). Cost Management: a Strategic Emphasis. McGrawHill International, New York, NY.

Cardos, I. R., (2014). New trends in budgeting - a literature review. SEA - Practical Application of Science, 2 (4).

Drury, C. (2000). Management \& Cost Accounting. London: Thomson.

Garrison, R. H., Noreen, E. W., Brewer, P. C., (2014). Managerial Accounting for Managers. New York: McGraw-Hill Irwin.

Hansen, S. C., Otley, D. T., Van der Stede, W. A., (2003). Practice developments in budgeting: an overview and research perspective. Journal of Management Accounting Research, 15, 95-116. https://doi.org/10.2308/jmar.2003.15.1.95

Hänninen, V., (2013). Budgeting at a Crossroads - The Viability Of Traditional Budgeting - a Case Study. Aalto University School of Business.

Henttu-Aho, T., Järvinen, J. (2013). A field study of the emerging practice of beyond budgeting in industrial companies: An institutional perspective, European Accounting Review, 22(4), 765-785. https://doi.org/10.1080/09638180.2012.758596

Hilton, R. W. \& Platt, D. E., (2013). Managerial Accounting: Creating Value in a Dynamic Business Environment. McGraw Hill Higher Education.

Hope, J., \& Fraser, R. (2003). Beyond Budgeting: How Managers Can Break Free from the Annual Performance Trap. Boston, Mass.: Harvard Business School Press.

Horngren, C. T., (2009). Cost Accounting: A Managerial Emphasis. Upper Saddle River: Pearson Prentice Hall. 
Král, B. (2010). Manažerské účetnictví. Praha: Management Press.

Lidia, T. G. (2014). Difficulties of the Budgeting Process and Factors Leading to the Decision to Implement this Management Tool. Procedia Economics and Finance, 15, 466-473. https://doi.org/10.1016/S2212-5671(14)00484-5

Libby, T., \& Lindsay, R. M. (2010). Beyond Budgeting or Budgeting Reconsidered? A Survey of North-American Budgeting Practice. Management Accounting Research. https://doi.org/10.1016/j.mar.2009.10.003

Libby, T., \& Murray, L., (2007). Beyond budgeting or better budgeting? Strategic Finance, Aug, $89(2), 47-51$.

Neely, A., Bourne, M., Adams, C., (2003). Better Budgeting or Beyond Budgeting? Measuring Business Excellence, 7(3), 22.28.

Neely, A., Sutcliffe, M. R. \& Heyns, H. R., (2001). Driving Value through Strategic Planning and Budgeting. London: Accenture.

Ostergren, K., \& Stensaker, I., (2011). Management Control without Budgets: A Field Study of Beyond Budgeting in Practice. European Accounting Review, Vol.20(1), 149-181. https://doi.org/10.1080/09638180903487842

Pietrzak, Z., (2013). Traditional Versus Activity-Based Budgeting in Nonmanufacturing Companies. Social Sciences, 82(4), 26-37.

Popesko, B., (2009). Moderní metody ř́zení nákladů: jak dosáhnout efektivního vynakládání nákladů a jejich snížení. Praha: Grada.

\section{Contact Information}

Jiří Dokulil

Tomas Bata University in Zlin

Faculty of Management and Economics

Mostní 5139, Zlín, 76001

E-mail: dokulil@fame.utb.cz

orcid.org/0000-0003-3990-1781

DOI: https://www.doi.org/10.7441/dokbat.2016.11 


\title{
ETHICAL ASPECTS OF NEUROMARKETING
}

\author{
Jana Durd'áková
}

\begin{abstract}
Due to the development of new technologies and new neuroscience findings, the desire to understand the brain of the consumer is increasing. Methods of neuromarketing can be used to identify the needs and wishes of consumers. The acquired information can then be applied to marketing, which helps to persuade, inform or influence current and also potential customers. The main aim of this article is to describe the consumer's decision-making process, present neuromarketing as a current trend in the field of marketing communications, and then discuss possible negative ethical aspects of neuromarketing.
\end{abstract}

Keywords: consumer purchase behavior, neuromarketing, neuromarketing methods, ethics in neuromarketing

\section{INTRODUCTION}

Current marketing is based on the satisfaction of customer needs and desires. The use of psychology in marketing follows the recognition that the two fields are closely related. Consumers' shopping decisions are based on their experience, motives, opinions, emotions but also senses, etc., all of which encourage marketers to discover customers' needs and desires through marketing research and then use the results to better sell products. Every consumer decision is brain based.

Ries (2006) says, that if psychology is the systematic study of human behavior, then marketing can be considered as the systematic study of human behavior in the marketplace. Psychologists also often refer to "the halo effect", e.g., when good-looking people tend to be considered by others as more intelligent, successful and popular. However, besides the halo effect, many principles of psychology can be used in marketing, e.g., when the first brand of new category is engraved in the human mind as the original, authentic or real thing: Kleenex for tissues, Heinz for ketchup, Clorox for bleach, etc.

An effort to completely understand the needs of consumers became the basis for the creation of a new field of marketing communication called neuromarketing. Neuromarketing, which is a combination of two disciplines, namely neuroscience and marketing. The purpose of this field, sometimes considered controversial, is to understand the mind of consumers via techniques of neuroscience. The most frequently used techniques are, e.g., EEG, GSR, FA or the eye tracking method, which uses an eye camera to track the eye movement of a respondent. Other techniques are fMRI, MEG, NIR or the PET method, which scans the brain of a consumer.

Neuromarketing broaches ethical issues. Opponents argue that neuromarketing coerces consumers and threatens their civil liberties. Philosophically speaking, if a neuromarketer can pre-determine a consumer's purchase, then the consumer is denied free will, which is generally considered a basic human right. On the other hand, argue proponents, neuromarketing increases consumer satisfaction. 
The following article deals with purchasing behaviors of consumers and their attributes that are associated with the purchase process. It describes neuromarketing as a new trend in marketing communications, generally characterizes neuromarketing and its methods, and then discusses the ethics of neuromarketing.

\section{CONSUMER PURCHASE BEHAVIOR}

Many associate this term only with retail and advertising, but nowadays it is necessary to see the wider meaning, which is to satisfy a customer's needs. The pillars of marketing uphold human needs, which are conditions requiring supply or relief and are an inseparable part of every human being. Desires can be characterised as human needs created by external cultural influences and individual personalities. As time passes and a society develops, its desires change. People have limited basic needs (sustenance, a place to live, etc.) but unlimited desires. If these desires are accompanied by the ability to pay for them, they become consumer demands. Marketing companies are trying to recognize and understand human needs and desires. To do so, they make surveys to identify consumer preferences. This particular understanding of needs, desires and demands serves as a catalyst for the creation and development of marketing strategies (Kotler, 2007).

According to Zamazalová et al. (2010) permanent orientation of the customer's needs is the substance of contemporary marketing conception. In developed market economies there appeared this conception in the 50th and 60th years of the 20th century, while dissemination of application marketing field was gradual. And just with broadening its application field diversifies marketing gradually and in these days it also specializes more (service marketing, industrial marketing, political marketing, etc.).

Everybody is a consumer. No matter if one buys electronics, cosmetics, food or anything else, shopping constitutes an important part of our everyday life. And this is exactly what is used by salesmen and by advertising experts. Adverts on the TV, banners on the Internet, billboards by the roads, shop windows and many others might serve to us as an example. The consumer has to face all these every day. The question is, whether he or she is capable to remember anything from the enormous amount of information about brands. What is it influenced by, that some piece of information gets into the consumers mind and another piece is forgotten (Lindstrom, 2009)?

You certainly know the situation when you come from somewhere, put your keys aside and within a while you don't know where they are. The data simply disappeared from the brain. Why? Because the brain, no matter if we realize it or not, processes many other pieces of information and because of the limited capacity of its temporary memory and in this case, keys were not of the importance to remain in such memory. The irony is that consumers cannot ask themselves some questions, because they usually don't know the answers. If that person from our example asked himself, whether he left the keys on the table, armchair or in his clothes, he wouldn't know the answer. And the same situation comes, when the consumer questions himself about buying a mobile phone, Casio watch, Diesel jeans, etc. He wouldn't have any idea, why he bought it. Nevertheless if businessmen knew, what is happening inside the customers' brain, while selecting between various brands, they would have a key to building real brands of the future (Lindstrom, 2009). 
Lindstrom (2009) also mentions that another such case might be a consumer in a supermarket in the aisle with peanut butter. Brands Skippy, Peter Pan and Jif can be found there. The decision takes most customers about 2 seconds. In this example, Jif butter was chosen. But was this choice rational? Far from it... If the consumers decision was conscious, he would have considered various possibilities and he would have led an unconscious conversation in his head: I remember Skippy from my childhood... it's been in existence for a very long time and I guess it is to be trusted... but isn't it full of sugar and other preservatives which I should not be eating?... These unconscious talks taking place in the consumers' head are rarely spoken aloud and instead of that, the consumer relies on his immediate abbreviations invented by the brain to make shopping decisions easier.

According to Zamazalová et al. (2010, p. 115) customers purchase behavior can be defined as "such behavior of individuals or institutions which is connected to a process which leads to a final market activity and which is connected with acquiring, using and the rating of products." It is about a wider area than just a person's own purchase decisions in that particular market situation. It also involves that current context, in which the decisions are being made, customers predispositions to that specific market behavior. Knowledge of customers purchase behavior is not only a solution, but also a necessary condition of a successful orientation in the market.

Purchase behavior as Zamazalová et al. (2010) further states, includes everything that is connected to a process leading to the final purchase activity and to other components of human behavior. On its basis it is possible to define specific attitudes, which enable a view of consumer behavior. There can be defined a rational attitude (rational components prevail in the market decision making, for example conscious acquiring and evaluating information, which is related to utility on one side and comparing it to prices, incomes, etc. on the other side.), psychological attitude (psychological factors might influence decision making, for example psychological process of learning to some consumer behavior) and sociological attitude (it is related with the consumers life in a specific environment, his purchase decision might depend on an effort to become a part of some social group, to reach a specific social status or to perform some social role).

What influences consumer behavior then? Vysekalová (2004) claims that psychological processes, that show us consumers' mental qualities, are the answer. That means recognition of psychological unusualness of that current individual, its characteristic in terms of psychological qualities or character traits. Among the most important psychological mechanisms that play their role in purchase decision-making, count mental qualities and dispositions (those prove themselves in all psychological processes), life experience, knowledge (those help the consumer with his purchase decisions), attitudes, mind and the effects of social background.

Vysekalová et al. (2014) adds that also emotions have a major impact on other psychological processes, which are given? Emotions have the closest relation to motivation, memory and learning. Origin, duration and also satisfying of needs as a basis of motivation is accompanied by emotions, satisfying of a need always has an emotional accent.

\section{NEUROMARKETING AS A NEW TREND OF MARKETING COMMUNICATION}

During the 20th century new marketing conceptions started to form. Those lead to modern marketing and marketing communication as one of the most important tools for influencing 
customer's behavior and company's environment. These days bring us lots of new things in this area (Přikrylová and Jahodová, 2010).

The world around us has according to Gálik (2012) changed a lot since those times, and demands on customers' decision-making processes as well. The purchase behavior of our ancestors was quite different from ours. There were no supermarkets, hypermarkets or shopping centres. People didn't go shopping at a petrol station or on the internet. They used mainly small shops and the range of goods was not that rich. One could not even imagine that he might buy everything from the comfort of his own home.

Technological changes in area of computing, telecommunication, microelectronics, etc. transfer the costumer to a new position as a decision-maker as Přikrylová and Jahodová (2010) state. Consumers already have ceased to be the object of marketing communication and are becoming its subject. Modern technologies offer new ways of communication to achieve smaller customer segments.

Therefore in these days we do not speak of marketing and marketing communication just as some discipline, but we speak about a large group of marketing techniques, which slowly transform themselves into specialized branches (Frey, 2011).

The following text deals with one of our biggest marketing trends, and that is with neuromarketing and its ethical aspects.

\section{NEUROMARKETING AND ITS RESEARCH METHODS}

Neuromarketing represents science, which is still covered by mystery. People do not know, whether they should be afraid or what to expect. Neuromarketing is a branch with a very big potential, but nowadays its existence is just at the very beginning (Gálik, 2012).

Neuromarketing, which can be defined as a field of marketing based on neuroscience research, is one element of new neuroculture. This new trend provides views into the development of brainbased narratives and into the potential problems that they could pose for medical ethics and the public understanding of science (Fisher, Chin and Klitzman, 2010).

The combination of neuro and marketing expresses merge of two branches, namely neuroscience and marketing. This term, however cannot be attributed solely to individual, as was the case in 2002. At that time, several US companies began to provide research and consulting in the field of neuromarketing, which promoted the use of knowledge and technology derived from the field of cognitive neuroscience. In essence, it can be said that as neuromarketing is marketing, as well neuropsychology is psychology. While neuropsychology examines relation among the brain, human knowledge and psychological functions, so neuromarketing helps importance of looking at consumer behavior in terms of the brain (Morin, 2011).

Neuromarketing studies, which parts of the brain, are activated when consumers are making purchase decisions or what is their reaction to advertisements. It tries to uncover especially memory or the unconsciousness of costumers. Marketing agencies use according to Koukolík the newest scientific pieces of knowledge to attract customers. And these pieces are given to them by neuromarketing. Thanks to it producers and big companies are able to acquire information about the functioning of the human brain in relation to shopping. On its basis they can point insertion or distribution of goods on the racks (Česká televize, c1996-2015). 
The aim of neuromarketing studies is to gain objective information regarding inner workings of the brains of consumers without referring to the subjective reports that have long been the main part of marketing studies (Murphy, Illes and Reiner, 2008).

Ariely and Berns (2010) deal with neuromarketing from different perspective ad define it as application of neuroimaging methods in product marketing. They also show two main reasons for this trend. The first reason may be the possibility that neuroimaging is cheaper and faster that other marketing methods. The second reason may represent hope that neuroimaging provide such information, which cannot be obtained through conventional marketing methods. Although neuroimaging seems to be still more expensive than other tools, there is increasing number of evidences that it may provide hidden information about consumer experiences.

Despite many common beliefs that marketing is inherently evil, its main goal is to help connect people with the product. According to Ariely and Berns (2010) argue that marketers achieve such a goal by providing information to product designers. The information is about consumer values and what consumers want before the product is created. Once the product appears on the market, marketers try to maximize sales by introducing the menus, pricing, ads or promotion.

Neuromarketing as a new marketing approach that combines knowledge of neuropsychology, cognitive psychology and neuroscience to marketing decision making environment, used according to Vysekalová et al. (2011) modern research techniques that give an answer to the question of how people make decisions when buying. Neurological findings of neuromarketing can then be applied to different areas of marketing: research and development of new products and services, packaging, marketing communication, etc.

The most frequently used methods of neuromarketing are especially the EEG method (electroencephalography) providing brain activity data in emotional center, the GSR (galvanic skin response) method measuring activity on the skin surface, the FA method (facial coding) coding face of respondent or the eye tracking method which uses an eye camera to monitoring the visual attention of the respondent, or the traceability where and how long is the respondent looking at (Vysekalová, 2014).

Other methods are fMRI (functional magnetic resonance imaging), MEG (magnetic encephalography), NIR (near infrared spectroscopy) and PET (positron emission tomography) as states Vysekalová et al. (2011). All of these techniques can be subsumed under the heading of brain scans and allow marketers to show, what is happening in the brain.

\section{ETHICS IN NEUROMARKETING}

Ethics can be generally described as a philosophical discipline, whose goal it is to find good, correct behavior. The term ethics comes from a Greek word "ethos", which means custom, tradition or character. Ethics is also called practical philosophy, which occupies itself with morals, it studies human behavior and correct ways of life. And by that it arouses questions about the sense of human life. That means about the value ladder of an individual - about values that are crucial for him, those that he wants to reach (Lörincz, 2009).

The author also adds that ethics will most probably play the determinative role for maintenance of life on this planet, because most of the world's problems, which endanger our lives, have an ethical character. If humans want to save the world, they have to give priority to ethical 
standpoints (as for example respecting some rules, economizing etc.) over human need to consume and own still more and more.

There are two main issues in the market area that are ethically evaluated negatively. The first issue bears on the effort to gain advantage because of rogue behavior. Unfortunately, this kind of behavior appears on the market very often. One example could be producers who intentionally produce labels whose name or image processing should cause mistaking with the successful brand, etc. In the other case the customer is under pressure, which leads to irrational behavior. This ethical issue is more complicated compared to the previous one, because marketing in general and advertising in particular are criticized, since they instigate to meaningless consumption (Bárta and Bártová, 2012).

Ethics and privacy concerns are an often discussed topic in connection with neuromarketing. According to Gatterer (in Kolar, 2014) people are afraid of manipulation and in times of advanced technology and applications that are used to obtain private information of people, they are worried about the risk of losing self-determination rights. Neuromarketing enables researchers to look into the human mind and provides possibilities to encode emotions and decision making processes that consumers would not voluntarily provide to others. To guarantee the ethical and lawful marketing and social research the world organizations ESOMAR (the European Society for Opinion and Marketing Research) and ICC (the International Chamber of Commerce) developed the international code which ensures that market researchers comply with all national and international laws, behave ethically and acting transparently.

Regarding the ethical issues and discussions on neuromarketing, human dignity should be the basis for ethical principles such as autonomy, self-determination, privacy, confidentiality, protection of vulnerable groups, reliability and honest interpretation of research in accordance with the risk of manipulation by commercial entities (Ulman, Cakar and Yildiz, 2014).

There is also the term "neuroethics", which is associated with several disciplines, says Levy (2007). Ethics is associated with neuroscience most obviously, but also with psychology, cognitive science, and philosophy of mind.

Neuroethics focuses on what is good and what is bad, or what is right or wrong in relation to using neuroimaging tools in order to understand brain mechanisms. In the context of neuromarketing, neuroethics is devoted to the protection of human subjects participating in marketing experiments that use neuroimaging (Olteanu, 2014).

The following table (Tab. 1) shows the authors and some ethical problems occurring in neuromarketing.

Table 8 Selected ethical problems in neuromarketing. Source: Own compilation

\section{Ethical problems in neuromarketing}

\begin{tabular}{|l|l|l|}
\hline Murphy & 2008 & $\begin{array}{l}\text { consumer free will } \\
\text { protection of consumer } \\
\text { privacy }\end{array}$ \\
\hline Wilson & 2008 & $\begin{array}{l}\text { threat for free, logical and } \\
\text { informed decision-making of } \\
\text { customers }\end{array}$ \\
\hline
\end{tabular}




\begin{tabular}{|l|l|l|}
\hline Rapp & 2009 & $\begin{array}{l}\text { threat to the privacy of } \\
\text { respondents }\end{array}$ \\
\hline Koukolík & 2012 & $\begin{array}{l}\text { misuse of psychological and } \\
\text { neurological knowledge in } \\
\text { marketing and politics } \\
\text { consumer susceptibility to } \\
\text { behave like a "flock of } \\
\text { sheep" }\end{array}$ \\
\hline Bercea Olteanu & 2014 & $\begin{array}{l}\text { consumer free will and } \\
\text { protection of consumer } \\
\text { privacy } \\
\text { threat of mind reading and } \\
\text { manipulation of the human } \\
\text { mind }\end{array}$ \\
\hline
\end{tabular}

Neuromarketing awakens many ethical issues. However, Murphy et al. (2008) concentrates his arguments about ethics mainly on issues of the customers' free will and of protection of his privacy. In the first case neuromarketing tries to find some "buy button" in the consumers' brain. The consumer would buy automatically after turning on this switch by marketing specialists.

If this ability of neuromarketing reaches a critical level of efficiency, it would mean a big threat for free, logical and informed decision-making of customers (Wilson et al., 2008).

Even bigger emphasis should be put on the privacy protection issues. Based on past experience it is known, that an information leak or trading with information can occur especially when this information is related to consumers preferences or when the information about consumers is known from advertisements or from the internet. Also providing data from neuroscientifical studies, which show that pathological findings in the brains of examined subjects occur in 1-2\% of cases, might be misused by some companies, such as insurance companies (Rapp et al., 2009).

Also Olteanu (2014) supports the view that consumer free will and privacy are the most discussed problems in neuroethics. Free will is related to moral responsibility, and people can take responsibility for their actions only if it is connected with free will. It is the consumer who should have the last word in purchasing a product.

Marketers want to learn more about the process of consumer choice-making and activation patterns that predict consumer behavior to better understand what consumers need and predict it in the future. Neuroimaging tools examine the social behavior of consumers using knowledge about the brain. This is also where the ethical problem lies. People fear that researchers will be able to read the minds of of the respondents, or will be able to manipulate the human mind. But the answer is that neither electroencephalography, nor functional magnetic resonance imaging are not able to read the minds of the respondents, or even manipulate their minds. Firms could reduce these concerns by being transparent in the research, such as notify the participants of the research, what is the purpose of the study and subsequently provide them information concerning the way they obtain the results. Another step to reduce concerns should be a certain caution of researches when analyzing the data collected from neuromarketing studies (Olteanu, 2014). 
The application of neuromarketing balances nowadays on the edge of ethics. Koukolík warns about various ways of misusing psychological and neurological findings in politics and also in marketing and he points out the problem of natural inclination of human beings to behave like a "flock of sheep". The above-mentioned behavior like a "flock of sheep" is according to Koukolík a human heritage from the past, when such behavior was understood as very beneficial for human cooperation. Cooperation is according to him a necessary condition for survival of small groups in the wild. The problem is, that mechanisms in the brain, which are connected to survival are useful just for a maximum of 150-200 people. The power of crowd can be according to him easily misused. If the "sheep" behavior leads the group to extinction, there should be at least one contra-sheep that tells the others "Do not do it" (Česká televize, c1996-2015).

On the other hand, Lee, Broderic a Chamberlain (2006) say that they see no reason why marketing research could not benefit from neuroimaging. Neuromarketing should be regarded as a legitimate and important field for future research that will allow marketers to better understand human behavior. Application of neuroimaging to marketing research should lead to not only a clearer understanding of the impact of marketing techniques, but also insight into the key issues in business relationships that have so far been difficult to capture.

Neuromarketing itself stands on scientific basis. Hlásek (in Vesecký, 2014) states that "every technology has to deal with ethical issues. Even when holding a stone or a twig in our hand, it is a matter of ethics, what we do with them. Neromarketing does not influence directly decisionmaking of human beings, it is used mainly for understanding human behavior in various situations, for there is a difference in how we feel and we think we feel and how we tell others about how we feel. Neuromarketing is no exception."

\section{CONCLUSION}

Traditional market research is based on available information which respondents knowingly provide for marketers. The problem of these studies is that respondents often do not answer the questions truthfully, and this leads to distortion of information. Neuromarketing as a new discipline of marketing communication uses neuroscientifical methods to understand of consumer behavior. The main goal of neuromarketing is to determine how and why consumers decide and which part of the brain affects this decision. Neuromarketing is based on the fact that most human activities and part of the thinking (also including emotions) are made subconsciously. In order for these knowledges to be used in the process of consumer purchase behavior, or in another area of marketing, marketers use different methods to identify customer's needs and desires. The main methods of neuromarketing include "neuroimaging methods", which are EEG (electroencephalography) measuring brain activity, fMRI (functional magnetic resonance imaging) operating on the basis of the magnetic signal and using for brain mapping, GSR (galvanic skin response) recording activity on the skin surface, FA (method of coding face of respondent) or eye tracking (method of mapping eye contact of respondent). Other methods are MEG (magnetic encephalography), NIR (near infrared spectroscopy), and PET (positron emission tomography). The use of these neuromarketing methods can provide for marketers deeper understanding of consumer behavior. These findings gained from neuromarketing research can eliminate the above-mentioned distortion emerging in the traditional research due to conscious behavior of customers. 
However, with the use of neuromarketing it is also necessary to consider the possible risks of misuse of brain knowledge and point to ethical issues in this area. Many critics warn of the problems concerning free will of consumers and protection of privacy. Their concerns are based on the assumption that marketers try to find "buy button" in the brain of consumer. The consumer would buy automatically after turning on this switch by marketers. What is more, potential misuse of privacy is nowadays multiplied by developing the Internet and use social networks. The issue of misuse of psychological and neurological knowledge in marketing and politics and the threat of mind reading and manipulation of the human mind are a result of technological development of our time. But these concerns are excessive because current methods of neuromarketing are not able to read minds or to manipulate the human mind of consumer. To eliminate these concerns should companies approach the research transparently and subsequently provide for consumers result of research and way they were achieved.

From the perspective of ethics is necessary to think about these issues and eliminate any concerns that arise from the use of neuromarketing. But on the other hand, the utility of this field, that by using its methods detects the wishes and needs of consumers, and thus contributes to their greater satisfaction, should be emphasized. Despite the negative opinions and ethical concerns neuromarketing is considered beneficial marketing communication tool and it is only a matter of time to show whether neuromarketing methods actually contribute to effective focus on consumers.

\section{Acknowledgment}

"The author is thankful to the Internal Grant Agency of FaME TBU No. IGA/FaME/2016/009 The Use of New Marketing Trends for Increasing of Companies' Performance in Selected Areas of Economy for financial support to carry out this research."

\section{References}

Bárta, V., \& Bártová, H. (2012). Homo spotřebitel. Praha: Oeconomica.

Bercea Olteanu, M. D. (2015). Neuroethics and Responsibility in Conducting Neuromarketing Research. Neuroethics, 8(2), 191-202. https://doi.org/10.1007/s12152-014-9227-y

Fisher, C. E., Chin, L., \& Klitzman, R. (2010). Defining Neuromarketing: Practices and Professional Challenges. Harvard Review of Psychiatry, 18(4), 230-237. https://doi.org/10.3109/10673229.2010.496623

Frey, P. (2011). Marketingový komunikace: Nové trendy 3.0. Praha: Management Press.

Gálik, S. (2012). Psychologie přesvědčování. Praha: Grada.

Kolar, E. (2014). Neuromarketing and Marketing Management: Contributions of Neuroscience for the traditional Marketing Mix. 3rd IBA Bachelor Thesis Conference, 1-15. Retrieved from http://essay.utwente.nl/65319/1/Kolar_BA_MB.pdf

Kotler, P. (2007). Moderní marketing. Praha: Grada.

Česká televize. (2012). Koukolík: Neuromarketing balancuje na hraně etiky. Retrieved October 3, 2012, from http://www.ceskatelevize.cz/ct24/domaci/1143004-koukolikneuromarketing-balancuje-na-hrane-etiky

Lee, N., Broderick, A. J., \& Chamberlain, L. (2007). What is 'neuromarketing'? A discussion and agenda for future research. International Journal of Psychophysiology, 63(2), 199204. /https://doi.org/10.1016/j.ijpsycho.2006.03.007 
Levy, N. (2007). Rethinking Neuroethics in the Light of the Extended Mind Thesis. The American Journal of Bioethics, 7(9), 3-11. https://doi.org/10.1080/15265160701518466

Lindstrom, M. (2009). Nákup•ologie: Pravda a lži o tom, proč nakupujeme. Brno: Computer Press.

Lörincz, T. (2009). Etika. Retrieved March 4, 2009, from http://tomlery.txt.cz/clanky/61952/zsv$22 b$

Murphy, E. M., Illes, J., \& Reiner, P. B. (2008). Neuroethics of neuromarketing. Journal of Consumer Behaviour, 7(4-5), 293-302. https://doi.org/10.1002/cb.252

Přikrylová, J., \& Jahodová, H. (2010). Moderní marketingová komunikace. Praha: Grada.

Rapp, J. et al. (2009). Advertising and Consumer Privacy. Journal of Advertising, 38(4), 51-61. https://doi.org/10.2753/JOA0091-3367380404

Ries, A. (2006). Understanding Marketing Psychology and the Halo Effect. Health Care Strategic Management, 24(6), 9.

Ulman, Y. I., Cakar, T., \& Yildiz, G. (2015). Ethical Issues in Neuromarketing: "I Consume, Therefore I am!”. Science and Engineering Ethics, 21(5), 1271-1284. https://doi.org/10.1007/s11948-014-9581-5

Vesecký, Z. (2014). Moderní neuromarketing funguje i v malých obchodech. A skoro zadarmo. Retrieved January 8, 2014, from http://www.podnikatel.cz/clanky/modernineuromarketing-funguje-i-v-malych-obchodech-a-skoro-zadarmo/

Vysekalová, J. (2004). Psychologie spotřebitele: Jak zákazníci nakupují. Praha: Grada.

Vysekalová, J. et al. (2014). Emoce v marketingu: Jak oslovit srdce zákazníka. Praha: Grada.

Vysekalová, J. et al. (2011). Chování zákazníka: Jak odkrýt tajemství „,černé skřriňky“. Praha: Grada.

Wilson, R. M., Gaines, J., \& Hill, R. P. (2008). Neuromarketing and Consumer Free Will. The Journal of Consumer Affairs, 42(3), 389-410. https://doi.org/10.1111/j.17456606.2008.00114.x

\section{Contact information}

Jana Durd’áková

Tomas Bata University in Zlín

Faculty of Management and Economics

Mostní 5139, 76001 Zlín

+420576032120

durdakova@fame.utb.cz

DOI: https://www.doi.org/10.7441/dokbat.2016.12 


\title{
LINKING COMPONENTS OF THE SERVICE SYSTEM AND PERFORMANCE MANAGEMENT SYSTEM
}

Fabianová Zuzana

\begin{abstract}
The service system is an abstraction of Service Science. Its purpose is to apply a co-production view of the service management, where the client plays the key role. Such role must be respected also by the setting of strategies, processes as well as mechanisms for performance management. Linking the service system with the performance management system through their components represents a complex issue and one possible solution of this issue is outlined in the presented paper.
\end{abstract}

Keywords: Service science, Service system, Performance management system, Service Level Agreement

\section{INTRODUCTION}

The service represents, with a certain simplification, an agreement between the service provider and receiver of benefits from the service, i.e. the client. The service utilises management principles and engineering approaches for its creation, performance and innovations (Maglio \& Spohrer, 2008). Such management and engineering approaches are materialised in the service system. The service system represents a dynamic configuration of resources, which create value together with another service system through sharing information and competences. From this perspective, the service system can be any organization or a combination thereof (enterprise, institution, corporation, community, but also for instance family or individual). The key view of service systems constitutes the perception of interaction of interested parties to the creation of value. (Bryson, 2014). Value management represents at the same time an important framework for the application of methods and tools of the performance management in the organization, as it links the interest to achieve objectives with the interest to minimise used resources for the achievement of such objectives.

This applies particularly in the case of public service institutions, where is the created value manifested also in results of institution operation and in consumption of resources spent to achieve such results. The performance and its management constitute a significant factor affecting the creation of value in public service institutions, as it focuses on efficiency and effectiveness of organization's work. Linking the service system to the performance management system requires knowledge of approaches in mentioned fields.

\section{DEVELOPMENT OF PERCEPTION OF THE SERVICE NOTION}

Smith as the founder of modern perception of economics deemed the "productive work" to be something that results in the creation of "physical product" - goods. If the work did not result in tangible product, work was deemed to be "non-productive" (Smit, 1907). Basically the first exclusion of services as a specific category has thus started, leading to the formation of a tertiary sector, with clear dividing line between the primary sector (agriculture), secondary sector 
(industry) and tertiary sector. The significance of the tertiary sector grew with the growth of employment rate and also with the onset of ICT, what induced the need to develop scientific thoughts about the service. Closer examination of the issue of services brought about questions related to service definition, measurement of service result, service management and coproduction of service.

\subsection{Service dominant logic}

Service, with regard to the change of its sector position providing $80 \%$ of employment, ceases to be perceived as one of product types - intangible product or addition to a product, the transition to the perception of service as to application of competences (knowledge and skills) in order to create benefit for another party starts (Vargo, Maglio, \& Akaka, 2008). This automatically induced also the need of theoretical examination, what led to the elaboration of Service Science. This theoretical perspective changed the perception of economy through the "logic of goods" (Goods Dominant Logic - GDL) to "logic of services" SDL (Service Dominant Logic). In SDL, service is conceptualized as a process that represents the basis of social and economic exchange. It is process of applying competences to benefit another moves the emphasis of exchange resources. Service Dominant Logic focuses on service as an activity with benefit for another party by implication the relationship between service, competency and resources (Bryson, 2014). Another change was the transition from the perception of services as process of using operating tangible resources (operand resources) in the process of value creation by means of certain activities, to the expression of value perception by means of intangible, dynamically developing resources (operant resources), which are capable to create value between at least two participating subjects in their mutual cooperation. So, whereas the GDL perceives services as the unit of output, SDL perceives the service as collaborative process, which creates value for another subject. The value is always co-created in SDL, whereas tangible products are sometimes involved in this process only as means for service provision.

Services are in both cases provided directly or by means of tangible products, through capabilities and knowledge (competences) of providers and receivers. It is not tangible products, but involved parties who represent the basic source of value creation, because tangible products only support the service implementation.

Service Dominant Logic indicates that the basis of managed service is a general understanding of economic activities of exchange and creation of value. It also requires a change of thinking from notions of "producer" and "consumer" to notions expressing the interaction and joint creation of value, to which corresponds the notion "service system" and co-production process. Evidence of application of this new logic can be found in various theoretically delimited areas, such as information technologies (e.g. information services), human resources (e.g. organizations as learning systems), marketing (e.g. network/social marketing), theory of organization (e.g. theory of resources evaluation), but also in practice.

\subsection{Service system}

The service system is the basic abstraction of service science and at the same time a useful abstraction for understanding value and value co-creation (Maglio, Vargo, Caswell, \& Spohrer, 2009). This abstraction enables to build common understanding and representation of the patterns and behaviours that exist between service providers and service client. Service system is according to Katzan (Katzan, 2008) socially constructed collection of service events in which 
participants exchange beneficial actions through a knowledge-based strategy that captures value from provider - client relationship (Fugate, Stank, \& Mentzer, 2009). Service system is always connected to other systems by value proposition (Lyons \& Tracy, 2012). If the service system is to be defined by means of value, the service system represents "value co-creation configuration of people, technology, value propositions connecting internal and external service systems and shared information". Resources in the service system include people, organizations, shared information (of language, laws, indicators, measures, methods) and technology, everything internally and externally interconnected with other service systems through value proposition. Resources have assigned rights, namely owned outright, leased/contracted, shared access, and privileged access. Each service system has a unique identity and is a type or class of service (people, enterprise, institutions). Various types of resources (people, shared information, technology) are used in the service system, with the nature of either a physical resources or conceptual/intangible resource.

Service system is represented especially by events having the nature of interactions. Each service system is represented basically by three types of interactions, which occur in chronological order upon service proposition, preparation of agreement on service and upon the service implementation. The proposition of value co-creation can represent the only interaction of welldefined value co-creation (e.g. document certification), or can represent not exhaustively defined and on-going series of interactions (e.g. preparation of tasks plan or training of a new employee). Agreements can be formal, codified in explicit or implicit legal contracts (for instance in relation of a central body of state administration to its directly controlled organization) or informal (for instance perfunctory determination and allocation of task), in which a misunderstanding or even a dispute can occur, leading to the need of wider negotiations between interested parties about any open issue.

Service Level Agreement (SLA) is an excellent tool for the solution of relationships arising from interaction and requirement for service co-production. SLA forms part of management of the provided service level and represents a set of people and systems in the organization, which enable the organization to assure that the SLA will be complied with and resources required to achieve the required level will be used efficiently. SLA describes products and services which the client receives from the provider, tasks and responsibilities of each involved party, financial issues, method of measurement of the service quality as well as method for recording measurements. 


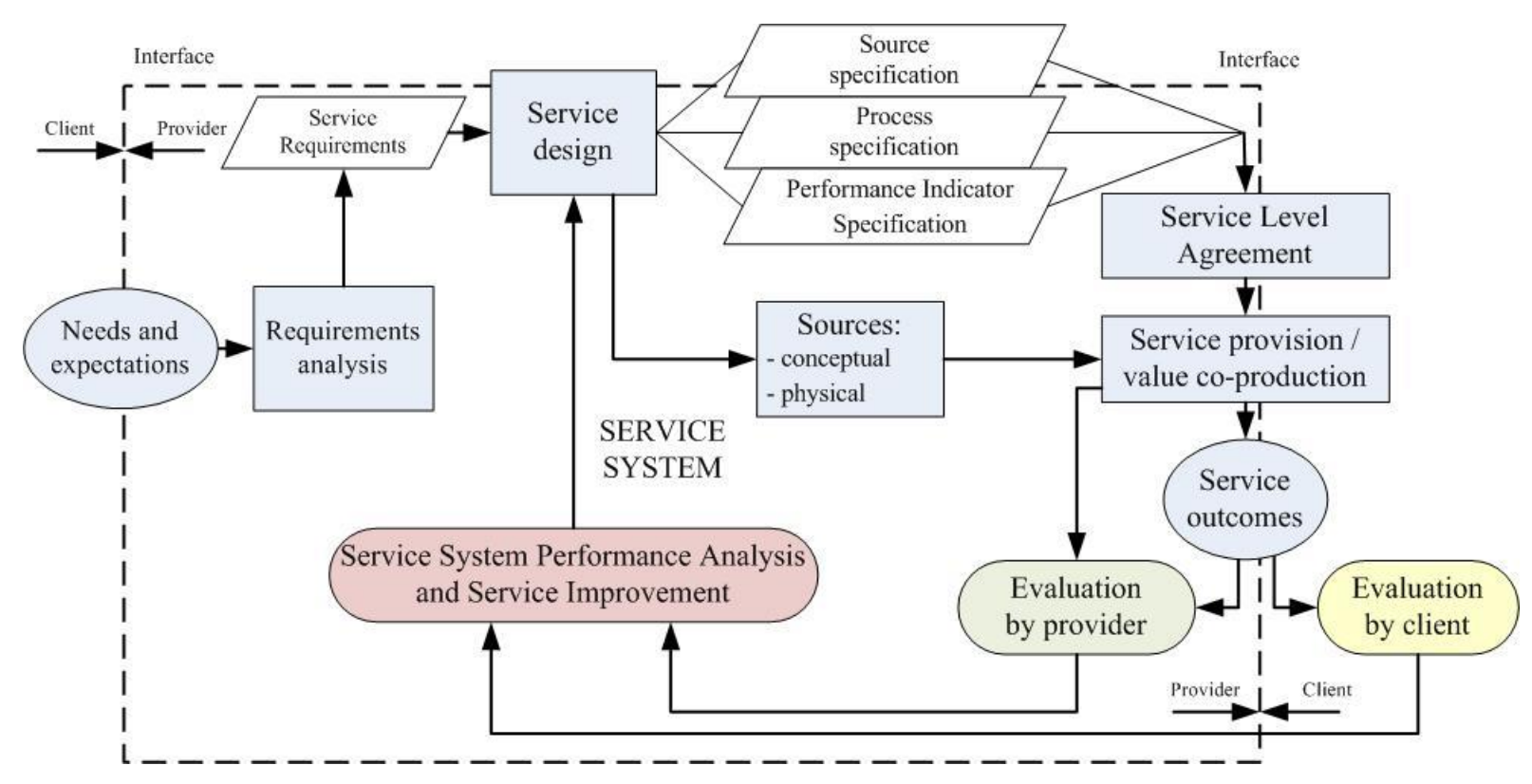

Figure 7 - Service System using SLA. Source: Own processing based on ISO 9004-2

The purpose of Service Level Agreement is to manage the interaction in the co-production of value creation and to minimise negative effects of accidents and problems. SLA therefore contains also the proposal and management of processes appropriate for coping and dealing with unplanned events by means of preparation of preventive activities. A typical example of participation in value co-creation using the SLA is when the client must make available information, workers, adapt access, equipment and resources needed by workers of the service provider for work on site of the service (at the client's). The system of measurement required for management through the SLA must cover all said aspects. Indicators for performance evaluation in the phase of service proposition but also implementation must be reflected in it in order to improve the service.

\subsection{Public service institution as a Service system}

Public service institutions have a double position in the service system. On one hand it represents the creator of legislative mechanisms affecting the interaction between the client (organization, citizen, community) and state, on the other hand it fulfils specific requirements reserved for state administration.

In the case of public service institutions, this represents the fulfilment of one of the main tasks the creation of optimal environment for the development of society (especially from the legislative point of view). That means that the interaction takes place between the public service institution and business environment. This interaction can be presented in a simplified manner as services provided by the public service institution to the business sector organization (its customer) by making available information to it and adjusting and integrating its sources similarly as it is done within the interaction by the business sector organization. Business sector organizations act as the cooperating system. Value is in this case prepared inside the public service organization (at the service provider), but it is delivered in interaction with the customer (business organization or business system, respectively) using the created environment and applying agreed rules. 
Public service institutions are typical organizations of the service provider. The emphasis on a knowledge-based strategy for the creation of value signifies the importance of people and competences of people in a service exchange. The system of performance management is in public service institutions traditionally focused on the area of financial results (effective consumption of resources) and less on institution strategies, processes and results in relation to interested parties (Bovaird, 2008).

\section{PERFORMANCE IN THE PUBLIC SERVICE INSTITUTION SYSTEM}

The role of the performance management is to manage competencies and sources effectively in order to achieve the highest possible benefit for participating parties. To express it more accurately, it means the task to maintain and improve the management system for effective achievement of objectives, respecting requirements of interested parties (Pulakos, 2004). The performance management must, in addition to evaluating outputs and results, include also indicators taking into account the availability and adequacy of competencies and sources as well as indicators taking into account the participation of interested parties in fast-changing environment (Emery, 2008).

There are 10 foundational premises of Service Dominant Logic (Vargo, Maglio, \& Akaka, 2008). The following three are most significant from the perspective of impact on the performance management:

- the customer is always a co-creator of value - performance parameters must be in the creation and utilization of the performance management system set especially for processes taking place in the interaction with the customer, as the value is created only within such interaction;

- the enterprise cannot deliver value, but only offer value propositions - correct proposition and making the service available is determining for the achievement of good performance;

- value is always uniquely and phenomenologically determined by the beneficiary - results of performance evaluation must be compared with results of customer satisfaction evaluation.

With reference to said premises, links of various intensity can be made between the service system and performance management system, which will point to the usability of the service system framework for the needs of performance management in public service institutions.

Extensive electronic survey concerning managers of public service institutions performed in 2013 contained also a section (22 questions) that enabled to examine chosen areas representing service system framework and performance management system components. Based on particular assignment of question pairs links between service system areas (lines) and performance management system components (columns) were created as shown in Table 1. Values of links (cells) were determined by the calculation of correlation coefficients of answer pairs with questions covering determined areas. Higher value of the correlation coefficient represents more significant link of that particular service system areas with the performance management components. Empty table cells represent links for which relevant opinion could not be obtained by survey.

Table 9 Links between areas of the Service Science framework and components of the performance management system. Source: Own processing 


\begin{tabular}{|l|c|c|c|c|c|c|}
\cline { 2 - 7 } \multicolumn{1}{c|}{} & $\begin{array}{c}\text { Institutional } \\
\text { strategies }\end{array}$ & $\begin{array}{c}\text { Institutional } \\
\text { processes }\end{array}$ & $\begin{array}{c}\text { Institutional } \\
\text { people results }\end{array}$ & $\begin{array}{c}\text { Institutional } \\
\text { culture results }\end{array}$ & $\begin{array}{c}\text { Institutional } \\
\text { results (outputs } \\
\text { and outcomes) }\end{array}$ & $\begin{array}{c}\text { Financial } \\
\text { (efficiency) } \\
\text { results }\end{array}$ \\
\hline Resources & 0,482 & 0,662 & & & 0,504 & 0,806 \\
\hline Access Rights & 0,721 & & 0,680 & 0,594 & & \\
\hline Entities & 0,503 & & 0,605 & 0,356 & & 0,633 \\
\hline Outcomes & & 0,600 & 0,711 & 0,557 & 0,845 & 0,712 \\
\hline Stakeholder & 0,747 & & & & 0,582 & \\
\hline Interaction & & 0,598 & 0,519 & 0,623 & & 0,617 \\
\hline Networks & & & & 0,541 & 0,571 & \\
\hline Ecology & 0,594 & 0,556 & & & & \\
\hline
\end{tabular}

Results show that the following areas of the service system have potentially the largest impact on the performance management setting:

- outcomes / institutional results,

- resources / financial results,

- stakeholder / institutional strategies,

- access rights / institutional strategies,

- stakeholder / financial results.

Links mentioned above can be used also in further research of performance management in public service institutions by examining possibilities of more accurate focus and strengthening of the performance management system in the said areas. Measures can concern not only characteristics and determination of indicators, but also the method of their measurement and evaluation. Distinguishing between directly and indirectly measured performance indicators, individually or collectively determined performance results can serve as an example. Distinction is similarly made between the activity output, result of achieved output and effect perceived by relevant interested parties.

\section{CONCLUSIONS}

Service involves at least two entities, one applying competence and another integrating the applied competences with other resources and determining benefit. When talking about performance management in public services from organizational perspective it is always referred to as factors considering not only quality requirements, but especially value creation. It is because factors which are not strictly defined and not clearly described in requirements are those factors from the service coproduction.

Service dominant logic is from the perspective of value driver oriented to value-in-use. Public service institutions utilise also another value driver, namely the value-in-context. This driver creates new perspective, which must be taken in account in setting and using the performance management system in the public service institution. Such system must include also the monitoring of making sources and competencies of the public service institution available and adjusting and integrating them with the aim to co-create the value with the customer.

Service Science represents an innovative element also for the performance management system, especially for the area of public service institutions, as it focuses on often neglected area creation of value in co-production. Examination of possibilities of better focus of the 
performance management system also on the value creation with respecting the Service Science framework draw the attention to areas where it is necessary to verify the sufficiency of setting and measurement of performance indicators. It is possible during the evaluation of results of performance measurements to return to areas identified as the strongest links between the Service Science framework and respective indicator and to search for improvement potential in the said area.

\section{References}

Bovaird, T. L. (2008). Evaluating the quality of public governance: Indicators, models and methodologies. International Review of Administrative Sciences, 69(3), 313-328. https://doi.org/10.1177/0020852303693002

Bryson, J. M. (2014). Public value governance: Moving beyond traditional public administration and the new public management. Public Administration Review, 74(4). https://doi.org/10.1111/puar.12238

Emery, Y. W. (2008). Swiss public servants' perceptions of performance in a fast-changing environment. International Review of Administrative Sciences, 74(2), 307-323 https://doi.org/10.1177/0020852308089906

Fugate, B. S., Stank, T. P., \& Mentzer, J. T. (September 2009). Linking improved knowledge management to operational and organizational performance. Journal of Operations Management, 27(3), 247-264. https://doi.org/10.1016/j.jom.2008.09.003

Katzan, H. (2008). Foundations of Services science concepts and facilities. Journal of Service Science 1(1), s. 1-22.

Lyons, K., \& Tracy, S. (2012). Characterizing Organizations as Service Systems. Human FActors and Ergonomics in Manufacturing \& Service Industries, 1(9), 1-9.

Maglio, P., \& Spohrer, J. (2008). Fundamentals of Service Science. Journal of Academic Marketing Science, 18-20. https://doi.org/10.1007/s11747-007-0058-9

Vargo S., M. P. (2008). On value and value co-creation: A service systems and logic perspective. European Management Journal, 145-152. https://doi.org/10.1016/j.emj.2008.04.003

\section{Contact information}

Zuzana Fabianová

University of Žilina, Faculty of Management Science and Informatics

Univerzitná 8215/1, 01026 Žilina

+421415134100

zuzana.fabianova@unicoas.sk

orcid.org/0000-0002-4985-0415

DOI: https://www.doi.org/10.7441/dokbat.2016.13 


\title{
AGENT-PRINCIPAL PROBLEM, STEWARDSHIP THEORY AND BEHAVIOURAL AGENCY MODEL IN THE EXPLANATION OF FAMILY BUSINESS PERFORMANCE
}

\author{
Gergely Farkas
}

\begin{abstract}
The paper examines, that there are inconsistent results about family business financial performance. Less agency cost is a plausible explanation when family businesses perform better than non-family businesses. Nonetheless minimizing agency cost through trust and strong social and emotional bonds in the family can lead to lower financial performance in several cases, because control is less strong. This way self-interested goals of family members lead to less good performance of the whole business. So less agency cost is not enough to make a general explanation. In stewardship theory the manager is not self-interested, but a long term oriented altruist. Based on strong social and emotional bonds the manager wants to follow financial and non-financial goals according to the needs of the family. Therefore, in the frame of stewardship theory performance can be lower in several cases, because resources are used up for nonfinancial goals. Both agency and stewardship theory says managers avoid risks for short or long term goals. In behavioural agency model family business managers is not seen as risk avoiders. Instead they avoid loss even if it means riskier decisions. They preserve the socioemotional wealth of the family, what is the most important capital for them. Family businesses in benign environment can follow long term non-financial goals. However, the manager is able to act as a homo economicus in a hostile environment, when socioemotional wealth is endangered. Behavioural agency model can explain why family business performance measures are inconsistent. In different circumstances family businesses risk tolerance is not static, socioemotional wealth is used as a reference point. So behavioural agency model can predict when will act a family business manager as an agent and raise financial performance to avoid loss. And it can tell us when is the time to follow family goals and let the usually short time oriented financial numbers be less impressive.
\end{abstract}

Keywords: agency, stewardship theory, family business, firm performance

\section{INTRODUCTION}

The goal of this paper is to review the literature of different management behaviour models in family firms. It is important to study how deeply changed the viewpoint of family business management during the decades. Agency and stewardship theories are like opposites of each other. Managers follow only short term goals in the one, and only long term goals in the other. Behavioural agency model is a new theory from the last decade to explain this controversion. With the methods of behaviural economics it can predict the results of decision better than prevous theories.

The literature review is not based on a strict methodology, but it focuses on the managerial behaviour effect on the firm performance. I use the family business and performance as it is in the literature: without a proper definition. Family business is a firm with the major ownership in 
the hands of a family, or at least under the strategic control of a family. Based on my research expereience even for entrepreneurs it is hard to decide if they are a family business or not. Sometimes they denies, but the managers accepts a successor from the family only. In other cases managers say they have a family business because it is so familiar, despite not a single relatives works there. Even the literature sees my first example as a family business and the second as a non-family business, it is hard to make this black and white. How many generations far cousins can be founders of a family business? Performance is mostly based on financial measures what makes the results single sided, and the indicators are many and various in different studies. Therefore evidence is often controversial, and definitions vary widely. It would not be a good idea to decide just about number of pro or contra results.

This paper is a preliminary study for a research what me and my collegaues do with qualitative method about family businesses. Our plan is to use it for describing different behaviours based on different theories appearing in the interviews with family business owners, managers and employees. For the readers it is an interesting summary of the above mentioned three concepts and a great journey through different viewpoints of the family business management.

\section{AGENT-PRINCIPAL PROBLEM}

In agent-principal problem two (or more) actor share the risk of decisions, but the attitudes of the actors toward risk can be different. The principal delegates a task for an agent, who does that on behalf of him. But it is not sure that the agent works in behalf of the principal. The connection of the actors is described as a contract. This cooperation is problematic because of two things. Firstly, the goals of the actors can be different because they perceive the risks differently, therefore the preferences of them are not the same. Secondly the price of the controlling is high, or difficult to accomplish for the principal. In the contract the behaviour or the output is the dominant part, what is influenced by the market uncertainty. In the case of lower uncertainty, the output based measurement is preferred. (Eisenhardt, 1989)

The study of agent-principal problem roots in the 1960s, when after the spread of nuclear power plants the people waited for a clean and unlimited energy source, but they realized the risk of catastrophes and the long time environmental pollution. The risk attitude of the people was different from the attitude of science about nuclear power. According to Starr (1969) the people are willing to take a thousand time more risk if they think it is their decision (like driving a car, or starting a new firm), than when the environment forces the choice on them (like nuclear power, or taxation).

Ross (1973) created the mathematical model of the agent-principal problem. Later Jensen and Meckling (1976) introduced the concept of agency cost, what includes the paiments of the agent and the price of the controlling. Even in our days it is an important question, that how can we mesaure this cost, and what kind of effects has an influence on it. In early explanations the information assymetry was in the focus, but it was obvious that personality and attitude are important things with big influence on risk avoidance or risk seeking. In the case of risk handling the personal recreancy is more important than ideological and sociodemographic variables combined according to Freudenburg (1993).

We can think that family firms are risk avoiders. They risk the family wealth, their livelihood, therefore they avoid the risky decisions. But in the same time they are risk seekers, because usually they investment is not diversificated, they have capital in one firm only (Beatty \& Zajac, 
1994). They follow a conservative strategy because they are interested to keep a constant welfare for the family, what requires to avoid risk until the status quo is safe (Bertrand \& Schoar, 2006). The meta-analysis of Hiebl (2012) showed that the risk behaviour of family businesses can be influenced by several not yet studied factros and based on the results so far it is not confirmable that family firms are more risk avoiders than non-family firms. However, Hiebl (2012) notes, that family businesses spend more on insurance, what can be a rational choice because the less diversification (Beatty \& Zajac, 1994), and the pursuit of long time persistence (Miller et al., 2008).

The information assymetry has a big influence in the cases where less controll is possible, like in radical R\&D investments. According to Gomez-Mejia et al. (2003) the compensation of family business manager is lower in case of $R \& D$ investments, because the less assymetry in information. The stronger bonds between family members can ensure better information distribution. Bartholomeusz and Tanewski (2006) also states, that because the well being of the family and the firm are in strong connection, therefore minimizing agency cost in the firm is in the interest of the family because this way they maximize the profit of the whole family.

Other factors can have a strong influence on agency cost also, what is appears in business performance. The performance of family business can increase or decrease because the agency cost (Christman et al., 2004). The direction depends mostly on the good or bad relationship of family members, and the size of the firm. Agency cost appears after different, more distinct roles needed in bigger families and in bigger firms (Karra et al. 2006).

If the agent and the principal is the same person then agency cost can be lower in the family business. Even in this case the agent-principal problem can appear between family members. Though the costs are lower because the high trust and common values. Agency cost declines also when the family members pursuit non-financial goals. For example the knowledge transfer for the next generation, when there is less control over the selection of successor than in non-family businesses. Another example when the family employes a non-productive relative to ensure his livelihood. In this later case control is more relaxed, because the agent is not productive enough to produce more value than his cost. For such cases the agency cost is lower, but the firm performance also decrease. (Christman et al., 2004)

In the case of family conflict the agency cost raises rapidly, because firing a relative is rearly an option. If goals and values are different, than family members compete for strategic control. Different interests appear often if family members connects to the firm in different ways (Dyer, 2006). According to Gomez-Mejia et al. (2001) the business performance gets better in such cases, if family member managers replaced by professional outsiders.

Agency cost also increase when family members do altruistic behaviour. In this paper I use altruism as helping someone for who he/she is, and not because of his behaviour. Altruism lowers effetciveness of control as stated by Greenwood (2003). Family members can trust in altruistic leader behaviour even if they act other way than the superior expects. Therefore the efficiency of the managment decreases. Problems of altruism are avoidable with some management hierarcy inside the family (Schultze et al., 2003). If the roles and processes are well definied than altruism is less needed, but the agency cost incrases in the same time because of the more control. Stowaways can appear without these, and detecting them can be problematic because of the subjective perception of each other within the family. 
Agency cost is usually very low or does not measurable during the first generation of the family business. More and more actor appears with the growing of the nuclear family and the firm, what brings in the agent-principal problem. This increases further when nepotism is the base of the succession. If the successor is less suitable for the managment role, than the value of the firm decreases. This declination can be also defined as an agency cost (Herrero, 2011). Family businesses tend to keep management in family hands to keep agency cost low even the successor selection is not ideal because of the nepotism (Lubatkin et. al., 2007), or the founder gets so old that his or her waning management performace influene the firm in a negative way (Shleifer \& Vishny, 1989). This is the so called entrenchment phneomenon, what promises more loss of profit than the ammount saved by lower agency cost (Herrero, 2011).

\section{STEWARDSHIP THEORY}

Stewardship theory stands for the above mentioned behaviour patterns. Contrary the viewpoint of the agent-principal problem, where the agent seeks his/her interest like a homo economicus, in stewardship theory the manager has long term goals and sustainable development is important. The goal of the agent is "to do a good job, to be a good steward of the corporate assets" (Donaldson \& Davis, 1991, pp. 51). Strong connections between actors is necessary, and they should relate to the same social network. These criteria are usually given in the case of family businesses (Christman et al., 2004).

Donaldson and Davis (1991) emphasize that it is important to give something motivating for the long term for the manager if the manager and the owner cannot be the same person. It is not defined what this long term package can be. It can be a bonus, a target bonus, a share, or something else. In the case of family businesses, the stakeholders do not connect with a formal, written contract to the firm. The head of the family does not promise a better Christmas gift if the firm performs well. However, the members will be loyal to organizational goals, because family wellbeing and honour depends on the firm, (Breton-Miller \& Miller, 2009).

Entrepreneurship for the leader is a tool for achieving personal and professional goals. It is peculiarly true for family businesses, where more family members can pursue these goals (Gomez-Mejía et al., 2007). Family business membership has a value, at least a distinctive value in the local community, what also strengthen loyalty (Sirmon \& Hitt, 2003). Succession also enhance the long term goals, because in the process not just knowledge and power is transfered, but the manager wants to deliver the firm assets in the best possible state for the successor (James, 1999).

Miller et al. (2008) describe the scientific knowledge about stewardship in family business as a perspective of the organization. They delineate three common forms of stewardship. First is continuity, what ensures the long term survival of the family business for the benefit of the later generations. Second is the organizational culture, what motivates and makes employees a loyal community. Third is the strong connections with outside stakeholders, especially with the customers, because these connections can help to pull through a financial crisis.

Three behaviours connect to the continuity aspect (Miller et al. 2008). First is the long term thinking, what takes in account the interest of the next generation. The less growth orientation, more conservative investment strategy can be the effect of this, meanwhile the family businesses spend more on $\mathrm{R} \& \mathrm{D}$, and innovation processes. This is because they know these help the long term survival of the firm and they are less shackled by short term financial indicators. Second 
behaviour is related to the reputation in the market, what also helps the long term stability, because better reputation causes more customer loyalty and helps to keep up the market share. Family businesses give more factual, valid information about they products or services to maintain the reputation of the family. Third behaviour is the building of the market share what also helps to "solidify the business for the future (Miller et al. 2008, pp. 54.).

The community is the second aspect. Most firms try to build a strong organizational culture because a motivated and loyal employee community is good for business, but Miller et al. (2008) emphasize the importance of it in family businesses. Studies what they cite state that these firms organize more training with extensive topics and to make sure that management and employees can cope with the uncertain future problems. Employees has a wider responsibility and role than in the case of non-family businesses. They are flexible in help to find the right employee for the right position, or to create informal communication networks in the firm. They are also tolerant with the work schedule problems and work from home. They accept women in management more easily than non-family firms. This behaviour is also interesting from the viewpoint of social transaction theory, because the manager can be a model for prosocial behaviour (Pearson \& Maler, 2010). The reciprocity based on the following of the model behaviour can lead to a stewardship culture in the organization.

The third aspect is focusing on the outside stakeholders, mainly on customers. Family businesses tend to extend the relationship with the customers. It does not happen just in the time of transactions, and they exchange information not related to the transactions. Because of long term goals they want long lasting relationships too. Miller et al. (2008) mentions many things about this behaviour what is typical of family businesses. The managers of the firm meet the customers more often. This increase trust, what lowers transactional costs. Of course this works only if the manager has some marketing skills. The firm can satisfy personal needs, and alter the offers for these customers. Convenience store is a good example for this: the room is small for a big supply, but based on local customer needs the shop can make an ideal mix of price and quality. This makes loyal customers because they find what they really need close to their home.

Result of stewardship is the collective utility instead of the fulfilling of personal needs (Welsh et al. 2013). While agent-principal problem is less frequent in family business, stewardship is not only a possibility, but it is almost inevitable because the strong social bonds and common values. The perceived stewardship can be different in the case of non-family employees. According to the research of Davis et al. (2010) the family and non-family employees have similarly high loyalty where stewardship exist, but the difference in the favour of family employees is still statistically significant. Non-family employees usually know that a family business manager will prefer relatives even if stewardship culture is strong in the firm.

Stewardship decline and agent-principal problems appear, if strong emotional bonds loosen and values get more and more different. This can happen because of a family conflict, or the generational expansion. There is evidence for the later in the transgenerational study of BretonMiller and Miller (2009). Dodd and Dyck (2015) uses an unusual qualitative method for creating new theory. They analysed ancient texts to develop new ideas for family business research. They define a business type where stewardship exists, but there are no relatives in the business. This is the universal-family business where stewardship is only based on kinship, but not on family relations. 


\section{BEHAVIOURAL AGENCY MODEL}

Agent-principal problem and stewardship theory have limitations when scientists try to verify them. Meta-analysis of Tosi et al. (2000) did not find a significant correlation between the salary of CEOs and the firm performance, however it should be some if agent-principal problem is not just a theory. The level of risk perception is constant in every actor according to the above mentioned theories, while they do not pay much attention for risk seeking behaviours (Kumeto, 2015). Therefore, the behaviour of the actors is rigid in these theories.

Behavioural agency model is based on the results of decision theory. It uses the conclusions of the experiments about the expectations theory to point on the utility of the substitution risk avoidance with loss avoidance. In that case the main goal of the manager is not to maximize the profit in the future, but to keep the existing level of wealth (Wiseman \& Gomez-Mejia, 1998). It can lead to a risky behaviour to minimize possible losses in an uncertain situation.

Instead of the constant risk attitudes, the behavioural agency model emphasizes the importance of the framing effect (Tversky \& Kahneman, 1986), what states that different varriables have impact on the decision of the agent. Someties the win, sometimes the loss is more important. In the contract of the agent and the principal there is a greater role of intrinsic and extrinsic motivations according to Pepper and Gore (2015), than the effect of efficiency and profit maximalization. We should note that in general the behavioural agency model has more theory in it, than evidence is available (Pepper \& Gore, 2015). Nonetheless it is popular in the field of family business research because of the works of Gomez-Mejia et al. (2007, 2014), who explain the behaviour related to the socioemotional wealth with this model.

Family businesses are interested in preserving their socioemotional wealth, what is not measurable in money, but it includes all the benefits of the social and emotioanl connections in the family business. This can appear in three different way in the behaviour. With keeping the ownership and control in the hand of the family, with nepotism, and with building of the reputation of the family. While building reputation has usually positive consecvences, meanwhile the napotism can be the source of many problems (Naldi et al. 2013). According to this family firm managers do not decide about how to increase efficiency, but to avoid loss of socioemotional wealth in any situation. This makes this type of wealth a primal referencer point (Naldi et al., 2013).

Socioemotional wealth is connected to the business and to the family, and family members cannot hide from it. Berrone, Cruz \& Gomez-Mejia 2012 states that this is the core of the difference between family and non-family firms, because this type of strong connection between family and work life can only exist in family firms. They summarized many empirical study in their paper where the sociemotional wealth level as a reference point influences the decesions in family business. They also notes the situation when firm perfomance anticipate the end of business with a bankruptcy. That time the aspiration level of socioemotional wealth can change to pursue financial goals of the firm for a short time and survive. Chrisman and Patel (2012) found evidence about that in crisis the family businesses spend more on $R \& D$, to ensure long time survival.

Behavioural agency model is useful to explain such idiosyncratic concepts of the field. Familiness describes a unique set of resources of the business and the family and can be the source of competitive advantage (Habbershon \& Williams, 1999). If we know the process it worth to measure the variables. What makes a family business unique and how much. Berrone et 
al. (2012) suggested five factors of socioemotional wealth. First is family control and influence, what can be direct or indirect. Second is the family members' identification with the firm. This causes that the firm works as an extension of the family in the eyes of outsiders. Third is the binding social ties, what also connects to outsider stakeholders. Fourth is the emotional attachment what is a topic without enough research data so far according to Berrone et al. (2012). The emotional life of the family has an influence on business, but we know little about how it works. Finally, the fifth factor can be the renewal of family bonds to the firm through dynastic succession. Zellweger et al. (2012) also describe this as important thing for the family firms. They tend to keep financial and knowledge capital both inside the family during succession.

Naldi et al. (2013) studied the relationship of the protection of the socioemotional wealth and the firm performance. In their results the business environment has a great impact on the effect of such behaviour. It can increase or decrease firm performance under different circumstances. This needs further research because they studied only a limited number of environmental variables.

It is worth to mention here the research of Gomez-Mejia et al. (2014) too, who became to the same conclusion in the case of high-tech family firms. This is interesting because R\&D is very important in this industry. Family businesses however invested less in it unless they expected a loss in their socioemotional wealth. In that case they spent more than non-family businesses. This also proves that risk attitude is not constant and impact on financial firm performance can be various. How this works exactly is still an open question for the future. Profund research needed to describe the connections between the variables. It would be necessary to measure changes in financial assets and socioemotional wealth in the same time. This can be a fruitful research area in the next years.

\section{DISCUSSION}

Agent-principal problem was an important construct for the description of the transactions and the contract between the owner and the manager. In contrary of this construct, the stewardship theory argues, that prosocial behaviours can appear in these connections, moreover it can be beneficial for the actors. It requires some factors what are more frequent in family businesses. But it is not required to choose either the always self-interested, either the always altruistic leader behaviour with the help of behavioural economics. Behavioural agency model can take into consideration the environmental variables and the inner bonds too. It can explain why managers sometimes self-interested, and sometimes altruistic. This model found a fertile ground in the field of family business research, because it clarifies behavioural explanations related to so far idiosyncratic constructs like the familiness or the transgenerational wealth. It is a work for the future to study further the mechanism of this model and to specify the possibilities of measurement. Socioemotional wealth can be a possibility to involve non-financial goals in performance studies in a measurable way.

\section{References}

Bartholomeusz, S., \& Tanewski, G. A. (2006). The relationship between family firms and corporate governance. Journal of small business management, 44(2), 245-267. https://doi.org/10.1111/j.1540-627X.2006.00166.x 
Beatty, R.P. \& Zajac, E.J. (1994). Managerial incentives, monitoring and risk bearing: A study of executive compensation, ownership, and board structure in initial public offerings, Administrative Science Quarterly, 39 (2), 313-335. https://doi.org/10.2307/2393238

Berrone, P., Cruz, C., \& Gomez-Mejia, L. R. (2012). Socioemotional wealth in family firms theoretical dimensions, assessment approaches, and agenda for future research. Family Business Review, 25 (3), 258-279. https://doi.org/10.1177/0894486511435355

Bertrand, M. \& A. Schoar. (2003). Managing with style: The effect of managers on firm policies, Quarterly Journal of Economics, 118 (4), $1169-1208$. https://doi.org/10.1162/003355303322552775

Breton-Miller, L., \& Miller, D. (2009). Agency vs. stewardship in public family firms: A social embeddedness reconciliation. Entrepreneurship Theory and Practice, 33(6), 1169-1191. https://doi.org/10.1111/j.1540-6520.2009.00339.x

Chrisman, J. J., J. H. Chua \& R. A. Litz (2004). Comparing the Agency Costs of Family and Non-Family Firms: Conceptual Issues and Exploratory Evidence. Entrepreneurship Theory and Practice, 28 (4): 335-354 https://doi.org/10.1111/j.1540-6520.2004.00049.x

Chrisman, J. J., \& Patel, P. C. (2012). Variations in R\&D investments of family and nonfamily firms: Behavioral agency and myopic loss aversion perspectives. Academy of management Journal, 55 (4), 976-997. https://doi.org/10.5465/amj.2011.0211

Davis, J. H., Allen, M. R., \& Hayes, H. D. (2010). Is blood thicker than water? A study of stewardship perceptions in family business. Entrepreneurship Theory and Practice, 34 (6), 1093-1116. https://doi.org/10.1111/j.1540-6520.2010.00415.x

Dodd, S. D., \& Dyck, B. (2015). Agency, Stewardship, and the Universal-Family Firm A Qualitative Historical Analysis. Family Business Review, 28 (4), 312-331. https://doi.org/10.1177/0894486515600860

Donaldson, L. \& J.H. Davis. (1991). Stewardship theory or agency theory, Australian Journal of Management 16 (1), 49-64. https://doi.org/10.1177/031289629101600103

Dyer, W. G. Jr. (2006). Examining the "Family Effect" on Firm Performance. Family Business Review, 19 (4): 253-273. https://doi.org/10.1111/j.1741-6248.2006.00074.x

Eisenhardt, K. M. (1989). Agency Theory: An Assessment and Review. The Academy of Management Review, 14 (1), 57-74.

Freudenburg, W. R. (1993). Risk and recreancy: Weber, the division of labor, and the rationality of risk perceptions. Social Forces, 71 (4), 909-932. https://doi.org/10.1093/sf/71.4.909

Greenwood, R. (2003). Commentary on: "Toward a theory of agency and altruism in family firms". Journal of Business Venturing, 18 (4), 491-494. https://doi.org/10.1016/S08839026(03)00056-9

Gomez-Mejia, L. R., Campbell, J. T., Martin, G., Hoskisson, R. E., Makri, M., \& Sirmon, D. G. (2014). Socioemotional wealth as a mixed gamble: Revisiting family firm R\&D investments with the behavioral agency model. Entrepreneurship Theory and Practice, 38 (6), 1351-1374.

Gomez-Mejia, L. R., Larraza-Kintana, M., \& Makri, M. (2003). The Determinants of Executive Compensation in Family-Controlled Public Corporations. The Academy of Management Journal, 46 (2), 226-237. https://doi.org/10.2307/30040616

Gomez-Mejia, L. R., M. Nuñez-Nickel \& I. Gutierrez (2001). The role of family ties in agency contracts. Academy of Management Journal, 44 (1), 81-95. https://doi.org/10.2307/3069338 
Gomez-Mejia, L.R., K. Takács Haynes, M. Nuñez-Nickel, K.J.L. Jacobson, and J. MoyanoFuentes. (2007), Socioemotional wealth and business risks in family-controlled firms: evidence from Spanish olive oil mills, Administrative Science Quarterly, 52 (1): 106-137. https://doi.org/10.2189/asqu.52.1.106

Habbershon, T. G., \& Williams, M. L. (1999). A resource-based framework for assessing the strategic advantages of family firms. Family Business Review, 12 (1), 1-25. https://doi.org/10.1111/j.1741-6248.1999.00001.x

Herrero, I. (2011). Agency costs, family ties, and firm efficiency. Journal of Management, 37 (3), 887-904. https://doi.org/10.1177/0149206310394866

Hiebl, M. R. (2012). Risk aversion in family firms: what do we really know?. The Journal of Risk Finance, 14 (1), 49-70. https://doi.org/10.1108/15265941311288103

James, H. S. (1999). Owner as manager, extended horizons and the family firm. International Journal of the Economics of Business, 6 (1), 41-55. https://doi.org/10.1080/13571519984304

Jensen, M. C., \& Meckling, W. H. (1976). Theory of the firm: Managerial behavior, agency costs and ownership structure. Journal of financial economics, 3 (4), 305-360. https://doi.org/10.1016/0304-405X(76)90026-X

Karra, N., P. Tracey \& N. Phillips (2006). Altruism and Agency in the Family Firm: Exploring the Role of Family, Kinship, and Ethnicity. Entrepreneurship Theory and Practice, 30 (6), 861-877. https://doi.org/10.1111/j.1540-6520.2006.00157.x

Kumeto, G. (2015) Behavioral Agency Theory and the Family Business. In: Nordqvist, M., Melin, L., Waldkirch, M., \& Kumeto, G. (Eds.). (2015). Theoretical Perspectives on Family Businesses. Edward Elgar Publishing.

Lubatkin, M.H., Y. Ling, \& W. Schulze. (2007). An organizational justice-based view of selfcontrol and agency costs in family firms, Journal of Management Studies. 44 (6), 955971. https://doi.org/10.1111/j.1467-6486.2006.00673.x

Miller, D., Breton-Miller, L., \& Scholnick, B. (2008). Stewardship vs. stagnation: An empirical comparison of small family and Non-Family businesses. Journal of Management Studies, 45 (1), 51-78.

Naldi, L., Cennamo, C., Corbetta, G., \& Gomez-Mejia, L. (2013). Preserving socioemotional wealth in family firms: Asset or liability? The moderating role of business context. Entrepreneurship Theory and Practice, 37 (6), 1341-1360. https://doi.org/10.1111/etap.12069

Pearson, A. W., \& Marler, L. E. (2010). A leadership perspective of reciprocal stewardship in family firms. Entrepreneurship Theory and Practice, 34 (6), 1117-1124. https://doi.org/10.1111/j.1540-6520.2010.00416.x

Pepper, A., \& Gore, J. (2015). Behavioral agency theory new foundations for theorizing about executive compensation. Journal of management, 41 (4), 1045-1068. https://doi.org/10.1177/0149206312461054

Ross, S. (1973). The economic theory of agency: The principal's problem. American Economic Review, 63 (2), 134-139.

Schulze, W. S., M. H. Lubatkin and R. N. Dino (2003). Toward a Theory of Agency and Altruism in Family Firms: Theory and Evidence. Journal of Business Venturing, 18 (4), 473-490. https://doi.org/10.1016/S0883-9026(03)00054-5 
Shleifer, A., \& Vishny, R. W. (1989). Management entrenchment: The case of manager-specific investments. Journal of financial economics, 25 (1), 123-139. https://doi.org/10.1016/0304-405X(89)90099-8

Sirmon, D. \& M. Hitt. (2003). Managing resources: Linking unique resource management and wealth creation in family firms, Entrepreneurship Theory and Practice, 27 (4), 339-358. https://doi.org/10.1111/1540-8520.t01-1-00013

Starr, C. (1969). Social Benefits versus Technological Risks. Science, 165 (3899), 1232-1238. https://doi.org/10.1126/science.165.3899.1232

Tosi, H. L., Werner, S., Katz, J. P., \& Gomez-Mejia, L. R. (2000). How much does performance matter? A meta-analysis of CEO pay studies. Journal of Management, 26 (2), 301-339. https://doi.org/10.1177/014920630002600207

Tversky, A., \& Kahneman, D. (1986). Rational choice and the framing of decisions. Journal of business, 59 (4) 251-278. https://doi.org/10.1086/296365

Welsh, D. H., Memili, E., Rosplock, K., Roure, J., \& Segurado, J. L. (2013). Perceptions of entrepreneurship across generations in family offices: A stewardship theory perspective. Journal of Family Business Strategy, 4 (3), 213-226. https://doi.org/10.1016/j.jfbs.2013.07.003

Wiseman, R. M., \& Gomez-Mejia, L. R. (1998). A behavioral agency model of managerial risk taking. Academy of management Review, 23 (1), 133-153.

Zellweger, T. M., Kellermanns, F. W., Chrisman, J. J., \& Chua, J. H. (2012). Family control and family firm valuation by family CEOs: The importance of intentions for transgenerational control. Organization Science, 23 (3), 851-868. https://doi.org/10.1287/orsc.1110.0665

\section{Contact information}

Gergely Farkas

University of Szeged, Faculty of Economics and Business Administration

Hungary, Szeged, Kálvária sgt. 1.

$+36702464647$

farkas.gergely@eco.u-szeged.hu

DOI: https://www.doi.org/10.7441/dokbat.2016.14 


\title{
HUMANS IN THE FOCUS FOR OUTSTANDING INNOVATION
}

\author{
Markus H. Gericke
}

\begin{abstract}
Innovation is regarded as being a process of recognition of current or future market needs and its conversion into products or services. In addition, process innovation is defined for internal or external change and redesign of workflows and societal behaviours. The efficiency of innovation is a conglomerate of organizational and leadership aspects, macro- and microeconomic backgrounds, technology access and more. The idea generation, the deployment and the development process is dependent on the corporate culture, management style but mainly of the employees in general.

The author has undertaken a market investigation to find out, which group of human resources in a company the main innovation impulses are generated from. The analysis discloses the fact, that a huge mass of unused potential can be awaked by a more active management, leadership and motivation of the existing sources! Potential for impulses for efficient innovation are many. Also the use of external knowledge and development resources offer the chance to reduce time to market and to get a higher degree of differentiation. Networking in a proactive and constructive result oriented way be a part or getting inspiration, ideas and solutions.

The successful path leads over the proper management of human resources, including shaping a mix of persons of various characters, selection of leaders, enabling and integrating more staff towards an active role in the innovation process and generous sponsorship by the top management. Enabling for performing and encouraging for heading to autonomous activity will lead to a leverage of individual contributions and the combination in a team and network to a higher output in quality or dimension.
\end{abstract}

Key words: Innovation efficiency, Idea finding, Corporate culture, Human resources, Leadership, Network

\section{WHICH ARE THE REAL INNOVATION DRIVERS?}

The global competition is increasing with high intensity. At the same time, the consumption stagnates; political conflicts disturb the growth of a sound industry.

Under such conditions, managing a profitable business, no matter how big or small it is, is a challenge. Creating products and services, that are demanded by the target market and achieving a differentiation to other suppliers increases the chances for scoring above average margins.

Under cost pressure and effects of globalisation, innovations must enable companies to offer in shorter cycles better products, customer focused and original services.

Combining ideas, skills, and knowledge to a product or service that is appreciated and purchased by the market, describes innovativeness that a company is looking for.

Various works that link panel survey datasets on the performance of enterprises and on the strategies that are implemented by these firms have demonstrated the significance of innovation to the growth and financial success of companies. Baldwin et al. (2002) demonstrate that in small 
and medium-size companies, a measure of success that is based on growth profitability and productivity is related strongly to the emphasis that firms place innovation. Baldwin explores further that there is evidence between success and innovation, but less evidence on the factors that condition whether a firm adopts an innovation policy.

Following factors play a key role in determining a successful product and service lifecycle and are therefore a condition of effective innovation:

- early recognition of market and technology trends, developments and changes;

- fast perception of customer needs and the capability to convert the often tacit wishes into solutions and products;

- to manage the development, design, construction and sales processes in time.

The driving elements for these factors are primarily found neither in technologies nor in strategies, but the capacity that is given by the companies' managers and employees! People are creative, recombine ideas, collect data and execute the development process, no matter if we speak about product innovation, process or service innovation.

Thus leadership, the corporate culture and knowledge management affect the innovation process.

"Today, most companies are complex systems in which individual staff members, managers, and "the" entrepreneur - as defined by the economist Joseph Schumpeter - as well, cannot cope with their duties by themselves if they don't work together as a team, based on a shared vision and a common view of the interdependencies in the company and in the market." (Management von Innovation und Wachstum, 1997).

A particular advantage of many $\mathrm{SME}^{1}$ can be that the "management" is substituted by leadership and this can be connected to the entrepreneur's passion. Such a particular situation inspires and encourages other employees and team members.

We should therefore look closer to the mix, selection and leading of the human resources.

A field survey should answer the question from which group of people in an enterprise main activities and impulses for innovation can be identified. Are these just team members of the $\mathrm{R} \& \mathrm{D}^{2}$ group, their managers or mainly the top management? The holistic management approach claims that as much employees as possible should participate in the innovation live.

Innovation is a process, not a single phase. In general starting with incubation, followed by the development and market introduction phases. Sources for innovation are required through all phases, not only in the incubation phase. Employees that are recognizing the fact that they can contribute to process or product innovation, independent on their function will be of great value.

\section{WHICH GROUP OF EMPLOYEES CONTRIBUTE TO THE INNOVATION?}

For the research the focus was set on small and medium size companies as they are confronted with a number of specific challenges as the limited access to technology, financial constraints, limitations in the available research capacity and in many cases the distraction by the daily business.

\footnotetext{
${ }^{1}$ SME: small and medium size companies
}

${ }^{2}$ R\&D: research and development 
The market survey was done with interviews and by questionnaires. The interrogation was established with the aim to get a view about the current innovation management of companies

Totally 44 companies have been interrogated. They follow an industrial activity and are SME.

Many additional discussions could be held with entrepreneurs as unstructured, open interviews to get an insight into their management of innovations.

Part 1 of the field research was examining the source of innovation ideas. This question is relevant regarding the broadness of technological input, the corporate culture and the integration of different knowledge bases into the development of the company. It offers us also an insight about the management of innovation.

Part 2 of the interrogation was focusing on the employees and their sensitivity for new ideas, their capability to be creative and also their attitude towards a self driven search for improvements. To what degree companies use creativity methods is therefore another cluster of questions. The answers give us an indication about creativity as describe above, the degree of organization of knowledge management, problem solving and research as well as its structure and systematic follow up in the companies.

\section{RESULTS OF THE FIELD STUDY}

\subsection{What are the sources of your innovation initiatives?}

The question to the sources of innovation initiatives was able to deliver many information and conclusions about the structure, organization, and culture of companies towards continuous change, spirit for new products and services.

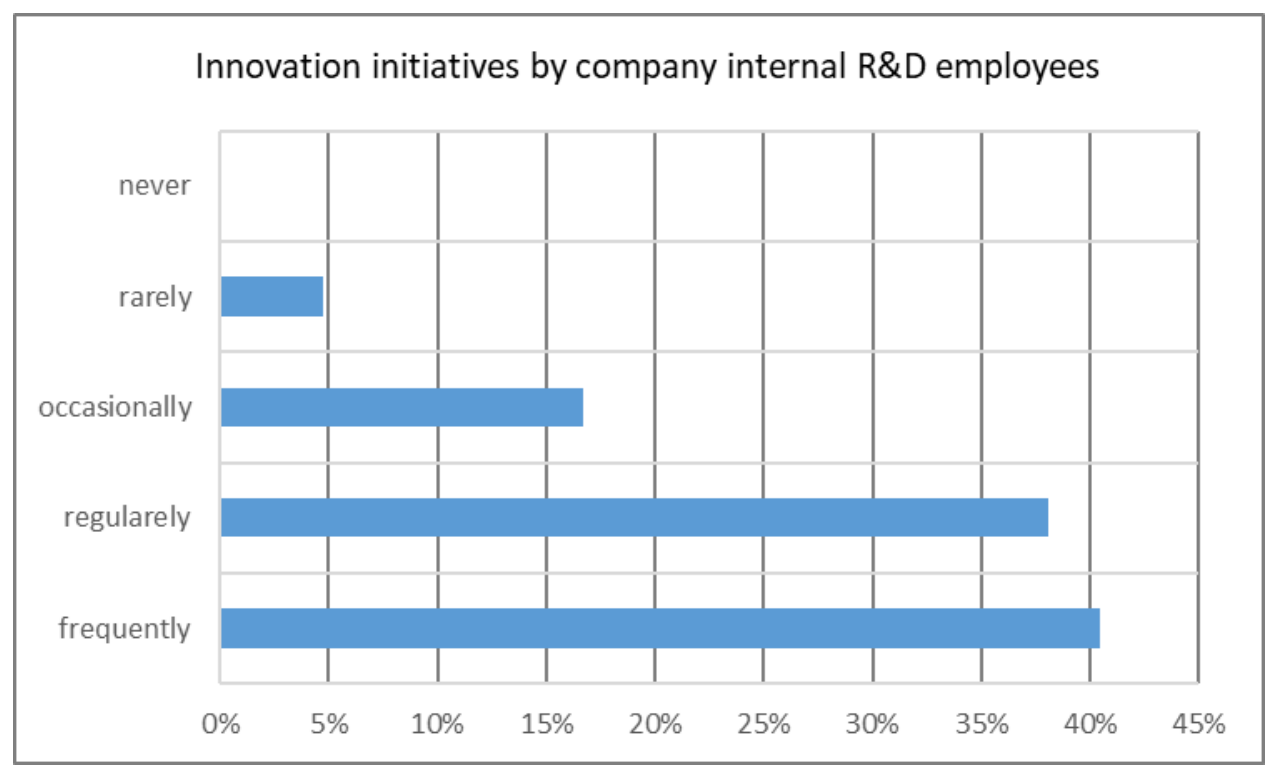

Figure 1 - Company internal R\&D as a source for innovation initiatives

The company internal resources are a base for developing ideas around new products in most of the companies. From discussions with managers R\&D engineers are mainly involved in the conversion of ideas into products and less in large milestone developments or changes. 
Hamamura from Grant Thornton puts it like this: „Products have an extremely short lifecycle, so incremental innovation is always critical" (Hiroyuki, 2009). A better communication of strategic tasks of the company by the managers to the engineers could widen their horizon and use their knowledge for strategic invention as well.

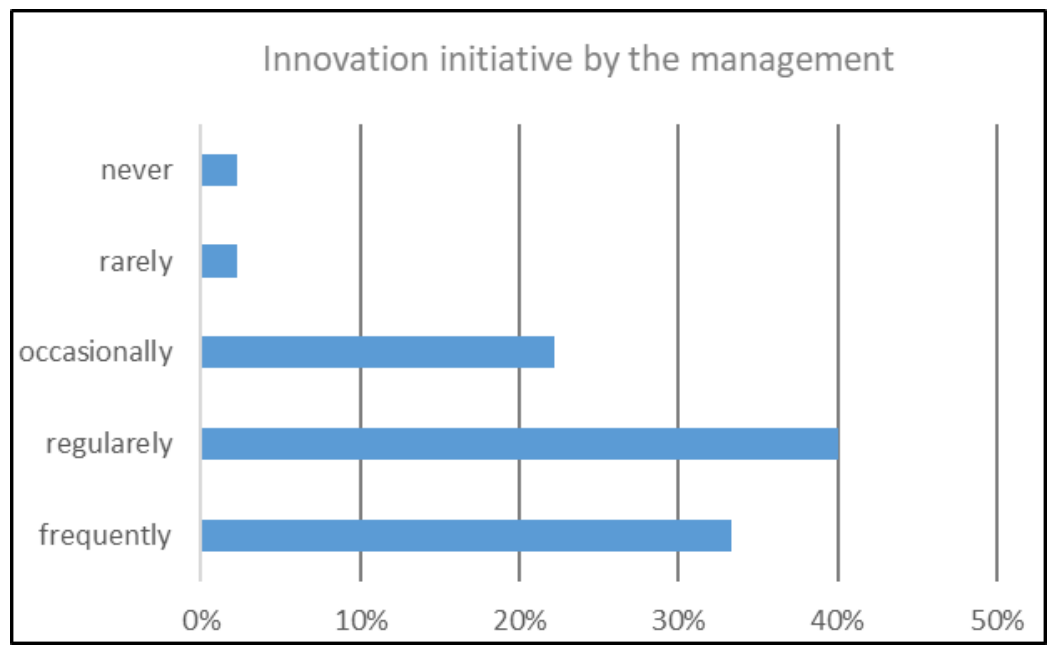

Figure 2 - Management as a source for innovation initiatives

The management is typically in SME the driving force for creative inventions. The hypothesis is that they are close to the market demand and are at the same time responsible for the evolution of a company. Managers are sensitive for the competition and have their strategic planning in their mind.

As Swiss market study made by Credit Suisse AG shows regional differences in this respect. In the French speaking part of Switzerland managers count for more idea contribution whereas in the German part a bigger portion of employees is participating directly in the creativity and innovation process (Brändle, et al., 2011)

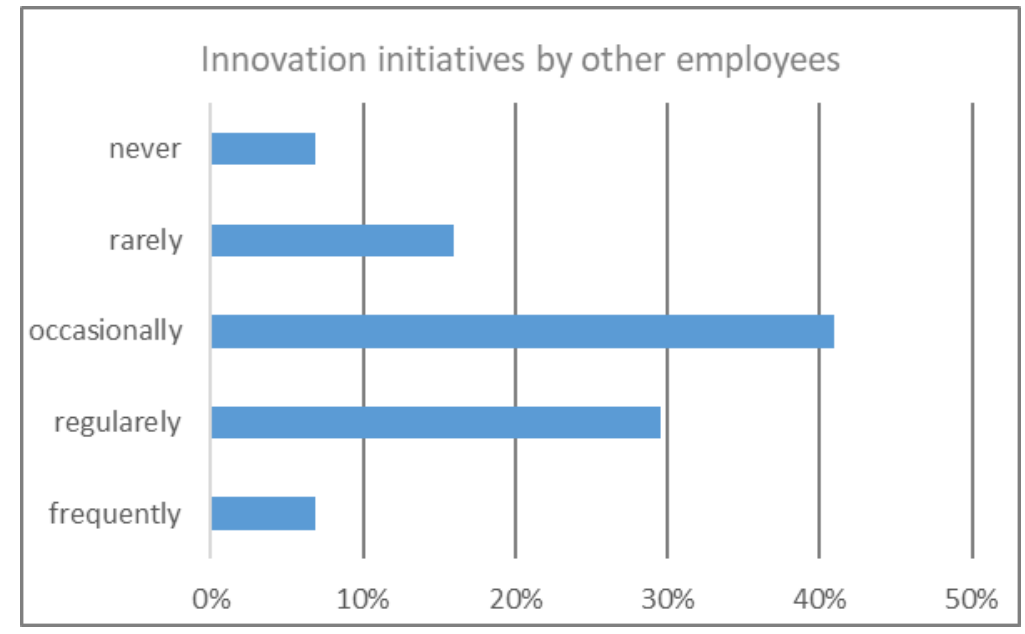

Figure - Management as a source for innovation initiatives

The result of this question is somehow sobering. It means that in general, the knowhow of the employees, this is the big part of the human resources are not included into the product lifecycle 
and innovation process or they are not interested. Entrepreneurs have to lead more by example! They need to provide their employees with tools and measures, to create the understanding for the need of innovation, to encourage for participation and change!

Some creativity techniques could be helpful, but contribute only when they are used by conviction:

- communication of the innovation strategy

- team meetings

- creativity techniques

- teaching or moderation in project management

The historical background of a region or country influences the type of companies present. Was the past industrialized and the companies autonom and independent or was the region used for remote manufacturing without "product or process or marketing intelligence" just for the sake of cheap sourcing. The result let us come to the assumption, that typically eastern European countries offered interesting opportunities for manufacturing due to the lower salary level In general the headquarters of such companies are located in another countries and such also the R\&D division. This is also reflected in the European Scoreboard (EU, 2009).

This finding is of highest significance for such economies as they are preferred manufacturing places but only as long as not cheaper alternatives are available.

Has an economy an interest to establish and host companies with key management functions located in that zone, it needs more. Optimal would be to grow up an entrepreneurial spirit in the local population, that leads to new companies founded and managed locally. The entire society is challenged by such a project. It needs a good education level, the motivation of the citizens to venture and start-up companies, a low level of regulations and a liberal labour market. Finally the funding of start-up companies need to be facilitated. The fact that industry is getting less bound to a specific location due to heavy capital investments and are focussing on service and software the opportunity to enter into a specific market increases for Regions that are interested to create jobs and take part in the economic development. The market needn't to be in front of the door. Networking plays exactly for such type of industries a crucial role. Crossborder sharing of knowledge is easier and opens the access to it to everybody. It is an advantage if a cluster for a specific application can be generated as the pool of available human resources gets better. This is of essence for the successful development.

\subsection{How to manage the sensitivity of employees for innovation and creativity?}

As a significant part of skills, experience and know how is hold by the employees of a company, a way for efficient invention and creativity lies in the use and conversion of these intangible assets. It makes a company strong, stays for entrepreneurial culture, spirit and activity. By such, the part 2 of the field research was investigating on how to manage sensitivity of employees for innovation and creativity. 


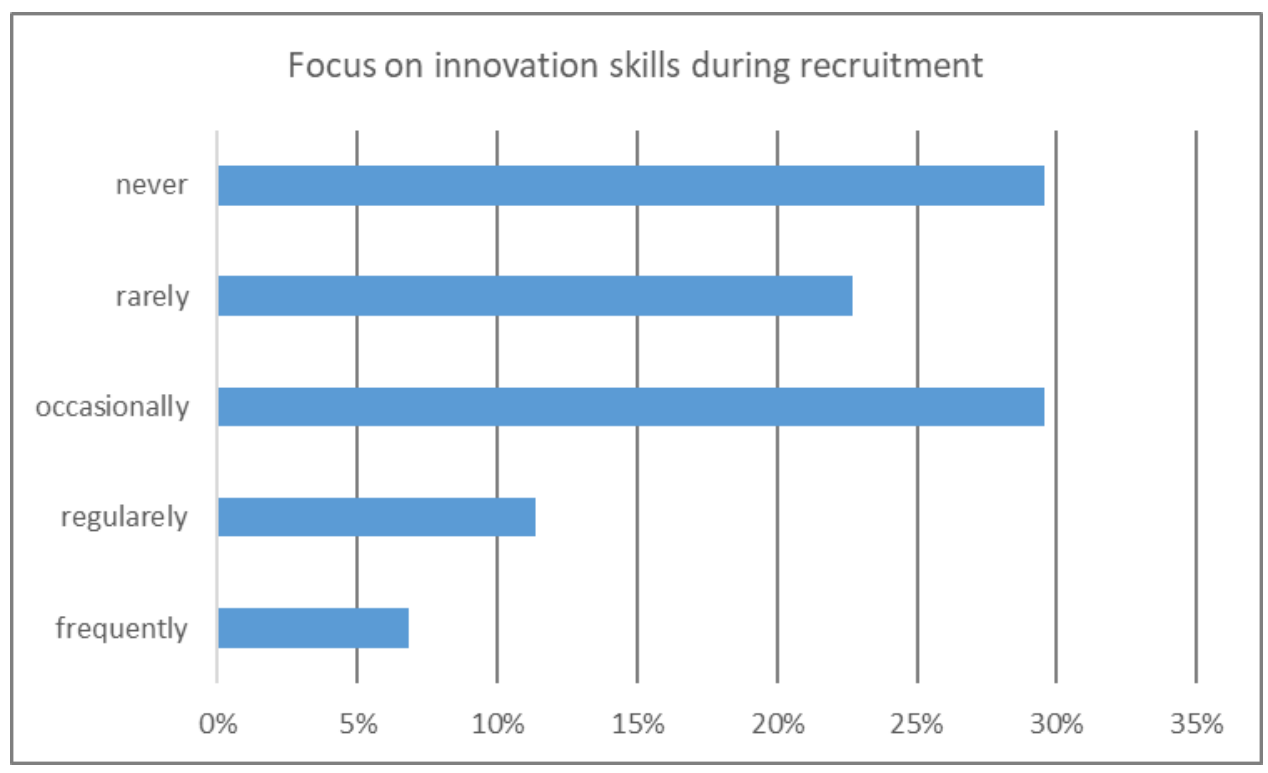

Figure 4 - Selection during recruitment

The result shows that during the selection process only occasionally or rarely a focus on the creativity of employees is laid. It is not easy to assess such attributes, but it would be worth to do put more focus on the personality in respect of creativity during recruitment processes!

How can we do this? The small number of interviews is seldom giving a clear picture about a person. I recommend to offer a trial period with some workshops, not just tasks. We need to learn about the person, how she behaves and communicates in a team. How is she using the network in and outside of a company. Another rule is also still valid but not easy to undergo: "Hire slow and fire fast". This somehow cruel proverb is true in the way that in general a manger waits too long until he separates from an underperforming employee. They are hindered by "giving another chance", by social scruples, by lack of leadership and responsibility taking and by cost arguments. Especially the later is totally wrong as the low performing employee is anyhow costing money for the company (opportunity cost) and earlier or later it will be replace.

Figure 5 - Coaching by internal or external moderators

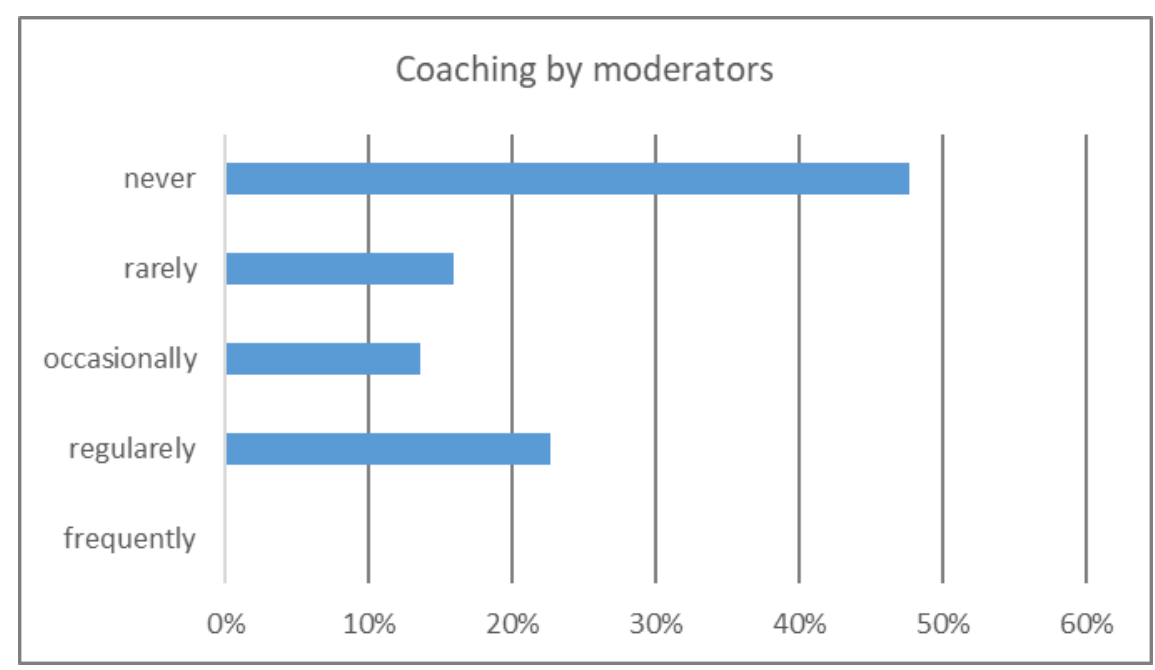


Coaching a team can increase the output and secure the diversity of ideas. Using a coach or moderator can act a pace maker, the team member have to deliver in time. Therefore such project work has frequently a shorter cycle time. From the survey we can conclude that using support of coaches or moderators during innovation processes is not widely spread.

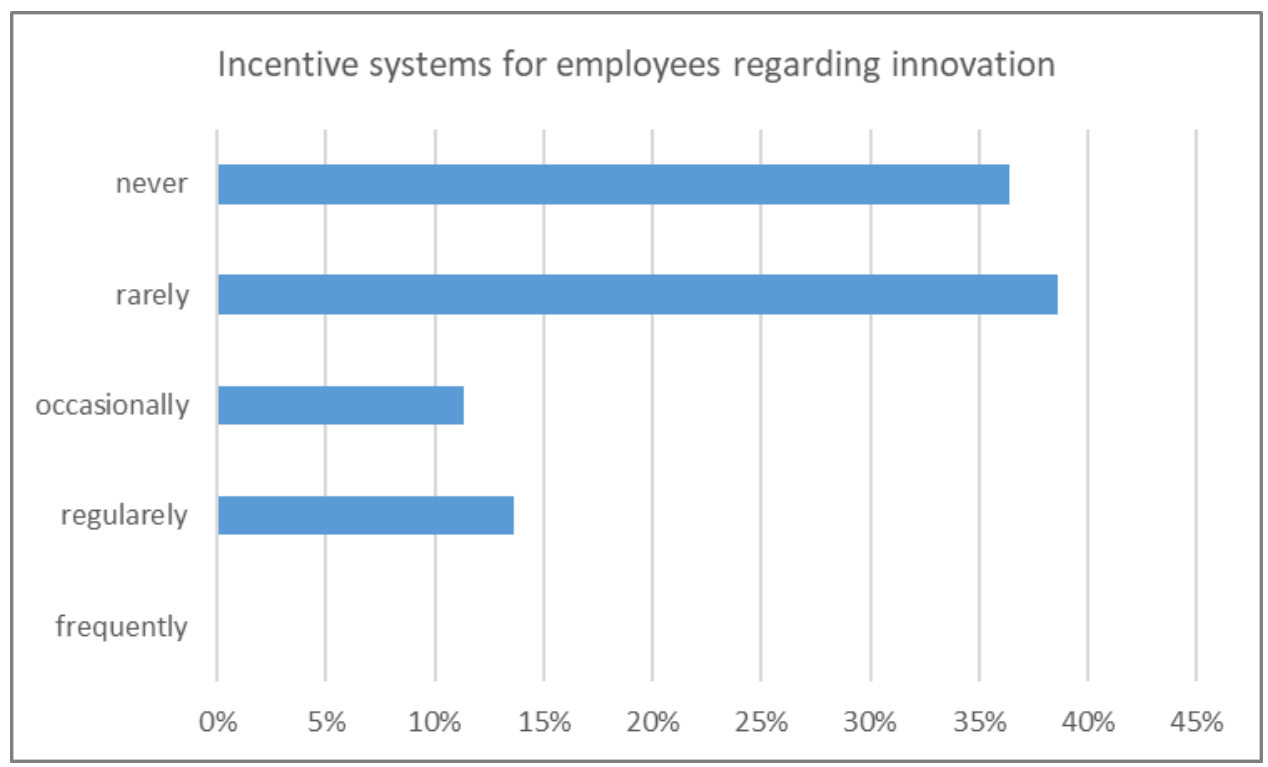

Figure 6 - The use of incentive systems to motivate employees for innovation

It is with astonishment that I read the result from this question. Only in a very few cases incentive systems are installed to encourage employees to participate in the initiation and invention phase of new products and services. Here is a hidden potential that could be activated also with small amounts of financial contributions. I think mainly on small premiums for the communication of good improvement ideas or bonuses for the successful market introduction of a new product.

\section{CONCLUSION}

The survey offers a vast number of starting points to improve the organisation of the human resource management within the innovation theme. The main tenor is about increasing the sensitivity for innovation aspects at all levels of employment and to shape an organisation that is capable to gather the ideas brought forward by the employees. The investigation clarifies that he main internal knowledge resources, the employees, could contribute much more to a continuous innovation process. In order to make this happen, the management is challenged and has to act more by good example. There is a large potential for faster innovation by using or integrating knowledge from company external sources.

It is a matter of organising and leading people. One of the first steps would be to get a right mix of individuals. This has to be done during the recruitment process already. A company needs the "pushers", those that place the requests for novelties to the innovation deciders, then project leaders, communicators as well as team workers and detail oriented specialists. A regular assessment of the existing human resource base with the needed skills will guide to the right decisions. 
Not all characteristics can be covered by internal staff. In such situations, which is probably the case generally in SME's, external temporary specialists or coaches can be added to the team.

To get more out of the existing staff in respect of innovation ideas is the goal. Beside of having the right structure of manpower this can be achieved by giving a more systematic attention to

- a better communication of the innovation strategy

- use of temporarily outsourced R\&D support

- to distinguish between incremental product improvement and large innovation steps

- to establish a network with universities and suppliers

The number of influence factors is too large, to give a recipe that would be valid for all industries and situations. The orientation on the correct selection of R\&D dedicated employees pared with the use of knowledge available in the entire company is the challenge for leaders. They have to integrate their care after the innovation team into a standard management rhythm.

A good practiced leadership itself will help to improve the outcome. Teaching instead of doing itself, informing about the goals instead of keeping this in the circle of the management team, passing responsibility to the staff instead of preserving the power in a small circle, sharing knowledge instead of artificially keeping ones position non exchangeable by not communicating! Networking is the contrary, it needs open minds and a fit for sharing.

\section{References:}

Management von Innovation und Wachstum. Arthur Little ed Wiesbaden: Gabler, 1997. ISBN: 3-409-19637-4

Baldwin, J., Hanel, P. and David, S. (2002). Determinants of innovative activity in Canadian manufacturing firms. New York: Palgrave. https://doi.org/10.1057/9780230595880_5

Brändle, N., Jörg, A., Merki, M. And Sterren, J. (2011). Megatrends-Chancen und Risiken für $K M U$. Credit Suisse Group AG ed Zürich: Neff M. Head Credit Suisse Economic Research

EUROPEAN_COMISSION (2009). European Innovation Scoreboard (EIS) 2009. ENTERPRISE \& INDUSTRY MAGAZINE ed Belgium: European Communities, 2009.Pro inno europ paper

Hiroyuki, H.(2009). Innovation: The key to global success? Grant Thornton Internationa Ltd. ed Grant Thornton International Ltd.

\section{Contact information}

Markus H. Gericke

Faculty of Management and Economics

Tomas Bata University, Zlín, Czech Republic

m.gericke@gericke.net

DOI: https://www.doi.org/10.7441/dokbat.2016.15 


\title{
BANK CAPITAL LEVERAGE: A SCHOLARLY LITERATURE REVIEW
}

\author{
Tung Thanh Ho
}

\begin{abstract}
This paper reviews previous academic studies on the "leverage ratio framework" under the Basel 3 framework. It focuses on the past two decades, especially on the effect of Basel 2 and 3 adoptions. This review chooses peer-reviewed journals and expert systems as the key sources for collection. The review is categorized by taking the aims of the authors that solve the problems in the denominator of the leverage ratio formula of the Basel 3, and each topic is discussed in chronological order. From the regulation perspective, reviewed sources propose new techniques and methods to manage risks related to the bank leverage topic. Suggestions related to the stricter leverage rules and improved disclosure systems were identified as the most important.
\end{abstract}

\section{INTRODUCTION}

The Basel Committee was the brainchild of a group of developed countries in order to undertake almost the same responsibility of the Bretton Woods System, which collapsed in the early 1970s (Basel Committee on Banking Supervision, 2014). The Basel standard is voluntary applied by non-member countries.

In 1988, the Basel Committee issued regulations as guidelines for banking regulations: the "1988 Basel Accord" or Basel 1, Basel 2 in 2004, and Basel 3 in 2010. All three regulations have shared the same core, consisting of three pillars related to capital regulation, supervision and information publishing. Basel 3 adds more technical details for applications.

The leverage ratio framework is a Basel 3 regulation, the objective of which is "improve the banking sector's ability to absorb shocks arising from financial and economic stress, whatever the source, thus reducing the risk of spillover from the financial sector to the real economy." The basis of the calculation is "the average of the monthly leverage ratio over the quarter based on the definitions of capital (the capital measure) and total exposure (the exposure measure)" (Basel Committee on Banking Supervision, 2010). In 2014, the Basel Committee issued a formula for it:

$$
\text { Leverageratio }=\frac{\text { Capital measure }}{\text { Exposure measure }}
$$

The study of bank capital leverage started with the issuing of Basel 1. Before Basel 3, some researchers mentioned the relationship between off-balance sheet (OBS) and bank risk (see Berger et al., 1995; Lazarus Angbazo, 1997; Boot, 1997). Breuer (2002) provides measures of implicit leverage in derivative contracts. Blum (2008) states that leverage should be reported to identify a bank's risk. Bordeleau et al. (2009) proved that the stabilization of Canadian banks could be based on their constraint of a lower leverage ratio in comparison with the leverage ratio of banks in the United States.

The 2014 Basel 3 leverage ratio framework and disclosure requirement is incomplete. The Basil Committee expects to complete the definition by 2017. So, this paper reviews the topic and provides some suggestions for the complete definition. 


\section{LEVERAGE COMPONENT}

Leverage ratio is calculated as its formula (1). The numerator has clear and simple elements derived from the balance sheet of banks, while the elements in the denominator are volatile and depend on the economic situation.

This review focuses on the denominator in the formula for the leverage ratio. Thus, the review is composed of, (i) Leverage research before Basel 3; (ii) On-Balance-Sheet exposures; (iii) OffBalance-Sheet exposures; (iv) derivative and securities transaction exposures; and some other ideas from bank leverage studies. Each topic is discussed in chronological order. Methods, data, findings and some details of the papers are listed.

\section{LEVERAGE RATIO RESEARCH}

\subsection{Overview}

Following the aim of the article, a tabular summary depicting the current status of bank leverage research is as follows: 
Table 1: Summary the bank leverage research

\begin{tabular}{|c|c|c|c|c|}
\hline $\begin{array}{c}\text { Author(s), } \\
\text { year of public }\end{array}$ & $\begin{array}{l}\text { Component } \\
\text { Mentioned }\end{array}$ & Approach & Findings & Suggestion \\
\hline Berger (1995) & $\begin{array}{l}\text { Financial institute } \\
\text { capital structure }\end{array}$ & Qualitative & $\begin{array}{l}\text { Capital requirements may create off- } \\
\text { balance sheet risks which is contributed to } \\
\text { a credit crunch }\end{array}$ & $\begin{array}{l}\text { Researchers should pay more attention on } \\
\text { such the problem of regulation and risk of } \\
\text { bank }\end{array}$ \\
\hline $\begin{array}{l}\text { Angbazo } \\
(1997)\end{array}$ & Off-balance-sheet & Regression model & $\begin{array}{l}\text { Off-balance-sheet activities improve } \\
\text { profitability of banks. } \\
\text { Interest rate risk, liquidity risk are related } \\
\text { with off-balance-sheet activities. }\end{array}$ & Moral hazard \\
\hline $\begin{array}{l}\text { Duffee et al. } \\
\quad(2001)\end{array}$ & $\begin{array}{l}\text { Credit derivatives in } \\
\text { banking }\end{array}$ & $\begin{array}{l}\text { Structure of the loan } \\
\text { payoff, net present } \\
\text { value, and the } \\
\text { probability of defaults }\end{array}$ & $\begin{array}{l}\text { Credit derivative is not a beneficial } \\
\text { instrument for risk managing }\end{array}$ & $\begin{array}{l}\text { Credit derivative may be the more choice for } \\
\text { capital allocation }\end{array}$ \\
\hline $\begin{array}{l}\text { Batten et al. } \\
\text { (2002) }\end{array}$ & Credit derivatives & Qualitative & $\begin{array}{l}\text { The information and risk management } \\
\text { methods at that time are not enough to } \\
\text { manage credit derivatives }\end{array}$ & $\begin{array}{l}\text { Need of information from original borrowers } \\
\text { and off-balance-sheet of lending banks }\end{array}$ \\
\hline Breuer (2002) & $\begin{array}{l}\text { On and Off-balance- } \\
\text { sheet }\end{array}$ & Value at Risk & $\begin{array}{l}\text { The substantial off-balance-sheet } \\
\text { leveraging activities and the limitations of } \\
\text { current capital adequacy measurement of } \\
\text { derivatives. }\end{array}$ & $\begin{array}{l}\text { Provides the measurement of leverage } \\
\text { implicit in derivative contracts by } \\
\text { decomposing the contracts into cash market } \\
\text { equivalent components }\end{array}$ \\
\hline Blum (2008) & $\begin{array}{l}\text { Analyzing the pros } \\
\text { and cons of Basel } 2\end{array}$ & Theories solving & $\begin{array}{l}\text { The mechanism of internal ratings based } \\
\text { approach (IRB approach) of Basel } 2 \text { is } \\
\text { letting banks to choose their requirement } \\
\text { capital themselves }\end{array}$ & Enforce penalty sanctions at dishonest banks \\
\hline $\begin{array}{l}\text { Bordeleau et } \\
\text { al. (2009) }\end{array}$ & $\begin{array}{c}\text { Leverage } \\
\text { management }\end{array}$ & $\begin{array}{c}\text { Discrete } \\
\text { autoregressive regime- } \\
\text { switching model }\end{array}$ & $\begin{array}{l}\text { Based on a tighter leverage ratio, } \\
\text { Canadian banks are more stable than the } \\
\text { US banks and the EU banks }\end{array}$ & $\begin{array}{l}\text { Leverage ceiling to complement risk- } \\
\text { weighted measures }\end{array}$ \\
\hline Koch (2014) & On balance-sheet & $\begin{array}{l}\text { Cointegration and } \\
\text { vector error correction } \\
\text { models (VFCMs) }\end{array}$ & $\begin{array}{l}\text { Two reactions of banks due to their } \\
\text { activities in short-run or long-run, in } \\
\text { which short-run are almost from } \\
\text { derivations of long-run }\end{array}$ & $\begin{array}{l}\text { The regulator might assess the short-run } \\
\text { reactions of banks to developments on } \\
\text { different financial markets; measures the } \\
\text { counter-cyclical capital of long-run liability } \\
\text { ratios }\end{array}$ \\
\hline $\begin{array}{c}\text { Author(s), } \\
\text { year of public }\end{array}$ & $\begin{array}{l}\text { Component } \\
\text { Mentioned }\end{array}$ & Approach & Findings & Suggestion \\
\hline $\begin{array}{l}\text { Kiema et al. } \\
(2014)\end{array}$ & On balance-sheet & $\begin{array}{l}\text { Single risk-factor } \\
\text { model }\end{array}$ & $\begin{array}{l}\text { Low leverage ratio contributes to decrease } \\
\text { the probability of bank failures }\end{array}$ & $\begin{array}{l}\text { A tighter leverage ratio requirement for } \\
\text { higher stability of banks }\end{array}$ \\
\hline Bargigli, et al. & On balance-sheet & Regression & The growing of leverage ratio will makes & The additional parameter can modify the \\
\hline
\end{tabular}




\begin{tabular}{|c|c|c|c|c|}
\hline$(2014)$ & & & banks lead to an unstable credit period & $\begin{array}{c}\text { skewness of bank degree and credit simulated } \\
\text { distributions for the simulation }\end{array}$ \\
\hline $\begin{array}{l}\text { Karim et al. } \\
\text { (2013) }\end{array}$ & Off-balance-sheet & Logic, Granger-cause & $\begin{array}{c}\text { Off-balance-sheet correlates with GDP } \\
\text { growth, and the fluctuation of real house } \\
\text { price causes the change of off-balance- } \\
\text { sheet }\end{array}$ & $\begin{array}{l}\text { Off-balance-sheet exposure should be } \\
\text { considered as a direct regulation }\end{array}$ \\
\hline Jarrow (2013) & Off-balance-sheet & VaR & $\begin{array}{l}\text { VaR and collateral have the same } \\
\text { probability of insolvency, but VaR } \\
\text { estimates cannot compare cross firms }\end{array}$ & $\begin{array}{c}\text { Banks only need to report their "haircut", so } \\
\text { regulators might compare banks' information } \\
\text { each other }\end{array}$ \\
\hline $\begin{array}{l}\text { Duran et al. } \\
\quad(2013)\end{array}$ & Off-balance-sheet & $\begin{array}{l}\text { Adverse selection } \\
\text { hypothesis }\end{array}$ & $\begin{array}{l}\text { If the assets quality of off-balance-sheet is } \\
\text { high, the ratio of off-balance-sheet to total } \\
\text { assets is negative relationship with } \\
\text { insolvency and portfolio risk; otherwise } \\
\text { the ratio is positive relationship with } \\
\text { liquidity and credit risk }\end{array}$ & Need of market discipline \\
\hline $\begin{array}{l}\text { Sakurai et al. } \\
\text { (2014) }\end{array}$ & $\begin{array}{l}\text { Off-balance-sheet } \\
\text { and collateral } \\
\text { derivatives }\end{array}$ & $\begin{array}{l}\text { "A jump-to-default } \\
\text { model" }\end{array}$ & $\begin{array}{l}\text { Off-balance-sheet leverage makes default } \\
\text { risk of derivatives dealers increase }\end{array}$ & $\begin{array}{l}\text { A derivative pricing framework with bilateral } \\
\text { counterparty credit risk that determines the } \\
\text { amount of rehypothecable collateral }\end{array}$ \\
\hline $\begin{array}{l}\text { Gibson et al. } \\
\quad(2013)\end{array}$ & $\begin{array}{l}\text { Derivative and } \\
\text { Securities transaction } \\
\text { exposures }\end{array}$ & Theory & $\begin{array}{l}\text { The margin from credit derivatives } \\
\text { increase default risk, and have an } \\
\text { ambiguous effect on welfare in the } \\
\text { banking sector }\end{array}$ & $\begin{array}{l}\text { Regulators should watch at the ways that } \\
\text { banks choose default risk mitigation } \\
\text { mechanism for their optimal margins }\end{array}$ \\
\hline $\begin{array}{l}\text { Mayordomo et } \\
\text { al. (2014) }\end{array}$ & $\begin{array}{l}\text { Derivatives and } \\
\text { Securities transaction } \\
\text { exposures }\end{array}$ & $\begin{array}{l}\text { DCoVaR, DCoES, } \\
\text { Asymmetric DCoVaR, } \\
\text { Gross Shapley Value }\end{array}$ & $\begin{array}{l}\text { Foreign exchange and credit derivatives } \\
\text { distribute to the systematic risk, while } \\
\text { interest rate derivatives does not }\end{array}$ & $\begin{array}{l}\text { More supervision at the derivatives activities } \\
\text { of banks }\end{array}$ \\
\hline \multicolumn{5}{|c|}{ Table (continued) } \\
\hline $\begin{array}{c}\text { Author(s), } \\
\text { year of public }\end{array}$ & $\begin{array}{l}\text { Component } \\
\text { Mentioned }\end{array}$ & Approach & Findings & Suggestion \\
\hline Keffala (2015) & $\begin{array}{l}\text { Derivative and } \\
\text { Securities transaction } \\
\text { exposures }\end{array}$ & $\begin{array}{l}\text { Generalized Methods } \\
\text { of Moments }\end{array}$ & $\begin{array}{l}\text { For banks in emerging countries, only } \\
\text { options and futures can be considered } \\
\text { risky derivatives, not forwards and swaps. }\end{array}$ & $\begin{array}{l}\text { Option and future style of derivatives can be } \\
\text { considered as risky derivatives of banks }\end{array}$ \\
\hline $\begin{array}{l}\text { Alnassar et al. } \\
\text { (2015) }\end{array}$ & Credit derivatives & Literature review & $\begin{array}{l}\text { Credit derivatives are mostly as hedging } \\
\text { instruments }\end{array}$ & $\begin{array}{l}\text { The instruments can be predicted through the } \\
\text { use of hedging theories. }\end{array}$ \\
\hline Chen (2013) & $\begin{array}{l}\text { Ratios of book } \\
\text { leverage and market } \\
\text { leverage. }\end{array}$ & Regression & $\begin{array}{l}\text { The market book is more significant to } \\
\text { announce the systematic risk than the } \\
\text { book leverage }\end{array}$ & $\begin{array}{l}\text { Use market leverage ratio could provide } \\
\text { more information for the regulators to } \\
\text { identify the distressed banks and to enhance }\end{array}$ \\
\hline
\end{tabular}




\begin{tabular}{|c|c|c|c|c|}
\hline & & & & market discipline \\
\hline $\begin{array}{l}\text { Goel et al. } \\
\text { (2014) }\end{array}$ & $\begin{array}{l}\text { Impact of house } \\
\text { price on capital } \\
\text { structure of banks } \\
\text { and capital structure } \\
\text { of mortgage } \\
\text { borrowers }\end{array}$ & Theories & $\begin{array}{l}\text { Bank's exposure to credit risk depends on } \\
\text { the leverage decisions of other banks }\end{array}$ & $\begin{array}{c}\text { Regulators should look at indicators of asset } \\
\text { quality }\end{array}$ \\
\hline $\begin{array}{l}\text { Dell et al. } \\
\text { (2014) }\end{array}$ & $\begin{array}{c}\text { Interest rate effect on } \\
\text { bank risk through the } \\
\text { volatility of the } \\
\text { leverage }\end{array}$ & Theories & Low interest rate may increases bank risk & $\begin{array}{l}\text { Policy makers and the supervisors should } \\
\text { consider the interest rate to assess the safety } \\
\text { of banks }\end{array}$ \\
\hline $\begin{array}{l}\text { Geanakoplos } \\
\text { (2014) }\end{array}$ & $\begin{array}{c}\text { Housing market, } \\
\text { mortgage market, } \\
\text { and the employment } \\
\text { indicate }\end{array}$ & Qualitative & The fluctuation of leverage, assets price & Monitor and forecast the whole credit surface \\
\hline $\begin{array}{l}\text { Cathcart et al. } \\
\text { (2015) }\end{array}$ & $\begin{array}{l}\text { Combine both bank } \\
\text { capital ratio and bank } \\
\text { leverage ratio in a } \\
\text { model }\end{array}$ & Regression & $\begin{array}{c}\text { The leverage ratio has a higher relation } \\
\text { with the crisis }\end{array}$ & $\begin{array}{l}\text { Provide a formula that relates the sensitivity } \\
\text { of the capital ratio to the leverage ratio, the } \\
\text { inverse of the credit risk ratio, and a new } \\
\text { factor conveniently dubbed asset proportion }\end{array}$ \\
\hline $\begin{array}{l}\text { Dermine } \\
(2015)\end{array}$ & $\begin{array}{c}\text { Loan default under the } \\
\text { leverage ratio } \\
\text { requirement of Basel } 3\end{array}$ & Theories solving & $\begin{array}{c}\text { Diversification or probabilities of loan } \\
\text { default which are based on capital relief } \\
\text { will leads to higher probability of banking }\end{array}$ & $\begin{array}{l}\text { Need the disclosure from credible } \\
\text { information to monitor such the mechanism }\end{array}$ \\
\hline
\end{tabular}




\subsection{Leverage research before Basel 3}

Angbazo (1997) tests the hypothesis that banks would select higher loan and deposit rates to achieve higher net interest margins. The author finds that interest-rate risk and liquidity risk are related to differences in off-balance-sheet exposure. Angbazo supposes the exploitation of off-balance-sheet should be consistent with the moral hazard.

Duffee et al. (2001) mentions credit derivatives in banking, the authors use structure of the loan payoff, net present value, and the probability of defaults to state that "the introduction of a credit-derivatives market is not necessarily desirable because it can cause other markets for loan risk-sharing to break down. The authors also say that if asymmetric information is got into the mechanism of credit derivative, weak banks would not be better. And credit derivative is not a beneficial instrument for risk managing. Instead, credit derivative may be the more choice for capital allocation. Batten et al. (2002) agrees with Duffee that credit derivative may be the more choice for capital allocation, moreover, Batten employs the GARCH model and approaches credit derivatives through the comparison between credit risk and bond default. The authors find that credit derivatives bring capital for bank and shift assets from off-balance-sheet. The findings suggest that credit derivatives might be the new techniques for risk management but the techniques lead to rise the need of information from both original borrowers and off-balance-sheet of lending banks.

In article of Breuer (2002), author supposes "leverage positions can trigger financial market turbulence", and the situation could be caused by the derivative of off-balance-sheet. This phenomenon must bring the risk on, and Breuer suggests the measuring off-balance-sheet exposure as an appropriate capitalization measure both on and off-balance-sheet. Analyzes on data of top 25 U.S banks in period from 1995 to 2000, this study approaches the leverage measuring through decomposition derivative contract into cash market equivalent. Using Value at Risk (VaR), the author explains the mechanism of decomposition leverage contracts based on the pricing assumption between securities price and investors assessment. This explanation pointed out the ratio of notional value over market value. Finally, Breuer suggests that this ratio shall be applied as a "convert the exposure" for equity and debt equivalent while the capital regulation be calculated. Then, while analyzing the pros and cons of Basel 2, Blum (2008) comments that the mechanism of internal ratings based approach (IRB approach) of Basel 2 is letting banks to choose their requirement capital themselves. Blum proves that it is necessary to enforce penalty sanctions at dishonest banks to equate the profit of these banks with the profit of honest banks. The proving of Blum rises up a leverage ratio included the minimum lever of capital and the risks of bank.

Bordeleau et al. (2009) examines the Canadian experience of the leverage management to support that a leverage ceiling would complement risk-weighted measures. In this study, the authors compare Tier1 evolution in period from 2000 to 2009 of Canadian banks, the US banks, the UK, and Europe. Then, the comparison is used again with the leverage of such the countries. Finally, the authors use discrete autoregressive regime-switching model to test their hypothesis and get the result: ".... a leverage ceiling would be useful tool to complement risk-weighted measures and mitigate procyclical tendencies in the financial system."

\subsection{On-Balance-Sheet exposures}

Koch (2014) develops a new approach, Koch employs cointegration and vector error correction models (VECMs) analysis to analyze the change of all German banks in period 2002 to 2010. The analysis is to derive cointegration relationships between various liability components and "balance sheet total". Koch found two reactions of banks due to their activities in short-run or long-run, in which the reactions of short-run are almost from 
derivations of long-run. Where all elements of on balance-sheet liability are adjusted by risks on equity market, bond and debt in domestic. These findings prove that banks with global operations deemed "systemically relevant", and the increase of their leverage shows that international banks expose their risk as their would-wide activities. the regulator might use such the analysis methods of Kock to assess the short-run reactions of banks to developments on different financial markets, and measures the counter-cyclical capital of long-run liability ratios.

By studying the effects of the leverage ratio requirement in part V of Basel III for lending of banks and its stability, Kiema et al. (2014) believed that this new complement of regulations will lead to a reduction in the banks' risk. To support the encouragement of this new regulation, the authors divided loans into high-risk and low-risk categories for high-risk and low-risk firms respectively and employed a single risk-factor model. In terms of discussion, the authors assumed that regulators, banks, and borrowers base their actions on common estimates of loan default probabilities. The study shows that low leverage ratio contributes to gross factors which are optimal for bank lending and decrease the probability of bank failures. And the authors conclude that they encourage for a tighter leverage ratio requirement for higher stability of banks. Bargigli et al. (2014) based on a similar idea and the way of approach as Kiema, the authors agree with previous studies that leverage has relationship with banks' stability. In addition, the authors use data of Japanese banks to prove that if the increase of market concentration effect banks, leverage ratio will grow and makes banks lead to an unstable credit period. Bargigli, et al. (2014) supposes that the additional parameter can modify the skewness of bank degree and credit simulated distributions for the simulation models with real data on credit networks.

\subsection{Off-Balance-Sheet exposures}

Karim et al. (2013) use logic approach and Granger-cause test to investigates banking crises in 14 OECD countries, authors recognize that off-balance-sheet correlates with GDP growth, and the fluctuation of real house price causes the change of off-balance-sheet. The authors suggest that off-balance-sheet exposure should be considered as a direct regulation because of its impact on the crisis probability. Additional, Jarrow (2013) proves that VaR and collateral have the same probability of insolvency, but VaR estimates cannot compare cross firms. So, Jarrow suggests that banks only need to report their "haircut" and this information will provide the regulators the relevant leverage ratios that regulators might compare banks each other.

Use an adverse selection hypothesis approach, Duran et al. (2013) analyses data from banks of European Union in period from 1996 to 2009. This study shows that if the assets quality of off-balance-sheet is high, the ratio of off-balance-sheet to total assets is negative relationship with insolvency and portfolio risk; if assets quality on off-balance-sheet is low, the ratio is positive relationship with liquidity and credit risk. These findings illuminate the need of market discipline-a requirement of Basel 3. Moreover, analysing the "credit immigration" of collateral derivatives, Sakurai et al. (2014) recommend that off-balance-sheet leverage makes default risk of derivatives dealers increase. The authors aim to analyse the collateral derivatives. So, this study will discuss more depth the matter of Sakurai et al. (2014) in the next section.

\subsection{Derivatives and Securities transaction exposures}

Gibson et al. (2013) investigates the effects of margining while banks use credit derivatives. The authors develop three optimistic margins hypotheses of credit derivatives which are based on the assumption that banks' objectives are to completely hedge their exposure to 
market risk, and they are to hedge themselves from interest rate risk. Gibson et al. (2013) find that the margin from credit derivatives increase default risk, and have "an ambiguous effect on welfare in the banking sector". The authors believe the ways banks get the optimal margins are caused by default risk mechanism that they chose. Whatever, the assumptions of Gibson et al. (2013) are too strong and ignore the act of speculators. On the similar approach line as Gibson, Sakurai et al. (2014) develops the "credit immigration" of collateral derivatives to fill the gap of this factor which belongs to off-balance-sheet leverage into derivatives activities study. The authors use "a jump-to-default model" to prove their opinion. Sakurai et al. (2014) assures that a rehypothecation derivative dealer can earn from this instrument by its positive relationship with default risk of rehypothecation, and it is the price of a derivative trade. Sakurai et al believe that "over-collateralization by Initial Margin plays an important role in determining the relationship between the risk and the return of rehypothecation.". As the result, the authors propose "a derivative pricing framework with bilateral counterparty credit risk that determines the amount of rehypothecable collateral".

Mayordomo et al. (2014) study the impact of financial derivatives on the contribution of individual bank to systematic risk. The authors use five measures of the individual contribution of banks to systematic risk: DCoVaR, DCoES, Asymmetric DCoVaR, Gross Shapley Value (GSV) and Net Shapley Value (NSV). The sample for the examine is data of 95 U.S. bank holding companies from 2002 to 2011. The authors point out that except interest rate derivatives, foreign exchange and credit derivatives distribute to the systematic risk. The findings of Mayordomo et al. (2014) are the skeptic that most types of derivatives do not all contribute to the systematic risk. The authors recommend the more supervision on the derivatives activities of banks.

Keffala (2015) employs Generalized Methods of Moments and data from 66 banks of emerging countries in period from 2003 to 2011 to investigate the effect of derivatives on bank stability. Keffala suggest that option and future style of derivatives can be considered as risky derivatives of banks. However, in this study, credit risk is one of many explanatory variables which are used in the model. Additionally, Alnassar et al. (2015) reviews several relevant articles which were published before the Basel 3, the authors conclude that the use of credit derivatives are mostly as hedging instruments, and the credit derivations have the relationship with bank's size, distress costs, capital position and level of credit risk. So, the authors suppose that the hedging instruments can be predicted through the use of hedging theories.

\subsection{Other bank leverage studies}

Chen (2013) investigates the performance of Japanese commercial banks during the period of financial crisis in the late 1990s. the author approaches two styles of leverage of Japanese commercial, those are book leverage and market leverage. Based on the analyses these two criteria, using regression method, Chen find that the market leverage is more significant to announce the systematic risk than the book leverage. As the results, the author believes that market leverage ratio could provide more information for the regulators to identify the distressed banks and to enhance market discipline. Goel et al. (2014) study the impact of house price on capital structure of banks and capital structure of mortgage borrowers. Developing the theories of house price and bank capital structure, analyzing the data of bank leverage and house price of the US in the period from 1995 to 2014, the authors point out four findings. First, leverage among borrowers is positively correlated with high leverage among banks; second, higher bank leverage leads to higher house price; third, bank's exposure to credit risk depends on the leverage decisions of other banks; forth, house prices is 
increased because of the mechanism of the three matters before. The authors recommend the regulators to look at indicators of asset quality.

Dell et al. (2014) study the effect of interest rate on bank risk through the volatility of the leverage. The authors develop a theory that interest rate may contribute to increase in bank risk taking. In addition, they use their model to analyze the data from 400 banks of the US in period from the second quarter of 1997 to the third quarter of 2009 to claim that a low interest rate may increases bank risk. The findings of the authors meet the twin objectives of price and financial stability, so the authors believe that the findings should be important for the central bank to the policy made and the supervisors to assess the safety of banks. Complementary to (Dell'Ariccia et al., 2014), Geanakoplos (2014) points out that the housing market and the mortgage market are correlated. The employment factor was ignored while central banks computed leverage cycle. Meanwhile, the employment fluctuation is effect on the number of borrowers of banks, then effect on house price. When the injection money from the governments to rescue banks till in the reserves, no more household borrowers can borrow from such foundations, that is meaning interest rate increased faster than house price, and the situations lead to credit default almost high. To prove his point, Geanakoplos analyzes the relevant data of the US and the EU in the period from 1997 to 2009 and shows that a high or low leverage is made sense by the interest rate. The author recommend that the central banks should consider the housing leverage, the mortgage leverage, interest rate, and pay attention to both the household borrowers and the investors. The general information was mentioned the so called "credit surface". Geanakoplos suggests that the central banks should consider the whole credit surface, and in extreme cases the central banks should intervene to regulate risky interest rates and impose partial debt forgiveness.Cathcart et al. (2015) develops a model which combines both bank capital ratio and bank leverage ratio. They use regression model to analyze data from the Federal Deposit Insurance Corporation Call Reports for the crunch periods 1990Q1-1991Q2 and 2007Q32009Q2 to investigate the correlation of both the ratios. On the one hand, authors find that the leverage ratio has a higher relation with the crisis. On the other hand, they point that their solution is a generic closed solution. Thus, the authors say that their results are helpful in the improvements for the new Basel 3 regulation. In addition, support for the leverage ratio of Basel 3, based on the probability of default, Dermine (2015) proves the impact of credit risk diversification and probability of loan default on the probability of a bank run. The author believes that "capital relief, which is induced by increased diversification or lower probabilities of loan default, leads to a higher probability of a bank run.". Thus, the mechanism needs the disclosure from credible information.

\section{DISCUSSION}

Basel 3 committee perceives the importance of the leverage. In this review, almost all of the researchers remind the threat and the contribution of leverage to the crisis. The researchers argue in favour of tightening leverage regulation. Authors postulate that a tighter management of bank leverage will lead to more stable banking environment

Quantitative approach is the most used approach in the studies. In the studies after Basel 3, most of researchers analyze data from the periods from before to after 2007. Previous research benefited from the financial crisis, because crisis provided an unique situation. Meanwhile most of theoretical studied pointed directly to the indicators which regulators should consider better risk management.

The suggestions of the studies both on- and off-balance-sheet are more addressable to the control of leverage component while the studies of derivatives mostly point to the need of 
banks' discipline and disclosure. The derivatives are considered as the riskiest activities because they expose relates to many factors. Risks related to the Credit derivatives are higher than other derivatives' risks. To manage credit derivatives, regulators need more information and the honesty of banks about their off-balance-sheet and their real loan loss. From the suggestions obtained from reviewed studies, Jarrow's (2013) "hair cut information" suggestion is the most interesting because of its simplicity and usefulness for the regulators when they compare the leverages of several banks. Cathcart et al. (2015) is a one of a few studies which approaches and suggests a method that may combine capital ratio and leverage ratio requirement. Along the "Phase-in Arrangement" of Basel 3, these two requirements will be in included in the pillar 1 altogether.

Interest rate, house price, GDP, and unemployment indicator may affect bank risk indirectly.

\section{CONCLUSION}

During the "Phase-in Arrangement" of Basel 3, leverage ratio is monitored as a parallel criterion with capital ratio. In January 2018, leverage ratio is going to be immigrated to pillar 1 together with capital ratio. Time from now until then, we will discover more from the related studies. Meantime, the previous studies, which are reviewed in this paper, are important for researchers in this area.

Findings obtained though this literature review point to two important issues that researchers should pay attention to. First, derivatives. Especially credit derivatives have more effect on the bank risks than the other factors. Second, the disclosure is needed to manage the bank risk. Reviewed studied suggest some indicators, parameters and point to information that regulator should consider. However, there are no suggestions for a particular criterion of leverage ratio component.

Research of banking, finance and related sciences mostly contributed to Basel regulation framework. We expect that the further studies will give the Basel Committee better suggestions for full application of Basel 3.

\section{References}

Alnassar, W. I., \& Chin, O. B. (2015). Why Banks Use Credit Derivatives? Review PaperProcedia Economics and Finance, 26, 566-574. https://doi.org/10.1016/S22125671(15)00956-9

Bargigli, L., Gallegati, M., Riccetti, L., \& Russo, A. (2014). Network analysis and calibration of the "leveraged network-based financial accelerator." Journal of Economic Behavior \& Organization, 99, 109-125. https://doi.org/10.1016/j.jebo.2013.12.018

Batten, J., \& Hogan, W. (2002). A perspective on credit derivatives. International Review of Financial Analysis, 11(3), 251-278. https://doi.org/10.1016/S1057-5219(02)00104-7

Berger, A. N., Herring, R. J., \& Szego, G. P. (1995). The Role of Capital in Financial Institutions. International Library of Critical Writings in Economics, 133, 3-40. https://doi.org/10.1016/0378-4266(95)00002-X

Blum, J. M. (2008). Why "Basel II" may need a leverage ratio restriction. Journal of Banking \& Finance, 32(8), 1699-1707. https://doi.org/10.1016/j.jbankfin.2007.12.003

Boot, A. W., \& Thakor, A. V. (1997). Financial system architecture. Review of Financial Studies, 10(3), 693-733. https://doi.org/10.1093/rfs/10.3.693

Bordeleau, E., Crawford, A., \& Graham, C. (2009a). Regulatory constraints on bank leverage: Issues and lessons from the Canadian experience. Bank of Canada Discussion Paper. Retrieved from http://www.econstor.eu/handle/10419/66923 
Bordeleau, E., Crawford, A., \& Graham, C. (2009b). Regulatory constraints on bank leverage: Issues and lessons from the Canadian experience. Bank of Canada Discussion Paper. Retrieved from http://www.econstor.eu/handle/10419/66923

Breuer, P. (2002). Measuring off-balance-sheet leverage. Journal of Banking \& Finance, 26(2), 223-242. https://doi.org/10.1016/S0378-4266(01)00220-5

Cathcart, L., El-Jahel, L., \& Jabbour, R. (2015). Can regulators allow banks to set their own capital ratios? Journal of Banking \& Finance, 53, 112-123. /https://doi.org/10.1016/j.jbankfin.2014.11.017

Chen, S. (2013). How do leverage ratios affect bank share performance during financial crises: The Japanese experience of the late 1990s. Journal of the Japanese and International Economies, 30, 1-18. https://doi.org/10.1016/j.jjie.2013.07.003

Dell'Ariccia, G., Laeven, L., \& Marquez, R. (2014). Real interest rates, leverage, and bank risk-taking. Journal of Economic Theory, 149, 65-99. https://doi.org/10.1016/j.jet.2013.06.002

Dermine, J. (2015). Basel III leverage ratio requirement and the probability of bank runs. Journal of Banking \& Finance, 53, 266-277. https://doi.org/10.1016/j.jbankfin.2014.12.007

Duffee, G. R., \& Zhou, C. (2001). Credit derivatives in banking: Useful tools for managing risk? Journal of Monetary Economics, 48(1), 25-54. https://doi.org/10.1016/S03043932(01)00063-0

Duran, M. A., \& Lozano-Vivas, A. (2013). Off-balance-sheet activity under adverse selection: The European experience. Journal of Economic Behavior \& Organization, 85, 176-190. https://doi.org/10.1016/j.jebo.2012.04.008

Geanakoplos, J. (2014). Leverage, Default, and Forgiveness: Lessons from the American and European Crises. Journal of Macroeconomics, 39, 313-333. https://doi.org/10.1016/j.jmacro.2014.01.001

Gibson, R., \& Murawski, C. (2013). Margining in derivatives markets and the stability of the banking sector. Journal of Banking \& Finance, 37(4), 1119-1132. https://doi.org/10.1016/j.jbankfin.2012.10.005

Goel, A. M., Song, F., \& Thakor, A. V. (2014). Correlated leverage and its ramifications. Journal of Financial Intermediation, 23(4), 471-503. https://doi.org/10.1016/j.jfi.2014.08.002

Jarrow, R. (2013). A leverage ratio rule for capital adequacy. Journal of Banking \& Finance, 37(3), 973-976. https://doi.org/10.1016/j.jbankfin.2012.10.009

Kiema, I., \& Jokivuolle, E. (2014). Does a leverage ratio requirement increase bank stability? Journal of Banking \& Finance, 39, 240-254. https://doi.org/10.1016/j.jbankfin.2013.11.009

Koch, C. T. (2014). Risky adjustments or adjustments to risks: Decomposing bank leverage. Journal of Banking \& Finance, 45, 242-254. https://doi.org/10.1016/j.jbankfin.2014.03.017

Lazarus Angbazo (1997). Commercial bank net interest margins, default risk, interest-rate risk, and off-balance sheet banking. Journal of Banking \& Finance, Volume 21, Issue 1, Pages 55-87. https://doi.org/10.1016/S0378-4266(96)00025-8

Mayordomo, S., Rodriguez-Moreno, M., \& Peña, J. I. (2014). Derivatives holdings and systemic risk in the U.S. banking sector. Journal of Banking \& Finance, 45, 84-104. https://doi.org/10.1016/j.jbankfin.2014.03.037

Sakurai, Y., \& Uchida, Y. (2014). Rehypothecation dilemma: Impact of collateral rehypothecation on derivative prices under bilateral counterparty credit risk. Journal of Banking \& Finance, 48, 361-373. https://doi.org/10.1016/j.jbankfin.2013.11.024 


\section{Contact information}

Tung Thanh Ho

Faculty of Management and Economic,

Tomas Bata University in Zlin, Czech. Republic.

Lecturer of Faculty of Finance and Banking,

Email: hothanhtung@tdt.edu.vn

DOI: https://www.doi.org/10.7441/dokbat.2016.16 


\title{
CLUSTER POLICIES AND INITIATIVES WITHIN THE SERVICE SECTOR - GOOD PRACTICES FROM EU COUNTRIES AND RECOMMENDATION FOR THE CZECH CLUSTER POLICY
}

\author{
Martin Horák
}

\begin{abstract}
The concept of clusters and clustering has recently gained enormous popularity among policy-makers, practitioners and academics, a fact reflected by the growing number of policies and initiatives in support of clusters. This article focuses on cluster policies and initiatives within the service sector. The main objective of the article is to present good practices of cluster initiatives within the service sector and to propose recommendation for the Czech cluster policy in the field of services. The article describes cluster policy and identifies two common approaches: top-down and bottom-up. It then presents European examples of good practices of developing the service sector through cluster initiatives: Service Cluster Denmark (national-wide) and initiatives within the Region of North Central Sweden (regional-wide). Based on case studies and other examples of initiatives in EU countries, recommendations are made for the cluster policy in the Czech service sector.
\end{abstract}

Keywords: cluster, cluster initiative, cluster policy, service sector

\section{INTRODUCTION}

The concept of cluster has been a popular scholarly topic (Swann \& Prevezer, 1996; Knorringa \& Meyer-Stamer, 1998; Cooke, 2001; Martin \& Sunley, 2003; Steiner \& Hartmann, 2006). The term cluster was firstly introduced by American professor Michael Porter in "The Competitive Advantage of Nations". Porter (1990, p. 30) defined clusters as "geographic concentrations of interconnected companies, specialized suppliers, service providers, firms in related industries, and associated institutions (universities, standards agencies, and trade associations) in particular fields that compete but also cooperate." His definition of cluster is the most cited among researchers and scholars.

In the context of cluster, there are also scholars who focus on ways to support cluster development and which cluster policies are applied in countries. Researchers describe the situation within the cluster policy in their countries or regions (Dohse, 2007; NowakowskaGrunt et al., 2014; Truel \& Volkov, 2015) and also among European countries (Hospers \& Beugelsdijk, 2002; Brakman \& Van Marrewijk, 2013; Obadić, 2013; Gafurov et al., 2014). Cluster policy is defined by Europe INNOVA and PRO INNO Europe (2008, p. 10) as "a specific governmental efforts to support clusters. Such cluster policies can take various forms and pursue different objectives, such as industrial policy, support for small and medium-sized enterprises or research and innovation policy." However, as Christensen, Lämmer-Gamp and Meier zu Köcker (2012) state, there is no unique and generally accepted cluster policy definition in European countries. Every cluster policy has different structure and aim, but some similarities can be detected. Cluster policies are generally seen as a vital element of building strong innovations system and the main goal of cluster policies is to improve and boost a particular regional economy which enhances the national economy (Christensen, Lämmer-Gamp \& Meier zu Köcker, 2012) Nevertheless, the implemented policy instruments depend on the type of cluster and specific regional needs. 
The research objectives of this article are the following: A general analysis of cluster policy; an analysis of cluster policy including presenting good practices in the service sector; a description of the cluster policy in the Czech Republic and a recommendation for the Czech service sector cluster policy.

The article is structured as follows: Section 2 introduces cluster policy in general and presents the top-down and bottom-up approaches. It also identifies types of cluster policies. Section 3 is focused on cluster policies and initiatives in the service sector and identifies good practices of developing the service sector through cluster initiatives. Section 4 briefly presents the Czech cluster policy and makes recommendations for the Czech service sector.

\section{THEORETICAL BACKGROUND: CLUSTER POLICY - GENERAL OVERVIEW}

Cluster policies are defined as a way to support clusters and their development. Cluster policy is often oriented to the areas or sectors where clusters already exist. Lindqvist, Ketels and Sölvell (2003) argue that support for clusters is different across countries. In Europe, the support is aimed at innovation-intensive areas like IT. Meanwhile in emerging economies the focus is mainly given to the more traditional sectors, such as manufacturing, food processing and tourism.

Cluster policies are in most cases supported and implemented by specific cluster programmes and cluster initiatives. Cluster initiatives can be then seen as "organized efforts to increase growth and competitiveness of clusters within a region, involving cluster firms, government and/or the research community" (Lindqvist, Ketels \& Sölvell, 2003, p. 9). As Ketels (2013) claims, cluster initiatives are more effective in the place where cooperation and trust among regional government, enterprises and academics are good, and where there is also a strong organisation which would run the initiative. Ketels (2013, p. 279) states that "cluster programmes can be launched by different levels of government, clusters and thus cluster initiatives are always regional in nature." Christensen, Lämmer-Gamp and Meier zu Köcker (2012) in this context suggest that policy-makers need to have in mind that cluster programmes applied in emerging areas are different from those for established clusters and are also more risky.

Support from government/policy-makers is sometimes crucial to help with the development of the appropriate cluster. Wolman and Hincapie (2015, p. 146) contend that policy-makers should:

- "Focus on clusters for which the region has existing assets, as evidenced by some existing concentration

- Focus on clusters for which the region has a competitive advantage relative to other regions

- Focus on clusters that are growing nationally

- Focus on clusters for which an intervention strategy is possible and for which intervention will make a difference in terms of affecting economic development objectives.

- Focus on clusters whose impacts or externalities particularly serve public purposes (e.g., employ more entry-level labor or promote energy“

The main reason of applying cluster programmes and initiatives is to improve the competitiveness of clusters which already exist rather than creating completely new clusters (Ketels, 2013). According to Obadić (2013), the most commonly used ministries to 
implement cluster policy are the Ministry of Industry (16 countries) and the Ministry of Finance/Economy (14 countries). The Ministry of Science and Research (9 countries), but also, other ministries and organizations are very common (11 countries). Obadić (2013) notes that there are differences between economies "in development" and "old EU members". One of the differences is for example in the position of the ministry of finance/economy. In the first group the ministry of finance/economy plays a key role in the context of developing cluster programmes/initiatives, meanwhile in the group of "old EU members," other ministries are involved.

Cluster policies are implemented in policy documents on both national and regional levels. Barsoumian, Severin and van der Spek (2011) identify countries which applied cluster policies on a national level: France, Luxembourg, Latvia, Lithuania, Portugal, Czech Republic, Greece, Poland, Romania, Bulgaria, Finland. They identify regional cluster policy in Belgium, Sweden, Austria.

\section{$2.1 \quad$ Top-down and bottom-up approach}

The guide called "Clusters and clustering policy: a guilde for regional and local policy makers" prepared by INNO Germany AG (2010, p. 101) suggest that "one of the first decisions of policy makers when facing the selection of clusters to be funded in the framework of a cluster programme is whether to pursue a top-down or bottom-up approach, or a combination of both. Top-down refers to measures to support (potential) clusters initiated by government bodies. In contrast, bottom-up processes are characterised by strong involvement by the private cluster actors." The main difference is that in a top-down approach policy-makers define criteria a priori, meanwhile bottom-up approach is about mobilisationof regional or local actors.

INNO Germany AG (2010) point out that selection of the cluster based on predetermined criteria (e.g. national strategic priorities, statistic characteristics) is labelled as top-down approach. OECD (2007) comment that bottom-up methods are the ones without any predefined criteria - group discussion, open calls. Combination of the bottom-up and the topdown approach is for example using restricted calls for tenders - assumptions are set topdown meanwhile the call is more bottom-up whereas the prerequisites are set top-down. Suitability of the approach is dependend on considered policy level and the strategic objectives of the appropriate policy.

A. Davis from OECD in the "Clusters and clustering policy: a guilde for regional and local policy makers" (INNO Germany AG, 2010, p. 101) describes the advantages of the approaches depending on the programme objective: "if it is the national government who wants to strengthen the biomedical industry, then it would use a top-down approach, it would preselect the areas it wants to target - as a national authority it can identify how strengths are located in biomedical research and firms. If you want to build general capacity at local level and you don't have set objectives, then the bottom-up approach is a good way of identifying whether there is the necessary motivation for a cluster."

\subsection{Types of cluster policy}

The types of cluster policies and their content are very different among European countries. According to CLOE (2006), there are usually three types of cluster policy:

- The first type deals with the strengthening "triple helix", particularly between industry, research and government agencies, ie. agencies or regional development agencies for research and technology 
- The second type focuses more on co-operation in research and development between companies and between companies and research organizations

- The third type aims to promote cooperation between businesses, regardless of whether this cooperation is carried out with research and development institutions, or is carried horizontally or vertically between competitors along the value chain

Andersson et al. (2004) in "The Cluster Policies Whitebook" go further in breaking down policy into even more categories including: broker policies, demand-side policies, training, promotion of international linkages and broader framework conditions. Broker policies can be described as a policy which is aimed at strengthening the framework for dialogue and cooperation between actors inside the cluster. Demand side policies are focused on applying innovative solutions and on supporting new ideas within clusters. The third type of policy, training policies, may be targeted at upgrading skills and competencies which are essential for effective clustering of SMEs. Type of international linkages should be applied when the country wants to support the interplay between foreign and domestic actors. Finally, framework policies are focused on improving infrastructure and institutional conditions which are necessary for clusters.

\section{CLUSTER POLICIES AND INITIATIVES WITHIN THE SERVICE SECTOR IN EUROPEAN COUNTRIES}

The service sector has recently become the most important economic sector in Europe. European Commission (2009) states in their report that almost all employment growth in the period 1995-2007 was identified in the service sector. In 2007, more than 155 million people are engaged in service activities, representing $69.2 \%$ of total employment and generates 71.6 $\%$ of gross value added generated by the twenty-seven states. From that point of view, European economy can be described as a service economy. According to Eurostat (2008), the terms service sector or services are generally used to refer to economic activities covered by Sections $\mathrm{G}$ to $\mathrm{U}$ of NACE revision 2.

Most of the cluster policies and cluster initiatives within the service sector exist at regional level or even at local level. The paper by European Commission (2009) called "Challenges for EU support to innovation in services - Fostering new markets and jobs through innovation" mentions that clusters in the service sector are spread worlwide. They can be found in Austria, Belgium, Bulgaria, Switzerland, Cyprus, Spain, Estonia, Finland, France, Ireland, Iceland, Italy, Luxembourg, Malta, the Netherlands, Norway, Portugal, Sweden and the United Kingdom. All of these countries focus on promoting service innovation through cluster initiatives. In France, for example there are three clusters of competitiveness in the service sector, namely Seine Normandie Logistic Competitiveness Cluster, Trade Industry Competitivenesss Cluster and Finance Innovation Competitiveness Cluster. In the United Kingdom were launched cluster initiatives by the Regional Development Agencies. These initiatives aimed to support development in specific service industries, such as software, digital content and creative industries. Germany also started to put more emphasis on promoting the service sector recently. The local government is shifting their support from traditional large clusters specializing in the production of steel and auto production to the clusters in the knowledge-intensive business services. Especially in Bavaria are very prosperous clusters working in the field of ICT services. Information and communication services in Bavaria accounts for $40 \%$ of all software companie sin Germany. For example, clusters IT Speicher, FIWM, and BICC-NET operate here among the ICT services. 
In the context of supporting clusters within the service sector, there is an interesting paper written by European Service Innovation Centre (2015) called "Promoting Service Innovation through Cluster Initiatives." The document gives examples of five cluster initiatives which use the concept of service innovation to promote innovation in either service industries or service elements of other industries. Cluster initiatives mentioned there are focused on service innovation in the following sectors: ICT (software, multimedia, ICT and safety), transport and services, health and wellness, tourism, financial services and logistics.European Service Innovation Centre (2015, p. 2) continues with recommendation for policy-makers within service innovation: "Policy-makers can support the use of service innovation by strengthening the critical framework conditions for service-based clusters such as those for digital-based industries, healthcare industries or experience-based industries. Such framework conditions include the development of a service infrastructure, the expansion of cultural and social capital and improved access to new types of funding, such as crowd funding or microloans."

\subsection{Good practices of developing service sector through cluster initiatives}

The following cases present cluster initiatives on a national and a regional level. These cases were chosen because they have already proven their success. The Service Cluster Denmark was the first European cluster which was awarded by ESCA Cluster Management Excellence Silver Label. On the other hand, the initiatives in the region of North central Sweden made significant improvement to moribound service sector. Denmark and Sweden have also rich history in the context of clustering and cluster policies.

On the pages below are presented good practices of cluster initiatives at national and at regional level which support service sector by different instruments.

\subsection{National level - Service Cluster Denmark}

Service Cluster Denmark was founded on December, 2010 under The Innovation Network program. The main idea of the program is to "create platforms for companies and research institutes to exchange knowledg eand enter into collaboration project" (Danish Agency for Science, Technology, and Innovation, 2015).

Service Cluster Denmark has 1100 members and operates in sectors connected with digital retail, B2B manual service, servitization and knowledge intensive services. The cluster is one of 22 national innovation clusters in Denmark financed by the Danish Agency for Science, Technology, and Innovation. (Service Cluster Denmark, 2015)

The key challenges, which were identified within the strategy concept of cluster to improve service innovation in Denmark, are following: internationalization, productivity, service strategy and management and qualified employees. Internationalization is about exploring practices from cluster members within the internationalization of services. Productivity stands for creating environment and settings to improve quality of services and reducing costs. Meanwhile the third challenge is about implemeting new strategies and concepts into services. In challenge qualified employees Service Cluster Denmark focuses on identifying the main demands of competences which are aimed to improve services. (Service Cluster Denmark, 2015)

The main goal of Service Cluster Denmark is to support innovation and competitiveness among service intensive businesses in Denmark. Cluster contributes to the service innovation by developing new possibilities for cooperation between research and academic institutions and business operating in the field of services. Service Cluster Denmark uses the following tools to foster service innovation: paid, personal membership, online project brokering, 
events and presentations, analysis and evaluation. For example online project brokering is a very usefull tool where members of the cluster can post ideas, contribute to others ideas, find partners and search for funding for service-related development projects. (European Service Innovation Centre, 2015)

Other supporting tools, which cluster uses, are described in the "Promoting Service Innovation through Cluster Initiatives" written by European Service Innovation Centre (2015) or at website of Service Cluster Denmark (http://www.serviceplatform.dk/).

\subsection{Regional level - Northern Central Sweden}

Another case, this time on a regional level, is from Northern Central Sweden. The NUTS 2 region Norra Mellansverige (Northern Central Sweden), with approximately 800,000 inhabitants, consists of three independent NUTS 3 regions of relatively equal size; Värmland, Dalarna and Gävleborg. Recently, the region paid much more attention to the service sector to increase regional competitiveness and employment in the services. (Regional Innovation Monitor, 2012)

According to the Regional Innovation Monitor (2012), three main challenges were identified in the region, such as: "broaden the innovation capacity, increase employment in the service sector and broaden the access to competence." One of the instrument which is region using to deal with these challenges, is supporting clusters through cluster initiatives.

The dominant position in this region had traditional manufacturing industries. In this context it is no surprise that first cluster initiatives were related to the development of traditional industry sectors, such as pulp and paper, steel and engineering. However, this situation is starting to change with the increasing role of services in economy. During the last years, several cluster initiatives were according to the Regional Innovation Monitor (2012) launched to support business in service based industries. Several initiatives in the region of Northern Central Sweden have a specific focus on the development of the service sector which include knowledge intensive services, creative industries, health care and tourism. In the region not only cluster initiatives but also other ways to support the service sector are applied. For example, support infrastructure for the many areas of service sector is on the rise, as Centre for Services Research at Karlstad University (combination of research institutions), support organisations such as the incubator INOVA, project VIVAN aimed to the health care innovation and the office for supporting innovation Four Leaf Clover (Regional Innovation Monitor, 2012). Another project launched by Borlänge municipality of Borlänge called BoomTown was made to stimulate entrepreneurship in the particular sector - music industry (Regional Innovation Monitor, 2012). Other successful example is Destination Dalarna, a cluster initiative, which is "developing an innovative growth environment for companies in the tourism sectoron Swedish and international markets. The initiative runs demand-driven joint development projects for Dalarna, which contributes towards developing the tourist industry and thusthe competitive strength of the region" (State of the Art Country Report Sweden, 2011, p. 12).

\section{CLUSTER POLICY IN THE CZECH REPUBLIC}

The key strategic document within the cluster policy in the Czech Republic is the "Economic Growth Strategy of the Czech Republic" approved by the Czech government on November 19, 2005. This document focuses on five areas which are crucial for the competitiveness in the Czech Republic. The issue of clusters is included in the first priority, where the emphasis is on increasing the intensity of business support, and in the third priority called 
infrastructure, which highlights importance of cooperation between entrepreneurs, universities and regional government. (Pavelková et al., 2009)

Cluster policy on a national level is implemented by National cluster strategy 2005-2008, which is a crucial document about clusters, although it has not been updated since the end of the year 2008. Its main aim is to support clusters in the manufacturing industries. The theme of clusters within the regional level is implemented among regions only marginally. (Pavelková et al., 2009)

Speaking about financial support for clusters, the most important within the Czech Republic are EU structural funds. The first opportunity to get financial resources was available through Operational Programme Industry and Enterprise in the period of 2004-2006, which included programme called Clusters aimed to promote the cluster initiative in two phases: in the identification of clusters and in the establishment of clusters and their development (Pavelková et al., 2009). In the followed programme period it was the Operational Programme Enterprise and Innovation 2007 -2013, which dealt with clusters within Priority Axis 5 "Environment for Enterprise and Innovation" in the programme cooperation-clusters (Pavelková et al., 2009). Nowadays, the applicants can get financial support from Operational Programme Enterpriseand Innovation for Competitiveness 2014 - 2020, which supports activities as collective research, shared infrastructure, internationalization of the clusters and development of cluster organisation (Ministry of Industry and Trade, 2015).

Main actors involved in developing clusters within the Czech Republic are according to Břusková (2014) following:

- Ministry of Industry and Trade - the agenda of his work is integration of cluster support in the OPs of the EU Structural Funds; ministry is also responsible for setting-up strategic priorities for the cluster policy (cooperation, $R \& D$ and innovation, internationalisation)

- CzechInvest - state agency which works as a managing body of the programmes supporting cluster organisations; setting-up rules for cluster organisations funding eligibility

- National Cluster Association - advocacy of the cluster concept and its sustainability within the Czech development strategies, cross-cluster cooperation and internationalisation promotion

- Faculty of Management and Economics, Tomas Bata University in Zlin - the centre of cluster studies and research; the Faculty is also author of the certified methodologies for cluster policies

In case of developing cluster concept, the Czech Republic also as other countries struggles with specific problems and barriers. Some of them were identified by Pavelková et al. (2013b) in the "Certified methodology for the Regional Cluster Policy", namely minimal knowledge and general low awareness of cluster concept. Based on interviews with representatives and regional government of the regions, it was found almost no awareness of the clusters operating in their regions, little or no communication with managers of clusters and total ignorance of the needs of the clusters (Pavelková et al., 2013b). Pavelková et al. (2013b) also point out new possibilities for influencing the strategic development of the regional government. Pavelková et al. (2013b) propose to create a new infrastructure of regional knowledge centers for cluster development ("cluster agencies"), which will carry out activities such as mapping and evaluation of clusters, facilitation of cluster initiatives incubation clusters and their governance, including subsequent monitoring and evaluation of performance of clusters and their impact on regional development. 


\subsection{What we could learn from practices abroad? Recommendation for the Czech Republic}

As presented in the chapter three, Denmark and Sweden made specific programmes to support small and medium sized enterprises in the service sector. These actions led to the succesfull development of specific service industries. In the context of cluster policy within the service sector there is no such thing in the Czech Republic. However, the majority of EU member states created cluster programmes and initiatives focused on supporting clusters in the service sector with the strong emphasis on service innovation. In this context, Rubalcaba (2015) suggests that each country adopts a particular strategy which is connected to past experiences in innovation policies, to the national innovation systems and also to the sectoral service capabilities. Rubalcaba (2015) continues with verdict that policy makers are in many regions not aware of the nature and specifics of service innovation. The main problem is a lack of understanding of what services stand for and their impact for national/regional economic growth. Service-innovation often does not have cover by policy documents and service-innovation culture in policy making is missing. It is no suprise then that many countries tend to traditional manufacturing programs instead of service oriented one which is also the case of the Czech Republic.

Although, it should be noted that service sector in the Czech Republic is undeveloped comparing to other European countries (Ministry of Education, Youth and Sports, 2014). The main driving sector of the Czech economy is manufacturing industry, meanwhile for example knowledge-intensive services (KIS) have lower significance compared to European countries (employment in KIS generates average 40\% within EU, in the Czech Republic only 32\%). One of the positive examples are IT and software services which are starting to have increasing importance and position in the Czech economy. According to the Ministry of Education, Youth and Sports (2014), the Czech Republic has competitive advantage within the service sector in transportation and logistics and tourism which corresponds to the geographical position of the Czech Republic. The Ministry of Education, Youth and Sports (2014) in the "National Research and Innovation strategy for smart specialization in the Czech Republic" also identified sectors (among the services) which have growth potencial, namely IT services and software and healthcare. However, this does not mean that the Czech Republic should only look to support these services, because other areas of services will soon or later rise as in other European countries. Considering these facts, Czech national government/ministries and region policy-makers should start think about giving support to the service sectors in general. Having in mind that European economies are becoming service-oriented and methods and programmes which were applied in EU countries, the Czech Republic shouldaim in future to:

- Create Innovation platform to support cooperation between service enterprises, research institutuons, academic sphere and regional/national government

- Create dedicated centers and clusters which would support service innovation

- Develop cluster and network type of policies that intentionally include services

- Find a ways to motivate potential cluster members within the service sector to cooperate

- Implement goal as service innovation into the cluster policy at national level

In the context of regional cluster policy, it is crucial to first identify and map clusters within the service sector among regions in the Czech Republic. Identification and mapping of these clusters could be managed by cluster agencies which would be created as a new infrastructure of regional knowledge centers for cluster development (Pavelková et al., 2013b). This agenda could be also secured by already established regional councils for innovation and 
competitivness. These institutions work in all 14 regions within the Czech Republic and their main goal is to implement RIS3 - Regional Innovation Strategy (Ministry of Education, Youth and Sports, 2014).

\section{CONCLUSION}

Based on the literature review and collected information, the first step regarding the Czech cluster policy within the service sector should be connected with giving more attention to that sector. Although, as noted, the dominant sector in the Czech economy is still manufacturing industry, the service sector is on the rise among all European countries. The service sectors which have the biggest growth potential within the Czech economy consists of IT and software services and healthcare.

Successful mentioned examples in this paper of cluster policies and initiatives cannot be just copied. Every country has different and unique history, cultural characteristics, specialisiation in industries and other national and regional specifics. However, presented cases should work as an inspiration how to support and develop service sector more effectively. At a national level, it is recommended to implement support for services and service innovation into cluster policy documents and other strategic documents. In the regional context within the service sector, the connection with the regional councils of innovation seems as the right way to go. These institutions, which are aimed for improving innovation and competitiveness, could work on a agenda of identification and mapping clusters in the service sector within the regions of the Czech Republic. After identifyng clusters with a competitive advantage in services among regions, the next step should be connected with mobilisation and involving regional businesses into the process which stands for bottom-up approach. This approach is about mobilisation of regional actors including the private sector with the academic communities and it builds on the inner strengths of each region and its entrepreneurial and competitive advantages. The national and regional policy makers also need to have in mind that if the preconditions for clustering in a country or in a region are absent, they should not create a cluster from scratch and rather focus their attention into different areas.

\section{Acknowledgment}

The authors are thankful to the Internal Grant Agency of FaME TBU project called " The concept of cluster policy impact on the emergence and viability of cluster organizations", which provided financial support for this research

\section{References}

Andersson, T., Schwaag Serger, S., Sörvik, J., Wise Hansson, E. (2004). The Cluster Policies Whitebook, International Organisation for Knowledge Economy and Enterprise Development (IKED): Malmö, Sweden.

Barsoumian, S., Severin, A., van der Spek, T. (2011). Eco-innovation and national cluster policies in Europe: a qualitative review. Brussels: Greenovate! Europe EEIG. 95 p.

Brakman, S., \& Van Marrewijk, C. (2013). Reflections on cluster policies. Cambridge Journal of Regions, Economy and Society, 6(2), 217-231. https://doi.org/10.1093/cjres/rst001

Břusková, P. (2014). Modern Cluster Policy Experience of the Czech Republic, Conference on cluster policy in Russia: Samara. 
CLOE. (2006). CLOE - Clusters Linked over Europe: Cluster Management Guide Guidelines for the Development and Management of Cluster Initiatives. EU INTERREG IIIc Project CLOE - Clusters Linked over Europe. Retrieved from:http://www.rismsk.cz/soubory_texty/34_1.pdf

Cooke, P. (2001). Regional innovation systems, clusters, and the knowledge economy, Industrial and Corporate Change, 10(4), 945-974. https://doi.org/10.1093/icc/10.4.945

Danish Agency for Science, Technology, and Innovation. (2015). The Danish Cluster Policy. Retrieved from: http://www.fbocorridor.eu/files/pdf/09_2015\%2005\%2005\%20DASTI_Morten\%20Solgaard\%20Tho msen_ok.pdf

Dohse, D. (2007). Cluster-based technology policy - the german experience, Industry and Innovation, 14(1), 69-94. https://doi.org/10.1080/13662710601130848

European Commission. (2009). Challenges for EU support to innovation in services Fostering new markets and jobs through innovation. Luxembourg: European Communities. Retrieved from: http://ec.europa.eu/enterprise/policies/innovation/files/swd_services_en.pdf

European Service Innovation Centre. (2015). Promoting Service Innovation through Cluster Initiatives. ESIC website. Morten Wied, DAMVAD. Retrieved from: http://ec.europa.eu/growth/tools-databases/esic/

Europe Innova and Pro Inno Europe. (2008). The Concept of Clusters and Cluster Policies and Their Role for Competitiveness and Innovation: Main Statistical Results and Lessons Learned. Luxembourg: Office for Official Publications of the European Communities. ISBN 978-92-79-09838-3. Retrived from: http://www.clusterplattform.at/fileadmin/user_upload/clusterbibliothek/445_Concept_ of_Clusters_and_Cluster_Policies.pdf

Eurostat. (2008). Nace Rev. 2: Statistical classification of economic activities in the European Community. Luxembourg: European Communities. Retrieved from:

http://ec.europa.eu/eurostat/documents/3859598/5902521/KS-RA-07-015EN.PDF/dd5443f5-b886-40e4-920d-9df03590ff91?version=1.0

Gafurov, I. R., Platonova, O. U., \& Pratchenko, O. V. (2014). New state economic policy cluster policy cluster policy as the factor of innovative development of europe. Mediterranean Journal of Social Sciences, 5(12), 107-111. https://doi.org/10.5901/mjss.2014.v5n12p107

Hospers, G., \& Beugelsdijk, S. (2002). Regional cluster policies: Learning by comparing? Kyklos, 55(3), 381-402. https://doi.org/10.1111/1467-6435.00192

Christensen, T. A., Lämmer-Gamp, T., Meier zu Köcker, G. (2012). Perfect Cluster Policy andCluster Program. Copenhagen/Berlin: Danish Ministry of Science, Technology and Innovation/Competence Networks.

INNO Germany Ag. (2010). Clusters and clustering policy: a guilde for regional and local policy makers [online]. European Union. Belgium. ISBN 978-92-895-0506-2. Retrieved from: http://cor.europa.eu/en/Archived/Documents/59e772fa-4526-45c1b679-1da3bae37f72.pdf

Ketels, C. (2013). Recent research on competitiveness and clusters: What are the implications for regional policy? Cambridge Journal of Regions, Economy and Society, 6(2), 269284. https://doi.org/10.1093/cjres/rst008

Knorringa, P., Meyer-Stamer, J. (1998). New dimensions in local enterprise co-operation and development: from clusters to industrial districts, ATAS Bulletin XI.

Lindqvist, G., Ketels, C., Sölvell, Ö. (2003). The Cluster Initiative Greenbook. Stockholm: Ivory Tower. 
Martin, R., \& Sunley, P. 2003. Deconstructing clusters: Chaotic concept or policy panacea? Journal of Economic Geography, 3, 5-35. https://doi.org/10.1093/jeg/3.1.5

Ministry of Education, Youth and Sports. (2014). National Research and Innovation strategy for smart specialization in the Czech Republic (National RIS3 strategy) [online]. Czech republic. Retrieved from: http://www.msmt.cz/strukturalni-fondy/ris3strategie-cr

Ministry of Industry and Trade. (2015). Operational Programme Enterprise and Innovation for Competitiveness 2014 - 2020. Retrieved from: http://www.mpo.cz/dokument157496.html

Nowakowska-Grunt, J., Jelonek, D., \& Koscielniak, H. (2014). Logistics' clusters as a part of regional policy in poland. Paper presented at the 2014 International Conference on Advanced Logistics and Transport, ICALT 2014, 206-210. https://doi.org/10.1109/ICAdLT.2014.6866313

Obadić, A. (2013). Specificities of EU cluster policies. Journal of Enterprising Communities, 7(1), 23-35. https://doi.org/10.1108/17506201311315581

OECD. (2007). OECD Reviews of Regional Innovation: Competitive Regional Clusters. Paris: OECD

Pavelková, D., et al. (2009). Klastry a jejich vliv na výkonnost firem. 1. vyd. Praha: Grada, 2009. ISBN 978-80-247-2689-2.

Pavelková, D., et al. (2013a). Certified methodology for the National Cluster Policy. Zlín: Tomas Bata University in Zlín, Faculty of Management and Economics. ISBN 97880-7454-326-5. Retrieved from: http://www.nca.cz/upload/nkp.pdf

Pavelková, D.,et al. (2013b). Certified methodology for the Regional Cluster Policy. Zlín: Tomas Bata University in Zlín, Faculty of Management and Economics. ISBN 97880-7454-327-2. Retrieved from: http://www.nca.cz/upload/rkp.pdf

Porter, M. (1990). The competitive advantage of nations. New York: The Free Press. https://doi.org/10.1007/978-1-349-11336-1

Regional Innovation Monitor. (2012). Regional Innovation Report (Northern Central Sweden) [online]. Retrieved from: https://ec.europa.eu/growth/toolsdatabases/regional-innovationmonitor/sites/default/files/report/northern_central_sweden_region_rim_report_12041 2.pdf

RUBALCABA L. (2015). Service innovation in developing economies: Policy rationale and framework. Emerging Markets Finance and Trade, 51(3), 540-557. https://doi.org/10.1080/1540496X.2015.1026694

Service cluster denmark. (2015). Facts and Features of Service Cluster Denmark. Retrieved from:

http://www.serviceplatform.dk/sites/default/files/download/SP\%20pixiebog_tryk_ENGLISH -0.pdf

State of the Art Country Report Sweden. (2011). Research driven clusters. European Commission - Lifelong Learning Programme Retrieved from: http://www.innosee.eu/en/publications/research-driven-clusters-europe-sweden/

Steiner, M., \& Hartmann, C. (2006). Organizational learning in clusters: A case study on material and immaterial dimensions of cooperation. Regional Studies, 40(5), 493-506. https://doi.org/10.1080/00343400600757494

Swann, P., \& Prevezer, M. (1996). A comparison of the dynamics of industrial clustering in computing and biotechnology. Research Policy, 25(7), 1139-1157. https://doi.org/10.1016/S0048-7333(96)00897-9

Truel, J., \& Volkov, S. K. (2015). Implementing a successful cluster policy: French experience. Revista Galega De Economia, 24(1), 111-120. 
Wolman, H., \& Hincapie, D. (2015). Clusters and cluster-based development policy. Economic Development Quarterly, 29(2), 135-149. https://doi.org/10.1177/0891242413517136

Contact information

Martin Horák

Tomas Bata University in Zlín

Faculty of Management and Economics

Mostní 5139, 76001 Zlín

Telephone number: 728483184

Email:mhorak@fame.utb.cz

DOI: https://www.doi.org/10.7441/dokbat.2016.17 


\title{
CRM SYSTEM IN SMALL AND MEDIUM-SIZED ENTERPRISES
}

\author{
Adéla Chromčáková
}

\begin{abstract}
This paper presents outputs of literature review on the topic of customer relationship management in small and medium-sized enterprises in business and management journals. In accordance to support narrative form of literature review a co-word analysis of abstracts from major articles on CRM was used. The aim of this paper is to identify the development of major topics within the CRM systems in SMEs and show possible directions for future research in the field. It also provides insight into research approaches, strategies and techniques used within the period from $2007-2013$.
\end{abstract}

Keywords: customer relationship management, CRM system, small and medium-sized enterprises (SMEs), co-word analysis

\section{INTRODUCTION}

The customer relationship management is considered as a major help for enterprises. Based on quality information and customer relationships it enables companies to determine the prediction of behavior and needs of consumers and subsequent fulfilment of these requirements. However, it is generally known that this system is dominantly used in large companies. These companies own sufficient resources and expert knowledge to effectively work with CRM system. Necessity is not to forget on the small and medium-sized enterprises, which hold a major part of entrepreneurships in our country. In this paper the definition of small and medium-sized enterprises by European Union is used.

This paper has a purpose to provide the literature review based on analysis with the VOSViewer program using. The literature review is in field of CRM system and small and medium-sized eneterprises. This information are important for future scientist research of the topic.

\subsection{Customer relationship management}

With the progressive development of business the options for managing relationship with existing and potential customers developed as well. This development of customer relationship management has to be managed to progressively gain the relevant information about consumers and also record these information continuously.

The primary author of ideas about customer relationship management is Levitt (1960), who emphasizesthat companies should focus on fulfilling the needs of its customers and not only sell a product or service. Day and Wensley (1983) extended this idea and defining the customer relationship management (CRM) as system, which enables to get detailed informations about customers and then use these information to customize their offers which are better connected with customer's needs than is in the case of competitors. Payne and Frow (2005) summarized the definition of CRM into three aspects (see. Figure No. 1) narrowly and tactically as a concrete implementation of technological solutions; CRM as implementation of integrated range of customers and CRM system is strategically and broadly defined - as a comprehensive approach to manage customer relationship management to create a value for shareholders. 


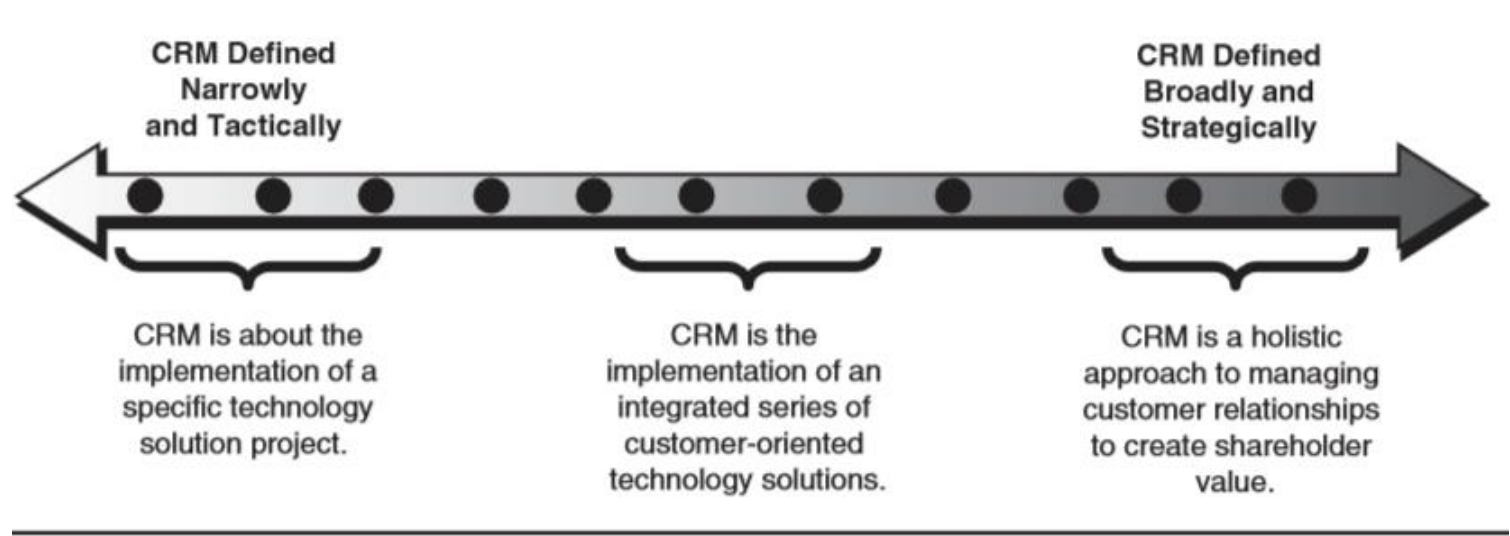

Figure 8 - The CRM Continuum. Source: Payne and Frow (2005)

Another marketing academics have focused their attention to the basic abilities of enterprises that are required for developing and maintaining good customer relationships. Specifically they engaged with analysis of "three C" that is customer, company, competitor. The results of this analysis are concepts such as a market orientation, (Kohli a Jaworski 1990; Narver and Slater 1990), market focus (Day 1994) and market training (Vorhies and Morgan 2005), which are used for creation of high - quality information processes and abilities to understand the needs and desires of customers. Therefore, the CRM system is associated with differentiation of business strategy which allows individual companies to achieve better results (Day a Wensley 1983). At the beginning it was comprehend only as CRM software. One of the first definition is providedby Kotler and Armstrong (2004) regarding the customer relationship management is mentioned as a special software program analysis technology which is used to integrate and use of huge amounts of data about individual customers listed in databases. According to the authors Payne and Frow (2005) was CRM system initially considered mainly for information technology (IT) to the customer solutions, for example as sales force automation. However, today's CRM is perceived as a holistic approach to the customer relationship managemet to create values for enterprise owners. Mentioned authors also reported numerous definitions about CRM system. Their definitions range from implement the specific technological solutions to comprehensive of customer relationship management, which simultaneously creates a value for consumers and also for enterprise, but this multitude of definitions caused significant confusion. Parvatiyar a Sheth (2001) noticed that a requierement for the unification of emerging fileds with already established area is to determine an acceptable definition, which characterize the main aspects of the concept. Payne and Frow determined this definition : CRM is related to strategy, managing a double value creation, an intelligent use of data and technology, obtaining the information about customers and spreading this knowledge to interested enterprise, the development of relevant (longterm) relatinoships with specific customers or groups of customers, an integration of processes across many areas of the company and through the companies network that work together to create values for customers. Other authors of CRM definition are Knox et. al. (2003) who perceive CRM system as strategic approach focused on enhancing of shareholder value through the development of relatinoships with key customers and segments which unite the potencial of information technology and marketing strategies for long-term profitable relationship. They also defined the CRM as an expression of the company to a stronger customer focus and show the top management the significant improvement of company performance through the quality of relationships with customers. However, Buttle (2009) 
and Karaskostas et. al. (2004) say that the various elements also represent different definitions. Buttle (2009) took the definition to another level and that is on strategic, operational and analytical dependence as a whole constituting definition. He perceives a strategic CRM system as a customer-oriented company culture with operational CRM which represents the automation of the customer towards towards enterprise part, while analytical CRM uses the customer information to enhance the consumer's and company value. Already there are a lots of definitions and konwledges about implementation or efficient work with customer relationship management. Variety of opinions on CRM systems effectivity exists as well. Individual authorsagree on the basic idea that quality of CRM system guarantees the future long-term prosperity of the company, but it is important this system efficiently managed and that could be a problem of many companies. Boulding (2005) with his colleagues says that CRM is focused on customer, not just to build the relationship with customers using systems for data collection and analysis, but it also includes the integretation of all these activities across the company. Deighton (2005) says that the area related to the consumers confidence could significally weaken the function of CRM system. Especially if customers lose their confidence and they are convinced that these obtained informations are used only for the purpose of their abuse, they are trying to hide their private data or contrarily distort this data.

\subsection{Small and medium-sized enterprises}

Small and medium-sized enterprises has an important role in the economies of nations and contribute to the economic growth through constant creation of new jobs even in time of economic crisis. Increasing number of small and medium-sized enterprises adopt an electronic trading with flexibility and an ability to respond to new opportunities and innovations (Sudhakar a Ravindran, 2012). Despite the importance of SMEs in terms of creating new jobs and production, these companiesin contrast with the large ones are facing the problem in obtaining external funds. These limitations restrict the growth and develop of enterprises. SMEs struggleswith gaining the financial resources from the bank sector and it is for several reasons, for example an insufficient collateral, difficult solvency proving, weak cash flows or high transaction costs (IFC, 2009).

As mentioned above, SMEs are very important part of the economies of individual countries, however, the definition of small and medium-sized enterprises is not uniform. To clarifythis definition, the classification by the European Commision or by law of SMEs support in particular countirees exists. Complience with the Czech statistical office from 1997 are companies divided into 3 groups according to the number of employees:

Table1 Structure of SMEs. Source: Czech Statistical Office

\begin{tabular}{|l|l|}
\hline Enterprises & Number of employees \\
\hline Small & up to 20 employees \\
\hline Medium & up to 100 employees \\
\hline Large & 100 and more employees \\
\hline
\end{tabular}


In contrary to the statistical dividing the European Commission presents different quantitative criteria for the classification of SMEs, namely the following four criteria: 1. the number of employees, 2. an annual turnover, 3. an annual balance sheet, 4. an independence.European Commission also classify the micro, small and medium enterprises. Company which employs 10 employees and annual turnover is up to 2 million EUR or atotal annual balance sheet is up to 2 mil. EUR falls into a category of micro enterprise (od small enterpreneur). Small enterprise is limited up to 50 employees, annual turnover up to $10 \mathrm{mil}$. EUR and the total annual balance sheet is up to 43 mil. EUR. The medium-sized enteprise employs maximum of 250 employees, annual turnover 50 mil. EUR and total annual balance sheet up to 43 mil. EUR (Veber and Srpová, 2012).

\subsection{CRM system in small and medium-sized enterprises}

Two views on the issue of CRM exist based on the previous research and published scientific articles about the topic. The first view is mainly concern about ownership and managing of this system for many reasons. The second view is already implemented system in SMEs, but these companies do not have sufficient knowledge to properly and effciently work with this system. The CRM system is a regular part of large companies, but CRM is not common in small and medium-sized enterprises. The most of SMEs do not implement this system for several reasons - the lack of knowledge about CRM, the lack of resources or insufficient professional knowledge to implement this system. It is essential that SMEs have started with the implementation of information system (IS) in their trade operations with the aim to improve the company value and obtain the major competitive advantage in market. The CRM system has the potential to improve the company values and competitiveness of SMEs. The majority of SMEs do not realize the benefits that CRM provide (Boon et. al., 2011). Marinescu et. al. (2007) say, that one of the reasons why companies do not implement the CRM system is that top management have a concern, because theyhave lack enoug knowledge and they do not know how they can work with this system. That means the lack of support from top management and barriers for employees to create this system. Primarily the Czech companies have not sufficient knowledge and do not realize the consequences of this situation. It is difficult to motivate the employees if the top management remains unconcerend. It is therefore necessary to begin with changes of thinking of top management. Only in this way companies can work quality and with mutual advantage to use customer relationships (Starzyczná et. al., 2007).Another reason that the SMEs refuse to work with system is the lack of financial resources. A lots of enterprises state this reason - the company does not have sufficiency resources for this system. One solution of this problem is the possibility to use the financial support which offer our country or European Union. Another way to solve this problem with resources is using the CRM system which is provided for free, for example by online Google documents or simple making of Excel tables. However, on the base of research which was realized by Stoklasa (2012), if company works with CRM system they do not know their key customers and on this way it is not possible to work with system correctly.

If SMEs have own information technology and sufficient professional knowledge, they can make own CRM system. Nevertheless, there are already a lots of sellers, who offer various CRM applications with extensive possibilities for using. A problem occurs in the right choice of CRM for company (Starzyczná et. al, 2007). 


\section{METHODS}

As mentioned in the Introduction the aim of this paper is to identify the development of major topics within the CRM systems in SMEs and show possible directions for future research in the field of dissertation thesis. The possibilities for future research are based on co-word analysis with using VOSviewer software. The VOSviewer (VOS) is software which is useful for creating, visualizing and exploring bibliometric maps of science and the aim is to provide the visualization of objects which are located in distance between any pair of objects. The program is available for free and it can be used for analyzing all of bibliometric network data (Van Eck \& Waltman, 2010). The program can be used to construct maps of authors based on co-citation data or maps of keywords on co-occurrence data. The VOS supports creating term maps which are based on a corpus of documents. This term map has two dimension in which are interpreted as an indication of the relatedness of the terms. If the distance between two terms is small that means the strong relation between them. The VOS can only handle English language documents(Van Eck \& Waltman, 2011).

For the VOSviewer analysis of 500 articles from the Web of Science which were found according to the keyword: CRM was used. The Web of Science have a lots of articles about CRM system in generally or CRM for large companies and that is reason why was necessary to add another keyword for better comparison : SMEs.

\section{RESUltS}

Firstly the VOS program for co-word analysis was used (see. Figure No. 2). This term map was created based on a corpus of publications from journal about the CRM system and small and medium-sized enterprises. This corpus was extracted from the Web of Science database from the Journal of Marketing because of the near terms of the topic. Using the text mining of VOSviewer a term map was created based on the titles and abstracts of 500 publications in the period 2006 - 2016. Out of the 1570 noun phrases that occur at least 10 publications in the corpus. The term map contains about 150 noun phrases which are the most relevant.

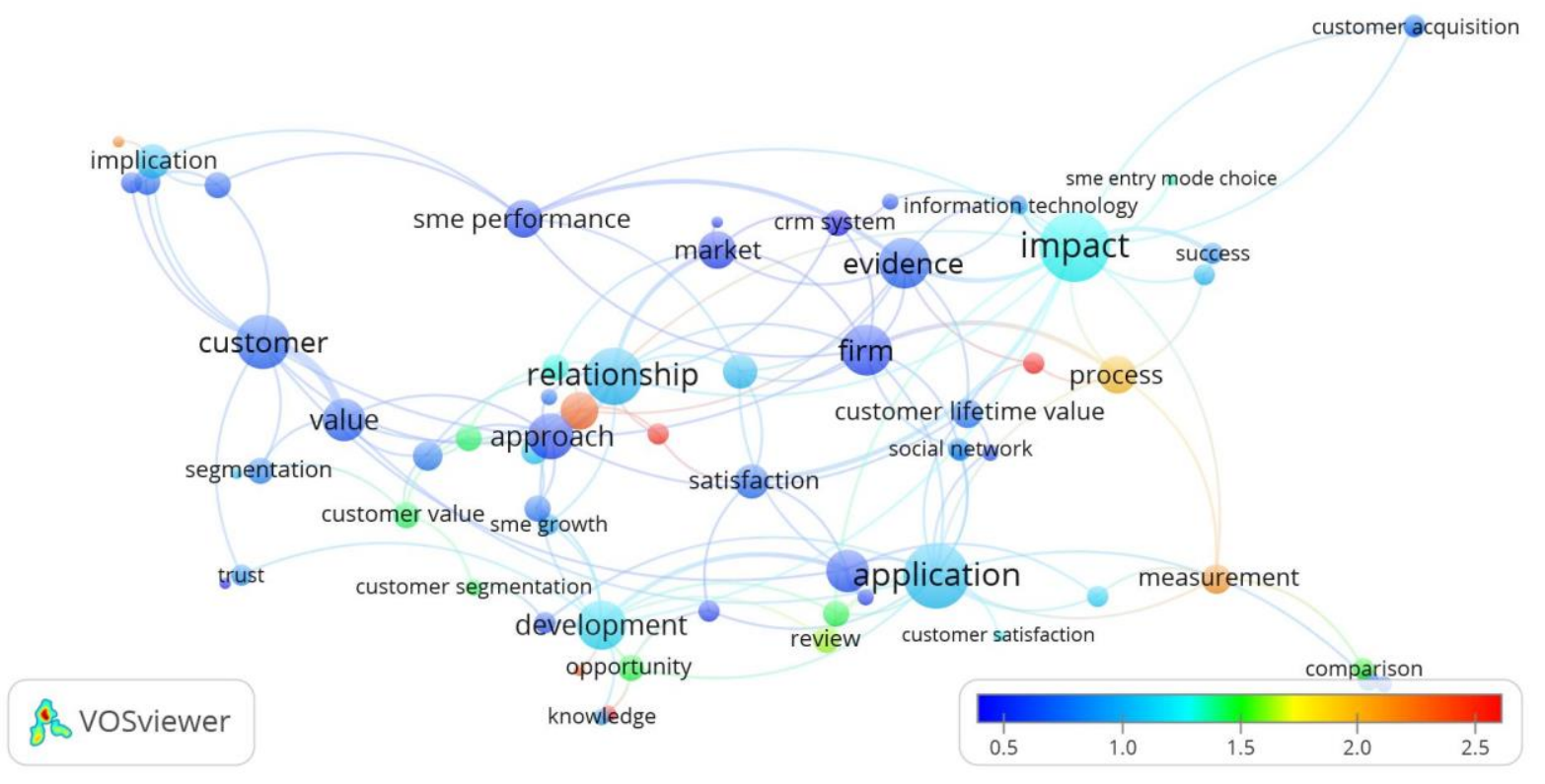

Figure 9 - The term map of the Journal of Marketing. Source: Author's work 
The color of a term indicates the average citation impact of the publications. Color range from blue (the lowest citation impact) to red (the highest citation impact). The cluster size shows the occurrence number of words. As can be seen in the map (see. Figure No 2) the main keywords of CRM system are in four clusters - the impact, application, relationship and customer. The word: impact is mostly connected with words: evidence, satisfaction, SME performance, development or measurement. The impact is not connected with the word: firm or customer. The relationship is connected with the market and the application is mostly connected with firm. The word: customer have connection with value. Another smaller but important clusters are: evidence, firm and development. Based on articles from the WoS database from the Journal of Marketing are only two words about SMEs, for example SME performace which is connected to the firm and evidence or SME entry mode choice have connection only with impact. This analysis is for future research of academic articles wich are written in field as mentioned.

The second step of using the VOSviewer in this paper is a term map of co-author analysis (see. Figure No. 3). This map was created based on 500 academic publications from the Web of Science. 121 authors that occur at least 5 publications in the corpus. The map shows 121 items in 17 clusters but the main authors are in five clusters.

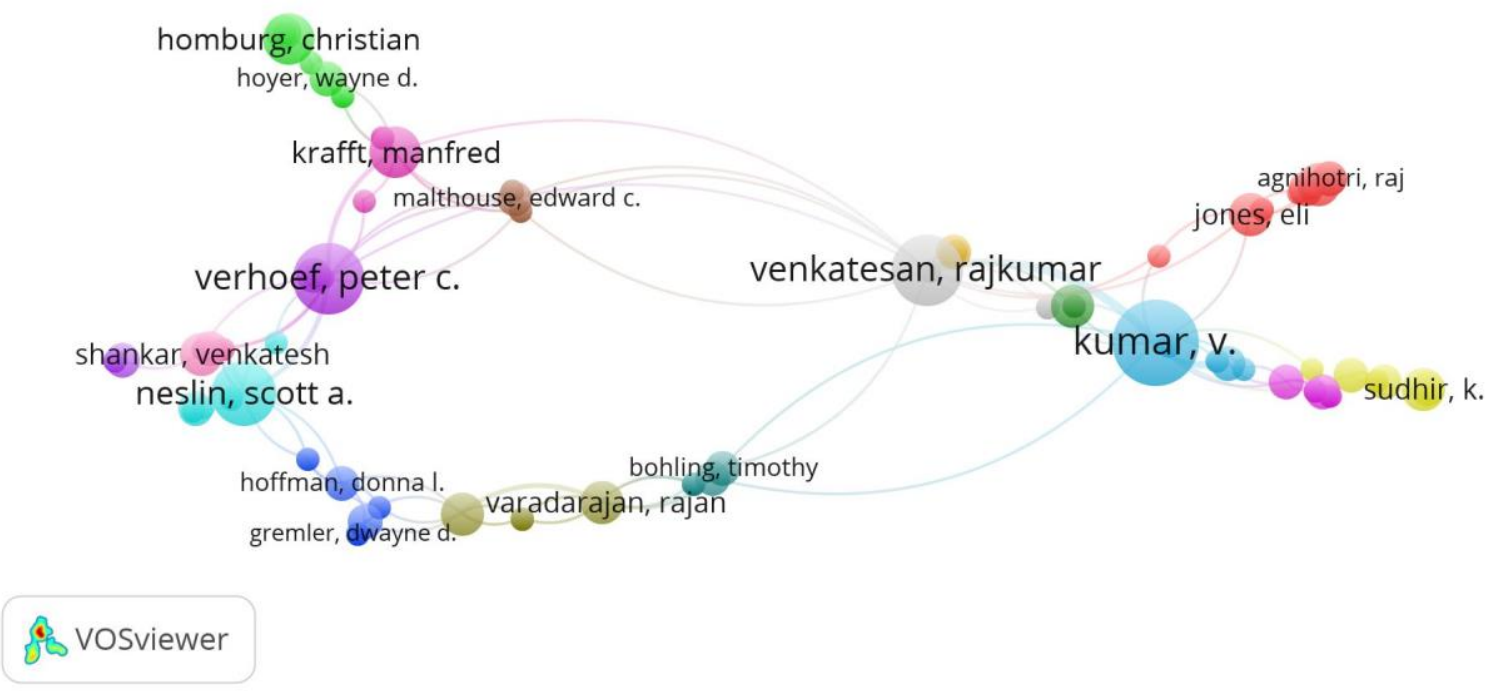

Figure 10 - The VOSviewer map of marketing academics. Source: Author's work

As can be seen the first and main cluster is author Kumar V. who is the most citated author. Kumar focuses on the customer lifetime value, customer needs and long-term customer relationship management. He says that relationship marketing emphasizes the need for maintaining long-term customer relationships and with Reinartz WJ. developed a framework profitability of customers in the computation of lifetime duration. The most often co-authorship is with Venkatesan Rajkumar who is market oriented and focus on the impact of multichannel shopping on customer profitability. His publications are also with Kumar V. and with Krafft Manfred. Krafft M. focus on customer management and on the question: How to manage relationships with customers effectively. He also often cooperate with Reinartz WJ. and with Verhoef Peter C. Verhoef is an author who writes mainly about customer experience management and customer engegament and cooperates 
with Neslin Scott A., who focuses on multichannel customer management and on the research-shopper phenomenon.

As mentioned above the main clusters of authors focused on customer - customer needs, lifetime value, engegament, shopping etc. These authors do not divide the size of enterprises (large, small or medium-sized enterprises). It means that from the Web of Science database are not too many authors who are interested in about CRM system in SMEs.

\section{Conclusion}

Based on the researches by Starzyczná (2007) and Stoklasa (2013) and published scientific articles is the CRM system in small and mediun-sized enterprises already implemented, but the companies have problem with sufficient knowledge to properly and effciently work with the system in one way. In second way the enterprises do not use this system, because they have a lack of financial resources and the top management of company do not see any advantage of the CRM system. Nowadays, there are a lots of free available programs that can be used for database about customers, but the question is if the company know about it or they only do not want to use this system because of the lack of time, any responsible employee or as mentioned above they do not see any advantage of using it.

The analysis based on VOS software shows the main authors in five clusters who are the top academic scientists in CRM area. Interesting information based on VOSviewer analysis and the Web of Science databse is that are not too many world scientists who are interested in area of CRM in small and medium-sized enterprises however, in European Union are the most companies just small and medium-sized.

\section{References}

Boulding, W, Staelin R., Ehret M. and J. Johnston W. (2005), A Customer Relationship Management Roadmap: What is known, potential pitfalls, and where to go, Journal of Marketing, 69 (October), 155-166. https://doi.org/10.1509/jmkg.2005.69.4.155

Buttle, F. (2009), Customer relationship management: concepts and technologies. 2nd ed. Amsterdam: Butterworth-Heinemann. ISBN 9781856175227.

Day, G. S., and Wensley, R. (1983). Marketing theory with strategic orientation. Journal of Marketing, 47(4), 79-89. https://doi.org/10.2307/1251401

Day, G. S. (1994), The Capabilities of Market-Driven Orga- nizations, Journal of Marketing, 58 (October), 37-52. https://doi.org/10.2307/1251915

Deighton, J. (2005), Privacy and Customer Management, Customer Management, (MSI conference summary). Cambridge, MA: Marketing Science Institute, 17-19.

Karakostas B, Kardars D, Papathanassiou E (2004). The State of CRM Adoption by Financial Services in the UK: An Empirical Investigation, Information \& Management: Elsevier.

Knox M, Maklan S, Payne A, Peppard J, Ryal L (2003). Customer Relationship Management: Perspective from Market Place, Oxford: Butterworth.

Kohli, Ajay K. and Bernard J. Jaworski (1990), Market Orienta- tion: The Construct, Research Propositions, and Managerial Implications, Journal of Marketing, 5 (April), 1-18. https://doi.org/10.2307/1251866

Kotler, P., Armstrong, G. Marketing (2004). Praha: Grada Publishing. ISBN 80-247-05133.

Levitt, T. (1960), Marketing Myopia, Harvard Business Review, 38 (July -August), 45-60. 
M. M. Marinescu, C. Mihaescu, and G. Niculescu-Aron (2007). Why should SME adopt IT enabled CRM strategy? Informatica Economica Journal, pp. 109-112.

Narver, John C. and Stanley F. Slater (1990), "The Effect of a Market Orientation on Business Profitability," Journal of Marketing, 20 (October), 20-35. https://doi.org/10.2307/1251757

Parvatiyar, A., and Sheth, J. (2001), Customer Relation- ship Management: Emerging Practice, Process and Discipline, Journal of Economic and Social Research, 3 (2), 134.

Payne, A., and Frow, P. (2005), A Strategic Framework for Customer Relationship Management," Journal of Marketing, 69 (October), 167-76. https://doi.org/10.1509/jmkg.2005.69.4.167

Starzyczná, H. (2007). Metodologie marketingu vztahů a její postavení v rámci strategického marketingu a ř́zení vztahů se zákazníkem (CRM) - praktické využití. V Karviné: Slezská univerzita v Opavě, Obchodně podnikatelská fakulta. ISBN 978-80-7248451-5.

Stoklasa, M. (2013). Využití vztahového marketingu v podnikání malých a středních firem: védecká monografie. Vyd. 1. Karviná: Slezská univerzita v Opavě, Obchodně podnikatelská fakulta v Karviné. ISBN 978-80-7248-936-7.

Sudhakar, S. and D. S. Ravindran (2012), Adoption of customer relationship management technologies among Indiand small and medium enterprises- a review and suggested model. Eur. Journal of Social Scientific, 8: 538 - 548.

Van Eck, N.J., \& Waltman, L. (2010). Software survey: VOSviewer, a computer program for bibliometric mapping. Scientometrics, 84(2), 523-538. https://doi.org/10.1007/s11192-009-0146-3

Van Eck, N.J., \& Waltman, L. (2011). Text mining and visualization using VOSviewer. ISSI Newsletter, 7(3), 50-54.

Veber, J., a Srpová, J. (2012). Podnikáni malé a střední firmy. 3., aktualiz. a dopl. vyd. Praha: Grada, 332 s. Expert (Grada). ISBN 978-80-247-4520-6.

Vorhies, D. W. and A. Morgan (2005), Benchmarking Marketing Capabilities for Sustainable Competitive Advan- tage, Journal of Marketing, 69 (January), 80-94. https://doi.org/10.1509/jmkg.69.1.80.55505

Webový portál Enterprise surveys [online] [vid. 18. listopadu 2015]. Dostupné z: http://www.enterprisesurveys.org/; Beck et al (2008b).

\section{Contact information}

Adéla Chromčáková

Silesian University in Opava

School of Business Administration in Karvina Address

Telephone: +420 777060303

Email: chromcakova@opf.slu.cz

DOI: https://www.doi.org/10.7441/dokbat.2016.18 


\title{
POSITION OF LOGISTICS IN ORGANIZATIONAL STRUCTURES - TRENDS
}

\author{
Jan Jakeš
}

\begin{abstract}
The aim is a description of the different types of organizational structures in companies, their strengths and weaknesses, and trends in the organizational structures. Than is described the position of logistics in organizational structures, different logistic systems in organizational structures from practise. The next section describes the structure of logistics centrally managed for manufacturing companies and types of information flows across the logistical structure of production. In conclusion are mentioned the latest trends in the structures of business logistics and the potential contribution of this work.
\end{abstract}

Keywords: Organizational structures of the company, the position of logistics in organizational structure, links beetween logistics and other department, centrally controlled logistics, information flows, globalization, trends, materials and components, production planning, business logistics.

\section{INTRODUCTION}

The aim of this paper is to describe the various organizational structures and the latest trends, the position of Logistics in the organizational structure, various types of organizations of logistics. From my perspective this is an interesting topic, which almost does not occur in professional publications of organizational structures in general and in scientific publications about logistics is their position in the organizational structures mentioned rarely. Regarding the current organizational structures in logistics, I drew mainly from my twelve-year experience in the logistics of various manufacturing companies. Status of logistics in the organizational structures of enterprises is a current topic, while other departments within the organizational structure regularly appear in various forms, logistics services begin to appear in the last 30 years. Professional literature about the status of procurement and logistics is chary and any information in this area as in IT and a marketing quickly becoming obsolete. The organizational structures of individual firms mentioned in specialized publications such Lambert, Stock, Ellram (2005) are likely have changed in real time, especially if it is a rerelease edition.

\section{TYPES OF ORGANIZATIONAL STRUCTURES}

Corporate organizational structure should be designed so as to create the best possible environment to achieve business objectives. Therefore there is no universally usable optimal organizational structure. For each company should be "tailored" according to his needs and it primarily it should support for the implementation of corporate strategy. Classical organizational structures have undergone a long evolution. They achieved some stability and transparency in the functioning of the company and created important preconditions for high discipline in fulfilling tasks. However these organizational structures are complex and difficult to control and they are often not very flexible and adaptable. The present time is full of turbulent change and it requires an ability to continuously cope with these changing conditions. Quality requirements rise, constantly are developed information and communication technologies. Current trends in the management of the organization are in ensuring the availability, flexibility, ability to adapt to the changes that occur in the market, by the competition and in the global environment. The trend is to reduce organizational levels, because just this direction enables highly efficient and flexible management. 


\subsection{Methods for generating organizational stucture}

The aim of the work is not to exhaustively describe all known types of organizational structures and their combinations, but the basic types and trends in the structure of enterprises will be described. As indicated Cejthamr and Dědina (2010), the nature of pyramidal organizational structures was born long evolution, but it was always influenced by specific economic, technological and social conditions of the place. Classification of organizational structure is not uniform, by developing are created hybrid organizational structures that is hard to describe.

The basic organizational structures based on the division of powers are:

- line (linear),

- staff,

- combined.

Organizational structures based on activities or their results are:

- functional,

- hybrid,

- centers,

- project,

- matrix,

- product,

- divisional,

- strategic business units.

\subsubsection{Line (linear) organizational structures}

These structures were the first stage of development of the organizations that were small in scale and in which there was only one management level, which was usually a business owner. In another development are starting to created more levels of management, which also brings new problems with demands on expertise of leadership and to fulfill support tasks. All this led to the formation of other types of organizational structures (e.g. linear - staff or functional). Linear structures include the direct command authority. Cejthamr and Dědina (2010) reported that linear structure is typical of the stage of development of small enterprise to about fifty employees. Beyond a certain size range a leader is no longer able to manage all subordinates. Than are created a specialized staff and talk about linear - staff organizational structure.

\subsubsection{Staff organizational structures}

Staff services are primarily designed to ensure a qualified decision of making line managers in their departmental units. Staff group consists of specialists in various fields and can be divided into personal staff line managers and professional staff that performs an indirect professional management. Staff organizational structure cannot exist independently in this sense but only in combination with linear, functional or other organizational structure. Smaller companies that are trying to implement logistics systems, and have not a necessary experience with modern logistics and can not afford to implement all the logistics department, often approach the establishment of logistics staff. It has a mostly advisory role, drawing up the strategy, but does not participate directly in the implementation and operation of logistics activities and chains. 


\subsubsection{Linear - staff organizational structures}

These structures may be linear, but much more frequent are multilinear structures. They arise at the moment when the unit with linear competence delegates a part of their decision-making powers to a staff organizatinal unit. From that becomes an organizational unit with some linear and some staff responsibilities. Often companies are facing difficulties in growth by adding more specialists and then creating complex hybrid structures with three or more levels of management. If the operation of the logistics staff mentioned above settles into the form, that permanently manages all logistics processes, it becomes a solid component within the linear staff structure.

\subsubsection{Functional organizational structures}

Functional organizational structures are structured by grouping workers into sections based on the similarity of tasks, skills and activities. The most common application of this structure can be found in midsize businesses that achieve top performance in the production of a small number of products that require a high level of specialization. One section head then manages the entire section, in which are grouped tasks and competences. Cejthamr and Dědina (2010) mentioned that although the functional organizational structure is considered as traditional and classic, its modification until recently have used or still use the tech leaders such as IBM or Apple. Regarding logistics, the higher a share of logistics costs in total costs and the more increases the risk of losses from bad logistics decisions, the more confidently the company will aim to create a central forms of logistical organization. Whether a company chooses hierarchically lower form a central logistics unit in the form of logistics department, or whether to choose a higher form such as a division, it is primarily influenced by a range of logistics activities in the company.

\subsubsection{Hybrid organizational structures}

Hybrid organizational structure combines functional and divisional structures. Logically strengthens the pros of both structures and suppresses the shortcomings. This structure consists of divisional units, but also includes functional sections centralized in top management.

\subsubsection{The organizational structure of the centers}

In an effort to simplify bloated and complicated organizational structures are also used economic centers in the linear - staff cultures. They occur in partial or complete decentralization of decision-making powers. Head of such economic center may be considered to some extend as "independent entrepreneur" within the whole company. Centers are most often used as cost, profit, investment, revenue and expenditure centers.

\subsubsection{Project organizational structures}

They are primarily increasingly difficult and complex tasks that require a systematic approach and at the same time grouping of nontraditional collectives. These groups are called organizational project teams. There are concentrated specialists from different professions in. In principle, there is a temporary type of secondary structure relative to the existing organizational structure. 


\subsubsection{Matrix organizational structures}

This group tries to combine the functional structures and the above mentioned project structures. It is characterized by a dual subordination, because the workers involved in the project to receive tasks as from project manager and from their functional executives.

\subsubsection{Product organizational structures}

Those structures are designed for large diversified companies. There are in one organizational unit that is responsible for one product type associated all the management activities. Ceithamr and Dědina (2010) state that this product structure utilizes holding Unilever. At the same time it uses a competitive holding company Procter \& Gamble.

\subsubsection{Divisional organizational structures}

Divisional structure is included to modifications of product organizational structures. Generally is stated that divisional organizational structures are selected in the case that the functional organization grows, operates in a dynamic environment and it is no longer capable of the required performance. The division is divided into individual relatively independent units, broken down by kind of product or service, geographic location or type of customer.

\subsubsection{Strategic business units (SBU)}

Where they are required specific knowledge production, sales and environments, are created by some large companies strategic business units from approximately 70 years of the 20th century. They are largely independent of management and inherently they carry out business within the company. The advantage is the combination of independence and direct link to the management.

\subsection{Trends and developments in the organizational structures}

As mentioned earlier, today's ever-accelerating environment requires new innovations as well as in the area of organizational structure. It is necessary to constantly cope with rapidly changing market conditions, competition, the rising quality requirements, rapid development of information technology, long periods of low growth and the persisting crisis. Traditional approaches are no longer sufficient and require modification. These classical approaches emphasize only one superior, on the precise definition of the role of the individual in the organization and its precise definition of competencies. A significant trend, however, becomes a release of hierarchical organization. Organizational levels are lower and organizational pyramids are flatter. Priority is given to two or three-stage management. Top manager is no longer dealing with the details, but delegates the authority and responsibility to lower levels. All this leads companies to experiment with unconventional organizational structures.

Among the traditional organizational structures includes:

- Process structures,

- Network organizations,

- amoebas, 
- slender structures,

- fraktalization,

- virtual organizations.

\subsubsection{Process structures}

Process management is looking at the organization as a set of processes. It establishes responsibilities for individual processes. Process owners are able to efficiently manage processes to maximize the value added by the customer and then figuratively achieve profitable growth. Process management introduces a flat organizational structure, which utilizes an autonomous organizational units which are linked by strong horizontal linkages. The aim is to create an organization with few levels, which offers companies greater flexibility to meet specific customer needs.

\subsubsection{Network Organizations}

Network organizations are formed on the basis of cooperation agreements between small and middle companies. Participants in the network are connected to each other by agreement, which brings benefits in terms of cost reduction, access to new technologies, access to new markets and faster innovation. In a sense, this group of companies is controlled spontaneously, there is no top management that would define the direction of the group.

\subsubsection{Amoebas}

Amoebas are loosely bound, organizational network structure without hierarchical arrangement. They function like a separated and independent companies, which have full responsibility as independent entrepreneurs. Most amoebas are sales or production units, which can buy and sell both inside and outside the company. If a company develops a new product, create a new ameba, after completion of the production program may disappear. For bigger flexibility amoebas lend to each other employees. The structure of the organization is flat.

\subsubsection{Lean organizations}

Lean organizations are based on creating teams with many tasks and powers, which in trying to perfect the implementation of all activities often utilize Kaizen methods. Production structure is very simple, hierarchical management levels and competencies are suppressed and organizational structure is maximally flat. As indicated Dědina and Malý (2005), the introduction of flat structures characteristic of a small number of organizational levels of the organizational pyramid is one of the main conditions for implementation of lean structures. As mentioned earlier, many companies striving for maximum lean manufacturing to be able to deal with increasingly frequent changes in the market, the competition on a global scale. In the past ten years we can notice that the company have demanded on the labor market a position "lean manager" that is looking for someone who is in the organizational structure reported directly to the $\mathrm{CEO}$ and is responsible for general implementation of lean manufacturing, lean operations and inventory levels and lean organizational structure. On the other hand, very frequent changes and fluctuations in customer demand mean a higher risk in organization with slim structure. Macurová (2011) mentions that organizations seeking to 
slim operations and lower stock levels are more vulnerable to unforeseen events and even relatively short delays in traffic can cause disruption of manufacturing operations.

\subsubsection{Fractalisation}

Fractalisation is an organizational structure consisting of several production units (fractals) which independently perform subtasks of a main company objectives and thereby they reduce transaction costs. Each fractal represents in fact a supplier for following units, himself is a customer for previous units. A part of fractalisation may be also an integration of suppliers.

\subsubsection{Virtual organization}

As the title implies this structure is linked with new technologies which some companies try to use to gain competitive advantage. The essence of the virtual organization is a combination of some number of smaller organizations that agree on the use of common information channels as a main communications medium. These are mostly temporary established network of companies that are trying to take advantage of this grouping in certain business opportunities. They operate independently, each contributs its own specific ability and gains what would otherwise be unable to obtain himself. Grouping therefore has no central leadership, no hierarchy nor is vertically integrated. Virtual organization ceases to exist at the moment when the opportunity was already used or the it expires.

\section{LOGISTICS IN ORGANISATIONAL STRUCTURES}

\subsection{Defining logistics}

The expression Logistics can be defined by many definitions. From simple to have everything int the right time at the right place to clarification of logistics as a system that includes planning, controlling the flow and storage of goods, services and information from point of origin to the point of production in order to satisfy the customer. In this work is dealed primarily with business logistics, there are also shipping logistics, the sector logistics, which includes agricultural enterprises, administrative institutions and others. Business Logistics was also sometimes previously called internal logistics, but in connection with the merger into larger units and logistic chains, this designation is no longer accurate. Business logistics includes primarily a distribution, an order processing, a product management, a purchasing and a storage. From the above definitions it is evident that logistics is inherently contained in almost every organizational structure in the form of either a separate section or department of logistics or logistics processes are assigned to one of the other sections.

\subsection{Linkages and relationships between purchasing and logistics}

Relationship of purchasing and logistics takes many forms. Basically, there are four basic systems linking procurement and logistics in organizational structures mainly manufacturing companies and related modifications.

The first organizational structure is a classic functional organization structure, in which major segments are a production, a purchase, sales, human resources and finance. A logistics is not centrally managed, logistics processes are controlled by a single major sections. All input logistics (ordering, shipping, warehousing of components and input material) is controlled by purchase, see fig. 1. This type of organizational structure can be found in some traditional industrial companies primarily in engineering, for example, the company Tawesco Ltd. 


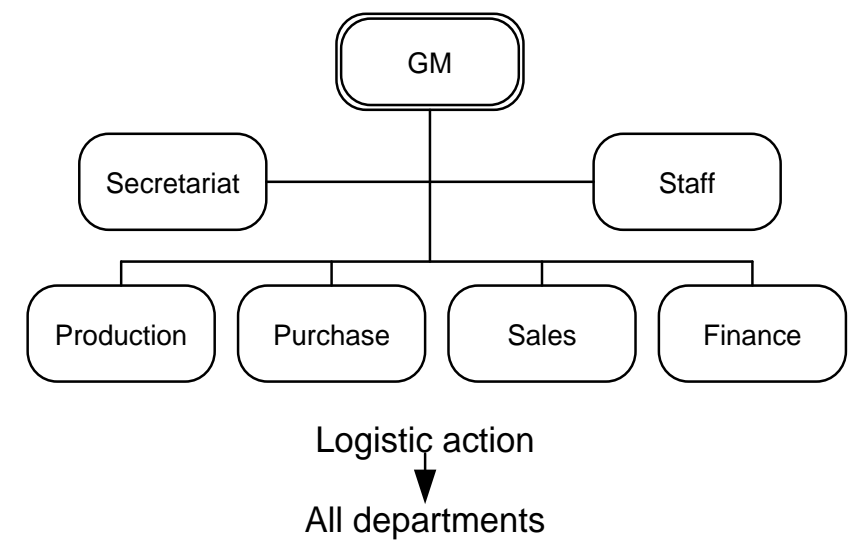

Figure 1 Classic organizational structure. Source: DĚDINA, J., MALÝ M. (2005). Decentralizace. Moderní organizační architektura. Praha: Alfa Publishing. pp. 55-87

The second case, which is not very common, it is basically the opposite of the first. Logistics department is placed in the main section of the frontline under the direct leadership and a purchase is incorporated in logistics. An example of such an arrangement can be found at the company ŽĽAS.

The third case linking procurement and logistics is located in functionally oriented matrix arrangement. Purchase Department is located between the vertically actuated implementing sections of the main functions and logistics segment is classified as a horizontally positioned interlocking sections to service function. Everything shown in fig. 2. In this case purchasing and logistics overlap and cooperate together on an equal basis.

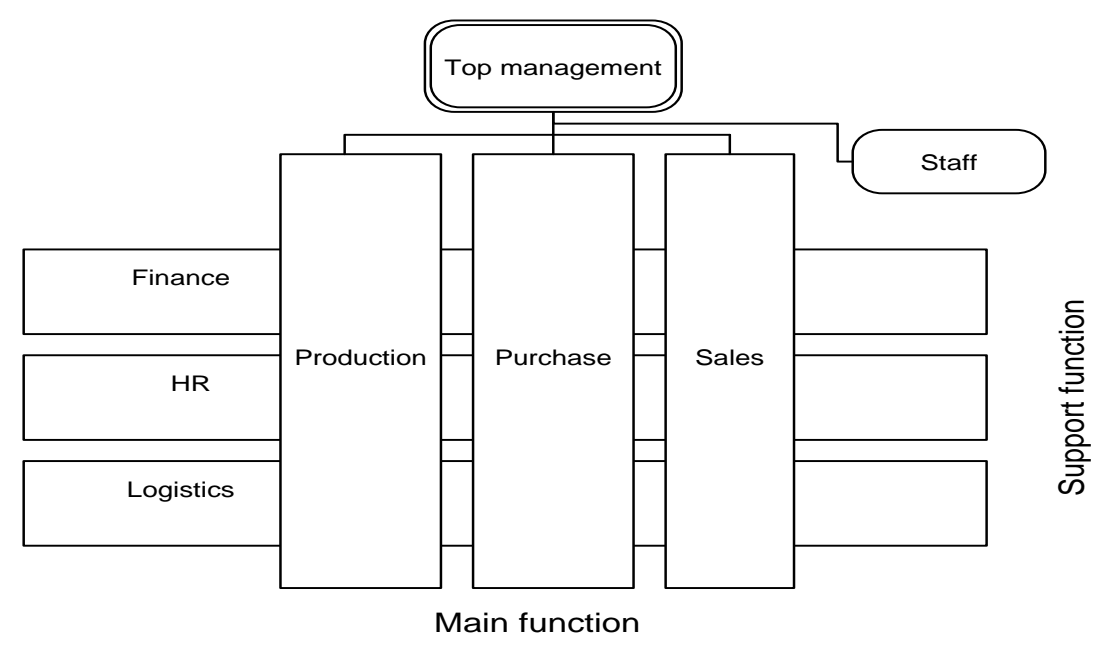

Figure 2 Functionally oriented matrix arrangement of Purchasing and Logistics. Source: Author

In the fourth case is a situation where on the first organizational level represented both sections. Regarding the activities section of the purchase is in charge of strategic and nonmanufacturing purchasing, logistics operative then solves the purchase of materials and components for production. This model is widely used by mid-sized manufacturing companies in the automotive industry. Such an arrangement of logistics and purchasing is for example in a company AGC Automotive Czech Inc.

\subsection{Logistics of manufacturing company in the organizational structure}

Role of Logistics in organizational structures of companies compare to other sectors is very variable. Almost each company has a different concept of logistics. Exceptions are companies 
operating in the automotive industry where logistics sections are similar in structure due to involvement in the united supply chain. Trends in the status of logistics in organizational structures are clear. In the past mainly manufacturing companies did not have separate sections of logistics and logistics were provided by other sections. The purchase department provided orders, transport and components storage, manufacturing division ensured the production planning and internal logistics and sales department was in charge of the warehouse finished goods and transportation of finished goods to customers. This organizational structure, when the logistics are not centrally managed, belongs among functional organizational structures and some companies still use it. At present increasing companies where logistics is centralized (Fig. 3), the logistics division reports directly to CEO.

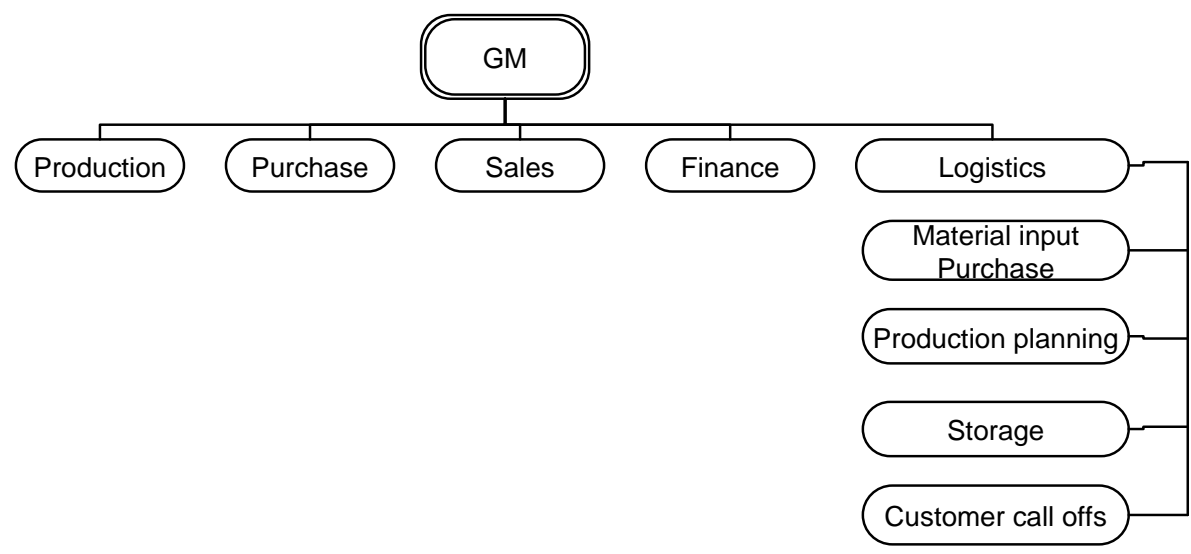

Figure 3 Centrally managed logistics. Source: Author

It is due to the fact that logistics costs relative to total costs rise, companies are involved in the supply chain, ever-evolving information technologies unite logistical flows. It can say that along with marketing logistics are among the areas that are increasingly perceived in the organizational structures and management companies. Centralized Logistics manages the flow of materials throughout the whole company. Logistics workers take customer orders, enter requests into the production plan, order components based on production plan, they manage the input material stores and final production warehouses.

\subsection{Competences in centralized logistics}

As regards the distribution of competences at the output of the company, logistics is in touch with the customer regarding operational requirements. Then sales department resolves a long-term customer requirements and agreements with them. Logistics cooperates with the purchase at input in company. Logistics sends contractors operational requirements arising as input material needed for the production plan, a purchase searches for suppliers, conclude contracts and bargains with suppliers in case of disputes and delivery problems. One of the topics is the in-house logistics, unambiguous definition of competencies between logistics and production handling, but it is not the subject of this paper.

An interesting issue is the location of the production planning department within the organizational structure. While in the past a production planning in most cases situated in the manufacturing sector, current trends allocating a production planning as a separate unit or it classified in the logistics sector. In traditional sense customer requirements were fit on longest batches compliant to production facilities. Production planning included in logistics takes into account not only the requirements of the customer and production, but it is able to 
work in a wider context, to consider supplier possibilities, to take into account a emerging information technologies and to corporate an involvement in logistics chains.

\subsection{Types of information flow in logistics sector}

Two types of information flow in logistics sector exist:

- Information flow through projects,

- Information flow through departments.

\subsubsection{Logistics divided by projects}

Information flows and responsibilities at the centrally managed production logistics can operate in two ways. Especially small and medium-sized businesses, that do not have a portfolio of hundreds finished products and also purchased items, and the flow of production is not very difficult, they have logistics divided by projects. This means that the logistic section has several logistic specialists. Each logistic specialist cares for several customers. The logistic specialist takes orders from customers, requests, he enters requests into the production plan and orders components for their projects from suppliers (Fig. 4). The advantage of this competence distribution is operational approach and lean logistics. In the event of an economic crisis and decline in orders from the customer is responsible logistic specialist able to respond quickly and immediately to decrease supplier orders.

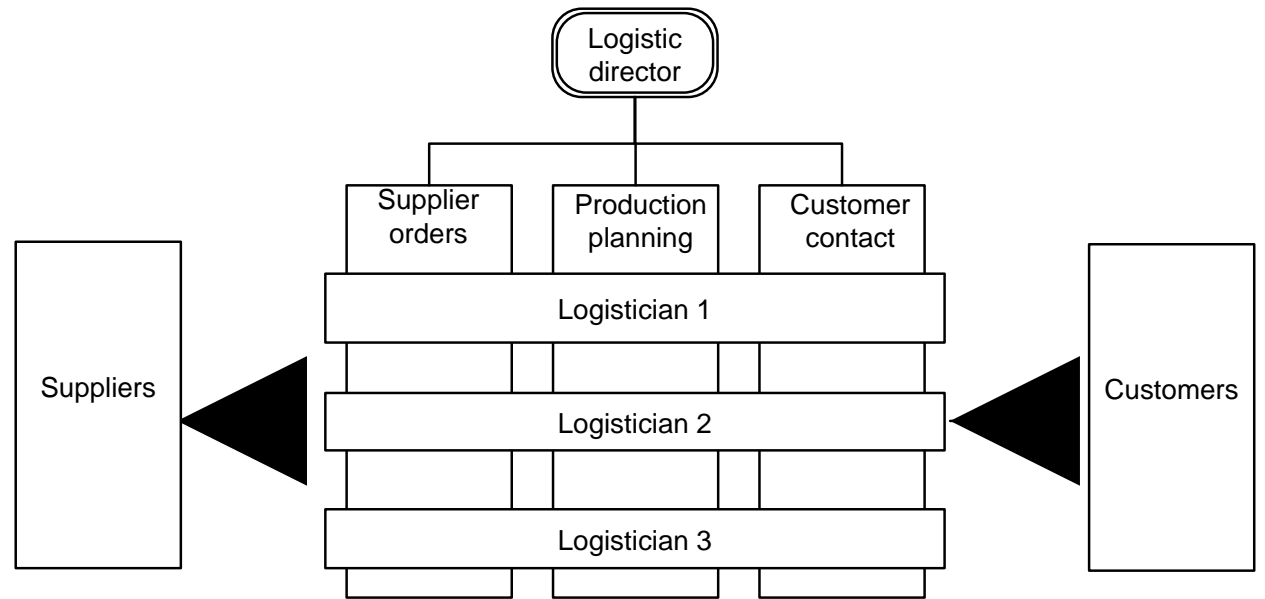

Figure 4 Logistics dividend by projects. Source: Author

The disadvantage may be that some contractors supplying components for multiple projects and they can receive orders from one customer from multiple sources from a different logistic specialists, which can be confusing.

\subsubsection{Information flow through departments}

Larger companies with a diverse portfolio of finished goods or input components prefer logistics flows through departments. Business logistics department receives requests from all customers, forwards them to the production planning department, that creates a plan which transmits information to input logistics department, and it orders and controls inputs of materials and components (Fig. 5). In this case, it is extremely important the proper flow of information, data and control mechanisms to prevent any inaccuracies and loss of information in the logistics flow. 


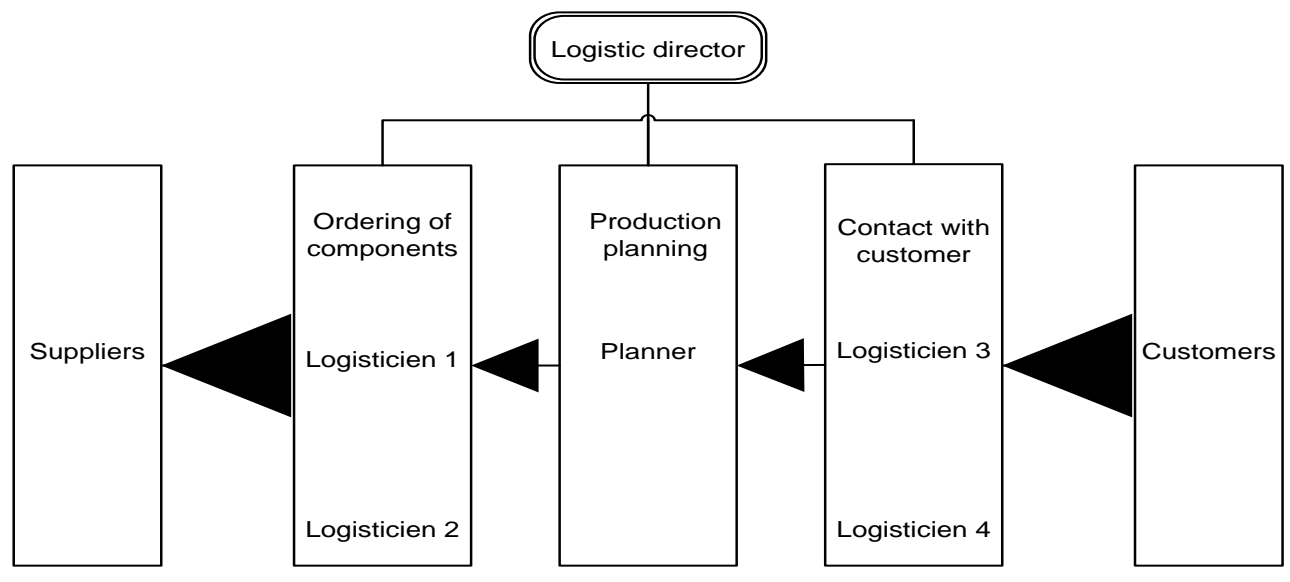

Figure 5 Information flow through departments. Source: Author

\section{CONCLUSION}

Role of Logistics in the organizational structures of companies takes many forms. Position of Logistics continues to grow in importance and is driven by the organizational structures of enterprises, especially in the context of globalization, development of new technologies and the growing importance of logistics chains. Long term crisis and accelerating development in all areas have also an effect on logistics systems. Finally logistics processes in companies will be significantly influenced by new trends. An example might be "Industry 4.0". It is an initiative of the German government, which is called the "fourth industrial revolution" and aims in the coming years, largely to support automation, digitization and robotics production and logistics processes of large manufacturing firms in order to strengthen the competitiveness of German companies. Given the interconnectedness of German economy (at the initiative of participating companies such as Siemens, Bosch and Volkswagen, which have a branches in the Czech Republic), these trends will also apply to companies operating in our territory.

The contribution of this work I can see that I tried in the second part describe the position of logistics in organizational structures mainly manufacturing companies and various types of logistics systems. As already mentioned at the outset, the issue in the literature is too absent and because of this work may provide some new insights from practice. Contribution for actual practice, among others, in finding that the importance of logistics and its position in the organizational structure of manufacturing companies continues to grow. In the modern conception are a comprehensive service and maintenance, which mainly provides logistics for the customer, at least as important as the product itself. I met with one senior manager's view, that a logistics has more important position than the production itself included all activities in a company.

\section{References}

Bělohlávek, F., Košt’an, P., \& Šuleř, O. (2006). Management. Brno: Computer press.

Buchta, M. and Siegl, M. (2005). Management.(pp. 81) Pardubice: Universita Pardubice.

Cejthamr, V. \& Dědina, J. (2010). Typy organizačních struktur a jejich členění. Management a organizační chování (pp.203-224). Praha: Grada Publishing.

Dědina, J. \& Malý, M. (2005). Decentralizace. Moderní organizační architektura (pp. 55-87) Praha: Alfa Publishing.

Gros, I. Kvantitativní metody v manažerském rozhodování. Praha: Grada, 2003. 
Lambert, D., Stock, J. R. \& Ellram, L. (2005). Organizace efektivního logistického systému. Logistika (pp. 431-466). Brno: CP Books

Macurová, P., Hančlová, J., Tvrdoň, L., Černý, J., Dejnega, O., Minárová, A. (2011). Opatření k ošetření rizik v logistice. Řízení rizik v logistice (pp. 128) Ostrava: Moravapress

Pernica, P. (1998). Logistický management. Praha: Radix

Stehlík, A. and Kapoun, J. (2008). Logistika pro manažery. Praha: Ekopress

\section{Contact information}

Jan Jakeš

Faculty of Economics, VŠB - Technical University of Ostrava

Sokolská třída 33

70121 Ostrava, Czech Republic

Telephone: +420 732809019

Email: jakesjij@volny.cz

DOI: https://www.doi.org/10.7441/dokbat.2016.19 


\title{
ENERGY FROM BIO-WASTE IN SLOVAKIA
}

\author{
Juraj Jaška, Nadežda Jankelová
}

\begin{abstract}
Nowadays we see a great opportunity for slovak municipalities, especialy a big challenge for Mayors to find out potential energy hiden in local bio-residues and use it for the wealth of common people. However we see an absence of more sophisticated ways of dealing with the bio-waste in everyday's life, turning it to the energy (Waste-to-Energy). More then $53 \%$ of total world population live in the urban areas. And of course they produce a waste. The evolution is clear. Energy is the phenomenon of time and its control, production will be crucial for the prospective development of the commune. Developed western countries as for example Denmark or Norway yet today use their municipal waste to produce energy. That's why it is a great challenge for Slovakia as well.

This report points out current, almost alarming situation in the use of renewable energy sources, especially bio-residues in Slovakia. Based on the survey we evaluate the status and use of EU funds in Slovak cities and municipalities. Thanks to the comparison methods of scientific knowledge, professional journals and monographs, we show the status of the problematics at home and in the world. Implementation process of new technological energy recovery from bio-waste is very difficult. We are trying to point out the possible ways. Academical enlightenment of this problematic is needed in order to become more independent from the foreign energy imports and to to conserve our environment.
\end{abstract}

Keywords: biomass, bio-residues management, energy recovery, municipal waste management, composting, waste to energy, combustion, biofuels, biowaste

\section{INTRODUCTION}

In Slovakia since 2016 it is forbidden to landfill Bio-degradable waste when it was already sorted out, combust municipal waste in free nature and in home combustion equipement. There is a great pressure from European Union(EU) side to reduce radically landfilling. All this has a huge impact on Slovakia's waste management. The way of thinking of the Mayors have to be changed. Municipal bio-residues management may therefore be construed and understood traditionaly, outdated forms or public leaders can see in biowaste an opportunity a source of wealth for the community. The evolution is clear. Energy is the phenomenon of time and its control, production will be crucial for the prospective development of the commune. The whole Europe starts to look at the bio-residues as a potencial and source of clean energy. We should have a closer look at the countries like Denmark, listen to advices of agencies like CEWEP ( Confederation of European Waste-To-Energy Plants) to learn their lessons in order to use a potential bio-waste. Rational management of inland renewable energy sources is in accordance with the principles of sustainable development, creates one of the pillars of the healthy economic development of the society.

Objective of the article is to animate a current situation of waste treatment in Slovakia and upon on this statement outline possible scenarios of waste management for slovak municipalities. 


\section{METHODOLOGY}

Solving research problem is primarily based on the formal reports from the current status of processing bio-waste management in Slovak municipalities. Various expert studies, forecasts and expectations of representatives of national and foreign institutions in terms of the future development of Slovak and European market for biomass utilization. Statistic department of Slovakia plays a key role among data resources. Many foreign and local magazines dedicated to waste management are used.

We have addressed our 29 bio-waste related questions (questionary-form in Google Forms) to 372 slovak municipalities (301 villages and 71 towns). Properly returned were 57 filled-in questionaries.

Afterwards an appropriate analyse was done in MS EXCEL and PSPP program.

\section{BIOWASTE (BIO-RESIDUES) AS A PART OF BIOMASS- RENEWABLE ENERGY SOURCE (RES)}

Our share use of RES in total energy consumption is only about $8 \%$, including large hydropower plants. Biomass has the highest energy potential of all renewable energy sources in Slovakia. If we analyze the energy potential of bio-waste in the municipal sector, we must first take a look to the definition, structure and properties of biological waste. Some anglophone literature indicate the word bio-waste, which we find the most exact, rather then biowaste. Organic waste is part of the municipal waste, while part of the community biomass. Communal biomass is one of the four sources of biomass itself.

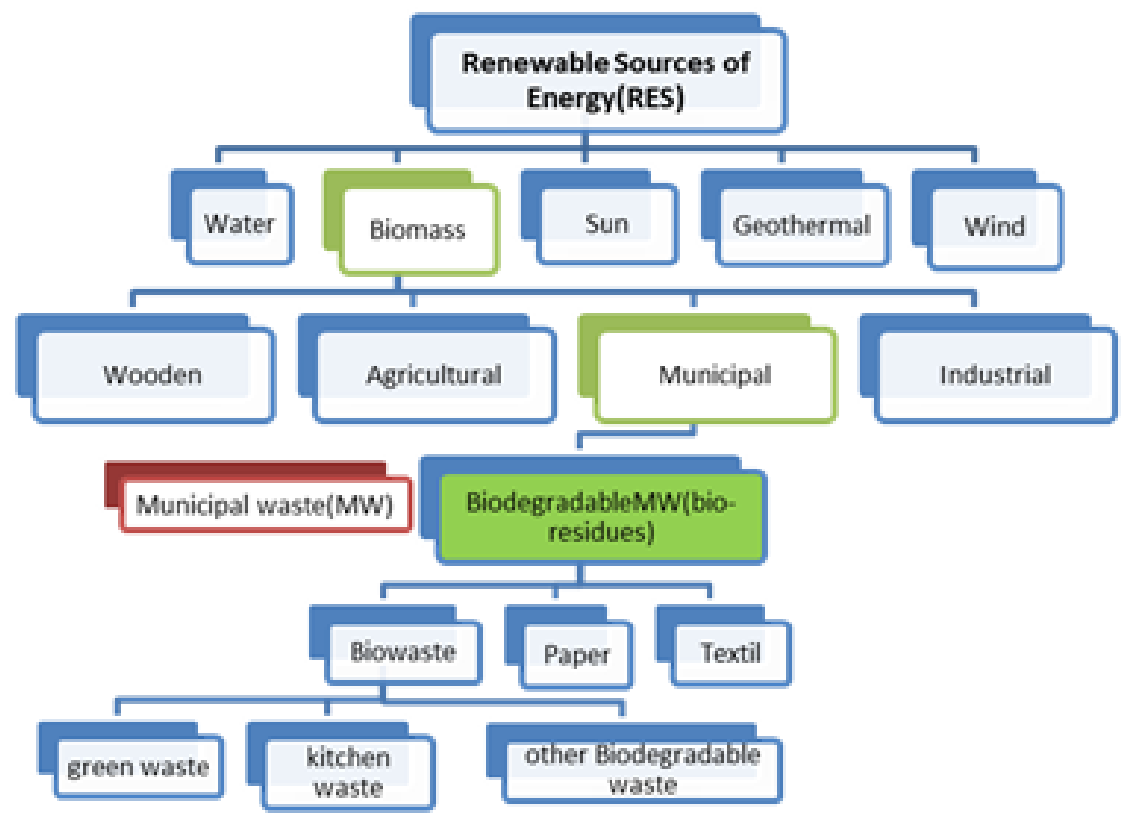

Figure 1 - Biological waste hierarchy. Source: own processing. Notes: Biodegradable municipal waste is a part of Municipal waste

\subsection{Biodegradable waste (biowaste;bio-residues)}

Biodegradable waste is a waste that is able to disintegrate itself by anaerobic or aerobic manner. For example food waste, paper and cardboard waste, garden waste, waste from parks 
etc.. Biodegradable waste is a significant component of municipal waste. They consist mainly of greenery waste, restaurant and catering waste and other components.

\subsection{Current situation in Slovakia in the field of waste treatment}

Slovak municipalities face different challenges in responding to the problem of biodegradable waste from households. These challenges can be taken as well as perfect opportunities and motivation for the development of sustainable governance and management of biodegradable waste. Sustainable management process can generate a range of benefits as it moves away from the traditional, unsustainable approach based mainly on waste disposal in landfills(In Slovakia more then $75 \%$ of total waste is landfilled). However many private companies already compost their biodegradable waste and, in some cases, decomposition of waste is present. Biowaste can be considered as a renewable energy source because for regeneration of used inventory is needed relatively a short time.

\subsection{Waste management in the municipality}

Nowadays we can compare administration of Slovak towns and villages to the company management. This means that senior manager, mayor, or mayor and his team must deal with everyday's agenda exactly as if it was a private company. This manager is absolutely responsible for all the operations, surviving and well-being. He is reported not only to his boss, but also to common citizens. Often it can be even more challenging than in purely commercial sphere. New investing projects are prepared and implemented by the mayors with one simple goal. That the municipality or the city is even more prosperious, modern and creates better and better conditions for the living. It is then the complex project management with all the usual phases as we know from commercial sphere. Problem with the bio-waste in local municipality a Mayor can manage in many ways. On of the most prosperous way is to consider bio-waste as a source of energy and therefore as a source of financial income for the municipality. Of course to undertake all the obstacles when deciding to go this modern way is very hard. The Mayor has many opponents. The municipal council, budget and of course local people to be persuaded. Therefore a complex project management process with all the phases is on table.

As writen before, we consider municipal managemnt very alike a company's commercial management. From few such a differencies of these two managements we chose to poit-out one: Mayor's decision making process.

\subsection{Mayor's decision making process}

According to Jassingera, A. A Pink, D. it is clear that the decision-making process is influenced by such a large number of factors that for mayor, it is not possible to reach the best solution to the problem. Illustrative examples of factors that can influence decision making process of the Mayor shows Figure 2-Ishikawa Diagram of decision making process for the Mayors. 


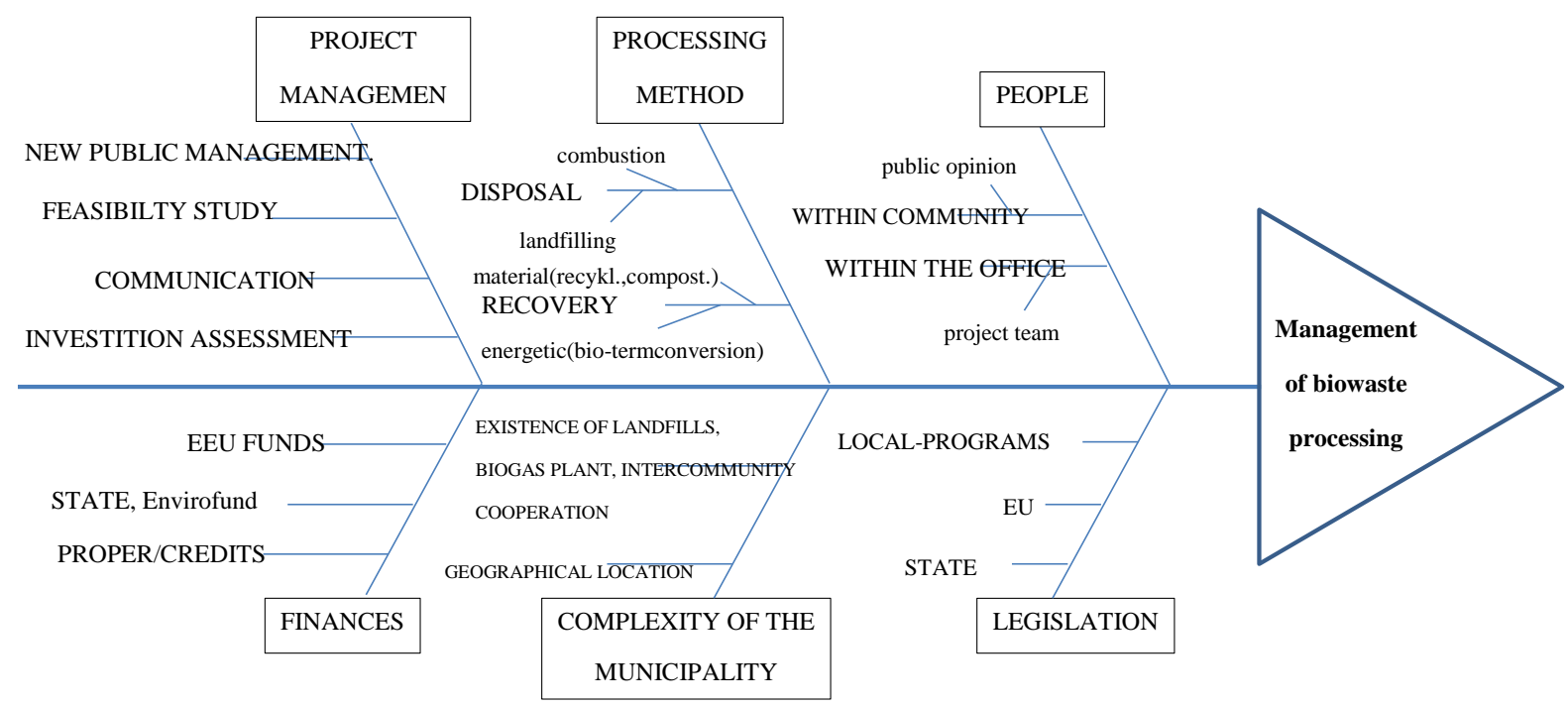

Figure 2 - Ishikawa Diagram of decision making process for the Mayors. Source: own processing

\section{GATHERING OF MUNICIPAL WASTE (MW)}

Choice of system for gathering and disposal of municipal waste depends on the structure of settlements, topography of land, transportation, quantity and type of waste. This classical approach in dealing with MW used by most Slovak municipalities. Evidently an absence of more sophysticated way of dealing with waste can be noted. In western countries more and more prefered solution is called energetic recovery of biowaste. The primary prerequisite for the processing of biological waste is that the municipality analyze possible sources of bioresidues.

\subsection{Selection of the appropriate technologies}

There are different technologies in this field. They are able to process different amounts for different waste in different space and in different period of time. It is important to take account of legislative conditions for processing various types of waste. Therefore, it is always necessary to consider the specific conditions if the "fine-tune" technology. Of course it also depends on what final product we want to get. For example selling an ecological compost can improve an economical situation of the commune.

\subsection{Economic calculation}

It is crucial to estimate financial and operational complexity of the project. Heads of towns or villages should take into account all possible inputs and outputs that will affect the economy. The aim of the project should be a maximum reduction of biowaste going to disposal. As largest as possible population involvement and non loosing or eventually profitable running. According to the mentioned research over $94 \%$ of Slovak municipal governments have an experience with the EU funds as shown on Figure 3. Even more than $51 \%$ of such municipalities has experienced usage of the EU funds for waste management-Figure 4. Shortly it can therefore be reasonably assumed that Mayors, when considering a potential waste-to-energy project investment could calculate at the income side financial „subsidies“ from European resources. 


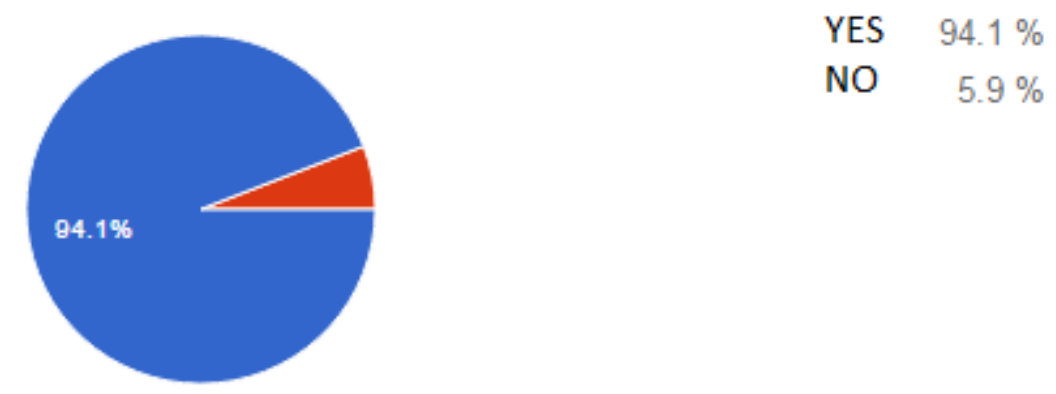

Figure 3 - Has the municipality experience with Eurofunding? Source: own processing

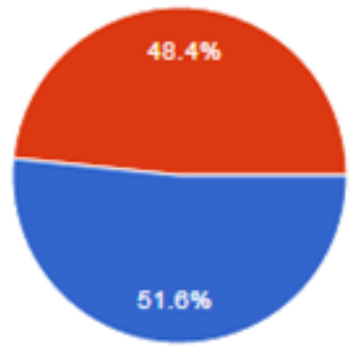

YES $51.6 \%$

NO $48.4 \%$

Figure 4 - An experience of the slovak municipalities with usage of EU funds for waste management. Source: own processing.

\subsection{Energetic potential of biowaste}

Bio-waste as a part of municipal waste can be processed by different processes and technologies. Starting from hydrolysis, gasification through to cracking. Waste can be disposed of either (landfilling, incineration) or recovered (material-recycling and composting, energy). It clearly states Figure 5.

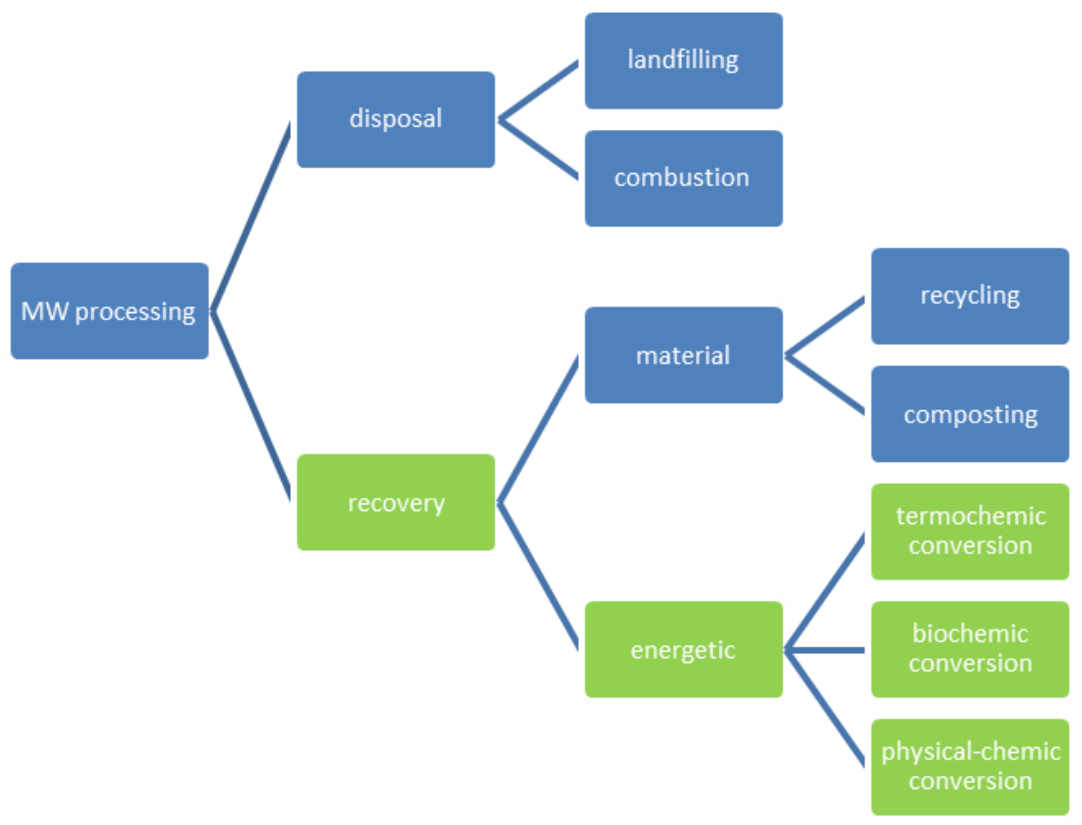

Figure 5 - Processing with municipal waste (MW). Source: own processing

As already written, in Slovakia, most of the time municipal waste is landfilled either on public landfills or combusted directly. Energetic potencial of such a biomass is absolutely not used. Moreover, today we have technologies that would enable such effective transformation. Financial resources are available, as writen above, either in the form of state grants, municipal, or local budgets, through collaboration with the private sector, and not least from the European Union. Villages and towns that began to separate household waste, showed 
lower production of municipal waste. The most interesting possibility of using bio-waste in the municipal sector is a "green branch" see Figure 5. It is the energy recovery use of biowaste. Organic waste can be calmly considered, due to its organic nature, as an „energy carrier". It is up to the heads of the local governments to discover and explore this ,hidden energy" and use it for the benefit of the community. Of course now the way in which the stored energy can be converted into real money is not easy, but technological development is progressing rapidly. Briefly we animate three major branches and thus opportunities for Mayors, what directions could be (in the near future) bio-residues processed.

Thermochemical conversion-COMBUSTION(Waste-To-Energy), Gassification, Pyrolysis

Physico-chemical conversion-(biodisel production)

Bio-chemical conversion-Anaerobic digestion(biogas production); Aerobic digestion(compost production); Ethanol, glycerin production

All these conversions are very interesting and certainly future promising. From all of them we would like to point-out one, which is very effective, cost comparative and which is already commonly used in western countries. Waste-to-Energy Plants operate 24 hours a day, 7 days a week, 365 days per year. They supply reliable base-load energy to the electricity grid. Also, about $50 \%$ of the energy produced by Waste-to-Energy Plants is renewable. EU legislation considers the biodegradable fraction of municipal and industrial waste as biomass, and thereby a source of renewable energy. An average family produces about $10 \mathrm{~kg}$ of residual waste per week, after the recyclable waste has been separated. Figure 6 shows what can be done with it.
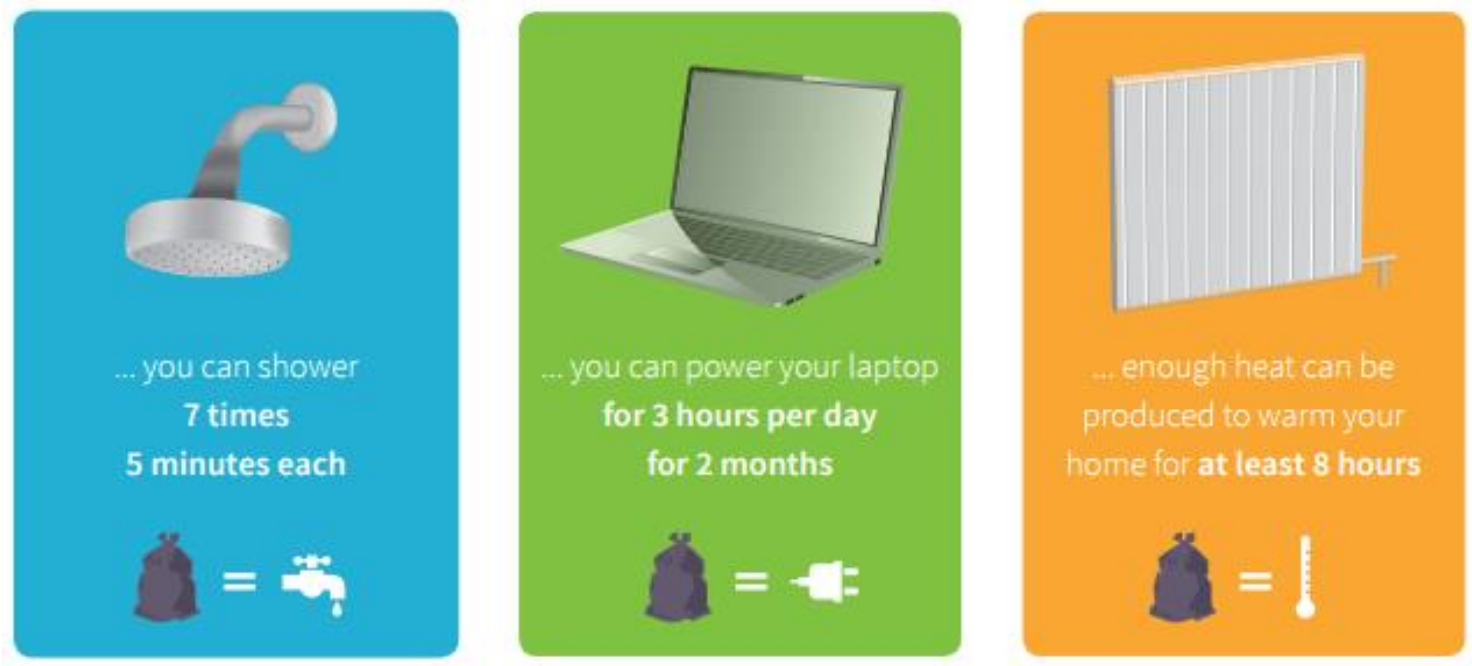

Figure 6- With the energy from $10 \mathrm{~kg}$ of residual waste can be...Source: CEWEP-Confederation of European Waste-to-Energy Plants, 2014 CEWEP Brochure Heating and Lighting from Waste, dostupné na www.cewep.eu

\subsection{Waste-To-Energy in Denmark}

Europe's most advanced country in the matter of WtE is Denmark. In Denmark the municipalities are responsible for the management of all waste. They have the responsibility and decision-making authority for the collection and treatment of household waste and control the flow of commercial and industrial waste to assigned treatment and disposal facilities. In order to recover the resources of the waste the first priority is to reuse or recycle it. The residual waste is either incinerated at waste-to-energy facilities or, as the last resort, land- filled. Denmark was the first country in Europe to introduce a ban on landfilling of waste suitable for incineration. This has proven to be a major benefit to the Danish economy and the environment. This has made Denmark the country in Europe that incinerates the 
greatest amount of waste per capita - under very strict environmental regulations. By far the majority of the facilities are owned by municipalities or inter-municipal companies. The municipal cooperation secures the establishment of the necessary incineration capacity. Moreover, it ensures that the waste is managed according to the principles of proximity and self-sufficiency. The waste-to-energy facilities are operated by non-profit companies, based on a cost coverage principle. This is why households, commerce and industry can have their waste treated in a safe and environmentally friendly manner at low cost.

\section{ConClusions}

The most ambitious and at the same time the most promising and economically beneficial way of handling organic waste lies in its energetic recovery. Although the initial investment in building facilities to enable such a transformation are demanding. Certain advantage could be in the fact that Slovak towns and municipalities have an experience with the usage of EU funds. The fact that by processing of municipal biowaste to energy a community can obtain a product which can be subsequently converted into real money is very appealing. In Western Europe citizens enjoys the benefits that these solutions bring. Slovak Mayors must lead their municipalities this modern way of treating bio-waste.

\section{References}

Altmann, A. (2010). Technika pro zpracovaní komunálníh odpadu. Praha:Česká zemedelská univerzita v Praze, 38 s. ISBN: 978-80-213-2022-2.

Jandačka, J. (2014) .Nakladanie s odpadmi v Moravskosliezskom a Žilinskom kraji, Žilina: Žilinská univerzita, Katedra energetickej techniky, [cit. 20.10.2015]. Retrived from: http://ket.uniza.sk/subory/clanky/cezhranicna/publikacna_cinnost_odpady/1/Studia_7 final.pdf

Jankelová, N. (2008). Rozhodovacie procesy v manažmente podnikov na Slovensku, Bratislava: Ekonóm. ISBN 978-80-225-2426-1

Majtán, M. et al. (2009). Manažment. Bratislava: Sprint dva. 2009.301 s. ISBN: 978-8089393-07-7.

Menikpura, S. N. M. (2013). Integrated Solid Waste Management: an approach for enhancing climate co-benefits through resource recovery. Journal of Cleaner Production,. 58, ISSN: 0959-6526.

Obnovitelné zdroje energie. (n.d.). Retrieved March 30, 2015, from http://www.minzp.sk/oblasti/obnovitelne-zdroje-energie/obnovitelne-zdroje-energie/

Pepich, Š. (2009). Pol'nohospodárska biomasa z pohl'adu regionálnej bioenergetiky, In Agriculturl economics. 2, 13. ISSN 1336-9660

Ramboll. (2006). The most efficient waste management system in Europe. Waste-to-energy in Denmark. . [online] 30.05.2006 [cit. 09.08.2014]. Retrived from: http://www.cewep.eu/media/www.cewep.eu/org/med_452/386_Waste_to_Energy_De nmark.pdf

Truneček, J. (1987). Stragetické rozhodovaci procesy v hospodářske praxi, Praha: Svoboda. ISBN 80-7357-189-7

\section{Contact information}

Juraj Jaška and Nadežda Jankelová

University, Faculty: University of Economics in Bratislava, Faculty of Business Management Address: Dolnozemská cesta 1, 85235 Bratislava, Slovakia

Telephone number: +421905385018

juraj.jaska@gmail.com

DOI: https://www.doi.org/10.7441/dokbat.2016.20 


\title{
THE APPLICATION OF EXPECTATION MAXIMIZATION TO \\ MANAGE MISSING DATA, BIASES VALUE-AT-RISK AND VOLATILITY MODELS IN FINANCIAL TIME SERIES?
}

\author{
Gábor Dávid Kiss, Marianna Sávai
}

\begin{abstract}
Multivariate time series analysis requires synchronized and continuous data for its models. However, there can be special occasions when one or some data is missing due to lack of trading activity. This paper focuses on the impact of different missing data handling methods on GARCH and Value-at-Risk model parameters, namely the volatility persistence and asymmetry and the fat-tailness of the corrected data. The main added value of current paper is the comparison of the impact of different methods (like listwise deletion, mean-substitution and maximum-likelihood-based Expectation Maximization) on daily financial time series, because this subject has insufficient literature. Current study tested daily closing data of floating currencies from Kenya (KES), Ghana (GHS), South Africa (ZAR), Tanzania (TZS), Uganda (UGX), Gambia (GMD), Madagascar (MGA) and Mozambique (MZN) in USD denomination against EUR/USD rate between March 82000 and March 62015 acquired from Bloomberg database. Current paper suggest the usage of mean substitution or listwise deletion for daily financial time series due to their tendency to have a close-to-zero first momentum.
\end{abstract}

Keywords: missing data, EM method, Value at Risk, GARCH

\section{INTRODUCTION}

Multivariate time series analysis requires synchronized and continuous data for its models. However, there can be special occasions when one or some data is missing due to lack of trading activity. This paper focuses on the impact of different missing data handling methods on GARCH and Value-at-Risk model parameters, namely the volatility persistence and asymmetry and the fat-tailness of the corrected data.

Missing data (or missing values) is defined "as the data value that is not stored for a variable in the observation of interest" (Kang 2013), where time series can be affected by wave nonresponse cases as the suspension of data generating process is only a temporary issue (Graham 2012). There is a strong supposition about time series: they should not contain missing observations without biasing the ARIMA and GARCH parameters, reduction of representativeness or statistical power due to their impact on the mean, variance, and autocorrelation (Juan Carlos et al. 2010, Kang 2013).

The main added value of current paper is the comparison of the impact of different methods (like listwise deletion, mean-substitution and maximum-likelihood-based Expectation Maximization) on daily financial time series, because this subject has insufficient literature.

Current study tested daily closing data of floating currencies from Kenya (KES), Ghana (GHS), South Africa (ZAR), Tanzania (TZS), Uganda (UGX), Gambia (GMD), Madagascar (MGA) and Mozambique (MZN) in USD denomination against EUR/USD rate between March 82000 and March 62015 acquired from Bloomberg database. 
The paper has the following structure: Theoretical Background section summarizes the main assumptions behind missingness of data, pointing on some differences between query and time series data. Then listwise deletion, mean substitution and Expectation Maximization approaches were introduced in Methods section as well as GARCH and DCC-GARCH models and a basic Value-at-Risk application. The Results and Data section presents the statistical properties of raw, unsynchronized time series and compares it with the three approaches to identify their tendencies for bias.

\section{THEORETICAL BACKGROUND}

Financial time series, like daily closing currency data can be missing due to the lack of trading activity on the specific data - while other markets are open. Therefore the phenomena has a multivariable-dimension. This temporary suspension of market data can be originated by national differences like holydays and weekends, or by market forces like illiquid situations (in small-cap shares mostly) or when trading activity is suspended due to a sudden collapse in pricing. There is a huge literature how pricing and market efficiency is affected by such brakes as the most cited "weekend effect" appears (Keim - Stambaugh 1984, Robins Smith 2015, Shahid - Mehmood 2015).

The literature distinguishes among three forms of mechanism behind missingness (Graham 2012, Junger - Leon 2015): one can assume that data is missing completely at random (MCAR), when missingness does not depend on the values of the data or other observed particular variable and their exclusion do not bias our estimations due to their homogeneity (Enders 2010, Junger - Leon 2015, Kang 2013). Missing at random (MAR) happens when dropout conditionally independent of the variable (Kang 2013), but we can assume some sort of mechanism what is behind the missingness (Graham 2012). Their exclusion may corrupt temporal structures such as autocorrelation, trends, and seasonality (Junger - Leon 2015). Missing no at random (MNAR) case occurs when it is possible to make and unbiased estimation to model the missing data. When missingness is beyond researcher's control (their distribution is unknown), MAR is only an assumption (Graham 2012).

Following Baraldi et al. (2015), there are three different approaches to assess the missing data problem. First we can remove those time intervals, when there is at least one missing data for a specific date. Listwise deletion or last observation carried forward scheme can make time series more fragmented or may introduce bias in the estimation of the parameters unless there is a chance that our missingness is MCAR (Kang 2013). Second approach substitutes the missing data by the unconditional mean value or the median (for skewed data, suggested by Junger - Leon 2015) of the available historical data. It has a similar impact like the last observation carried forward scheme for the calculated logarithmic returns for time series with zero mean and mode (Assuming that $\mathrm{P}_{\mathrm{t}}$ and $\mathrm{P}_{\mathrm{T}-1}$ prices are equal, their logarithmic return will be zero: $r_{\mathrm{T}}=\log \left(\mathrm{P}_{\mathrm{t}} / \mathrm{P}_{\mathrm{T}-1}\right)=\left(\mathrm{P}_{\mathrm{t}}-\mathrm{P}_{\mathrm{T}-1}\right)=0$.). This solution is not recommended by Graham (2012) due to its distortions to make a higher concentration around the mean and underestimate errors and varience at MCAR states (Junger - Leon 2015, Enders 2010). Third, there are the modern, computation based approaches to reconstruct missing data trough minimization of an error function, derived from mean variance or a likelihood ratio (Baraldi et al. 2015, Ceylan et al. 2013, Juan Carlos 2010). Expectation maximization (EM) models applying maximum likelihoods to estimate variance, covariance matrixes of the data, while there are also neural networks-based and genetic structure-based approaches as well (Ceylan et al. 2013, Juan Carlos 2010). The expectation maximization takes more computation time, because EM algorithm may be as difficult to compute as the likelihood function itself (Ruud 1991) and they require more specification of a data generation model (Houari et al. 2013), but 
they do not rely on the MCAR requirement is a feature that remains to be fully exploited. Unbiasedness under MAR and higher efficiency under MCAR make maximum likelihood the method of choice in situation with incomplete multinormal data (Wothke 1998). They are less biased than listwise and pairwise deletion and mean-imputation methods, but this advantage depends on the missing-data rate, the covariance structure of the data and size of the sample (Wothke 1998).

Missing data problems can affect daily time series under multivariate applications like volatility spillover, extreme fluctuation or contagion modelling, where assumptions about conditional variance, covariance and correlation are critical.

\section{METHODS}

This paper applies and compares three different missing value handling method to capture their ability to maintain central moments, autocorrelation, volatility persistence and extreme movements. All methods were used on daily closing data of African floating currencies and EUR in USD denomination between March 82000 and March 62015.

Let us assume $\mathrm{n}$ foreign exchange rates (1), where the ith $(1 \leq i \leq n)$ currency has the following $\mathrm{p}$ price for every $\mathrm{y}$ trading day with $\mathrm{v}$ sample size:

$P_{i}=\left[\begin{array}{cc}y_{1} & p_{i, 1} \\ \ldots & \ldots \\ y_{v} & p_{i, v}\end{array}\right]$.

There is also a kth $(1 \leq k \leq n$, and $k \neq i)$ currency (2) with w data, and $\mathrm{z}(z \neq y)$ time indices:

$P_{k}=\left[\begin{array}{cc}z_{1} & p_{k, 1} \\ \ldots & \ldots \\ z_{w} & p_{k w}\end{array}\right]$.

Upper $P_{1_{m, i, k_{n m} n}}$ matrices should be united for purposes of multivariate analysis, what requires the synchronization of time indices.

Listwise deletion (3) means a T cap of specific time indices to exclude all cases where at least one value is missing:

$T=Y \cap Z$.

Mean substitution (4) can be applied only on logarithmic returns due to their near zero mean and mode. Last observation carried forward (LSCF) scheme similar benefits on prices - with a zeroed logarithmic return at the end:

$T=(Y \cup Z)$ with $p_{i, o}=p_{i, o-1}$ for $T \notin(Y \cap Z)$.

Regularized expectation maximization (EM) algorithm based on iterated linear regression analyses, but it replaces the conditional maximum likelihood estimation of regression parameters for Gaussian data (5), following Schneider (2001). For each $p_{t, i} \in P$ with missing values, the relationship between the prices with missing values (trading days) and the prices with available values is modelled by a linear regression model:

$p_{\text {NaN }}=\mu_{\text {NaN }}+\left(p_{a}-\mu_{a}\right) B+\varepsilon$ 
Where a represents available data, and $B \in \Re^{n_{a} \times n_{N a N}}$ is a matrix of regression coefficients with covariance matrix with missing and available data from $\mathrm{n}$ all sample markets. The $\varepsilon \in \Re^{1 \times n_{\text {NaN }}}$ residual is assumed to be a zero-mean and $C \in \Re^{n_{\text {NaN }}{ }^{X} n_{\text {NaN }}}$ unknown covariance matrix vector. In each iteration of the EM algorithm, estimates of the mean $\mu \in \Re^{\mathbb{1 \times n}}$ and of the $\Sigma \in \Re^{n \times n}$ covariance matrix are taken as given, and from these estimates, the conditional maximum likelihood estimates of the matrix of regression coefficients $\mathrm{B}$ and of the covariance matrix $\mathrm{C}$ of the residual are computed for each record with missing values - to fill each missing values are with imputed values, before recomputation of the entire $\mu$ vector and $\Sigma$ matrix. Then the estimated regression coefficients will be the product of the two (missing-missing and available-missing) estimated covariance matrixes: $\hat{B}=\widehat{\Sigma_{a a}^{-1}} \widehat{\Sigma_{a N a N}}$ to estimate the residual covariance matrix later. However, the regularized $\mathrm{EM}$ algorithm for each record with missing values uses $\hat{B}=\left(\widehat{\Sigma_{a a}}+h^{2} \operatorname{Diag}\left(\widehat{\Sigma_{a a}}\right)\right)^{-1} \widehat{\Sigma_{a N a N}}$ with a $\mathrm{h}$ regularization parameter to inflate diagonal elements with a $1+h^{2}$ factor.

Sensitivity analysis is required to examine the bias of uncertain input on the model, where the maintenance of the central tendencies, autocorrelation is studied as well as the patterns of the percentage of missing data (Kang 2013, Graham 2012). Variance models can be affected by missing data, making model selection and parameterization biased. Different GARCH models were fitted on the data to analyse patterns of volatility persistence, following Cappeiello, Engle and Sheppard (2006). The applied GARCH(p,q), GJR GARCH(p,o,q), TARCH(p,o,q) and $\operatorname{APARCH}(\mathrm{p}, \mathrm{o}, \mathrm{q})(6-10)$ models can be useful to capture volatility developments and their clustering in time (heteroscedasticity).

$\operatorname{GARCH}(\mathrm{p}, \mathrm{q}): \quad \sigma_{t}^{2}=\omega+\sum_{i=1}^{p} \alpha_{i} \varepsilon_{t-i}^{2}+\sum_{j=1}^{q} \beta_{i} \sigma_{t-j}^{2}$.

where $\sigma_{t}^{2}$ represents present variance, $\omega$ is a constant term, $\mathrm{p}$ denotes the lag number of squared past $\varepsilon_{t-i}^{2}$ innovations with $\alpha_{i}$ parameters, while q denotes the lag number of past $\sigma_{t-j}^{2}$.variances with $\beta_{i}$ parameters to represent volatility persistence. Asymmetric GARCH models can be introduced via

$\left\{\begin{array}{l}S_{t-i}^{-}=1, \text { if } \varepsilon_{t-i}<0 \\ S_{t-i}^{-}=0, \text { if } \varepsilon_{t-i} \geq 0\end{array}\right.$ as a sign asymmetric reaction to decreasing returns.

$\operatorname{GJR} \operatorname{GARCH}(\mathrm{p}, \mathrm{o}, \mathrm{q}): \sigma_{t}=\omega+\sum_{i=1}^{p} \alpha_{i}\left|\varepsilon_{t-i}\right|+\sum_{i=1}^{o} \gamma_{i} S_{t-i}^{-}\left|\varepsilon_{t-i}\right|+\sum_{j=1}^{q} \beta_{i} \sigma_{t-j}$,

$\operatorname{TARCH}(\mathrm{p}, \mathrm{o}, \mathrm{q}): \quad \sigma_{t}^{2}=\omega+\sum_{i=1}^{p} \alpha_{i} \varepsilon_{t-i}^{2}+\sum_{i=1}^{o} \gamma_{i} S_{t-i}^{-} \varepsilon_{t-i}^{2}+\sum_{j=1}^{q} \beta_{i} \sigma_{t-j}^{2}$,

$\operatorname{APARCH}(\mathrm{p}, \mathrm{o}, \mathrm{q}): \quad \sigma_{t}^{\delta}=\omega+\sum_{i=1}^{p} \alpha_{i}\left(\left|\varepsilon_{t-i}\right|-\gamma_{i} \varepsilon_{t-i}\right)^{\delta}+\sum_{j=1}^{q} \beta_{j} \sigma_{t-j}^{\delta}$,

where $\alpha \mathrm{i}>0(\mathrm{i}=1, \ldots, \mathrm{p}), \gamma \mathrm{i}+\alpha \mathrm{i}>0(\mathrm{i}=1, \ldots, 0), \beta \mathrm{i} \geq 0 \quad(\mathrm{i}=1, \ldots, \mathrm{q}), \alpha \mathrm{i}+0,5 \gamma \mathrm{j}+\beta \mathrm{k}+<1 \quad(\mathrm{i}=1, \ldots, \mathrm{p}$, $\mathrm{j}=1, \ldots, \mathrm{o}, \mathrm{k}=1, \ldots, \mathrm{q})$ and $\delta$ index parameter can be between 1 and 2 .

Model selection was made with focus on homoscedastic residuals (using a 2 lagged ARCHLM test), searching for the lowest Bayesian Information Criteria (BIC). This study applies 
DCC-GARCH model, following Engle (2002), to analyze the daily common movements of the selected markets.

Missing values have an impact on the density function of the data - listwise deletion assumed to make more data on the tails, while mean substitution can increase the representation of the expected value. The EM should produce data between these mean and extremes. Extreme fluctuation of the data was tested with ordinary Value-at-Risk model (11), where the weight of extreme data and the kurtosis of non-extreme data were the variables of my sensitivity analysis.

$r=r_{n}+r_{x}^{-}+r_{x}^{+}$, where $r_{x}^{-}<\mu-1.65 * \sigma$ and $r_{x}^{+}>\mu+1.65 * \sigma$,

where $r$ is a logarithmic return, $\mu$ unconditional mean, $\sigma$ unconditional standard deviation, $r_{x}^{-}$represents extreme negative, $r_{x}^{+}$extreme positive returns and $r_{n}$ denotes a non-extreme subset of data (Madura 2008).

This study applies Dynamic Conditional Correlation GARCH (DCC-GARCH) model (12), following Engle (2002), to analyze the daily common movements of the selected markets. It is defined as:

$r_{t}=\mu_{t}+\alpha_{t}, \alpha_{t}=H_{t}^{1 / 2} z_{t}, H_{t}=D_{t} R_{t} D_{t}, R_{t}=Q_{t}^{*-1} Q_{t} Q_{t}^{*-1}, Q_{t}=(1-a-b) \bar{Q}+$ $a \varepsilon_{t-1} \varepsilon_{t-1}^{T}+b Q_{t-1}$

Where $r_{t}$ denotes log returns, $\alpha_{t}$ mean-corrected returns $\left(E\left[\alpha_{t}\right]=0\right.$ and $\left.\operatorname{Cov}\left[\alpha_{t}\right]=H_{t}\right), \mu_{t}$

expected value of the conditional $r_{t}, H_{t}$ matrix of conditional variances of $\alpha_{t}, H_{t}^{1 / 2}$ after Choelsky factorization, $D_{t}$ conditional standard deviations of,$R_{t}$ conditional correlation matrix, $z_{t}$ vector of independent and identically distributed errors, $Q_{t}$ unconditional covariance matrix of the standardized errors $\varepsilon_{t}$ (Cappeiello et al. 2006).

Current paper applies the following setup during the comparison of three different methods: deviation between raw and refined data was studied in central moments, autocorrelation, heteroscedasticity, normal distribution, weak stationarity, GARCH model and parameter selection and Value-at-Risk weights and kurtosis as well as dynamic conditional correlation results.

\section{RESULTS AND DATA}

Statistical properties of raw and refined data were compared in this section to present the underlying differences among missing value handling approaches and their impact on model parameterization.

\subsection{Raw data}

Floating African currencies, the Euro-fixed CFA Franc (XAF) and Euro in USD denomination was tested between March 82000 and March 6 2015. CFA Franc (XAF) followed strictly the euro only, due to its fixed regime, showing an appreciation against US dollar during the entire time set on Figure 1. Kenyan Shilling (KES) and South African Rand (ZAR) presented an appreciating trend before the subprime crisis only, otherwise the entire currency set suffered from depreciation. 


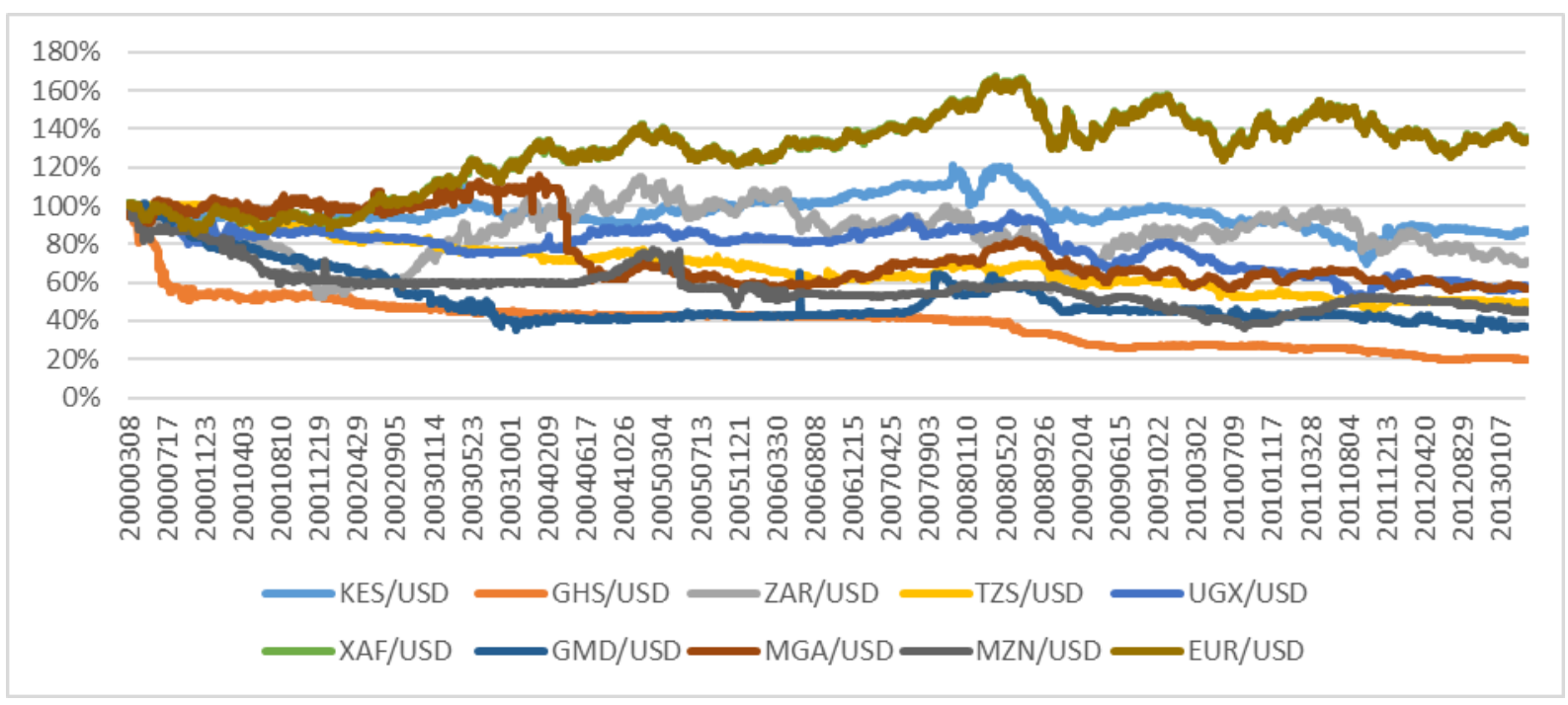

Figure 1: Developments of Selected African Currencies between 2000 and 2015 (March 8 2000=100\%). Source: Bloomberg

Logarithmic returns of raw data had zero mean and low standard deviation, while symmetry appeared only for EUR and GMD (table 1). Excess kurtosis presented higher-than-expected occurrence for extreme fluctuation - pegged XAF and EUR presented a moderated level only. None of the currencies followed normal distribution and most of the data suffered from autocorrelation (except EUR) and heteroscedasticity (except KES, ZAR and EUR) at 2 lags. The entire sample was weak stationary.

Table 1: Descriptive statistics of the raw data. Source: author's calculation, using Kevin Sheppard's MFE Toolbox for Matlab

\begin{tabular}{|c|c|c|c|c|c|c|c|c|}
\hline & & & & & $\begin{array}{l}\text { normal } \\
\text { distribution }\end{array}$ & $\begin{array}{l}\text { autocorrelati } \\
\text { on }\end{array}$ & $\begin{array}{l}\text { heteroscedastici } \\
\text { ty }\end{array}$ & $\begin{array}{l}\text { i stationarit } \\
\text { y }\end{array}$ \\
\hline currency & $\begin{array}{l}\text { mea } \\
n\end{array}$ & std & $\begin{array}{l}\text { skewne } \\
\text { ss }\end{array}$ & $\begin{array}{l}\text { kurtosi } \\
\text { s }\end{array}$ & Jarque-Bera (p) & $\begin{array}{l}\text { Ljung-Box } \\
\text { (p) }\end{array}$ & ARCH-LM (p) & $\mathrm{ADF}(\mathrm{p})$ \\
\hline $\begin{array}{l}\text { KES/US } \\
\mathrm{D}\end{array}$ & 0,00 & $\begin{array}{l}0,0 \\
1\end{array}$ & $-0,32$ & 20,51 & 0,00 & 0,00 & $0,10 * *$ & 0,00 \\
\hline $\begin{array}{l}\text { GHS/US } \\
\text { D }\end{array}$ & 0,00 & $\begin{array}{l}0,0 \\
1\end{array}$ & $-1,23$ & 33,77 & 0,00 & 0,00 & 0,00 & 0,00 \\
\hline $\begin{array}{l}\text { ZAR/US } \\
\text { D }\end{array}$ & 0,00 & $\begin{array}{l}0,0 \\
1\end{array}$ & $-1,05$ & 15,74 & 0,00 & 0,01 & $0,14 * *$ & 0,00 \\
\hline TZS/USD & 0,00 & $\begin{array}{l}0,0 \\
1\end{array}$ & 0,82 & 39,78 & 0,00 & 0,00 & 0,00 & 0,00 \\
\hline $\begin{array}{l}\text { UGX/US } \\
\text { D }\end{array}$ & 0,00 & $\begin{array}{l}0,0 \\
1\end{array}$ & $-0,47$ & 16,76 & 0,00 & 0,00 & 0,02 & 0,00 \\
\hline XAF/US & 0,00 & 0,0 & 0,13 & 5,14 & 0,00 & 0,00 & 0,00 & 0,00 \\
\hline
\end{tabular}




\begin{tabular}{|c|c|c|c|c|c|c|c|c|}
\hline D & & 1 & & & & & & \\
\hline $\begin{array}{l}\text { GMD/US } \\
\text { D }\end{array}$ & 0,00 & $\begin{array}{l}0,0 \\
2\end{array}$ & 0,05 & 169,41 & 0,00 & 0,00 & 0,03 & 0,00 \\
\hline $\begin{array}{l}\text { MGA/US } \\
\text { D }\end{array}$ & 0,00 & $\begin{array}{l}0,0 \\
1\end{array}$ & $-1,63$ & 54,41 & 0,00 & 0,00 & 0,00 & 0,00 \\
\hline $\begin{array}{l}\mathrm{MZN} / \mathrm{US} \\
\mathrm{D}\end{array}$ & 0,00 & $\begin{array}{l}0,0 \\
1\end{array}$ & $-0,80$ & 42,11 & 0,00 & 0,00 & 0,00 & 0,00 \\
\hline $\begin{array}{l}\text { EUR/US } \\
\text { D }\end{array}$ & 0,00 & $\begin{array}{l}0,0 \\
1\end{array}$ & $-0,02$ & 4,39 & 0,00 & $0,52^{*}$ & $0,59 * *$ & 0,00 \\
\hline
\end{tabular}

Notes: *: non autocorrelated at 2 lags, **: homoscedastic at 2 lags

Four (GARCH, TARCH, GJR-GARCH, APARCH) GARCH models with 13 different lagnumber setup was fitted on the raw dataset to find the most fitting model trough searching for the lower BIC. Half of the sample preferred asymmetric models (except GHS, TZS, UGX, EUR), but previous volatilities had major role in the estimation of present volatility innovations were important at GMD only (table 2).

Table 2: GARCH models of raw data. Source: author's calculation, using Kevin Sheppard's UCSD Toolbox for Matlab

\begin{tabular}{|l|l|l|l|l|l|l|l|l|l|}
\hline currency & model & constant & alpha 1 & alpha 2 & gamma & beta 1 beta 2 & delta & BIC \\
\hline KES/USD & TARCH $(1,1,2)$ & 0,00 & 0,26 & & $-0,03$ & 0,46 & 0,29 & & $-4,20$ \\
\hline GHS/USD & GARCH(1,2) & 0,00 & 0,11 & & & 0,37 & 0,51 & & $-3,70$ \\
\hline ZAR/USD & GJR GARCH(1,1,1) & 0,00 & 0,12 & & $-0,10$ & 0,93 & & & $-3,21$ \\
\hline TZS/USD & GARCH(1,1) & 0,00 & 0,21 & & & 0,79 & & & $-3,91$ \\
\hline UGX/USD & GARCH(1,1) & 0,00 & 0,20 & & & 0,80 & & & $-3,82$ \\
\hline XAF/USD $*$ & & & & & & & & & \\
\hline GMD/USD & TARCH(2,1,1) & 0,00 & 0,30 & 0,30 & $-0,16$ & 0,48 & & & $-2,81$ \\
\hline MGA/USD & GJRGARCH(1,1,2) & 0,00 & 0,02 & & 0,03 & 0,47 & 0,49 & & $-3,18$ \\
\hline MZN/USD & GJRGARCH(1,1,2) & 0,00 & 0,26 & & $-0,11$ & 0,29 & 0,51 & & $-3,32$ \\
\hline EUR/USD & GARCH(1,1) & 0,00 & 0,04 & & & 0,96 & & $-3,71$ \\
\hline
\end{tabular}

Notes: *: none of the models were able to provide homoscedastic residuals with normal distribution

Value-at-Risk (table 3) was able to create a close-to-symmetric set of non-extreme returns, while kurtosis dropped under 5. Extreme fluctuations had lower weight than $10 \%$ (except the 
$11 \%$ of XAF and EUR), so the method was able to capture those rare cases, which were responsible for most of the fat tailness of the data.

Table 3: Value-at-Risk properties of raw data (in USD). Source: author's calculation, following Madura (2008)

\begin{tabular}{|l|c|c|c|c|c|c|c|c|c|c|}
\hline currency & KES & GHS & ZAR & TZS & UGX & XAF & GMD & MGA & MZN & EUR \\
\hline mean & 0,00 & 0,00 & 0,00 & 0,00 & 0,00 & 0,00 & 0,00 & 0,00 & 0,00 & 0,00 \\
\hline standard deviation & 0,00 & 0,01 & 0,01 & 0,00 & 0,00 & 0,00 & 0,01 & 0,01 & 0,01 & 0,00 \\
\hline skewness & 0,07 & $-0,14$ & $-0,04$ & $-0,02$ & $-0,02$ & 0,02 & $-0,04$ & 0,04 & 0,05 & 0,01 \\
\hline kurtosis & 3,48 & 4,34 & 2,51 & 3,16 & 2,84 & 2,52 & 4,07 & 3,68 & 4,24 & 2,48 \\
\hline X- treshold & $-0,01$ & $-0,02$ & $-0,02$ & $-0,01$ & $-0,01$ & $-0,01$ & $-0,03$ & $-0,02$ & $-0,02$ & $-0,01$ \\
\hline X+ treshold & 0,01 & 0,02 & 0,02 & 0,01 & 0,01 & 0,01 & 0,03 & 0,02 & 0,02 & 0,01 \\
\hline Number of X- & 148 & 121 & 179 & 136 & 149 & 190 & 105 & 100 & 123 & 189 \\
\hline Number of X+ & 138 & 128 & 145 & 121 & 127 & 178 & 95 & 90 & 107 & 207 \\
\hline Number of non-extreme returns & 3606 & 3573 & 3589 & 3578 & 3563 & 3455 & 3589 & 3424 & 3598 & 3517 \\
\hline
\end{tabular}

\subsection{Comparison of Methods}

Temporary distribution of missing data (number of days between two missing data after each other) was not random, so the MCAR hypothesis can be rejected, we can assume MAR case only (table 4). MGA currency suffered from missingness at most, while ZAR and EUR had none of them. Listwise deletion was the most restrictive approach, while other two methods made less dramatic reduction in the length of the entire dataset.

Table 4: Number of missing days to data length under different approaches. Source: author's calculation

\begin{tabular}{|l|l|l|l|l|}
\hline \multicolumn{2}{|l|}{} & \multicolumn{2}{l}{ Percentage of missing } & normal distribution of missing days \\
\hline Currency & Listwise deletion & Mean substitution & EM & Kolmogorov-Smirmov-test (p) \\
\hline KES/USD & $1 \%$ & $1 \%$ & $1 \%$ & 0,00 \\
\hline GHS/USD & $3 \%$ & $2 \%$ & $2 \%$ & 0,00 \\
\hline ZAR/USD & $0 \%$ & $0 \%$ & $0 \%$ & NaN \\
\hline TZS/USD & $2 \%$ & $2 \%$ & $2 \%$ & 0,00 \\
\hline UGX/USD & $2 \%$ & $2 \%$ & $2 \%$ & 0,00 \\
\hline XAF/USD & $3 \%$ & $2 \%$ & $2 \%$ & 0,00 \\
\hline GMD/USD & $4 \%$ & $3 \%$ & $3 \%$ & 0,00 \\
\hline
\end{tabular}




\begin{tabular}{|l|l|l|l|l|} 
MGA/USD & $9 \%$ & $8 \%$ & $8 \%$ & 0,00 \\
\hline MZN/USD & $2 \%$ & $2 \%$ & $2 \%$ & 0,00 \\
\hline EUR/USD & $0 \%$ & $0 \%$ & $0 \%$ & NaN \\
\hline
\end{tabular}

Appendix 1 contains the comparison of the descriptive statistics of reined data by three different approaches. Mean remained close to zero as at the raw data, but standard deviation doubled or tripled in $60 \%$ of the cases at EM method. Asymmetry of the data was completely distorted by all of the methods, but kurtosis was increased in the $40 \%$ of the cases and remained at the previous level in the other $40 \%$ at listwise deletion. Kurtosis increased in the half of the cases under mean substitution or remained stable. Kurtosis dramatically increased under EM method. Data remained non-normal distributed and weak stationer, and there were no significant changes in the autocorrelation of heteroscedasticity properties.

Results about Value-at-Risk has the same message as kurtosis (Appendix 2), where EM approach provided less VaR signals, but the "non-extreme" subset suffered from the increase of kurtosis in $80 \%$ of the sample (except ZAR and EUR). It means that VaR-based risk management can be biased by missing data if it is managed trough EM methodology. Listwise approach presented the lower impact on VaR properties.

Listwise approach in volatility modelling (Appendix 3) had a moderate impact on parameters only and suggested a different model for MGA and MZN, while it was now possible to fit a GARCH model on XAF data. Innovation parameters increased while previous volatility decreased a bit, and models presented a better fit - despite the expected higher fragmentation of the approach. Mean substitution pushed MGN and GHS currencies towards the more complicated APARCH model, but only GHS lost its former symmetric design. This approach increased the parameters of volatility persistence with similar BIC. The EM approach suggested asymmetric models instead of former symmetric models (for KES, GHS, TZS, UGX), while three former asymmetric preference decreased to symmetry (GMD, MGA, MZN) - but BIC increased almost everywhere, suggesting that it was harder to find wellfitting models with homoscedastic residuals. ZAR and EUR was completely unaffected by the different approaches (despite that they had to lost the most value to meet listwise deletion standards), while MGA and MZN was completely the subject of missing data management.

Despite significant share of the European Union and the US in sample countries balance of payments, unconditional correlation was mediocre between EUR/USD and ZAR/USD as well as high between XAF/USD and EUR/USD in the selected time period under listwise deletion and mean substitution (Appendix 4). Other markets remained isolated from international currency fluctuations, while ZAR correlated with XAF as well. Results were augmented by the EM method, signing medium common movement $(\rho=0.64)$ between GHS and UGX and mediocre levels $(0.3<\rho<0.5)$ among GHS and KES, TZS, GMD, MGA, MZN or between UGX and KES, TZS and UGX, TZS and MZN, GMD and MZN. Due to the former results about the biased results of the EM procedure this sudden appearance of mediocre correlations is hardly questionable. Sample currencies were tested by Dynamic Conditional Correlation (DCC) against EUR/USD were only ZAR and XAF presented some sort of common movement, like it happened before at the unconditional case. Listwise deletion provided higher mean in both cases, but DCC of ZAR/USD-EUR/USD was significant different from Mean substitution or EM counter pairs only - according to the two sampled ttest (where $\mathrm{p}=0.55$ and $\mathrm{p}=0.00$ for all other cases). 
Table 5: Dynamic Conditional Correlation moments - with EUR/USD. Source: author's calculation

\begin{tabular}{|c|c|c|c|c|c|c|c|c|c|c|c|c|}
\hline & \multicolumn{4}{|c|}{ Listwise deletion } & \multicolumn{4}{|c|}{ Mean substitution } & \multicolumn{4}{|l|}{ EM } \\
\hline & mean & std & $\begin{array}{l}\text { skewne } \\
\text { ss }\end{array}$ & $\begin{array}{l}\text { kurtos } \\
\text { is }\end{array}$ & mean & std & $\begin{array}{l}\text { skewne } \\
\text { ss }\end{array}$ & $\begin{array}{l}\text { kurtos } \\
\text { is }\end{array}$ & mean & std & $\begin{array}{l}\text { skewne } \\
\text { ss }\end{array}$ & $\begin{array}{l}\text { kurtosi } \\
\mathrm{s}\end{array}$ \\
\hline KES/US & 0,045 & $\begin{array}{l}0,048 \\
9\end{array}$ & 01880 & 2,335 & 0,035 & $\begin{array}{l}0,045 \\
9\end{array}$ & 5519 & $\begin{array}{l}2,671 \\
5\end{array}$ & 0,014 & $\begin{array}{l}0,035 \\
4\end{array}$ & -12180 & 34391 \\
\hline GHS/US & $\begin{array}{l}0,001 \\
0\end{array}$ & $\begin{array}{l}0,016 \\
6\end{array}$ & 00417 & $\begin{array}{l}6,904 \\
8\end{array}$ & 0,005 & 0,009 & 1457 & 8,059 & 0,029 & 0,015 & L 7023 & 27211 \\
\hline ZAR/US & 0,429 & 0,177 & & 3,466 & 0,411 & 0,171 & 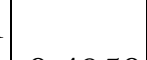 & 2,952 & 0,411 & 0,171 & & \\
\hline & & 5 & $-0,6407$ & 4 & 9 & & $-0,4950$ & & 9 & & $-0,4950$ & 2,9529 \\
\hline TZS/US & 0,003 & 0,021 & & 10,27 & 0,035 & 0,008 & & 1,928 & 0,005 & 0,002 & 13,066 & 201,95 \\
\hline & 7 & 6 & $0,4166 \mid$ & 84 & 1 & 8 & $-0,3345$ & 2 & 9 & 3 & 8 & 01 \\
\hline UGX/US & 0,038 & 0,021 & & 4,884 & 0,056 & 0,016 & & 1,721 & 0,034 & 0,022 & & \\
\hline D & 4 & 4 & 0,2245 & 1 & 9 & 7 & 0,2014 & 5 & 3 & 8 & 0,4147 & 3,8064 \\
\hline XAF/US & 0,837 & 0,175 & & 4,662 & 0,768 & 0,231 & & 5,318 & 0,764 & 0,240 & & \\
\hline & 3 & 5 & $-1,3723$ & 8 & 6 & 3 & $-1,4152$ & 4 & 2 & 3 & $-1,4034$ & $+5,0187$ \\
\hline GMD/U & 0,032 & 0,015 & & 2,179 & 0,029 & 0,015 & & 2,228 & 0,006 & 0,007 & & 20,506 \\
\hline SD & 1 & 1 & $-0,5513$ & 8 & 6 & 6 & $-0,5877$ & 6 & 0 & 3 & 0,7218 & 7 \\
\hline MGA/U & 0,063 & 0,032 & & 2,735 & 0,053 & 0,021 & & 2,506 & 0,055 & 0,011 & & \\
\hline & 4 & 2 & $-0,1573$ & 2 & 1 & 4 & $-0,0327$ & & 8 & 7 & 0,5373 & 2,1534 \\
\hline MZN/US & 0,005 & 0,019 & & 2,190 & 0,005 & 0,039 & & 2,681 & 0,018 & 0,035 & & \\
\hline D & 4 & 1 & $-0,1388$ & 2 & 5 & 0 & $-0,8071$ & 9 & 7 & 0 & $-0,936$ & 3,1454 \\
\hline
\end{tabular}

\section{CONCLUSION}

The maximum-likelihood-based Expectation Maximization (EM) models have high popularity nowadays to manage missing data in query data due to its ability to maintain the covariance matrix of the data. However, compared to listwise deletion or mean substitution methods, the EM method presented many biases on daily closing data of financial time series. This application increased the second and fourth moment dramatically, providing a reduced VaR-signal performance and made conditional volatility more asymmetric. Contagion studies can be also biased by the choice of method, but results were limited here. 
Results of application comparison in current paper suggest the usage of mean substitution or listwise deletion for daily financial time series due to their tendency to have a close-to-zero first momentum.

\section{References}

Baraldi, P., Di Maio, F., Genini, D., Zio, E. (2015). Reconstruction of missing data in multidimensional time series by fuzzy similarity. Applied Soft Computing Journal, 26: 1-9 https://doi.org/10.1016/j.asoc.2014.09.038

Cappeiello, L., Engle, R. F., Sheppard, K., (2006). Asymmetric Dynamics in the Correlations of Global Equity and Bond Returns. Journal of Financial Econometrics, 4: 537-572 https://doi.org/10.1093/jjfinec/nbl005

Ceylan, Y., Sipan, A., Cem, I., Inci, B. (2013). Comparison of missing value imputation methods in time series: the case of Turkish meteorological data. Theoretical \& Applied Climatology, 112(1/2): 143-167

Engle, R. F., (2002). Dynamic Conditional Correlation - A Simple Class of Multivariate GARCH Models. Journal of Business and Economic Statistics, 20(3): 377-389 https://doi.org/10.1198/073500102288618487

Graham, J. W. (2012). Missing Data Analysis and Design. Springer New York Heidelberg Dordrecht London https://doi.org/10.1007/978-1-4614-4018-5

Houari, R., Bounceur, A., Kechadi, T., Euler, R. (2013). A New Method for Estimation of Missing Data Based on Sampling Methods for Data Mining. CCSEIT https://doi.org/10.1007/978-3-319-00951-3_9

Juan Carlos, F. G., Dusko, K., Bello, L., Amilcar, C. (2010). An Evolutionary Approach for Imputing Missing Data in Time Series. Journal of Circuits, Systems \& Computers, 19(1): 107-121 https://doi.org/10.1142/S0218126610006050

Junger, W.L., Ponce de Leon, A. (2015). Imputation of missing data in time series for air pollutants. Atmospheric Environment, 102: 96-104 https://doi.org/10.1016/j.atmosenv.2014.11.049

Kang, H. (2013). The prevention and handling of the missing data. Korean J Anesthesiol, 64(5): 402-406 https://doi.org/10.4097/kjae.2013.64.5.402

Keim, D. B., Stambaugh, R. F. (1984). A further investigation of the weekend effect in stock returns. The Journal of Finance, 39(3): 819-835 https://doi.org/10.1111/j.15406261.1984.tb03675.x

Madura, J. (2008). International Financial Management. Mason: Thomson

Robins, R. P., Smith, G. P. (2015). No More Weekend Effect. Critical Finance Review, Forthcoming.

Ruud, P. A. (1991). Extensions of estimation methods using the EM algorithm. Journal of Econometrics, 49(3): 305-341 https://doi.org/10.1016/0304-4076(91)90001-T

Schneider, T. (2001). Analysis of incomplete climate data: Estimation of mean values and covariance matrices and imputation of missing values. Journal of Climate, 14: 853871. https://doi.org/10.1175/1520-0442(2001)014<0853:AOICDE>2.0.CO;2

Shahid, M. N., Mehmood, Z. (2015). Calendar Anomalies in Stock Market: A Case of KSE 100 Index. International Journal of African and Asian Studies, 7: 16-23

The estimation based on the Oxford MFE and UCSD toolboxs, developed by Kevin Sheppard: http://www.kevinsheppard.com/

Wothke, W. (1998). Longitudinal and multi-group modelling with missing data. Mahwah. NJ: Lawrence Erlbaum Associates. 
Appendix 1 - Descriptive statistics of refined data

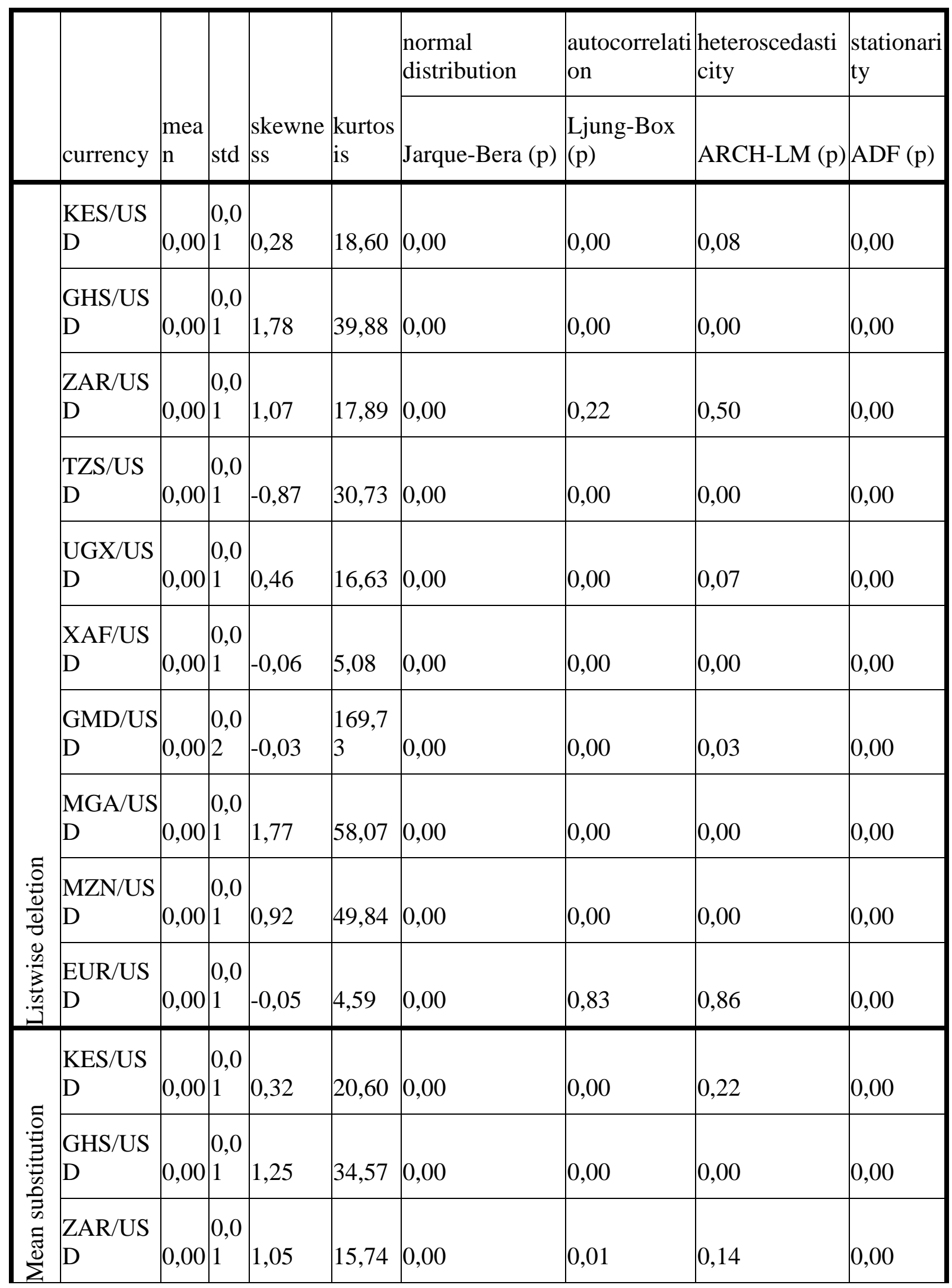




\begin{tabular}{|c|c|c|c|c|c|c|c|c|c|}
\hline & $\begin{array}{l}\text { TZS/US } \\
\mathrm{D}\end{array}$ & $0,00 \mid \begin{array}{l}c \\
1\end{array}$ & $\begin{array}{l}0,0 \\
1\end{array}$ & $-0,84$ & 40,52 & 0,00 & 0,00 & 0,00 & 0,00 \\
\hline & $\begin{array}{l}\text { UGX/US } \\
\text { D }\end{array}$ & 0,00 & $\begin{array}{l}0,0 \\
1\end{array}$ & 0,46 & 16,99 & 0,00 & 0,00 & 0,02 & 0,00 \\
\hline & $\begin{array}{l}\text { XAF/US } \\
\text { D }\end{array}$ & $0,00 \mid$ & $\begin{array}{l}0,0 \\
1\end{array}$ & $-0,14$ & 5,26 & 0,00 & 0,00 & 0,00 & 0,00 \\
\hline & $\begin{array}{l}\text { GMD/US } \\
\mathrm{D}\end{array}$ & 0,00 & $\begin{array}{l}0,0 \\
2\end{array}$ & $-0,05$ & $\mid \begin{array}{l}174,9 \\
1\end{array}$ & 0,00 & 0,00 & 0,03 & 0,00 \\
\hline & $\begin{array}{l}\text { MGA/US } \\
\text { D }\end{array}$ & $0,00 \mid$ & $\left|\begin{array}{l}0,0 \\
1\end{array}\right|$ & 1,61 & 57,71 & 0,00 & 0,00 & 0,00 & 0,00 \\
\hline & $\begin{array}{l}\mathrm{MZN} / \mathrm{US} \\
\mathrm{D}\end{array}$ & 0,00 & $\begin{array}{l}0,0 \\
1\end{array}$ & 0,81 & 43,03 & 0,00 & 0,00 & 0,00 & 0,00 \\
\hline & $\begin{array}{l}\text { EUR/US } \\
\text { D }\end{array}$ & $0,00 \mid$ & $\begin{array}{l}0,0 \\
1\end{array}$ & $-0,02$ & 4,39 & 0,00 & 0,51 & 0,59 & 0,00 \\
\hline & \begin{tabular}{|l} 
KES/US \\
$\mathrm{D}$
\end{tabular} & $0,00 \mid \begin{array}{l}\mid \\
1\end{array}$ & $\begin{array}{l}0,0 \\
1\end{array} \mid$ & 0,98 & $\begin{array}{l}181,0 \\
4\end{array}$ & 0,00 & 0,00 & 0,02 & 0,00 \\
\hline & $\begin{array}{l}\text { GHS/US } \\
\text { D }\end{array}$ & $0,00 \mid 3$ & $\begin{array}{l}0,0 \\
3\end{array}$ & $-0,02$ & $\mid \begin{array}{l}358,5 \\
1\end{array}$ & 0,00 & 0,00 & 0,06 & 0,00 \\
\hline & $\begin{array}{l}\text { ZAR/US } \\
\mathrm{D}\end{array}$ & $0,00 \mid$ & $\left|\begin{array}{l}0,0 \\
1\end{array}\right|$ & 1,05 & 15,74 & 0,00 & 0,01 & 0,14 & 0,00 \\
\hline & \begin{tabular}{|l} 
TZS/US \\
$\mathrm{D}$
\end{tabular} & $0,00 \mid$ & $\begin{array}{l}0,0 \\
2\end{array} \mid$ & 0,04 & $\begin{array}{l}198,9 \\
8\end{array}$ & 0,00 & 0,00 & 0,00 & 0,00 \\
\hline & $\begin{array}{l}\text { UGX/US } \\
\text { D }\end{array}$ & 0,00 & $\begin{array}{l}0,0 \\
2\end{array}$ & 0,03 & $\mid \begin{array}{l}121,7 \\
5\end{array}$ & 0,00 & 0,00 & 0,00 & 0,00 \\
\hline & $\begin{array}{l}\text { XAF/US } \\
\mathrm{D}\end{array}$ & $0,00 \mid$ & $\begin{array}{l}0,0 \\
1\end{array}$ & $-0,21$ & 13,08 & 0,00 & 0,00 & 0,00 & 0,00 \\
\hline & $\begin{array}{l}\text { GMD/US } \\
\mathrm{D}\end{array}$ & 0,00 & $\begin{array}{l}0,0 \\
3\end{array}$ & $-0,07$ & 74,16 & 0,00 & 0,00 & 0,00 & 0,00 \\
\hline & $\begin{array}{l}\text { MGA/US } \\
\text { D }\end{array}$ & 0,00 & $\begin{array}{l}0,0 \\
4\end{array}$ & 0,11 & 24,16 & 0,00 & 0,00 & 0,00 & 0,00 \\
\hline$\sum_{-1} \mid \begin{array}{l}\Lambda \\
D\end{array}$ & $\begin{array}{l}\text { MZN/US } \\
\mathrm{D}\end{array}$ & 0,00 & $\begin{array}{l}0,0 \\
2\end{array}$ & 0,14 & 55,40 & 0,00 & 0,00 & 0,00 & 0,00 \\
\hline
\end{tabular}



EUR/US
D
$0,00 \mid$\begin{tabular}{l|l|l}
0,0 & \\
1 & $-0,02$
\end{tabular}
$4,39 \quad 0,00$
0,51
0,59
0,00

Appendix 2 - Value-at-Risk of refined data (in USD)

\begin{tabular}{|c|c|c|c|c|c|c|c|c|c|c|c|}
\hline & currency & KES & GHS & ZAR & TZS & UGX & XAF & GMD & MGA & $\mathrm{MZN}$ & EUR \\
\hline \multirow{9}{*}{$\begin{array}{l}\frac{0}{0} \\
\frac{0}{0} \\
\frac{0}{0} \\
0 \\
\frac{0}{3} \\
.000\end{array}$} & mean & 0,00 & 0,00 & 0,00 & 0,00 & 0,00 & 0,00 & 0,00 & 0,00 & 0,00 & 0,00 \\
\hline & standard deviation & 0,00 & 0,01 & 0,01 & 0,00 & 0,00 & 0,01 & 0,01 & 0,01 & 0,01 & 0,00 \\
\hline & skewness & $-0,05$ & 0,09 & 0,06 & 0,06 & 0,00 & $-0,02$ & 0,02 & $-0,02$ & $-0,02$ & 0,00 \\
\hline & kurtosis & 3,49 & 4,31 & 2,54 & 3,03 & 2,87 & 2,52 & 4,05 & 3,69 & 4,02 & 2,50 \\
\hline & X-threshold & $-0,01$ & $-0,02$ & $-0,02$ & $-0,01$ & $-0,01$ & $-0,01$ & $-0,03$ & $-0,02$ & $-0,02$ & $-0,01$ \\
\hline & $\mathrm{X}+$ threshold & 0,01 & 0,02 & 0,02 & 0,01 & 0,01 & 0,01 & 0,03 & 0,02 & 0,02 & 0,01 \\
\hline & No X- & 130 & 111 & 119 & 119 & 115 & 159 & 84 & 87 & 82 & 160 \\
\hline & No X+ & 136 & 105 & 153 & 135 & 130 & 169 & 97 & 90 & 91 & 173 \\
\hline & No Normal & 3146 & 3196 & 3140 & 3158 & 3167 & 3084 & 3231 & 3235 & 3239 & 3079 \\
\hline \multirow{9}{*}{ 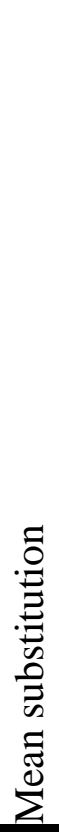 } & mean & 0,00 & 0,00 & 0,00 & 0,00 & 0,00 & 0,00 & 0,00 & 0,00 & 0,00 & 0,00 \\
\hline & standard deviation & 0,00 & 0,01 & 0,01 & 0,00 & 0,00 & 0,00 & 0,01 & 0,01 & 0,01 & 0,00 \\
\hline & skewness & $-0,07$ & 0,13 & 0,04 & 0,01 & 0,00 & $-0,03$ & 0,05 & $-0,10$ & $-0,02$ & 0,00 \\
\hline & kurtosis & 3,51 & 4,47 & 2,51 & 3,25 & 2,88 & 2,59 & 4,37 & 3,95 & 4,38 & 2,48 \\
\hline & X-threshold & $-0,01$ & $-0,02$ & $-0,02$ & $-0,01$ & $-0,01$ & $-0,01$ & $-0,03$ & $-0,02$ & $-0,02$ & $-0,01$ \\
\hline & $\mathrm{X}+$ threshold & 0,01 & 0,02 & 0,02 & 0,01 & 0,01 & 0,01 & 0,03 & 0,02 & 0,02 & 0,01 \\
\hline & No X- & 138 & 128 & 145 & 121 & 129 & 188 & 97 & 102 & 111 & 189 \\
\hline & No $\mathrm{X}+$ & 148 & 124 & 179 & 135 & 149 & 192 & 107 & 105 & 123 & 207 \\
\hline & No Normal & 3626 & 3660 & 3588 & 3656 & 3634 & 3532 & 3708 & 3705 & 3678 & 3516 \\
\hline$\sum_{\square=1}$ & mean & 0,00 & 0,00 & 0,00 & 0,00 & 0,00 & 0,00 & 0,00 & 0,00 & 0,00 & 0,00 \\
\hline
\end{tabular}




\begin{tabular}{|l|l|l|l|l|l|l|l|l|l|l|l|}
\hline standard deviation & 0,00 & 0,01 & 0,01 & 0,01 & 0,01 & 0,01 & 0,01 & 0,01 & 0,01 & 0,00 \\
\hline skewness & $-0,05$ & 0,04 & 0,04 & $-0,16$ & $-0,03$ & $-0,02$ & 0,08 & $-0,20$ & $-0,05$ & 0,00 \\
\hline kurtosis & 5,58 & 9,62 & 2,51 & 7,01 & 5,63 & 2,66 & 5,30 & 10,66 & 5,11 & 2,48 \\
\hline X- threshold & $-0,02$ & $-0,05$ & $-0,02$ & $-0,03$ & $-0,03$ & $-0,01$ & $-0,06$ & $-0,07$ & $-0,04$ & $-0,01$ \\
\hline X+ threshold & 0,02 & 0,06 & 0,02 & 0,03 & 0,03 & 0,01 & 0,06 & 0,07 & 0,04 & 0,01 \\
\hline No X- & 45 & 26 & 145 & 38 & 56 & 144 & 76 & 127 & 94 & 189 \\
\hline No X+ & 50 & 30 & 179 & 41 & 67 & 159 & 84 & 129 & 113 & 207 \\
\hline No Normal & 3817 & 3856 & 3588 & 3833 & 3789 & 3609 & 3752 & 3656 & 3705 & 3516 \\
\hline
\end{tabular}

Appendix 3-GARCH models of refined data

\begin{tabular}{|c|c|c|c|c|c|c|c|c|c|c|}
\hline & currency & model & constant & alpha & 1 alpha 2 & 2 gamma & beta 1 & beta 2 & delta & $\mathrm{BIC}$ \\
\hline \multirow{10}{*}{ 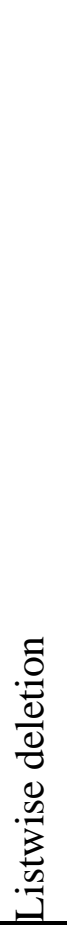 } & KES/USD & TARCH $(1,1,2)$ & 0,00 & 0,23 & & 0,04 & 0,40 & 0,36 & & $-4,12$ \\
\hline & GHS/USD & GARCH(1,2) & 0,00 & 0,13 & & & 0,35 & 0,52 & & $-3,68$ \\
\hline & ZAR/USD & TARCH $(1,1,1)$ & 0,00 & 0,05 & & 0,07 & 0,91 & & & $-3,13$ \\
\hline & TZS/USD & $\operatorname{GARCH}(1,1)$ & 0,00 & 0,25 & & & 0,75 & & & $-3,96$ \\
\hline & UGX/USD & $\operatorname{GARCH}(1,1)$ & 0,00 & 0,21 & & & 0,79 & & & $-3,80$ \\
\hline & XAF/USD & GARCH $(1,1)$ & 0,00 & 0,04 & & & 0,95 & & & $-3,57$ \\
\hline & GMD/USD & TARCH(2,1,1) & 0,01 & 0,15 & 0,38 & 0,10 & 0,42 & & & $-2,76$ \\
\hline & MGA/USD & $\operatorname{APARCH}(1,1,1)$ & 0,00 & 0,02 & & 0,05 & 0,94 & & 3,98 & $-3,22$ \\
\hline & MZN/USD & GARCH(1,2) & 0,00 & 0,23 & & & 0,30 & 0,47 & & $-3,36$ \\
\hline & EUR/USD & $\operatorname{GARCH}(1,1)$ & 0,00 & 0,05 & & & 0,95 & & & $-3,63$ \\
\hline \multirow{4}{*}{ 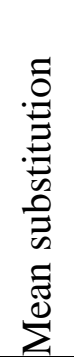 } & KES/USD & TARCH $(1,1,2)$ & 0,00 & 0,23 & & 0,03 & 0,44 & 0,32 & & $-4,20$ \\
\hline & GHS/USD & APARCH( $1,1,1)$ & 0,00 & 0,05 & & $-0,01$ & 0,89 & & 3,66 & $-3,69$ \\
\hline & ZAR/USD & $\operatorname{GJRGARCH}(1,1,1)$ & 0,00 & 0,02 & & 0,10 & 0,93 & & & $-3,21$ \\
\hline & TZS/USD & GARCH $(1,1)$ & 0,00 & 0,20 & & & 0,80 & & & $-3,92$ \\
\hline
\end{tabular}




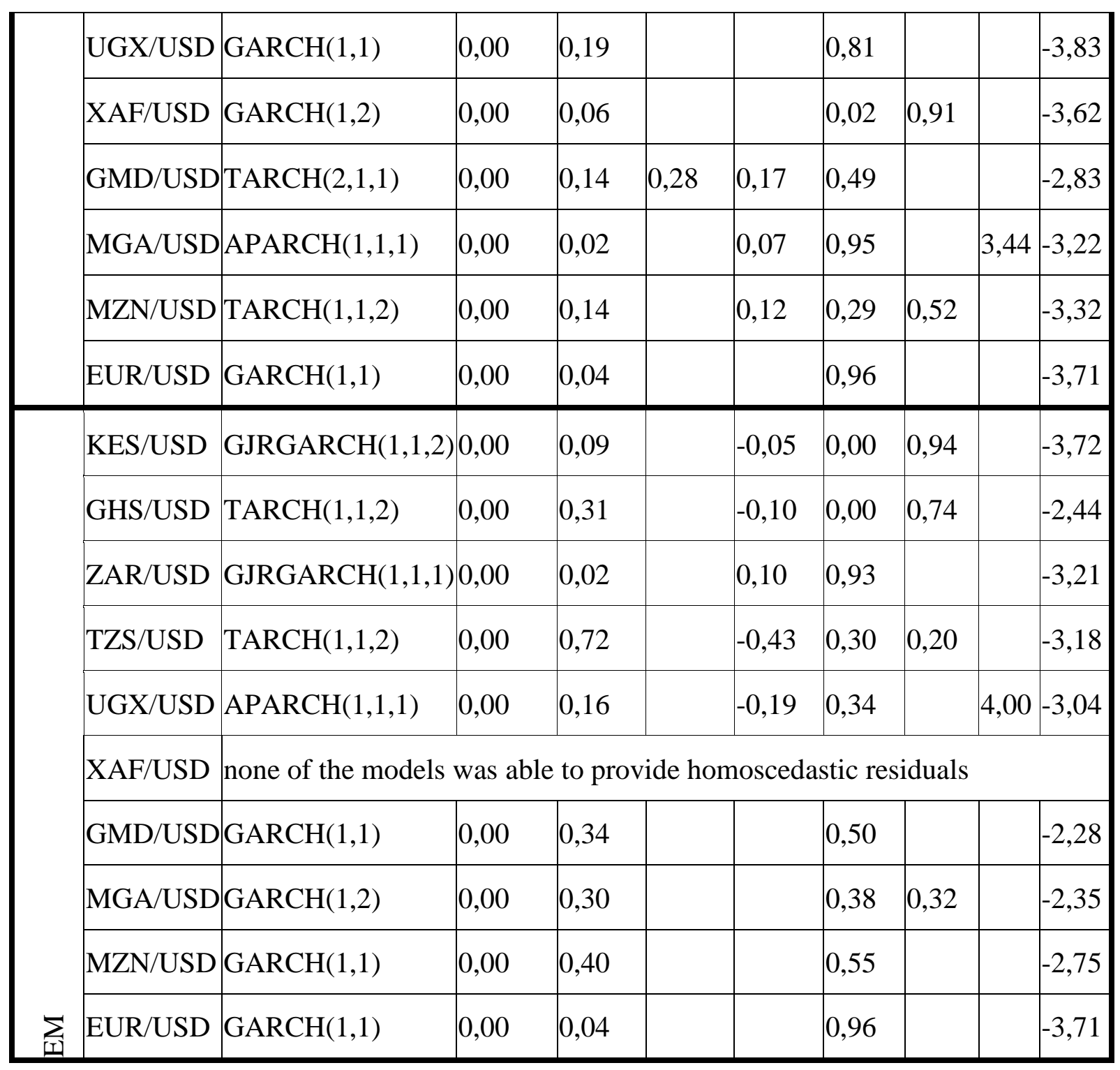

Appendix 4 - Unconditional correlations - calculated on homoscedastic GARCH residuals

\begin{tabular}{|c|c|c|c|c|c|c|c|c|c|c|c|}
\hline & $\begin{array}{l}\text { KES/U } \\
\text { SD }\end{array}$ & $\begin{array}{l}\text { GHS/U } \\
\text { SD }\end{array}$ & $\begin{array}{l}\mathrm{ZAR} / \mathrm{U} \\
\mathrm{SD}\end{array}$ & $\begin{array}{l}\mathrm{TZS} / \mathrm{U} \\
\mathrm{SD}\end{array}$ & $\begin{array}{l}\mathrm{UGX} / \mathrm{U} \\
\mathrm{SD}\end{array}$ & $\mid \begin{array}{l}\mathrm{XAF} / \mathrm{U} \\
\mathrm{SD}\end{array}$ & $\begin{array}{l}\text { GMD/ } \\
\text { USD }\end{array}$ & $\begin{array}{l}\text { MGA/ } \\
\text { USD }\end{array}$ & $\begin{array}{l}\text { MZN/U } \\
\text { SD }\end{array}$ & $\begin{array}{l}\mathrm{J} \text { EUR/U } \\
\mathrm{SD}\end{array}$ & \\
\hline $\begin{array}{l}\mathrm{KES} / \mathrm{U} \\
\mathrm{SD}\end{array}$ & 0,00 & 0,00 & 0,05 & 0,04 & 0,09 & 0,06 & 0,00 & 0,05 & 0,00 & 0,05 & \\
\hline $\begin{array}{l}\text { GHS/U } \\
\text { SD }\end{array}$ & 0,00 & 0,00 & 0,00 & 0,00 & 0,00 & 0,00 & 0,00 & 0,00 & 0,00 & 0,00 & $\frac{0}{\frac{0}{0}}$ \\
\hline $\begin{array}{l}\mathrm{ZAR} / \mathrm{U} \\
\mathrm{SD}\end{array}$ & 0,05 & 0,00 & 0,00 & 0,00 & 0,00 & 0,38 & 0,00 & 0,00 & 0,00 & 0,43 & $\cdot \frac{\infty}{3}$ \\
\hline
\end{tabular}




\begin{tabular}{|c|c|c|c|c|c|c|c|c|c|c|c|}
\hline $\begin{array}{l}\mathrm{TZS} / \mathrm{U} \\
\mathrm{SD}\end{array}$ & 0,04 & 0,00 & 0,00 & 0,00 & 0,08 & 0,00 & 0,00 & 0,00 & 0,04 & 0,00 & \\
\hline $\begin{array}{l}\mathrm{UGX} / \mathrm{U} \\
\mathrm{SD}\end{array}$ & 0,09 & 0,00 & 0,00 & 0,08 & 0,00 & 0,04 & 0,05 & 0,00 & 0,00 & 0,04 & \\
\hline \begin{tabular}{|l}
$\mathrm{XAF} / \mathrm{U}$ \\
$\mathrm{SD}$
\end{tabular} & 0,06 & 0,00 & 0,38 & 0,00 & 0,04 & 0,00 & 0,00 & 0,07 & 0,00 & 0,83 & \\
\hline $\begin{array}{l}\text { GMD/ } \\
\text { USD }\end{array}$ & 0,00 & 0,00 & 0,00 & 0,00 & 0,05 & 0,00 & 0,00 & 0,00 & 0,00 & 0,00 & \\
\hline $\begin{array}{l}\text { MGA/ } \\
\text { USD }\end{array}$ & 0,05 & 0,00 & 0,00 & 0,00 & 0,00 & 0,07 & 0,00 & 0,00 & 0,00 & 0,06 & \\
\hline $\begin{array}{l}\mathrm{MZN} / \mathrm{U} \\
\mathrm{SD}\end{array}$ & 0,00 & 0,00 & 0,00 & 0,04 & 0,00 & 0,00 & 0,00 & 0,00 & 0,00 & 0,00 & \\
\hline \begin{tabular}{|l} 
EUR/U \\
$\mathrm{SD}$
\end{tabular} & 0,05 & 0,00 & 0,43 & 0,00 & 0,04 & 0,83 & 0,00 & 0,06 & 0,00 & 0,00 & \\
\hline $\begin{array}{l}\mathrm{KES} / \mathrm{U} \\
\mathrm{SD}\end{array}$ & 0,00 & 0,00 & 0,03 & 0,05 & 0,08 & 0,06 & 0,00 & 0,00 & 0,00 & 0,04 & \\
\hline $\begin{array}{l}\text { GHS/U } \\
\mathrm{SD}\end{array}$ & 0,00 & 0,00 & 0,00 & 0,00 & 0,00 & 0,00 & 0,00 & 0,00 & 0,00 & 0,00 & \\
\hline $\begin{array}{l}\mathrm{ZAR} / \mathrm{U} \\
\mathrm{SD}\end{array}$ & 0,03 & 0,00 & 0,00 & 0,00 & 0,00 & 0,35 & 0,00 & 0,00 & 0,00 & 0,41 & \\
\hline $\begin{array}{l}\text { TZS/U } \\
\mathrm{SD}\end{array}$ & 0,05 & 0,00 & 0,00 & 0,00 & 0,08 & 0,00 & 0,00 & 0,00 & 0,00 & 0,00 & \\
\hline $\begin{array}{l}\mathrm{UGX} / \mathrm{U} \\
\mathrm{SD}\end{array}$ & 0,08 & 0,00 & 0,00 & 0,08 & 0,00 & 0,04 & 0,04 & 0,00 & $-0,05$ & 0,00 & \\
\hline \begin{tabular}{|l}
$\mathrm{XAF} / \mathrm{U}$ \\
$\mathrm{SD}$
\end{tabular} & 0,06 & 0,00 & 0,35 & 0,00 & 0,04 & 0,00 & 0,00 & 0,06 & 0,00 & 0,76 & \\
\hline $\begin{array}{l}\text { GMD/ } \\
\text { USD }\end{array}$ & 0,00 & 0,00 & 0,00 & 0,00 & 0,04 & 0,00 & 0,00 & 0,00 & 0,00 & 0,00 & \\
\hline $\begin{array}{l}\text { MGA/ } \\
\text { USD }\end{array}$ & 0,00 & 0,00 & 0,00 & 0,00 & 0,00 & 0,06 & 0,00 & 0,00 & 0,00 & 0,05 & \\
\hline $\begin{array}{l}\mathrm{MZN} / \mathrm{U} \\
\mathrm{SD}\end{array}$ & 0,00 & 0,00 & 0,00 & 0,00 & $-0,05$ & 0,00 & 0,00 & 0,00 & 0,00 & 0,00 & : \\
\hline $\begin{array}{l}\text { EUR/U } \\
\mathrm{SD}\end{array}$ & 0,04 & 0,00 & 0,41 & 0,00 & 0,00 & 0,76 & 0,00 & 0,05 & 0,00 & 0,00 & $\stackrel{\infty}{\tilde{\Xi}}^{\infty}$ \\
\hline
\end{tabular}




\begin{tabular}{|l|l|l|l|l|l|l|l|l|l|l|}
$\begin{array}{l}\text { KES/U } \\
\text { SD }\end{array}$ & 0,00 & 0,32 & 0,00 & 0,17 & 0,33 & 0,05 & 0,08 & 0,13 & 0,14 & 0,03 \\
\hline $\begin{array}{l}\text { GHS/U } \\
\text { SD }\end{array}$ & 0,32 & 0,00 & 0,00 & 0,46 & 0,64 & $-0,03$ & 0,33 & 0,38 & 0,46 & 0,00 \\
\hline $\begin{array}{l}\text { ZAR/U } \\
\text { SD }\end{array}$ & 0,00 & 0,00 & 0,00 & 0,00 & 0,00 & 0,30 & 0,00 & 0,00 & 0,03 & 0,41 \\
\hline $\begin{array}{l}\text { TZS/U } \\
\text { SD }\end{array}$ & 0,17 & 0,46 & 0,00 & 0,00 & 0,41 & 0,00 & 0,29 & 0,29 & 0,38 & 0,00 \\
\hline $\begin{array}{l}\text { UGX/U } \\
\text { SD }\end{array}$ & 0,33 & 0,64 & 0,00 & 0,41 & 0,00 & 0,00 & 0,25 & 0,27 & 0,29 & 0,03 \\
\hline $\begin{array}{l}\text { XAF/U } \\
\text { SD }\end{array}$ & 0,05 & $-0,03$ & 0,30 & 0,00 & 0,00 & 0,00 & 0,00 & 0,04 & $-0,03$ & 0,66 \\
\hline $\begin{array}{l}\text { GMD/ } \\
\text { USD }\end{array}$ & 0,08 & 0,33 & 0,00 & 0,29 & 0,25 & 0,00 & 0,00 & 0,07 & 0,36 & 0,00 \\
\hline $\begin{array}{l}\text { MGA/ } \\
\text { USD }\end{array}$ & 0,13 & 0,38 & 0,00 & 0,29 & 0,27 & 0,04 & 0,07 & 0,00 & 0,22 & 0,00 \\
\hline $\begin{array}{l}\text { MZN/U } \\
\text { SD }\end{array}$ & 0,14 & 0,46 & 0,03 & 0,38 & 0,29 & $-0,03$ & 0,36 & 0,22 & 0,00 & 0,00 \\
\hline $\begin{array}{l}\text { EUR/U } \\
\text { SD }\end{array}$ & 0,03 & 0,00 & 0,41 & 0,00 & 0,03 & 0,66 & 0,00 & 0,00 & 0,00 & 0,00 \\
\hline
\end{tabular}

Notes: only significant $(\mathrm{p}<0.05)$ unconditional correlations

\section{Contact information}

Gábor Dávid Kiss

University of Szeged, Faculty of Economics and Business Administration

6722 Szeged, Kálvária sgt. 1, Hungary

0036305010578

kiss.gabor.david@eco.u-szeged.hu

orcid.org/0000-0003-0373-9970

Marianna Sávai

University of Szeged, Faculty of Economics and Business Administration 6722 Szeged, Kálvária sgt. 1, Hungary

savai.marianna@eco.u-szeged.hu

DOI: https://www.doi.org/10.7441/dokbat.2016.21 


\title{
CREATING SHARED VALUE: OPPORTUNITY FOR DESTINATION MANAGEMENT IN THE CZECH REPUBLIC?
}

\author{
Marek Koňařik
}

\begin{abstract}
The main goal of this paper is to introduce the innovative concept of Creating Shared Value by M. E. Porter and M. R. Kramer, to describe discrepancies in adopting of destination management to destinations in the Czech Republic and to suggest possible way of use of the CSV concept in tourism sector. The CSV concept considers business and society as closely related to each other and lies on business strategies that enhance the competitiveness of companies, while at the same time advancing the economic and social conditions of the society they operate in. The current theoretical and practical discourse of tourism in the Czech Republic is still focused on the area of economic benefits and positives that tourism generates, but there is missing wide discussion about the threats and negative consequences, externalities of tourism. Some Czech authors of destination management theory resign from natural control/regulation function of management that could cause unsustainability of development of tourism in the Czech Republic. The setting of destination management activities in a destination may resign on sustainable principles within designed destination strategy, so the tourism company with implemented CSV concept could prevent this risk of environmental or social harms. The CSV concept could be the opportunity to reduce or eliminate threats and externalities caused by tourism activities. Therefore, the development of tourism could be much more sustainable.
\end{abstract}

Keywords: creating shared value, destination, destination management, management functions, strategy, tourism

\section{INTRODUTION}

The article stems from the innovative concept of Creating Shared Value (first used in a Harvard Business School article by Michael E. Porter and Mark R. Kramer in 2011) - CSV, i.e. the strategy of channelling investments in long-term business competitiveness that simultaneously address social and environmental objectives. According to this concept, business and society are not separated groups but they are closely related to each other. A successful business needs a healthy, productive and well-functioning community not only to create demand for its products, but also to have supportive environment and economic stability. The other way round a society needs business to create employment, raise social standards and create wealth.

The concept of shared value recognizes that societal needs, not just conventional economic needs, define markets, Porter and Kramer (2011) explain. It also recognizes that social harms or weaknesses frequently create internal costs for firms - such as wasted energy or raw materials, costly accidents, and the need for remedial training to compensate for inadequacies in education. And addressing societal harms and constraints does not necessarily raise costs for firms, because they can innovate through using new technologies, operating methods, and management approaches - and as a result, increase their productivity and expand their markets.

Porter and Kramer position CSV as a holistic approach that has the potential to redefine the role and purpose of companies within society and address the three major goals of (1) 
restoring the legitimacy of business by reconnecting society and business, (2) fostering growth and innovation in three ways (see below) and (3) increasing the competitive advantage of individual companies by addressing societal challenges.

The tourism sector could be an inspiring example of implementation of the CSV concept. There exist high pressure on sustainability in this sector but a lot of destinations have problems with environmental issues, high concentration of tourists, damages of cultural heritage, outflow of local people from the city centres, etc. Some destinations of the Czech Republic challenge this issues, so the article identifies where are the problems and what could be done.

\section{THE CSV CONCEPT}

The focus of the CSV concept lies in business strategies that enhance the competitiveness of a firm, while at the same time advancing the economic and social conditions of the society it operates in. Societal needs and environmental problems must be in the scope of strategic thinking and represent new opportunities for companies to create corporate values

\subsection{Methods of the CSV concept}

Porter and Kramer (2011) present three distinctive ways which could be shared value created to meet societal and environmental challenges:

\section{Reconceiving products and markets}

Companies can deliberately build their competitive strategy on meeting the biggest needs of our society that are largely unmet by the global economy. These are improved nutrition, superior healthcare, better housing, services for ageing population, and practices and products, which cause less environmental damages. The reconceiving of the existing products and services through the pathway of innovation and redefinition of products together with the chance to perceive new markets related, among others, to new societal challenges represents great opportunities for companies.

\section{Redefining productivity in the value chain}

The improvements can take part in any sphere of the company's value chain, such as energy, logistics, sustainable procurement, distribution system, working conditions, and equal treatment in the workplace. The workers' productivity can include better safety standards, training possibilities, health preventive measures etc. The synergy increases when firms approach societal issues from a shared value perspective and invent new ways of operating to address them. So far, however, few companies have reaped the full productivity benefits in areas such as health, safety environmental performance, and employee retention and capability.

\section{Enabling local cluster development}

Productivity, competitiveness and innovation rely on regional clusters, the concentration of suppliers and related businesses in key regional industries. The support of clusters by regional governments enables the networked companies to focus on the biggest constraints to their success, deficiencies in the general framework conditions and remedying them through joint actions.

Each of these three methods of creating shared value brings the company managers and policy-makers a unique opportunity to address societal challenges by means of seeking for innovation in production processes, improvement of productivity of workers, and increase of 
the company efficiency and quality of products. These processes, however, are carried out on the basis of creative, innovative and discovery thinking unique for each firm, applying the four building blocks of the CSV (Bocksstette, Stamp, 2011) consisting of an explicit VISION of the company as an engine for creating shared value; a robust STRATEGY that identifies a clear focus and articulates ambitious goals; effective DELIVERY that leverages assets and expertise across functions and business units within the company, as well as from external partners and stakeholders; and management for PERFORMANCE that seeks to measure and learn from results, bring successful efforts to scale, and communicate progress.

Specific examples of the impacts are shown in three CSV approaches in practice (Kindermann, 2013):

1) Reconceiving Products and Markets: Thomas Reuters company monthly provides small farmers with information. Information are related to crop pricing, weather forecasts, and agricultural advisory for a fee of 5 USD per quarter. This service reaches over 2 million farmers and helped to increase the income of at least 60 percent of them. Reuters spotted the lack of ability of farmers in developing countries to get important information for their business and found a way to serve them with a new service tool. The efficiency of the agricultural sector has increased and simultaneously profits are made, thus consequently creating shared value.

2) Redefining Productivity in the Value Chain: Johnson and Johnson company saved 250 million USD by implementing a stop smoking and different other wellness programs for their staff. Since then, the company employed a more productive workforce than ever before. Rather than putting increasing pressure on workers or leveling down wages, the introduction of better safety standards, training possibilities, promotion prospects, and higher wages have significant positive effects on the productivity of employees and reduce costs of the company, due to less sick reports and therefore less lost workdays. Poor health of the workforce costs the company most often more than the health benefits, as preventive measures, would.

3) Enabling Local Cluster Development. The mineral fertilizer producer Yara recognized that the insufficiency of the logistical infrastructure in parts of Africa was putting a strain on the ability of local farmers to purchase necessary fertilizers and other vital inputs and also to market their own corps. Yara invested in the infrastructure in Mozambique and Tanzania in corporation with local governments, which now supports 200.000 small rural farmers. The project created jobs, new opportunities for the farmers leading to several multiplier effects within the cluster, and increase the sales of company's products at the same time. In consequence, shared value creation took place.

The CSV is a part of the competitive strategy of a company, which is based on a precise study of the company's value chain in order to understand social and environmental consequences of each corporate activity. The way in which a company can create shared value may differ relating to its industry or organisational structure. However, every enterprise has the ability to realise shared value creation. The third segment of the CSV concept, i.e. enabling local cluster development, imposes the same task on policy-makers, mobilising them in understanding the regional competitiveness fundamental and the capitalisation of the regional cluster. As a result of the CSV approach implementation, the competitiveness of companies and the regions grows and the quality of life improves.

\subsection{CSV vs. CSR concepts}

The concept of CSV has a common denominator with the CSR (Corporate social responsibility) concept and it may be seen strong overlaps between both concepts in various areas. Moreover, the CSV is often viewed as the new wave of the CSR. The CSR 
programmes have been the pioneering concept of lessening the gap between the economic and social thinking and brought a new dimension in the corporate strategy, which is placing CSR among vital corporate-to-society tools. However, the CSR programmes' focus mostly on reputation and their limited connection to the business, make them hard to justify and maintain over the long run. In contrast, CSV is integral to a company's profitability and competitive position. It leverages the unique resources and expertise of the company to create economic value by creating social value.

The CSV concept was born out of the philosophy that companies need to go beyond the CSR - not just allotting a budget or a timetable for social responsibility campaigns, but really existing as a business for the community.

\subsection{Criticism of the CSV concept}

Although the concept of the CSV is innovative and the strategic guidelines are very useful, Porter and Kramer are not free from criticism. For example, regarding demand conditions for creating CSV, they only emphasized the market and product sides (Moon et al., 2011). The most critical paper is written by Crane \& Palazzo (et al., 2014). They deconstruct and criticise each key message and give an evidence about results of CSR research. They present serious shortcomings of the CSV concept: "it is unoriginal; it ignores the tensions inherent to responsible business activity; it is naïve about business compliance; and it is based on a shallow conception of the corporation's role in society". They also present following strengths of the concept: positive feedback from practitioners and also academic management literature, elevation of social goals to strategic level, clear identification of the governments' role in the social initiatives of companies, conceptual contribution to the debate about "caring" capitalism and it is an umbrella concept for other less anchored concepts.

\section{THEORETICAL DISCREPANCIES IN ADOPTING OF DESTINATION MANAGEMENT TO DESTINATIONS}

The following text identifies only the fundamental discrepancies due to the application of destination management in the Czech Republic.

There exist numbers of definitions of destination. We present one universal created by UNWTO (2002): "A local tourism destination is a physical space in which a visitor spends at least one overnight. It includes tourism products such as support services and attractions, and tourism resources within one day's return travel time. It has physical and administrative boundaries defining its management, images and perceptions defining its market competitiveness. Local tourism destinations incorporate various stakeholders often including a host community, and can nest and network to form larger destinations." The most cited definitions were developed by Pásková \& Zelenka (2012) or Bieger (2005, In: Palatková, 2006) in the Czech Republic. The key attributes of destination is geographical space where are available services and attractions, tourism products, which are marketed, and the result is high and long-time concentration of visitors.

The second key term is management. The definition of this term was created by many authors with more or less differences. For our disputation we use the definition of management by Henry Fayol: "To manage is to forecast and to plan, to organize, to command, to coordinate and to control". The author of Holistic management prof. Porvazník (2014) adds, that there is no uniformity in the definition of management functions in local or foreign literature and the most used definition of management functions are: to plan, to organize, to command and to 
control. His model of the management functions consists of planning, deciding, organizing, regulating, controlling and coordinating.

The destination management "is committed to respond positively to the growing need for systematic, multidisciplinary and intersectoral strategies for tourism at local, regional and national level and in particular to provide strategic guidance in destination management which is a recent conceptualization of a micro-level activity at national, regional and/or local level in which the tourism stakeholders carry out their individual and organizational responsibilities in a coordinated manner aiming to achieve the macro-level policies (UNWTO, 2002). This wide definition does not reflect all management functions explicitely as were named by Fayol or Porovazník. One of the key functions - controlling or regulation is missing.

Resent work of Czech authors Pásková \& Zelenka (2012) and Holešinská (2012) defined term "destination management" with one crucial difference. Pásková \& Zelenka (2012) in their definition explicitly present that one of the function of destination management is regulation of tourism in a destination. Similarly Boruta (2007) presents, that one of the function of destination management is regulation.

Holešinská (2012) determines destination management on the three principles - cooperation, coordination and communication: the cooperation of tourism stakeholders, the coordination in the field of planning, organizing and decision making in a destination, and the key successful factor of realization of destination management is the communication between tourism stakeholders. She argues that there is not the regulation function of destination management but there are realized influencing activities within destination management.

The current Czech theoretical background of the destination management is based especially on West Europe authors and their research. The most cited authors are T. Bieger, C. Kaspar or H. Bratl and F. Schmidt in the Czech Republic. But the conditions within tourism sector are very different from Western Europe. The approach of Holešinská (2012), similarly Nejdl (2011), does not answer the question, how should be fulfilled the principles of sustainable development of tourism in a destination, who should be responsible for development, implementation and control of some regulation measures for sustainable tourism, esp. carrying capacity of a destination, named by Palatková (2008). Should it be carry out by destination management organization?

The activities which are mainly realized by destination management organizations in the Czech Republic are: communication with tourism stakeholders, elaboration and submission of grant applications focused on information services for tourists and marketing activities, like planning and realization of marketing strategies, building of destination image or public relations (Holešinská, 2010). Management of destination management organization (DMO) has two main responsibilities (Bieger, 2005; In: Nejdl, 2011). The management board is responsible for management of own organization, the second responsibility is coordinating, resp. managing tourism proceses inside of the given destination. The DMO elaborates and develops own organization strategy and simultaneously develops and implements strategy of the destination (Nejdl, 2011). Bieger (2005, In: Nejdl) calls the destination as a virtual enterprise, Patúš (2007) labels the destination as a strategic business unit. Both approaches transform the territory to organization.

From the perspective of strategic management Fotr (et al., 2012), Johnson, Scholes, Whittington (2006), Keřkovský, Vykypěl (2002) or Lednický (2000) distinguish three levels of organization strategy. It is an enterprise level, level of strategic business units (SBU) and functional level. Malachovský (2002) argues that part of the tourism development strategy 
are, among other, even functional (partial) strategies that are implemented through tourism policy as a set of related measures. His view is closer to the application of strategic management at the organization level. Vice versa, Lednický (2003) highlights significant differences of the territorial strategy and organization strategy. The organization creates functional strategies, but the territory development strategy consists of the targeted programs in individual areas. Thus, the strategy of organizational unit will differ from similar organizations (Donnelly, Gibson and Ivancevich, 1997). Nevertheless, Lednický (2003) argues that territory development strategy is a broad consensus of the community. He distinguishes three types of strategies: a) strategy of life - career, b) organization strategy, c) territorial strategy, which differs from others that it has to create conditions for success of the whole territory consists of a various types and various amounts of subjects with different interests.

\section{CONCLUSION}

The current theoretical and practical discourse of tourism in the Czech Republic is still focused on the area of economic benefits and positives that tourism generates in terms of GDP, employment, foreign exchange earnings or regional development. But there is missing wide discussion about the threats and negative consequences, externalities of tourism in areas for local communities, cultural heritage, local culture as a whole, but also environmental and socio-economic conditions of the environment.

Some Czech authors of destination management theory resign from natural control/regulation function of management, destination management organizations are focused especially on marketing activities, fundraising or communication and coordination activities, they are meeting economic goals, but without accent on other limits of the destinations than economic. It was argued that there exist differences between strategy of organization and territorial strategy. Tourism stakeholders operate in the territory, in the destination, so this fact has to be taken into account within development of tourism strategy. Without set of indicators reflecting sustainable development like carrying capacity of the destination could not be the strategy considered as sustainable.

One of the main activities of the destination management should be to harmonize and to coordinate different interests of various tourism stakeholders including local community. It is very challenging issue. The concept of Creating Shared Value (CSV), described in the beginning, could be very useful for solution of plenty of problems in tourism like positive or negative externalities caused by tourism, it could deepen cooperation of tourism stakeholders together with local communities and simultaneously increase competitiveness of tourism enterprises and the whole destination.

The key to success to avoid or to decrease of externalities in tourism is hidden in setting of strategy of tourism enterprise. It could be said that it may be a kind of autoregulation. The setting of destination management activities in a destination may resign on sustainable principles within designed destination strategy, so the company could prevent this risk of environmental or social harms.

The CSV is a part of the competitive strategy of a company, which is based on a precise study of the company's value chain in order to understand social and environmental consequences of each business activity. The way in which a company can create shared value may differ relating to its industry or organisational structure. However, every enterprise has the ability to realise shared value creation. The third segment of the CSV concept, i.e. enabling local cluster development, imposes the same task on policy-makers, mobilising 
them in understanding the regional competitiveness fundamental and the capitalisation of the regional tourism cluster.

Generally, the broad adoption and implementation of the CSV concept in tourism practice could represent a key social innovation driven by private sector. It could be demonstrated through the three main impact segments: a) competitiveness enhancement: a company that creates the most shared value and is most efficient in its trade-off efforts will out-compete its peers in the long-term, b) contribution to the collective goal of sustainable development: the business activity based on creating shared value ensures its long-term viability, c) creating positive social change: any business should seek to maximize its social value and drive its social costs to zero, while maintaining competitive economic returns.

\section{Acknowledgement}

The author is thankful to the Internal Grant Agency of FaME TBU No. IGA/FaME/2015/026 "Návrh modelu vzniku klastrové organizace v oblasti zemědělství a cestovního ruchu v podmínkách České republiky a v oblasti designu na Slovensku" for financial support to carry out this research.

\section{References}

Bieger, T. (2005). Management von Destinacionen. 6. Vyd. In: NEJDL, Karel. Management destinace cestovního ruchu. Vyd. 1. Praha: Wolters Kluwer Česká republika, 2011. 204 s. ISBN 978-80-7357-673-8.

Bieger, T. (2005). Management von Destinacionen. 6. Vyd. In: Palatková, M. 2006. Marketingová strategie destinace cestovního ruchu: jak získat více př́ijmů z cestovního ruchu. 1. vyd. Praha: Grada, 2006, 341 s. ISBN 80-247-1014-5.

Bockstette, V. and Stamp, M., (2011). Creating SHAREDVALUE: A How-to Guide for the New Corporate $(R)$ evolution.

Boruta, T. (2007). Management a marketing destinace cestovního ruchu [CD-ROM]. Ostrava: Ostravská univerzita, 2007. ISBN 978-80-7368-348-1.

Crane, A., Palazzo, G., Spence, L. J. and Matten, D., (2014). Contesting the Value of "Creating Shared Value". California management review, 56(2), 130-149. /https://doi.org/10.1525/cmr.2014.56.2.130

Donnelly, J. H., Gibson, J. L. a Ivancevich, J. M. (1997). Management. Praha: Grada, 1997. 821 s. ISBN 80-7169-422-3.

Fayol, H.. (1954). General and industrial management.

Fotr, J. et al. (2012). Tvorba strategie a strategické plánování: teorie a praxe. Vyd. 1. Praha: Grada Publishing, 2012. 381 s. ISBN 978-80-247-3985-4.

Holešinská, A. (2010). Destinační management jako nástroj regionální politiky cestovního ruchu. Disertační práce. Brno: Masarykova univerzita, Ekonomicko-správní fakulta, 2012, 135 s. Vedoucí práce Jičí Vystoupil.

Holešinská, A. (2012). Destinační management jako nástroj regionální politiky cestovního ruchu. 1. vyd. Brno: Masarykova univerzita, Ekonomicko-správní fakulta, 2012, 151 s. ISBN 978-80-210-5847-7.

Johnson, G., Scholes, K., Whittington, R. (2006). Exploring corporate strategy. 7th enhanced media edition. Harlow: Prentice Hall, 2006. 1033 s. ISBN 0-273-71017-6.

Kaspar, C. (1995). Základy cestovného ruchu. 1.vyd. 1995 : Cestovatel'. 142 s. ISBN 80901166-5-5.

Keřkovský, M. a Vykypěl, O. (2006). Strategické ř́zeni: teorie pro praxi. 2. vyd. Praha: C.H. Beck, 2006. 206 s. ISBN 80-7179-453-8. 
Kindermann, S. (2013). Innovative Approaches to Determine Corporate Value Creation. Saarbrücken: AV Akademikerverlag. ISBN: 978-3-639-49352-8.

Lednický, V. (2000). Strategický management. Ostrava: Akademie Jana Ámose Komenského, 2000. 179 s. ISBN 80-7048-019-X.

Lednický, V. (2003). Tvorba strategie územního celku. 1. vyd. Ostrava: VŠB - Technická univerzita, 2003. 142 s. ISBN 80-248-0468-9.

Malachovský, A. (2002). Strategický manažment cestovného ruchu a predpoklady jeho uplatňovania na Slovensku. 1. vyd. Banská Bystrica : Univerzita Mateja Bela, 2002. 127 s. ISBN 80-8055-698-9.

Moon, H.C., Parc, J., Yim, S.H. and Park, N., (2011). An Extension of Porter and Kramer's Creating Shared Value (CSV): Reorienting Strategies and Seeking International Cooperation. Jias, 18(2), 49-64.

Nejdl, K. (2011). Management destinace cestovního ruchu. Vyd. 1. Praha: Wolters Kluwer Česká republika, 204 s. ISBN 978-80-7357-673-8.

Pásková, M. a Zelenka, J. (2002). Výkladový slovník cestovního ruchu. Praha: Ministerstvo pro místní rozvoj, 2002. 448 s. ISBN 80-239-0152-4.

Pásková, M. (2008). Udržitelnost rozvoje cestovního ruchu. Vyd. 1. Hradec Králové: Gaudeamus, 2008, 298 s. ISBN 978-80-7041-658-7.

Patúš, P. (2007). Manažment stredísk cestovného ruchu na Slovensku. Ekonomická revue cestovného ruchu. 2007. 40:2.

Porvazník, J. (2014). Holistický management. Bratislava: IRIS, 2014.

Porter, M.E. and Kramer, M.R., (2011). Creating Shared Value. Harvard business review, 89(1-2), pp. 62-77.

\section{Contact information}

Marek Koňařík

Tomas Bata Univerzity in Zlín, Faculty of Management and Economics

Mostní 5139, 76001 Zlín

Telephone: +420 773477735

Email: marek@konarik.info

DOI: https://www.doi.org/10.7441/dokbat.2016.22 


\title{
EU COHESION POLICY AS AN INSTRUMENT FOR THE DEVELOPMENT OF THE SMART CITY CONCEPT
}

\author{
Filip Kučera
}

\begin{abstract}
The concept of smart city is a modern tool for efficient city management with emphasis on the latest trends and technological knowledge. The article analyses the concept in terms of EU, with particular emphasis on investment opportunities of the European structural and investment funds. Concept of smart city is also focused on social dimension and human capital in urban areas.
\end{abstract}

Keywords: Cohesion Policy, Smart City, European structural and investment funds.

\section{SMART CITY: OPPORTUNITY FOR SUSTAINABLE URBAN DEVELOPMENT IN EUROPE}

Smart city concept is closely related to the sustainable development of urban areas. It is clear that in last decades there is a massive extent of urbanization, and by a number of studies there can be expected continuation of this trend. More and more residents will live in urban areas, which also brings the potential risks associated with the concentration of such population in a relatively small area.

In 1950 just over $50 \%$ of residents of the EU lived in urban areas (classified as urban according to the country specific criteria selected by the UN). In 2010 it was more than $75 \%$ of population and prognosis for the future indicates that in 2050 it will be nearly $85 \%$ of EU population. (Cargliu, 2009)

The urbanization rate is variable depending on the economic development and spatial structure of specific countries. In the EU there are countries, according to the United Nations, which already achieved a high degree of urbanization, above $85 \%$ level in 2011. For example Belgium, Denmark, France, Luxembourg and Sweden. (United Nations, 2014) There is already urgent need to develope new smart solutions for sustainable urban grow of cities and soon it will be even more intense. It brings related issues with regard to the environment and social relations.

Smart city is a relatively new concept, for that the definition is not settled in literature. It is a multidisciplinary concept, which in itself embrace technological aspects, as well as aspects of human capital. The most common explanation of smart city term is a concept created by researchers from Vienna: Centre of Regional Science, which describes a smart city in the following six dimensions: "smart economy; smart mobility; smart environment; smart people; smart living; and, finally, smart governance". Giffinger et al. (2007) describes the various dimensions of the concept as follows: 


\begin{tabular}{|c|c|}
\hline Smart economy (Competitiveness) & Smart people (Social and Human Capital) \\
\hline Innovative spirit & Level of qualification \\
\hline Entrepreneurship & Affinity to life-long learning \\
\hline Economic image \& trademarks & Social and ethnic plurality \\
\hline Productivity & Flexibility \\
\hline Flexibility of labour market & Creativity \\
\hline International embeddedness & Cosmopolitanism/Open-mindedness \\
\hline Ability to transform & Participation in public life \\
\hline $\begin{array}{l}\text { Smart governance (Participation) } \\
\text { Participation in decision-making } \\
\text { Public and social services Transparent } \\
\text { governance } \\
\text { Political strategies \& perspectives }\end{array}$ & $\begin{array}{l}\text { Smart mobility (Transport and ICT) } \\
\text { Local accessibility } \\
\text { (Inter-)national accessibility } \\
\text { Availability of ICT-infrastructure } \\
\text { Sustainable, innovative and safe transport } \\
\text { systems }\end{array}$ \\
\hline $\begin{array}{l}\text { Smart environment (Natural resources) } \\
\text { Attractivity of natural conditions } \\
\text { Pollution } \\
\text { Environmental protection } \\
\text { Sustainable resource management }\end{array}$ & $\begin{array}{l}\text { Smart living (Quality of life) } \\
\text { Cultural facilities } \\
\text { Health conditions } \\
\text { Individual safety } \\
\text { Housing quality } \\
\text { Education facilities } \\
\text { Touristic attractivity } \\
\text { Social cohesion }\end{array}$ \\
\hline
\end{tabular}

Figure 11 - Smart city dimensions. Source: Giffinger et al. (2007)

Smart city concept is widely perceived technologically with an emphasis on Information and Communication Technologies (ICT) development. Many researchers, however, recently starting to focus also on the field of human and social capital and environmental interest.

Cragliu (2009) believe a "city to be smart when investments in human and social capital and traditional (transport) and modern (ICT) communication infrastructure fuel sustainable economic growth and a high quality of life, with a wise management of natural resources, through participatory governance".

In practice and scientific research exists different aproaches on each parts of the Smart city concept. The EU Cohesion Policy for the period 2014-2020 in relation to smart city underlines the dimension of smart mobility and smart environment, as will be discussed in the next section. Related to this are settings of priorities for resources from European structural and investment funds. 
In contrast, for example the City of Vienna in its strategy of Smart City Wien (2014), places a strong emphasis on quality of living with focus on social inclusion, participation and healthcare. Recall that Vienna was proclaimed as the city with the highest quality of life in the world under The Mercer Quality of Living Survey in 2015.

\section{EU COHESION POLICY: FROM REDUCING REGIONAL DISPARITIES TO THE ENGINE OF EUROPEAN GROWTH}

Perception of Cohesion Policy as an instrument in which the richer regions help to the less developed regions is one of the foundations of the European integration process. Under the Treaty on the Functioning of the EU (2012) the main goal of Cohesion Policy is to promote overall harmonious development towards strengthening economic, social and territorial cohesion.

Hájek (2011) points out that the need for harmonious development and reducing disparities between regions were already mentioned in the Treaty of Rome relating to the creation of the European Economic Community in 1957. In the same year was established the European Social Fund (ESF). In 1974 was created European Regional Development Fund (ERDF). Establishment of the fund is closely associated to the EU enlargement on the Great Britain, Ireland and Denmark. The first two countries suffered considerable regional disparities. Bachtler et al. (2013) underlines that the emergence of the ERDF was largely a political decision. Representatives of Great Britain gained a significant financial argument to support the country's EU membership. Note that the Irish economic miracle is often attributed to interventions co-financed by structural funds. (Bachtler et al., 2013)

The real significance of Cohesion Policy is related to the approval of the Single European Act in 1986. During this time European Commission started to transform policy from an insignificant resource transfer of $\mathrm{EU}$ finance to real and functional tool for regional development. (Bachtler et al. 2013)

Concept of economic and social cohesion was contractually embedded according to the Single European Act. The territorial dimension had been added through the Treaty of Lisbon. Balancing regional disparities is an important precondition for the introduction of the common European currency and the creation of a Single Economic Space. The concept of structural funds (European Regional Development Fund and European Social Fund) was in 1993 extended to the Cohesion Fund. (Bachtler et al. 2013)

\section{FINANCING OF SMART CITY CONCEPT FROM THE EU COHESION POLICY IN THE PERIOD 2014 - 2020}

Position of Cohesion Policy in EU budget is continually strengthening. In 1975 the allocation consisted $6 \%$ of EU budget, in the programming period 2014-2020 it is almost 34\%. In total payments will amount 367 billion euros. (Baun, Marek, 2014)

A strategy for smart, sustainable and inclusive growth (2010), hereinafter referred as the Europe 2020 strategy, is a long-term strategic EU document, which aims to achieve economic growth and increase of employment. Strategy is a fundamental document for the orientation of economic and budgetary policies at EU level.

European Union, according to the Strategy Europe 2020 (2012), lays down a five ambitious objectives concerning the employment of the population (75\% of the population aged 20-64 years should be employed); investment in research and development (3\% of EU GDP); achieving the goals "20-20-20" in climate and energy; education level (the share of early 
school leavers should be under $10 \%$ and at least $40 \%$ of the younger generation should have a tertiary education) and the threat of poverty (the number of affected persons should fall by 20 million).

Within the Europe 2020 Strategy we find virtually no mention of purposeful development and the importance of urban space for the development of the EU. However, the connection with the implementation of smart city concept is obvious. At least in the area of climate and energy, in which should be achieved "20-20-20" goals. By this is meant decreases in greenhouse gas emissions by $20 \%$ compared to 1990 levels, increase the share of renewable energy sources in final energy consumption to $20 \%$ and a shift to increase energy efficiency by $20 \%$. This strategic objective cannot be achieved without implementing smart solutions at urban space in EU.

Cohesion Policy for the period 2014 - 2020 still offers a variety of options to promote the development of the concept of smart city. The Europe 2020 Strategy provides a framework for the eleven thematic objectives of the EU, which are more fully developed and embedded in the Regulation (EU) No 1303/2013 of the European Parliament and of the Council of 17 December 2013.

In terms of thematic relevance to the promotion of the concept of smart city must be mention the following thematic objectives:

- thematic objective 1) strengthening research, technological development and innovation;

- thematic objective 2) improving the access, use and quality of information and communication technologies

- thematic objective 6) preserving and protecting the environment and promoting resource efficiency,

- thematic objective 7) promoting sustainable transport and removing obstacles in crucial network infrastructures.

Indicative focus of Member States to achieve the thematic objectives of the Europe 2020 Strategy are defined in the Partnership Agreement, which are prepared at national level, subject to approval by the European Commission. Dominant interpretation of smart city concept in relation to ICT is worth attention to Regulation (EU) No. 1301/2013 of the European Parliament and of the Council of 17 December 2013 on the European Regional Development Fund. Regulation clearly defines the need to implement measures to tackle the economic, environmental, climatic, demographic and social challenges affects urban areas. Legislative safeguard for realization of the investment amount directly to the development of urban areas requires at least $5 \%$ of the ERDF resources allocated at national level. This has to be determined to integrated actions for sustainable urban development.

Supported activities from the ERDF related to smart solution are focussed especially on information and communication technologies to support low-carbon economy and developing transport solutions. A variety funds for the development of smart city are also available in the ESF and Cohesion Fund. 


\section{OPERATIONAL PROGRAMME ENVIRONMENT IN THE CZECH REPUBLIC: A SPECIFIC EXAMPLE OF SOLUTIONS FOR THE SMART CITY CONCEPT THROUGH THE EUROPEAN STRUCTURAL AND INVESTMENT FUNDS}

Operational Programme Environment 2014-2020 (2015) is one from the sectoral operational programs for the implementation of funds from the European Regional Development Fund and the Cohesion Fund for the current programming period in Czech Republic. The total allocation for the program is a $€ 2.6$ billion. Managing Authority of the programme is Ministry of the Environment.

Operational Programme (2015) focuses on a investments in the following areas:

1) Improving water quality and reducing flood risks,

2) Improving air quality in human settlements,

3) Waste and material flows, environmental burden and risks

4) Protection and care for nature and landscape,

5) Energy savings.

Most relevant to the smart city concept is supported area 5) Energy savings. Elaborate in more details on activities under specific objective 5.1) Reduce the energy demands of public buildings and increase the use of renewable energy sources. This is a typical example of a project measures contributing to the fulfillment of the concept of a smart city. Filling defined specific target 5.1 is achieved through specific projects that are listed in the following overview. Introduced measures are intended primarily for local authorities and other public administration authorities.

Operational program, the total allocation:

Operational Programme Environment 2014-2020, 2.6 billion $€$

\section{ESI Funds:}

Cohesion Fund

\section{Priority axis, the total allocation:}

5) Energy savings, 529.6 milion $€$

\section{Specific objective, the total allocation:}

5.1) Reduce the energy demands of public buildings and increase the use of renewable energy sources, 509.6 milion $€$

\section{Project measures:}

- reducing energy consumption by improving the thermal properties of building structures, including additional measures to reduce the energy performance of buildings

- implementation of technologies on a utilization of waste heat

- implementation of low-emission and renewable heatRecipients: local authorities and other government agencies, nongovernmental organizations

\section{Grant support:}

Maximally $45 \%$ 


\section{Link to the smart city concept:}

Smart environment - sustainable resource management

\section{CONCLUSION}

The concept of smart city is a modern tool for sustainable urban development, which can be financed by the EU Cohesion Policy. Implementation of the concept is expensive, and for the cities it is difficult to find investment funds from their own limited resources. European Structural and Investment Funds represents appropriate instrument for the financing of smart solutions. However, cohesion policy has its limits. The main issue is in excessive focus on supporting infrastructure projects. These activities fulfilling dimension of smart mobility and smart environment, but smart city concept is much broader and also consists an investment in human capital and social relations.

For cities considering the implementation of the smart city concept, it is important to look for other external sources beyond EU Cohesion Policy and overall support for the development of smart city. It offers a reflection on the larger role of the city as moderator of development on its territory with the supportive role for inhabitants themselves and other as a main holders of smart solutions.

\section{References}

European Commission (2010). A strategy for smart, sustainable and inclusive growth.

Bachtler, J. a Turok, I. (2004'. The Coherence of EU Regional Policy: Contrasting Perpectives on the Structural Funds. London: Routledge. ISBN 0-117-02357-4.

BAUN, M. a MAREK, D. 2014. Cohesion Policy in the European Union: European Union Series. London: Palgrave. ISBN 978-0-230-30313-3.

Cargliu, A., BO, C. D., \& Nijkamp, P. (2009). Smart cities in Europe. 3rd Central European Conference in Regional Science - CERS, 45-59.

Consolidated version of the Treaty on the Functioning of the European Union. (2012).

Giffinger, R., et al. (2007). Smart cities: Ranking of European medium-sized cities. Centre of Regional Science (SRF), Vienna University of Technology.

Hájek, O. a Novosák J. (2011). Kohezní politika v širších souvislostech. Žilina: Georg . ISBN 978-80-89401-9-2.

The Population Division of the Department of Economic and Social Affairs of the United Nations. (2014). World Urbanization Prospects. Retrieved from http://esa.un.org/unpd/wup/

Ministry of the Environment. (2015). Operational Programme Environment 2014-2020.

Regulation (EU) No. 1301/2013 of the European Parliament and of the Council of 17 December 2013 on the European Regional Development Fund. 2013

Regulation (EU) No 1303/2013 of the European Parliament and of the Council of 17 December 2013. 2013

Vienna City Administration. (2014). Strategy Smart City Wien. Retrieved from https://smartcity.wien.gv.at/site/files/2014/10/140924_KF_SCW_gesamt_ENG.pdf

\section{Contact information}

Filip Kučera

Tomas Bata University in Zlín

Faculty of Management and Economics 
Mostní 5139, 76001 Zlín

E-mail: fkucera@fame.utb.cz orcid.org/0000-0003-0500-8952

DOI: https://www.doi.org/10.7441/dokbat.2016.23 


\title{
EXPLORING REASONS OF PROJECT PROPOSAL REJECTION Alok Kumar
}

\begin{abstract}
Many proposals are submitted at universities- a type of organisation, but only a handful of them get approved for funding. A doctoral research is being carried out at the University of West Bohemia (UWB) in Pilsen in which the core of the research is why projects at organisations such as universities even fail to get approval for funding? At UWB, like many other universities, various project proposals are submitted in response to various calls over a period of time. Along with many proposals submitted, the evaluators scores are compared and analysed. The author is using data analysis to point out some of the partial findings.

The partial result presented in this paper point towards deficiency in attention paid to the proposal-making process. The initiation phase of the project management lifecycle is almost ubiquitously ignored, highlighting why some projects even fail to take off despite having some of the best ideas and concepts for furthering research and development in the Czech Republic. The doctoral research is an attempt to highlight the vital role of a project proposal, hitherto not given adequate attention, either by the project managers or the project management offices of the organisations.
\end{abstract}

Keywords: Organisation; Programme Management; Project Management; Project Management Lifecycle; Project Proposal

\section{INTRODUCTION}

Organisations of all types have projects. Universities are no different. Research project proposals are submitted to a group of independent evaluators. These evaluators score the proposals on pre-determined criteria. Thereafter, proposals are either approved for funding or rejected based on the score obtained. A host of project proposals are accepted but a far greater number is rejected (Project Office, UWB). funded usually on the basis of funding awarded to the proposal which is submitted in response to a call. Project proposal failures occur at business organisations. Numerous studies about project proposal failures in business organisations are available but only a handful of literature talk about the project proposal at organisations like universities. This scenario exists despite the realisation that project proposal failures at universities are equally important and something that should be addressed comprehensively. "The long list of prominent project failures, ranging from product developments to government social programs, from computers to pharmaceutical, and from public transit to supersonic transport, reminds us of this reality (Cicmil et al. 2006; Gulla 2012; Lemon et al. 2002; Standish Group 2013). Many projects do not live up to their expectations or outright fail even before their technical completion in spite of careful feasibility analysis during their proposal or selection stages (El Emam and Koru 2008; Shore 2008). Obviously, the ability to evaluate project proposals and assess future success and organizational value are critical to overall business performance (H.J. Thamhain, 2013). Project proposal failure in winning funding approval is largely attributed to the project office to lack of expertise of the project proposers. As project proposals fail to get approval, the funding begins to dwindle. The paper is an attempt to reverse the position by increasing project proposal approval.

To understand it would be pertinent to at first know some usual steps in preparing a proposal is given. Also, some advice, some common mistakes that occur while preparing a proposal is 
mentioned too. Some project proposals submitted under OPVK (Operational Program for Education for Competitiveness), has been analysed in order to throw some fresh light on the issues involved.

\section{LITERATURE REVIEW}

"There are two different lifecycles that work in conjunction with one another throughout the course of every project. The project lifecycle describes the tasks that must be completed to produce a product or service. The project management lifecycle defines how to manage a project. It will always be the same, regardless of the project lifecycle being employed. One of a project manager's challenges is to understand how to align the specific project lifecycle with the project management lifecycle. Project tasks and project management tasks are concurrent and ongoing, and can be associated with project management deliverables. The Project Schedule, for example, contains both project and project management task. Phases in the two lifecycles will overlap, depending upon the project lifecycle being employed. The project manager needs to be aware of how the inputs and outputs of one lifecycle affect and shape the other." (Patel. 2008). Further, the proposal-making phase itself has its own stages. The paper looks at one of the most critical aspects of a project management lifecycle. If this phase is not dealt with properly, the project itself won't get the go-ahead signal. As mentioned above, in the organisation, irrespective of its basic nature, the pre-project initiation phase must be carried out diligently by the project manager to get approval for funding.

The researcher has selected one of the most important set of project proposals which are submitted every time the managing authority, Ministry of Education, Youth and Sports (http://www.msmt.cz/) the Czech Republic invites submission of proposals from the tertiary sector- namely the publicly funded universities located within the territory of the Czech Republic. A host of information concerning the said operational programme, a part of the strategic initiative of the government of the Czech Republic can be found on the website http://www.op-vk.cz/. The new programming period the operational programs - OP Education for Competitiveness and OP Research and Development for Innovation - will be replaced by OP Research, Development and Education (OP VVV).

Some tips while submitting grants are important to adhere to. These tips are adapted on Bourne and Chalupa's "ten simple tips for getting grants" in 2006. The seven suggested tips are as follows:

1. Be new and original, but not chimerical

2. Read the call / request application carefully, and respond to the request adequately

3. Adhere to the submission guidelines carefully with full compliance

4. Be clear, concise and complete while proposal writing

5. Time management is the key while preparing and submitting the proposal

6. Proposal evaluators' task be made easy by the proposal writer, and

7. Accept rejection and don't abandon proposal making.

Some commonly made errors to be avoided are, lack of full compliance with the call request, submission after the deadline, giving very little time for internal review and ignoring the project management aspect of the project proposal. 


\section{METHODS}

The project proposals which are being analysed were submitted through the web application BENEFIT7 run by the Ministry for Regional Development Benefit, (2012). For further analysis, the proposals submitted under the programme OPVK were randomly selected by the project management office (PMO) of University of West Bohemia (UWB). More information about the project management office can be accessed by visiting its website http:Ilwww.zcu.cz/research/projects/.

The proposals which were carefully collated are the ones belonging to submissions and their evaluations covering the call period 2007-2011.

Replying to specific "calls" under the OPVK programme, the University of West Bohemia too participated by submitting various proposals as per the guidelines - "Prríručka pro individuální hodnotitele a zpravodaje IP a GP OP VK". Depending on the size of the project, proposals varied from about thirty pages to well over a hundred pages. A click on the link www.op-vk.cz/filemanager/files/file.php?file $=52597$ would give you the complete details of which institution received grants under various calls. Naturally, a careful look would update you about how much the University of West Bohemia has received under this program. This list would also help the researcher in comparing the grants received by the University of West Bohemia with a similarly sized university in the Czech Republic. This analysis will be included in the dissertation of the researcher.

The project proposals were collated from a group of many proposals that were submitted from the University of West Bohemia responding to different calls under the strategic programme of the Ministry of Education, Youth and Sports (MSMT). The calls, proposals and evaluations were issued in the national language of the Czech Republic-Czech.

Proposal evaluations or result of the application is sent after independent evaluators score the proposal under various criteria and come up with a weighted score out of a total of 100 . The evaluations are given below for the reader to familiarise with the evaluations of the proposals.

The cover page of the evaluation details the call number, registration number of the proposal submitted, Name of the university from which the proposal submission was made, Name of the project, Location of project realization, Term of the project run and Duration of the project in months.

Table 1 - Individual scorecard/ op vk grant project proposal. Source: Adapted on data provided by the Project office, UWB

\begin{tabular}{|l|l|}
\hline Registration number & XYZ \\
\hline $\begin{array}{l}\text { Name of the proposal submitting } \\
\text { organization }\end{array}$ & University of West Bohemia, Pilsen \\
\hline Name of the project & XYZ \\
\hline Location of project realization & XYZ \\
\hline Planned project term & $1.03 .2009-31.12 .2011$ \\
\hline Project duration in months & 34 \\
\hline
\end{tabular}

These evaluations (with anonymised evaluators) are sent by program administration body to the university and then distributed by the project office to the respective proposers. These evaluations provide a very valuable feedback to proposals and also form the basis for the author's research. 
detailed evaluations, as given below, include the points scored in the category and its subcategories. The scores are followed up with brief commentary by the evaluators who give their assessment of the number of points scored by the proposer. This is done for all of the categories on which a project proposal is scored. Based on the aggregate score a proposal is either accepted or rejected. The final acceptance or rejection is included in the evaluation too. The minimum qualifying score is $65 / 100$. A sample presentation of an important criterion of evaluation is mentioned below. This criterion figures as the second criterion on which the proposals are evaluated.

Table 2 - Sample presentation of Individual Scorecard for one criterion. Source: Project office, University of West Bohemia

\begin{tabular}{|c|lcccc}
\hline 2 & Target Group & $\begin{array}{c}\text { Assigned } \\
\text { points }\end{array}$ & $\begin{array}{c}\text { Maximum possible } \\
\text { points }\end{array}$ & $\begin{array}{c}\text { Binding to application } \\
\text { section }\end{array}$ \\
\hline 2.1 & $\begin{array}{l}\text { Definition and adequacy } \\
\text { target groups }\end{array}$ & 3 & 5 & Project description \\
2.2 & $\begin{array}{l}\text { Method of Involvement of } \\
\text { target groups }\end{array}$ & 4 & 5 & Project description \\
Total for criterion 2 & 7 & 10 & \\
\hline
\end{tabular}

\section{RESULTS: SOME EVALUATION SCORES AT A GLANCE}

The project proposals are submitted by the project managers to the respective faculty project administration from where it is routed to the UWB project office. Upon submission to the project office, the proposals are checked against the formal requirements of the call and if no changes are required, the project office routes it to the ministry for evaluation by ministry appointed a team of project evaluators. Upon receipt of the proposals the evaluators score the proposals on each of the criteria for which the proposal has been made. This results in a total score out for each of the proposals out of a maximum of 100 points. The scorecard thus obtained is duly passed on to the respective project manager by the project office of UWB which receives the scores from the ministry. In no circumstances are the names of the evaluators divulged to maintain the integrity of the evaluation system. Some tables are produced below to show some highlights of such evaluation scores received by project proposals:

Table 3 - Summarised table of Individual Scorecard of grant project proposals under Calls '7' \& '9'. Source: Self- processed

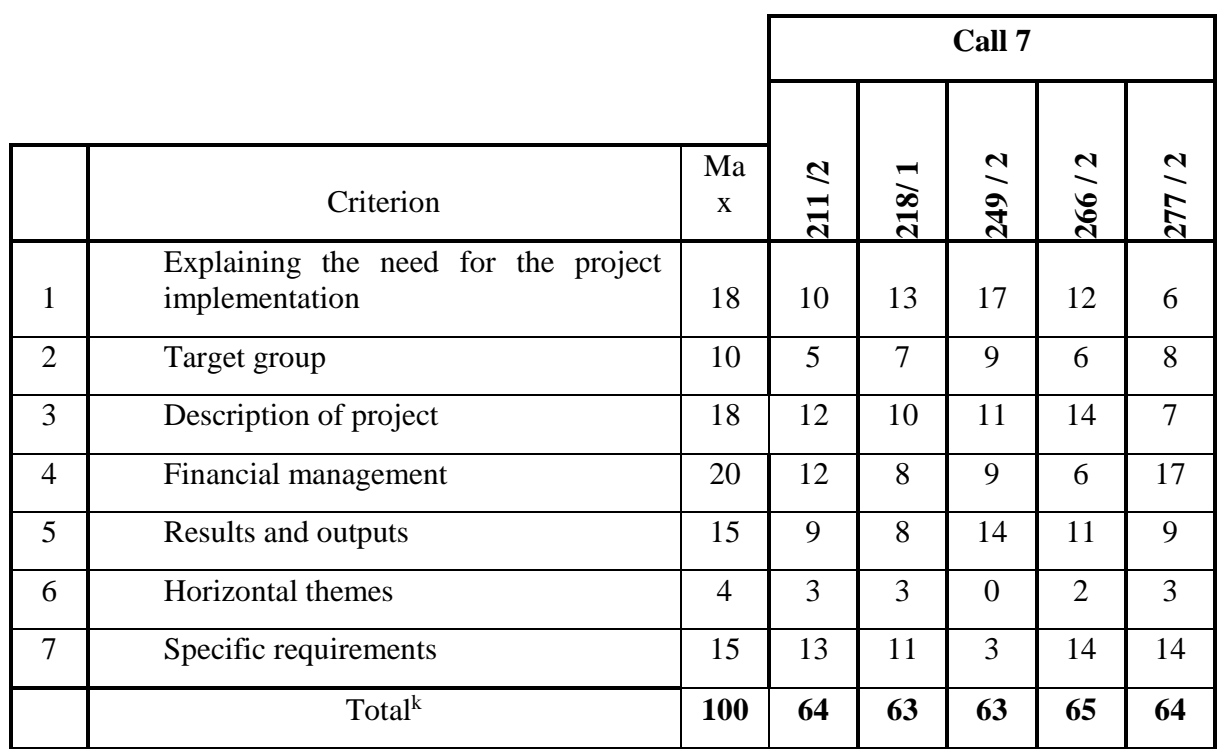

\begin{tabular}{|c|c|c|c|}
\hline \multicolumn{4}{|c|}{ Call 9} \\
\hline$\frac{1}{8}$ & $\frac{N}{\Sigma}$ & $\Xi$ & $\stackrel{N}{\Xi}$ \\
\hline 13 & 15 & 13 & 14 \\
\hline 8 & 6 & 6 & 10 \\
\hline 7 & 7 & 13 & 11 \\
\hline 14 & 11 & 9 & 8 \\
\hline 6 & 4 & 7 & 9 \\
\hline 4 & 0 & 2 & 0 \\
\hline 7 & 7 & 9 & 11 \\
\hline 59 & 50 & 59 & 63 \\
\hline
\end{tabular}



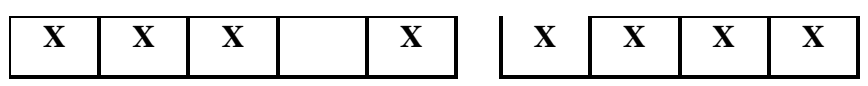

As with the tabular presentation given above, three more call proposals' evaluations are presented in Table 2. These tables represent only the aggregate total scored by each of the proposals. Given the threshold required for approval, it is easy to identify which proposal was approved for funding or not.

Table 4 - Summarised table of Individual Scorecard of grant project proposals under Calls '15', '20' \& '31'

\begin{tabular}{|c|c|c|c|c|c|}
\hline & \multicolumn{5}{|c|}{ Call 15} \\
\hline 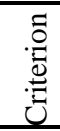 & $\frac{F}{N}$ & ๙ૂ & ळ్ & $\frac{1}{2}$ & $\frac{7}{\frac{1}{8}}$ \\
\hline 1 & 9 & 10 & 13 & 14 & 9 \\
\hline 2 & 7 & 8 & 7 & 7 & 7 \\
\hline 3 & 12 & 13 & 13 & 10 & 10 \\
\hline 4 & 11 & 14 & 13 & 7 & 11 \\
\hline 5 & 11 & 11 & 12 & 11 & 12 \\
\hline $6^{*}$ & 0 & 0 & 0 & 0 & 0 \\
\hline 7 & 11 & 7 & 4 & 12 & 13 \\
\hline $\begin{array}{c}\text { Tot } \\
\text { al }\end{array}$ & 61 & 63 & 62 & 61 & 62 \\
\hline & $\mathbf{X}$ & $\bar{X}$ & $\mathbf{X}$ & $\mathbf{X}$ & $\mathbf{X}$ \\
\hline
\end{tabular}

\begin{tabular}{|c|c|c|c|c|c|c|c|c|}
\hline \multicolumn{9}{|c|}{ Call 20} \\
\hline$\stackrel{1}{\circ}$ & సે & $\bar{m}$ & 戸 & $\underset{\frac{1}{2}}{\overline{2}}$ & $\Xi$ & $\underset{\mathcal{Y}}{\mathcal{J}}$ & $\underset{\text { స్ }}{\bar{d}}$ & $\frac{\bar{\partial}}{\hat{\sigma}}$ \\
\hline 11 & 12 & 4 & 10 & 12 & 12 & 12 & 14 & 15 \\
\hline 4 & 6 & 5 & 7 & 4 & 5 & 7 & 6 & 5 \\
\hline 11 & 14 & 9 & 13 & 14 & 12 & 13 & 14 & 12 \\
\hline 13 & 13 & 14 & 13 & 13 & 13 & 13 & 17 & 13 \\
\hline 12 & 14 & 8 & 11 & 10 & 9 & 7 & 12 & 5 \\
\hline 0 & 0 & 0 & 0 & 2 & 0 & 0 & 0 & 0 \\
\hline 14 & 13 & 5 & 10 & 9 & 9 & 9 & 8 & 13 \\
\hline \multirow[t]{2}{*}{65} & 72 & 45 & 64 & 64 & 60 & 61 & 71 & 63 \\
\hline & & $\mathbf{X}$ & $\mathbf{X}$ & $\mathbf{X}$ & $\mathbf{X}$ & $\mathbf{X}$ & & $\mathbf{X}$ \\
\hline
\end{tabular}

\begin{tabular}{|c|c|c|c|c|c|}
\hline \multicolumn{6}{|c|}{ Call 31} \\
\hline$\underset{\infty}{\infty}$ & $\frac{F}{\xi}$ & $\underset{7}{\ddagger}$ & $\frac{7}{\infty}$ & $\bar{\S}$ & $\bar{\Sigma}$ \\
\hline 14 & 8 & 8 & 17 & 15 & 15 \\
\hline 9 & 7 & 8 & 12 & 8 & 8 \\
\hline 14 & 7 & 12 & 13 & 12 & 14 \\
\hline 13 & 18 & 10 & 14 & 18 & 11 \\
\hline 8 & 8 & 10 & 13 & 13 & 8 \\
\hline 0 & 0 & 0 & 0 & 0 & 0 \\
\hline 11 & 3 & 5 & 13 & 9 & 10 \\
\hline 69 & 51 & 53 & 82 & 75 & 66 \\
\hline & $\mathbf{X}$ & $\mathbf{X}$ & & & \\
\hline
\end{tabular}

Source: Self- processed

*Exception to 6: Points under the $6^{\text {th }}$ criteria "horizontal themes" were added to the $2^{\text {nd }}$ criteria "target group" for Calls '15', '20' and ' 31 '.

\section{Recommended for funding}

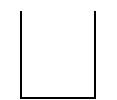

\section{Not-recommended for funding}

The minimum number of points necessary for "recommended for funding" is 65 .

Note: But even reaching this threshold does not mean that the program will be financed; in the final stage of evaluation the projects are prioritized according to the number of points and then the money are allocated to them until the budget for the call is exhausted. The project under the line are put on a reserve list, and not financed.

The tables above namely, "Table 1" and "Table 2" comprise of some proposals that were randomly chosen for analysis in this paper. Call inviting proposals are issued by the ministry. Once a proposal is submitted it gets a unique id, i.e. registration number, which can be found under the call number in Tables 1 and 2 .

\section{DISCUSSION}

Some general comments about the above tabular presentation of project proposals are as follows:

1. Out of a total of 29 proposals analysed, barring one proposal having a score of " 82 " none of the proposals could obtain a score of more than a total of " 80 ".

2. One proposal could not even muster up $50 \%$ of the possible score. 
3. The mean of scores is 62.7 , the median of scores is 63 , and the mode is 63 .

4. In 3 of the proposals, no points were allocated under the criterion "horizontal themes".

5. Of all the twenty-nine proposals, only two could score seventeen out of a maximum score of 18 in the $1^{\text {st }}$ criteria- explaining the need for project implementation.

6. Of the 20 proposals made under calls 15, 20 and 31 for criterion 2 "Target group", only one proposal fetched 12 points out of a maximum of 14 .

7. Under the criteria 2 "Target group", two of the proposals from Call 20 could not even score $50 \%$ of the possible score. Despite such low score at targeting the project group, the proposals won the approval because there is no threshold value for the criterion and total score is $>65$, so that there is no contradiction.

8. As far the $3^{\text {rd }}$ criterion "Description of project" is concerned, the later "call" proposals have fared better than the earlier "call" proposals

9. Under the $3^{\text {rd }}$ criterion, it was worth noting that one proposal won the approval despite scoring less than $45 \%$ of the possible score- as per the point noted in the previous comment no. 9.

10. The results in the $4^{\text {th }}$ category "financial management" are the most staggering. Only two proposals scored $18 / 20$ under this criterion. 18 is more than a third of $65-$ necessary to get the evaluators' nod. Yet out of the two proposals scoring 18 , only one received the approval.

11. One proposal under this criterion scored "6". Despite such a perilous score the proposal ended up being approved.

12. Under the criterion "financial management" six of the twenty-nine proposals received less than " 10 " out of a total of " 20 ", yet only one failed to receive the final nod.

13. The score of " 13 " is not the "unlucky" number. In fact, every time a proposal obtained " 13 " in the $4^{\text {th }}$ criteria, that proposal ended up getting the evaluators' nod.

14. "Results and Outputs" is the fifth criterion on which the submitted proposals receive points. One of the proposal scored " 5 " out of a possible total of " 15 " and yet won the approval. Because no threshold score is assigned, the proposal gets approved for funding despite scoring low in a particular criterion.

15. "Horizontal themes" criterion didn't throw up any noteworthy observation.

16. The last criterion on which the evaluators scored and commented upon is "specific requirements". This is the only criterion that shows expected scoring. Every proposal that scored about $50 \%$ of the total possible " 15 " has received approval from the evaluators.

The tables 1 and 2 represent the collated call evaluations/ scores that the proposals from the University of West Bohemia received the calls of OP VK between the years 2009-2013. The author of this paper would like to discuss each of the criteria in detail in a future paper or the thesis dissertation. It would be interesting to draw out some further statistical analysis and find out whether a correlation exists between high score in one criterion and the project approval by the evaluators. Also, it would be worth noting why some proposals scored so low in the "financial management" criteria. Is low score an indication of the lack of training in budget preparation for the project managers submitting project proposals? What should be done to enhance the budget preparatory skills of project managers? These are some of the questions that would be answered in a future paper or in the doctoral dissertation of the author. 


\section{CONCLUSION}

The proposals have been analysed based on some general attributes like "maximum score" vs the "total score" and some proposal success despite receiving a very low score in the important component, i.e. financial management of the proposal. It was also noted that some proposals did exceedingly well but were found weak in some other important criteria. The author through the analysis of these proposals attempted to show the importance of project proposal submission while presenting a case for organisational portfolio management that encompasses the project and programme management to achieve the desired organisational strategy. The author also desired to explain the importance of certain criterion that most certainly play a vital role in getting project evaluators' nod. Prospective analyses of proposals could well give new insights into the strategic needs of an organisation and how proposals must be dealt with carefully, thereby suggesting some best practices that could be emulated to enhance project proposal success rate considerably. The discussion of results points out a glaring error in certain project proposals - that is "financial management" is primarily ignored by the project managers while proposing.

It is worth pointing out that the author's findings are in a way contrasting to the generally held belief that the proposals do not get approved for lack of addressing the core of the requested call. Together with the tips, the findings recommend a holistic approach towards proposal making where all elements of proposal making are given due importance and dealt with accordingly so as to obtain the minimum threshold necessary to get approval for funding.

\section{Acknowledgements}

The author acknowledges the support of UWB Project Office that provided evaluation sheets for the analysis.

\section{References}

Bourne, P. E., Chalupa, L. M. (2006). Ten Simple Rules for Getting Grants. PLoS Comput Biol, 2(2). https://doi.org/10.1371/journal.pcbi.0020012

Cole, G. A. (1997). Organisational behaviour. London: DP Publications LPBB. ISBN 1858053072.

GARLICK, A. (2007). Estimating risk: a management approach. Burlington, VT: Ashgate,. ISBN 9780566087769.

Gray, L. D. (2011). Project management: the managerial process. 4th Ed. New Delhi: Tata McGraw-Hill Education. ISBN 9780070700857.

Grants Manual - Section on: Proposal submission and evaluation. (n.d.). Retrieved February 2, 2016, from http://www.nust.edu.pk/Research/Download Section/H2020-GuideSubmission-Evaluation.pdf.

Hallows, J. (2002). The Project Management Office Toolkit: a Step by Step Guide to Setting Up a Project Management Office. New York: AMACOM. ISBN 0814406637.

Handy, Ch. B. (1997) Understanding organisations. London: Penguin Lpbb. ISBN 9780140268416.

Hiltz, M. J. (1994). Project Management Handbook of Checklists. Vol.1, Conceptual Definition and Project Initiation. Ontario, Canada: Mark Check Publishing. ISBN $096972022 X$. 
Jerdee, T. H., \& Rosen, B. (1977). Advantages and Limitations of an Independent Research Proposal Review System. Academy of Management Review, 2(4), 659-662.

Kyle, M. (1998). Making it Happen: A Non Technical Guide to Project Management. Toronto, Canada: John Wiley \& Sons, Canada Ltd. ISBN 0471642347

Levine, H. A. (2002). Practical Project Management. 2002 New York: McGraw-Hill. ISBN 0471203033

PMBOK (2013). A Guide to the Project management body of knowledge (PMBOK guide) $5^{\text {th }}$ edition. Pennsylvania (USA): Project Management Institute. ISBN 9781933890517

WYSOCKI, Robert K. (2007) Effective Project Management: Wiley. ISBN 978-0470042618.

Benefit 7 (2012). Retrieved May 12, 2014, from http://www.eu-zadost.cz/uvod.aspx

Operační program Výzkum a vývoj pro inovace (2013). Retrieved June 30, 2014 from http://www.opvavpi.cz/

Operační program Vzdělávání pro konkurenceschopnost (2013). Retrieved June 25, 2014 from http://www.op-vk.cz/

Patel, V.N. (2008). Project Management. Jaipur: Oxford Book Company

Prezentace OP VK (2014). Retrieved July 1, 2014 from http://www.opvk.cz/filemanager/files/file.php?file $=44107$

Př́ručka pro individuální hodnotitele a zpravodaje IP a GP OP VK (2013). Retrieved May 29, 2015 from www.msmt.cz/file/2902_1_1/

Seznam přijemců OP VK (2015). Retrieved June 29, 2014 http://www.op-vk.cz/

Thamhain, H. J. (2013). Contemporary methods for evaluating complex project proposals. Journal of Industrial Engineering International J Ind Eng Int, 9(1), 34. https://doi.org/10.1186/2251-712X-9-34

http://slideplayer.cz/slide/1948974/(2014). Retrieved August 29, 2014 from http://slideplayer.cz

\section{Contact information}

Alok Kumar M.A

University of West Bohemia, Faculty of Economics, Department of Business Administration and Management

Husova 11, 30614 Pilsen, Czech Republic

Telephone: +420734706010

Email: kumar@students.zcu.cz

DOI: https://www.doi.org/10.7441/dokbat.2016.24 


\title{
THE IMPACT OF EARNINGS ANNOUNCEMENT ON CONSERVATISM IN VIETNAMESE FINANCIAL STATEMENTS
}

\author{
Le Tuan Bach
}

\begin{abstract}
Although there has been a diverse range of research topics regarding accounting conservatism in financial reporting, the issue of the impact of earnings announcement on conservatism in Vietnamese financial statements has not drawn researchers' attention. Based on Basu' $\mathrm{s}$ model (1997), I use intra-announcement period returns and fiscal year returns to serve as economic news reflected in earnings within earnings announcement period and prior to earnings announcement, respectively. Next, I test conservatism in financial reporting of Vietnamese listed firms over the period of 2005 to 2014 using the two returns measures. The results show that conservatism principle is only ensured within earnings announcement period when auditors participate in preparing the firm's financial statements. The findings have implications for our understanding of the role of auditors in improving the quality of accounting information.
\end{abstract}

Keywords: accounting standards, listed firms, conservatism, earnings announcement

\section{INTRODUCTION}

This paper examines the impact of earnings announcement on conservatism, defined as the tendency of accountants to recognize bad news on a timelier basis than good news (Basu, 1997). Watts (2003) suggests that conservatism' existence is explained by contracting motivation, tax optimization, litigation risk and regulatory demands. In particular, because of litigation risk aversion, management and auditors have incentives to exercise conservatism. Consequently, conservatism is likely to be warranted in the period of the involvement of auditors in preparing financial statements.

Basu (1997) use inter-announcement period returns and fiscal year returns measure economic news reflected asymmetrically in earnings. The inter-announcement period return is calculated to end three months after fiscal year to ensure that the market response to prior year's earnings is ruled out. Fiscal year return is used as an alternative to exclude the market reaction to the current year's earnings announcement. Financial statements mostly are audited and disclosed within after the end of annual fiscal period; therefore, firms have to work with auditors in the preparation of financial statements in three months after fiscal year. Although, Basu's tests (1997) of conservatism using different economic news primarily aim to check the robustness of the model, the results imply the difference of conservatism in intra-earnings announcement period and period occurring before earning announcement. Furthermore, three months after fiscal year is also the period when Vietnamese public companies must disclose audited financial statements. Auditors' participation in the preparation of financial statements probably leads to conservatism assurance. To put it another way, the level of conservatism in intra-earnings announcement period is likely to be higher than that in period occurring before earnings announcement.

I perform empirical tests on a sample of firm-year observation over the period 2005 to 2014. The results show that conservatism is ensured in intra-earnings announcement period, consistent with Basu (1997). However, I find that Vietnamese firms are inclined not to comply with conservatism in financial reporting without auditors' involvement in the 
preparation of financial statements. This confirms the important role of auditors in improving the quality of accounting information.

Section 2 outlines the nature of conservatism and introduces its measurement. Section 3 explains research design. Section 4 describes sample selection procedures and provides summary statistics. Section 5 presents results and conclusions are reached in Section 6.

\section{MEASUREMENT OF CONSERVATISM AND HYPOTHESIS}

Basu (1997) states conservatism as "denoting the accountants' tendency to require a higher degree of verification to recognize good news as gains than to recognize bad news as losses". Following Basu (1997), Watt (2003) calls conservatism as "the asymmetrical verification requirements for gains and losses". In order to test conservatism, Basu (1997) suggests testing asymmetric news recognition timeliness. For instance, unrealized losses will be recognized more instantly than unrealized gains. Furthermore, because economic information is reflected in stock prices (Ball and Brown, 1968; Beaaver et al., 1980; Kothari and Sloan, 1992), Basu (1997) uses the stock return for the firm to measure economic news. Negative returns proxy for bad news and positive returns proxy for good news. We use fiscal returns to measure economic news captured before earnings announcement. On the other hand, returns calculated to end three months after fiscal year are proxy for economic news purified by auditors. In a nutshell, we test conservatism using the two returns measures for the purpose of finding the impact of earnings announcement period on conservatism. The hypothesis regarding the impact of earnings announcement period on conservatism is stated in null form.

$\mathrm{H}_{1}$ : There is no difference in the level of conservatism in intra-earnings announcement period and period occurring before earning announcement

\section{RESEARCH DESIGN}

\section{Asymmetric news recognitions timeliness}

The timeliness of earnings in response to stock returns (economic news) is expressed by the pooled cross-sectional regression of beginning-of-fiscal-year price deflated accounting earnings $\left(E_{i t} / P_{t-1}\right)$ on concurrent stock returns $\left(R_{i t}\right)$ :

$$
\frac{E_{i t}}{P_{i t-1}}=\alpha_{0}+\beta_{0} R_{i t}+\varepsilon_{i t}
$$

In regression (1), the slope coefficient on stock returns $\left(\beta_{0}\right)$, measuring the sensitivity of earnings to stock return, is expected to be positive. This implies that economic news navigates the timeliness of earnings. In addition, I regress separately earnings on negative stock returns ("bad news") and on positive stock returns "good news". Earnings are predicted to be timelier in recognizing "bad news" than "good news"; therefore, R-squared $\left(\operatorname{Adj} . R^{2}\right)$ of regression (1) for "bad news" $\left(R_{i t}<0\right)$ sample is expected to be higher than that for "good news" $\left(R_{i t} \geq 0\right)$ sample.

The asymmetric timeliness of earnings in respect of stock returns is alternatively inferred from the pooled cross-sectional regression of beginning-of-fiscal-year price deflated accounting earnings on concurrent stock return with dummy variable $\left(D_{i t}\right)$, which equals one for negative stock returns ("bad news"), zero otherwise: 


$$
\frac{E_{i t}}{P_{i t-1}}=\alpha_{0}+\alpha_{1} D_{i t}+\beta_{0} R_{i t}+\beta_{1} R_{i t} D_{i t}+\varepsilon_{i t}
$$

In regression (2), the slope coefficients on stock returns, $\beta_{0}$ and $\left(\beta_{0}+\beta_{1}\right)$, serve as the measures of the sensitivity of earnings to positive stock returns and negative stock returns, respectively. The interactive slope coefficient $\left(\beta_{1}\right)$ measures the difference in the sensitivity of earnings to negative stock returns and positive stock returns. They are expected to be positive, which indicates that the timeliness of earnings is asymmetrically greater for "bad news" than for "good news". Furthermore, the relative sensitivity of earnings with "bad news" compared to "good news" is measured by the ratio of the slope coefficient on negative stock returns to that on positive stock returns $\left[\left(\beta_{0}+\beta_{1}\right) / \beta_{0}\right]$.

\section{Measurement of returns}

Returns computed to end three months after fiscal year and fiscal year returns are used in the regression above in succession.

\section{DATA AND RESULTS}

\section{Data}

The sample is obtained from financial statements of non-financial firms listed on Hochiminh Stock Exchange (HSX) and Hanoi Stock Exchange (HNX) over the period from 2005 to 2014. Earnings and stock returns, measured per share, are deflated by beginning-of-fiscalyear stock price to ensure that heteroskedasticity is controlled. In addition, I use White-Huber standard errors (1980) to compute t-statistic, called heteroskedasitcity-robust t statistic. I exlcude observations falling in the top or bottom $1 \%$ of beginning-of-fiscal-year deflated earnings and stock returns to avoid the potential influence of outliers on the regression results. The change in observations corresponding to requirements of each test is described in each table.

\section{Results}

Table I reports regression results of earnings on intra-announcement period returns. In Panel A, the results of regression (1) in row (1) shows that R-squared (19.87\%) is fairly higher than that of the studies of Lev (1989) and Basu (1997). Consistent with Basu (1997), the estimated slope coefficient of 0.108 on stock returns is significantly positive at the $1 \%$ level, which implies that economic news affects accounting earnings. Row (2) and row (3) display the results of separate regressions (1) on positive return sample and negative return sample. Rsquared of the negative return sample of $12.17 \%$ is higher than that of the positive return sample (4.98\%), which indicates that earnings is more sensitive to bad news than good news. Row (4) reports the results of regression (2). The slope coefficients on $R$ and $(R \times D)$ are 0.064 and 0.172 , which are significant at $1 \%$ level. It is consistent with Basu (1997). The sensitivity of earnings to "bad news" is $3.68([0,172+0,064] / 0,064)$ times as much as that to good news, which confirms that "bad news" is recognized into earnings on a timelier basis. The results suggest the existence of conservatism within the period of audited financial statement disclosure.

Table I reports regression results of earnings on fiscal returns. In Panel B, although estimated slope coefficient of 0.02 on stock returns is significantly positive at the $1 \%$ level, R-squared $(0.025 \%)$ decreases dramatically. This is inconsistent with Basu (1997). Row (2) and row (3) display the results of separate regressions (1) on positive return sample and negative return sample. R-squared of the positive return sample of $0.08 \%$ is higher than that of the negative return sample $(0.01 \%)$, which indicates that earnings is more sensitive to good news than bad 
news. This implies that there is no asymmetric news recognition timeliness. It is confirmed with the result in row (4) reporting the results of regression (2). The slope coefficient $(R \times D)$ is -0.013 , which is insignificant. The sensitivity of earnings to "bad news" is not significantly higher than good news. Consequently, there is no empirical evidence for conservatism in the period occurring before earnings announcement.

Table 1 - Asymmetric News Recognition Timeliness. Source: Own calculation

Regression (1): $E_{i} / P_{i t-1}=\alpha_{0}+\beta_{0} R_{i t}$

$$
(+)
$$

Regression (2): $E_{i t} / P_{i t-1}=\alpha_{0}+\alpha_{1} D_{i t}+\beta_{0} R_{i t}+\beta_{1} R_{i t} D_{i t}$

$$
(+) \quad(+)
$$

\begin{tabular}{|c|c|c|c|c|c|c|}
\hline & Sample & $\alpha_{0}$ & $\alpha_{1}$ & $\boldsymbol{\beta}_{0}$ & $\boldsymbol{\beta}_{1}$ & $\operatorname{Adj.} R^{2}(\%)$ \\
\hline \multirow[t]{2}{*}{ (1) } & & 0.099 & & 0.108 & & 19.87 \\
\hline & & $(36.67)^{* * *}$ & & $(20.94)^{* * *}$ & & \\
\hline \multirow[t]{2}{*}{ (2) } & $R_{i t} \geq 0$ & 0.131 & & 0.064 & & 4.98 \\
\hline & 921 obs & $(19.96)^{* * *}$ & & $(7.77)^{* * *}$ & & \\
\hline \multirow[t]{2}{*}{ (3) } & $R_{i t}<0$ & 0.136 & & 0.236 & & 12.17 \\
\hline & 1,187 obs & $(18.95)^{* * *}$ & & $(11.76)^{* * *}$ & & \\
\hline \multirow[t]{2}{*}{ (4) } & & 0.131 & 0.006 & 0.064 & 0.172 & 22.42 \\
\hline & & $(19.96)^{* * *}$ & $(0.52)$ & $(7.77)^{* * *}$ & $(7.91)^{* * *}$ & \\
\hline
\end{tabular}

Panel A: Intra-announcement period returns ${ }^{\mathrm{a}}$

Panel B: Fiscal year returns ${ }^{b}$

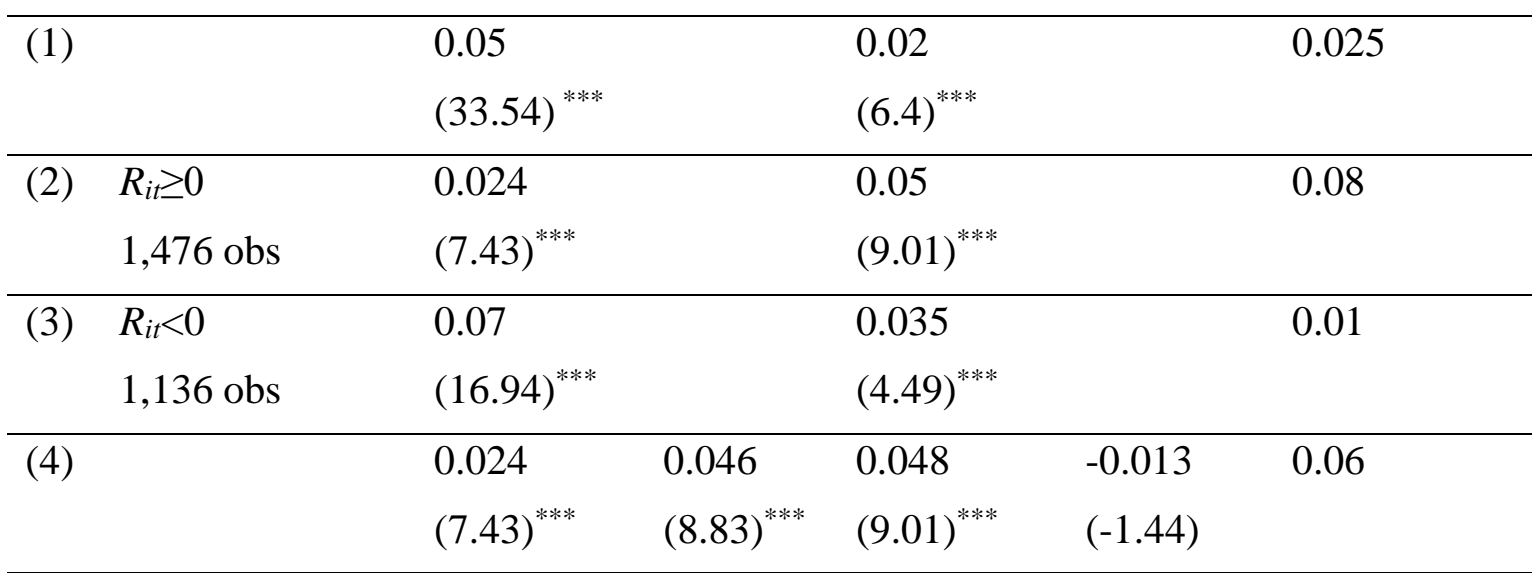

$E_{i t}$ is earnings per share for firm $i$ at year $t, P_{i t-1}$ is stock price per share of the beginning day of fiscal year $t$.

${ }^{\text {a }} R_{i t}$ is stock return for firm $i$ over the period from 9 months before fiscal year-end $\mathrm{t}$ to three months after fiscal year-end $t, D_{i t}$ is a dummy variable, equal to 1 if $R_{i t}<0,=0$ otherwise. The full sample consists of 2,108 observations from 2005 to 2014 .

${ }^{\mathrm{b}} R_{i t}$ is fiscal year return. The dummy variable is redefined to match the adjustment of $R_{i t}$. The tests are conducted on 2,612 observations from 2005 to 2014 .

*** Significant at $1 \%$ level. Heteroskedascity-robust $\mathrm{t}$ statistic is indicated in parentheses below estimated coefficients. 


\section{CONCLUSION}

In this paper, I test the impact of earnings announcement on conservatism in financial reporting in Vietnam using the sample over the period of 2005 to 2014. I find that earnings announcement drive managers to enable accounting conservatism. In particular, asymmetric news recognition timeliness is statistically significant in the period of audited financial statement disclosure, whereas the reverse is for the period before earning announcement. Differently phrased, conservatism is only exercised as auditors involve in the preparation of financial statements. The results imply that auditors have made a positive impact on improving the quality of accounting information. Overall, I note that there are possible opportunities for future research on the relationship between financial information disclosure and accounting conservatism. I believe such research is necessary to fully understand accounting conservatism.

\section{References}

Ball, R., P. Brown (1968). An Empirical Evaluation of Accounting Income Numbers, Journal of Accounting research, 6, 159-178. https://doi.org/10.2307/2490232

Basu, S. (1997). The Conservatism Principle and the Asymmetric Timeliness of Earnings, Journal of accounting and economics, 24(1), 3-37. https://doi.org/10.1016/S01654101(97)00014-1

Beaver, W. H., R. Lambert and D. Morse (1980). The Information Content of Security Prices, Journal of Accounting and Economics, 2, 3-28. https://doi.org/10.1016/01654101(80)90013-0

Kothari, S. P., R. Sloan (1992). Information in Prices about Future Earnings: Implications for Earnings Response Coefficients, Journal of Accounting and Economics, 15, 143-172. https://doi.org/10.1016/0165-4101(92)90016-U

Watts, R.L. (2003). Conservatism in Accounting Part I: Explanations and Implications", Accounting Horizon, 17, 207-221. https://doi.org/10.2308/acch.2003.17.3.207

White, H. (1980). Heteroskedasticity Consistent Covariance Matrix Estimator and a Direct Test of Heteroskedasticity, Econometrica, 48, 817-838. https://doi.org/10.2307/1912934

\section{Contact information}

Le Tuan Bach

Tomas Bata University in Zlín, Faculty of Management and Economics

Mostní 5139 - Zlín (U2 Building) - Czech Republic

Telephone number: +420770 662845

Email: bachstep1008@gmail.com

orcid.org/0000-0002-2448-2046

DOI: https://www.doi.org/10.7441/dokbat.2016.25 


\title{
REGULATION, PRICING OF DRUGS AND PARALLEL TRADE IN CZECH REPUBLIC
}

\author{
Tereza Lukášová
}

\begin{abstract}
Healthcare expenditures in Czech Republic comes mostly from public sources. Approximately $75-80 \%$ is from public health insurance and $5-8 \%$ comes from public budgets the rest is spending from private sources. The major part of drug costs is paid by health insurance companies. Czech Republic seen a large increase in the consumption of drugs in producer prices. Since Czech Republic entered European Union there is a problem with parallel trade with drugs. This situation is caused mainly by drug control policy in which prices are set by the three countries where the drugs are cheapest. With this method of regulating Czech Republic is one of the countries where the drugs are cheapest. Distributors pay to access pricing arbitrage. As a result of parallel trade in drugs, there is a shortage of certain kinds. The Government of Czech Republic is trying to solve this situation by legislation. This study describes the legislation, regulation, pricing of drugs in Czech Republic and also main causes and impacts of parallel trade.
\end{abstract}

Keywords: parallel trade, healthcare system, Czech Republic

\section{INTRODUCTION}

Parallel trade in pharmaceuticals in the EU works thanks to the internal market, where there is a free movement of goods, services, capital and persons. A necessary condition for the internal market have been removing administrative, technical and other obstacles. This situation was in store medicines solved a common legislative framework for the registration of medicines. At present, due to current legislation can be re-exported medicines intended for the Czech market to other EU countries, but also in third countries. Marketing authorization holders of medicines have an obligation to provide sufficient medicine to cover the needs of Czech patients. The registration holder is also obliged to supply the market with this drug designation in the Czech language, which applies in other countries in that language as well. Drug delivery may at the same time the marketing authorization holders also provide distributors. In this case, the simultaneous distribution when it was given by the European Medicines Agency and on parallel imports if the decision issued by the State Institute for Drug Control. In both cases, the contractor needs to obtain a permit national regulatory authority. The main reason for parallel trade is entrepreneurial profit. It is basically a price arbitrage and thanks to regulate the market not to align prices. The Czech Republic ranks among the EU countries with the lowest prices of medicines and therefore also one of the countries where the drugs are re-exported. As a result parallel exports or re-exports there is a loss drugs on the Czech market and thus may be endangering the health of Czech patients. Re-exports also lead to a reduction in profit margins for producers which may affect their investment in research and development. Another negative consequence may be an increased public costs resulting from the public health insurance system if the drugs are having an outage replaced by a more expensive substitute. Czech Republic is thus faced with the unavailability of some medicines as a result of re-exports and in response to a threat to the health of Czech patients. 


\section{PRICING MECHANISM IN CZECH REPUBLIC}

The price difference in different EU countries provides scope for price arbitrage respectively parallel trade in pharmaceuticals. This price differential is caused mainly by different price levels in EU countries in different ways pricing of medicines, exchange rate. The main reason for the difference in prices between EU countries is a different settings of health care systems.

\subsection{Price regulation in Czech Republic}

The regulator of drug prices in Czech Republic is State Institute for Drug Control (SÚKL). The regulator also sets up maximum prices of medicines if they are covered by public health insurance.

The subject of regulation is the price of producer and margin of distributor. SÚKL sets maximum price of pharmaceuticals on the basis of the Act no. 48/1997 Sb.

According to $\S 39$ provides SÚKL maximum price of the producer like:

a. Average prices considered a medicinal product in the three EU countries which has the lowest price (except the Czech Republic, Estonia, Cyprus, Luxembourg, Malta and Germany). Reference countries are referred to as reference basket of the country, and this applies to point $a$ and $b$.

b. Average prices of manufacturers of the medicinal product under consideration from three EU member states (with the exception of Bulgaria, the Czech Republic, Estonia, Luxembourg, Germany, Austria, Romania, Cyprus and Malta).

c. If it is not possible to use either of the above methods, SÚKL determines the price according to the producer price closest therapeutically comparable medicinal product in the Czech Republic. If no such product in the Czech Republic are available, the lowest price the manufacturer specified in the reference basket (Zákon č. 48/1997 Sb).

\subsection{Determination and regulation of drug prices}

Before a medicinal product is put on the market it has to go through the administrative procedure of registration and inclusion in the Anatomical Therapeutic Chemical Classification System (ATC). Price regulation is subject only to medicinal products which are covered by public health insurance. Drugs that are not covered by public health insurance are not subject to the price regulation. Sales of such drugs are subject to market principles (Ministerstvo zdravotnictví České republiky, 2010a).

\subsection{Calculation of drug prices}

Regulation of drug prices is a complex system that defines:

- Single component prices, which will be subject of regulation,

- Drugs that are subject to regulation,

- The way in which the individual components of the price are regulated,

- Provide specific amounts of regulated prices (Ministerstvo zdravotnictví České republiky, 2010b). 
Price of any drug consists of several components. There is not regulated the final price but the price of individual components. In the Czech Republic is subject to regulation component factory price and the trading margin.

\subsection{The maximum price of the manufacturer}

The manufacturer price is regulated only if it is set according to the mechanism required. This rule was introduced in 2007 with the intention to liberalize the system of price regulation. Whether to regulate the price of a particular drug required is determined by the following rule: "If within one medicinal agents and routes of administration are at least 4 medicines from at least four manufacturers, then the" market "of the active substance to be sufficiently competitive and price manufacturer regulate." (Ministerstvo zdravotnictví České republiky, 2010c). The producer price is determined by the maximum possible price, which is the highest price at which the manufacturer can sell the drug to the distributor (Ministerstvo zdravotnictví České republiky, 2010d).

The maximum price of the manufacturer is determined by SÚKL in accordance with law no. 48/1997 Sb.

\subsection{The maximum price margin}

Regulating trade margins vary from price controls on manufacturers that regulation applies to all actors in the supply chain. This implies that are engaged in the delivery from the manufacturer to the patient four subjects (the European average) and all of these entities are sharing one regulated trade premium. The margin is also set as a maximum amount.

\subsection{Distribution chain}

It is very important to know how the distribution chain in the pharmaceutical industry works if we want to understand and explain the parallel trade.

As previously written, before the drug reaches the patient passes through several intermediate steps. Manufacturer - pharmaceutical company place the drug on the market and sells it to the first distributor (pre-wholesale). The first distributor of the product must add required package, store product and provide logistics etc. The product, which is already fully prepared is sold to another distributor who sells the product to pharmacies. Pharmacy then sells the product to the patient. Parallel trade in medicines usually begins with the first distributor (European Alliance for Access to Safe Medicines, 2007).

\section{PARALLEL TRADE IN PHARMACEUTICALS IN THE CZECH REPUBLIC}

\subsection{Legislation}

In Czech legislation, the parallel trade of medicines already appeared in 1997 in the Pharmaceuticals Act (Act no. 79/1997 Sb.). There was a parallel import defined in Section 28, paragraph 1: "Parallel importation means the importation of a medicinal product, which is currently registered in the Czech Republic and in the Member State to the Czech Republic, 
which is not provided by the marketing authorization holder of a medicinal product in the Czech Republic or in collaboration with him." (zákon č. 79/1997 Sb.).

In the Pharmaceuticals Act (Zákon č. 378/2007 Sb.), The trade is spelled "Parallel importation means the distribution of a medicinal product from another member state to Czech Republic, if this medicinal product has been granted in Czech Republic and in another member state and distribution is provided by the marketing authorization holder of a medicinal product in Czech Republic or in conjunction with it. Make parallel import of a medicinal product may be subject to permission for parallel import of a medicinal product. For parallel importation is not the distribution of another Member State to the Czech Republic, in the case of a medicinal product authorized pursuant to $\S 25$ par. 1 point. b). "(ie. The centralized procedure).", (zákon č. 378/2007 Sb.).

With Czech Republic's accession to the EU also the free movement of goods came into force, citizens and capital under Art. 23 to 31 of the EC Treaty. Under Articles 23 to 31, it is possible to transport goods marketed in one EU country to another EU country without restrictions.

Act no. 378/2007 Sb.: provides parallel import drug products and its conditions.

Act $228 / 2008 \mathrm{Sb}$., on the registration of medicines for human use in $\S 13$ lays down detailed rules for parallel imports (zákon č. 378/2007 Sb.).

SÚKL - REG 86 version 2 - Permitting parallel imports of medicinal products; supersedes guideline REG-86, version 1, with effect from 4. 1. 2016, which replaced with effect from November 1, 2011 the former guideline UST-28th.

REG-86 version 2 explains aspects of parallel importation of medicines into the country. Clarifies the interpretation of the Act no. 378/2007 Sb., because the law does not provide a clear explanation. Among other things specifies the conditions for authorization of parallel imports, the labelling of the packaging of parallel imported drugs, editing package leaflets and conditions repackaging of parallel imported product on the packaging in one product repackaged, the conditions of applying for a parallel import authorization, procedure for parallel import conditions the granting of a parallel import authorization, disclosure authorization of parallel imports and also establishes the obligations of the holder of the parallel import authorization and the possibility of renewal applications for parallel import authorization and the possibility of suspension or revocation of parallel import authorization Státní ústav pro kontrolu léčiv, 2016)

The main legislative act is also the Act 527/1990 Sb. $\S 13 \mathrm{~b}$ introduces the legal concept of exhaustion on the basis that: "The patent owner has the right to prohibit third parties to dispose of the product that is the subject of the protected invention, if the product was launched in the Czech Republic by the patentee or with his consent, unless there were reasons for the extension of patent rights to the mentioned activities.", (zákon č. 527/1990 Sb., ). From an international perspective there are two possibilities for the functioning of the Institute of exhaustion.

\section{National exhaustion of intellectual property rights (national exhaustion)}

In this case the exhaustion of rights only on their territory. Thus parallel trade can't occur.

2. The international exhaustion of intellectual property rights (international exhaustion)

Exhaustion occurs at the moment when the product is placed on the market in any country of the World. From now on the product can be sold across the border a third party the nonoriginal intellectual right. International exhaustion of rights can be applied unilaterally and 
reciprocally on the basis of reciprocal international agreements (Van Den Bossche, 2013) In international exhaustion of intellectual property rights parallel trade is allowed.

The EU applies the principle of Community exhaustion which is based primarily on the principle of free movement of goods, persons and services.

The Czech Republic in 2013 tried principle of free movement of goods, persons and services, reduce amendment to the Act on Pharmaceuticals $\S 77$ par., Which determines the operator pharmacy who is also the holder of a distribution of drugs stated in the documentation that draws preparations in the role of distributor or operator of pharmacies, (zákon č. 378/2007 Sb.).

The latest legislative change that would prevent parallel trade in drugs, concerns Act no. 378/2007 Sb. Amendments to the Act should restrict parallel re-exports of drugs from the country.

\subsection{What is parallel trade from economic point of view?}

Parallel trade is specific case of price arbitrage. It is form of resale when wholesaler buys in one country with lower price and sell to the other country with the higher price. Price arbitrage is normal economical phenomenon which can be seen in trading with lot of goods. But in most of other goods markets the price arbitrage leads to the law of one price. In European Union is one open market for all goods, but for pharmaceuticals there is possibility for each country to regulate the prices of prescription drugs on its own and this is the main reason why law of one price is not enforced.

There are three economic theories of parallel trade. First one is the theory of exclusive territories and vertical price control, which says that there are some exclusive distribution chains which can be claimed by risk of free-riding in marketing investments and after sales services it there is a free competition in distribution and services (Gallini).

Investment and Ramsey pricing theory identifies development and innovations protected by intellectual property as a case of competition for the market. The main issue is to recover the fixed costs of innovations (which is really high in pharmaceutical business). Second best fixed cost recovery is not possible to achieve while there is permitted arbitrage, (Danzon, 1997).

Third theory of parallel trade is economic theory of price discrimination accurately the third degree of price discrimination. In this theory a welfare of consumers increases with increasing number of consumers. Parallel trade can lead to the lower willingness to pay and shut down of some markets which would lead to lower welfare of consumers, (Malueg, 1994).

\subsection{Causes of parallel trade in European Union}

There are many causes of pharmaceutical parallel trade there are incentives for pharmacies to buy reimported drugs which are cheaper than would be the drugs imported originally to the country. The $70 \%$ of EU parallel trade happens in United Kingdom (Kanavos, 2004). The reason is that there can be used clawbacks which means indirect financial benefit for payer. There is also financial incentives to pharmacy practised in Denmark, Germany, Netherlands, Norway, Sweden and UK. And also very usual is using of financial incentives for pharmacist to buy drugs from the cheapest supplier,( European Patient Safety and Parallel Pharmaceutical Trade, 2007) 


\subsection{Impact of parallel trade in medicines on the market in Czech Republic}

Czech Republic is among the countries from which drugs are re-exported to other EU countries. This situation is caused mainly by drug control policy in which prices are set by the three countries where the drugs are cheapest. With this method of regulating Czech Republic is one of the countries where the drugs are cheapest. Distributors pay to access pricing arbitrage. As a result of parallel trade in drugs, there is a shortage of certain kinds. At the moment of failure are treated to replace medications in generic drugs, but it may not be available or may be more expensive than the original drug. If there is outage it usually cause arise of health cost for the patient who needs to be treated and can't. If there is more expensive generic product available it increases costs of public health insurance hence the state.

Total Czech Republic expenditure on health care in the long term is around 7\% of GDP (Ústav zdravotnických informací a statistiky ČR, 2014) Approximately $10 \%$ of these expenses are on drugs, see in Table 1.

Table 10 Total expenditure on pharmaceuticals, health insurance reimbursement incl. additional payment of patients in Czech Republic. Source: SÚKL, own modification

\begin{tabular}{|c|c|c|c|}
\hline Year & $\begin{array}{l}\text { Expenditures } \\
\text { (mil. CZK) }\end{array}$ & $\begin{array}{l}\text { Expenditures covered } \\
\text { by } \quad \text { Healthcare } \\
\text { insurance companies } \\
\text { (mil. CZK) }\end{array}$ & $\begin{array}{l}\text { Additional payment } \\
\text { (mil. CZK) }\end{array}$ \\
\hline 2012 & 25061 & 23334 & 1726 \\
\hline 2013 & 30249 & 28527 & 1722 \\
\hline 2014 & 30156 & 28213 & 1943 \\
\hline
\end{tabular}

Comparing the data in Table. 1 and Table. 2 shows that the proportion of drugs re-exported and total spending on drugs is considerable. In 2012 amounted to re-export drugs more than $20 \%$. However, it is evident from Table no. 2 that there is an interesting trend of annual decline in re-exports. This trend can be justified by a change in drug prices in the importing countries, exchange rate fluctuations, the announced decision of producers to supply the Czech market directly without a distributor, a decline in prices of drugs in the target countries.

Table 2 Extent of paralell export from Czech Republic, Source: Sprinx, (Sprinx FarmakoIndex), own modification

\begin{tabular}{|l|l|l|l|l|}
\hline Year & 2012 & 2013 & 2014 & 2015 \\
\hline $\begin{array}{l}\text { Extent in mil. CZK - } \\
\text { whole year }\end{array}$ & 5343 & 5125 & 4560 & N/A \\
\hline $\begin{array}{l}\text { Extent in mil. CZK } \\
\text { Jan. - Apr. }\end{array}$ & 1896 & 1772 & 1674 & 1261 \\
\hline
\end{tabular}




\begin{tabular}{|l|l|l|l|l|}
\hline $\begin{array}{l}\text { Annual change Jan. } \\
- \text { Apr. }\end{array}$ & - & $-7 \%$ & $-6 \%$ & $-25 \%$ \\
\hline $\begin{array}{l}\text { Annual cahnge - } \\
\text { total }\end{array}$ & - & $-4 \%$ & $-11 \%$ & N/A \\
\hline
\end{tabular}

\section{CONCLUSION}

Pharmaceutical parallel trade s one of EU economic problem. For exporting countries it is economic but also health problem. There is uncountable value of health of patients who needs their medication and can't reach it because it was exported. This is the biggest problem with high price drugs which are usually used for treatment of serious illnesses like cancer. Governments of exporting countries try to solve this situation by legislation and Although we can see the downward trend of re-export of drugs from the Czech Republic the phenomenon is constantly needs to be addressed because there is a loss of drugs on the Czech market and it is a health hazard for Czech patients and unnecessary expenditure of public funds.

\section{References}

Cenová regulace léčiv. Ministerstvo zdravotnictví České republiky [online]. Praha, 2010 [cit. 2016-02-08]. Dostupné z: http://www.mzcr.cz/dokumenty/cenova-regulaceleciv_5886_2516_1.html.

Cenová regulace léčiv. Ministerstvo zdravotnictví České republiky [online]. Praha, 2010 [cit. 2016-02-08]. Accessible from: http://www.mzcr.cz/dokumenty/cenova-regulaceleciv_5886_2516_1.html.

Cenová regulace léčiv. Ministerstvo zdravotnictví České republiky [online]. Praha, 2010 [cit. 2016-02-08]. Accessible from: http://www.mzcr.cz/dokumenty/cenova-regulaceleciv_5886_2516_1.html.

Cenová regulace léčiv. Ministerstvo zdravotnictví České republiky [online]. Praha, 2010 [cit. 2016-02-08]. Dostupné $\quad \mathrm{z}$ : http://www.mzcr.cz/dokumenty/cenova-regulaceleciv_5886_2516_1.html.

Danzon, P. (1997). Price discrimination for pharmaceuticals: Welfare effects in the US and the EU, International Journal of the Economics of Business, 4 (3), 301-21.

Ekonomické informace ve zdravotnictví 2013. 1. Praha: Ústav zdravotnických informací a statistiky ČR, 2014. ISBN 978-80-7472-133-5.

European Patient Safety and Parallel Pharmaceutical Trade: - a potential public health disaster? [online]. 1. United Kingdom: European Alliance for Access to Safe Medicines, 2007 [cit. 2016-02-08]. Accessible from: http://www.eaasm.eu/cache/downloads/t6hd9dyk1twg8ckws4s04osg/Patient_safety_r eport_FINAL\%20VERSION\%20p1.pdf.

European Patient Safety and Parallel Pharmaceutical Trade [online]. 2007 [cit. 2016-04-15]. Dostupné http://www.eaasm.eu/cache/downloads/t6hd9dyk1twg8ckws4s04osg/Patient_safety_r eport_FINAL\%20VERSION\%20p1.pdf

Gallini, N., and Hollis. A. Contractual Approach To The Gray Market [online]. [cit. 2016-04$15]$.

Dostupné

$\mathrm{z}$ : 
http://citeseerx.ist.psu.edu/viewdoc/download?doi=10.1.1.200.4827\&rep=rep1\&type= pdf

Kanavos, P., et al. (2004). The Economic Impact of Pharmaceutical Parallel Trade in European Union Member States: A Stakeholder Analysis [online]. 1st. London, 2004 [cit. 2016-04-15]. Dostupné http://archives.who.int/prioritymeds/report/append/829Paper.pdf

Malueg, D. and M. Schwartz (1994). Parallel imports, demand dispersion and international price discrimination, Journal of International Economics, 37, 167-95. https://doi.org/10.1016/0022-1996(94)90044-2

REG-86 verze 2: Povolování souběžného dovozu léčivého přípravku. Státní ústav pro kontrolu léčiv [online]. Praha, 2016 [cit. 2016-02-08]. Accessible from: http://www.sukl.cz/leciva/reg-

862?highlightWords=S\%C3\%9AKL+\%E2\%80\%93+pokyn+REG+\%E2\%80\%93+Po volov\%C3\%A1n\%C3\%AD+soub\%C4\%9B\%C5\%BEn\%C3\%A9ho+dovozu+hum\%C 3\%A1nn\%C3\%ADho+1\%C3\%A9\%C4\%8Div\%C3\%A9ho+p\%C5\%99\%C3\%ADprav $\mathrm{ku} \% 3 \mathrm{~B}$.

Smlouva o založení Evropského společenství. Accessible from: http://www.euroskop.cz/gallery/2/756-smlouva_o_es_nice.pdf.

Sprinx FarmakoIndex: Paralelní export se propadl o 25 procent. Homeopatika se prodávala o skoro 44 procent více [online]. 4 [cit. 2016-02-11]. Dostupné z: http://www.sprinx.com/getattachment/fc6ab5a7-0bc9-497e-bcaf-

74e39e0b16d0/150615_sprinx_farmakoindex.aspx

Van Den Bossche, P., and Zdouc, W. (2013). The Law and Policy of the World Trade Organization: Text, Cases and Materials. 3rd Edition. Cambridge, 2013. ISBN 9781107694293.

Zákon o léčivech (zákon č. 79/1997 Sb.). Accessible from: http://www.epravo.cz/top/zakony/sbirka-zakonu/zakon-ze-dne-19-brezna-1997-olecivech-a-o-zmenach-a-doplneni-nekterych-souvisejicich-zakonu-3876.html.

Zákon o léčivech (zákon č. 378/2007 Sb.). Accessible from: https://portal.gov.cz/app/zakony/zakonPar.jsp?idBiblio=65289\&nr=378 2F2007\&rpp $=15 \#$ local-content.

Zákon o léčivech (zákon č. 378/2007 Sb.). Accessible from: https://portal.gov.cz/app/zakony/zakonPar.jsp?idBiblio=65289\&nr=378 2F2007\&rpp $=15 \#$ local-content

Zákon 527/1990 Sb., ze dne 27. listopadu 1990 o vynálezech a zlepšovacích návrzích. Accessible from: https://portal.gov.cz/app/zakony/zakonPar.jsp?page=0\&idBiblio=38896\&recShow=1 4\&nr=527 2F1990\&rpp=15\#parCnt.

Zákon č. 48/1997 Sb., o veřejném zdravotním pojištění a o změně a doplnění některých souv. Zákonů. Accessible from: https://portal.gov.cz/app/zakony/zakonPar.jsp?idBiblio=45178\&nr=48 2F1997\&rpp= 15\#local-content.

Zákon o léčivech (zákon č. 378/2007 Sb.). Accessible from: https://portal.gov.cz/app/zakony/zakonPar.jsp?idBiblio=65289\&nr=378 2F2007\&rpp $=15 \#$ local-content

\section{Acknowledgement}

This article was supported by the Internal Grant Agency of the University of Economics,Prague No. 51/2016, IG504026 


\section{Contact information}

Tereza Lukášová

University of Economics, Faculty of Economics náměstí Winstona Churchilla 1938/4,

13067 Praha 3

Email: tereza.lukasova@vse.cz

DOI: https://www.doi.org/10.7441/dokbat.2016.26 


\title{
CONSUMER BEHAVIOR IN THE CONTEXT OF WINE TOURISM
}

\author{
Lena Malačka, Jitka Veselá
}

\begin{abstract}
Wine industry and wine tourism are on the rise. In some regions of the Czech Republic income from these activities can generate more incomes for municipal budgets. Not only because of the fact that they are contributing to region development and are making the region more attractive for bigger investors and entrepreneurs who offers new working opportunities but also because new forms of tourism connected to the wine industry are developing. The aim of this paper is to confirm if there is a significant dependence between the consumers' preference of local producers and their relation to the wine tourism. This relation was confirmed by using the Spearman's coefficient figured out on the base of gathered data. It means that the respondents were influenced by the the purchase at local producer winery to take part on the wine tourism activity.
\end{abstract}

Keywords: tourism, wine tourism, consumer behaviour, country of origin effect

\section{INTRODUCTION}

Tourism has become in recent decades an important economic activity with a positive impact on economic development and employment because of its cumulated development potential (multiplier effects). It is linked with a number of other industries and sectors - eg. accommodation, hospitality, transportation or construction. In recent years, tourism has also become an inseparable part of the lifestyles of many people. This is evidenced by the fact that tourism has recorded positive numbers in the number of incoming tourists since 2010 (Lejsek, 2013). Alongside traditional tourists on vacation (they stay outside their place of habitual residence longer than 3 nights) (Ryglová, Burian \& Vajčnerová, 2011) are more often so called short-term tourists who spend at final destination less than 3 nights. The reason of their visit may be relaxing stays in the form of visits in spas and wellness centres, hiking in the form of hiking or increasingly popular so called adventure tourism or agritourism which are part of the rural tourism (Ramu \& Kathleen, 2014). Generally, tourists lately tend to shorter trips closer to his home (Lejsek, 2013).

\section{WINE TOURISM}

Among the current trends in tourism are also gastronomical experiences and their associated activities. Generally, this kind of tourism is described as a culinary tourism which is becoming increasingly popular and sought. According to the research of Gourmet Magazine and Travel Association of America $17 \%$ of travelers were reported to the culinary tourism in 2006 (Kotíková, 2013). Discovering regional cuisine is also closely associated with the winery since gastronomical experiences is very often accompanied with food and wine pairings. This of course brings synergistic effects for the whole region because tourism development helps to improve economic growth in the region (do Paco, Alves \& Nunes, 2012). One of the positive effects can be seen particular growth in sales in the wineries located in the region or even creating new trade and business opportunities (Lopez-Guzman, Rodríguez-García, Sánchez-Cañizares \& Luján-Garcia, 2011; Zielinska, 2009).

As follows from the previous text, tourism is one of the important and growing part of the wine industry and on the contraty winery is one component of tourism, namely internationally (Leighann \& Judith, 2014). So called „,wine tourism“ is defined as "a 
visitation to vineyards, wineries, wine festivals and wine shows for which grape wine casting and/or experiencing the attributes of a grape wine region are the prime motivation factors for visitors" (Hall, Sharples, Cambourne \& Macionis, 2002).

The basic definition of wine tourism is mentioned above. This definition, however, can be also supplemented by the claim that the visit of wine-growing region is not necessarily the primary motivator. Leighann \& Judith (2014) states that a visit to the winery is just one of the activities that the tourists included in the entire set of activities realized in the region. Wine tourism in this context is part of a package of activities which include also exploring the cultural, historical attractions and other leisure activities.

\section{COUNTRY OF ORIGIN EFFECT IT THE CONTEXT OF CONSUMER BEHAVIOUR}

At the present time a remarkable effort may be traced to homogenize markets. Consequently, companies can save costs, which, otherwise, such companies would have to spend to adjust marketing mix to foreign markets. Simultaneously, a second aspect is demonstrated - i.e., fostering of national pride of both companies and consumers.

\subsection{Coutry of origin effect}

Above mentioned phenomena are accompanied with an elimination of barriers to entry into other (foreign) markets; consequently, companies can use such markets as places, where their production could be moved. I.e., other savings could be achieved, e.g., cheaper labour force, lower material costs etc. Nevertheless, in connection with such movement companies are under the influence of country of origin effect (COO effect), (Chu, Chang, Chen \& Wang, 2008) not necessarily only in foreign markets. COO effect may influence competitiveness of producers in their local markets.

The country of origin effect is demonstrated by differing evaluations of the identical product by consumers of various nationalities (Agrawal \& Kamakura, 1999; Štrach, 2009). Products are exposed to the influence of said effect and consumer might be interested to know in which country a particular product, which he/she has already bought or would like to buy (Chu, Chang, Chen \& Wang, 2008; Zeugner-Roth, Diamantopoulos \& Montesinos, 2008; Kunczik, 1997) has been produced.

\subsection{Consumer behaviour}

If we talk about the country of origin effect it is necessary to mention other terms which are in connection with influence of the national aspects on consumer behaviour. Consumer purchase decision is affected not only by the national image (in the form of COO effect) but also by the level of consumer ethnocentrism or consumer patriotism. These two terms will be explained in the following text.

\section{Consumer Ethnocentrism}

The rate of ethnocentrism of consumer plays an important role in connection with the enforcement of domestic products in foreign markets. The more ethnocentric consumer is, the more significant is the effect of country of origin as regards the evaluation of particular product, intention to purchase particular product and willingness to purchase foreign products (Světlík, 2011; Štrach, 2009). The rate may be reflected in the trust of consumer and his/her attitudes to the country, which such product comes from (Kunczik, 1997) and the awareness of foreign product can be both, negatively or positively, influenced. Marketers should try to influence either positive or negative attitudes of consumers to products coming from 
particular country via appeal to their positive ethnocentric attitudes - e.g., giving preference to local production as having better quality, being healthier, more valuable, enabling employment of local inhabitants and, consequently, supporting employment rate in the region and country and facilitating development of national industry (Štrach, 2009).

\section{Consumer Patriotism}

Patriotisms, in the original meaning of the word, meant loyalty to church (MacNabb). Consumer patriotism is linked with the expression of love and support to own nation. Concepts of consumer patriotism and ethnocentrism match in this point. Nevertheless, fundamental difference is reflected in relation of consumers to other nations.

If - in case of ethnocentrism - consumer prefers local production and in a way underestimates foreign production, in case of patriotism in spite of the fact that consumer expresses his/her solidarity with the country in which he/she lives, such fact does not negatively influence his/her attitude to foreign products at any price. However, the fact should be highlighted that mutual relation of such phenomena, though they complement each other, depend on cultural environment and differs in various countries (Vassella, Fountain \& Fountain, 2010).

\section{CONSUMER BEHAVIOUR IN THE CONTEXT OF WINE TOURISM}

Consumers are influenced by many circumstances when choosing wine. The consumer usually makes the choice on the basis of three aspects: brand, country of origin and price in relation to the quality, suitability and use in different situations (Heslop, Cray \& Armenakyan, 2010). According to the conducted surveys there are some other factors which mostly influence customers it the selection of wine, e.g. in particular the kind and type of wine, the variety and the consumer's experience. As an example of country of origin effect can be mentioned Czech consumers who clearly prefer wine from South Moravia or as the case may be, from Bohemia (Veselá \& Zich, 2015). Only less than a third of consumers prefer wines produced in other countries (Vinařský fond, 2012).

According to Govindasamy \& Kelley (2014), tourists visiting destinations within the conception of agritourism tend to attend events which have wine tasting as their primary aim. The prevailing number of respondents in this tourist category thinks that the offer of wine varieties is better with the winemaker than in the supermarket, and considers the price of winemakers more favourable than the price in supermarkets.

The question is whether there is a direct interaction between wine tourism and decision making in the selection of wine with regard to the country (region) of origin. The research of Famularo, Bruwer \& Li (2010) and McCutcheon, Bruwer \& Li (2009) suggests that the region of origin is a relevant factor influencing the buying decision in the process of wine purchase. There were also revealed some important relationships between the region of origin as an aspect affecting the buying decision and various reasons why people visit wine-growing regions. These relationships were measured using Pearson product-moment correlation coefficient; the first examined element is always the region of origin as an aspect affecting the buying decision and the second one is the reason why people visit the wine-growing region. The correlations are as follows:

- $\quad$ Medium to strong correlation with obtaining knowledge about wine (0.498);

- Medium to strong correlation with wine tourism and obtaining knowledge about production of wine $(0.439)$; 
- $\quad$ Medium to strong correlation with wine tasting in winemakers' cellars (0.433);

- Medium to strong correlation with wine purchase in winemakers' cellars (0.411).

Above mentioned findings stress that the visit to a wine-growing region may lead to greater interest in wine. The fact that the tourist can taste and buy wine directly at the producer shall influence him/her during the next purchase of wine.

However, in case the tourists visit the wine region for the purpose of relaxation or sports, mutual interaction with the inclusion of the region of origin into the buying decision is represented by a relatively weak, negative correlation.

In conclusion we must not omit the fact that women put more weight on the region of origin as a factor influencing the buying decision than men (McCutcheon et al., 2009).

\subsection{Research methodology}

Following statistical methods were used for statistical description of the respondents' samplemodus, median, Spearman's rank correlation coefficient and box plot graph.

Modus is the most frequently occurring value in the analyzed file (Walker, 2013).

Median is the value that divides the data into two equal parts (the number of values smaller or equally large as the median is the same as the number of values greater than or equally large as the median). The median is insensitive to extreme values (Chráska, 2007).

The Pearson product-moment correlation coefficient (r) is a linearcorrelationneccessary to findthedegreeoftheassociationoftwosetsofvariables, $\mathrm{X}$ and $\mathrm{Y}$ (Paler-Calmorin \& Calmorin,

1997). For this coefficient applies $-1 \leq r \geq 1$. The more it is closer to 1 , the stronger serial correlation is between variables $\mathrm{X}$ and $\mathrm{Y}$, the closer it is to -1 , the stronger indirect offsets dependence is between variables $\mathrm{X}$ and $\mathrm{Y}$. Calculation formula for this coefficient is (Evangelu \& Neubauer, 2014):

$r_{x y}=\frac{\sum_{i=1}^{n}\left(x_{i}-\vec{x}\right)\left(y_{i}-\bar{y}\right)}{\sqrt{\sum_{i=1}^{n}\left(x_{i}-\vec{x}\right)^{2}} \sqrt{\sum_{i=1}^{n}\left(y_{i}-\bar{y}\right)^{2}}}$.

Within the statistical processing was used box plot graph. The definition is: "A simple way of representing statistical data on a plot in which a rectangle is drawn to represent the second and third quartiles, usually with a vertical line inside to indicate the median value. The lower and upper quartiles are shown as horizontal lines either side of the rectangle." (Oxford Dictionaries, c2016)

\subsection{Geodemographics of respondents}

Table 1 provides the goedemographical characteristics of respondents who were part of the research. For purposes of this research the stratified sampling was used, more precisely the quota sampling. The research was held during March and April 2015.

As can be seen the sample was constructed to represent the whole Czech Republic statistics. There is great distribution of gender and region of origin in the sample. Only one cotegory of age (26-37) was over-represented. This category is considered as a category which is one of the most interesting for wine producers. According to the research held by The Vinařský fond (2012) wine consumers included in that category are called as "Helpful" - it means that they are willing to buy a bottle of wine and they are also easily persuadable in their purchase decision. 
Table 11 Respondents geodemographic contrasted with Czech over 18 year-old population. Source: Own results and ČSÚ

\begin{tabular}{|c|c|c|}
\hline Category & Sample (\%) & Population (\%) \\
\hline Gender & & \\
\hline Male & 45 & 49 \\
\hline Female & 55 & 51 \\
\hline Region of origin & & \\
\hline Prague & 13 & 12 \\
\hline Central Bohemian & 13 & 12 \\
\hline South Bohemian & 4 & 6 \\
\hline Pilsen & 5 & 5 \\
\hline Karlovarský & 2 & 3 \\
\hline Usti & 6 & 8 \\
\hline Liberec & 4 & 4 \\
\hline Hradec Kralove & 6 & 5 \\
\hline Pardubice & 5 & 5 \\
\hline Vysocina & 7 & 5 \\
\hline South Moravian & 12 & 11 \\
\hline Olomouc & 6 & 6 \\
\hline
\end{tabular}




\begin{tabular}{|l|l|l|}
\hline Moravian-Silesian & 10 & 12 \\
\hline Zlin & 7 & 6 \\
\hline Age (years) & 18 & 11 \\
\hline $18-25$ & 44 & 22 \\
\hline $26-37$ & 21 & 23 \\
\hline $38-50$ & 14 & 30 \\
\hline $51-69$ & 3 & 14 \\
\hline 70 and more & 34 & \\
\hline
\end{tabular}

\subsection{Wine consumption relation to the tourism}

In line with overall objective of the article, the hypothesis to be tested is:

H0: Consumers who buy wine by the local producers more often link the wine purchase with the wine tourism

The respondents were asked how their relation to the wine consumption is. Table 2 shows that almost $60 \%$ of respondents drink wine at least once a week. These people can be described as experienced wine consumers who are looking for more quality, are more finical when buying a wine and they are also more willing to pay more money for it. According to their responses in consumption they prefer white wine $(68 \%)$ rather than red wine $(21 \%)$ or rosé wine (11\%).

In the research respondents also had to point out on a five point Lickert scale $(1-$ least affected, 5 most affected) if they are influenced by the country of origin of the wine, in this case if they are influenced by the fact that the wine was produced in the Czech Republic. The mean points according to figure 1 tend to positive influence (mean 3.9 points; modus 4; standard deviation 1.233) and what is more they also prefer local wine producers (mean 3.7; modus 4; standard deviation 1.215). And to complement the information more than $75 \%$ of white wine drinkers, almost $70 \%$ of red wine drinkers and about $67 \%$ of rosé wine drinkers are positively inclined to the consumption of Czech wines.

Table 12 Respondents relation to the wine consumption. Source: Own results

\begin{tabular}{|l|l|}
\hline "Your relation to the wine consumption" & Response (\%) \\
\hline Do not drink wine, only shop & 5 \\
\hline
\end{tabular}




\begin{tabular}{|l|l|}
\hline Drink wine occasionally (max 1 times a month) & 38 \\
\hline Drink wine sometimes (max once a week) & 34 \\
\hline Drink wine often (more than three times a week) & 19 \\
\hline Drink wine daily & 4 \\
\hline
\end{tabular}

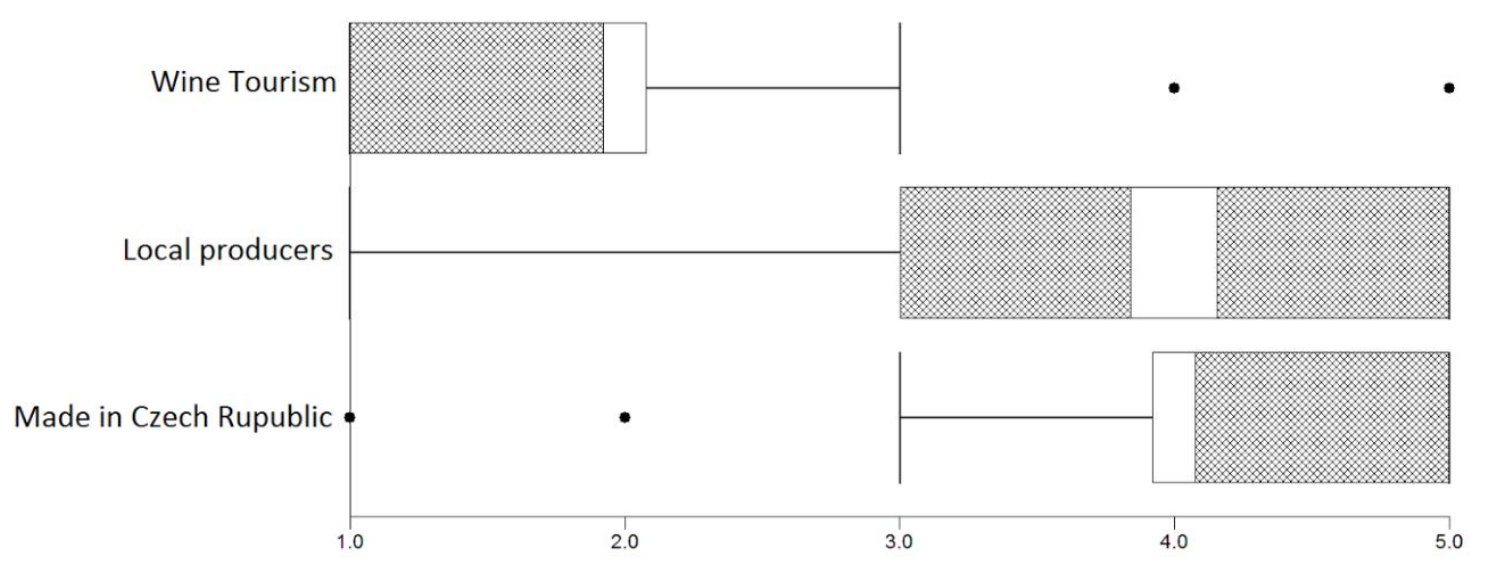

Figure 12 - Responses - link to wine tourism, preference of local producers, influence by the country of origin. Source: Own results

To prove if there is a significant dependence between the fact that people are interested in wine tourism and that they are buying wine from the local producers. On the base of Table 3 Pearson's product-moment correlation coefficient was figured out to find out if there is a dependence of wine consumption in relation to wine tourism and preference of local producers. Pearson's product-moment correlation coefficient for this relation is 0.212 what means that there is a weak dependence between above mentioned factors.

To confirm or reject the hypothesis' authors used p-value 0.00002298 . The Alfa value is greater it means that there is a significant dependence, this dependence is confirmed at 99. $9977 \%$ and also the hypothesis H0 is confirmed.

Table 13 Relation between wine consumption connected to tourism and preference of local wine producers. Source: Own results

\begin{tabular}{|l|l|l|l|l|l|l|}
\hline $\begin{array}{l}\text { Preference of local wine } \\
\text { producers }\end{array}$ & $4^{*}$ & $3 *$ & $2 *$ & $1 *$ & Total \\
\hline $\begin{array}{l}\text { Wine consumption connected to } \\
\text { tourism }\end{array}$ & & & & \\
\hline
\end{tabular}




\begin{tabular}{|l|l|l|l|l|l|l|}
\hline Cannot judge & $3.23 \%$ & $0.00 \%$ & $0.00 \%$ & $19.35 \%$ & $77.42 \%$ & $100.00 \%$ \\
\hline Rather yes & $7.30 \%$ & $9.49 \%$ & $1.46 \%$ & $44.53 \%$ & $37.23 \%$ & $100.00 \%$ \\
\hline Rather no & $4.88 \%$ & $7.32 \%$ & $0.00 \%$ & $40.24 \%$ & $47.56 \%$ & $100.00 \%$ \\
\hline Definitely yes & $10.85 \%$ & $18.60 \%$ & $0.78 \%$ & $38.76 \%$ & $31.01 \%$ & $100.00 \%$ \\
\hline Definitely no & $0.00 \%$ & $0.00 \%$ & $0.00 \%$ & $53.85 \%$ & $46.15 \%$ & $100.00 \%$ \\
\hline Total & $7.40 \%$ & $10.97 \%$ & $0.77 \%$ & $40.05 \%$ & $40.82 \%$ & $100.00 \%$ \\
\hline
\end{tabular}

*numbers in columns represent the local wine products influence on purchase decision: 1 less influenced, 5 most influenced

\section{CONCLUSION}

Presented paper is focused on possible influence of consumer behavior by choosing and buying wine on wine tourism. Wine tourism has become an important economic activity with a positive impact on economic development and employment because it encourages sustainable economic growth of smaller regions through the tourism development and primarily, in the wine areas where the wine tourism is connected to the main product of agricultural production that is declining.

To describe the influence between consumer behavior and wine tourism research was conducted. The research sample corresponds almost in all geodemografical categories to the Czech population. Only one category of age (26-37) was over-represented. This category is considered as a category which is one of the most interesting for wine producers.

There was stated the hypothesis: H0: Consumers who buy wine by the local producers more often link the wine purchase with the wine tourism.

Typical Czech wine consumer can be described as person who drinks wine at least once a week, is well experienced, is looking for more quality, is more finical when buying a wine and he/she is also more willing to pay more money for it. This consumer prefers mostly white wines rather than red wine or rosé wine. Czech wine consumers are also influenced by country of origin and origin from local producers.

To prove if there is a significant dependence between the fact that people are interested in wine tourism and that they are buying wine from the local producers was used Pearson's product-moment correlation coefficient. The value 0.212 shows significant dependece between above mentioned factors. Hypothesis $\mathrm{H} 0$ can be considered as confirmed.

Similar results came from surveys conducted by Famularo, Brewer \& Li (2010) and McCutcheon, Bruwer \& Li (2009) which showed a strong association between the winegrowing region and purchasing wine, which influences consumer behavior. This fact could be important for local producers because when tourists attend wine tourism activities in their 
region there is higher probability they are willing to buy products right there. The advance for consumers is that they can taste the wine right during the wine tourism programmes and then they buy known brand.

\section{References}

Chráska, M. (2007). Metody pedagogického výzkumu. Praha: Grada.

Chu, P., Chang, CH., Chen, CH. \& Wang, T. (2010). Countering Negative Country-of-Origin Effects: The Role of Evaluation Mode. European Journal of Marketing, 44(7/8), 1055-1076. ISSN 0309-0566. https://doi.org/10.1108/03090561011047526

do Paço, A., Alves, H., \& Nunes, C. (2012). Ecotourism from both hotels and tourists' perspective. Economics \& Sociology, 5(2), 132-142, 154. https://doi.org/10.14254/2071-789X.2012/5-2/10

Evangelu, J. E. \& Neubauer, J. (2014). Testy pro personální práci: Jak je správně vytvářet a používat. Praha: Grada.

Famularo, B., Bruwer, J., \& Li, E. (2010). Region of origin as choice factor: Wine knowledge and wine tourism involvement influence. Intl Jnl of Wine Business Res, 22(4), 362385. https://doi.org/10.1108/17511061011092410

Govindasamy, R. \& Kelley, K. (2014). Agritourism consumers' participation in wine tasting events: An econometric analysis. International Journal of Wine Business Research, 26(2), 120 - 138. https://doi.org/10.1108/IJWBR-04-2013-0011

Hall, C. M., Sharples, L., Cambourne, B., \& Macionis, N. (2002). Wine tourism around the world taylor \& francis.

Heslop, L. A., Cray, D., \& Armenakyan, A. (2010). Cue incongruity in wine personality formation and purchasing. Intl Jnl of Wine Business Res, 22(3), 288-307. https://doi.org/10.1108/17511061011075400

Kotíková, H. (2013). Nové trendy v nabídce cestovního ruchu. Praha: Grada.

Kunczik, M. (1997). Images of Nations and International Public Relations. New Jersey: Lawrence Erlbaum Associates.

Leighann, N., \& Judith, M. (2014). Using winery web sites to attract wine tourists: An international comparison. Intl Jnl of Wine Business Res, 26(1), 2-26. https://doi.org/10.1108/IJWBR-07-2012-0022

Lejsek, Z. (2013). Cestovní ruch se stal globálním odvětvím. Statistika\&my, 3(7-8). Retrieved from http://www.statistikaamy.cz/2014/06/cestovni-ruch-se-stal-globalnimodvetvim/

López-Guzmán, T., Rodríguez-García, J., Sánchez-Cañizares, S., \& Luján-García, M. J. (2011). The development of wine tourism in Spain. Intl Jnl of Wine Business Res, 23(4), 374-386. https://doi.org/10.1108/17511061111186523

MacNabb, A. S. Sandy. Patriotism. In: Lodge Presentation Program Paper, Logde no. 57.

McCutcheon, E., Bruwer, J., \& Li, E. (2009). Region of origin and its importance among choice factors in the wine-buying decision making of consumers. Intl Jnl of Wine Business Res, 21(3), 212-234. https://doi.org/10.1108/17511060910985953

Oxford Dictionaries (c2016). Definition of box plot in English. Retrieved March 18, 2016, from http://www.oxforddictionaries.com/definition/english/box-plot

Paler-Calmorin, L. \& Calmorin, M.A. (1997). Statistics in Education and the Sciences: with Application to Research. Manila: Rex Book Store.

Ramu, G., \& Kathleen, K. (2014). Agritourism consumers' participation in wine tasting events. Intl Jnl of Wine Business Res, 26(2), 120-138. https://doi.org/10.1108/IJWBR04-2013-0011

Ryglová, K., Burian, M., \& Vajčnerová, I. (2011). Cestovní ruch-podnikatelské principy a príležitosti v praxi. Praha: Grada. 
Štrach, P. (2009). Mezinárodní management. Praha: Grada.

Světlík, J. (2011). Globální značky a jejich komunikace. Marketing a komunikace, 21(3) 6-7. ISSN 1211-5622.

Vassella, M. C., Fountain, P. D. "Pat" \& Fountain, U. K. (2010). Consumer Ethnocentrism, Patriotism, Global Openness and Country of Origin Rffect: A Literature Review. In: ASBBS Annual conference, 17(1) 868-882.

Veselá, J., \& Zich, R. (2015). The country-of-origin effect and its influence on consumer's purchasing decision: Case study of wine industry. Acta Universitatis Agriculturae Et Silviculturae Mendelianae Brunensis, 63(2) https://doi.org/10.11118/actaun201563020667

Vinařský fond. (2012). Spotřebitelskývýzkumkonzumentůvína v roce 2012.

Walker, I. (2013). Výzkumné metody a statistika. Praha: Grada.

Zeugner-Roth, K. P., Diamantopoulos, A. \& Montesinos, M. A. (2008). Home Country Image, Country Brand Equity and Consumers' Product Preferences: an Empirical Study. Management International Review, 48(5) 577-602. ISSN 0938-8249. https://doi.org/10.1007/s11575-008-0031-y

\section{Contact information}

Lena Malačka

Tomas Bata University in Zlín, Faculty of Management and Economics

Mostní 5139, 76001 Zlín

Telephone: +420732403874

Email: malacka@fame.utb.cz

orcid.org/0000-0002-5699-9269

Jitka Veselá

Private College of Economic Studies in Znojmo, Department of Marketing and Management Loucká 656/21, 66902 Znojmo

Telephone: +420 736269273

Email:vesela@svse.cz

DOI: https://www.doi.org/10.7441/dokbat.2016.27 


\title{
STATE HOUSING POLICY IN SLOVAK REPUBLIC AS THE MEAN OF STIMULATING DEMAND IN THE REAL ESTATE MARKET
}

\author{
Daniela Nemcova
}

\begin{abstract}
The subject of article is the state housing policy in Slovak Republic. State housing policy can be considered as one of the most important tools in finding the way out from financial and economic crisis. The main aim of the article is to underline the importance of state housing policy as the tool of stimulating demand in the Slovak real estate market. In terms of global financial crises requires the strengthening the purchasing power of the population the application of a number of tools of monetary and fiscal policy. The Slovak government implemented the State Housing Policy Concept to 2020 with the intention to revive the property market. Young people and families gained easier access to funds to ensure own housing. The article describes the state housing policy in Slovak Republic, development of Real Estate Market in Slovakia since the year 1989 and direct and indirect subsidies, which have been applied by the Slovak government in order to stimulate the demand in real estate market. The methods used for writing the article are as following: search of domestic literature related to subject of the paper, description of the most important concepts, fusion as a general scientific method of connecting different parts to a certain whole, induction as a method used to create conclusions of the paper, graphical representation of selected economic indicators. The outcome of the paper is the importance of state housing policy concept in terms of strengthening the purchasing power in the national economy. On the other hand, the government should set more strict rules regarding to providing the loans for citizens. Nowadays, young people and families have quite easy access to obtain the loan for private housing. On the other side, this part of population is able to meet the obligations of bank institutions now and during following years. The government has to think in long term context to avoid the mortgage bubble burst and the formation of empty residential areas.
\end{abstract}

Keywords: Real Estate Market in Slovak Republic, State Housing Policy in Slovak Republic, State Housing Development Fund, Direct State Support, Indirect State Support

\section{STATE HOUSING POLICY IN SLOVAK REPUBLIC AS THE MEAN OF STIMULATING DEMAND IN THE REAL ESTATE MARKET}

The financial and economic crisis which broke out in 2007 in the United States as a result of uncontrolled monetary and credit expansion gradually acquired a global dimension, as a result of a globally interconnected financial markets. The economies of individual countries were forced to apply the various regulatory instruments in the direction of recovery the domestic demand. There were applied various tools with a view to stimulate demand in the real estate market in Slovakia, which in turn affects the functioning in all other markets.

The growth in demand of real estate activates the investment growth, it also stimulates demand in other markets. As a result of the development and construction of residential houses there is an increased need for labor in different sectors of the national economy, as growth in demand for building materials to a higher degree of utilization of ancillary services (legal and banking services, real estate agents and others). Increased need for workforce contributes to employment growth and thus to stimulate demand in other markets (food, consumer goods, etc.) and also the growth of gross domestic product. 
The primary objective of the state housing policy is to improve the quality of housing and security, accessing adequate housing residents for Slovak citizens. Ministry of Transport, Construction and Regional Development of the Slovak Republic establishes objectives and housing policy always for period of five years. There is currently used a framework document State Housing Policy Concept to 2020. As part of the document Ministry declared the main objectives, which are not only supporting the construction of new apartment buildings and houses, as well as conversions and extensions of the existing flats to match the technical specifications and requirements for housing by the actual or potential users.

\subsection{Development of Real Estate Market in Slovak Republic}

The current situation in the real estate market in Slovakia is a result of national historical development in an environment of transforming economy. The system of housing financing was a subject to the centrally planned national economy before 1989. At that time, the comprehensive housing construction was in charge state. (MTCRD SR, 2015).

The year 1989 brought with it major changes especially in the area of housing policy, where changing social conditions transferred the responsibility for the acquisition of private housing to citizens. The first stage of the transformation of housing policy took place in 1993 through the "Reform of the Housing Policy." The relevant legislative reform determined rules that should provide the legal framework and material preconditions for the formation of the real estate market in Slovakia. (Špriková, Ivanička, Finka, 2009).

„Manifesto of the Government of the Slovak Republic in July 1992 shifted solutions to housing problems and the application of economic mechanisms in a new light. The following solutions were suggested:

- review of the existing system of financing housing construction,

- creation of conditions for the completion of unfinished integrated parts of the former complex housing policy,

- sale of flats,

- development of building savings system,

- completion the reform of the rent" (Špriková, Ivanička, Finka, 2009, p. 51).

State Housing Policy, which defined the problems in housing and formulated economic instruments of housing subsidiary was approved by the Government in late 1995. As part of the concept the municipalities became responsible for direct and indirect housing development. The role of municipalities is primarily the planning of land-use, the availability of vacant land intended for housing construction, management and participation in the development of housing and related infrastructure.

During the transition from centrally planned economy to the capital market in Slovakia there is a rise in prices, resulting in difficult conditions to obtain own housing. Due to the growing interest of young families in the construction of own housing-with support from the State Housing Development Fund occurs in the years 1996 to 1997 a slight recovery in housing construction.

„The development of the real estate market in the 2000s highlighted the positive development of the gross domestic product (GDP), which had an impact mainly on industry, construction and agriculture, and in which GDP growth exceeded overall economic performance. Final household consumption contributed positively to GDP growth due to real wage growth and the impact of low interest rates, and thus the availability of credit to support life and consumption in debt. Gradually the growth of gross fixed capital formation, suggesting a revival of investment activity in our economy.“ (Špriková, Ivanička, Finka, 2009, p. 52). 
Figure 13 - Slovakia GDP Growth Rate 1998 - 2014. Source: National Bank of Slovakia

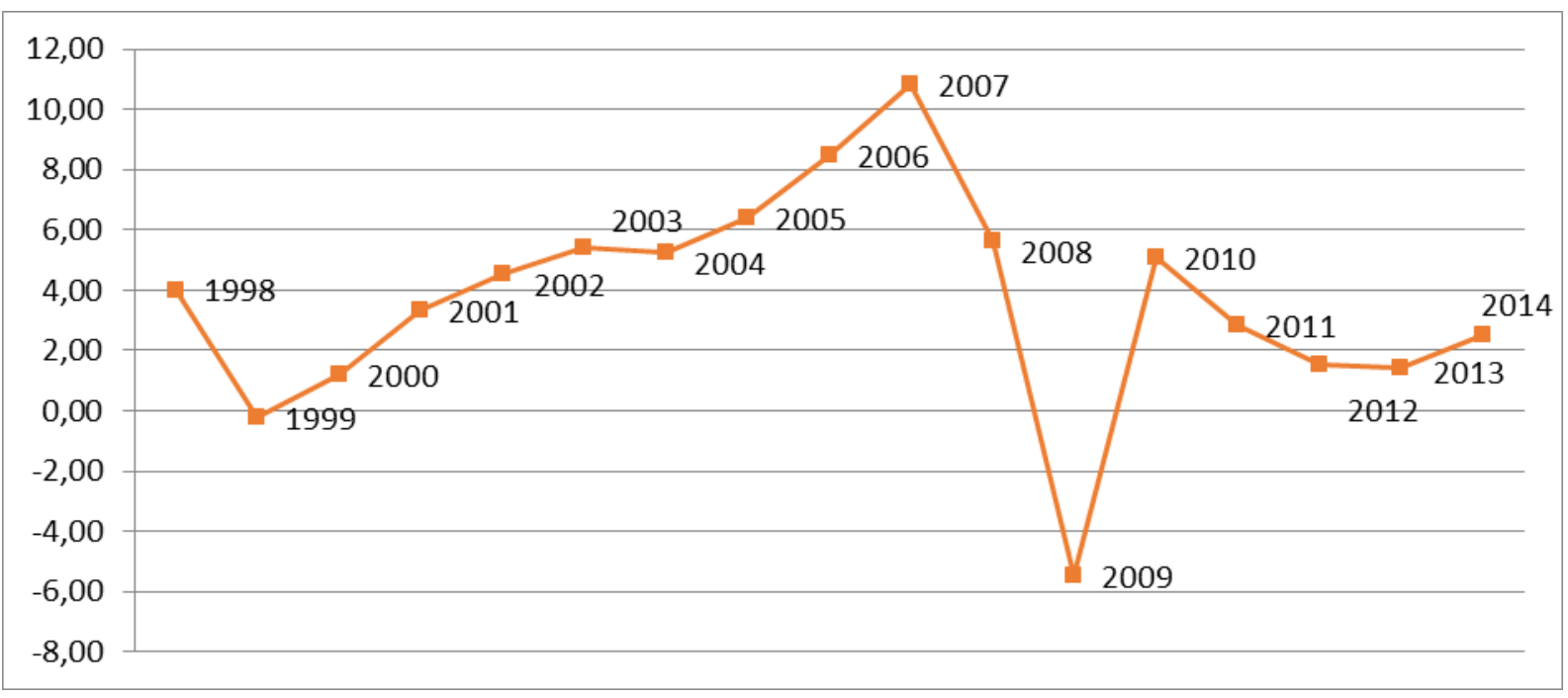

Under the development of the real estate market has signed a significant inflow of foreign direct investment in 2000. The total volume of foreign investment reached 5.9 billion EUR, which is almost twice more than in 1999. The most important investors are ENEL and KIA 2.

As reported by Špirková, Ivanička and Finka (2009) other determinant which supported the entry of foreign investors into the Slovak market was re-granting investment rating of the world's leading rating agency Japan Credit Rating Agency that responded to previous improve the rating of Slovakia. Subsequently, there was a reduction in interest rates and improvement of finance options.

The increase of intensity of housing construction occurred in Slovakia in 2005 when it accounted 2.76 completed flats for 1,000 people. Shortage of supply of apartments in Slovakia caused an increasing demand for residential property. It also caused a rise in prices of the commodity. Increased demand for residential buildings is a result of rapidly growing economy, income and demographic development.

The development of the real estate market was strongly supported by new forms of financing such as leasing and mortgage financing, project financing and new types of retail funding.

Mutual cooperation of private financial and government institutions facilitate access to funds to ensure own housing. The current market offers opportunities in the direction of combining various loan products with forms of government housing support. The relatively wide availability of credit resources was significantly affected by a favorable development of interest rates, which has a downward trend after 2000. 
Figure 2 - Slovakia Interest Rate on Loans to Householders 2004 - 2015. Source: National Bank of Slovakia

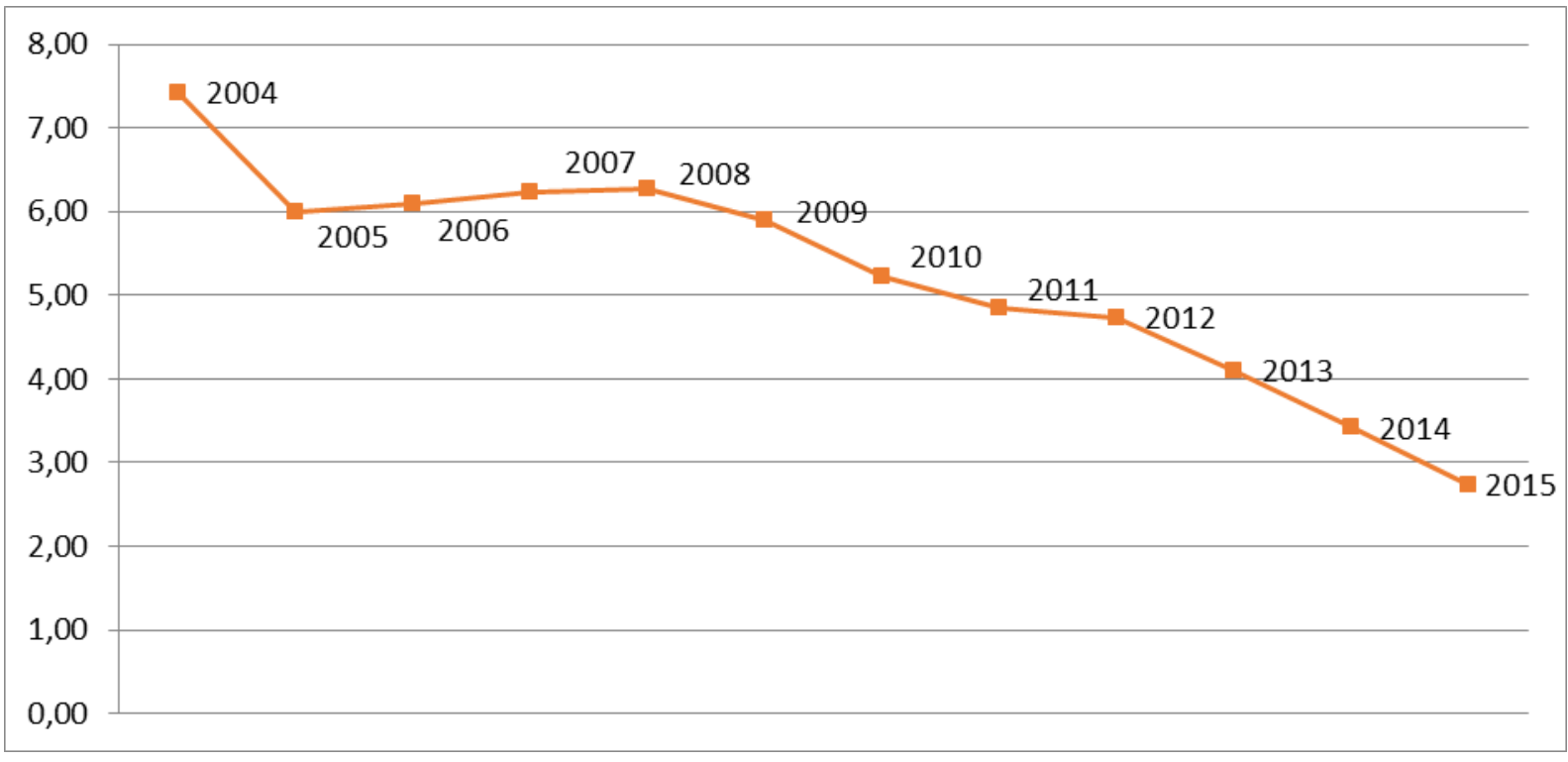

As we can see from graphs the interest rate on loans to householders has been decreasing since the year 2009 as the result of government support. Since the 2010 we can see the GDP growth in Slovak market. The government has used the interest rate as one of the tools to strengthen the purchasing power of Slovak population. The decreased interest rate encourage and enable population to obtain their own housing which also stimulates the demand in other areas of national economy.

\subsection{Housing development support as one of the options to financial crisis resolution}

„The State Housing Policy Concept to 2020 as a framework document of the state in the area of housing reflects the complex targets of the state for housing policy, defines the tools to achieve them, and formulates the responsibility of citizens, government, municipalities, higher territorial units and the private sector in providing housing" (MTCRD SR, 2015).

The economies of individual countries had several regulatory instruments, which can be used for stimulating demand. In Slovakia were implemented the following tools over the period 2010-2015 by legislative amendment of the state budget (MTCRD SR, 2010):

1) subsidies for rental flats and other forms of permanent housing intended for people on low incomes, including groups at risk of social exclusion and marginalized groups (appropriate forms of housing have certain limits in terms of size, price and level of amenities),

2) grants for housing reconstruction, especially elimination of system failures residential buildings, increasing energy efficiency and the like,

3) subsidies for the procurement of technical equipment, which are used for the construction and use of new housing (with the assumption that their supply is gradually cancelled),

4) government bonus to building savings,

5) transfer to the State Housing Development Funds from which support is provided mostly to rental flats and housing reconstruction. 
6) government contribution in the interest rate payments on mortgage loans for selected groups of the population.

At present, is the system of housing development support implemented through direct and indirect support.

Direct state support:

- The subsidies provided by the Ministry of Transport, Construction and Regional Development of Slovak Republic for the acquisition of rental housing, technical infrastructure and system failures removal of residential buildings under the Act no. 443/2010 Coll. a subsidy for housing and development of social housing as amended by Act no. 134/2003 Coll.

- Preferential loans granted from the State Housing Development Fund (hereinafter "SHDF") under Act no. 150/2003 Coll. the State Housing Development Fund. These funds are yet designed especially for rental flats and renewal of current housing. (MTCRD SR, 2015).

\section{Indirect state support:}

- The program of state support for renewal of housing units approved by the Government of the Slovak Republic by providing credit guarantees with a view to stimulate housing construction and create conditions for the renewal of current housing.

- Mortgage financing provided to individuals by state contribution to mortgage loans and the state subsidy for young people according to the law no. 483/2001 Coll. on banks and on amendments to certain laws, as amended. State subsidy for young people is provided to individuals who have reached to the date of application for the loan the age of 18 years and did not exceed 35 years of age. The appropriate form of support makes it easier to obtain mortgage loans to young families with limited income to the acquisition, construction, renovation and reconstruction of housing.

- Building savings with state support in the form of state bonus to building savings provided to individuals and communities of owners of apartments and office space according to the Slovak National Council. 310/1992 Coll. home savings, as amended. (MTCRD SR, 2015).

In the housing policy in the European Union, it is maintaining the principle of subsidiarity, which means that housing policy remains the responsibility of individual countries. This is managed by the European Union only in the case where they are able to achieve the goals established with higher efficiency than the respective member countries.

Despite the fact that housing policy remains a national competence, the legal framework of the European Union affects other areas that significantly affect the sphere of housing. In particular, the rules on public procurement, rules of construction products and materials, state aid rules, the professional qualifications and recognition of authorized architects and designers, energy policy, guarantee of product properties and services, and the like. (MTCRD SR, 2015).

SHDF provided loans worth 261,32 million Euros for 1024 applicants in 2015. The state signed 631 loan agreements in the amount of 171.29 million Euros. The amount of 109,38 
million Euros were used for the reconstruction of 22830 apartments $(24,54$ mil. Euros for 5 080 apartments, from the EU funds 84,85 mil. Euros for 17750 apartments). Loans in the amount of 61.28 mil. Euros were used for the purchasing of 2006 apartments (57,38 mil. Euros for 1900 rental housing financed by communities with a subsidy, 2,22 mil. Euros used for 73 residential entities and 1,67 mil. Euros for 33 apartments of individuals). There was also granted a loan in amount of 618,2 thousand Euros for building of 40 units in the social service facility. (SITA, 2016).

State contribution to mortgage loans amounted over 33 million Euros in 2015, which is slightly more than the amount approved by government. From the amount of 33 million Euros were used as the state subsidy for young people 26,85 million Euros and the amount of 6,18 million Euros as the state contribution. (SITA, 2016).

The government bonus to building savings reached 35,88 million Euros instead of 41 million approved by government. The number of recipients of state bonus to building savings was 721 453. (SITA, 2016).

Ministry of Transport, Construction and Regional Development of the Slovak Republic provides additional tools applied in the direction of stimulating supply and demand in the real estate market - tax instruments applied mainly in developed countries. One option is to reduce the tax based on significant value of investment or the interests paid to the bank for the loan.

In our opinion the complex system of financing own housing brings the question of safety of the various forms of loans provided by private institutions, as well as state subsidies. The global financial and economic crisis was in Slovakia demonstrated by decreased number of jobs, outflows of foreign direct investment, a reduction in income and purchasing power.

In terms of the real estate market there was not a collapse in Slovakia as a result of global financial crises. Today, however, we can see the easier access to obtain loan for private and business housing. The supply of housing continuously grows. On the site are therefore concerns about the consequences of the mortgage bubble burst and the formation of empty residential areas. The government should set more strict rules regarding to providing the loans to citizens. Young people and families are able to meet the obligations of bank institutions now and during following years. The government has to think in long term context to avoid the mortgage bubble burst and the formation of empty residential areas.

\section{References}

Ministry of Transport, Construction and Regional Development of the Slovak Republic. (2010). Koncepcia štátnej bytovej politiky do roku 2015. [online]. MTCRD SR, 2010. [2015.11.15]. Retrieved from: http://www.telecom.gov.sk/index/index.php?ids=81554

Ministry of Transport, Construction and Regional Development of the Slovak Republic. (2015). Koncepcia štátnej bytovej politiky do roku 2020. [online]. MTCRD SR, 2015. [2015.11.15]. Retrieved from: http://www.telecom.gov.sk/index/index.php?ids=81554

National Bank of Slovakia. (2015). Macroeconomics database. [online]. [2016.02.24].

Retrieved from: http://www.nbs.sk/sk/menova-politika/makroekonomickadatabaza/makroekonomicke-ukazovatele-graf

SITA. (2016). Na podporu bývania dal štát 206 miliónov eur. [online]. [2016.04.08]. Retrieved from: http://byvanie.pravda.sk/peniaze-a-paragrafy/clanok/389070-napodporu-byvani-dal-stat-206-milionov-eur/

Špirková, D., Ivanička, K. \& Finka, M. (2009). Bývanie a bytová politika. Vývoj, determinanty rozvoja bývania a nové prístupy $v$ nájomnej bytovej politike na Slovensku. Bratislava: STU, 2009. 191 p. ISBN 978-80-227-3173-7. 


\section{Contact information}

Daniela Nemcova

University of Economics in Bratislava, Faculty of Commerce

Address: Dolnozemská cesta 1, 85235 Bratislava 5, Slovak Republic

Telephone: +421903768765

Email: danka.nemcova@gmail.com

DOI: https://www.doi.org/10.7441/dokbat.2016.28 


\title{
THE DETERMINANTS OF SATISFACTION WITH ONLINE GROUP- BUYING PURCHASES: AN EXTENDED PERSPECTIVE OF DELONE \& MCLEAN IS SUCCESS MODEL AND TRUST
}

\author{
Pavlína Pawlasová
}

\begin{abstract}
The purpose of this research is to identify the determinants of satisfaction with online group-buying purchases. The perspective of DeLone \& McLean IS success model and trust is integrated in order to explore these determinants. While DeLone \& McLean IS success model was applied to examine the impacts of website characteristics and perceptions of sellers in many prior researches, the impact of these factors on the overall satisfaction with online group-buying purchases is examined only in limited extend. This paper focuses on the identification of the determinants of the overall satisfaction according to DeLone \& McLean IS success model and trust. The overall satisfaction is considered as one of the predictors of customer repurchases intention in this paper. The proposed model of relations between determinants was tested by applying the method of structural equation modelling using the data collected from 419 respondents in the Czech Republic. According to the results, the perceived size of website influences the trust in website and it influences the perceived quality of website. The satisfaction with website is influenced the most with the perceived quality of website. The results show that satisfaction with website has strong impact on the customer overall satisfaction, whilst the satisfaction with sellers is not statistically significant. The results also confirm that there is the positive relation between repurchase intention and overall satisfaction. The discussion and the managerial implications are also discussed in this paper.
\end{abstract}

Keywords: online group-buying, repurchase intention, satisfaction, structural equation modelling

\section{INTRODUCTION}

Social commerce containing online group-buying became popular all over the world and has been still growing across the world (Turban et al., 2015; Jang et al., 2013; Erdogmus \& Cicek, 2011). Online group-buying refers to a business method in which a specific product or service is sold at a discounted price when enough buyers participate in the purchase. The attainment of the required number of buyers within a limited time is the necessary requirement for transaction realization (Jang et al., 2013; Shiau \& Luo, 2012).

This paper deals with this phenomenon in the Czech Republic. Michl (2013) confirms that this topic cannot be omitted there. When Czech customers want to buy some discounted thing, online group-buying websites are the third most common place for them to look. Pilik (2012) states that the Czech customers are very conservative customers. They were found far more responsible in their spending than customers from other countries and online groupbuying is just another way for them to be responsible.

There are about 40 providers of online group-buying websites nowadays in the Czech Republic and prior studies have found that only a small minority of online customers return to the websites to make another purchase (Gupta \& Kim, 2007; Qureshi et al., 2009). According to Zamazalová (2009) a high consumer satisfaction rate can increase a consumer loyalty to the online group-buying provider significantly. According to Shiau \& Luo (2012) 
consumer satisfaction helps companies to establish long-term relationships with consumers and loyalty customers bring substantial revenues to firms (Otim \& Grover, 2006) and reduce the transaction costs (Anderson, Fornell \& Lehmann, 1994). Therefore service providers should try to achieve the maximum user satisfaction with services, products or purchases that lead to the customer repurchase intention. Therefore the quality of service and purchase satisfaction becomes issues of maximum importance (de Oña, de Oña, Eboli, \& Mazzulla, 2013).

\subsection{The aim of the paper}

The aim of this paper is to identify the determinants of the overall satisfaction according to extended perspective of DeLone \& McLean IS success model and trust in the Czech Republic. The affecting factors were identified according to DeLone \& McLean IS success model and trust that was applied in Hsu et al. (2014) for identification of factors that affect users' satisfaction with online group-buying in Taiwan. This approach primarily deals with information system (IS) website quality perception and satisfaction with IS and was extended with trust and customers perception of sellers' quality and satisfaction with sellers. The satisfaction with sellers and the satisfaction with IS are creating the customer overall satisfaction and the customer overall satisfaction is considered as one of the predictors of customers repurchase intention in this paper.

This article contains the theoretical background of satisfaction measurement and DeLone \& McLean IS success model and trust. The subsequent practical part of the article contains the research methodology and an introduction to the method of structural equation modelling (SEM), which is used to evaluate the factors in the Czech Republic. Eventually, the results are described and a discussion of the results and a conclusion are included.

\section{THEORETICAL BACKGROUND OF CUSTOMER SATISFACTION MEASUREMENT AND DELONE \& MCLEAN IS SUCCESS MODEL AND TRUST}

Customer satisfaction means the difference between consumer expectation and actual satisfaction measured after a purchase (Shiau \& Luo, 2012). The customers' perspective of satisfaction measurement is widely accepted. Then the most important is the customers' perceptions about the each factor describing the satisfaction. However it is not important to know the perceptions about each factor affecting customer satisfaction but the most important is to identify which factors have the highest impact on the global assessment of the purchase and which factors have the lowest impact on it (de Oña, de Oña, Eboli, \& Mazzulla, 2013).

Nowadays the questionnaires where customers express their opinions about the importance of each service attribute are widely used, but it can lead to the erroneous results. Respondents can evaluate some factors as important even though their impact on the overall satisfaction is low, or their impact is important only in one of the moments of the evaluation (de Oña, de Oña, Eboli, \& Mazzulla, 2013). Therefore using one of the derived methods which identify the importance of the factors by statistically testing the strength of the relation of the individual factors with the overall satisfaction is recommended (Weinstein, 2000). In e.g. Shiau \& Luo (2012), Hsu et al. (2014) and Aktepe et al. (2015), there was a structural equation modelling applied for the customer satisfaction measurement. 


\subsection{Introduction of DeLone \& McLean IS success model and trust}

As mentioned before, this study applies DeLone \& McLean IS success model and trust in order to explore these factors affecting customer satisfaction. DeLone \& McLean IS success model is a theoretical model for predicting of individuals' behaviour. This model states that IS website quality perception and satisfaction with IS impact customers' repurchase intention in the online shopping Hsu et al. (2014).

DeLone \& McLean IS success model in the updated version from 2003 states that the quality of IS is the predictor of intention to use and user satisfaction. The quality has three major dimensions; these are information quality, system quality and service quality. The system quality measures the desired features of an e-commerce system. These are usability, availability, reliability, adaptability and response time as examples of the valued features by users. The information quality describes the issues of e-commerce content. Users expect that website content will be personalized, complete, relevant, easy to understand and secure. The service quality is the overall support delivered by the service provider. The poor user support will translate into the loose of customers and also sales. The usage captures everything from a visit to a website, to navigation within it, to information retrieval, to execution of a transaction. The user satisfaction measures our customers' opinions of e-commerce system and it covers the entire customer experience cycle from information retrieval through purchase, payment, receipt, and service (DeLone \& McLean, 2003).

In prior study of Hsu et al. (2014), there was DeLone \& McLean IS success model extended by trust, respectively by trust in website and trust in sellers. Trust as a strong predictor of satisfaction was confirmed e. g. in Lin \& Wang, 2006; Shiau \& Luo, 2012 and Pawlasová, 2015.

According to Kim, Xu, \& Koh (2004) and Hsu et al. (2014) it is important to perceive the ecommerce user in dual role. Each e-commerce user is not only a website user, but also he is a buyer. This approach of dual roles is applied also in this study.

Moreover, in prior studies there is satisfaction explored as separated satisfaction with website and satisfaction with sellers. However in this study there is the customer overall satisfaction as a result of satisfaction with website and satisfaction with sellers explored. Figure 1 presents the graphical design of the research model. 


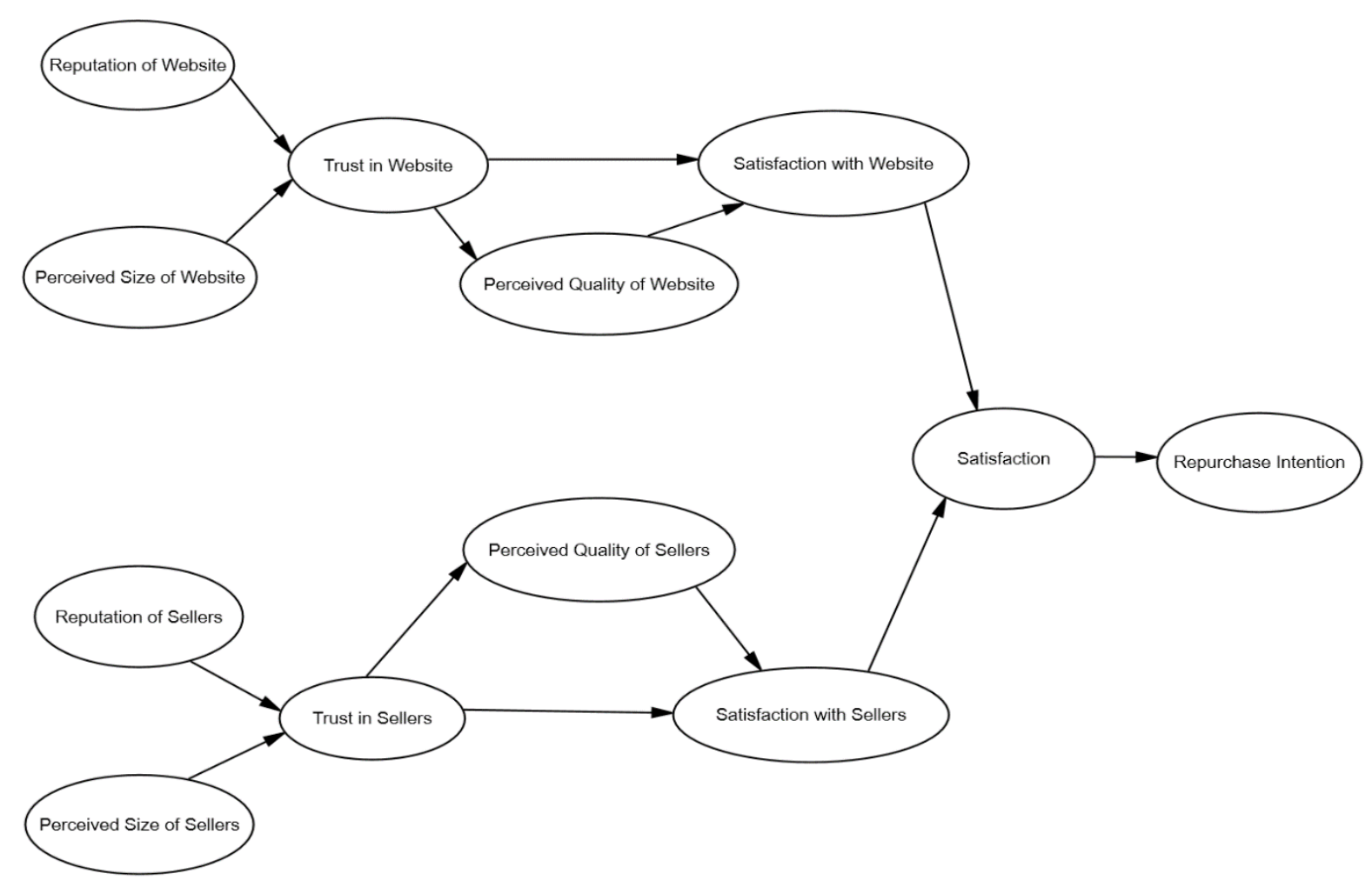

Figure 14 - Research model. Source: Author's modification of Hsu et al. (2014).

\section{DATA COLLECTION AND RESEARCH METHOD}

The purpose of this research was the identification of factors influencing customers' satisfaction with online group-buying in the Czech Republic according to DeLone \& McLean IS success model and trust.

The data were obtained in primary research, online questioning, conducted in September 2015. This method was applied because of its connection with the research concern. The population was all online group-buying customers, meaning everyone who has ever bought in online group-buying. The sample consisted of 419 respondents. The structure of the sample was equal to the structure of the customers of online group-buying websites and the control variables were frequency of online group-buying purchases, gender, age, education. The detailed structure of respondents is shown in Table 1.

Table 1 Structure of sample of respondents $(n=419)$. Source: Author's calculations.

\begin{tabular}{|l|l|l|l|l|l|}
\hline \multicolumn{2}{|l|}{ Frequency of online group-buying purchases } & Gender & \multicolumn{2}{l|}{ Age } \\
\hline Once a fortnight & $12.2 \%$ & Man & $30.3 \%$ & $18-34$ & $60.9 \%$ \\
\hline Once a month & $56.3 \%$ & Woman & $69.7 \%$ & $35-54$ & $28.6 \%$ \\
\hline Quarterly & $25.8 \%$ & Total & $100.0 \%$ & $55+$ & $10.5 \%$ \\
\hline Less often & $5.7 \%$ & & & Total & $100.0 \%$ \\
\cline { 1 - 2 } Total & $100.0 \%$ & & & & \\
\cline { 1 - 2 } & & & & &
\end{tabular}


The respondents expressed their satisfaction regarding to the statements. The statements about the factors with impact on the satisfaction with online group-buying were accepted from Hsu et al. (2014). The respondents expressed their satisfaction with factors using a Likert scale of 1 to 5 , where 1 described a positive statement and 5 described a negative statement.

The analysis was conducted in IBM SPSS 20 and IBM SPSS Amos 20. It is used the significance level of 0.05 .

\subsection{Method of analysis}

A structural equation modelling (SEM) was used to evaluate the proposed model of behaviour of Czech customers of online group-buying websites. Structural equation modelling (SEM) is a statistical method which permits to define latent indicators really appearing in such a phenomenon in which there are some latent indicators due to the respondent subjectivity. SEM is similar to the regression modelling but it is more advanced (de Oña, de Oña, Eboli, \& Mazzulla, 2013). A general structural model consists of two parts, a measurement model and a structural model (Nachtigall et al., 2003).

A measurement model identifies the relations between the observed and the latent variables. The measurement model does not infer the residual segment of the variance. The residual variance is considered as an unobserved variable (Urbánek, 2000).

A measurement model is algebraically calculated as two systems of equations in matrix form (de Oña, de Oña, Eboli, \& Mazzulla, 2013):

$$
\begin{gathered}
\vec{x}=\Lambda_{x} \vec{\xi}+\vec{\delta}, \\
\vec{y}=\Lambda_{y} \vec{\eta}+\vec{\varepsilon},
\end{gathered}
$$

where $\vec{x}$ is the vector of the indicator for the vector of unobserved variable $\vec{\xi}, \vec{y}$ identifies the vector of the indicator for the vector of unobserved variable $\vec{\eta}, \vec{\xi}$ is the vector for the unobserved exogenous variable, $\vec{\eta}$ stands for the vector for the unobserved endogenous variable, $\Lambda_{x}$ and $\Lambda_{y}$ represent the matrixes of the structural coefficients for the relations of variables' vectors $\vec{x}$ and $\vec{\xi}$ and variables $\vec{y}$ and $\vec{\delta}$ and $\vec{\varepsilon}$ and $\vec{\delta}$ constitute the vectors of residual variables for the vectors $\vec{x}$ and $\vec{y}$.

The measurement model is also created by the covariation matrixes $\Theta_{\delta}$ and $\Theta_{\varepsilon}$ of the vectors of the residual variables. These matrixes are usually diagonal and residual variables do not correlate in the model (de Oña, de Oña, Eboli, \& Mazzulla, 2013).

A structural model identifies the relations between the latent variables. This model detects which latent variable is independent (exogenous) and which latent variable is dependent (endogenous). The exogenous variable is the variable not affected by any of the independent variables, whilst the endogenous variable is affected by other variables. The structural model is algebraically calculated as (de Oña, de Oña, Eboli, \& Mazzulla, 2013):

$$
\vec{\eta}=\mathrm{B} \vec{\eta}+\Gamma \vec{\xi}+\vec{\zeta}
$$

where $\mathrm{B}$ and $\Gamma$ interpret the matrixes of the structural coefficients of the latent endogenous (exogenous) variables and $\vec{\zeta}$ represents the measurement errors. 
The validity of the proposed model can be tested with multiple chi-squared tests. CFI, NFI and Cronbach's Alpha were applied in this paper. The rate of change of a conditional mean is interpreted as a regression coefficient. Standardized regression coefficients should take values of 0.5 and higher if the relations between the variables are important (Hair et al., 2010).

The comparative fit index (CFI) can be algebraically interpreted as:

$$
C F I=\frac{P_{N}}{P_{N_{b}}},
$$

where $P_{N}$ and $P_{N_{h}}$ constitute the parameters of noncentrality for the estimated and the basic model. The CFI should be close to 1.000 for the optimal model (Urbánek, 2000).

The normed fit index (NFI) can be algebraically calculated as:

$$
N F I=1-\frac{F}{F_{b}}
$$

where $F$ is the minimum value of the loss function for the estimated model and $F_{b}$ is the value of the loss function as the minimum for the basic model (Urbánek, 2000). The NFI index should also be close to 1.000 (Hooper, Coughlan, \& Mullen, 2008).

Another used coefficient is Cronbach's Alpha which is one of the most frequently applied coefficients of reliability. It computes reliability as internal consistency. It is a measure of reliability used to evaluate the degree to which different test items that probe the same construct produce similar results. The Cronbach's Alpha can be computed as:

$$
\alpha=\frac{k}{k-1}\left(1-\frac{\sum_{i=1}^{k} \sigma_{i}^{3}}{\sigma_{t}^{3}}\right)
$$

where $k$ is the number of estimated (free) parameters, $\sigma_{i}^{2}$ stands for the variance of component $i$ for the current sample and $\sigma_{t}^{2}$ constitutes the variance of the observed total test scores. The actual value of the Cronbach s Alpha should be higher than 0.7 for each latent variable. The tested latent variable is valid if the actual value of Cronbach's Alpha of the latent variable exceeds 0.7 (Urbánek et al., 2011).

\section{MODEL ANALYSIS AND RESULTS}

The structure of the original model and the structure of the optimal model with the validation of the model are described in this part of the paper.

\subsection{Variables in the original model}

First, the original model designed according to Hsu et al. (2014) was tested for the behaviour of Czech customers. There were 86 variables in the original proposed model, these were 37 observed variables and 49 latent variables, including 37 residual variables. The residual variables were all variables e1 - e37, the other latent variables were Reputation of Website, Perceived Size of Website, Trust in Website, Perceived Quality of Website, Satisfaction with Website, Reputation of Sellers, Perceived Size of Sellers, Trust in Sellers, Perceived Quality of Sellers, Satisfaction with Sellers, Satisfaction and Repurchase Intention. 
There were 37 observed variables and these are specified below. The first latent variable „Reputation of Website “ was measured by the three observed variables. Specifically the following factors were evaluated:

RW_market the online group-buying has a good reputation in the market,

RW_wellknown the online group-buying websites are well-known group-buying websites,

RW_honest the online group-buying companies have a good reputation for being honest.

The second latent variable „Perceived Size of Website“ was measured by three observed variables. To be precise, we explored the respondents' perceptions about the following:

PSW_largecompany the online group-buying companies are very large companies,

PSW_player the online group-buying companies are big players in market,

PSW_famousfirms many famous firms sell their products in the online group-buying websites.

Another latent variable „Reputation of Sellers“ was measured by three observed variables. Specifically the following factors were evaluated:

RS_goodrep the sellers of the online group-buying have good reputations,

RS_customers the sellers of the online group-buying concerned about customers,

RS_honest the sellers of the online group-buying have a good reputation for being honest.

The fourth latent variable „Perceived Size of Sellers“ was measured by two observed variables. To be precise, we explored the customers' perceptions about the following:

PSS_large the sellers of the online group-buying are large companies,

PSS_players the sellers of the online group-buying are big players in market.

The fifth latent variable "Trust in Website“ was measured by three observed variables. Specifically the following factors were evaluated:

TW_secure I think the online group-buying websites are secure,

TW_ reliable I think the online group-buying websites are reliable,

TW_trustworthy I think the online group-buying websites are trustworthy.

The sixth latent variable „Trust in Sellers“ was also measured by three observed variables and specifically the following factors were evaluated:

TS_reliable I think the sellers of online group-buying are reliable,

TS_promises I think the sellers of online group-buying keep promises and commitments,

TS_ interestsinmind I think the sellers of online group-buying keep customers' best interest in mind.

Another latent variable „Perceived Quality of Website“ was measured by seven observed variables. To be precise, we explored the respondents' perceptions about the following:

PQW_dependable the online group-buying websites provide dependable services to me, 
PQW_prompt the online group-buying websites give me prompt services,

PQW_easyuse the online group-buying websites are easy to use,

PQW_usersfriendly the online group-buying websites are user-friendly,

PQW_sufficientinfo the online group-buying websites provide sufficient information,

PQW_preciseinfo the online group-buying websites provide precise information,

PQW_uptodateinfo the online group-buying websites provide up-to-date information.

The eighth latent variable „Perceived Quality of Sellers“ was measured by six observed variables. Specifically the following factors were evaluated:

PQS_dependable

services provided by sellers of the online group-buying are dependable,

PQS_prompt

the sellers of the online group-buying give me prompt services,

PQS_answered

the sellers of the online group-buying answered all my questions about

the product,

PQS_sufficientinfo the sellers of the online group-buying provide sufficient information,

PQS_preciseinfo the sellers of the online group-buying provide precise information,

PQS_uptodateinfo the sellers of the online group-buying provide up-to-date information.

The ninth latent variable „Satisfaction with Website“ was measured by three observed variables. To be precise, we explored the respondents' perceptions about the following:

SAW_prepurchase I am satisfied with the pre-purchase experience of the online groupbuying websites (e. g. product search, quality of information about products etc.),

SAW_purchase I am satisfied with the purchase experience of the online group-buying websites (e. g. ordering, payment procedure),

SAW_postpurchase I am satisfied with the post-purchase experience of the online groupbuying websites (e. g. after sales service, handling of returns/refunds, delivery care).

Another latent variable „Satisfaction with Sellers“ was also measured by three observed variables. To be precise, we explored the respondents' perceptions about the following:

SAS_feelgood I feel good regarding my decision to purchase products from sellers of the online group-buying,

SAS_goodidea

I think that purchasing products from sellers of the online group-buying is a good idea,

SAS_satisfied I am satisfied with the overall purchase experience of purchasing products from sellers of the online group-buying.

Another latent variable „Satisfaction“ was measured by one observed variables. To be precise, we explored the respondents' perceptions about the overall satisfaction of online group-buying purchases (SAS_satisfied).

Last latent variable „Repurchase Intention“ was measured by three observed variables and specifically the following factors were evaluated:

RPI_wouldlike if I could, I would like to continue using the online group-buying websites to purchase products and services,

RPI_plan I plan to continue using the online group-buying websites to purchase products and services in the future, 
RPI_likely it is likely I will continue purchasing products and services from the online group-buying websites in the future.

\subsection{Validity of the original model}

According to data analysis in SPSS Amos 20 the original model is not optimal for describing behaviour of Czech customers of online group-buying websites. The number of variables had to be reduced in order to optimise the model. It means that statistically unreliable and insignificant variables were excluded from the model. These were all observed variables creating the latent variable Reputation of Website and Reputation of Sellers, all observed variables creating the latent variable Perceived Size of Sellers, Trust in Sellers and Perceived Quality of Sellers as well as all observed variables creating the latent variable Satisfaction with Sellers. It can be considered that these factors are not significantly important for Czech customers' satisfaction.

\subsection{Variables in the optimal model}

There are 20 observed variables and 26 latent variables, including 20 residual variables in the optimal model. The following Tab. 1 shows the variables in the tested model. The residual variables were all variables e1 - e20, the other latent variables were Perceived Size of Website, Trust in Website, Perceived Quality of Website, Satisfaction with Website, Satisfaction and Repurchase Intention. The observed variables creating these latent variables are described above.

\subsection{Validity of the optimal model}

The validity of the designed model was conducted according to significance level and standardised regression coefficients in the measurement model, structural model and also the Goodness-of-Fit Indexes were calculated. Figure 2 shows relations between variables in the measurement model according (1) and (2) and relations between variables in the structural model according (3). 


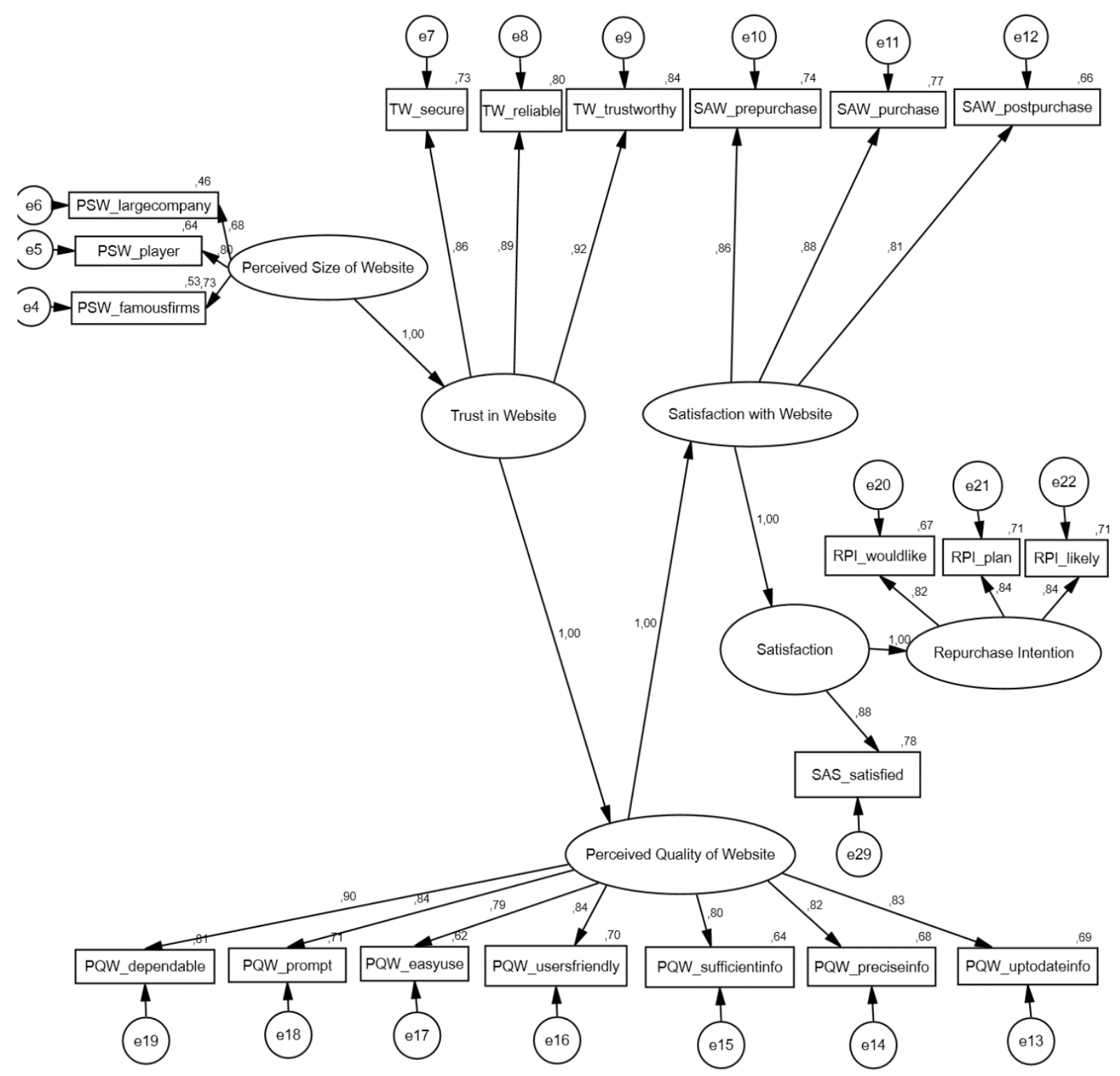

Figure 2 - Standardised regression coefficients of the measurement and the structural model. Source: Author's calculations.

Validity of measurement model

Table 2 shows the values of standardized regression coefficients in the measurement model. 
Table 2 The actual values of standardised regression coefficients in the measurement model. Source: Author's calculations.

\begin{tabular}{|c|c|c|c|}
\hline Latent variable & Observed variable & Significance & $\begin{array}{l}\text { Standardised regression } \\
\text { coefficients }\end{array}$ \\
\hline \multirow{3}{*}{$\begin{array}{l}\text { Perceived Size of } \\
\text { Website }\end{array}$} & PSW_famousfirms & 0.000 & 0.727 \\
\hline & PSW_player & 0.000 & 0.803 \\
\hline & PSW_largecompany & 0.000 & 0.675 \\
\hline \multirow{7}{*}{$\begin{array}{l}\text { Perceived Quality of } \\
\text { Website }\end{array}$} & PQW_easyuse & 0.000 & 0.788 \\
\hline & PQW_prompt & 0.000 & 0.845 \\
\hline & PQW_dependable & 0.000 & 0.901 \\
\hline & PQW_usersfriendly & 0.000 & 0.835 \\
\hline & PQW_sufficientinfo & 0.000 & 0.799 \\
\hline & PQW_preciseinfo & 0.000 & 0.822 \\
\hline & PQW_uptodateinfo & 0.000 & 0.829 \\
\hline \multirow{3}{*}{ Repurchase Intention } & RPI_wouldlike & 0.000 & 0.820 \\
\hline & RPI_plan & 0.000 & 0.840 \\
\hline & RPI_likely & 0.000 & 0.841 \\
\hline Satisfaction & SAS_satisfied & 0.000 & 0.882 \\
\hline \multirow{3}{*}{ Trust in Website } & TW_secure & 0.000 & 0.857 \\
\hline & TW_reliable & 0.000 & 0.895 \\
\hline & TW_trustworthy & 0.000 & 0.917 \\
\hline \multirow{3}{*}{$\begin{array}{l}\text { Satisfaction with } \\
\text { Website }\end{array}$} & SAW_prepurchase & 0.000 & 0.862 \\
\hline & SAW_purchase & 0.000 & 0.877 \\
\hline & SAW_postpurchase & 0.000 & 0.814 \\
\hline
\end{tabular}

All observed variables in the measurement model are statistically reliable at the significance level of 0.05 ; see Table 2 .

Considering 0.5 as the minimum value for a significant relation between variables, all the tested variables are significant. The actual value of standardized regression coefficient of 
variable PSW_largecompany, measuring the latent construct Perceived Size of Website, show the relation is moderate. The impact of observed variable on latent variable is moderate.

The most of the observed variables are the variables with strong relations to their latent variables. Their actual values of standardized regression coefficients are higher than 0.7 but lower than 0.9 and these are variables PSW_famousfirms, PSW_player measuring the latent variable Perceived Size of Website, as well as all the variables of the latent variable Perceived Quality of Website except the variable PQW_dependable and all the variables of the latent variable Trust in Website except the variable TW_trustworthy. The strong relation was found also between the latent construct Repurchase Intention and all of its observed variables, as well as between the latent construct Satisfaction with Website and all of its observed variables.

It was found that the observed variables I think the online group-buying websites are trustworthy (TW_ trustworthy) and the online group-buying websites provide dependable services to me (PQW_dependable) have the very strong relation with their latent variables, Trust in Website and Perceived Quality of Website respectively. Their actual values of standardized regression coefficients are higher than 0.9 .

Validity of the structural model

The relations between latent endogenous and latent exogenous variables were tested in the structural model. The following Table 3 shows the actual values of the standardised regression coefficients in the structural model.

Table 3 The actual values of standardised regression coefficients in the structural model. Source: Author's calculations.

\begin{tabular}{|l|l|l|l|}
\hline $\begin{array}{l}\text { Latent endogenous } \\
\text { variable }\end{array}$ & Latent exogenous variable & Significance & $\begin{array}{l}\text { Standardised regression } \\
\text { coefficients }\end{array}$ \\
\hline Trust in Website & Perceived Size of Website & 0.000 & 1.000 \\
\hline $\begin{array}{l}\text { Perceived Quality } \\
\text { of Website }\end{array}$ & Trust in Website & 0.000 & 1.000 \\
\hline $\begin{array}{l}\text { Satisfaction with } \\
\text { Website }\end{array}$ & $\begin{array}{l}\text { Perceived Quality of } \\
\text { Website }\end{array}$ & 0.000 & 1.000 \\
\hline Satisfaction & Satisfaction with Website & 0.000 & 1.000 \\
\hline $\begin{array}{l}\text { Repurchase } \\
\text { Intention }\end{array}$ & Satisfaction & 0.000 & 1.000 \\
\hline
\end{tabular}

If we consider the significance level of 0.05 , the relations between the all latent exogenous variables and their latent endogenous variables are statistically reliable. The Repurchase Intention of customers is affected by overall satisfaction and their overall satisfaction is affected the most with the Satisfaction with Website. The indicator of the Satisfaction with Website is the Perceived Quality of Website and its predictor is the Trust in Website. The Preceived Size of Website is the predictor of the Trust in Website.

Goodness-of-fit indexes of the optimal model

The comparative fit index (CFI) and normed fit index (NFI) were applied to validate the model. The internal consistency as reliability for each latent variable was measured by the 
Cronbach's Alpha. The actual values of the indexes is presented in Table 4. The CFI was calculated as (4), the NFI was calculated as (5) and Cronbach's Alpha was calculated as (6).

Table 4 The actual values of standardised regression coefficients in the structural model. Source: Author's calculations.

\begin{tabular}{|l|l|l|}
\hline Model & CFI & NFI \\
\hline Default model & 0.990 & 0.931 \\
\hline
\end{tabular}

The CFI index of the tested model takes the value of 0.990 . This is a very high value, because it is close to the recommended value of 1.00. In addition, the NFI index, which takes the value of 0.931 , shows that the model can be improved only minimally. According to the NFI index, the proposed model fits the real data with $93 \%$. All applied indexes confirmed that this model is optimal.

The actual values of Cronbach's Alpha for each latent variable are shown in Table 5. The Cronbach's Alpha for the latent variable Satisfaction was not possible to calculate because this latent variable is measured only by one observed variable.

Table 5 The actual values of Cronbach's Alpha for each latent variable. Source: Author's calculations.

\begin{tabular}{|l|l|l|}
\hline Latent variable & Cronbach's Alpha & N of items \\
\hline Perceived Size of Website & 0.790 & 3 \\
\hline Trust in Website & 0.942 & 3 \\
\hline Perceived Quality of Website & 0.950 & 7 \\
\hline Satisfaction with Website & 0.899 & 3 \\
\hline Repurchase Intention & 0.956 & 3 \\
\hline
\end{tabular}

It was found each actual value of Cronbach's Alpha for each latent variable is higher than 0.7 therefore all latent variables are valid. It is possible to determine this model is valid.

\subsection{Discussion and managerial implication}

According to the data analysis the dual role of customers, meaning a role of buyer and a role of website user, was not confirmed. The overall satisfaction of customers is not influenced by satisfaction with sellers whereas it is influenced by satisfaction with website. The results show that the Czech customers carefully separate the online group-buying providers and sellers of online group-buying websites. We can also expect that dissatisfaction with a seller does not mean the dissatisfaction with online group-buying provider.

The results also confirmed the results of prior studies, such as Pawlasová (2015) and Shiau and Luo (2012), the trust is a very important factor. In this case, the trust in website is very important for the Czech customers. The customers have to think that the online group-buying websites are trustworthy, meaning these websites have to have trustworthy impression and design. That is why online group-buying providers should increase buyers' trust in this method of purchasing and their websites. It is possible to recommend money refunds if there is a problem with the service, insurance of vouchers or withdrawing from the contract after a longer period than 14 days. The providers also can involve security gates for payment, 
certificates of quality, secure certificates and they also can be members of associations of online group-buying. All of this possible information have to be clearly and visibly shown on the online group-buying websites.

The results also confirmed the results of prior studies, such as Pawlasová (2015), the Czech customers do not perceived the reputation as important factor affecting their satisfaction. The Czech customers do not think about the reputation about sellers on online group-buying websites or about the reputation of online group-buying websites. The reason of this can be a dominant positive image of Czech online group-buying providers.

The perceived size of website can be connected with the image of online group-buying providers. The Czech customers want to have an impression that these are large companies, big players on the market and these are famous firms. The management of online groupbuying should create an image in this sense.

The Czech customers overall satisfaction with online group-buying is influenced the most by the variable Satisfaction with Website. It means that managers of online group-buying websites should take care about pre-purchase experience of the online group-buying websites, such as product search, quality of information about products etc., they also should take care about purchase experience of the online group-buying websites, such as ordering or payment procedure and also about the post-purchase experience of the online group-buying websites (e. g. after sales service, handling of returns/refunds or delivery care).

The predictor of this satisfaction with website is perceived quality of website. The online group-buying websites should give the customers prompt services, the website should be also easy to use, be user-friendly and provide sufficient, precise and up-to-date information. The online group-buying website also have to provide dependable services to customers. The management of online group-buying websites should keep in mind these factors.

\section{CONCLUSION}

This contribution discusses the factors affecting the Czech customers' satisfaction with online group-buying purchases. The overall satisfaction is considered as one of the predictors of customers repurchases intention in this paper. DeLone \& McLean IS success model and trust was used to identify these factors. The contribution also explores the dual role of customers the buyer and the website user. Therefore the overall satisfaction is affected with satisfaction with sellers and satisfaction with website.

The aim of this research is to identify the factors affecting customers' satisfaction with online group-buying in the Czech Republic. This paper includes the theoretical background of online group-buying as well as DeLone \& McLean IS success model and trust, which is the base of the proposed model. A structural equation modelling was applied to find the optimal model with the most significant indicators. The theoretical background of this method is also the part of this contribution. The analysed data came from the primary research, conducted by the online questioning. Goodness-of-fit indexes, specifically CFI and NFI, and Cronbach's Alpha were applied to validate the proposed model.

The optimal model of the Czech customers' behaviour was determined. The customers' satisfaction with online group-buying is affected the most by the variable satisfaction with website. The perceived size, trust in website and the perceived quality of website are the predictors affecting the customers' satisfaction with website. The results confirmed that satisfaction with sellers is not statistically significant for the Czech online group-buying customers. Also the reputation, specifically the reputation of sellers and the reputation of website, is not statistically significant. 


\section{Acknowledgements}

This contribution was created within the project SGS An Intergenerational Comparison of Consumer Behaviour in the International Context, project registration number SP2016/106 and was supported within Operational Programme Education for Competitiveness - Project No. CZ.1.07/2.3.00/20.0296.

\section{References}

Anderson, E. W., Fornell, C., \& Lehmann, D. R. (1994). Customer satisfaction, market share and profitability: Findings from Sweden. Journal of Marketing, 58(3), 53-66. https://doi.org/10.2307/1252310

Aktepe, A. et al. (2015). Customer satisfaction and loyalty analysis with classification algorithms and Structural Equation Modeling. Computers \& Industrial Engineering, 86: 95-106. https://doi.org/10.1016/j.cie.2014.09.031

de Oña, J., de Oña, R., Eboli, L., \& Mazzulla, G. (2013). Perceived service quality in bus transit service: A structural equation approach. Transport Policy, 29219-226. https://doi.org/10.1016/j.tranpol.2013.07.001

DeLone, W. H. \& McLean, E. R. (2003). The DeLone and McLean model of information systems success: A ten-year update. Journal of Management Information Systems, 19(4), 9-30. https://doi.org/10.1080/07421222.2003.11045748

Erdogmus, I. E. \& Çicek, M. (2011). Online Group Buying: What Is There For the Consumers?. Procedia - Social and Behavioral Sciences. Kidlington: Elsevier Science, 24: 308-316.

Gupta, S., \& Kim, H. W. (2007). The moderating effect of transaction experience on the decision calculus in on-line purchase. International Journal of Electronic Commerce, 12(1), 127-158. https://doi.org/10.2753/JEC1086-4415120105

Hair, J. F. et al. (2010). Multivariate Data Analysis (7th ed.). Upper Saddle River, New Jersey: Prentice Hall.

Hooper, D., Coughlan, J., \& Mullen, M. R. (2008). Structural Equation Modelling: Guidelines for Determining Model Fit. Electronic Journal Of Business Research Methods, 6(1), 53-59.

Hsu, M.-H. et al. (2014). Determinants of repurchase intention in online group-buying: The perspectives of DeLone \& McLean IS success model and trust. Computers in Human Behavior, 36: 234-245. https://doi.org/10.1016/j.chb.2014.03.065

Jang, H. et al. (2013). The Effect of Group-Buy Social Commerce and Coupon on Satisfaction and Continuance Intention -- Focusing on the Expectation Confirmation Model (ECM). In: 46th Hawaii International Conference on System Sciences (HICSS). Wailea, HI, USA, 7 - 10 January 2013, 2938-2948. https://doi.org/10.1109/HICSS.2013.516

Kim, H. W., Xu, Y., \& Koh, J. (2004). A comparison of online trust building factors between potential customers and repeat customers. Journal of the Association for Infrormation Systems, 5(10), 392-420. https://doi.org/10.17705/1jais.00056

Lin, H. H., \& Wang, Y. S. (2006). An examination of the determinants of customer loyalty in mobile commerce contests. Information \& Management, 43, 271-282. https://doi.org/10.1016/j.im.2005.08.001

Michl, P. (2013). Infografika: Slevové portály si vedou rok od roku lépe [online]. Marketing journal. Focus Agency, s.r.o., (C) 2004-2013. [accessed 2014-12-10]. Available at: http://www.m-journal.cz/cs/aktuality/Infografika:-Slevove-portaly-si-vedou-rok-odroku-lepe_s288x9729.html 
Nachtigall, C. et al. (2003). (Why) Should We Use SEM? Pros and Cons of Structural Equation Modelling. Methods of Psychological Research Online, 8(2), 1-22. Retrieved from Deutsche Gesellschaft für Psychologie e.V., DGPs. Retrieved from http://www.dgps.de/fachgruppen/methoden/mpr-online/issue20/art1/mpr127_11.pdf

Otim, S., \& Grover, V. (2006). An empirical study on web-based services and customer loyalty. European Journal of Information Systems, 15(6), 527-541. https://doi.org/10.1057/palgrave.ejis.3000652

Pawlasová, P. (2015). Factors affecting users' satisfaction with online group buying: A social exchange theory approach. Central European Review of Economic Issues Ekonomická Revue, 18(2), 97-107. doi: 10.7327/cerei.2015.06.03

Pilík, M. (2012). On-line Shopping on B2C Markets in the Czech Republic. Journal of Competitiveness, 4(4): 36-49. https://doi.org/10.7441/joc.2012.04.03

Qureshi, I. et al. (2009). Understanding online customer repurchasing intention and the mediating role of trust - An empirical investigation in two developed countries. European Journal of Information Systems, 18(3), 205-222. https://doi.org/10.1057/ejis.2009.15

Shiau, W., \& Luo, M. M. (2012). Factors affecting online group buying intention and satisfaction: A social exchange theory perspective. Computers In Human Behavior, 28(6), 2431-2444. https://doi.org/10.1016/j.chb.2012.07.030

Turban, E. et al. (2015). Social Commerce: Marketing, Technology and Management. Cham: Springer International Publishing.

Urbánek, T. et al. (2011). Psychometrika: Měrení v psychologii. Praha: Portál.

Urbánek, T. (2000). Strukturální modelování v psychologii. Brno: Psychologický ústav AV ČR a Nakladatelství Pavel Křepela.

Weinstein, A. (2000). Customer satisfaction among transit riders: How customers rank the relative importance of various service attributes. Transportation Research Record, 1735, 123-132. https://doi.org/10.3141/1735-15

Zamazalová, M. (2009). Marketing obchodni firmy. Praha: Grada.

\section{Contact information}

Pavlína Pawlasová

VŠB - Technical University of Ostrava, Faculty of Economics

Sokolská tř́́da 33, Ostrava, 72101

Telephone: +420 597322445

Email: pavlina.pawlasova@vsb.cz

DOI: https://www.doi.org/10.7441/dokbat.2016.29 


\title{
BEHAVIORAL ASPECTS IN RESIDENTIAL ENERGY USE
}

\author{
Viera Pechancová
}

\begin{abstract}
Residential energy use is a field, which calls for a dynamic theoretical and analytical approach. Bearing in mind the instant technological innovations, the decision models in the energy use need to be designed in holistic way. As the energy consumption is influenced also by non-technical and non-economic factors, sustainable energy use is expected to include behavioral aspects as well.

The aim of this article is to provide insight into theoretical concepts in behavioral research especially in residential energy use. Behavioral aspects relevant for the energy use are detected and the main emphasis is given to the prospect theory. Energy efficiency is explained and analysed in broader perspective. This paper shows that following the complexity of relationships in energy field the behavioral economics has a good potential to be more influential in the future of the energy.
\end{abstract}

Keywords: residential energy use, energy efficiency, prospect theory

\section{INTRODUCTION}

After 1970s energy crises scientific considerations about energy consumption began to gain more importance. Intensive discussions about security of supply, natural resources and efficiency related issues appeared subsequently. The energy use and energy efficiency were firstly concentrated on technical improvements of equipment. With rising importance of environmental issues and sustainability aspects, energy use demanded more complex view.

To be able to provide holistic approach to the energy use research, the „classic“ economic model of general-equilibrium needs to be behavioralised. Within the neoclassical synthesis, it is based upon profit maximization by firms and utility maximization by consumers. Behavioral economics tries to clarify some phenomena, which cannot be explained by classic utility theory in microeconomics.

The combination of behavioral research and energy use originates in the thought that even the technical world of energy is influenced by non-technical and non-economic factors overreaching up to the fields of psychology. Generally speaking, the price is not the only motivation in case of reduced energy consumption.

In particular, weather, buildings and technical parameters of devices are researched by meteorology, physics, and engineering. Consumer behavior related to purchase of energy devices and how the devices are used is studied by theories in economics, sociology, psychology and anthropology.

Moezzi et al (2010) identified four basic residential energy use dimensions, which represent broad theoretical and practical applications. Engineering focuses on characteristics of buildings and technology. Economics studies price signals and considers the consumers from the perspective of maximizing utility. Psychology then concentrates on individual consumption choices and hence conservation behavior. Finally, social studies and anthropology as opposed to individual considerations, reflect variability and patterns of consumption within cultures and social systems. 
Following the broad perspectives in energy use research, the article analyses the behavioral considerations of energy consumption. Beginning with introduction to behavioral finance, principles of prospect theory are explained. Energy efficiency is then further elaborated and relevant research areas identified. Behavioral biases in energy use and implications for energy policy interventions are summarized in conclusion.

\section{BEHAVIORAL FINANCE}

Observed behavior and application of psychologogy into finance is reflected in the behavioral finance: "Behavioral finance is the study of how psychology impacts financial decisions in households, markets and organizations." (De Bondt et al 2008). At the microeconomic level, individual decision biases on the contrary to the rational investor choice need to be included. In macroeconomics, the deviations from efficient market hypothesis assigned to the assymetric information in markets are to be reflected.

The basic theoretical concept in behavioral finance is the Prospect Theory (PT) (Kahneman \& Tversky, 1979; Tversky \& Kahneman, 1992). Originally, it was developed as a critique of expected utility theory. One of the main principles within the theory is bounded rationality as consumer decisions are not always perfectly rational and behavioral failures occur. The energy consumption decisions are thereby not an exception.

The PT is based on value function (lower positive effect from a gain in an investment than the harm felt from a similar loss), weighting function (tendency for individuals to overweight low probability outcomes and underweight high probability outcomes) and the concept of reference point (usually status quo situation). Further, the PT postulates heuristics and loss aversion.

The framework for PT includes also specific behavioral effects and biases. The effects include representativeness and availability (judging probability of an event by stereotypes and neglecting Bayes rule of probabilities) and anchoring (estimates compared to the initial value). Further biases include framing and mental accounting: categorizing financial decisions and evaluating thus separate accounts instead of overall portfolio performance (Perren et al 2015).

Agency theory (Ross 1973, Mitnick 1973, Fama 1998 and others) might be applicable to solving energy using problems as well. The agency theory is relevant for the situations where one party (the principal) delegates authority - in terms of control and decision-making- to another party (the agent). The principle of ownership and control separation in the field of energy research is highly relevant. Number of case studies were perfomed to detect agency problems, such as information assymetry and moral hazard in energy efficiency (International Energy Agency, 2007).

\section{ENERGY EFFICIENCY AND ENERGY CONSUMPTION}

In the field of energy consumption the energy efficiency is being intesively studied. Thorough search in the academic databases revealed there is an increasing amount of literature related to the topic, including empirical research and field studies.

Quantification of the energy efficiency field is rooted in physics and in wider perspective in classical economics. Energy efficiency is generally defined as using less energy input to produce certain amount of output. The energy efficiency formula is broadly defined by following straight forward ratio (Patterson, 1996): 


\section{Useful output \\ Energy input}

Reducing energy consumption is often related to increased efficiency. However, more efficient does not mean lower energy use and similarly, emissions reduction is different to increased efficiency. Energy conservation in form of reduced energy consumption is influenced by regulation, consumer behaviour and lifestyle. Examples include turning off lights, reducing device usage or unplugging appliances. Energy efficiency on the other hand, is more of a technical process when old equipment is replaced by newer one (Herring, 2006). It includes purchasing energy-efficient equipment or products (e.g., compact fluorescent light bulbs) or investing in structural or building envelope changes (Karlin et al., 2014). It is worth to mention that increased levels of both energy efficiency and energy consumption have been evidenced in the research (Herring, 2006).

Energy efficiency gap represents a key concept for behavioral contribution to the economic and technical analyses. According to Jaffe \& Stavins (1994a),,an energy efficiency gap exists between current or expected future energy use, on the one hand, and optimal current or future energy use, on the other hand". The explanation for under-investment in energy efficiency might be found in the lack of information, financial lack, incentives ineffectiveness or market barriers.

In relation to the efficiency, the rebound effect was identified. The behavioral response in case of higher achieved efficiency is connected to higher energy consumption and thus to certain decrease in the real efficiency. It is though relatively complicated to measure such counter-effect and due to lack of data only occasional studies were perfomed. Greening et al (2000) conclude that although the rebound effect is not insignificant, the efficiency measures should overweight this effect.

Behavioral theory can further contribute to the explaination of the energy paradox. This paradox states only gradual diffusion of convenient and cost effective energy saving technologies. The reasoning is explained by market failures and principal/agent causality. Non-market failures such as information cost and heterogenity of users were identified as well (Jaffe \& Stavins, 1994b).

\section{REVIEW OF BEHAVIORAL RESEARCH IN ENERGY USE}

Within the behavioral model of energy use, van Raaij (Van Raaij \& Verhallen, 1983) identified several categories of variables influencing energy use. The energy-related household behavior, energy-related attitudes, home characteristics, sociodemographic and personality variables, energy prices and feedback information about energy use were closely analysed.

A psychological model of energy use introduced by Stern (1992) contributed to the reasoning why some policy measures for energy conservation are not successful in implementation. Energy conservation programs examined by psychological research revealed the importance of framing of information in energy policy. Further, behaviorally interconnected topics included commitment to cut energy consumption, intentions to install energy saving appliances or belief that households can help with national energy problem.

Lutzenhiser (1993) in his review article "Social and Behavioral Aspects of Energy Use scrutinized the dominating physical-technical-economic model (PTEM) of energy consumption. Micro-behavioral studies and macro-social organization of energy use in energy demand forecasting and policy planning were considered as important. 
Bin et al (2005) proposed a concept of lifestyle in relation to personal energy consumption. The framework includes a consumer-oriented integrated assessment for analysis of energy use and $\mathrm{CO}^{2}$ emissions (the Consumer Lifestyle Approach). External environment, individual determinants, household characteristics, consumer choices and consequencies were considered there.

Interdisciplinary intervention policies were reviewed by Wilson et al (2007). The decision theories in residential energy use are based on neoclassical and behavioral economics, technology adoption theory and attitude-based decision making, social and environmental psychology and sociology.

Dietz et al. (2009) proposed a specific categorization of energy conservation behavior. The major categories are desribed as WEMAD (Weatherization, Equipment, Maintenance, Adjustments, and Daily behavior). Weatherization and equipment both involve adoption of equipment, adjustments and daily behavior both involve changes in equipment usage. According to the research, national implementation of behaviorally targeted policies could save $20 \%$ of household direct emissions within 10 years with little or no reduction in household well-being.

\section{BEHAVIORAL BIASES APPLICABLE TO RESIDENTIAL ENERGY USE}

Residential energy use is affected by overall consumer behavior as well as by specific aspects related to the character of energy commodity. The energy demand can be described as indirect, depending on lifestlyle and reflecting longterm household values, beliefs or environmental concerns. Domestic energy use is largely invisible to the consumers, behavior is thus governed by unconscious, habitual actions. Also, energy use is rarely individual, rather collective.

As argued by Allcott (2010), the price and information relevant for traditional economic models can be updated by inclusion of behavioral aspect serving thus as more complex model than strictly rational choice. Energy use decisions are matter of bias, influencing thus the energy efficiency. The challenge is to detect individual biases and introduce effective interventions reflecting those findings. Individual decision biases in energy use are grouped and further scrutinized in detail: framing, bounded rationality, pro-environmental behavior, time inconsistency and incentives (Houde et al, 2011).

The basic theoretical finding of framing of decisions reveals that preferencies are not independent. On the contrary, it is important to know how the information, situation or product is presented. Related loss aversion preference documents that people dislike losses much more than they like gains. As people concentrate more on loss than potential gain, it is more effective to stress the loss in energy (and money) when not replacing some old energy device, than to appeal for money saving (see Fig. 1). As people tend to make comparison relative to a reference point (status quo or average energy consumption), optimal benchmark in residential energy consumption should be defined. 


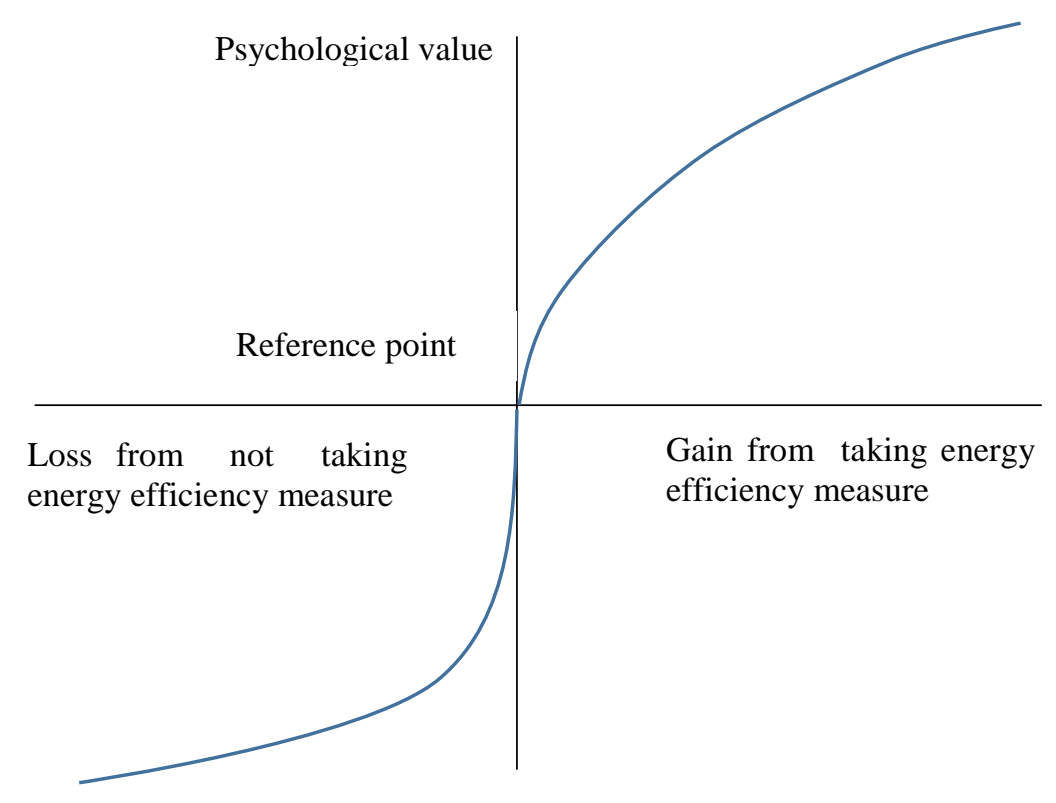

Fig. 1 Value function of losses and gaines in energy saving programmes applied from (Kahneman \& Tversky, 1979)

Bounded rationality in energy use decisions can be seen as supplier choice overload. The consumers do not benefit from the massive supply tarrifs variability in the liberalised energy market. Similarly, too many information on possibilities for energy saving can lead to suboptimal decisions. On the other hand, most consumers only hardly estimate the energy use for different purposes. Hence, in case adequate information feedback on consumption is available (using of smart meters), consumers tend to change their energy behaviors. Feedback on consumption is therefore important for energy savings (Darby, 2006).

Pro-social behavior is in case of energy use reflected directy into the pro-environmental behavior. Lifestyle, social norms and society opinion build important basis for environmental action. The information about comparison to neighbours has positive effect on the own action of energy conservation (Nolan et al 2008).

Time inconsistency and intertemporal choice reflect tradeoff decisions among costs and benefits within different time horizons (Shane et al 2002). Buying an energy saving device and discounting future savings are often not optimally analysed. Procrastination plays then a special role in decision making process - individuals do not make decisions in a time-consistent manner using a constant discount (thermostat regulation in buildings or capital investments in energy saving technologies).

\section{POLICY IMPLICATIONS FOR COMMUNITY ENERGY INICIATIVES}

Communities and social networks might have a higher positive impact on behavior change than individually aimed policies. The above mentioned individual biases can be therefore transformed into effective regional iniciatives. Public institutions such as regional energy agencies can develop effective measures and tools to enhance sustainable energy policy. The basic „trilemma of energy security, sustainable development and cost effectiveness“ can be transformed to economy, ecology and effectiveness (Wang \& Poh, 2014). Within each of these elements, fields of behavioral applications can be detected. 
The British Psychological Society set a behavioral research group and identified segmentation groups of potential energy saving program: „Monitor Enthusiasts“," the Aspiring Energy Savers“ and ,the Energy Non-Engaged“. Individual behavior change has been adressed and reflects climate change urgency. The appeal to energy conservation represents a part of governmental programme.

Another challenge is to support local energy sourcing and energy decentralisation. New promising technologies allow to use flexible sources (fuel cells, micro cogeneration). Trends in local district heating show new possibilies for renewable sourcing as well (i.e. solar energy storage systems). Also waste separation, waste-to-energy and recycling need to be supported not only by financial motives.

There are successful best practice examples of innovative energy sourcing in municipalities (Kněžice village in the Czech Republic), operating with biogas stations, using biodegradable waste from village and closed energy cycle producing publicly available electricity and heat for the local consumption. Generally, energy independency by off-grid energy sourcing for public institutions is desirable.

In the study by Masini \& Menichetti (2012) the behavioral considerations were examined in regard to the decisions made by investors of renewable energy sources as a tool for low carbon economy. Investors aversion to technological and financial risk associated with investments in the renewable technologies were related to social acceptance of renewable innovations.

Detailed research of behavioral insights into regional energy initiatives might contribute to targeted energy policies. It is desirable to find common interaction points and possible scope of relevancy to the field of energy consumption planning at three levels: household, company and municipality. Behavioral motivation might be more effective for certain consumer groups. Potential research topics include then behavioral ways to cut energy consumption and $\mathrm{CO}^{2}$ emissions. The role of energy taxes and regulation is to be considered in detail.

\section{CONCLUSION}

From the increasing amount of literature within the behavioral economics it is obvious that environmental aspects of energy use need more behavioral backround. The basic question is then, to which extent we want to understand and follow the non-financial and non-technical aspects in the future.

Individual decision biases might be helpful in search for behavior change regarding energy conservation and $\mathrm{CO} 2$ mitigation. Adequate framing of energy information contributes to energy efficiency increase and to better energy policy implementation in residential, commercial and regional energy consumption. Promotion of pro-environmental behavior needs to be supported by complexly determined combination of social and psychological factors.

The exlanatory power of the psychological and sociological concepts shows promising research area in sustainable energy use and adoption of new energy technologies. To conclude, targeted policy programs on state level as well as regional interventions and incentives need to be examined in terms of implementation effectivity. 


\section{References}

Allcott, H., \& Mullainathan, S. (2010). Behavior and Energy Policy. Science, 1204-1205. https://doi.org/10.1126/science.1180775

Bin, S., \& Dowlatabadi, H. (2005). Consumer lifestyle approach to US energy use and the related CO2 emissions. Energy Policy, 33(2), 197-208. https://doi.org/10.1016/S0301-4215(03)00210-6

Darby, S. (2006). The effectiveness of feedback on energy consumption. A Review for DEFRA of the Literature on Metering, Billing and Direct Displays, 486, 2006.

De Bondt, W., Muradoglu, G., Shefrin, H., \& Staikouras, S. K. (2008). Behavioral Finance: Quo Vadis? Journal of Applied Finance, 18(2), 7-21.

Dietz, T., Gardner, G. T., Gilligan, J., Stern, P. C., \& Vandenbergh, M. P. (2009). Household actions can provide a behavioral wedge to rapidly reduce US carbon emissions. Proceedings of the National Academy of Sciences, 106(44), 18452-18456. https://doi.org/10.1073/pnas.0908738106

Fama, E. F. (1998). Market efficiency, long-term returns, and behavioral finance1. Journal of Financial Economics, 49(3), 283-306. https://doi.org/10.1016/S0304405X(98)00026-9

Greening, L., A., Greene, D. L., \& Difiglio, C. (2000). Energy efficiency and consumption the rebound effect - a survey. Energy Policy, 28(6-7), 389-401. https://doi.org/10.1016/S0301-4215(00)00021-5

Herring, H. (2006). Energy efficiency - a critical view. The Second Biennial International Workshop 'Advances in Energy Studies', 31(1), 10-20. https://doi.org/10.1016/j.energy.2004.04.055

Houde, Sebastien, \& Todd, Annika. (2011). List of Behavioral Economics Principles that can Inform Energy $\quad$ Policy. $\quad$ Retrieved from http://www.annikatodd.com/Annika_Todd_Behav

International Energy Agency. (2007). Mind the Gap.

Jaffe, A. B., \& Stavins, R. N. (1994a). Markets for energy efficiencyThe energy-efficiency gap What does it mean? Energy Policy, 22(10), 804-810. https://doi.org/10.1016/0301-4215(94)90138-4

Jaffe, A. B., \& Stavins, R. N. (1994b). The energy paradox and the diffusion of conservation technology. Resource and Energy Economics, 16(2), 91-122. https://doi.org/10.1016/0928-7655(94)90001-9

Kahneman, D., \& Tversky, A. (1979). PROSPECT THEORY: AN ANALYSIS OF DECISION UNDER RISK. Econometrica (pre-1986), 47(2), 263.

Karlin, B., Davis, N., Sanguinetti, A., Gamble, K., Kirkby, D., \& Stokols, D. (2014). Dimensions of conservation exploring differences among energy behaviors. Environment and Behavior, 46(4), 423-452.

Lutzenhiser, L. (1993). Social and behavioral aspects of energy use. Annual Review of Energy and the Environment, 18(1), 247-289.

Masini, A., \& Menichetti, E. (2012). The impact of behavioural factors in the renewable energy investment decision making process: Conceptual framework and empirical findings. Strategic Choices for Renewable Energy Investment, 40, 28-38. https://doi.org/10.1016/j.enpol.2010.06.062

Mitnick, B. (1973). Fiduciary rationality and public policy: the theory of agency and some consequences.

Moezzi, M., \& Lutzenhiser, L. (2010). What's Missing in Theories of the Residential Energy User. Presented at the ACEEE Summer Study on Energy Efficiency in Buildings. 
Patterson, M. G. (1996). What is energy efficiency?: Concepts, indicators and methodological issues. Energy Policy, 24(5), 377-390. https://doi.org/10.1016/0301-4215(96)00017-1

Perren, M., Faseruk, A., \& Cooper, T. (2015). Making Sense of Behavioral Finance. The Journal of Business Diversity, 15(1), 14-22.

Ross, S. A. (1973). The Economic Theory of Agency: The Principal's Problem. The American Economic Review, 63(2), 134-139.

Shane, F., Loewenstein, G., \& O'Donoghue, T. (2002). Time discounting and time preference: A critical review. Journal of Economic Literature, 40(2), 351-401.

Stern, Paul. (1992). What psychology knows about energy conservation. American Psychologist. https://doi.org/47:1224-32

Tversky, A., \& Kahneman, D. (1992). Advances in Prospect Theory: Cumulative Representation of Uncertainty. Journal of Risk and Uncertainty, 5(4), 297-323.

Van Raaij, W. F., \& Verhallen, T. M. M. (1983). A behavioral model of residential energy use. Journal of Economic Psychology, 3(1), 39-63. https://doi.org/10.1016/01674870(83)90057-0

Wang, Q., \& Poh, K. L. (2014). A survey of integrated decision analysis in energy and environmental modeling. Energy, 77, 691-702. https://doi.org/10.1016/j.energy.2014.09.060

\section{Contact information}

Viera Pechancová

Tomas Bata University in Zlín

Faculty of Management and Economics

Mostní 5139, 76001 Zlín

Email:pechancova@fame.utb.cz

DOI: https://www.doi.org/10.7441/dokbat.2016.30 


\title{
CZECH MISSION STATEMENTS IN THE LIGHT OF 21ST CENTURY
}

\author{
Pernica Karel, Tyll Ladislav
}

\begin{abstract}
Mission statement represents essential message to all the shareholders regarding company's mission, its goals, values and competitive advantages offered to its customers. This message should be easily accessible, communicable, unique and understandable. The research focuses on the situation by leading Czech companies listed in the Czech TOP 100 ranking (2012, 2013, 2014) registered in the Czech Republic in terms of accessibility - the publication of missions and particularly in terms of content. The testing sample consisted of 214 companies. Only $33 \%$ of them publish its mission statement. These missions were analyzed further. About $66 \%$ of them fulfills its role as a mission and its mission is tailored to enterprise needs. In other cases, these are general statements and phrases that can be used for any company. Czech companies are often focusing on their products, services and they are emphasizing the importance of their customers in their mission statements. In terms of length mission statements of Czech companies could be considered as quality ones and follow global trends.
\end{abstract}

Keywords: mission statements analysis, content analysis, accessibility

\section{INTRODUCTION}

For more than 40 years mission statements have been valuable strategic tool of the companies. Its message is reflected in almost every company's activity. Starting with the strategic planning, production, marketing, public relations, personnel management, inspiration and motivation of employees, all the way to the corporate social responsibility and many more. Mission statement is considered to be a perfect basic building block for the company's strategic management process (David, 1984; Staples and Black, 1984). Cochran, David and Gibson (2008) believe, that the most visible and, at the same time, public part of the strategic plan should be a mission statement.

Theoretical basis for mission statement drafting was formed mostly in the 80s of the 20th century. These approaches appears to be obsolete nowadays. In this context it is important to examine, whether the companies operating in Czech Republic are approaching to the missions appropriately in terms of length, content and accessibility. The purpose and goal of this article is to present a practical recommendations for managers developing the unique, attractive and effective mission statement, based on the findings.

\section{MISSION STATEMENT}

\subsection{Definition}

Company asking the question "What we do?" is practically asking "What is our mission?" (Drucker, 1974). It outlines the reason of its existence, as well as the ambitions, philosophies and attitudes. Formally stated mission also helps company to distinguish itself from the competition. (Drucker, 1974) If company is not able to define its mission, there is probably no need for its further existence. (Tyll, 2014) Therefore, it is assumed that every organisation has its reason for existing. Regardless of whether it is called "mission statement", "mission", a "credo", "our philosophy", "core values" or something else. (Williams, 2008) 


\subsection{Characteristics and components}

Every mission should be as unique as possible. Several guidelines has been introduced over a years about which key components should be included. They vary in numbers or names, however the content is still more less the same. In this respect, one of the most often cited author is Fred. R. David (2011) and his nine components approach. According to David, company should provide information about the customers, product and services, markets, technology, concern for survival, growth and profitability, philosophy, self-concept and concern for employees. He also provides an explanations of the components:

1. Customers - Who are the enterprise's customers?

2. Products or services - What are the firm's major products or services?

3. Location - Where does the firm compete?

4. Technology - What is the firm's basic technology?

5. Concern for survival - What is the firm's commitment to economic objectives?

6. Philosophy - What are the basic beliefs, values, aspirations, and philosophical priorities of the firm?

7. Self-concept - What are the firm's major strengths and competitive advantages?

8. Concern for public image - What are the firm's public responsibilities, and what image is desired?

9. Concern for employees - What is the firm's attitude toward its employees?

Mission statement is most effective when it is approximately 100 words in length and when it avoids inclusion of monetary amounts, numbers, percentages, ratios of objectives. (David and Davis, 2003, Davies and Glaister, 1997, Kemp and Dwyer, 2003) Well designed mission should also create an emotional bond between company and its employees or customers. (Campbell and Yeung, 1991)

\subsection{New perspective}

According to Trout (2006) the main task of the statement is to differentiate from the competition. Widely used guidelines led to the situation, that vast majority of the missions are nothing more than empty phrases and clichés. He also criticizes a process of writing such a statement. There is no need of spending weeks writing it. It should be matter of one day.

Jeremy Bullmore (1997) analyzed the book called The Mission Statement Book, which contains 301 mission statements from America's top companies. He counted the most frequently used words, which were: service - 230 times, customers - 211, quality - 194, value - 183, employees - 157, growth - 118, environment - 117, profit - 114 , leader - 104, best 102. The result is that many of these 301 statements were completely interchangeable. Bullmore also provides an example of such a statement:

'Our corporate goals consist of satisfying needs of our customers; providing meaningful work for our employees; producing a quality return to our shareholders; and preserving the health of our business.'

It is impossible to tell on which market organisation operates or what its business is. 
Susan Gunelius (2011) emphasizes the importance of tailored mission statement to each company. Companies should make sure their mission statement tells a story and sparks an interest among its readers.

\section{METHODOLOGY}

\subsection{Sample selection}

Tested sample of top companies operating in Czech Republic was chosen from the ranking of the organisation CZECH TOP 100, which tracks companies in Czech Republic from 1994. On the basis of objective criteria and with cooperation with leading experts they publish rankings 100 leading companies, 100 most admired companies, Best annual reports and so on.

Ranking 100 leading companies is based on hard economic data and is built with cooperation with the University of Economics, Prague. Main ranking is built according to companies' revenues. Another rankings included takes in account profit, productivity, revenues growth, profit growth.

Ranking 100 most admired companies comes from almost 1000 companies, ranked by the independent reviewers, who are managers, analysts, academicians and government members. They evaluate innovation, quality of management, relationship to society and environment, product quality, financial stability and other criteria not related to hard economic data.

For the purposes of the research were selected the companies out of the 100 leading companies for the years 2012 and 2013 and the 100 most admired companies for the year 2014. The sample includes all companies that were in the main ranking and also those that was in top five within the industry or top five ranked by the profit, productivity and other mentioned above. Duplicities were removed, as well as the companies no longer operating on Czech market or ones, which became part of a holding, which already is in the sample.

\subsection{Mission collection}

Missions were searched both on the companies' websites and the most recent annual reports available (available on portal www.justice.cz). All content was always carefully analyzed and in case company did not have its mission explicitly stated, was searched at least for some statement of the company that meets the parameters of the mission (as above mentioned credos, philosophies, etc.)

\subsection{Content and components}

The content and the recommended components of mission by David (2011) were evaluated as follows: if the mission included the component, it was awarded two points. In case the component was only partially included or not stated clearly, the mission was awarded one point. Zero points for missing component.

To determine the number of words and characters (including spaces) was used the MS Word text editor. Number of sentences was counted manually. Listing of words and number of its occurrences was obtained by using application Text analysis - NTX.cz (NTX.cz, 2015).

\section{RESULTS}

In total 214 mission were collected out of above mentioned rankings. In only 70 cases the mission statement was found (only $33 \%$ of the sample). Explicitly stated as a mission 
statement were only 55 of them (79\% of the total number of companies with a mission and only $26 \%$ of the tested sample). In these cases companies refer to this statement as a "business plan", a "goal of the company", "basic strategy", "our philosophy" and even one vision statements met the requirements of the mission. Considering the fact that only $26 \%$ of the leading and most admired companies has formally stated mission statement it is clear, that the result is rather low.

\subsection{Accessibility of mission statements}

In the 21 st century is very essential for the companies how they present themselves online. Using this channel should be absolute must for communicating the mission statements towards all stakeholders. One can hardly imagine that someone would be searching for the mission statement primarily in the annual reports. 47 companies has placed their mission statements only on their websites $(67 \%$ of the total number of companies with a mission and only $22 \%$ of the tested sample). In 12 cases (17\%) the mission was stated only in annual report and 11 statements $(16 \%)$ were located both online and in the annual report. In total 58 companies $(83 \%)$ have published their missions on the websites, what can clearly be considered as a high number.

Companies should also strive to make their mission within the website most visible and accessible. Therefore, the number of clicks needed to get to the mission was counted. It includes both the number of actual clicks and also the cases when it is necessary to get the cursor to a certain area of the page to access the drop down menu. Average number of clicks need to make the site visitor come to the mission statement was 1,89 , whereas the ideal number of clicks is 1 . Under this assumption, visitors are not bothered by a mission right after entering the website, what could be distracting and annoying. On the other hand the link to the mission statement should be clearly visible. In one case visitors have to search for the mission using 4 clicks, what is unacceptable. One mission statement was even found only through the web search engine, because it was, for some reason, unfindable on the company's website.

\subsection{Length of the mission statements}

According to the theoretical basis, missions should be no longer than approximately 100 words. Companies from the tested sample used on average 40,69 words and 2,94 sentences to formulate their missions. It is always necessary to take in account the minimum and maximum values. If these extremes are to low or high, the average value can be greatly disorted. In such cases it is preferable to use the median for describing the data sample, which was 33 for the words count and 2 for sentences. Lowest number of words used was 4, the highest was 154. Lowest number of sentences was 1, highest 11.

Given numbers and statistics reveal that the mission statements of companies operating in Czech Republic are on a very decent level. However the recommended 100 words approach seems to be obsolete. The best mission statements are those who can create a bond between the readers and the company. What more, they should be easy to remember. In this respect there is a rule the shorter the mission is the better. One sentence mission statement could be very effective, but at the same time very confusing. As a bad example could be considered the company, that put 43 words in one sentence.

\subsection{Content analysis and interchangeability}

Analysis of the particular components included in the mission statements brought interesting findings. The best companies awarded with the highest scores has rather long and dull 
mission statements. On the contrary, missions with the lowest scores, on the opposite end of the ranking were mostly very short and appealing. Nevertheless it cannot be considered as a rule. Even the short mission could be really poor quality one. In some cases companies stated a mission statement in form of list of their business activities.

Table 1 below provides an overview of how many times particular components were included in the statements. The most frequent component ( $81 \%$ of the total number of companies with a mission statement) was with no surprise the products and services offered by the company. Second place belongs to the component customers with $67 \%$. One of the often used component was also the philosophy (51\%), where companies presents their core values, aspirations or ethical priorities. Component which occurred the least was the concern for employees $(24 \%)$.

Table 1 - Occurrence of the components in the sample. Source: Authors.

\begin{tabular}{lllll}
\hline & Total & \multicolumn{3}{l}{$\%$} \\
\cline { 2 - 5 } & Included & Not included & Included & Not included \\
\hline Customers & 47 & 23 & $67 \%$ & $33 \%$ \\
Products and services & 57 & 13 & $81 \%$ & $19 \%$ \\
Markets (location) & 24 & 46 & $34 \%$ & $66 \%$ \\
Technology & 27 & 43 & $39 \%$ & $61 \%$ \\
Concern for survival & 23 & 47 & $33 \%$ & $67 \%$ \\
Philosophy & 36 & 34 & $51 \%$ & $49 \%$ \\
Self-concept & 26 & 44 & $37 \%$ & $63 \%$ \\
Concern for public image & 24 & 46 & $34 \%$ & $66 \%$ \\
Concern for employees & 17 & 53 & $24 \%$ & $76 \%$ \\
\hline
\end{tabular}

A well-formulated mission should be tailored to each individual company. Out of this sample 24 companies (34\% of the total number of companies with a mission statement) has a mission that can easily be used for any company. What remains true, is that 8 of this companies implemented its name into the statement. However, when we put them aside, the missions are completely interchangeable.

Tab. 2 - Interchangeability of the mission statements. Source: Authors.

\begin{tabular}{lll}
\hline Total number of the companies with a mission: & 70 & $100 \%$ \\
\hline Companies with uniquely formulated mission: & 46 & $66 \%$ \\
Companies with interchangeable missions: & 24 & $34 \%$ \\
\hline Company's name in uniquely formulated missions: & 19 & $27 \%$ \\
Company's name in interchangeable missions: & 8 & $12 \%$ \\
Missions without company's name included: & 43 & $61 \%$ \\
\hline
\end{tabular}

\subsection{Analysis of used dictionary}

The three most frequently used words are the same as those identified by Bullmore. Those are "service", "customers" and "quality". What differs is the frequency of its appearance. While in the Bullmore's sample the "service" was included in $76 \%$ of the mission statements, the "customers" in $70 \%$ and "quality" in $64 \%$, in the sample tested in this paper the "service" was included only in $53 \%$, the "customers" in $51 \%$ and the "quality" in $37 \%$. This could be evidence that writing of such a statements is developing in the right direction and the companies are striving more for differentiation from the competition. 


\section{CONCLUSION}

The current situation in the field of drafting the mission statements is not ideal. Despite the fact that mission statement is very valuable tool of corporate strategy, only $33 \%$ of the companies from the tested sample have formally stated mission. Even worse percentage of the companies has its mission posted on their websites $-22 \%$. However, accessibility in most cases meets the requirements of 21 st century with wide spread internet. Nevertheless the companies can still do better with making their mission statements even more accessible. The optimal number of clicks needed to find the mission on company's website is considered to be 1 . The average number in frame of our tested sample was 1,89 clicks.

It is highly advised to keep the mission statement as simple and short as possible. This helps particularly to make such a statement easy to remember, easy to understand and last but not least, extremely long mission statements could easily discourage the stakeholders from even reading it. It is also very appreciated when a mission can create some emotional bond between the company and the reader of the statement. What remains the same after a decades is the fact, that the mission should be used for the differentiation from other competitors.

The nine components approach from David (2011) proved to be obsolete. Including all of the components cannot lead to anything else than complete interchangeability of the statements, which are then useful and needless.

The practical recommendations can be summarized in following points:

- The shorter the statements is, the better.

- Go online with your mission statements.

- Do not hide your statement on your website. Make is as accessible as possible.

- Do not stick strictly or at all to the old recommended components approaches.

- Be original, unique, attractive, easy to remember.

- Try to create an emotional bond with your stakeholders.

\section{References}

Bullmore, J. (1997). Was there life before mission statements? Marketing Magazine.. $\begin{array}{llll}\text { Accessed } & \text { on } & \text { March } & 2016 .\end{array}$ http://www.marketingmagazine.co.uk/article/54464/life-mission-statements.

Campbell, A, and Sally Y. (1991). Creating a Sense of Mission, Long Range Planning 24(4), 10-20. https://doi.org/10.1016/0024-6301(91)90002-6

Cochran, D S., et al. (2008). A framework for developing an effective mission statement. . Journal of Business Strategies, 25(2) 27-39.

CZECH TOP 100. "100 nejvýznamějších firem ČR." Czech Top 100 . 2015. Accessed on March 20, 2016. http://www.czechtop100.cz/nase-projekty/zebrickoveprojekty/zebrickove-projekty.html.

CZECH TOP 100. "100 nejobdivovanějších firem ČR." Czech Top 100. 2015. Accessed on March 20, 2016. http://www.czechtop100.cz/nase-projekty/zebrickoveprojekty/zebrickove-projekty.html.

David, F. R. (1984). Towards an integration of strategic management models. Southern Management Association. Proceedings. 195-197.

David, F R., and. David, F. R. (2003). It's Time to Redraft Your Mission Statement. Journal of Business Strategy, 24(1), 11-14. /https://doi.org/10.1108/02756660310508218 
David, R. (2011). Strategic Management: Concepts and Cases. Upper Saddle River, NJ: Prentice Hall.

Davies, S W., and. Glaister, K W. (1997). Business School Mission Statements-the Bland Leading the Bland?" Long Range Planning 30(4), 481-604. https://doi.org/10.1016/S0024-6301(97)00038-1

Drucker, P F. (1974). Management: Tasks, Responsibilities, Practices. New York: Harper \& Row.

Gunelius, S. (2011). Five Reasons Why Your Mission Statement Probably Stinks. Enterpreneur. 2011. Accessed on March 20, 2016. http://www.entrepreneur.com/article/219544.

Kemp, S, and Dwyer, L. (2003). Mission Statements of International Airlines: A Content Analysis. Tourism Management 24(6), 635-53. https://doi.org/10.1016/S02615177(03)00049-9

NTX.CZ. "Analýza textu." NTX.cz. 2012. Accessed on March 20, 2016. http://ntx.cz/zdroje/73/analyza-textu/.

Staples, W A. and Black, K. U. (1984). Defining our business mission: A strategic perspective. Journal of Business Strategies. 1, 33-39

Trout, J. (2006). Mission Statement Words. Forbes. 2006. Accessed on March 20, 2016. http://www.forbes.com/2006/08/18/jack-trout-on-marketing-cx_jt_0821mission.html.

Tyll, L. (2014). Podniková Strategie. Praha: C.H. Beck.

Williams, L. S. (2008). The Mission Statement: A Corporate Reporting Tool With a Past, Present, and Future. Journal of Business Communication 45(2), 94-119. https://doi.org/10.1177/0021943607313989

\section{Contact information}

Karel Pernica

University of Economics, Prague, Faculty of Business Administration

Nám. W. Churchilla 4, 13067 Praha 3

+420605151607

karel.pernica@vse.cz

Ladislav Tyll

University of Economics, Prague, Faculty of Business Administration

Nám. W. Churchilla 4, 13067 Praha 3

+420603461099

ladislav.tyll@vse.cz

DOI: https://www.doi.org/10.7441/dokbat.2016.31 


\title{
INVESTMENT EFFICIENCY OF INVESTMENT INCENTIVES IN THE CZECH REPUBLIC
}

\author{
Šárka Pindorová
}

\begin{abstract}
The investment incentives belong to important instrument of government which should attract foreign investors into the Czech Republic. The purpose of this support from the state should be to attract companies that will create new jobs and increase foreign investments. This article is aimed at evaluating the effectiveness of investment incentives in employment view and gives the answer to research question. How effective impact investments are beneficial for reducing unemployment. How much state will save thanks to the inflow of new foreign companies that invest and creating new jobs in our country? Analyses of secondary data from the Czech Statistical Office and the data of the Investment and Business Development Agency CzechInvest were used to find out the amount of investment and new jobs by country of origin and in the regions of Czech Republic. Using a mathematical model has been detected correlation values of the factors that affect the investment climate and the result are analyzed in the context of this article. The results confirmed that investors have contributed to the increase of employment in individual regions and the state saved state budget expenditures.
\end{abstract}

Keywords: Investment incentives, employment, industry, investors, region

\section{INTRODUCTION}

Multinational companies greatly affect the shaping of the international economic climate thanks to their capital strength. The arrival of multinational companies is an integral part of the development of economy in the Czech Republic. In the last two decades international firms gained constantly increasing importance not only in the area of employment.

Main objective of the article is to analyse the role the international companies have in formation of new job opportunities and in the development of economy in the Czech Republic and to find out which country of origin have brought to the Czech Republic the largest investment and created most new jobs.

\section{OBJECTIVES AND THEORETICAL FRAMEWORK}

Objective of this research is testing how effective impact investments are beneficial for reducing unemployment. How much state will save thanks to the inflow of new foreign companies that invest and creating new jobs in our country?

Investment incentives are one of the forms of public aid. Public aid can significantly favour one business entity before the second. Then, in open and interdependent economies, it can cause a non-competitive environment between companies of other states to each other. (EUROPA, 2015) The investors, who placed their investment in the territory of the Czech Republic, can get support in the form of investment incentives (CzechInvest, 2015) and either Czech or foreign legal or natural person-entrepreneur may apply for investment incentives. The recipient of investment incentives may be the only legal person established on the territory of the Czech Republic. Recipients of investment incentives may be only legal person established on the territory of the Czech Republic. The law provides for the conditions for each activity that is needed in order to apply for investor investment incentive. 
Act No. 72/2000 Coll., on investment incentives in wording of Act. No. 84/2015 Coll., (in effect from May 1, 2015)

Following on from the directly applicable Regulation of the European Union for granting regional investment aid and aid for employment and education this Act shall govern the general conditions for granting investment incentives, the procedure to be followed in the granting of investment incentives and the exercise of related state administration for the purpose of supporting economic development and the creation of jobs on the territory of the Czech Republic. The Ministry of Industry and Trade (hereinafter referred to as the "Ministry") shall comply with the reporting obligation for the provision of investment incentives under this Act arising for the Czech Republic from the directly applicable Regulation of the European Union. Investment incentives are available not only to investors launching or expanding production, but also to technological and strategic service centers. On May 1, 2015 the amendment on investment incentives came into effect. The amendment introduces new types of incentives and at the same time removes the current limitations in the Act on investment Incentives and connected acts.

\section{METHODOLOGY}

In this article is used mainly analysis of data from statistical databases. The list constitutes of two main parts, specifically the theoretical framework and the application part. In order to create the theoretical part, study of appropriate literature to corporate with investment incentives and the creation of work. For the fulfilment of article objectives general theoretical methods have been selected: description, analogies, analysis, synthesis, abstraction and generalizations, which were used in different parts of the work. At the conclusion of the work the results are evaluated, questions are answered, and proposed recommendations are formulated.

The intent to apply for investment incentives should be submitted by the applicant for investment incentives, i.e., a foreign or Czech business entity (a sole trader or a company). The intent should be submitted to the CzechInvest Agency and should be in the Czech language, in paper form with simultaneous 6 electronic submissions on the required data medium (CD-ROM). A foreign person/entity may submit memorandum of association or other founder's agreement, articles of associations (if any) in the English language. The law (Act No. 72/2000) determines the eligibility criteria which investors have to meet when they apply for investment incentives. In case of each of the activities it applies the conditions must be met within three years from the date of the granting the investment incentive i.e. since the release of decision about the promise of investment incentives.

For all types of activities it applies that the recipient of incentives shall not start work on the project (i.e. shall not acquire any assets including orders of machines and equipment and shall not commence construction works) prior to issuance of the confirmation of project registration by CzechInvest, and that the recipient shall retain the required assets and created jobs throughout the entire period of utilising state aid (at least for a period of five years). (CZECHINVEST, 2015)

Corporate income tax relief, transfer of land for a discounted price, cash grant for jobs creation, cash grants for training and retraining of new employees, exemption from property tax, cash grants for acquisition of assets.

I used excel for function analysis data and I did a simple regression analysis with confidence level on $95 \%$. The result is, that there is a linear dependence between the selected variables, 
since the coefficients of regression function are statistically significant in 2007, 2008 and 2014. The significance value is $\mathrm{F}<0,05$.

In the other years, the significance values are greater than $0.05 \mathrm{~F}$ and therefore these coefficients of the regression function are statistically insignificant. (Table 1) However, it is necessary to emphasize that this result may be cause a small amount of data for regression. I used a value of only 13 counties for each year in each year in the Czech Republic.

Table 1 - Regression analysis new jobs \& unemployment. Source: own elaboration

\begin{tabular}{|c|c|c|c|c|c|c|c|c|c|}
\hline year & 2007 & 2008 & 2009 & 2010 & 2011 & 2012 & 2013 & 2014 & 2015 \\
\hline P-value (Significance F) & $4.72 \mathrm{E}-09$ & $8.28 \mathrm{E}-10$ & 0.72 & 0.71 & 0.7 & 0.74 & 0.74 & 0.05 & 0.11 \\
\hline jobs/L & 2.21 & 5.17 & 1.71 & 0.21 & 1.12 & 0.61 & 2.15 & 2.94 & 1 \\
\hline
\end{tabular}

The share between unemployment and newly created jobs is ranging between $0.21 \%$ to $5.17 \%$ in 2007-2015. The largest contribution for employment in the Czech Republic of investment incentives was in 2008. (Table 1)

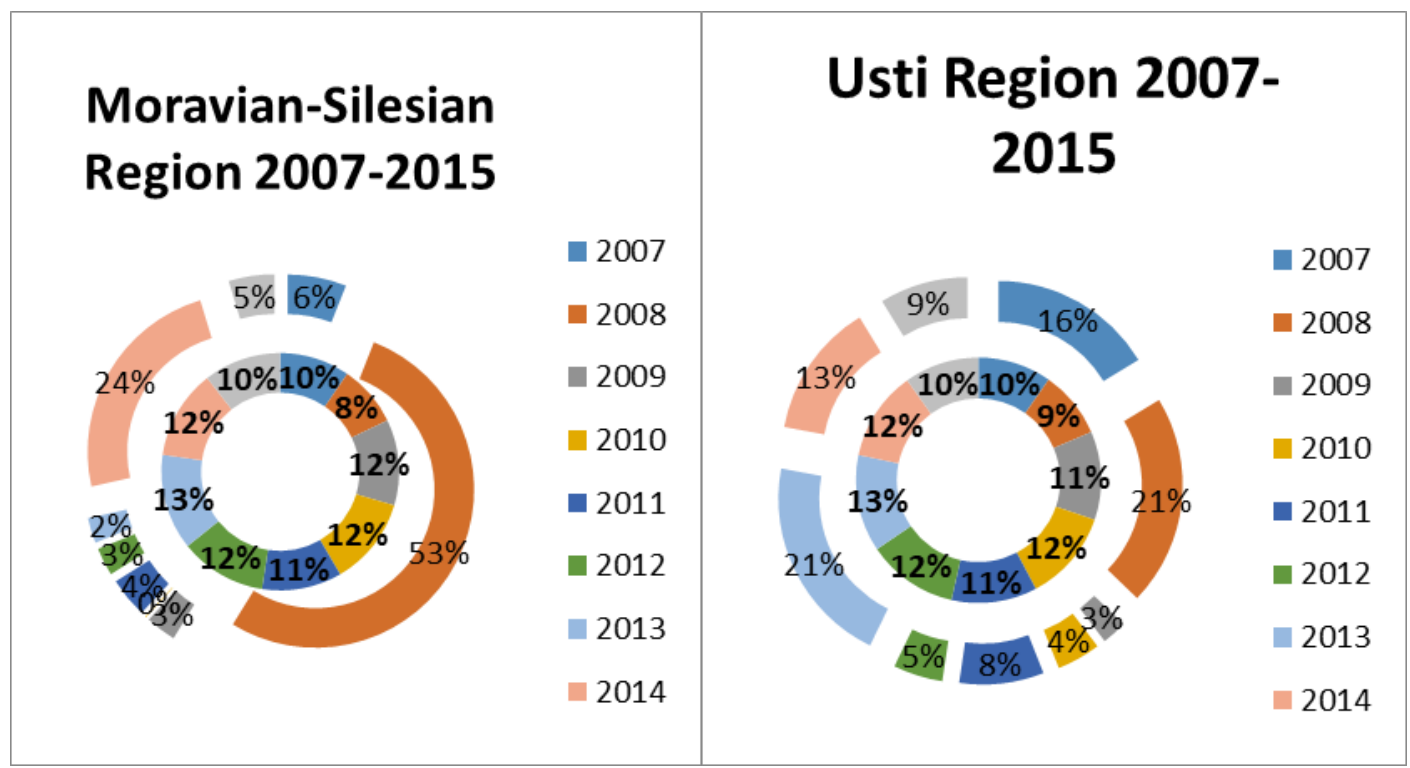

Figure 1 - Unemployment \& jobs with support investment incentives 2007-2015. Source: own elaboration

The Moravia-Silesia region ranks among the leaders in the number of approved with investment incentives. This is evident in the inflow and expansion of investors in automotive sectors with high- tech. The Moravia-Silesia region has a strong industrial base and boasts an unemployment rate in last year's.

The Moravian-Silesian Region in the period 2007-2015 was the most registered unemployed in 2008. The number of unemployed persons was 57,455 , and of the new company employed 7,225 new employees. This accounts for $12 \%$ of the total unemployed in a given year. Thanks to the company Hyundai Motor Manufacturing Czech Ltd. created 3514 new jobs in region. The company Mobis Automotive Czech Ltd. created 840 jobs. Both companies involved in the automotive industry. Other companies in the automotive industry created 1,223 new jobs. Engineering and chemical companies have created the remaining 1,648 new jobs in 2008. (Figure 1) 
For example, the company IVAX Pharmaceuticals Ltd. which operates with the chemical and pharmaceutical industries and company ITT Holdings Czech Republic Ltd. from the engineering industry.

The Usti Region in the period 2007-2015 was the most registered unemployed in 2013 and 2008. The number of unemployed persons was 95,820, and of the new company employed 1,205 new employees in 2013. The number of unemployed persons was 45,657 and of the new company employed 1,885 new created jobs in 2013.

Table 2 -The biggest company with the largest number of new jobs in 2007-2015, Source: Web portal Czech incest [online] [vid. 20.3.2016] and own elaboration.

\begin{tabular}{|l|l|l|}
\hline \multicolumn{1}{|c|}{ Company } & \multicolumn{1}{c|}{ Country } & \multicolumn{2}{c|}{ Sector } \\
\hline Faurecia Components Písek, s.r.o. & France & automotive \\
\hline Daikin Device Czech Republic s.r.o. & Japan & engineering \\
\hline ADC Czech Republic, s.r.o. & USA & engineering \\
\hline ŠKODA AUTO a.s. & Germany & automotive \\
\hline ŠKODA AUTO a.s. & Netherlands & automotive \\
\hline SUNGWOO HITECH s.r.o. & Korea & automotive \\
\hline Mobis Automotive Czech s.r.o. & Korea & automotive \\
\hline Hyundai Motor Manufacturing Czech s.r.o. & Korea & automotive \\
\hline CROMODORA WHEELS s.r.o. & Italy & automotive \\
\hline Brembo Czech s.r.o. & Italy & automotive \\
\hline Gates Hydraulics s.r.o. & Great Britain & rubber and plastic industry \\
\hline ITT Holdings Czech Republic s.r.o. & Luxembourg & engineering \\
\hline Foxconn Technology CZ s.r.o. & Netherlands & electronics and electrotechnic \\
\hline KIEKERT - CS, s.r.o. & Germany & engineering \\
\hline Johnson Controls Automotive Bor s.r.o. & USA & automotive \\
\hline Faurecia PIzeň, s.r.o. & France & automotive \\
\hline Panasonic AVC Networks Czech, s.r.o. & Great Britain & electronics and electrotechnic \\
\hline IPS Alpha Technology Europe, s.r.o. & Japan & electronics and electrotechnic \\
\hline Hitachi Home Electronics (Czech), s.r.o. & Japan & electronics and electrotechnic \\
\hline ELBEL s.r.o. & Italy & electronics and electrotechnic \\
\hline Guardian Automotive Czechia s.r.o. & Luxembourg & rubber and plastic industry \\
\hline
\end{tabular}

The analysis was made of companies that create the most new jobs, with the support of investment incentives in the Czech regions. The research showed that most companies are contributed to employment in different regions and in each year. Table 3 are mentioned only two of the biggest companies of each year in the period 2007-2015 which contributed the most to employment growth. The creation of new jobs was mainly due to the ten companies from the automotive industry, five of the electronics and electrical sector, four engineering and two rubber companies. These companies in the table 2 created a total of 28,265 new jobs in the period of nine years. 
Table 3 - The biggest company with the largest number of new jobs in 2007-2015, Source: Web portal Czech invest [online] [vid. 20.3.2016] and own elaboration.

\begin{tabular}{|l|r|r|r|}
\hline \multicolumn{1}{|c|}{ Country of origin } & New Jobs & \multicolumn{2}{c|}{$\begin{array}{c}\text { Investment (mil. } \\
\text { CZK) }\end{array}$} \\
\hline Czech Republic & 44478 & 248,477 & 2 \\
\hline Germany & 36453 & 146,820 & 3 \\
\hline Netherlands & 24184 & 74,631 & 4 \\
\hline Japan & 15569 & 63,282 & 5 \\
\hline Korea & 7494 & 44,197 & 6 \\
\hline USA & 5761 & 19,263 & 7 \\
\hline France & 5741 & 15,885 & 8 \\
\hline Italy & 3676 & 12,142 & 9 \\
\hline Luxembourg & 3555 & 8,667 & 10 \\
\hline United Kingdom & 3525 & 9,929 & \\
\hline
\end{tabular}

Ten most successful companies, with the support of investment incentives according to county of origin and the number of new created jobs 2007-2015 are displayed in table 3. According to statistical data was carried out research on the most successful companies that participated in the investment in the Czech Republic by country of origin during the period 2007-2015 ranking company in the top 10 places according to the amount of investments remained almost the same as for companies that create most new jobs. Only companies from Japan and Austria to replace the company's country of origin from Luxembourg and the United Kingdom in the first ten positions. Analyses of the number of jobs created by country of origin 2007-2015 are demonstrated in Table 3. Main leaders of international companies by country of origin are Germany, the Netherlands and Asia. According to the Czech Statistical Office the Germany companies has created 36453 new jobs. The Netherlands companies created 24.184 jobs. Asian companies have created 23.063 jobs. Out of that Japan 15569 new jobs and invested CZK 63.282 mil. Korea companies employed 7.494 new employees with support of investment incentives. (Table 3)

Table 4 - Creating jobs and investment by country of origin 2015, Source: own elaboration+ Czech Invest

\begin{tabular}{|l|r|r|r|}
\hline & & & \\
\multicolumn{1}{|c|}{ Country of origin } & Created jobs 2015 & Invest in mil. CZK & \% job origin country \\
\hline Germany & 36453 & 146,820 & $21 \%$ \\
\hline Czech Republic & 44478 & 248,477 & $26 \%$ \\
\hline Japan & 15569 & 63,282 & $9 \%$ \\
\hline Netherlands & 24184 & 74,631 & $14 \%$ \\
\hline Korea & 7494 & 44,197 & $4 \%$ \\
\hline Other & 42905 & $\mathbf{7 1 5 , 0 1 1}$ & $26 \%$ \\
\hline Total & $\mathbf{1 7 1 0 8 3}$ & $\mathbf{1 , 2 9 2 , 4 1 9}$ & $\mathbf{1 0 0 \%}$ \\
\hline
\end{tabular}

Analysis of the number of created jobs according to the county of origin in 2015 shows Table 4. Four leaders are international companies belong to Germany (21\%), Netherlands (14\%), Japan (9\%) and 4\% to Korea. According to the Czech Statistical Office the Czech companies invested CZK 248.477 mil., German companies invested CZK 146.820 mil., and Netherlands invested CZK 74.631 mil. and Asian companies invested totally CZK 107.479 mil. (Table 4) 
Table 5 - Status of projects from 1998 to the date of December 31, 2015, Source: Web portal Czech invest

\begin{tabular}{|l|c|c|c|c|}
\hline \multicolumn{1}{c|}{ Region } & Projects & Invest. in mil. EUR & $\begin{array}{c}\text { Invest in mil. } \\
\text { CZK }\end{array}$ & $\begin{array}{c}\text { Newly created } \\
\text { jobs }\end{array}$ \\
\hline Central Bohemia & 123 & $4,109.71$ & $129,028.01$ & 24,185 \\
\hline Moravia-Silesia & 133 & $3,905.59$ & $112,509.53$ & 21,387 \\
\hline Usti nad Labem & 155 & $3,820.50$ & $118,293.09$ & 26,434 \\
\hline
\end{tabular}

The number of projects with the support of the investment incentives (1998-2015) according to regions is displayed in table no.5. The leaders were: the Moravian-Silesian region with 133 projects and 21.387 jobs, Usti region with 155 projects (26.434 job positions) and Central Bohemia 123 projects and created 24.185 new jobs. According to the recorded data, it can concluded that, thanks to the material aid of the state were created in the Czech Republic more than 72.006 jobs and reduced unemployment in the regions.(Table 5)

Table 6 - Unemployed persony \& created new jobs. Source: Web portal ČSÚ + own elaboration

\begin{tabular}{|l|c|r|r|r|r|r|r|c|c|}
\hline & \multicolumn{1}{|c|}{$\mathbf{2 0 0 6}$} & \multicolumn{1}{c|}{$\mathbf{2 0 0 7}$} & \multicolumn{1}{c|}{$\mathbf{2 0 0 8}$} & \multicolumn{1}{c|}{$\mathbf{2 0 0 9}$} & $\mathbf{2 0 1 0}$ & $\mathbf{2 0 1 1}$ & $\mathbf{2 0 1 2}$ & $\mathbf{2 0 1 3}$ & $\mathbf{2 0 1 4}$ \\
\hline unemployed & 85,422 & 65,816 & 57,455 & 80,581 & 82,776 & 75,019 & 81,099 & 89,976 & 83,877 \\
\hline created jobs & 10,417 & 2,719 & 14,606 & 5,769 & 10,000 & 9,654 & 12,326 & 10,519 & 16,116 \\
\hline
\end{tabular}

The average wage is CZK 26.611/month. One average unemployed Czech costs the public budget more than 109,000 crowns per year. This means 9083 per month. On average, were created, due to investment incentives, 10236 jobs in years 2006-2014, which means that these workers costs state CZK 92,973,588 (10236 times 9083 per month.). The state would be paid for employees CZK 92,973,588, if their positions have been created and they have been remained in employment department. The state gives a one-time grant for one created job on average CZK 100000 - 200 000. State investment incentive per one employee will cover the annual costs of the company and in following years the employee does not cost anything. (Table 6)

On the contrary, in other years, the company pays for the employee $34 \%$ of his salary to the state treasury for social and health insurance and income tax of 15\% (34\% *26,611 (average salary of 2015)). This saves the state 100 thousand per year, which he would have had to pay if the employee has been in employment department. The money raised per employee each month CZK 9,047 (CZK 108,564 per year). Totally, for one year the state will save 108,564 for charges which comes from a company that employed a person from employment department and 109 thousand for saved expenses that government would have to pay for the unemployed. Total income for the state is 217,564 for the creation one new job. When in years 2006-2014 was on average created 10,236 jobs from investment incentives per year, we can conclude that the state will save on average $2,226,985,104$ CZK per year $(10,236$ seats * 217564).(Table 6)

\section{DISCUSSION AND DIRECTION FOR FUTURE RESEARCH}

In 2016 an amendment to the act on investment incentives come into force and due to this fact, the topic of ,investment incentives“" pays great attention to economists. The government wants to create good conditions for direct foreign investment and support the inflow of new companies to the Czech Republic. Investment incentives are available not only to investors 
launching or expanding production, but also to technological and strategic service centers. The amendment introduces new types of incentives and at the same time removes the current limitations in the Act on investment Incentives and connected acts. (CzechInvest, 2015)

What brought amendment to the investment incentives act, which come into force in July this year 2016? The answers to these questions were looking by trio of experts at the forum Business online, which organized Economic newspaper in cooperation with Deloitte Academy. Experts in the forum came to these conclusions. „The Czech Republic is due to the amendment of the act conclusively more attractive country for investors", agreed the representatives of Deloitte, CzechInvest and Siemens. For example, the alteration, which extending the deadline for drawdown of the tax credit from five to ten years, according to them attracted significantly more investors in second half of this year, that in his first half to the Czech Republic.(Economic newspaper, 2016)

I think, it is very important to find out how influenced amendment of the investment incentives the positive and negative effects of investment incentive in future research. Effectiveness of investment support can be evaluated according to various aspects and divide into the positive and negative effects. In this article was evaluation focused on employment in the Czech Republic. When we do the research of evaluating the effectiveness of investment incentives is important take into account different opinions and evaluate investment incentives as well as from the perspective of the state budget and the different effects that bring investments.

Among the positive effects of major investments include more dynamic industrial restructuring and technological development, higher utilization of export potential, development of small and medium business, focus on skilled workforce, improve the business image of the region, positive impact on regional and local labour markets. Among the negative effects or damping effects may include transfer-pricing, displacement effect caused by situation on market of production factors. (Wokoun R., Damborský M., Kadeřábková B., 2011)

\section{CONCLUSION}

Aim of this article is evaluating the effectiveness of the investment incentives in employment view and gives the answers to research questions. How effective impact of investments are beneficial for reducing unemployment. How much will state save thanks to the inflow of new foreign companies that invest and creating new jobs in our country? The presence of international companies in specific regions greatly affects the competitiveness and employment in the Czech Republic. Totally, for one year the state will save 108,564 for charges which comes from a company that employed a person from employment department and 109 thousand for saved expenses that government would have to pay for the unemployed. Total income for the state is 217,564 for the creation one new job. When in years 2006-2014 was on average created 10,236 jobs from investment incentives per year, we can conclude that the state will save on average 2,226,985,104 CZK per year. (Table 6)

The results confirmed that investors have contributed to the increase of employment in individual regions and the state saved state budget expenditures. In recent years, German, Netherland, Korean and Japanese companies occupy the first place in the number of new jobs created in the Czech Republic because the investment incentives are here. Thanks to these companies 128.178 new jobs were created until December 31, 2015. (Table 4). Not only the international companies with investment incentives, but also suppliers and customers, employing more staff and new jobs are benefits for international investments. On the basis of 
recorded data from the Statistical office a large number of international companies were found, which invested in the Czech Republic and took advantage of the investment incentives. Companies from Germany most contributed to the creation of new jobs in the Czech Republic.

Analysis of the number of jobs created by the country of origin in 2015 shows Chart no 4 . Four leaders formed by international companies belong to Germany (21\%), Netherlands (14\%), Japan (9\%) and 4\% Korea. Using a mathematical model has been detected correlation values of unemployment and created new jobs with investment incentives. I used excel for function analysis data and I did a simple regression analysis with confidence level on 95\%. The result is that there is a linear dependence between the selected variables, since the coefficients of regression function are statistically significant in 2007, 2008 and 2014. The significance value is $F<0,05$. In the other years, the significance values are greater than 0.05 $\mathrm{F}$ and therefore these coefficients of the regression function are statistically insignificant. (Table 4)

In recent years, many have invested and contributed to reducing unemployment by investment firms of the industry. Especially created new jobs company from the automotive industry, engineering companies and investors from the electronic industry. According to the results of the analysis the culture of the country of origin of the international companies had influence in deciding whether the applicant will apply for investment incentives. Of course, we cannot do final conclusion, in the context of the issues solved only from this article because this topic deserves a deeper and more comprehensive research.

\section{References}

Bracewell-Milnes, J. B., Bracewell-Milnes, B., \& Huiskamp, J. C. (1977). Investment incentives: A comparative analysis of the systems in the EEC, the USA and Sweden.

Český statistický úřrad. (2002). Výroční zpráva. Praha: Český statistický úřad.

Hague, P. N. (2003). Průzkum trhu: Příprava, výběr vhodných metod, provedení, interpretace získaných údajů. Praha: Computer Press.

Economic newspaper. Retrieved April 13, 2016, from http://byznys.ihned.cz/tagy/investicnipobidky-4283

Ionascu, D., \& Cour, L. L. (2007). Firm productivity: The role of competition and of the initial firm efficiency: EEvidence from the Czech Republic. København.

Kincl, M. (2003). Investiční pobídky jako forma veřejné podpory. Praha: Linde.

Macey, J. R. (2008). Classics in corporate law and economics. Northampton, MA: Edward Elgar Publishing. https://doi.org/10.4337/9781785366864

Nikitin, G. A. (n.d.). Establishment success and failure in developing economies: Evidence from the Czech Republic and Indonesia.

Oficiální EUROSKOP, 2015. (n.d.). Retrieved March 28, 2016, from http://europa.eu/index cz.htm

Act No. 72/2000 Coll., on investment incentives (n.d.). Retrieved March 28, 2016, from http://www.czechinvest.org/data/files/act-on-investment-incentives-may-1-2015.

Výroční zpráva 2007. (n.d.). Retrieved March 28, 2016, from http://www.czechinvest.org/vyrocni-zprava-2007

Výroční zpráva 2008. (n.d.). Retrieved March 28, 2016, from http://www.czechinvest.org/vyrocni-zprava-2008.

Výroční zpráva 2009. (n.d.). Retrieved March 28, 2016, from http://www.czechinvest.org/vyrocni-zprava-2009.

Výroční zpráva 2010. (n.d.). Retrieved March 28, 2016, from http://www.czechinvest.org/vyrocni-zprava-2010. 
Výroční zpráva 2011. (n.d.). Retrieved March 28, 2016, from http://www.czechinvest.org/vyrocni-zprava-2011

Výroční zpráva 2012. (n.d.). Retrieved March 28, 2016, from http://www.czechinvest.org/vyrocni-zprava-2012

Výroční zpráva 2013. (n.d.). Retrieved March 28, 2016, from http://www.czechinvest.org/vyrocni-zprava-2013.

Výroční zpráva 2014. (n.d.). Retrieved March 28, 2016, from http://www.czechinvest.org/vyrocni-zprava-2014.

Výroční zpráva 2015. (n.d.). Retrieved March 28, 2016, from http://www.czechinvest.org/vyrocni-zprava-2015.

Wokoun R., Damborsky M., Kadeřábková B., (2011).aj. Analýza navrhované novely zákona o investičních pobídkách. Praha: Národohospodářská fakulta Vysoké školy ekonomické v Praze.

\section{Contact information}

Šárka Pindorová

Silesian University in Opava, School of Business Administration in Karvina

Univerzitní nám. 1934/3

73340 Karviná, Czech Republic

$+420724967921$

DOI: https://www.doi.org/10.7441/dokbat.2016.32 


\title{
STRUCTURE CREATION OF VALUE MANAGEMENT MAKING PROVISION FOR STAKEHOLDERS IN BUSINESS PRACTICE
}

\author{
Tatiana Potkanová, Mária Ďurišová
}

\begin{abstract}
In present-day dynamic era it is necessary to realize activities which increase company value in bulk. Basis of this kind of orientation of company's effort is correct recognition of market opportunities. In connection with opportunities and value management, which significance is constantly growing, it is necessary to think of a value from the point of view of more stakeholders. Each of them expects to maximize perceived value what is not reachable without knowing of current provided value. European standards insist on stakeholders, only minimum of companies focus on this field. This trend is at the beginning in business practice. The article includes essential theoretical base and analyse of some precepts of law as well as procedures of activities which could help to know the problematics of value management more deeply. On the basis of previous statements there was defined aim of the article to compile the structure creation of value management from the point of view of all stakeholders.
\end{abstract}

Keywords: value, value management, stakeholders, value analysis, finance

\section{INTRODUCTION}

Market economy businesses should insist on creating such products or services which will bring specific rate of satisfaction of conscious or unconscious needs for consumers. If this condition is fulfilled in maximum rate, consumer will like such product/service and he will use it in the future, too. Rate of satisfaction is related to value perception, which is process holder of needs satisfaction. Value as such isn't clearly quantitatively determinant element because each consumer feels value different way. One consumer can be satisfied with something but it can be without value for another one. This expression is closely connected with preferences of individual customers.

If businesses want to achieve higher market value, which is connected with higher profit, it is necessary to deal with provided value. This value can be operated intuitively or through aimed focus on value in stakeholders through activities of value management. Value management is one of the fields of general management. There are some identical elements, some elements are partly adjusted directly for needs of this scientific field. Value management is often used only in case of view at consumer. More businesses are trying to increase value entirely for this stakeholder. Omission of other stakeholders in this field is common display, which is negatively showed with certain time delay. For this reason, too, it is necessary that businesses should integrate value management into fields, which don't bring immediate positive effect, but their long-term effect will be more significant from the point of view of other stakeholders.

\section{VALUE MANAGEMENT THEORY}

This field of management was established on the basis of understanding of importance of notion value with functional approach usage. Founder was American engineer Lawrence D. Miles, at that time he was purchase manager in Locke Insulator (related company General Electric, Co.), who in $40 \mathrm{~s}$ to $50 \mathrm{~s}$ of $20^{\text {th }}$ century produced value analysis which improved sensed value of products. The founder planned to decrease expenses and found out that it can bring in specific conditions productivity improving of input sources. Over time value analysis 
started to apply on service sector or projects, too. Value makes provision for other techniques such as Design to Cost and Functional Performance Specification.(Inovace 2015, Proč inovovat?)

Value management is a field which belongs to general management. Its main task is increasing of a value from the point of view customer and so increase business prosperity, volume of product sales or servicesas well as increase competitiveness. Value management according to Kubina and Lendel (2007, p. 29) is possible to define as "management style, which core motive and aim of whole methodical effort is to maximize value for customer. Value management as methodologically solid, management tool is oriented on increasing of business competitiveness through people motivation and development of their skills." According to Vlček, value management is defined as "special type of management, expressly concentrated on creation and value increasing for customer in parallel growth of company value." (2008, p. 53) European standard ČSN EN 12 973, valid even in Czech Republic defines value management "as a style of management concentrated mainly on people motivation, knowledge development, support of collaboration and innovations with aim to maximize overall organization efficiency." (Dostál, Loubal, Bartes, 2009, p. 22) On the basis of these definitions it is possible to assume that value management isn't sufficiently oriented on stakeholders.

Value management has its theories. Some are taken over from other fields (e.g. from general management) and other are oriented directly for needs of value management. Individual kinds are possible to be named as general and constructive theories. In using tools and methods there are application theories of value management which have significant role.

General theory is characterized as theory oriented on value (especially for customer) and function. It contains own terms as well as own methods oriented on determining of value level for customers.

This general theory is subdivided on function theories and functional approach and on value theory and value approach.

Function theoryis based on relation between need and object, like its characteristics, which satisfy need itself. It is mutual relation and so there is important what characteristics object has and how it uses them to satisfy needs. This theory is set up on customer and on determining of his needs. From the need there is possible to deduce definite function which customer requires. It is necessary to satisfy this function in required quality and quantity ergo on optimal level of need fulfilment. Idea of function includes creating of such object structure which has prospect to transform outer inputs to required behaviour elements with relations to required performance of a function into account.

Functional approach theoryis the second part. This kind of approach creates base for realization of value approach on the basis of which value management is based. This theory perceives objects as basis for determining of characteristics on needs fulfilment and so its aim is to maximize value for customer. Theory extracts from side influence, too, which influences customer behaviour. This is solely oriented on object characteristics which, in maximal way, fulfil presented needs. Functional approach takes into account optimisation of needs satisfying at the lowest possible costs. It is often expressed by modification of original functions the way that completely new object would arise, which will be capable to satisfy needs on higher level, where perceived value will be higher, too. Functional approach component is functional modelling, too. It depicts operations with functions. (Vlček, 2008)

Value theory is based mainly on general benefit of an object. In this connection it is possible to define effectiveness as practicality and quality rate of product/object. This theory gives 
possibility to measure benefit level. Value isn't united and for each customer it is individual even in using the same object. Core of a value for customer is material or immaterial object, which is bearer of a need satisfaction function showed through effectiveness and benefit. Effectiveness is possible to define as ability of conversion of inputs into outputs. In case of that they belong to classification of economic indices or elements, it specifies itself as economical effectiveness or effectivity in which invested and achieved financial sources of transformation are taken into account. Then we can distinguish technical effectiveness, which offers expressing of inputs and outputs in technical units it means what input power it necessary to achieve specified performance. From the general point of view of value management and value for customer there is specific combination whereas inputs are expressed in expenses and outputs in performance let us say in individual benefit. Principle of change of technical parameters of performance into economical it is ground for value approach.(Vlček, 2008)

Value approach theoryis the way of realization of value for customer. One of the tools of this theory are innovations through which it is possible to achieve positive changes of value for customer. According to Vlček value approach is "methodological concept searching for answer on question: how else it is possible to ensure set of functions of innovated object which by the effective operating can satisfy needs." (2008, p. 77) Activities connected with value management can run by official way or by permanent intuitive optimization of everyday company behavior. On this approach all four application disciplines of value management are established. Value approach has significant place both in analytical (functional analysis) and synthetic phase (functional synthesis) of discipline application of value management. Functional analysis consists of identification, defining and organization of object functions or need as well as defining of function meaning value and level of fulfilment. In this analysis heuristic and criterion role of object are interconnected. Critical assessment in process of creative thinking is composed, too. The aim of functional synthesis is detection of new ideas which would bring high value for stakeholders.

Constructive theory is oriented mostly on creation, adjustment and interconnection of methods and individual tools of value management. This theory comes from general theory through which it is possible to define concrete procedures and appropriate tools for verification of offered value level.

Value management isn't ordinary theory. Serviceability of this discipline is evident and consists mainly from analyses which are possible to be used in practice. From this reason there were created application disciplines which represent system of methods and tools assigned by value management theories. To such disciplines belongs four essential which are mostly innovations. There belongs following disciplines:

- value analysis,

- inverse value analysis,

- value projecting,

- value product strategy.

Through value analysis, which was created by L. D. Miles, there are designed various procedures, which offer answers how to achieve better oriented product functions filling customer's needs. This method consists of principles, which are necessary that organizations would remember in their application. One of them is fact that product as such presents package of functions serving to need fulfilment. There exists base functionof product through which it is assessed. There are mainly rated: importance, invested costs or for example level of need fulfilment. Each customer in rational system tries to optimize benefit with minimal costs.(Vlček, 1992) 
After implementation of all required steps it is possible to identify objects, their functions and level of perceived value for customer. On the basis of findings it is possible to determine suitable strategy oriented on various fields of organization reigning. By suitable chosen strategies or tactics, company is able to increase its competitiveness and become leader in market.

Inversion value analysis holds reverse way of value analysis. This procedure looks for use of existing product or in some cases determine functions on needs fulfilment. This way of analysis doesn't have such use as it is in case of value analysis. Some fields, like ecological problem solving, are confronted solely with this way of value analysis.

Value projecting or Value Engineering consists of use of value approach in object creation. This field is oriented purely on development of new products and focuses on innovations in different fields. Value projecting understands new product as creation of new function which will fulfil customers' needs. This method compared to classical value analysis is enriched by additional procedures which are part of fifth phase - object research, object development, object prototyping and technological readiness of an object. This way of value analysis is concentrated on innovative products which would create new needs in customers.

Value product strategy in concentrated on production program. This way of running of companies helps to progress of maintainable competitive power of products. Its main task is to prognosticate and suggest precautions in specific objects. Object can be existing, established on market, or completely new. This method looks on problematics of value analysis partly different way. Production program of organization and market needs as whole are monitored. This way gain necessary functions by selection among current object functions and required needs which are required by market. On the basis of these activities it is possible to determine success and unsuccess of products.

Value management includes three essential roles in itself. First one of them is stimulative, which ensures specific degree of employees' motivation for increasing of perceived value at customers. Employees influence it mostly with product quality which are offered to customers. Second role is harmonization, through which there isn't maximized only value for customers, but even for owners or shareholders. Last but not least fills knowledge role which covers necessary knowledge base of value management. (Vlček, 2002)

\section{VALUE MANAGEMENT FROM THE STAKEHOLDERS POINT OF VIEW}

General value management is bringing itself to companies' attention. It is often connected purely with value which customers perceive. Companies solely concentrate on added value which they have potential to offer to their customers. Such orientation of value management is too narrowly specified. Standard itself EN 1325-1 which is created by technical commission CEN/TC 279 "Value management - Value analysis, functional analysis", which secretariat covers AFNOR, defines value as: "measure which expresses how well an organization, project or product satisfies stakeholders' needs in relation to the resources consumed."(EN 1325, p. 8) This definition points to the fact that value management should focus on needs of all stakeholders and not only on needs of customer that is part of stakeholders. Likewise standard EN 12973 points on meaning of stakeholders in value management. Such looking in problematics of value management is too narrow, whereas mentioned standard explains value by wider input note this way: "When making an assessment of value some organizations may examine the global perspective as well as the organizational perspective. This implies that, in addition to stakeholders need and consumption of resources, positive and negative impacts beyond the interests of the stakeholders should be considered." (EN 1325, p. 10) Through this fact is evident that value 
management should be enriched by other elements like impacts which enter to process of value appraisal and even out of needs of stakeholders. Value management should "apply at the corporate perspective, Value management relies on a value culture taking into account value for both stakeholders and customers." (EN 1325, p. 14)

Despite of standard clearly specifies that value management and thus value is concentrated on stakeholders, in practice this approach isn't run-in enough. Companies use view of customer whereby value for other stakeholders (owners/shareholders, suppliers, customers, employees, state) takes into account minimally or not at all. Implementation problematics of all stakeholders into value management is solved minimally nowadays. Nevertheless their significance and contribution in field of value management is significant. By choosing of right tools it is possible to increase overall market value of company which would be positively perceived by all stakeholders.

Companies are mostly oriented on customer and it isn't bad technique. View of other stakeholders absents in considerable way and they receive specific value through products or services of company, too. Another important link to value management is financial stability of business. It can influence satisfaction of almost all stakeholders. Financial stability benefit for stakeholders is undoubted. Exactness of decisions and financial security brings them higher effect and so higher value, too. Supplier doesn't need to be afraid of problems with payment condition violation when there is financial stability of company and it influences its willingness of co-operation and quality of provided goods as it is in case of consumers. Stakeholder of customers can confide in product quality and promptness of despatchment his order, whereas company doesn't feel shortage or breakdown in transforming process. With employees, financial stability is expressed through optimal system of wages which employees indirectly evaluate through perceived value. Last but not least, state and state institutions also perceive higher value in behalf of financial stable companies and mainly for their optimal level of liquidity through which they are able to pay their debts to state almost immediately. These influences are shown in figure 1:

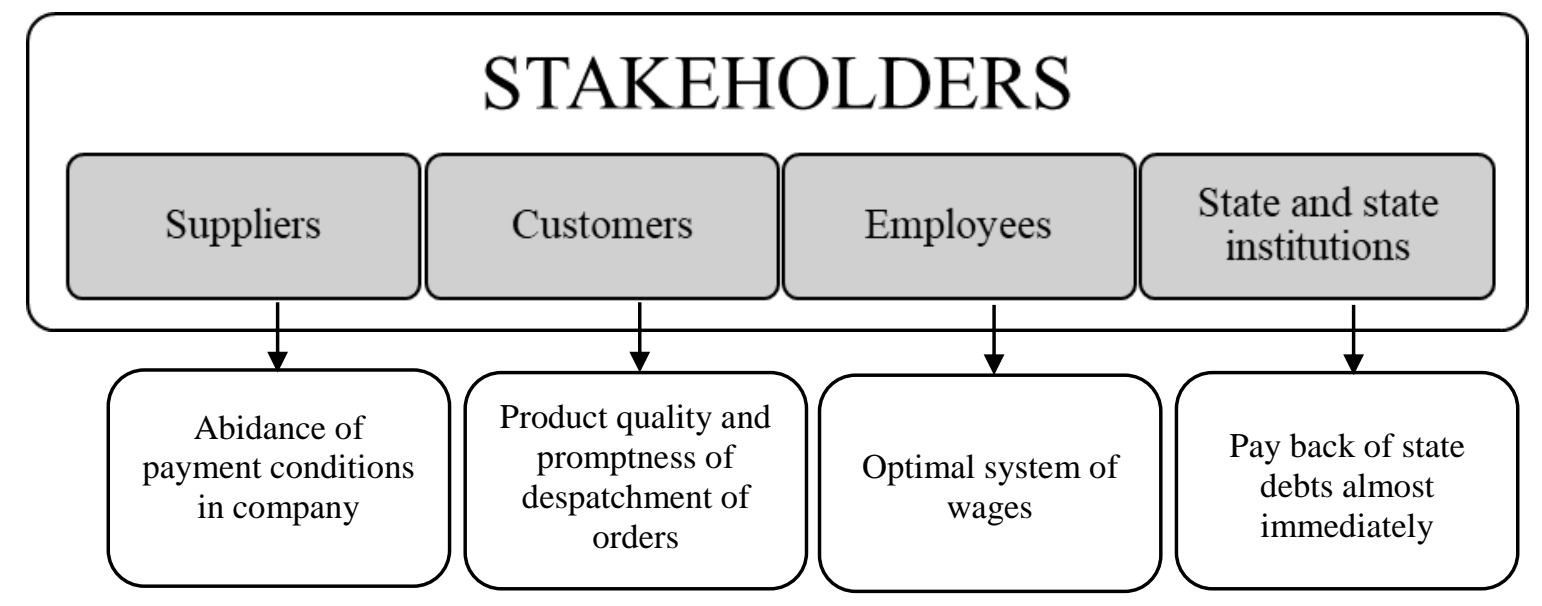

Figure 1 -Influence of financial stability on stakeholders [own processing]

Problematics of financial stability and liquidity is only one of the parts by which company can influence value and value management. Wider notion which helps to build up values is overall economic situation including liquidity index, rentability, liability and activity. Searching for optimal level of individual elements of economic situation of company provides financial managing of company. By right chosen precautions in this field there can be maximized provided value for stakeholders. 


\section{PROCESS OF VALUE MANAGEMENT}

In case of value management each phase of this process is important. Likewise, as it is in case of general management these phases are: value planning, value creation value realization and value controling.

Phase of value planning includes setting goals concentrated on offered value, in case of value management which makes provision for all stakeholders it is value for individual stakeholders. For accurate formulation of goals it is necessary that company fully knows current state on which it can build keystones of goals. Current state includes state of offered value of individual stakeholders as well as its possibilities and resources (information resources, human resources, financial resources, disposition resources). Planning has got priority in process of value management. On its basis are derived other phases which are conformed to set goals. In other phases it is expected that planning was realized in required degree with use of all accessible information either from outer or inner environment of company. In case of that it is really like this other activities are realisable easier way. Planning doesn't only provide setting goals but even means and ways how to achieve them. All these elements of planning should be divided on individual stakeholders of company in value management.

What is analysed in phase of planning by company, in phase of value creation it can be integrated. Looking for possible ways to achieve maximal level of offered value is in this phase contributing. Here are taken into consideration resources with which company disposes. For right understanding of value management from the point of view of more stakeholders, company tries to detect coherences among individual elements of company. These can both positively and negatively influence perceiving of value. Value management is often connected with culture of company which is superior to value culture which standard defines as: "attitude, awareness and sufficient knowledge of what the concept of value represent for an organization and its stakeholders and of the factors that may affect this value." (EN 1325, p. 14) It is necessary that value creation supports activities done in phase of planning.

Another phase of value management is value realization. In this phase all precautions are implemented which were set in previous phases. Realization is narrowly connected with value creation because from this phase is derived overall success of implementation of changes/building offered value for stakeholders. Like in previous phases, this phase of value realisation has to monitor level of resources and continuously analyse their serviceability and accessibility. Only results of this phase can get to individual stakeholders.

Last phase of value management is its controlling. It is phase in which it is necessary to summarize individual, yet realized, phases and evaluate their successfulness. Controlling gives feedback about value management effectiveness for company management or process creators of value management. It should be confronted with volume of used company's resources.

Phase of controlling doesn't mean the end of value management process. It is permanent process which company has to innovate. Individual stakeholders are changing and with them elements of value management must change, too. After execution of value controlling phase it is necessary that company continues with value planning phase. Value management should be permanent process which looks for new possibilities for building business value and the last but not least looks for possibilities how to increase company's competitiveness. 


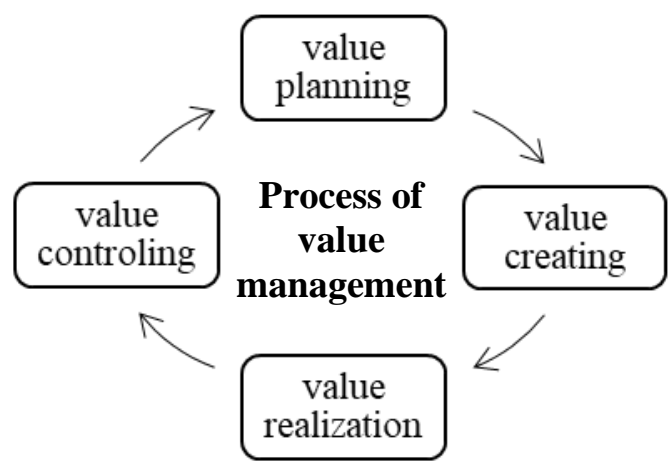

Figure 2 - Process of value management [own processing]

Competition significantly influences process of value management. On the one hand competition drives company's value management forward, on the other hand it can complicate existence on market quite a lot. Competition influences almost all stakeholders to whom value is offered. Each of them has got different preferences and in many cases it can decide to leave from company. Competitors have got the most significant influence on consumers. They can with their decision, emerged from perceived value, influence existence of business itself. Competition influences on employees about staying or leaving the organization. For this reason it is necessary that companies in process of value management takes into account impacts of competitive businesses. Their effect can change in time and therefore their activities should be monitored. In case of serious competitive changes, management of company should accept specific reformative precautions even in field of value management.

\section{STRUCTURE OF VALUE MANAGEMENT CREATION}

All previous findings in field of value management is necessary perceive as possible business opportunity. Company can achieve higher market value by right understanding of elements and their next implementation. This is easier to achieve in case of improving of organization reputation, which all stakeholders perceive. This is also reason why companies should try to apply value management oriented on company's stakeholders.

Mentioned elements, phases, tools and stakeholders are necessary to be brought into consonance into one solid model of value management. Nowadays, such specifically created system of value management applicable in business practice doesn't have definitely general conception valid for all organizations operating on different markets. Each business should keep track of its individual needs as well as needs of all its stakeholders with taking into account possibilities and abilities of company.

Companies exist in specific conditions and it is practically impossible to create clear sequence of activities which would lead to maximization of offered value and at the same time for all stakeholders. Generally valid procedures of value management basically doesn't exist. Individual elements can be partly generalized on which business shouldn't forget in process of value increasing in stakeholders. For these reasons there was created graphical design of elements, phases, tools and stakeholders which influence value and who are influenced by value (figure 3). Scheme depicts overall structure which helps in creation of value management and it is with orientation on all stakeholders. Through this structure companies should adjust their activities concentrated on provided value and off course on the basis of findings of current provided value level.

In centre of whole structure is situated value management together with its theories and application disciplines from which is fully deriving. Company shouldn't forget on all roles 
which value management fulfils in business practice. Creation and orientation of this type of management should be adjusted to all stakeholders who are significant element of business (shareholders, suppliers, customers, employees, state and consumers). In case of relation of value management and stakeholders it is mutual relation, because they are influencing themselves by significant way. On the edge of creation there is important factor - process of value management creation which is derived from usable company's resources. They are considerable influenced by economic situation of concrete company on the basis of which activities of financial management are reflexing. Value management structure further depicts weaker competition link which affects one-way and in evidently lower rate as it is in other companies' stakeholders building value management.

In case that company would decide to be inspired by depicted structure and took into account all elements in it, its activity supporting value management will be oriented maximally complex. Consciousness of individual links is necessary mainly for detecting of preferred elements of value management. As it was mentioned, it is necessary that company would take into account current and past situation from different point of views of stakeholders. On its basis it is possible to build and create value and value management. 


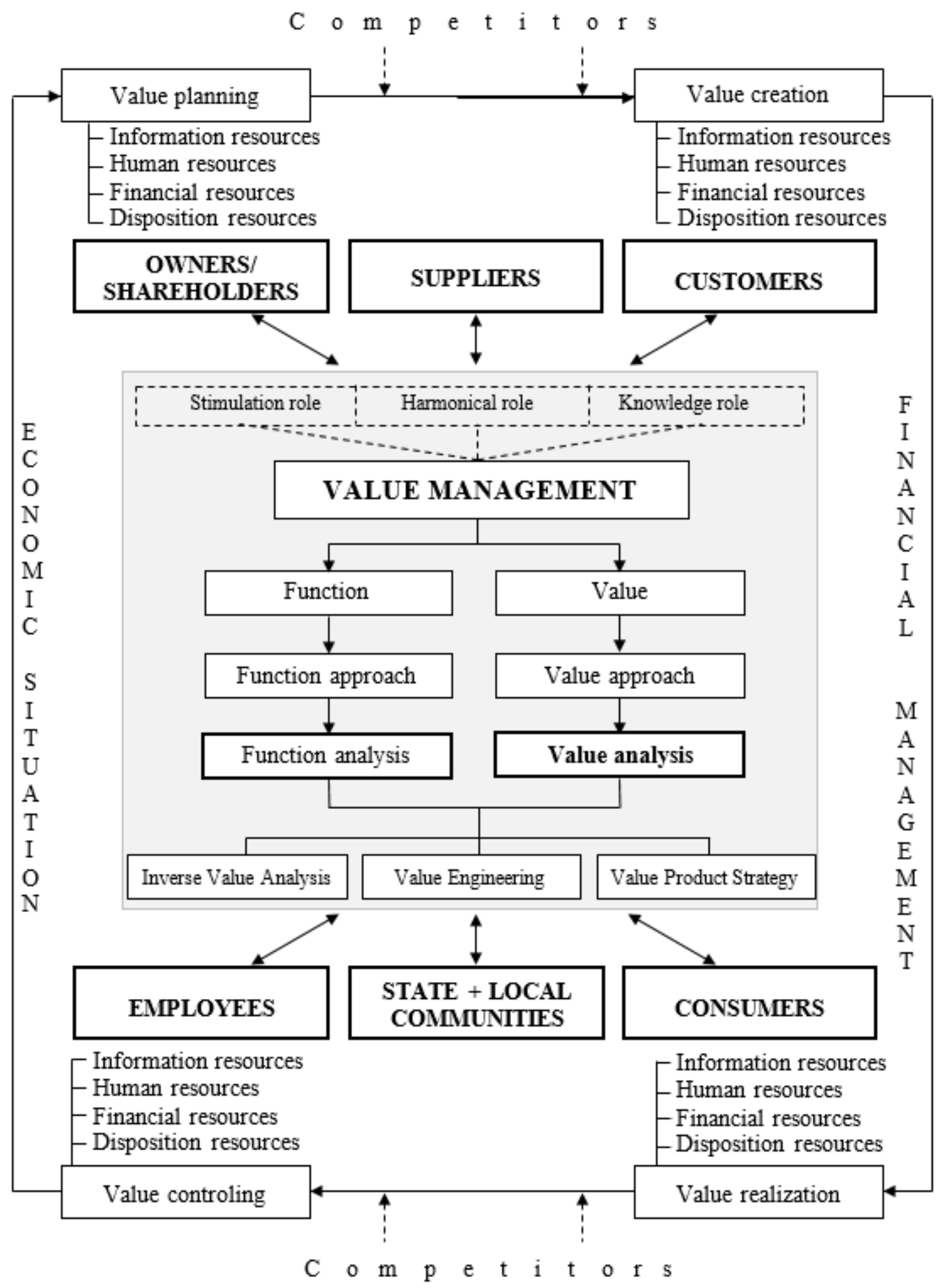

Figure 3 - Structureof value management provision for stakeholders[own processing] 


\section{CONCLUSION}

Value management is one of the complex but at the same time one of the necessary kinds of general management. It has got its specific theories as well as application disciplines which companies use in determining of level and creation of value and it is of course only in case if they are concerning with value management.

Popularity of value management grows nowadays. Consciousness of provided value for customer has become common component. Need of definite determination of value is one of the conditions of right implementation of value management elements. At this stakeholder (if we compare it with other ones) finding of perceived value is relatively easy.

There exists standards which specify value as perceived element of all stakeholders. This finding incites to similar approach to determining of value also in other stakeholders (shareholders, suppliers, customers, employees, state). Problematics revealed through analysis of standards is wide and many companies don't deal with it nowadays. This new view at value management offers possibilities of increasing market value and by this way improves financial situation of companies, which decide to implement findings and recommendations.

The article gives interesting view of connection of value management with all stakeholders affecting concrete business. Their influence on prosperity of business isn't small and so company should concern with it. Revealing of their expectations and determining of preferences can in maximal rate help to right setting of elements of value management. Only company itself is responsible whether will be follow needs of all stakeholders or will prefer only some of them. This decision is solely on preferences of company as well as on possibilities of current state findings. This kind of stakeholder is for example state, in case of which unveiling of provided value is high up toilsome and for conditions of company it is low specified.

Optimal way of value management creation is taking into account all stakeholders, all elements, phases or tools. This view authors offered through scheme depicting structure of value management creation. There were all significant items of value management which company should take into account. There exists assumption which provides complexity of value management specialization right by inspiration of progression of author's structure. It is maximally flexible and usable in all kinds of companies affecting in different fields and on different markets.

Revealing of perceived value is difficult process, which in many phases runs by chaotic way. Companies, which will decide to use value management and focus it on customers are often demotivated and they miss out other stakeholders. There exists strenuous procedure when it is possible to find out and reveal perceived value of individual kinds of stakeholders for example by personal survey (by conversations) or individually created questionnaire for individual group of stakeholder. In determining of selective sample it is necessary to consider number and accepted deviations.

Created structure can help in creation of value management system for companies and it is minimally the way that shows on individual significant elements and supports assurance of businessmen in focusing of value.

\section{References}

Bytheway, C.W.: Lesson V. in Value Engineering - How do you determine which basic function to evaluate? FAST (Functional Analysis System Technique) diagrams show the way. Product Engineering, August 1965, 61 - 67 
Dostál, V., Loubal, J., Bartes, F. (2009). Hodnotové inženýrství - Cesta k dosažení komerčně úspěšného výrobku. Ostrava: KEY Publishing, 2009, p. 374. ISBN 978-80-7418-0033

European standard EN 12973 - Value Management

European standard EN 1325 - Value Management

Gage, W.L. ( 1967). Value Analysis. London, McGraw-Hill, , p. 186. OCLC 439545341

Gale, B.T. (1994). Managing Customer Value. New York, The Free Press, ISBN 978-0-0291$1-0454$

Inovace 2015, Proč inovovat? [online] [19.03.2015] Available on the internet: http://www.mmspektrum.com/clanek/inovace-2015-tema-1-proc-inovovat.html

Kubina, M., lendel, V. (277). Manažment v teórií a praxi/on-line odborný časopis o nových trendoch v manažmente. 4/2007. ISSN 1336-7137

Miles, L.D. (1961). Techniques of Value Analysis and Engineering. New York, McGrawHill, 1961, p. 351. ISBN 978-00704-1926-1

Vlček, R. (2002). Hodnota pro zákazníka. Praha: Management Press, 2002, p. 443. ISBN 807261-068-6

Vlček, R. (2008).Management hodnotových inovací. Praha: Management Press, 2008, p. 239. ISBN 978-80-7261-164-5

Vlček, R. (1992). Hodnotový management. Praha: Management Press, 1992, p. 102. ISBN 80-85603-09-8

\section{Contact information}

Tatiana Potkanová

University of Žilina, Faculty of Management Science and Informatics, Department of Macro and Microeconomics

Univerzitná 8215/1, 01026 Žilina, Slovakia

+421415134409

tatiana.potkanova@fri.uniza.sk

Mária Ďurišová

University of Žilina, Faculty of Management Science and Informatics, Department of Macro and Microeconomics

Univerzitná 8215/1, 01026 Žilina, Slovakia

+421415134400

maria.durisova@fri.uniza.sk

DOI: https://www.doi.org/10.7441/dokbat.2016.33 


\title{
TALENT MANAGEMENT IN AN ORGANIZATION
}

\author{
Věra Rubáková
}

\begin{abstract}
There is currently no single and generally accepted definition of the term talent in an organizational context. The variety of approaches to understanding and defining the term talent implies that there are different approaches to managing talent in organizations. Terms such as talent, talent management, talent management strategy and its approaches are currently of concern, not only to personnel departments and authors of professional publications and articles throughout the world, but also to managers of organizations. In recent years, international advisers have been paying close attention to the problem of talent management in their studies, research and analysis. They attempt to define the term, find the causes and try to formulate methods for their successful resolution. The fundamental question "What is talent?" may be one of the most significant obstacles to the creation of a broad, complete and generally accepted concept of talent management. The aim of this presented work is to contribute to the theoretical understanding of talent management and specifically to a deeper understanding of the term talent.
\end{abstract}

Keywords: talent management, talent, war for talent, talent management strategy, pool of talents

\section{INTRODUCTION}

In the current global and highly competitive environment organizations are becoming increasingly aware that the knowledge, skills and abilities of their talented employees are a significant source of their own competitiveness (Iles et al., 2010).

Business practice has shown that talent management has become a driving force behind organizational success and is increasingly understood and incorporated as a strategical issue within corporations and institutions. In spite of the growing importance of talent management, it has been shown that the practical realization of its concept is ineffective in many organizations (Egerová, 2015, s. 45). According to a study by the CIPD (The Chartered Institute of Personnel and Development, 2012) only $6 \%$ of organizations questioned declared the realization of talent management in their organization to be highly effective. Egerová (2015) suggests that one of the causes is an insufficient theoretical definition of the problematics invloved, including the fundamental terms talent and talent management. According to Collings and Mellahi (2009), a definitive definition of the term talent can only rarely be found in professional practices focussing on talent management. Similarly, Thunnissen et al., (2013), on the basis of their own analysis, reached the conclusion that only half of the texts analysed contained any definition of talent while the others entirely failed to put forward any definition of the term at all. The fundamental question "What is talent?" may be one of the most significant obstacles to the creation of a complete and widely accepted concept of talent management (Thunninsen, 2013, Garraldo-Galardo et al., 2013).

On the other hand the question arises as to whether, and to what extent, any definition of talent should be universal if we take into account that any particular definition and understanding of the term is determined significantly by both context and time. It is clear that, in business practice, there will be a variety of approaches to, and concepts of talent. Despite this, Egerová (2015) supposes a theoretical understanding of the term talent to be essential. 
The following article is therefore concerned with the terminology and processes of talent management in an organization. I shall also discuss how different approaches to defining and understanding the term talent determines talent management in an organization. The aim of this contribution is to answer three basic questions: What is talent? What is meant by the "war for talent"? Who does talent management concern? Answers to these questions are important for creating a talent management strategy for a particular organization.

\section{METHODOLOGY}

The methods employed in the preparation of this contribution extend from the set aims of the theme. In the fulfillment of this aim, to which end the main theoretical and methodological approaches of talent management will be defined and compared, some secondary sources will be employed, ie. Both domestic and foreign professional literature and expert contributions, articles in print, scientific studies and research reports on the theme of the definition of talent, the processes of managing talent and the strategies for managing talent. In connection to the above, historical methods will be made use of first in order to follow and describe the genesis of individual theoretical and methodological approaches to talent management. Individual approaches will be analyzed and compared with each other. Scientific methods of analysis and comparison will be made use of. A comparison of individual sources of information allows different approaches to particular problems to be uncovered. The benefit of this contribution lies mainly in the summarization and comparison of the main theoretical and methodological approaches in the field of working with talented employees and above all in the formulation of a relatively comprehensive theoretical system of talent management. Literary sources: studies, articles in print, contributions and research were chosen by the author based upon the themes set by her and which will also be a part of the theoretical foundation of her thesis work. In this article, definitions are made of terms which were obtained through the study of secondary sources.

\section{THEORETICAL BASES FOR TALENT MANAGEMENT}

One of the key challenges scholars have experienced over the past decade has been unanswered questions regarding both the definition and goals of talent management. As Lewis \& Heckman conclude, there is "a disturbing lack of clarity regarding the definition, scope and overall goals of talent management" (2006, p.139). This might be one reason why those involved in its practice find its realisation to be somewhat challenging despite its being extremely important for the company's future (BCG, 2008).

To date, the field of characterisations and explanations as to what constitutes the essence of talent management is immense. Nevertheless, as several authors have observed, there are certain commonly held views in widespread evidence (e.g., Collings \& Mellahi, 2009; Lewis \& Heckman, 2006; Silzer \& Dowell, 2010).

"Talent management comprises the recruitment, development and stabilization of personnel that consistently achieve higher performance levels" (Davis et al., 2007).

"Talent management is a strategic activity which is part of a business strategy with the aim of attracting, developing and stabilizing talented employees at all levels of the organisation" (Hatum, 2010).

According to Lewis and Hackman (2006), talent management is defined in three ways:

1) as a combination of standard approaches in the management of human resources such as acquisition or the selection or development of a career; 
2) as the creation of an extensive pool of talented individuals which satisfies the quantitative and qualitative requirements of an organization, involving the periodical planning of succession or the planning of human resources;

3) as a logical approach born out of need to safeguard talented people in accordance with demographic development.

Talent management is the process of ensuring that an organization has the talented people that it requires in order to fulfill its goals. This includes the regulating of the flow of talent within the organization and to this end the stimulation and maintenance of the influx of talent (Armstrong, 2015).

Iles et al., (2010) defined three broader perspectives on talent management:

[1] Talent management does not differ fundamentally from the management of human resources or the development of human resources. These are always concerned with having the right people at the right time in the right place and how to control the intake and development of the people that the organization needs.

[2] Talent management is simply the integrated development of human resources which is selectively focused on the chosen "talented" portion of the organization's workforce.

[3] Talent management represents the deliberate development of the abilities of an organization to direct and maintain the flow of talent within an organization. Attention is focused more on the intake of talent rather than on a pool of talent. This is narrowly connected to the planning of succession and the planning of human resources.

Discussions are ongoing as to whether talent management is really a new approach or simply an assemblage of preexisting approaches (Armstrong, 2015).

\subsection{Defining the term talent}

There is currently no single and generally accepted definition of the term talent in an organizational context (Štefko \& Sojka, 2014).

Egerová (2015) states in her article that according to the results of a study by Towers Perrin (2003) $87 \%$ of questioned organizations have their own definition of talent which is universally accepted throughout the organization, while none of the questioned organizations share an identical definition of talent with another organization. They further state that similar conclusions were also reached by a study CIPD (2007), that showed organizations to prefer formulating their own definition of talent and that there are differences in the definition of talent between individual organizations, their definitions of talent being primarily determined by the specifications of each individual organization. It is also a significant discovery that the definition of talent is dynamic, changes over the course of time, namely according to the priorities of an organization. In spite of the claims stated above Egerová (2015) states talent is most often referred to within an organization in connection with employees with high performance levels and high potential. This is also supported by Meyers et al. (2014) who, on the basis of extensive analysis of 1023 articles published in professional journals, reached the conclusion that, in an organizational context, talent is associated expressions pertaining to high potential, high performance and also with the term competence.

"A talent is an individual who gives both a high performance and reveals a high potential" (Horváthová, 2011, p. 26). "Talent is displayed by all employees in an organization who distinguish themselves significantly regarding knowledge, skills and abilities" (Vaiman, Vance, 2008, pp. 3 - 4). "Every person in an organization has talent even if some have more than others" (Armstrong, 2007, p. 327). 
From the point of view of a systematic definition of the term talent Egerová (2015) regards the work of Garraldo-Garraldo et al., (2013) as crucial. The authors, on the basis of analysis and comparisons of the content of definitions of talent from more than 170 professional articles taken from the database Science Direct, Google Scholar, Emerald and Business Source Complete, 9 doctoral works, 44 monographs, 6 work texts and 20 reports by human resource managers, identified the following two approaches to defining the term talent:

- talent as object (talent as related to specific characteristics of a person);

- talent as subject (talent as related to people).

\section{Within the second approach there are further divisions:}

- an inclusive approach (with all employees regarded as a talent);

- an exclusive approach (with a specific group of employees regarded as talents).

On the basis of a study by Delloite (2008), in which a total of 58 companies in the Czech Republic participated, it was found that Czech companies give attention to talent management and, to varying degrees, a strategy developed for the management of talent.

Cannon and McGee claim that every organisation should make it absolutely clear what they mean by the term talent. In defining talent it is necessary to consider various factors including the measurement of current performance, output and results (Cannon \& McGee, 2007).

Similarly and Pocztowski states that a talented individual displays the abilities for strategic thinking, leadership, emotional intelligence, the ability to influence others, entrepreneurial spirit, orientation towards results, the ability to adapt to change, teamwork and corresponding expert knowledge (Pocztowski et al., 2008).

Thorne and Pellant describe talented people as creative, lively, tenacious, individual and distinctive. They suggest that the list of words that describe talent is basically infinite. The same authors also suggest the following examples of descriptions of talent: "Concentrated, focussed on performance, understanding themselves, emotionally flexible, possessing selfbelief, optimistic, pragmatic, self-assured, adventurous in spirit" or "a gifted person is someone who has a greater ability than others and for whom it is not difficult to make use of it. They excel in unaffected natural charm. A talented person has a certain charisma born of abilities that others try to equal and from whom ordinary mortals draw inspiration," or "to understand initiatives, harness inspiration, to aim for success, to be tenacious, highly singleminded, understandable, possessing self-belief, a natural leader“" (Thorne \& Pellant, 2007).

Furthermore, a global survey was carried out amongst 4741 managers in 83 countries in May 2008 which was presented in London by the organisations The Boston Consulting Group (BCG) and the World Federation of Personnel Management Associations (WFPMA), identifying current and future work priorities. Talent management is a current issue all around the world and a decisive challenge and will, in the near future, remain at the top of the agenda or near it in all regions and sectors. The main finding of the study Creating people 
Advantage: How to address HR Challenges Worldwide Through 2015 were presented at the start of May at the international conference WFPMA in London. This study suggests, among other things, that managers named improvement to development of leadership and managing the balance between work and private life as being an acute priority. Talent management ranked among the most important challenges in 9 of 17 countries including the USA, Australia, Singapore, Japan and Great Britain. In a further 14 of 17 countries studied this theme ranked at least among the top three most important. Managers expected help in solving these problems in the future in the form of support in the global search for talent (The Boston Consulting Group, 2008).

\subsection{The War for Talent}

"Talent management, made up of the planning and development of talents, is a relatively new concept which first appeared sometime after the year 2000. It is taken from the phrase "war for talent", which was first used at the end of the nineties as a means of explaining problems which organizations had with regards to the acquisition and maintenance of talented people (Hečko, 2014).

The phrase "War for talent" became a well-known metaphor in the management of talents thanks to the McKinsey \& Company Group (Armstrong 2015). Michaels et al. (2001) defined five essential steps which must be taken by any organization if they want to win what is termed "the war for management talents":

- Create an attractive, valuable offer for employees which is guaranteed to concern and attract talented people.

- Shift from acquiring talented individuals on the basis of ostentatious advertising towards the acquisition of talent on the basis of a long-term strategy.

- Make use of work experience, coaching and mentoring in the development of potential managers.

- Complete a pool of talent through investment in A-players, development of B-players, and decisive handling in the case of C-players.

- Share the conviction that competitive advantages stem from an organization's having talented people on all levels.

Pfeffer (2001, p. 258) however expressed doubts concerning the concept entitled "the war for talent" in that it is a poor metaphor for the success of an organization. Pfeffer suggests: Placing emphasis on "the war for talent" may easily result in a situation whereby the majority of employees express dissatisfaction or a readiness to leave. Organizations focus on the acquisition of more and more talented people, especially form external sources, instead of focusing on the conditions in an organization, namely on the culture and applied management system that is established, which are aspects that are decisive for performance.

\section{PROCESSES OF TALENT MANAGEMENT}

A foundation of effective work with talented employees is the formulation of a strategy for talent management that is in accordance with organizations business strategy. Only such a strategy, through the auspices of the strategies of the human resources department, can key decisions be made as to whether or which activities of talent management should be realized. The aim of such a strategy for talent management is to secure a pool of highly talented, qualified, committed and dedicated individuals capable of contributing to the achievement of the current and future requirements of the organization, namely a talent-pool. A practical 
outcome of talent management strategy are the three basic groups of processes leading to the securing of a corresponding talent-pool. It concerns the acquisition, development and maintenance of talents when each of these processes themselves involve a whole range of related activities and individual components. Talent management will only be successful if linked to the internal and external recruitment, education and development of talented individuals, their reward system, evaluation, motivation, management and internal communication (Horváthová, 2014). Talent management is clearly made up of a wide range of areas and activities. As Armstrong (2007) has stated, an organization is distinguished by how it manages its talent. Ideally all, or at least most of these activities will be linked in the way that certain organizations are actually trying to achieve. Some companies, however, only focus on one or two activities which fails to constitute a systematic approach to talent management.

Armstrong (2015, p. 315) has stated that the process of managing talents comes from the conviction that "the organization with the best people will succeed". This originated at the end of the nineties at the end of the 20th century when McKinsey \& Company promoted the "war for talent". The processes of talent management are now a significant part of securing human resources and a point of departure for the concept of talent management - it is essential to engage in planning for talented individuals to ensure an influx of talents and to create a pool of talents; this is the central theme of talent management (Amstrong, 2015). Tansley and Tietze (2013) defined talent management in the following way: "Talent management includes a strategy and politics aimed towards the systematic diagnosis, acquisition, stabilizing, use and development of individuals with high potential which bring their own individual value to the company". Nevertheless, this definition places too much stress on the "individual with high potential", and although this it can be a common interpretation of talent management, some people take talent management to concern every individual; rising from the notion that everyone has talent and that talent management should not be limited to a select few. There are many versions of talent management but, one way or another, most of them employ the typical activities of managing human resources such as the assessment of potential, development of management and leadership, the planning of progression or the mapping out of a career (Armstrong, 2015). The management of talent represents an important source of competitive advantage for organizations worldwide and that the prosperity of an organization depends on its ability to manage its talents effectively (Collings; Mellahi 2013; Nilsson; Ellstrőm; 2012).

The aim of any process of talent management is to ensure the influx and create a pool of the talented people an organization requires. To this end the entire process of talent management includes the following activities:

- The planning of talent - the process of establishing the number and types of talented people that an organization requires and will require through the use of talent audits.

- Acquiring talents - the planning of talent is the basis for acquiring talented individuals from internal and external sources.

- The identification of talents - the carrying out of audits with the aim of identifying individuals which could fall under the term talented and could be entered into a program aimed at education and development and the management of a career.

- The management of relations with talented individuals - the establishment of effective relations with people and their roles as employees.

- Talent development - policies and programs for education and development are key elements of talent management. 
- The stabilization of talent - the establishment of policies developed with the aim of ensuring that talented people do not leave the organization and remain dedicated and commited members of the organization.

- Career management - people being provided with the opportunity to develop their abilities and establish their careers which will ensure that an organization maintains the influx of talent that it requires while allowing people to fulfill their desires.

- Planning succession in management - Ensuring that an organization has the managers it needs to achieve its goals.

- The influx of talent - processes for the acquisition of talents, development of talents and career management, all of which guarantees an influx of talent and allows for the creation of a pool of talented individuals.

- A pool of talent - A source of talented people which an organization has at its disposal (Armstrong, 2015).

The purpose of this research study is to provide an insight on talent management in organisations in the Czech Republic. The shift towards strategic approach to talent management is, from our point of view, the most important challenge for organisations and a way of achieving future sustainability.

\section{STRATEGIES OF TALENT MANAGEMENT}

According to Cappeli (2008) a successful talent management strategy is characterized by the enabling of any disharmony between the supply of, and demand for talent to be dealt with and resolved. He stated that far too many organizations suffer from a surplus of employees or a lack of talent and this always at an inopportune time.

Armstrong (2015) has shown that a strategy for the management of talented individuals enables the achievement of a concordance between the process of talent management and the general goal of talent management - to acquire and develop talent wherever possible and necessary and the employment of a range of policies and approaches that are mutually beneficial.

Koubek (2008) shows in his article that two strategies play an exceptional role in talent management:

the strategy of talent acquisition and the strategy of talent stabilization.

1. A strategy for talent acquisition is based on the establishment of a good employment reputation by an organization in its attempts to become an attractive employer. This is related to a heightened awareness of the process of acquiring employees and its systematic efficiency , for example with the aid of the application of certain approaches in marketing. It is important to analyze what potential applicants for a position want and require and, when making the final decision, to take into consideration what should be offered and how it should be offered. This also concerns the values of a company, the methods of management, the leadership style and to a large degree their approach towards people. The good reputation of an organization is of course also born out of a fair reward system, care of workers and the working environment, opportunities for development and growth, a balance between the working and private lives of individuals, the quality of the managers, and the climate and interpersonal relationships within and organization.

2. A strategy for the stabilization of talent must take into account that there is a lack of capable talented people, and that key talents within any organization will be offered many 
opportunities by other organizations. It should be realized, that the departure of key workers could have exceptional and uncountable negative consequences on the performance of an organization and that the people the organization wishes to hold on to are often those which are most likely to leave it. Armstrong (2007) states: "If we wish to keep talented people we must come to an agreement with them and we must cooperate with them but there are limits as to what any organization can offer. It is also necessary to get the greatest possible contribution towards the goals of the organization from the existing talented individuals and to make evaluations and rewards based upon this". He continues: "A strategy of stabilization should be based on an understanding of the factors that influence this stabilization. Promotion is a highly significant factor for workers in the early phases of their career (at ages of 30 years old or less). Workers in the middle phases of their careers (31-50 years of age) appreciate the ability to manage their own career and to achieve job satisfaction. Workers in the latter stages of their career (above 50 years of age) will be interested in security.

Silzer and Dowell (2010) point out the difference between talent management and strategic talent management. Particularly in the phase of formulating a talent management strategy when it is necessary to bear in mind not only a strategy for human resources management, but to link this to the strategies and plans of the organization. It is necessary to ensure that every aspect of TM strategy contributes in some way to the overall plan of the company and the formulation of its values and that it is directly connected to other strategical processes related to human resource management in the organization.

\section{TALENT MANAGEMENT AND RESEARCH RESULTS FROM THE CZECH REPUBLIC}

Only a limited number of resources provide an insight into talent management in organizations in the Czech Republic. The first study was presented by Horvathová in 2011 but was only focused on a small selection of companies. Horváthová (2011) summarized: A lack of knowledge and awareness of talent management is one of the most frequent causes of the weak application of talent management in Czech organizations. For example, even in 2011, the Robert Half International study presented that almost $75 \%$ of enterprises pay little attention to issues associated with talent development.

A more recent survey was made by Hečko (2014). The author interviewed 450 enterprises (2011 - 2012), of which $20 \%$ employ talent management while $9 \%$ only some parts of talent management approaches.

New research by Egerova et al (2015) empirically explores the implementation of talent management in business organizations in the Czech Republic and Slovakia. The results confirmed that there are differences in the implementation of talent management practices between large, small and medium-sized enterprises in the Czech Republic and Slovakia. Talent management is preferred as a modern approach to HR management by large enterprises where the need for talented individuals is objectively greater than in smaller enterprises.

Current plans for new research should contribute to a better understanding of talent management implementation in SMEs.

\section{CONCLUSION}

Talented people have particular dispositions, abilities, and characteristics which enable them to work effectively. Talent management is the process of identifying, acquiring, stabilizing, 
using, and developing talented people. At present there is no single and generally accepted definition of the term talent in an organizational context. The term talent is perceived in different ways and from different perspectives. In an organizational context, talent is most commonly linked to high potential, high performance, and to competence. The defining of the term talent within the environment of an organization is usually limited to two dimensions. The first dimension distinguishes between an understanding of talent as objective or subjective. The other dimension distinguishes between inclusive and exclusive approaches Egerová (2015). Talent management comes from the competitive strategy of an organization in determining the future demand for talented people. The aim of the process of talent management is to ensure an influx and create a pool of talented people. To this end the entire process of talent management includes planning for talented individuals, acquiring talent, identifying talent, management of relationships with talented people, talent development, stabilization of talents, career management and planning the succession of managers. A strategy for talent management allows a harmony to be achieved between the process of managing talents and the general aim of talent management - to acquire and develop talented people wherever possible and necessary, through the employment of a series of policies and approaches that are mutually fulfilling.

\section{References}

Armstrong, M. (2007). Human Resources Management. Praha: Grada Publishing.

Armstrong, M. (2015). Human Resources Management. Praha: Grada Publishing.

Cannon, J. A. and McGee, R. (2007). Talent Management and Succession Planning. London: CIPD.

Cappelli, P. (200. Talent on Demand: Managing talent in an uncertain age. Boston MA: Harvard Business School Press.

CIPD (2007). Talent: Strategy, Management, Measurement. London: Chartered Institute of Personnel and Development. [online]. Available at: http://www.cipd.co.uk/NR/rdonlyres/B513502C-8F42-419C-818C-

D3C12D87E0D3/0/talentmanage.pdf?q=talentmanagement.

Collings, D. G., \& Mellahi, K. (2009). Strategic Talent Management: What is it and how does it matter? Human Resource Management Review, 19 (4), 304-313. https://doi.org/10.1016/j.hrmr.2009.04.001

Collings, D. G., Mellahi, K. (2013 Commentary on: "Talent-innate or acquired? Theoretical considerations and their implications for talent management." Human Resource Management Review, 23, 322-325. https://doi.org/10.1016/j.hrmr.2013.08.003

Davis, T. et al. (2007). Talent Assessment: a New Strategy for Talent Management. Aldershot: Gower Publishing. Deloitte, (2008). Do you have enough talented workers? A Key point for management programs. [online]. [18. 11. 2013]. Available at: http://www.deloitte.com/dtt/research/0,1015,cid\%253D220038,00.html.

Egerová, D. (2015). Talent in an organizational environment - Theoretical approaches and implications for talent management. Trends in Business 5 (1), 45-54.

Egerová, D., Lančarič, D., Eger, L., \& Savov, R. (2015) Perspectives of talent management: Records from Czech and Slovak business organisations. E+M. Ekonomie a Management, 18 (4), 108-120. /https://doi.org/10.15240/tul/001/2015-4-008

Gallardo-Gallardo, E., Dries, N., \& González-Cruz, T. F. (2013), What is the meaning of 'talent' in the world of work? Human Resource Management Review. 23 (4), 290-300. https://doi.org/10.1016/j.hrmr.2013.05.002

Hatum, A. (2010). Next Generation Talent Management: Talent Management to Survive Turmoil. New York : Palgrave Macmillan. https://doi.org/10.1057/9780230295094

Hečko, Š. (2014): Talent management in Czech companies, Opava: Slezská univerzita. 
Horváthová, P. (2011). Talent management. Praha: Wolters Kluwer.

Iles, P., Chuai, X., \& Preece, D. (2010). Talent Management and HRM in Multinational companies in Beijing: Definitions, differences and drivers. Journal of World Business. 45 (2), pp. 179 - 189. https://doi.org/10.1016/j.jwb.2009.09.014

Koubek, J. (2008). Human resources management. Praha: Management Press.

Lewis, R.E., \& Heckman, R.J. (2006), Talent Management: A Critical Review. Human Resource Management Review, 16, 139-154. https://doi.org/10.1016/j.hrmr.2006.03.001

Meyers, M. Ch., \& Woerkom, M. (2014). The influence of underlying philosophies on talent management: Theory, implications for practice, and research agenda. Journal of World Business. 49 (2), 192-203. https://doi.org/10.1016/j.jwb.2013.11.003

Michaels, E., Handfield-Jones, H., \& Axelrod, B. (2001). The War for Talent. Boston: Havard Business School Press.

Nilsson, S., \& Ellström, P. (2012). Employability and talent management: Challenges for HRD. European Journal of Training and Development, 36(1), 26-45. https://doi.org/10.1108/03090591211192610

Pfeffer, J. (2001), Fighting the War for Talent is Hazardous to Your Organization's Health. Organizational Dynamics, 29, pp.248-259. https://doi.org/10.1016/S00902616(01)00031-6

Pocztowski, A. et al. (2008). Managing talent in organizations. Poland: Wolters Kluwer. Robert Half International. (2011). $75 \%$ of Czech companies do not actively work with talents. [online]. Available at: http://www.roberthalf.cz/CZ/CZ/RHI/talentmanagement.asp.

Silzer, R., \& Dowell, B. E. (Eds.) (2010). Strategy-Driven Talent Management. San Francisco: John Wiley \& Son s.

Štefko, R., \& Sojka, L. (2014). Position of talent management in context of organizational functions. European Scientific Journal. Special edition 1, pp. 346-356.

Tansley, C. \& Tietze, S.,(2013). Rites of passage through talent management stages: an identity work perspective. Internanaional Human Resource Management. London: Sage Publications.

The Boston Consulting Group. (2008). Creating people advantage. How to address HR challenges worldwide through 2015. [online]. Available at: http://www.cchra.ca/uploadedFiles/Content_Primary/Creating_People_Advantage_ES _April_2008.pdf

Thorne, K., \& Pellant, A. (2007). The Essential Quide to Managing Talent: How Top Companies Recruit, Train Retain the Best Employees. London: Kogan Page.

Towers Perrins T. (2003). Working today: Understanding what drives employee engagement. [online]. Available at: http://www.towesperin.com/tp/getwebcachedoc?web=HRS/USA/2003200309/talent_ 2003.pdf.Vaiman,

V., \& Vance A. (2008). Smart Talent Management : Building Knowledge Assets for Competitive Advantage. Cheltenham : Edward Elgar Publishing.

Contact information

Věra Rubáková

University of West Bohemia, Faculty of Economics

Husova 11, 30614 Plzeň ,Czech Republic

Telephone: +420 775694210

vera.rubakova@centrum.cz

DOI: https://www.doi.org/10.7441/dokbat.2016.34 


\title{
USE OF CORPORATE SOCIAL RESPONSIBILITY FOR THE SUSTAINABLE DEVELOPMENT OF ORGANIZATION
}

\author{
Anusua Saha
}

\begin{abstract}
The importance of Corporate Social Responsibility (CSR) is becoming an important criteria for the sustainable growth and development of organization. The principle of sustainable development and integration of the knowledge results in the entire change of socio-economic life. With the greater awareness of environmental and social awareness and more efficient communication, the companies responsibility goes beyond purely legal or profit related agenda into a more holistic approach which has gain new impetus. Organizations worldwide are adopting mission statement and governance activities related to corporate social responsibility (CSR) and sustainable development. The main objective of this paper; CSR is to embrace responsibility for the company's actions and encourage a positive impact through its activities on its environment, customers, employees and public stakeholders who are the major participants in increasing expectations for organizations to act in a more responsible and sustainable ways. The research aims to highlight issues linked to necessity of approaching in Indian companies which might bring a revolutionary difference when the companies starts to get the real idea of CSR and apply it in their firms. The objective of this paper is to examine the nature and extent of corporate social responsibility (CSR) initiatives undertaken by Indian companies and to study the relevance of CSR in business.
\end{abstract}

Keywords: sustainable development, Corporate Social Responsibility, Stakeholders, Social responsibility of enterprise

\section{INTRODUCTION}

Corporate social responsibility (CSR) is a form of corporate self-regulation integrated into a business model. It's an evolving term that does not have a standard definition. CSR is generally understood to be the way a company achieves a balance or integration of economic, environmental and social imperatives at the same time addressing the shareholders and stakeholders expectations. The sustainable development as a concept and objective means a better life quality for us and our surroundings and it involves the integration of the economic, social and environmental dimension. The sustainable development as anconcept and objective has in view building "a better life quality for us, for our children and for our grandchildren" and it involves the integration of the economic, social and environmental dimension. In order to achieve this goal it is "necessary an economic growth that would favour the social progress and

would respect the environment, a social policy that would stimulate the economy and theenvironmental policy that should be effective and economical." In order to achieve this goal it's necessary that the concept should be formulated in this that will favor the economic growth with respect to social progress and the environment. The concept of CSR can seem to be just theoretical but it can be profitable if a social policy that would stimulate the economy and the environmental policy that should be effective and economical. The responsibility for CSR depends upon the effectiveness of governance, risk management and internal control processes associated with CSR.

The evolution of corporate social responsibility in India refers to the changes over time in India of the cultural norms of corporation's engagement of CSR, with CSR referring to way 
that businesses are managed to bring about an overall positive impact on the communities, cultures, societies and environments in which they operate. The concept of CSR for the Indian companies is not so new however it's been very less practiced throughout. Companies like TATA and BIRLA have been imbibing the case for social good in their operations for decades long before CSR become a popular cause (Khanna; Gupta, 2011). In spite of having such life size successful examples, CSR in India is in a very nascent stage. It is still one of the least understood initiatives in the Indian development sector. It is followed by a handful of public companies as dictated by the very basis of their existence, and by a few private companies, with international shareholding as this is the practice followed by them in their respective foreign country. This has form the basis of my paper for research to find out the effectiveness of the CSR for the sustainable development of the organization and to provide with solution to reach out to the other private companies in India.

\subsection{The Perception and Use of Corporate Social Responsibility}

Altough the concept has been developed since the early 1970s, there is no single, commonly accepted definition of "Corporate Social Responsibility" (CSR). There are different perceptions of the concept among the private sector, governments and civil society organizations. Depending on the perspective, CSR may cover:

a) A company running its business responsibly in relation to internal stakeholders

(shareholders, employees, customers and suppliers);

b) The role of business in relationship to the state, locally and nationally, as well as to interstate institutions or standards;

c) Business performance as a responsible member of the society in which it operates and the global community.

The first perspective includes ensuring good corporate governance, product responsibility, employment conditions, workers' rights, training and education. The second includes corporate compliance with relevant legislation, and the company's responsibility as a taxpayer, ensuring that the state can function effectively. The third perspective is multilayered and may involve the company's relations with the people and environment in the communities in which it operates, and those to which it exports. (Reyes 2002). All the concerns and problems that are associated with the CSR concept, as it has been stated before, have a global dimension. In fact, an increasing number of European companies, and not only, develops their activities in several other countries, obtaining profits as a result of these markets openings. The globalization and trade relations, the investment and sustainable development have become the fundamental problems in addressing CSR. Acknowledging the issues and concerns related to CSR, favour the investments, develop the cooperation and stimulate the technologic transfer. Furthermore, the CRS represents the microeconomic dimension of the macroeconomic concept of sustainable development.

\subsection{The favourable premises of CSR development}

CSR is generally seen as the business contribution to sustainable development which has been defined as "development that meets the needs of the present without compromising the ability of future generations to meet their own needs", and is generally understood as focusing on how to achieve the integration of economic, environmental, and social imperatives.

CSR commitments and activities typically address aspects of a firm's behavior (including its policies and practices) with respect to such key elements as; health and safety, environmental protection, human rights, human resource management practices, corporate governance, 
community development, and consumer protection, labor protection, supplier relations, business ethics, and stakeholder rights.

Corporations are motivated to involve stakeholders in their decision-making and to address societal challenges because today's stakeholders are increasingly aware of the importance and impact of corporate decisions upon society and the environment. The stakeholders can reward or punish corporations. Corporations can be motivated to change their corporate behavior in response to the business case which a CSR approach potentially promises. This includes:

1. Stronger financial performance and profitability (e.g. through eco-efficiency),

2. Improved accountability to and assessments from the investment community,

3. Enhanced employee commitment

4. Decreased vulnerability through stronger relationships with communities

5. Improved reputation and branding

Many companies use the strategy of benchmarking to compete within their respective industries in CSR policy, implementation, and effectiveness. Benchmarking involves reviewing competitor CSR initiatives, as well as measuring and evaluating the impact that those policies have on society and the environment, and how customers perceive competitor CSR strategy. After a comprehensive study of competitor strategy and an internal policy review performed, a comparison can be drawn and a strategy developed for competition with CSR initiatives.

The premises which favour the adoption and the development of CSR attitude may be the global tendency to reduce the state's role in the economy as a result of some reunited factors under the name of "globalization"

- The liberalization of international trade and financial transactions;

- The consolidation of firms in the global transnational corporations;

- Increasing information flows through the development of new technologies and reducing the state's role in achieving the expectations of its citizens, ensuring social and environmental protection.

- In this context, they are long term viable, but only those enterprises which:

- Stimulate the formation, providing suitable environment for the transmission of knowledge, access to culture and the formation of lifelong learning, expertise development and transmission, basic elements of knowledge society;

- $\quad$ Provide an environment adapted to diversity, equality, openness, transparency, taking into account the consequences of the decisions on sustainable development; domain;

Answer to a large number of issues regarding the competencies in the enterprises

Negotiate the instruments capable of measuring the performance of enterprises and report and negotiate targets; ensuring the necessary framework for exchanging the points of view between all stakeholders.

The globalization leads to complex economic change, where the enterprise, as major factor of this process, must redefine its position, being placed in a new interdependence with "stakeholders", the implementation of generous humanitarian principles mentioned above, sometimes too vague / general to be able to work with them at a microeconomic level; it is necessary to find and integrate them with specific operational tools, accessible to the height 
of each economic unit. From a progressive business perspective, CSR usually involves focusing on new opportunities as a way to respond to interrelated economic, societal and environmental demands in the marketplace. Many firms believe that this focus provides a clear competitive advantage and stimulates corporate innovation.

\section{THE INDIAN SCENARIO}

Even much before the issue became a global concern, India was aware of corporate social responsibility (CSR), due to the efforts of organisations such as the Tata Group. (Around 66 per cent of Tata Sons, the holding group of the Tata Group, is today owned by a trust).

Corporate companies like ITC have made farmer development a vital part of its business strategy, and made major efforts to improve the livelihood standards of rural communities. Unilever is using micro enterprises to strategically augment the penetration of consumer products in rural markets. IT companies like TCS and Wipro have developed software to help teachers and children in schools across India to further the cause of education. The adult literacy software has been a significant factor in reducing illiteracy in remote communities. Banks and insurance companies are targeting migrant labourers and street vendors to help them through micro-credits and related schemes. In June 2008, a survey was carried out by TNS India (a research organization) and the Times Foundation with the aim of providing an understanding of the role of corporations in CSR. The findings revealed that over 90 per cent of all major Indian organizations surveyed were involved in CSR initiatives. In fact, the private sector was more involved in CSR activities than the public and government sectors. The leading areas that corporations were involved in were livelihood promotion, education, health, environment, and women's empowerment. Most of CSR ventures were done as internal projects while a small proportion were as direct financial support to voluntary organizations or communities.

In a survey carried out by the Asian Governance Association, which ranks the top 10 Asian countries on corporate governance parameters, India has consistently ranked among the top three along with Singapore and Hong Kong, for the last eight years.

In another study undertaken by automotive research company, TNS Automotive, India has been ranked second in global corporate social responsibility. State-owned Bharat Petroleum and Maruti Udyog were ranked as the best companies in India. Bharat Petroleum and Maruti Udyog came on top with 134 points each, followed by Tata Motors and Hero Honda. The study was based on a public goodwill index and India received 119 points in the index against a global average of 100. Thailand was at the top slot with 124 points. Several foundations run by corporate houses plan to devise a common strategy to ensure transparency in their social and community development operations, such as tracking spending in and progress of such projects in their annual reports.

CSR is not new to India; companies like TATA and BIRLA have been imbibing the case for social good in their operations for decades long before CSR become a popular cause. In spite of having such life size successful examples, CSR in India is in a very nascent stage. It is still one of the least understood initiatives in the Indian development sector. It is followed by a handful of public companies as dictated by the very basis of their existence, and by a few private companies, with international shareholding as this is the practice followed by them in their respective foreign country. Thus the situation is far from perfect as the emphasis is not on social good but rather on a policy that needs to be implemented. Reliance Industries and two Tata Group firms - Tata Motors and Tata Steel-are the country's most admired 
companies for their corporate social responsibility initiatives, according to a Nielsen survey released in May 2009.

-Respect is the first thing we look for when doing anything,\| says N.R. Narayana Murthy, Chairman Infosys Technologies, the company that was crowned the Most Respected Company in the survey this year.[Source: Business world, January 2003] [India's most respected companies]. Hindustan Levers Ltd., known as Uniliver to the world outside India, is another company that has remained in the top three most respected companies for the past decade, and has topped the chart four times, the maximum number of times yet for any company. There has been a long history of CSR in India and the Tata have been the role models on this path. The Tata Business Excellence Model integrates social responsibility into the framework of corporate management wherein social responsibility is encapsulated as Key Business Process. Corporate Social Responsibility programmes at the Tata group of companies extend across a wide spectrum including rural development, community development and social welfare, family initiatives, tribal development and water management. The Birla groups of companies are also among the pioneers in the field of corporate social responsibility in India. As part of the Aditya Vikram Birla Group's Social Reach., the Birla group runs as many as 15 hospitals in India; includes Adult education and schools conducting as many as 78 schools all over India; rehabilitates Handicapped persons having touched more than 5000 physically challenged individuals. More than 1,00,000 patients have been examined under the Group's medical programmes. Over 15,000 children along with 2000 pregnant women have been immunized, over 500 cataract patients operated, 2000 TB patients provided medical care, 100 leprosy- afflicted attended to, free of cost. Among corporate who have displayed deep commitment to Corporate Social responsibility over long years is Mahindra \& Mahindra. The Mahindra Education Trust established to promote education at all levels. The Mahindra Search for Talent Scholarships is a scheme established in 34 schools in India to enthuse and reward students who have achieved excellence in their academic pursuits. As part of its Corporate Service Corps (CSC) programme, IBM has joined hands with the Tribal Development Department of Gujarat for a development project aimed at upliftment of tribals in the Sasan area of Gir forest. The financial services sector is going green in a steady manner. With an eye on preserving energy, companies have started easing the carbon footprint in their offices. The year 2009 witnessed initiatives including application of renewable energy technologies, moving to paperless operations and recognition of environmental standards. Efforts by companies such as HSBC India, Max New York Life and Standard Chartered Bank have ensured that the green movement has kept its momentum by asking their customers to shift to estatements and ereceipts. As of now the CSR programs of BILT are carried out at the following levels Integrated Rural \& Urban Community Development programmes with communities living in the periphery of our Mills, employees are encouraged to volunteer time to work on social issues, 1EV/AIDS prevention with employees, and support to NGO's for Universalizing Primary Education and arresting school dropouts. Similar commitment to CSR has been displayed by several corporates in India. The list, which at best can be far from complete, includes Arvind Mills, Escorts, Dabur, Bajaj, Godrej, Hero Honda, DCM Sriram, Ashok Leyland, Ballarpur Industries, Eicher, Kinetic Group, Kirloskar, Infosys, Reliance, Ranbaxy, Wipro, each of which has been deeply committed to their communities engaging in programmes encompassing education, health, education, integrated rural development. Beyond the private sector, corporate players in India's public sector too have been actively involved in corporate social responsibility initiatives. As many as 47 profit-making CPSEs failed to comply with the CSR norms prescribed by the government in 2011-12, said CAG in its report tabled in Parliament. -Out of the total 110 CPSEs earning profit of 
more than Rs 10 crore, 47 CPSEs did not comply with the Department of Public Enterprises (DPE) norms in terms of the minimum.

\subsection{CSR Initiatives by Major Companies}

Some examples of CSR initiatives for sustainable development taken by corporates in

India are listed below:

o ITC: ITC's globally recognized in e-Choupal program' is the world's largest rural digital infrastructure benefiting over 4 million farmers and -Social and Farm Forestry initiativell which has greened nearly 96,000 hectares, creating an estimated 43 million person-days of employment among the disadvantage. ITC's —Watershed Development initiativell brings precious water to over

46,000 hectares of dry lands and moisturestressed areas. First company in India to be certified to the SA 8000 social Accountability standard.

o Microsoft: Rozgar/ Kshamta'programs geared towards creating employable workforce, is creating a skilled workforce in the country. The company is providing free developmental software to small and medium enterprises (Microsoft Biz Spark) and provision of adolescent special security program for PCs are all very good examples of sustainable CSR.

o Indian Oil Corporation: Dedicates $0.75 \%$ of net profit to community development.

o Larsen and Toubro: One of first corporate to launch an HIV/AIDS programme.

o Infosys: Pioneering evaluation of human capital using an education index for employees.

o BHEL: All BHEL units are certified to the ISO14001 environmental management system.

o HDFC: HDFC has started a - village adoption\| scheme to improve the investment climate in Indian villages.

o Tata Iron and Steel: First Indian Company to publish a sustainability report in line with Global Reporting Initiative guidelines.

o Mahindra Shubhlabh: The agriculture business arm of Mahindra \& Mahindra, aims to use especially cultured seeds to improve contract-farming productivity.

o Sustainable CSR Initiatives: Sustainable CSR initiatives like ProjectShiksha‘, Project Jyoti“ and Project Vikas' has also helped the company to build an image of socially responsible firm.

\subsection{Challenges to CSR Initiatives in India}

Nowadays, with the issue of environmental concern it has been argued that the decision making in managerial practice must incorporate environmental sustainability, efficient use of available resources or resource conservation (Drumwright, 1994; Hart, 1995; Shrivastava, 1995a).This means inclusion of some multi-dimensional theory which will not only focus on financial valuebut will also include the Triple Bottom Line (TBL) approach i.e. People, Planet and Profit for the benefit of all (Robins, 2006). Unfortunately, most of the businesses has still focused its target by means of financial value not by the TBL approaches (Johnson, 2003). This explains the neoclassical approach of economic perspective where marketers are more interested in targeting green consumers and extracting more value from them, than focusing solely on the societal impact of marketing. The question lies is it possible to change the mind-set of business process for a green and sustainable development. The present time 
demands innovation and product improvement all the time, giving the opportunity to initiate proactive and environmental measures into the system.

- Lack of community participation in CSR activities. There is a lack of interest of the local community in participating and contributing to CSR activities of companies. This is largely attributable to the fact that there exists little or no knowledge about CSR and instils confidence in local communities about such initiatives.

- Need to build local capacities. There is a need for capacity building of the local nongovernmental organizations as there is serious, trained and efficient organisations that can effectively contribute to the ongoing CSR activity well initiated by companies.

- Issues of transparency. There is lack of transparency on the part of the local implementing agencies as they do not have adequate efforts to disclose information on their programmes, audit issues, impact assessment and utilisation of funds.

- Non availability of well organised non-governmental organisations. It is also reported that there is non-availability of well organised nongovernmental organisations in remote and rural areas that can assess and identify real needs of the community and the work along with companies to ensure successful implementation of CSR activities.

\section{CONCLUSION}

Globalization has changed corporate social responsibility, the boundaries between domestic and foreign industry and between in-house and out-houses activities which had led corporate to view from both political and economic view. On one side multinational company have taken the role of state and thus they should behave responsibly and on the other hand they need to have corporate social behaviour in order to protect their image

The concept of corporate social responsibility has gained prominence from all avenues. Organizations must realize that government alone will not be able to get success in its endeavour to uplift the downtrodden of society. The present societal marketing concept of companies is constantly evolving and has given rise to a new concept-Corporate Social Responsibility. Many of the leading corporations across the world had realized the importance of being associated with socially relevant causes as a means of promoting their brands. It stems from the desire to do good and get self-satisfaction in return as well as societal obligation of business. It can be concluded that in today's informative world where information are readily available to general public CSR has been an important part of any organization to be successful. Organization in present world cannot be successful without taking into account the social responsibility. CSR has been a vital component for any organization to have perpetual success and to create brand.

\section{References}

Barbier, E. (1987). The concept of sustainable economic development. Environmental Conservation, 14, 101-110. https://doi.org/10.1017/S0376892900011449

Body of Law and Regulation on Corporate Responsibility, Governance, and Sustainability, 4. Chahoud, T., et al. (2007). Corporate Social and Environmental Responsibility in India Assessing the UN Global Compact's Role" Crowther, David \& Capaldi, Nicholas (2008). Corporate Social Responsibility. Ashgate.

Chen, S., Ravallion, M., (2012). An Update to the World Bank's Estimates of Consumption Poverty in the Developing World. World Bank, Washington, DC. 
Chandra, Prasad, Corporate Social Responsibility of Indian Companies- A study“[online] 2011[cited 2011-22-06]. Availability at <http://www.indianmba.com/Faculty_Column/FC955/fc955.html >

Demaria, F., et al. (2013). What is degrowth? From an Activist slogan to a social movement. Environ, 22, 191-215. https://doi.org/10.3197/096327113X13581561725194

Dopfer, K. (2005). The Evolutionary Foundations of Economics. New York: Cambridge University Press. https://doi.org/10.1017/CBO9780511492297

Drumwright, M. E. (1994). Socially responsible organizational buying: Environmental concern as a non-economic buying criterion. Journal of Marketing, 58(3), 1-19. https://doi.org/10.2307/1252307

Furubotn, E. G., \& Richter, R. (2000). Institutions and Economic Theory. Michigan: University of Michigan Press.

Global Corporate Citizenship: The Leadership Challenge for CEOs and Boards\|, World Economic Forum and The Prince of Wales International Business Leaders Forum, http://www.weforum.org/pdf/GCCI/GCC_CEOstatement.pdf.

Horrigan, Bryan T. (2007). Macquarie Journal of Business Law 21st Century

Corporate Social Responsibility Trends - An Emerging Comparative

Khanna, P.; Gupta, G. (2011). PARUL KHANNA Paper-

Corporate_Social_Responsibility-1[1.pdf "Status of Corporate Social Responsibility: In Indian Context"

Reyes J. and N. Twose (2002). Education-focused Corporate Social Responsibility in El Salvador; World Bank Technical Assistance Study, Washington D.C.

Yakovleva, Natalia (2005). Corporate Social Responsibility in the Mining Industries. Corporate Social Responsibility Series, Ashgate Publishing.

Vogel, D., Is There a Market for Virtue? A Critical Appraisal of Corporate Social Responsibility.World Economic Forum, Global Agenda, Issue No.1.

\section{Contact information}

Anusua Saha

Tomas Bata University in Zlin,

Faculty of Management and Economics

Nam. T.G. Masaryka 5555

76001 Zlin

Mob: +420-776275502

E-mail : anusua08@yahoo.com

DOI: https://www.doi.org/10.7441/dokbat.2016.35 


\title{
HOW CAN BE THE HOLISTIC MANAGEMENT USED IN THE CLUSTER ORGANISATION?
}

\author{
Markéta Slováková
}

\begin{abstract}
Holistic management connects all the components of management. In the same way are created also the cluster or cluster organisations. They connect interdependent actors. Therefore this article deal with the use of holistic management within the cluster organisation.

Main tasks and activities of company management and in the cluster structure are the same. But the cluster management is promoted to the level of cooperation of many organisations. Therefore, the cluster manager has to create the credible and professional environment, where they interface competition with cooperation and common purpose.

Interdependence, cooperation, competitiveness, stability, innovation, technology and infrastructure. These are links between the business sector and the establishment of cluster organisations. These benefits are the engine for sustainable regional development.

This article is focused on linking of managerial tasks within the cluster organisations and cluster initiatives into the holistic management of the organisation. Work presents managerial project that aims to effectively connect and expand of economic, scientific and public subjects in the cluster organisation.
\end{abstract}

Keywords: holistic management, cluster, manager, competitiveness, innovation

\section{INTRODUCTION}

Interdependence, cooperation, competitiveness, stability, innovation, technology and infrastructure. These are links between the business sector and the establishment of cluster organisations. These benefits are the engine for sustainable regional development.

Currently, the emphasis is given to innovation and development of modern technology. In this case the consistency with other countries is necessary, thus maintenance the international contacts and comparison. When the comparison at the international level is not common, it resorts to negative phenomena such as the so-called "lock-in" (Tödtling and Trippl, 2004, p. 2) tendency, when there is stagnation in the creation of new innovative strategies and aversion to linking mutual knowledge networks at local, national or international level, although the market competition is maintained.

Collaboration between business institutions is limited because excessive cooperation in the region distorts the economic competition. Greatly increasing cooperation can be observed also in innovation-oriented enterprises and research institution.

Suitable cluster manager has to eliminate or, conversely, to strengthen correctly all these criteria to create for cluster organisation a competitive business environment.

\subsection{Connectedness}

Cluster organisations and cluster initiatives are strongly linked with management. Appropriately selected cluster organisation management is almost a guarantee of success of this organisation for future years. As the main tasks of the management of cluster initiatives were by Cluster Management Guide set on daily activities: 


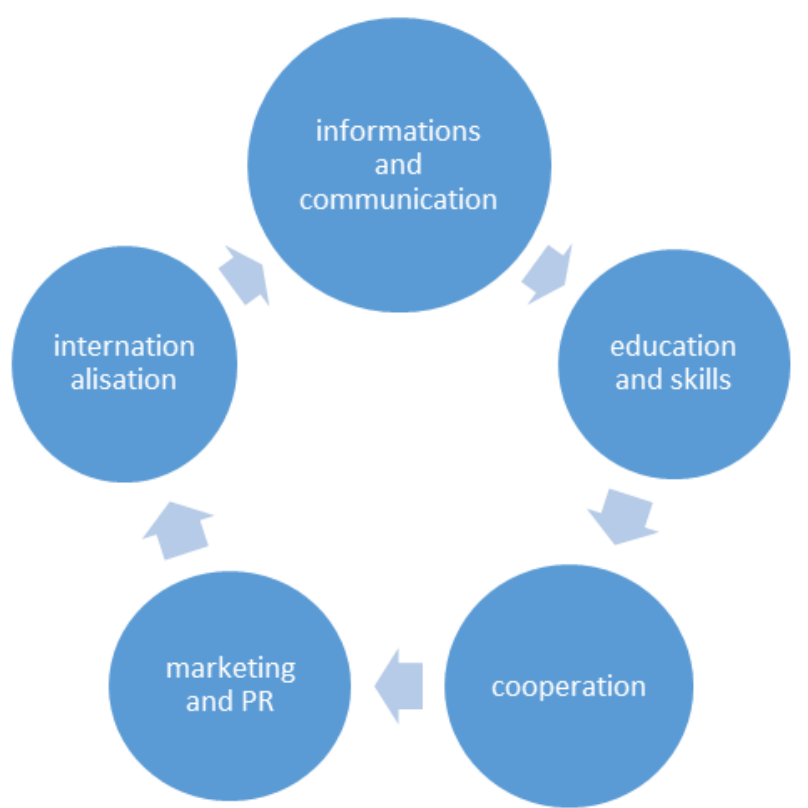

Figure 15 - Five areas of activity of cluster initiative. Source: CLOE, 2006

Cluster management supports its activities and daily work of the cluster initiative. Activities, which are described above, having the structure and content, which serves as a tool for cluster managers, team. Each of these five areas has its own structure and content fields.

While representatives of bigger European cluster organisations and political parties, especially in Western Europe, prefer the internationalization and international networking, a significant part of European organisations, in the wider context also the region, tends to "lock-in" tendency. These tendencies turn to the stagnation of creation the new innovative strategies and also to aversion to linking mutual knowledge networks at local, national and international level (Tödtling and Trippl, 2004).

\section{MANAGEMENT}

Interpretation of the concept of management is very complex. Often, however, we meet with concepts management, administration or management. A particular organisation or enterprise. Also individual nations understand the concept of management differently. (Lang, 2007)

Peter Ferdinand Drucker, the founder of modern management as an independent theoretical field, defines management in his books Concept Corporation (1946) and Practice Management (1954) as a practical discipline that draws on other areas such as economics, psychology, mathematics, political theory, history and philosophy. That does not mean that management is not a separate discipline with its own assumptions, intentions, objectives or performance criteria. According to Drucker is the best designation for management the "free art". (Lang, 2007 and Management Mania, 2013)

Commonly used definitions of management can be broadly divided into three groups (Vodáček and Vodáčková, 2006). These are Leadership, Specific functions performed by managers and The course of study and its purpose. The course of study and its purpose. 


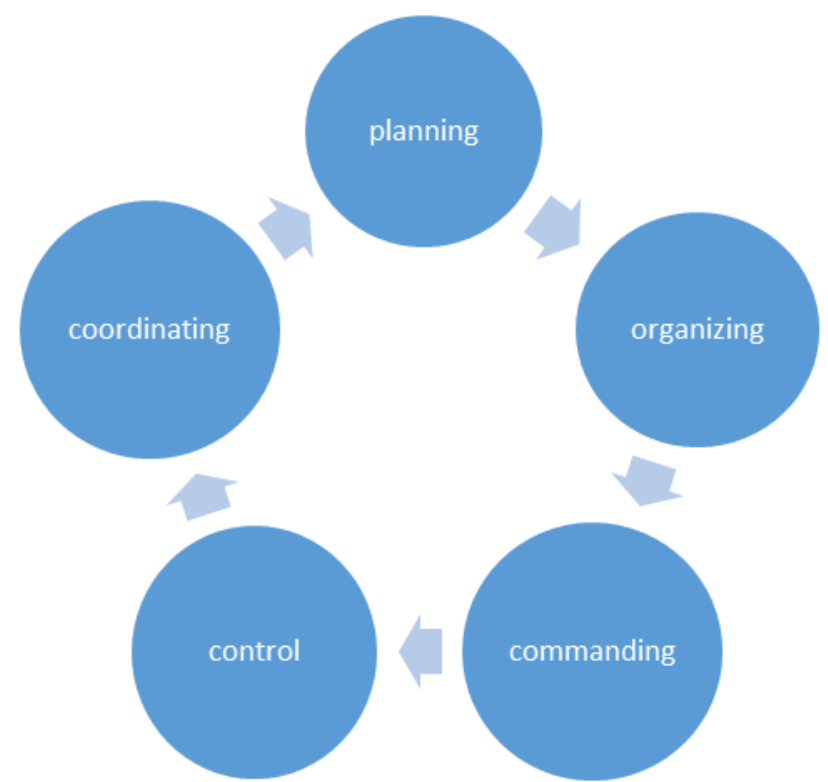

Figure 16 - Management activities by Henri Fayol (1916). Source: Management Mania, 2013

\subsection{Holistic Management}

Holistic approach or holism refer to interaction of particles that later form a unit. This unit has its own mission and purposefulness. It cannot be understood simply as a list of individual factors, but just as a mutual synergy and interconnectedness of actors. As part of a holistic understanding or a holistic approach is important as exploring the relationships and structures of interrelated subjects. The need for knowledge of such links, synergies and structures is essential for ensuring sustainable unit existence and its development. This necessity depends on properly selected management of all units. In the organisations management is necessary to achieve a responsible and balanced utilization of material and financial resources. (Porvazník, 2014)

New concept, holism, was appeared in the 20 years of the 20th century. Jan Christian Smuts is known as pioneer of this theory. He changed in his book Holism and Evolution (1926) the outdated view of science and management, a mechanical approach. He described, that the world is not made up of things, but the models. Smuts (1926) said "If you take patterns as the ultimate structure of the world, if it is arrangements and not stuff that make up the world, the new concept leads you to the concept of wholes. Wholes have no stuff, they are arrangements. Science has come round to the view that the world consists of patterns, and I construe that to be that world consists of wholes." So there is nothing individually but as a whole. Holistic management is perceived in this way. (Savory and Butterfield, 1999, p. 19)

Porvazník (2014) defines the goal of holistic management such as elimination of mechanical approach to management and the perception of the unit.

Mechanical approach to management is perceived as a given procedure how to react or how to behave during the company's control. There are given different situations, not its own invention. Man is seen such as an object of manipulation. He has to be as perfect as the machine. In this approach we can see an intensive inspection activity. (Trevor-Roberts, 1976)

This approach was developed over the years. One of the first authors who were engaged by mechanical approach to management was Max Weber, who defined six principles of the organisation of work: division of labor, rights and obligations, set of rules, impersonal and fair trial, work as a service and necessity for order, stability and efficiency (Podnikator.cz, (C) 2012). 
If we look at the examined organisation as on a set of separate elements that work independently on each other, we can never so selected unit to move within knowledge and innovation. The most important is the interconnection, interoperability and partial sharing both knowledge and technology and information. (Porvazník, 2014)

There are many approaches to holistic management, therefore the holistic planning is diverse. An example of holistic planning is shown in the following figure.

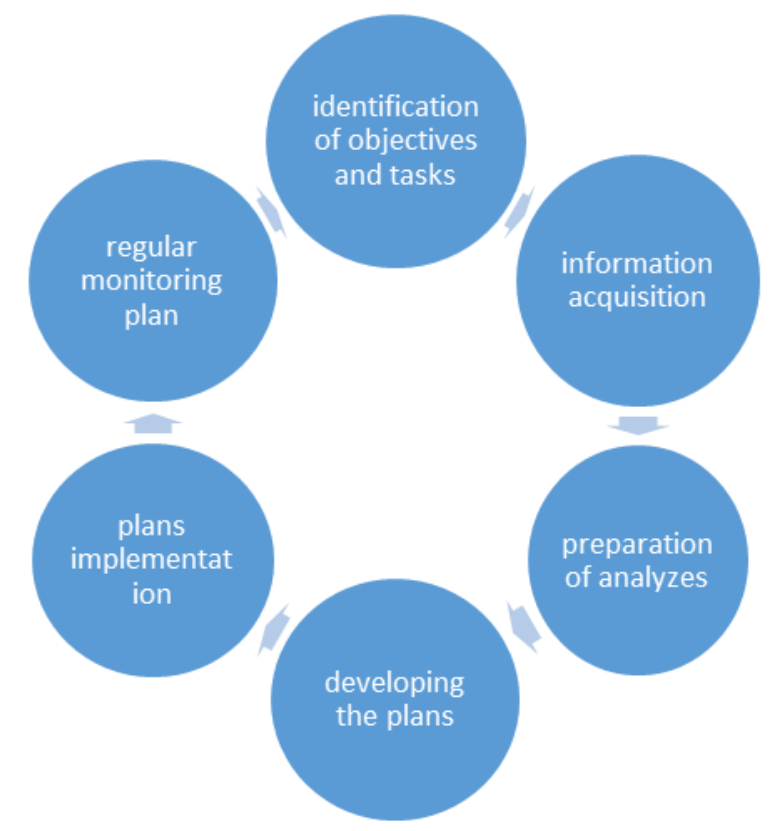

Figure 17 - One possibility of holistic planning. Source: Own processing

Holistic management approach has long been recognized not only in the private sphere, that sphere of business, but also in the public sphere, thus administrative organisations. (Porvazník, 2014)

\section{CLUSTER}

The notion of clusters occurs in the literature since the 90 s of the 20th century, when was the label introduced by Michael Porter. However, the idea of interdependence companies in a similar field of business in region has been working for a long time. Historically, the first economist, who described the relationship of economic activity and geography, was Alfred Marshall in his book Principles of Economic (1920). In this book were defined the externalities of specialized industrial localities. This idea was followed by many economists, such as Perroux (1950), Hirschman (1958), Jacobs (1961) and Krugman (1991). (Looijen and Heijman, 2013)

Definition of clusters takes many forms, but the main idea is maintained. According to Porter (2000, p. 15): „Clusters are geographic concentrations of interconnected companies, specialized suppliers, service providers, firms in related industries, and associated institutions (e.g., universities, standards agencies, trade associations) in a particular field that compete but also cooperate. Clusters, or critical masses of unusual competitive success in particular business areas, are a striking feature of virtually every national, regional, state, and even metropolitan economy, especially in more advanced nations."

Clusters and their influence mingle the whole economy, both at the macro and micro level. The clusters occurrence reveals important information about the competition and the role of 
localization as a competitive advantage. Clusters represent a new perception of national, state and local economies, which require ever new roles and tasks for businesses, governments and other institutions in strengthening the region's competitiveness. (Porter, 1990)

Also other economists put the emphasis on the creation of close functional links between actors in the defined territory, e.g. Stroper and Venables (Hájek, Novosák and Hovorková, 2011)

\subsection{Cluster Initiative}

Creating a stable and competitive cluster organisation is a long-term project. Main goal in this project is to prepare a sustainable management plan.

Cluster initiatives are organized efforts to promote the development of a cluster, people, organisations or consortium of leading positions (OECD, 2010).

According to Williams (2010), cluster initiative is based mainly on the basis of financial assistance to government, government subsidies, bank loans and other financial grants, which is the base of all cluster efforts leading to the creation of a stable cluster organisations. But in last years the cluster managers to realize, that the cluster idea and cluster initiative can't be built only on transfers, but it is important to find the ways of self-reliance and creativity.

\subsection{Cluster Organisation}

Under the word "cluster" lies, outside the definition of economist Porter, therefore coherence and concentration of locally nearby businesses and institutions, also the definition notions of cluster organisation. A cluster organisation is an institution which has legal personality, its own leadership and show all the signs of a cluster definition.

Clusters and cluster organisations are mostly very heterogeneous systems, which consist of several member companies and partners. As described Schreer and Zallinger (2007), the awareness, communication and cooperation of cluster organisation should be structured and organized. From this perspective, a cluster organisation has a crucial importance, because the organisation and rules for cooperation and commitment of a cluster should ensure the transparency and accountability for all members. Cluster organisation is also the foundation for mutual trust, which is an important link for successful cooperation. Cluster organisation defines the features and benefits for the cluster members. It helps to members identify themselves with the cluster. It supports the creation of a "corporate identity". Moreover, well managed cluster organisations have crucial impact on cluster and the region competitiveness. 


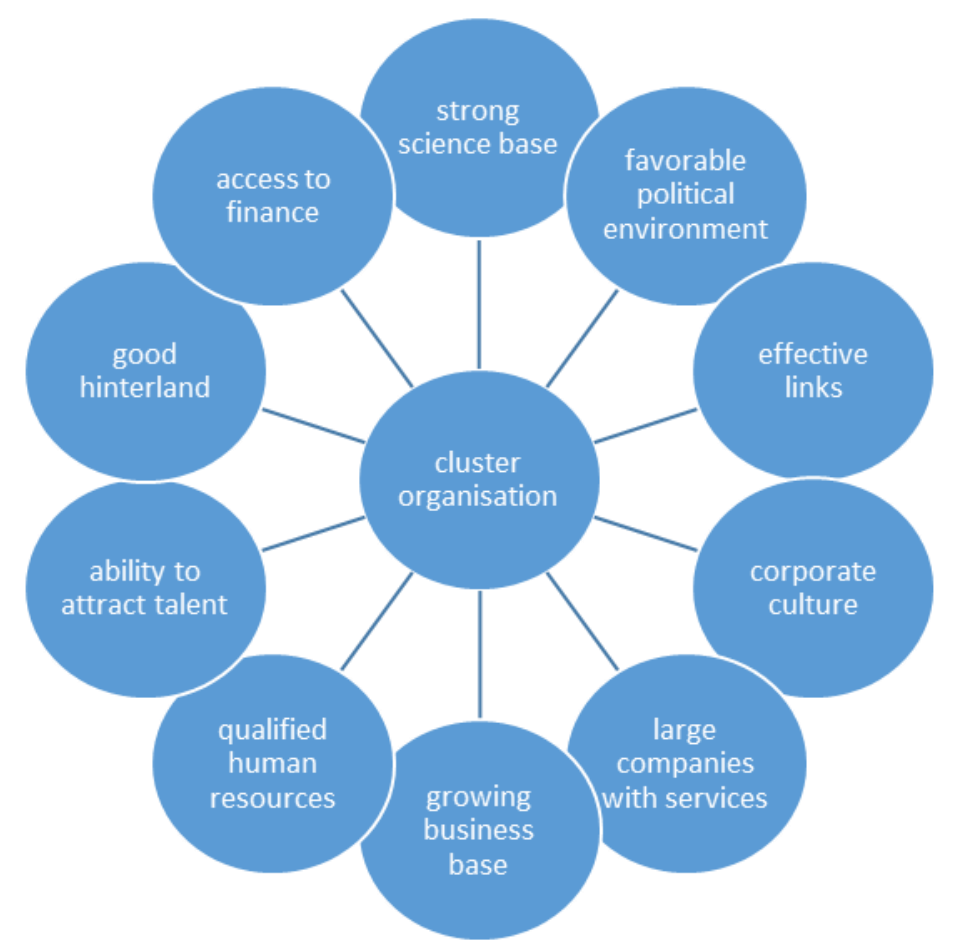

Figure 18 - The structure of cluster organizations. Source: Biocat, (C2013

\subsection{Cluster Policy}

Cluster policy is by Zahradník (2012, p. 3) an "expression of a targeted, focused strategies to create political priorities and allocating funding to support innovation, regional development or other policy objectives". Cluster policies are specific to government efforts in support of clusters, which can take various forms and follow different objectives e.g. policies promoting SMEs or research and innovation policy. According Polozhetseva and Klevtsova (2015) used cluster policy, especially in developed countries, as one of the most effective forms of structural organization of businesses in the region as well as one of the most desirable instruments of regional competitiveness.

In the Czech Republic arose in recent years two strategic documents focusing on cluster policy - national cluster policy and regional cluster policy. Both documents are designed as a summary of the current status in the Czech Republic and guidelines for the development of other initiatives and the possibility of co-financing of cluster organisations. While national cluster policy was created as a strategic document for an already functioning cluster organisations, regional cluster policy is designed to support regional cluster initiatives, awareness of regional potential and increase the competitiveness of the territory. (Pavelková et al., 2013)

According to the OECD report, cluster policies are supported on several levels. Already two programming periods are supported at the transnational level - European Union policy, at national, regional and local level. The fact that the level of financing to be used depends on several factors - the impact of the expected positive externalities and side effects, available resources and tools, and the ability to create and implement cluster policy.

Cluster policies in many European Union countries are supported by various political currents that have different tools and targets. Targets may be regional development policy, economic development, science - technology - innovation, industrial and enterprise policy and more 
support for education. These objectives can be pursued individually or may be afraid chooses no more goals. (OECD, 2010)

\section{MANAGEMENT PLAN OF CLUSTER ORGANISATION}

Cluster organisations management, the leadership of the organisation, aims to increase profitability, boost competitiveness, ensure economic and regional stability, develop creative and innovative environment, and highlight the professionalism of the entire cluster organisations, thus individual members.

From experience we know that the cluster members are diverse and it is very difficult to establish the same language from the beginning. Creating management plan is a long-term issue. The manager has to be a man, who has experience in a given economic sector and can flexibly adaptive the cluster policy needs to individual members. The members are not institutions that form a cluster, respectively cluster organisation, but the people. Within the European Union are the cluster organisation and management policy evaluated. They organized workshops, seminars and meetings with individual managers in order to create ideas and suggestions for emerging or long-established cluster organisations. In Norway was created the science park, which is used to bring young scientists and company representatives to support each other and create a collective business plan (On Clusters, 2010).

Each region has much to offer, it is only a question of how to rise to this challenge each regional players. In the Czech Republic has the main patronage over cluster initiatives the National Cluster Association. The first cluster was appeared before the Czech Republic's accession to the European Union, specifically in 2003, and it was the engineering cluster. Since then, the number of clusters in the Czech Republic increased and there is an effort to extend the clusters and cluster organisations in all sectors of the economy, because they work in their areas and regions as drivers of economic and innovative power (NCA, 2014).

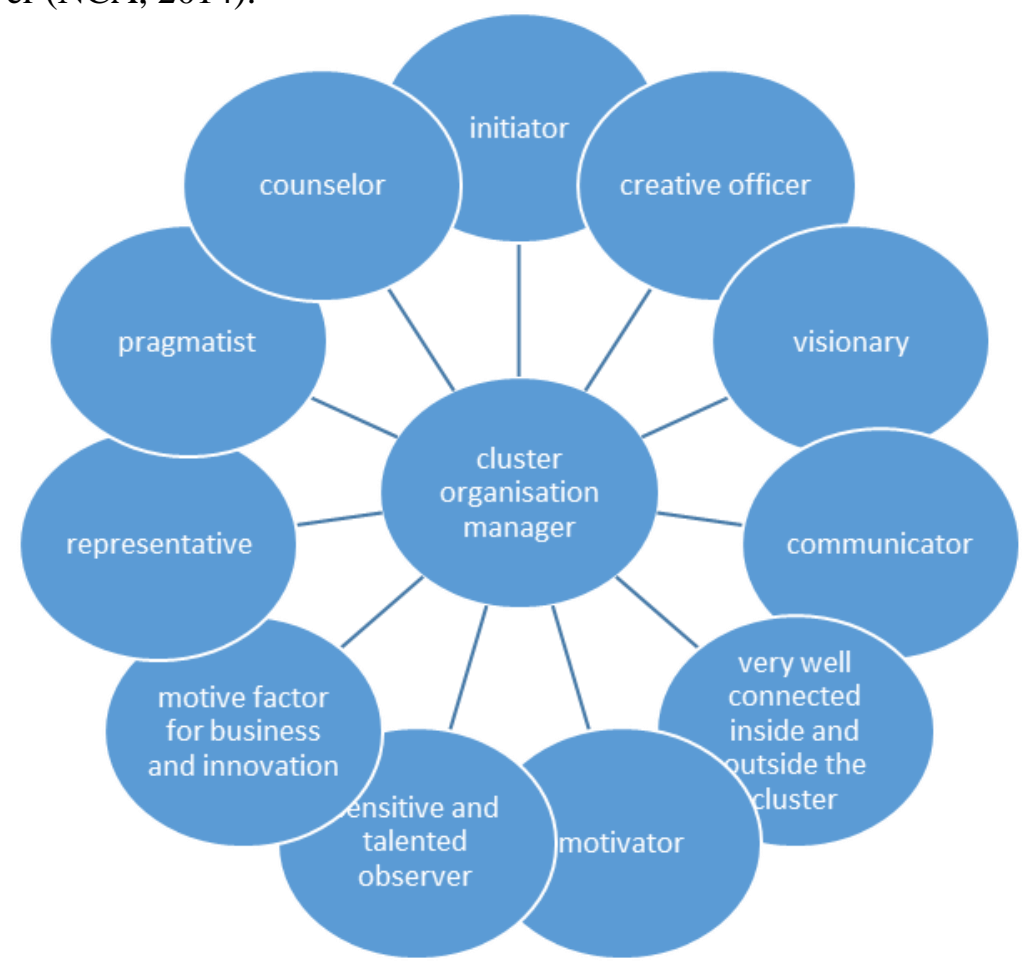

Figure 19 - Cluster manager characteristics. Source: Own processing 


\subsection{The dimension of social networks}

One of the important activities of the cluster manager is also expanding its own borders and innovativeness. In this way can be created the topical plan to enhance scientific and technological part of the cluster. It is necessary to properly grasp the everyday human communication, respectively companies, and highly scientific and distinguished form present it to the users. All social networks are very favoured in these days. Such as help for cluster managers could be develop a program that would connect all the actors of the cluster, including the media and the financial sector.

It would create a social network that would have been paid and monitored. There would have occurred three levels - local, regional and national. Local level would include municipal powers, regional level the regional powers and the national level includes the republic scope. All components of the private sector, which would like to cooperate, will be divided according to economic sector in which they operate. Other participants would be divided according to key activities and could fall into several groups. All participants should create a portfolio, according to which the contact and communicate. This would begin to create a network, which should aim to elevate and refine corporate and municipal strategy.
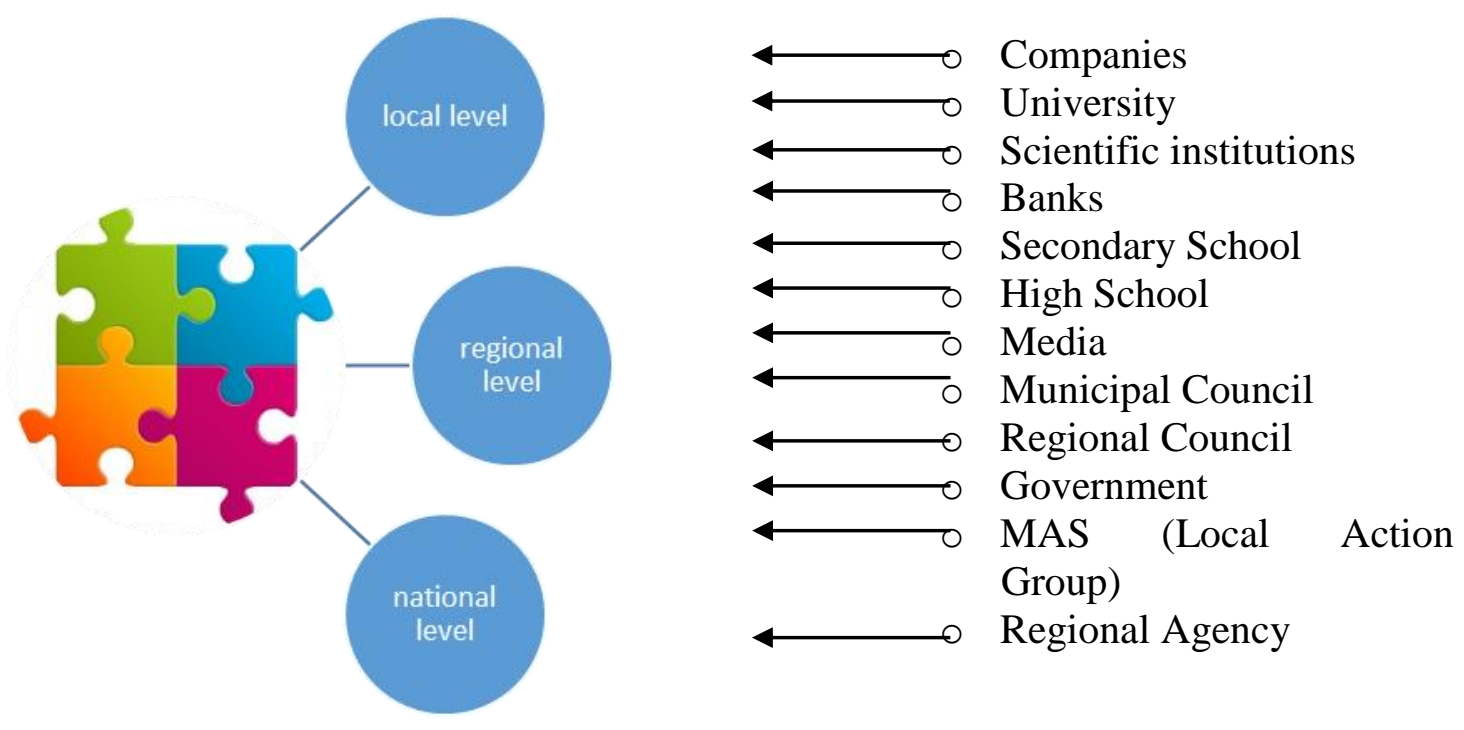

Figure 20 - Diagram of network connectivity program. Source: Own processing

\section{CONCLUSION}

The twentieth century is the century of strong changes and transformation. Even in science. Several approaches are alternated and replaced, and this is true even of different approaches in management.

The newest approaches to management includes also the holistic management. Previously was the different approaches and practices separated in parts, holistic management focuses on all of them as a unit.

A holistic approach is the ideal resource for a cluster management organisation. It connects all elements of the organisation with all management approaches. It is not focus on one part of the management or process management.

Such an approach offers a number of practices and ideas that the organisation can develop and improve. Regions and organisations can cooperate at a higher level - it creates synergies that could lead to cluster initiatives and subsequently to the cluster organisation. These 
regions are the place of cooperation between private, public and scientific spheres. Currently, the basic structure of the cluster organisation is extended by more subjects, such as media or financial institution. This is the reason why the management of such organisations has be flexible to adapt to all members, and hence the changes, that such cooperation takes. However, it is necessary to maintain a competitive efforts among different firms. Competition and efforts to achieve better results in individual subjects increase their revenue base, human resources, technological facilities and innovative potential.

The present work focuses on the description of the cluster as a whole and then each cluster mutations, such as the cluster initiative, cluster organisation and the active cluster policy. The management area was given to the holistic management, its history and current status. It was given the plan, which would link all members of the cluster organisations and offer to cluster organisations managers an innovative tool for expanding own membership and gave impulse to develop and introduce the new, more competitive and sustainable organisational strategies.

\section{Acknowledgment}

The author is thankful to the Internal Grant Agency of FaME TBU No. IGA/FaME/2015/026 "Návrh modelu vzniku klastrové organizace $\mathrm{v}$ oblasti zemědělství a cestovního ruchu $\mathrm{v}$ podmínkách České republiky a v oblasti designu na Slovensku" for financial support to carry out this research.

\section{References}

Biocat, (2013). Cluster consolidation. About Biocat. Available from: http://www.biocat.cat/en/cluster-consolidation

CLOE (2006). Cluster Management Guide - Guidlines for the Development and Management od Cluster Initiatives. Cluster Linked over Europe. Austria. Available from: http://www.interreg4c.eu/uploads/media/pdf/2_Cluster_Management_Guide_C LOE.pdf

HÁJEK, O., NOVOSÁK. J., and Hovorková, Z. (2011). Inovace a region: Klastry a regionální inovační systém Zlínského kraje. E+M Ekonomie a management, 2, 31-44. Available from: http://www.ekonomie-management.cz/archiv/vyhledavani/detail/741inovace-a-region-klastry-a-regionalni-inovacni-system-zlinskeho-kraje/

Lang, H, (2007). Management. Prague: C. H. Beck. Iss. 1. ISBN: 978-80-7179-683-1

Looien, A., a Heijman, W. (2013). European Agricultural Clusters: How Can European Agricultural Clusters Be Measured and Identified? Netherlands. Economics of Agriculture 2/2013, 337-353. Available from: http://ageconsearch.umn.edu/bitstream/152812/2/10\%20-

\%20Looijen,\%20Heijman.pdf

Management Mania, (2013). Co je Řizení (Management). Řizení (Management). Available from: https://managementmania.com/cs/rizeni.pdf

Marshall, A. (1920). Principles of Economics. London: Macmillan and Co. Iss. 8. 627 p. Available from: http://oll.libertyfund.org/titles/1676

NCA, (2014). Národní klastrová asociace. Členové NCA. Available from: http://www.nca.cz/cs/clenove-nca

OECD (2010). Cluster policies. OECD Innovation Policy Platform. Available from: http://www.oecd.org/innovation/policyplatform/48137710.pdf

On Clusters, Cluster management (3-3). Clusterobservatory. Youtube.com, 30. 3. 2010. Available from: https://www.youtube.com/watch?v=U98qsVfJrtU

Pavelková, D. a kol. (2013). Národni klastrová politika. TBU in Zlín. ISBN: 978-80-7454326-5 
Podnikátor.cz, C2012. Mechanické přístupy k managementu (začátek 20. století). Vývoj managementu a př́istupů k řízení. Available from: http://www.podnikator.cz/provozfirmy/management/rady-pro-manazery/n:16337/Vyvoj-managementu-a-pristupu-krizeni

Polozhentseva, Y., Klevtsova, M. (2015). Instruments of Development of Cluster Policy: Stages, Models, International Practice. Procedia Economics and Finance, 22nd International Economic Conference of Sibiu 2015, IECS 2015 "Economic Prospects in the Context of Growing Global and Regional Interdependencies", p. 529-537. https://doi.org/10.1016/S2212-5671(15)01029-1

Porter, M E. (1990). The Competitive Advantage of Nations. Harvard Business Review. Available from: http://dl1.cuni.cz/pluginfile.php/50387/mod_resource/content/0/Porter-competitiveadvantage.pdf https://doi.org/10.1007/978-1-349-11336-1

Porter, M. E., (2000b). Location, Competition and Economic Develop-ment:Local Clusters in a Global Economy. Economic Development Quarterly. 14(1), DOI: 10.1177/089124240001400105. Available from: http://ibr.hi.is/sites/ibr.hi.is/files/Location_CCompetition_and_Economic_Developme nt_Local_Clusters_in_a_Global_Economy.pdf https://doi.org/10.1177/089124240001400105

Porvazník, J. (2014). Celostní management. Bratislava: IRIS. Iss. 3. ISBN: 978-80-8153-0302.

Savory, A., Butterfield, J. (1999). Holistic Management: A New Framework for Decision Making. Island Press, 616 p. ISBN: 978-155963-488-5

Scheer, G., von Zallinger, L. (2007). Cluster Management - A Practical Guide. Part A: Overview. Economic Development and Employment Division. Deutsche Gesellschaft für Technische Zusammenarbeit GmbH. Available from: http://www.clusterportalbw.de/fileadmin/media/Download/Downloads_News_Presse/Cluster_Management__A_Practical_Guide._Part_A_Overview.pdf

Tödtling, F., Trippl, M. (2004). One size fits all?: Towards a differentiated policy approach with respekt to regional innovation systems. Regionalization of Innovation Policy: Options and Experiences, 1. Available from: http://epub.wu.ac.at/944/1/document.pdf

Trevor - Roberts, P. B., (1976). A System Approach to Personnel Management. Fort Hare University Press. ISBN: 094997434 X

Vodáček, L.; Vodáčková, O. (2006). Moderni management v teorii a praxi. Iss. 1. Prague: Ma-nagement Press. 295 p. ISBN 80-7261-143-7.

Williams, Ifort Ffowcs (2010). Cluster Initiatives. On Cluster: Cluster Management. Available from: https://www.youtube.com/watch?v=U98qsVfJrtU

Zahradník, P. (2012). Koncept klastrů a konkurenceschopnost v politikách EU. EU Office České spořitelny. Speciální analýzy. Available from: http://ec.europa.eu/ceskarepublika/news/120816_csas_cs.htm

\section{Contact information}

Markéta Slováková

Tomas Bata University in Zlín, Faculty of Management and Economics

Mostní 5139, 76001 Czech Republic

+420-576-032-810

m1_slovakova@fame.utb.cz

DOI: https://www.doi.org/10.7441/dokbat.2016.36 


\title{
VALIDITY AND RELIABILITY OF PERSONALITY TESTS
}

\author{
Bernhard Stocker
}

\begin{abstract}
The purpose of this study is to determine the most valid and reliable personality type test in order to be able to set up an empirical study to connect personality types with motivational factors. The ultimate aim is to establish motivational factors that would lead to an increase in productivity and efficiency in certain specific personality types.
\end{abstract}

Keywords: motivation, personality type, validity, reliability, performance

\section{INTRODUCTION}

Furnham et al. (2009) highlight that personality predetermines the variance of motivation factors to $20-30 \% \%$. A meta-analysis provided by Judge and Illies (2002) has shown that such personality tests as Big Five could be used as an important source of performance motivation.

Since there are dozens of personality type tests in existence and the number is still growing, it is quite important to choose the most appropriate and valid one in order to conduct proper research. Therefore the author's main priorities for conducting this research is to choose the most reliable and valid personality type test in existence as well as to analyse motivational factors and how they are related to certain behaviour and personality types.

\section{MOTIVATION}

"Personality refers to an individual's characteristic patterns of thought, emotion, and behaviour, together with the psychological mechanisms-hidden or not-behind those patterns."

As mentioned above, Furnham et al. (2009) highlight that personality predetermines the variance of motivation factors to 20-30\%\%. Furnham et al. (2009) also argue that for example extraverts could be motivated by intrinsic factors, such as recognition, positive feedback or other reward factors, whereas introverts will be motivated to avoid punishment. Chen et al argue in their research that extrinsic traits have a positive impact on creativity, whereas intrinsic traits have an impact on innovative behaviour.

From the point of view of behavioural theory the decisions individuals make are influenced by their values and believes. From this point of view personality characteristics play an important role in behaviour. Individual's characteristics are responsible for the way an individual perceives a world, including working environment. Existing research on the influence of personality on motivation is divided into two main trends, which sometimes are interconnected, namely a link between personal traits and job satisfaction (Furnham et al.,2005; Furnham et al., 2009) and a link between personal traits and achievement motivation. Herzberg et al. (1959) examined in his work the relationship between motivation and job satisfaction. He suggested a two-factor model of motivation, which proposes that dissatisfaction is not the opposite of satisfaction, but means absence of satisfaction. He distinguishes between two facets of work "hygiene factors" and "motivators". Hygiene factors are based on extrinsic approach to motivation and could lead to employee dissatisfaction, if they are not met. Hygiene factors include supervision, working conditions, company policies, salary, and relations with co-workers. Motivators are based on intrinsic 
approach to motivation and include aspects such as achievement, development, responsibility and recognition. Developing the two-factor model of motivation, Furnham (1997) points out an important role of intrinsic factors such as recognition and positive feedback as motivating factors for extraverts. These findings coincide with the results of a study, provided by Gray (1975), who found out that reward motivators are more important to extraverts than introverts. Furnham et al. (2005) analysed the relationships between personality and work values. They found out the motivator factors were positively associated with extraversion and negatively with openness. Hygiene factor were negatively associated with both extraversion and openness. Furnham et al. (2005) point out that job satisfaction is higher for individuals that have higher score in openness. This let them be more innovative and learn new skills. According to researchers, work vales and attitudes are accounted to $40 \%$ by genetic factors, and may stay stable despite the changes of occupation and employers (e.g. Staw and Ross, 1985).

Other researchers focus on the analysis of the relationship between personality and achievement motivation.

Cassidy and Lynn (1989) developed a system to measure achievement motivation. They propose seven dimensions. Work ethic refers to the desire to work hard, which effect a person's values, attributes and behaviour (Cassidy \& Lynn, 1989). Pursuit of excellence refers to the desire to perform the best personal results in order to achieve the personally defined standard of excellence. Status aspiration refers to evaluation of an individuals' status in view of others and is inspired with the desire to be a leader and to achieve a certain hierarchical status. Dominance, which sometimes is described as a part of status aspiration, has been identified as a separate factor referring to be in a position of authority. Competitiveness shows a high desire to compete with the ultimate goal to outperform others in the competitive task or activity. Acquisitiveness for money and material wealth refers to socio-economic status, which can be achieved by means of money and other material objects. Mastery in nature is similar to competitiveness but with oneself instead of with others. Difficult tasks and problem solving are functioning as motivation factors.

Furthermore, the system explored by Cassidy and Lynn (1989) could be integrated into a widely used two-dimensional model of achievement motivation, intrinsic and extrinsic motivation. The status aspiration, dominance, competitiveness, and acquisitiveness measures fall on extrinsic motivation, whereas mastery, work ethic, and excellence fall on intrinsic motivation.

Developing further this approach, Deci and Ryan (2008) differentiated autonomous and controlled motivation. Autonomous motivation is based on internal demands through willingness and sense of choice. Controlled motivation is based on external demands through pressure or demand. Autonomous motivation plays an important role in feeling of satisfaction, and helps to achieve effective performance in education, work, sport or other activities. Elliot and Dweck (2005) developed the theory of motivation identifying two types of motivation. Achievement motivation is focusing on completion of tasks, which are characterised by moderate challenges and risks. Competence or self-efficacy motivation is derived from the belief that people can solve difficult tasks in their own ability.

The literature review has shown a fair amount of research on the relationship of personality traits and achievement motivation in education or among students (e.g. Rahman, 2014; Hart, Stasson, Mahoney \& Story, 2007; Story, Hart, Stasson \& Mahoney, 2009). Hart, Stasson, Mahoney \& Story, P. (2007) examined the relationship between Big Five and achievement motivation. The study examined 777 students. The researchers have found out that “...[c]onscientiousness, openness, and extraversion were positively associated with intrinsic 
achievement motivation, whereas extraversion, conscientiousness, and neuroticism were positively related to extrinsic achievement motivation.“ (p. 267). In a further study Rahman (2014) has examined 180 undergraduate and postgraduate students, and have found that "[a]mong the personality factors, PG students seem to have more agreeableness, conscientiousness and openness and they also show lesser neuroticism. Among the UG [undergraduate] students, openness and neuroticism were found to be positively correlated with achievement motivation" (p. 40). Rahmen (2014) made some gender comparison, the results of which have shown that women are more achievement oriented than men, whereas conscientiousness and openness have higher score among men. "For women; extraversion, conscientiousness and openness and for men, agreeableness and conscientiousness correlated with achievement motivation." (p. 40).

Smola and Sutton (2002) argue that the social context in an individual has an impact of an individual's attitude towards authority, their understanding of organisations, the value of work define goals of work and shape work ethic. This is being confirmed by the finding of Wong, Gardiner, Lang \& Coulon (2008), who identified a relationship between socio-cultural context and personality development. They argue that social context of every generation impacts the value of work and individual's expectations from work.

\section{PERSONALITY AND LEADERSHIP}

One of the biggest questions in management is, whether leaders are born to be leaders, or whether these skills could be acquired.

Furnham et al. (2009) found out that high scores in extrinsic rewards (such as pay and bonuses) were negatively associated with job status. The reason for that is that for those who are lower in the hierarchy, hygiene factors are more important than for those, who are higher up in status However, those who are higher in status accept hygiene factors as granted, and for them power and status - or motivators - are more important. This goes in line with the Maslow theory of motivation.

As a rule, leadership is connected with taking risks. Several researchers analysed the correlation between personality and risky behaviour.

Tok (2011) found out a positive correlation between readiness to take risks and extraversion and openness, and a negative correlation with conscientiousness and neuroticism.

Seibokaite and Endriulaitiene (2012) analysed the impact of personality traits on risky behaviour, particularly on driving behaviour. They found out that conscientiousness is positively associated with risky behaviour. Conscientiousness showed a strong correlation with higher levels of work motivation and higher levels of perceived safety climate. Less risky behaviour was associated with extraversion, agreeableness, conscientiousness and lower levels of neuroticism. Seibokaite and Endriulaitiene (2012) explain this with high social responsiveness, performance norms, low aggressiveness and sociability of individuals with high score in these traits.

\section{RELIABILITY AND VALIDITY}

The main criteria to judge the worth of a test are validity and reliability. However, many tests fail on both criteria. For example, according to the survey of the Federal Office of Technology Assessment, $73 \%$ to $97 \%$ of people who fail integrity test are incorrectly classified as dishonest. Several researches (e.g. Morgeson et al., 2007), which have been 
taken recently, do not show high validity score of such tests. A meta-analysis of personality tests published between 1964 and 1982 showed relative low levels of validity (about 0.2). Ghiselli (2010), by analysing the validity of tests for personnel selection, has concluded that personality tests can only predict the level of proficiency likely to be attained by executives, but they are less useful for foremen. Ones et al. (2007) analysed personality tests from the point of view of predictors of performance. This analysis showed a positive correlation. Reddock, Biderman \& Nguyen (2011) refer to two factors that could enhance the validity of personality tests - namely the frame-of-reference (FOR) and intra-individual or within-person variability.

Other tests fail on reliability criteria. For example, three-quarters of the Myer-Briggs-test takers are assigned to a different type when re-taking the test, although the test claims to test their inborn, unchanging personality types.

In order to understand the complexity of concepts of validity and reliability, the following theoretical overview of these two constraints needs to be provided.

\subsection{Reliability of personality tests}

Test reliability consists of two parts: a test-retest reliability, which refers to the outcome stability over time, and internal consistency reliability. Research measuring a mood can have perfect internal consistency but poor retest reliability. Conversely, a research measuring such data as date of birth, social security number, height or weight is an example of a scale with low internal consistency but near-perfect retest reliability, because they might stay constant for many years.

Test-retest (or just retest) reliability is scored in a rage from +1 to -1 . The higher the correlation coefficient, the more similar the tests are. If the correlation equals to 0 , there is no relationship between two sets of scores. In general, test-retest reliability of most psychological test is less than one. This can be explained by several factors.

1. Time gap: if test takers will retake a test after a short period of time, they can remember the expressions, and therefore the test-retest reliability will be low. In order to avoid that, researchers suggest retaking the test not earlier as three months.

2. Changes of the test subject: in a gap period between the tests some changes of subject can occur, and the results may differ from the previous attempt.

3. Subject group: it is important to provide a retest to the same (sample) group. For example, if the first test has been done by jobseekers, and the second test by managers, the testretest reliability will be low, as it does not cover the same target group.

4. Subject group size: in order to reduce a standard error, the group size should be sufficiently large. Kline (1999) suggests using groups of at least 100 participants.

5. Measurement error: such factors as uncomfortable chair, a poor pen or headache or just fatigue may lower test-retest reliability scores. Poor test instructions, subjective scoring or guessing only increases confusion of a test taker and lower the test-retake reliability score.

Internal consistency reliability reflects the cohesion of the components of a test. The most common measurement of internal consistency is coefficient (Cronbach's) alpha, which (according to researchers) should be at least .07 or even .09 in order to provide high validity of a test.

Coefficient alpha is represented by a formula: 
$\mathrm{r}_{\mathrm{tt}}=\frac{n}{n-1}\left(1-\frac{\sum_{i} p_{i q i}}{\sigma_{t}{ }^{2}}\right) ;(i=1,2,3, \ldots n)$.

where

$\mathrm{r}^{\mathrm{tt}}=$ the alpha coefficient of attest of $n$ items;

$n=$ the number of items;

$\sum_{i} p_{i} q_{i}=$ the item variance;

$\sigma_{t}^{2}=$ the test variance

For good tests high internal consistency reliability is desirable but not sufficient.

\subsection{Validity of personality tests}

Validity is a much more complex constraint. Generally, a test is valid if it measures what it claims to measure. There is no widely approved coefficient to calculate validity. A test is always made for some purpose and certain conditions, which differ from test to test.

Researchers distinguish several types of validity:

Face validity: Face validity means that a test appears to be measuring what it claims to measure. The problem with this is that test-subjects are able to guess what a face-valid test is measuring. Therefore personality tests are structured in a way, that they have a lack of face validity and still possess general validity.

Concurrent validity: "A test is said to posses concurrent validity if it can be shown to correlate highly with another test of the same variable which was administered at the same time."

Predictive validity: refers to the extent to which scores from the test are able to predict some criteria or other.

Content validity: enables to measure the extent of content representativeness. Sometimes it might be overlapping with face validity, but it represents a different aspect. For example, the question "Do you sometimes feel anxious, for no particular reason?", the face-valid item is the measurement of anxiety. However, this anxiety can be distorted by deliberate lying, by imperfect self-awareness, or by ignorance. A fearful subject might put some negative result.

\section{References}

Chen, S.C.,Wu, M.C. and Chen, C.H. (2010). Employee's Personality Traits, Work Motivation and Innovative Behavior in Marine Tourism Industry. Journal of Service Science and Management, 3, 198-205. https://doi.org/10.4236/jssm.2010.32024

Cronbach, L.J. (1951). Coefficient alpha and the internal structure of tests. Psychometrika,16, 297-333. https://doi.org/10.1007/BF02310555

Dakin, S., Nilakant, V., \& Jensen, R. (1994). The role of personality testing in managerial selection. Journal of Managerial Psychology, 9(5), 3. Retrieved from http://search.proquest.com/docview/215866104?accountid=15518 https://doi.org/10.1108/02683949410066309

Elliot, A., J. \& Dweck, D.C. (Eds.) (2005). Handbook of Competence and Motivation. New York, USA: The Guilford Press.

Funder, D.C. (2013). The Personality Puzzle, 6th ed. New York: Lindaxo

Furnham, A., Eracleous, A., \& Chamorro-Premuzic, T. (2009). Personality, motivation and job satisfaction: Hertzberg meets the Big Five. Journal of Managerial Psychology, 24(8), 765-779. https://doi.org/10.1108/02683940910996789 
Furnham, A., Petrides, K. V, Tsaousis, I., Pappas, K., \& Garrod, D. (2005). A cross-cultural investigation into the relationships between personality traits and work values. The Journal of Psychology, 139(1), 5-32. https://doi.org/10.3200/JRLP.139.1.5-32

Ghiselli, E.E. (1973). The Validity of Aptitude Tests in Personnel Selection, Personnel Psychology, 26(4). https://doi.org/10.1111/j.1744-6570.1973.tb01150.x

Hart, J.W; Stasson, M. F; Mahoney, J. M; Story, P. (2007). The Big Five and Achievement Motivation: Exploring the Relationship Between Personality and a Two-factor Model of Motivation. Individual Differences Research, 5 (4), 267-274

Herzberg, F., Mausner, B. and Snyderman, B.B. (1959). The Motivation to Work. 2nd ed., John Wiley \& Sons, New York, NY.

Judge, T. and Illies, R. (2002). Relationship of personality to performance motivation, Journal of Applied Psychology, 87, 797-807. https://doi.org/10.1037/00219010.87.4.797

Khaireddin, M. (2015). The Impact of the Big Five Personality Traits on the Leadership Styles: An Empirical Study Applied on the Branch Managers of Banks Working at the Hashemite Kingdom of Jordan. International Journal of Business and Management; 10 (9), 193-206. https://doi.org/10.5539/ijbm.v10n9p193

Kline, P. (1999). Handbook of Psychological Testing (2nd Ed.) London, UK: Routledge

McCrae, R. R., Kurtz,J. E., Yamagata, S., \& Terracciano, A. (2011). Internal consistency, retest reliability, and their implications for personality scale validity. Personality and Social Psychology Review, 15(1) 28-50. https://doi.org/10.1177/1088868310366253

Ones, D. S., Dilchert, S., Viswesvaran, C., \& Judge, T. A. (2007). In support of personality assessment in organizational settings. Personnel Psychology. https://doi.org/10.1111/j.1744-6570.2007.00099.x

Paul, A.M. (2005, February 13): The cult of personality tests. A flawed but trendy management tool. Globe Newspaper Company, Inc., Retrieved from http://www.boston.com/news/globe/editorial_opinion/oped/articles/2005/02/13/the_cu lt_of_personality_tests?pg=full

Rahman, S. (2014). Effect of personality factor on achievement motivation. Indian Journal of Health and Wellbeing, 5(1), 40-45.

Reddock. C, Biderman M. and Nguyen, N. (2011). The Relationship of Reliability and Validity of Personality Tests to Frame-of-Reference. Instructions and Within-Person Inconsistency. International Journal of Selection and Assessment, 19(2) https://doi.org/10.1111/j.1468-2389.2011.00540.x

Seibokaite, L., \& Endriulaitiene, A. (2012). The role of personality traits, work motivation and organizational safety climate in risky occupational performance of professional drivers. Baltic Journal of Management, 7(1), 103-118. https://doi.org/10.1108/17465261211195892

Smola, K. W. E. Y., \& Sutton, C. D. (2002). Generational differences : revisiting generational work values for the new millennium. Journal of Organizational Behavior, 23, 363382. https://doi.org/10.1002/job.147

Staw, B.M. and Ross, J. (1985), Stability in the midst of change: a dispositional approach to job attitudes, Journal of Applied Psychology, 70, 469-80. https://doi.org/10.1037/0021-9010.70.3.469

Story, P. a., Hart, J. W., Stasson, M. F., \& Mahoney, J. M. (2009). Using a two-factor theory of achievement motivation to examine performance-based outcomes and selfregulatory processes. Personality and Individual Differences, 46(4), 391-395. https://doi.org/10.1016/j.paid.2008.10.023 
Story, P. A., Stasson, M. F., Mahoney, J. M., \& Hart, J. W. (2008). A two-factor model of achievement motivation. Social Behavior and Personality, 36, 707-708. https://doi.org/10.2224/sbp.2008.36.5.707

Tok, S. (2011). The Big Five Personality Traits and Risky Sport Participation. Social Behavior and Personality, 1105-1112. https://doi.org/10.2224/sbp.2011.39.8.1105

Segal, D.L. and Coolidge, F.L. (2003). Objective Assessment of Personality and Psychopathology: An Overview. In Hilsenroth, M.J. et. All. (Eds.) Comprehensive Handbook of Psychological Assessment, Volume 2, Personality Assessment

U.S. Congress, Office of Technology Assessment (1990). The use of integrity tests for preemployment screening, OTA-SET-442.Washington, DC: US. Government Printing Office, September 1990). Retrieved from http://www.fas.org/ota/reports/9042.pdf

Wong, M., Gardiner, E., Lang, W., \& Coulon, L. (2008). Generational differences in personality and motivation: do they exist and what are the implications for the workplace? Journal of Managerial Psychology, 23(8), 878-890. https://doi.org/10.1108/02683940810904376

\section{Contact information}

Bernhard Stocker

DOI: https://www.doi.org/10.7441/dokbat.2016.37 


\title{
MONEY ILLUSION AND THE EURO: DOES THE SINGLE CURRENCY LEAD TO SUB-OPTIMAL ECONOMIC CHOICES?
}

\author{
Ivo Strejček
}

\begin{abstract}
The "money illusion" phenomenon describes behavioral bias under which people calculate with the nominal value of money instead of its real value. The problem of unfamiliarity with the real purchasing power of money is regarded by the mainstream economy as irrational behaviour. Contrariwise behavioral approach considers money illusion as a real-world problem of sub-optimal decision-making. This paper describes the money illusion phenomenon and reviews current literature on this topic. The second half deals with a socalled Euro illusion, which is a form of money illusion suffered by economic agents during a transition period of change from national currencies to the single currency Euro. After analysis of empirical research conducted in major Euro-area countries the paper concludes that economic agents in Euro-area countries were in transitory period confused by the new nominal values of the Euro currency and made sub-optimal economic choices. The paper finally discusses possibilities of reducing sub-optimal behaviour in the transitory period after the Czech accession to the Eurozone.
\end{abstract}

\section{Keywords: money illusion, Euro illusion, Euro, cognitive bias}

\section{Introduction}

In documents of accession to the European Union the Czech government made a bounding commitment of the future accession to the Euro single currency system. It is economic and political decision but both economists as well as politicians should care not only about macroeconomic aspects of this very important and almost irreversible step (so-called Maastricht criteria), but also about microeconomic impact of the introduction of new exchange rates on individual agents, firms and households in the economy. Microeconomic effects should be regarded even as more important than arbitrary macroeconomic criteria. One of possible negative consequences could be the "Euro illusion" and structural bias in mental accounting, caused by rounding of nominal values and prices. This could - on the aggregate level - lead to non-optimal decision-making and significantly large unintended transfers of wealth due to bad optimization of agents.

This paper in its first part briefly introduces the economic concept of "money illusion" phenomena and demonstrates how this cognitive bias affects our everyday economic behavior. The second part outlines hypothesis that introduction of the Euro currency led to the so-called "Euro illusion". The hypothesis is tested on evidence gathered in studies from chosen Western European countries, which adopted the Euro in 2002. The third and concluding part humbly lays out possible solutions for reducing risk of the "Euro illusion" in time of adoption of the Euro in the Czech Republic.

\section{The Money Illusion ConcePt}

Adam Smith, one of the first modern economists and founder of the field of economic science, noticed difference between nominal and real value of money in his vast deliberations about currency and money (Smith, 1776, Chapter V, p. 35). Nominal value of money is measured in units of currency and it is basically just a plain number. On the other hand, real value of money is measured in its purchasing power (i.e. how much goods and services can consumer purchase for given banknote, coin or virtual record on bank's servers). Smith 
argues that purchasing power of money depends on demand for it and thus the real value is variable over time. In this dualism of value - nominal and real, economic subjects should not care about how much money they nominally earn or have in a pocket, but more importantly how much goods and services they can purchase for their income.

From Smith's approach stems the Homo oeconomicus approach to human behavior, widely embraced by the neoclassical mainstream in economic theory. Fully rational economic agent model expects perfect information about real value of money, all prices and their relations in the economy and neutrality of nominal changes in income (i.e. inflation has no real effects). On top of that it is expected that computing capacity of agents is limitless and they are able to make the right decision every time with no cognitive costs. But our daily experience proves us otherwise: full rationality in economic behavior as it is theoretically described does not exist. We do not have perfect information about the real value of a banknote in our wallet and relative prices of all goods and services in the economy, nor we can translate nominal values into real ones with zero or even low cognitive costs. In the real world people ignore real value of money and rather use its nominal value as a proxy for the real value. It means they consider nominal rather than in real terms of trade. This phenomenon is in economics called the money illusion.

Probably the biggest promoter of "animal instincts" and flaws of economic judgment due to the money illusion was John Maynard Keynes (Keynes, 1936) whose interpretation of the causes of the Great Crisis and "bastardized" derivatives of his work took over the field of economics for almost four decades. But one of the first economists who grasped the money illusion phenomenon with rigorous scientific approach was Irving Fisher (1913, 1928). After the WW1 Fisher noticed that "the dollar is not the same as it was before the war" (Fisher, 1928). Even under the gold standard, the value of dollar was unstable and the war inflation consumed almost one third of the real value of money held by public. Fisher's basis assumption was that people generally do not understand inflation and they use a nominal value of currency as an anchoring value to which all other nominal prices of goods, services and foreign currency are compared. We can see the evidence of almost a century old Fisher's idea when people complain that "costs of living went up" and not that "value of Czech crown went down".

Fisher's contribution to the theory of nominal and real interest rates and thus duality of price of money became one of the alternative explanations of the Great Depression. It persuasively explained why people during episodes of low interest rates and inflation of "easy" or "cheap" money consider not only their nominal, but also real disposable income higher and invest in bull stock market, dragged up by high supply of money (thus breaking neutrality of money assumption). The market bubble is fed on misunderstanding that the real value of income does not grow proportionately with its nominal value unless the productivity grows; ultimately leading to spectacular crash of markets and shattering of savings invested in speculative shares and bonds.

Despite different approaches in methodology and theory, all major schools of economic thought had paid attention to the money illusion problem. Economists nowadays are returning back to the origins of Smithian approach to human behavior and try to de-mathematize and simplify economics. In past decades the money illusion phenomenon had been in focus of work of the Nobel Prize winners George Akerlof (Akerlof, 2002; Akerlof, Shiller, 2009), Daniel Kahneman and Amos Tversky (Tversky, Kahneman, 1981), Peter Diamond and other prominent economists and winners of the Nobel Prize in Economics (Diamond, Shafir, Tversky, 1997).

The mere existence of the money illusion has important consequences for economic science. If we embrace money illusion as a real world feature of behavior, neoclassical models with simplified assumptions do not work very well as they do not predict or take into account 
skewed consumer behavior caused by our cognitive biases. We might consider economists as people, who posses high level of rationality - they should at least know "guts" of models, principles of game theory, are able to (up to some extent) predict future market behavior based on current trends in the society. On top of that we might expect that they should discriminate between nominal and real values in their ordinary lives. But as experimental results show, economists are equally blinded by the money illusion as the rest of the population. Wong (2005) examined impact of money illusion in a survey conducted among students of economics major and non-econ majors. He concluded that results of economics major students were no better than their peers with different majors.

Extent of money illusion varies with frequency of market interactions and stakes put in the interaction. When we buy a car (on average once in about three years), we consider many variables and compare our decision with the next-best alternative with much more attention than when we buy a candy bar at the supermarket cash register. The theoretical reasoning is rather clear - the less frequent market transaction is and the bigger share of our wealth is invested in them, the more carefully we tend to allocate our sources into purchase of more information as the marginal utility derived from them is greater due to higher stakes of the decision. The key variable for a rational decision-maker (on the both sides of the deal) would be incorporation of inflationary indexing of prices (as the inflation consumes part of lender's wealth and on the other hand makes price of borrowed money cheaper for the debtor). Failure to do this could be considered money illusion as well because people base their decisions on nominal rather than real terms.

But even when the stakes are high and people as well as banking institutions make deals bounding them in creditor-debtor positions for decades ahead, cognitive bias is present in more cases than we would expect. Brunnermeier and Julliard (2006) showed in the case of American and British real estate markets that the money illusion is present in decisionmaking process of market agents. The same works for the capital and financial markets. Modigliani and Cohn have formulated theory of underestimation of inflation in valuation of investment opportunities in their paper almost four decades ago (Modigliani, Cohn, 1979). They empirically confirmed that investment brokers index real cash flow with nominal rather than real interest rates (less inflation). This structural bias reduces their (and of their investor) net wealth in periods of positive inflation. Modiglinani's conclusions are in today's world of quantitative easing and "free money" very current and could pose a serious problem in the near future. The solution to the money illusion bias in the financial market offers Cohen (Cohen et al., 2005) with the idea of stable inflationary expectations and transfer from nominal to real indexation of government bonds.

The money illusion phenomenon also causes downward non-flexibility of wages. Shafir, Diamond and Tversky (1997) explored problem of incomplete contracts. Even under deflationary monetary policy (when a price level goes down and the real value of money rises), employees consider proportional reduction of their wages as not fair and they respond reciprocally by lowering their work efficiency (Akerlof, 1982). On the other hand, during periods of high inflation incomplete contracts do not offset the hike in real values by proportional increase of real-term wages in the majority of instances. Fochmann et al. (2013) also suggest that money illusion plays important role in setting tax burden with regard to effort put in labour. Contrary to popular belief they found, that even when net income stays the same, people tent to work harder under higher tax rates.

\section{The Euro Illusion}

In the year 2002 the European single currency - the Euro - was introduced in the first ten countries of the European Union (Belgium, Finland, France, Ireland, Italy, Luxemburg, 
Germany, Netherlands, Portugal, Austria and Spain). Almost overnight the basic nominal unit of economic calculation in each country changed dramatically. The virtual Euro (used between 1999 and $31^{\text {st }}$ December 2001) was used mostly for inter-bank or government purposes and on the New Year's Day of 2002 individual consumers had no prior experience with the new currency.

Even after large government and EU expenditure in information campaigns and mandatory periods of listing old (in national currency) and new prices (in Euros), the transition brought significant costs for microeconomic agents. Table 1 shows exchange rates of national currencies to the Euro as they were set on $31^{\text {st }}$ December 1998. All national currencies except the Irish pound had nominally lower value than the Euro (for the same purchasing power of the currency unit).

Table 1: Exchange rates of national currencies to Euro. Source: ECB.

\begin{tabular}{|l|l|l|}
\hline Country & Currency & Exchange Coefficient to Euro \\
\hline Austria & schilling & 13.7603 \\
\hline Belgium & franc & 40.3399 \\
\hline Germany & Mark & 1.9559 \\
\hline Netherlands & guilder & 2.2037 \\
\hline Finland & markka & 5.9457 \\
\hline Ireland & pound & 0.7877 \\
\hline Italy & lira & 1936.27 \\
\hline Portugal & escudo & 200.482 \\
\hline Spain & peseta & 166.386 \\
\hline Luxemburg & franc & 40.3399 \\
\hline France & franc & 6.5596 \\
\hline
\end{tabular}

People has tendency to round up numbers while performing mental accounting (Thaler, 1999). But exchange rates between national currencies and the Euro did not help them much in smooth transition. Our hypothesis may be that people count with exchange rates 14 or 15 shillings to one Euro rather than with official rate 13.7603 (and thus they make mistake of calculation by $1.7 \%$ and $9 \%$ respectively). This imprecise calculation then leads to suboptimal decision-making and unintended transfers of wealth.

There were also other negative costs of the transition to the Euro. The first one is the cost of price transformation (people must pay higher attention, allocate more resources in their decision-making). The second one was the physical (nominal) form of the currency. There are eight coins in the Euro $(1 \mathrm{c}, 2 \mathrm{c}, 5 \mathrm{c}, 10 \mathrm{c}, 20 \mathrm{c}, € 1, € 2)$ and seven notes $(€ 5, € 10, € 20, € 50$, $€ 100, € 200, € 500)$. People had to get used to almost no value of nominally "smallest" coins for which they would find no good use in the daily financial transaction and high value of bank notes. As most of the countries' nominal exchange rates were expressed in rates to which there existed national bank notes (40 Belgian francs to 1 Euro), subjective decrease of the value of money due to the transition of a bank note form to a coin form was significant 
(Ranyard, 2007). It is interesting to note that the longest negative effect of denomination of Euro was present in Ireland, which had the best exchange terms of all above-listed countries (in 2006 there was even a petition of Italian Members of the European Parliament demanding introduction of $€ 1$ and $€ 2$ bank notes).

The physical form of the currency and nominal values of bank notes and coins may lead to serious problems with a management of personal finance (Routh, Burgoyne, 1989). It was no exception that people could not plan their flow of monthly expenditure according to inflow of income. Many of them were even unable to effectively use ATM machines to match liquidity needs as they withdrew usually lower amounts than they needed. Groups of people with low personal financial management skills even considered exchange rates between national currency and the Euro as one-to-one (i.e. 1 Euro for 1 lira in Italy or 1 Euro for 1 Slovak crown later in 2008), which led to significant mistakes in personal finance management.

As a method how to experimentally test size of Euro illusion phenomenon, economists gathered data on church charity collections in Italy and Ireland in 2001 and 2002 (Cannon, Cipriani, 2006). Advantage of such an approach is in year-to-year comparability of the collected data (the charity collections are held in the same season, people who go to church are roughly the same group, the benefited institutions are widely-known). The data from 113 Catholic churches in Verona and 77 Anglican churches in Ireland confirmed hypothesis that donors gave significantly more after introduction of the Euro than before (difference $+11 \%$ in Italy and $+13 \%$ in Ireland). In the control group of British Anglican churches there was no such hike in collected money. Italian experience cannot be explained merely by economic growth $(+3.13 \%)$ and rounding up (rounded 2000 liras to 1 Euro is $4 \%$ more than official exchange rate). On the other hand in Ireland the growth of charity collections might be attributed to the economic growth of $12 \%$. Ranyard (2007) argues that the solution might be in the long term positive sentiment towards the Euro in Ireland as well as the exchange rate which was nominally the nearest to the Euro (1 Irish pound $=1.26$ Euros).

The Dutch experience gives us another proof of importance of the effect of exchange rate rounding. Study of Kooreman, Faber and Hofmans (Kooreman et al., 2004) shows that charity collections jumped up by $11.1 \%$ between 2001 and 2002 which might be attributed to rounding up in mental accounting (from 2.2 gulden to 1 Euro to 2.0 gulden to 1 Euro, which is roughly $10 \%$ difference). Trends towards overestimation or underestimation of the real money value disappeared in following years.

The widely discussed argument against the Euro is an increase in prices after its introduction. In economic theory external nominal shock in the value of money would not cause any damage as the real value of money and relative values of goods and services remain the same. But contrary is true and people behave significantly different (Fehr, Tyran, 2001, 2007). Glauben, Loy and Meyer (2004) tested the German market for green leaf salad and frozen chicken (which are part of the typical consumer basket and are quite invariable in quality) before and after the introduction of the Euro. Their robust analysis of data showed that over $20 \%$ of German supermarkets raised prices of the above-mentioned goods over inflationadjusted past prices. The level of the price increase depends on competition (supermarkets face higher competition than countryside markets) and probability of regulator's checks.

Study of van Raaij and van Rijen (2003) concludes that consumers were willing to pay more in Euros for the same deodorant and shampoo (basic hygiene needs) in Euros than in Dutch guilder with higher nominal value but lower real value (exchange rate was set on 2.2037 guilder for one Euro). If we generalize this experiment to the extent of all-market consumer behavior, people are willing to pay more when the price tag is in Euros (and nominally lower) than in higher nominal values of national currencies. Higher costs of living due to "Euro illusion tax" lead to partial loss of disposable income. 


\section{LESSONS FOR THE CZECH REPUBLIC}

The Czech Republic could not evade tackling this problem in the transitory period after our accession to the single currency. Policy-makers will be facing decisions how to minimize costs and adverse aspects of such transition. It is important to state that government intrusion in the decision-making process of economic agents may bring unintended consequences into the economy, but as the Czech National Bank broke the taboo of arbitrary exchange rate adjustment in 2013, it is possible to imagine using such operations with similar means and goals in the future again to achieve specifically set goals to mitigate negative transitory impact of the Euro on the decision-making process. The paper suggests that it is possible to offset people's natural bias towards rounding of values by setting the exchange rate as close to an easily apprehensible integer as possible. In case of the Czech Republic it could be fixing the market value of Czech Crown to the Euro before the accession to ERM-II system on a non-confusing value (i.e. 23.0431 CZK/EUR and not 23.4279 EUR, difference is almost 2 $\%$ ). Having the price of national currency in Euros floating at reasonable values (useful for mental accounting) could stop significant transfers of wealth between groups of people (i.e. debtors and creditors, consumers and supermarket chains) in the economy caused by money and Euro illusions. Miao and Xie (2013) also suggest, that even low money illusion adversely affects long-term growth rate, which could retard catching up process of economic convergence of the Czech Republic and Western European countries.

\section{Conclusion}

Some economic subjects fail on average to distinguish between real and nominal values. Framing of decision-making process seems to alter detrimental choices seems to offer ways how to diminish adverse impact of money illusion confusion. The Euro illusion phenomenon, which describes inability to maintain consistent decision making after introduction of a new currency, may lead to need of adjustment in mental accounting. Based on aforementioned evidence gathered by analyses from Eurozone countries, we might conclude that the Euro illusion is with high probability a real-world phenomenon, which scope and extent may vary based on preliminary condition of the economy, framing of accession to the single currency, information campaigns and habits of economic agents. Aim of Czech policy-makers should careful consideration of timing of the accession to the Eurozone in order to diminish mental, pecuniary and other costs of change of accounting units and to stop unintended transfers of wealth between groups of economic agents.

\section{Acknowledgements}

This project was kindly supported by Internal Grant Agency of the University of Economics in Prague under grant number VŠE IGS F5/56/2016.

\section{References}

Akerlof, G. A. (1982). Labor Contracts as Partial Gift Exchange. The Quarterly Journal of Economics, 97(4), 543-569. https://doi.org/10.2307/1885099

Akerlof, G. A. (2002). Behavioral Macroeconomics and Macroeconomic Behavior. The American Economic Review, 92(3), 411-433. https://doi.org/10.1257/00028280260136192

Akerlof, G. A., \& Shiller, R. J. (2009). Animal spirits: how human psychology drives the economy, and why it matters for global capitalism. Princeton: Princeton University Press. 
Brunnermeier, M. K., \& Julliard, C. (2008). Money Illusion and Housing Frenzies. The Review of Financial Studies, 21(1), 135-180. https://doi.org/10.1093/rfs/hhm043

Cannon, E., \& Cipriani, G. P. (2006). Euro-Illusion: A Natural Experiment. Journal of Money, Credit and Banking, 38(5), 1391-1403. https://doi.org/10.1353/mcb.2006.0066

Cohen, R. B., Polk, C., \& Vuolteenaho, T. (2005a). Money Illusion in the Stock Market: The Modigliani-Cohn Hypothesis. The Quarterly Journal of Economics, 120(2), 639-668. https://doi.org/10.3386/w11018

Cohen, R. B., Polk, C., \& Vuolteenaho, T. (2005b). Money Illusion in the Stock Market: The Modigliani-Cohn Hypothesis. The Quarterly Journal of Economics, 120(2), 639-668. https://doi.org/10.3386/w11018

Determination of the Euro conversion rates: ECB. (31st December 1998). Retrieved from: http://bit.ly/1Qh7883.

Fehr, E., \& Tyran, J.-R. (2001). Does Money Illusion Matter? The American Economic Review, 91(5), 1239-1262. https://doi.org/10.1257/aer.91.5.1239

Fehr, E., \& Tyran, J.-R. (2007). Money Illusion and Coordination Failure. Games and Economic Behavior, 58(2), 246-268. https://doi.org/10.1016/j.geb.2006.04.005

Fisher, I. (1913). A Remedy for the Rising Cost of Living: Standardizing the Dollar. The American Economic Review, 3(1), 20-28.

Fisher, I. (1928). The Money Illusion. Adelphi Company.

Fochmann, M., Weimann, J., Blaufus, K., Hundsdoerfer, J., \& Kiesewetter, D. (2013). Net Wage Illusion in a Real-Effort Experiment. The Scandinavian Journal of Economics, 115(2), 476-484. https://doi.org/10.1111/sjoe.12007

Glauben, T., Loy, J.-P., \& Meyer, J. (2004). Does Money Illusion Matter? The Impact of Euro on the Vertical Tranmission of Food Price in Germany. (2004 Annual meeting, August 1-4, Denver, CO No. 20104). American Agricultural Economics Association (New Name 2008: Agricultural and Applied Economics Association).

Kooreman, P., Faber, R. P., \& Hofmans, H. M. J. (2004a). Charity Donations and the Euro Introduction: Some Quasi-Experimental Evidence on Money Illusion. Journal of Money, Credit and Banking, 36(6), 1121-1124. https://doi.org/10.1353/mcb.2005.0011

Kooreman, P., Faber, R. P., \& Hofmans, H. M. J. (2004b). Charity Donations and the Euro Introduction: Some Quasi-Experimental Evidence on Money Illusion. Journal of Money, Credit and Banking, 36(6), 1121-1124. https://doi.org/10.1353/mcb.2005.0011

Miao, J., \& Xie, D. (2013). Economic growth under money illusion. Journal of Economic Dynamics and Control, 37(1), 84-103. https://doi.org/10.1016/j.jedc.2012.06.012

Ranyard, R. (2007). Euro Stories: The Irish Experience of Currency Change. Journal of Consumer Policy, 30(4), 313-322. https://doi.org/10.1007/s10603-007-9050-5

Routh D., Burgoyne C. (1989). Absent-mindedness with Money: Its incidence, classification, and correlates. In Tyszka \& Gasparski (Eds.), Homo Oeconomicus: Facts and Presumptions. Polish Academy of Sciences. 2, 619-633.

Shafir, E., Diamond, P., \& Tversky, A. (1997a). Money Illusion. The Quarterly Journal of Economics, 112(2), 341-374. https://doi.org/10.1162/003355397555208

Shafir, E., Diamond, P., \& Tversky, A. (1997b). Money Illusion. The Quarterly Journal of Economics, 112(2), 341-374. https://doi.org/10.1162/003355397555208

Smith, A. (1776). An Inquiry Into the Nature and Causes of the Wealth of Nations. Strahan. https://doi.org/10.1093/oseo/instance.00043218 
Thaler, R. H. (1999). Mental Accounting Matters. Journal of Behavioral Decision Making, 12(3), 183. https://doi.org/10.1002/(SICI)1099-0771(199909)12:3<183::AIDBDM318>3.0.CO;2-F

Tversky, A., \& Kahneman, D. (1981). The Framing of Decisions and the Psychology of Choice. Science, 211(4481), 453-458. https://doi.org/10.1126/science.7455683

\section{Contact information}

Ivo Strejček

University of Economics in Prague, Faculty of Economics

nám. W. Churchilla, 130 76, Prague

00420224095550

xstri00@vse.cz

DOI: https://www.doi.org/10.7441/dokbat.2016.38 


\title{
BASIC FINANCIAL LITERACY OVER DEMOGRAPHIC CHARACTERISTICS: A STUDY COMMERCIAL BANKS' CUSTOMERS IN VIETNAM
}

\author{
Thi Anh Nhu Nguyen
}

\begin{abstract}
The goal of this research is to assess the level of basic financial literacy of commercial banks' customers. The present paper reflects the results of the author's conducted survey based on the sample of 211 respondents. A set of 14 questions on financial knowledge and sociodemographic characteristics was developed to detect the importance of basic financial literacy, as well as to identify the association between financial literacy and a range of sociodemographic attributes. Data was processed by means of SPSS, applying analyst descriptive statistics. The results of descriptive statistics indicated that the average of basic financial knowledge of commercial banks' customers in Vietnam is moderated. Results of this research can assist to improve the level of individuals' financial knowledge by creating a wide range of education programmers related to finance and have other research into this field done in Vietnam.
\end{abstract}

Keywords: basic financial literacy, socio - demographic characteristics

\section{INTRODUCTION}

Over the last two decades, an increase in individuals' ability to obtain personal financial wellbeing has brought significant effects on both individuals and society as a whole. This has been done owing to a number of interventions in a series of policy. IFC (International Finance Corporation) World Bank group concluded that 70 percent of the adult population in developing countries do not have formal access to finance and for many countries financial inclusion - the provision of financial services such as savings, credit, payments, and insurance to the unbanked and under-banked - is a critical priority. Microfinance and financial inclusion have included a dual objective of social and financial bottom lines for many years.

Owing to Vietnam's political and economic reforms launched in 1986, the country has been converted from one of the poorest in the world, with per capita income of about $\$ 100$, to lower middle income status, with per capita income of over $\$ 2,000$ by the end of 2014 in a period of over 25 years. Although Vietnam's population has reached 90 million people, the issue of financial literacy level and personal finance planning is left open. There are very low percentage of Vietnamese people use basic financial services. Therefore, if we assess the level of financial literacy of customers of commercial banks in Vietnam, experts in personal financial planning and financial institutions supplying personal financial services and products know how to impart knowledge of finance and inform their customers so that individuals can have access to and use financial services better. In addition, this research is one of the initial studies about the financial knowledge of Vietnamese and future researches about this area can be developed based on this study.

Although a number of researches into financial literacy have been carried out in western countries, there are not many studies in this field available in Asian countries According to Hilgert et al. (2003), the majority of US citizens do not understand basic financial concepts, especially those associating with bonds, stocks, and mutual funds. More evidence of financial 
illiteracy was found in Lusardi \& Mitchell $(2008,2011)$ research on financial literacy for the 2004 Health and Retirement Study (HRS).

This paper is organized as follows: In Section two provides a review of the current literature on financial literacy and socio - demographic characteristics. Section three covers data and methods. Section four indicates results and discussion. And finally, conclusion and future areas of research in this field is discussed.

\section{LITERATURE REVIEW}

Financial literacy has played an important role as it connects saving behavior with portfolio choice. For instance, less financially literate individuals are less likely to plan for their retirement (Lusardi \& Mitchell, 2007, 2008, 2011), and to join the stock market (van Rooij et al., 2011). In addition, they are less likely to select mutual funds with lower fees as they often connect financial knowledge to just one type of transaction. For instance, in a prior study Moore (2003) indicates that less financially literate participants are more likely to have expensive mortgages. Campbell (2006) also shows that respondents with lower incomes and lower education levels which are closely associated with financial literacy.

Although the importance of financial literacy has been widely acknowledged, there is a lack of consensus on financial literacy definition. In order to define financial literacy, Noctor et al. (1992) first defined financial literacy as the ability to make informed judgments and effective decisions related to the use and management of money. In this definition, consumers' ability to make judgment and decisions is the main priority. While this definition has been used by Worthington (2006) as it is flexible, others have suggested definitions which include a different viewpoint. For example, in Graham's (1980) definition, financial literacy was described as 'the ability to interpret, communicate, compute, develop independent judgment, and take actions resulting from those processes in order to thrive in our complex financial world', as applied by Danes and Haberman (2007). According to the Jump\$tart Coalition for Personal Financial Literacy (Mandell, 2008), financial literacy is a combination of knowledge, skills and action: 'Financial literacy is the ability to use knowledge and skills to manage one's financial resources effectively for lifetime financial security'. This comprehensive definition has been used by Hung, et al., (2009).

Many attempts are shown in the literature about assessment of financial literacy. In that, many scientists argue that financial literacy is far beyond knowledge of finance. In line with assessment of financial literacy, Lusardi \& Tufano (2015) have tested respondents' knowledge of finance using a large sample of respondents. Whereas, Borden et al., (2008); Hung et al. (2009) have given respondents knowledge questions with binary yes-or-no responses, most of them have designed knowledge questions with four answer options (Lusardi \& Mitchell, 2008; Chen and Volpe, 2002).

In previous researches, Kempson (2009) and van Rooij et al. (2011) have indicated that many socio-demographic characteristics namely gender, age, marital status, income and employment affect one's financial knowledge. The impact of gender on financial knowledge was examined by Lusardi \& Tufano (2015), van Rooij et al. (2011), and these researchers found that men generally have greater financial knowledge. Furthermore, their results have shown a positive relationship between income and wealth and financial literacy. Other demographic variables including marital status, and employment were identified in prior research (van Rooij et al., 2011; Agarwal et al. (2013) suggested that financial knowledge can be acquired by using financial products which gave evidence for the positive role of the use 
of financial products in improving financial literacy. It is proved that after an account is opened, the fees of new card holders pay fall by $75 \%$ within the first 3 years.

It is a fact that different aspects and methods to measure financial literacy were used in previous researches. This study is carried out based on the measurements from past studies of financial literacy modifying questionnaires in line with objectives of this study. These questions of basic financial literacy is generally consisted with working of compound interest, inflation, time value of money and money illusion.

\section{Objective of the study}

To analyses basic financial knowledge over demographic characteristics of commercial banks' customers in Vietnam.

\section{METHODS AND DATA}

This study uses primary data for the analysis obtaining data by a survey. Primary data is obtained from a sample survey of 211 Vietnamese adults' respondents who are loyal customers of commercial banks from Ho Chi Minh City. Customers of commercial banks were selected for this study as bank customers in Vietnam are known to be vigilant and curious about their personal finance. In order to maintain the consistency of all customers who use different banks, respondents were randomly selected at twelve (12) branches of different commercial banks in Ho Chi Minh City. Systematic sampling technique was used to select 240 respondents. Due to inadequate information appear in responses, twenty nine questionnaires were rejected in the tabulation process. The questionnaire consists with 10 multiple-choice questions in two main sections; (1) basic financial knowledge related data and (2) socio - demographic data. Modification to the adopted instruments were made in order to fit to the level of the respondents. The survey was conducted in January, 2016. Data were analyzed using descriptive statistical techniques.

\section{RESULTS AND DISCUSSION}

This analysis can be mainly divided into two parts. First, overview of the sample the financial literacy of bank customers will be carried over their basic financial knowledge. Second, the analysis of demographic characteristics and basic financial literacy of commercial banks' customers in Vietnam will be assessed. Accordingly, this chapter consists with overview of the sample (3.1), and basic financial literacy (3.2).

\subsection{Overview of the sample}

As this sample survey was designed to conceptualize the basic financial literacy of general public, it has to cover many aspects and different respondents in the survey. In order to bring the real views of respondents to this survey, the researcher selected commercial bank branches as those places are convenient and appropriate place to meet respondents. Table 1 shows the main characteristics of the sample.

Table 1 - General characteristics of the sample. Source: Researcher developed based on sample survey

\begin{tabular}{|l|c|c|}
\hline \multicolumn{1}{|c|}{ Variables } & $\begin{array}{c}\text { Number of } \\
\text { participants }\end{array}$ & $\%$ \\
\hline Gender & & \\
Male & 102 & 48.3 \\
Female & 109 & 51.7 \\
Total & 211 & 100 \\
\hline Age & & \\
$18-25$ & 55 & 26.1 \\
\hline
\end{tabular}




\begin{tabular}{|l|c|c|}
\hline $26-35$ & 82 & 38.9 \\
$36-45$ & 43 & 20.4 \\
$46-55$ & 22 & 10.4 \\
$>55$ & 9 & 4.2 \\
\hline Education & 5 & \\
Secondary school & 42 & 2.4 \\
High school & 152 & 19.9 \\
Undergraduate degree & 12 & 72.0 \\
Graduate degree & & 5.7 \\
\hline Job status & 184 & \\
Employed & 27 & 87.2 \\
Non-employed (Part-time, household, & & 12.8 \\
Retired, Unemployment, Students) & & \\
\hline Marital status & 114 & 54.0 \\
Single & 97 & 46.0 \\
Married & & \\
Income & 131 & 62.1 \\
<=9 million VND & 29 & 13.7 \\
$>9$ - 20 million VND & 7 & 3.3 \\
$>$ 20 million VND & 44 & 20.9 \\
\hline Prefer not to answer & & \\
\hline
\end{tabular}

From a total of 211 respondents, $85 \%$ of the respondents in this survey have the age from 18 to 45 . The percentage of male and female is fairly equal with $48.3 \%$ and $51.7 \%$ respectively. In terms of education, around $70 \%$ have undergraduate education (diploma and bachelor degree). Most of them have an average income level (below or equal to 9 million VND).

\subsection{Basis financial literacy}

Table 2, panel A shows that for the four questions (Q1-Q4) that relate to basic financial literacy, the percentages of correct responses range from 51 percent to 56 percent for each question. Panel B of Table 2 presents the cumulative numbers of correct responses for these four questions. This result indicates that while a "medium respondents" answered each individual question correctly, the proportion of respondents who answered all four questions correctly is only 12.3 percent, and approximately 10 percent of respondents who answered no question correctly or they answered "don't know". The result shows that there are some respondents display lack knowledge of basic financial literacy.

These questions were developed to measure the knowledge about basic concepts in finance. The result shows that $56.9 \%, 52.6 \%, 55.9 \%$ and $51.2 \%$ of respondents have given a correct answer to questions related to compound interest, inflation, time value of money and money illusion respectively, whereas about $23 \%$ did not know the answer to inflation question and the percentage of those who answered incorrectly to these questions is between $24.6 \%$ and $38.4 \%$. Overall, respondents' general knowledge related to basic financial concepts can be regarded as medium. Although these concepts may appear familiar and relatively simple, it should be considered that respondents of this survey are a precondition for daily financial transactions. Nevertheless, the percentage of about 50\% correct answer to each question can be seen as relatively medium.

Table 2 - Frequencies of responses for basic financial literacy questions $(N=211)$. Source: Researcher developed based on sample survey

Panel A: Percentage of Correct, Incorrect, and Don't Know Responses 


\begin{tabular}{|c|c|c|c|c|c|c|}
\hline & Correct & & Incorrect & \multicolumn{3}{|c|}{ Don't know } \\
\hline Q1: Compound interest & $56.9 \%$ & & $33.6 \%$ & & & $9.5 \%$ \\
\hline Q2: Inflation & $52.6 \%$ & & $24.6 \%$ & & & $22.8 \%$ \\
\hline Q3: Time value of money & $55.9 \%$ & & $27.0 \%$ & & & $17.1 \%$ \\
\hline Q4: Money illusion & $51.2 \%$ & & $38.4 \%$ & & & $10.4 \%$ \\
\hline $\begin{array}{l}\text { Panel B: Number of correct } \\
\text { respondents }\end{array}$ & None & 1 & 2 & 3 & All & Mean \\
\hline $\begin{array}{c}\mathrm{N} \text { correct } \\
\%\end{array}$ & $\begin{array}{l}20 \\
9.5\end{array}$ & $\begin{array}{c}36 \\
17.1\end{array}$ & $\begin{array}{c}69 \\
32.7\end{array}$ & $\begin{array}{c}60 \\
28.4\end{array}$ & $\begin{array}{c}26 \\
12.3\end{array}$ & 2.17 \\
\hline
\end{tabular}

Table 2 - panel A indicates that 23 percent and 17 percent customers of Commercial Bank in Vietnam have not awareness financial knowledge for inflation and time value of money respectively. This occurs mainly as inflation is not taken into consideration in personal level and it takes in macroeconomic level. Therefore, individuals of the country are lacking knowledge about that. Time value of money is known only to people who have educated about the basic financial concepts. As a result, customers of Commercial Bank in Vietnam have limited knowledge about time value of money.

Comparing with prior studies in which the same questions about basic financial literacy were used, there was a relatively big gap in the percentage of respondents' correct answers. For instance, in the studies of Lusardi \& Mitchell (2009), van Rooij et al., (2011) and Bateman et al., (2012), respectively $69 \%, 76.2 \%$ and $72 \%$ of respondents have given correct answers to the compound interest question, compared with $56.9 \%$ in this study. Similarly, for the question connected to inflation, the corresponding percentages of correct answers in these prior studies were $87.1 \%, 82.6 \%$ and $78.4 \%$ respectively, while this study represents only $52.6 \%$. Generally, the percentage of correct answers to questions regarding basic financial knowledge of commercial banks' customer in Vietnam in this survey is lower than those in previous studies. Specifically, 80\% of European people have awareness of inflation, while only over $50 \%$ of Vietnamese people in this research have this knowledge. Therefore, the results suggest that in general the sample in this study shows lower levels of basic general financial literacy than those in previous studies. These differences may be partly explained by the fact that the sample of developing countries has less chance of access to knowledge and awareness of personal finance as well as financial products than those of western countries.

Table 3 - Descriptive statistics for basic financial literacy variables. Source: Researcher developed based on sample survey

$$
\begin{array}{lllll}
\text { Mean } & \text { SD } & \text { Q1 } & \text { Q2 } & \text { Q3 }
\end{array}
$$

Q1 Compound interest $\quad 0.76 \quad 0.612$

\begin{tabular}{|c|c|c|c|c|c|}
\hline Q2 Inflation & 0.98 & 0.688 & $0.145^{*}$ & & \\
\hline Q3Timevalue of money & 0.90 & 0.658 & $0.200^{* *}$ & $0.195^{* *}$ & \\
\hline Q4 Money illusion & 0.72 & 0.642 & 0.045 & $0.159 *$ & $0.227 * *$ \\
\hline
\end{tabular}

Overall, correlations among most of these variables are significant but in a different range. For example, the correlations among the basic financial literacy variables ranged moderate to low levels $(r=0.145$ to $r=0.227, p<0.01$ ), while there are no correlation significant among 
the compound interest indicator to money illusion indicator. This result show that respondents may perceive and understand about compound interest, but they can do wrong answer about money illusion and vice versa.

Table 4 - Distribution percentage of responses to basic financial knowledge questions by Gender, Age, Education level, Income and employment status. Source: Researcher developed

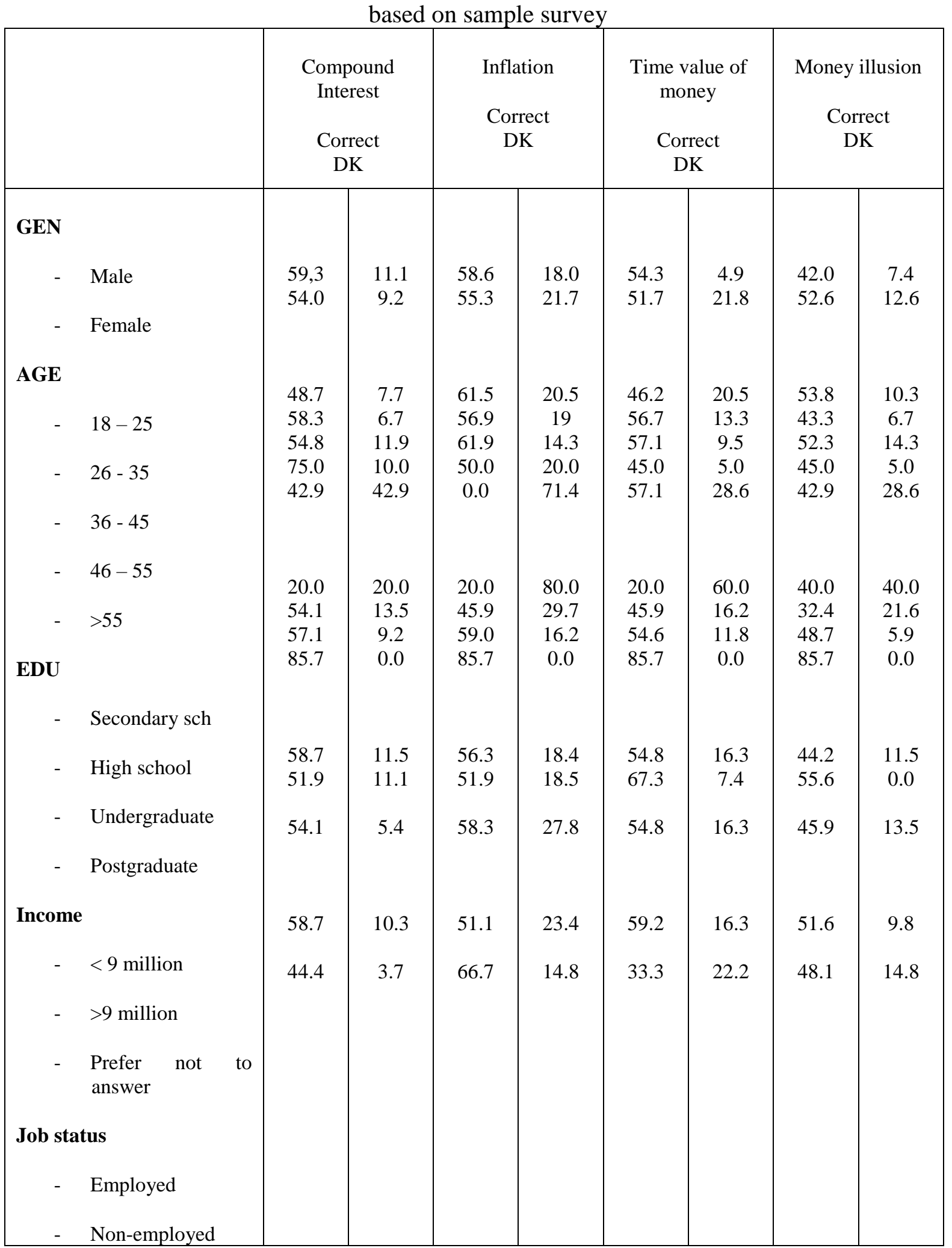


The breakdown of financial literacy group by gender is presented in Table 4 . The results show that most of the financial literacy indices with women displaying lower correct percentage than men, except the question of money illusion. These findings are similar to those reported by Lusardi and Mitchell (2009) and the findings in other literacy surveys (Bateman et al., 2012; Gallery et al., 2011). In addition, the results show that there are proportionally more respondents with higher education levels have given correct answer to the question of basic financial literacy. Whereas the age variable of oldest respondents who are over 55 years shows the lowest correct answers for questions.

Regarding level of income, people with income more than 9 million Dong, they have more proportion correct answer to time value of money and money illusion questions than people's income less than 9 million Dong. While there is negligible difference on the level of income to awareness of inflation and interest rates, both of them have similar percentages for correct answer. Furthermore, people with employed or non-employed they have the same perceived money illusion but they cannot understand about time value of money. Only about 33 percent unemployed respondents have given correct answer for this question.

\section{CONCLUSION}

The results of descriptive statistics indicated that the average of basic financial knowledge of commercial banks' customers in Vietnam is moderated.

Analysis of basic financial literacy over key demographic characteristics shows that more respondents who have higher level of education tend to have more knowledge of basic financial literacy. Besides, the result indicates that females display lower number of correct answers to questions than male. Furthermore, the oldest respondents' age over 55 have shown lower understanding than young people.

Financial literacy level has an enormous effect on financial well-being of individuals and their countries. In this regard, a process of implementation and development of national strategies was initiated in many countries to enhance financial literacy level. The initial step of this process is the evaluation of the current situation which requires a measurement method. Thus, the purpose of the study is expected to measure the basic financial literacy of commercial banks' customers in Vietnam. This study could conclude estimating the basic financial knowledge and which demographic factors affect those of commercial banks' customers in Vietnam.

\section{Reference}

Agarwal, S., Driscoll, J., Gabaix, X. \& Laibson, D. (2013) Learning in the credit card market. SSRN Working Paper. from: http://papers.ssrn.com/sol3/papers.cfm?abstract_id=1091623 (accessed on 18 March 2016).

Bateman, H., Eckert, C., Geweke, J., Louviere, J., Thorp, S., \& Satchell, S. (2012). Financial Competence and Expectations Formation: Evidence from Australia*: Financial Competence and Expectations Formation. Economic Record, 88(280), 39-63. https://doi.org/10.1111/j.1475-4932.2011.00766.x

Borden, L. M., Lee, S.-A., Serido, J., \& Collins, D. (2008). Changing College Students' Financial Knowledge, Attitudes, and Behavior through Seminar Participation. Journal of Family and Economic Issues, 29(1), 23-40. https://doi.org/10.1007/s10834-0079087-2 
Campbell, J. Y. (2006). Household finance. The Journal of Finance, 61(4), 1553-1604. https://doi.org/10.1111/j.1540-6261.2006.00883.x

Chen, H. \& Volpe, R.P. (2002) Gender differences in personal financial literacy among college students. Financial Services Review, 11, 289-307.

Danes, S.M., \& Haberman, H.R. (2007). Teen financial knowledge, self-efficacy, and behavior: A gender view. Financial Counseling and Planning, 18(2), 48-60

Graham, P. (1980) Whither the equality of educational opportunity? Daedalus, 109, 115-132.

Hilgert, M. A., Hogarth, J. M. and Beverly, S. G. (2003) Household financial management: the connection between knowledge and behavior. Federal Reserve Bulletin, 89(7): 309-322.

Hung, A., Parker, A. M., \& Yoong, J. (2009). Defining and measuring financial literacy. Retrieved from http://papers.ssrn.com/sol3/papers.cfm?abstract_id=1498674 https://doi.org/10.2139/ssrn.1498674

Kempson, E. (2009). Framework for the Development of Financial Literacy Baseline Surveys (OECD Working Papers on Finance, Insurance and Private Pensions No. 1). Retrieved from http://www.oecd-ilibrary.org/finance-and-investment/framework-for-thedevelopment-of-financial-literacy-baseline-surveys_5kmddpz7m9zq-en

Lusardi, A., \& Mitchell, O. S. (2007). Baby Boomer retirement security: The roles of planning, financial literacy, and housing wealth. Journal of Monetary Economics, 54(1), 205-224. https://doi.org/10.1016/j.jmoneco.2006.12.001

Lusardi, A., \& Mitchell, O. S. (2008). Planning and Financial Literacy: How Do Women Fare? American Economic Review, 98(2), 413-417. https://doi.org/10.1257/aer.98.2.413

Lusardi, A., \& Mitchell, O. S. (2009). How ordinary consumers make complex economic decisions: Financial literacy and retirement readiness. National Bureau of Economic Research. Retrieved from http://www.nber.org/papers/w15350 https://doi.org/10.3386/w15350

Lusardi, A., \& Mitchell, O. S. (2011). Financial literacy around the world: an overview. Journal of Pension Economics and Finance, 10(4), 497-508. https://doi.org/10.1017/S1474747211000448

Lusardi, A., \& Tufano, P. (2015). Debt literacy, financial experiences, and over indebtedness. Journal of Pension Economics and Finance, 14(04), 332-368. https://doi.org/10.1017/S1474747215000232

Mandell, L. (2008). The financial literacy of young American adults. Results of the 2008 National Jump \$ Tart Coalition Survey of High School Seniors and College Students. Retrieved from http://deca.smgww.org/assets/pdf/2008\%20JumpStart\%20Financial\%20Literacy\%20 Survey.pdf

Moore, D. (2003) Survey of Financial Literacy in Washington State: Knowledge, Behavior, Attitudes and Experiences, Technical Report 03-39, Washington State University Social and Economic Sciences Research Center.

Noctor, M., Stoney, S. \& Stradling, R. (1992) Financial literacy: a discussion of concepts and competences of financial literacy and opportunities for its introduction into young people's learning. Report prepared for the National Westminster Bank, National Foundation for Education Research, London.

van Rooij, M., Lusardi, A., \& Alessie, R. (2011). Financial literacy and stock market participation. Journal of Financial Economics, 101(2), 449-472. https://doi.org/10.1016/j.jfineco.2011.03.006

Worthington, A. C. (2006). Predicting financial literacy in Australia. Retrieved from http://ro.uow.edu.au/commpapers/116/ 


\section{Contact information}

Thi Anh Nhu Nguyen

Tomas Bata University in Zlin

Faculty of Management and Economics

Department of Enterprise Economics

Mostni 5139, 76001 Zlin

Czech Republic

Telephone number: +420773043180

anhnhu80@gmail.com

orcid.org/0000-0003-3619-4655

DOI: https://www.doi.org/10.7441/dokbat.2016.39 


\title{
THE USAGE OF SELECTED MODELS PREDICTING THE FINANCIAL CONDITIONS OF FIRMS: CASE FROM SLOVAKIA
}

\author{
Miloš Tumpach, Adriana Stanková
}

\begin{abstract}
The current instability of the economic environment is causing many problems for many business entities. A phase of economic expansion, during which the Slovak economic policy has been closer to the standards of developed economies, was interrupted in 2008 by the global crisis, which started a phase of economic recession. At present, a period of economic growth and recovery is expected in Slovakia. However, the crisis, also referred to as "the deepest economic crisis since the Great Depression of the 30's in the 20th century", has sparked a wave of questions dealing with the financial analysis and predictions of the future financial situation. At present, various models of discriminant analysis and logistic regression, most of which originated in the 20th century and under the conditions of different economies, are predominantly used for the forecasting the financial situation of companies in the Slovak Republic. The usefulness of these models is now questionable in countries where they primarily originated and therefore all the more in the Slovak Republic. This article is a review of studies looking at the ability to predict the financial situation through the most well-known prediction models. However, the primary focus is to assess their predictive power and usability in Slovakia.
\end{abstract}

Keywords: discrimination analysis, Altman, IN05, financial forecasting

\section{ALTMAN'S MODELS}

The success of prediction of bad financial conditions based on the original Z-Score model was tested and published by Altman alone in 2006 for the period 1969-1975 on 86 companies, from 1976 to 1995, on 110 companies from 1997 to 1999, and on 120 companies. The highest ability to predict the a bankruptcy of a company one year before it actually occurs was achieved in the original sample of 66 companies and in the last testing period of 1997-1999, where success was 94\%. In the other two testing samples, the success rate was only $85 \%$. Ability to correctly classify businesses two years before bankruptcy was best in the test samples for the period 1976 - 1995 and 1997 - 1999, where success ranged from 74\% to $75 \%$. The ZETA model's bankruptcy classification accuracy rate ranges from over $96 \%$ (93\% holdout) one period prior to bankruptcy to $70 \%$ five annual reporting periods prior (Altman, Haldeman, Narayanan, 1977). In a study published by Hyránek, Fetisovová, Grell, and Nagy (2014) the ZETA model works for short-term forecasts with similar reliability as the original model. Both models provide 93\% - 95\% correct classification. However, the relevance of the ZETA model lies mostly in the long-term forecasting of the financial situation. The ZETA model has been extremely accurate for five years before the deterioration of the overall financial situation, the total error is only 23.4\% (Hyránek, Fetisovová, Grell, Nagy, 2014). Sherbo and Smith (2013) have tested whether the 45 year-old model from 1968 could be used for the prediction of bankruptcy two years ahead even today. They used the same sample as Altman used in modeling - 33 failed and 33 successful industrial enterprises in the period from 2007 to 2009. The result of the test was that two years ahead of the bankruptcy the Altman model correctly predicted the collapse of 21 companies out of 33 , which is the $64 \%$ success rate. Among the successful companies, 18 of 
33 were properly classified as solvent companies with a reliability rate of $55 \%$. The 1968 Altman Z-Score can still be used as a tool to evaluate the future financial health of a corporation and the prediction of bankruptcy two years in advance of bankruptcy.

For Slovakia, Delina and Packová (2013) tested the ability of prediction of the Altman models on a larger sample. They analyzed the successful prediction rate of the model three years ahead the actual bankruptcy, based on the overall sample of data from 1560 Slovak companies (covering periods 1993-2007), out of which 103 companies went bankrupt during these periods. Businesses in the analyzed sample were large, medium and small; both profit and non-profit; trading, manufacturing or providing services; with locations throughout the Slovak Republic. When validating the models, the authors have chosen an unconventional approach different from the conventional statistical method, that relies on access to the testing power used in data mining - a selection process of browsing and modeling in great volumes of data that serves in revealing previously unknown relationships in the data. The evaluation of success with the data mining approach have been carried out on two levels - accuracy and return. The results of validation through the Altman model inform us of about 428 predicted bankruptcies. The error of bankruptcy prediction is $87.62 \%$ (which makes prediction accuracy of the model equal to $12.38 \%$ ) and return prediction is $51.46 \%$. The original Altman model was also tested in Slovakia by Mihalovič (2015). The analyzed sample consists from data of those 384 limited liability and joint stock companies (covering the years 2009 through 2014), which were restructured during the respective periods. The accuracy of the Altman Z-score was $33.3 \%$ for $2009,65.5 \%$ for $2010,67.1 \%$ in $2011,79.6 \%$ in 2012 , $68.8 \%$ in $2013,78.5 \%$ in 2014 . The overall accuracy was $70.5 \%$.

Not surprisingly, experts are careful in the ex-ante analysis in the Slovak Republic by means of these models and many of them modify the original Altman models so as to reflect the particularities of each country. There is a clear reasoning behind this approach: the model was reflecting the conditions of the US economy in the sixties and eighties of the 20th century (and, even more, it has been based on a rather limited sample of companies). Thus, in its original firm the models is not well correlated to with current economic conditions - not even the US. Moreover, in 2009 Beaver, et al. pointed out that there is a bias in predicting bankruptcy. Altman also drew attention to the fact that most models use a sample composed of two priority groups: "bankrupt" and "non-bankrupt" companies. However, even the essential definition of a bankruptcy may vary in various countries and various periods (Altman, Narayanan, 1997). Consequently, there could be also differences in establishing the moment when bankruptcy occurs (which could have impact on the relevance of the prediction as well). Another drawback is that these models are not suitable for prediction of the financial situation of companies whose total value of assets does not exceed $\$ 1,000,000$. In addition, the classification of companies is carried out on the basis of data obtained from the financial statements and models are not reflecting differences in accounting and reporting requirement in various countries. Also the models (both the original one and its modifications) are not immune to inaccurate accounting procedures. Furthermore, from the results of a single number it is very difficult to analyze the factors which lead to the final classification of the subject. On the other hand, the models enjoy their popularity because of their simplicity both from the point of their application and interpretation of the resulting values.

\section{IN05}

Neumaierová and Neumaier in 2013 published a study in which they presented the results of the application of IN05 index in prediction of the negative financial situation Czech nonfinancial companies (based on the data covering the year 2011). Apart from the companies 
used for the creation of the IN05 index, the sample contains also other companies. In the test sample, $63.89 \%$ of business entities were classified by IN05 as bankrupt and all of these subjects were indeed bankrupt, so they were classified correctly. Only $3.55 \%$ of non-bankrupt companies were incorrectly classified by the index as bankrupt. Among the non-bankrupt companies, $81.77 \%$ of enterprises were accurately included and $18.57 \%$ were incorrectly classified by index IN05 as bankrupt companies. $17.54 \%$ bankrupt and $14.68 \%$ non-bankrupt companies were included in a "gray zone". At the time when IN05 was created, 77\% of bankrupt enterprises were classified correctly, while only $64 \%$ in 2011. Eighty-eight percent of solvent companies were classified correctly at the time when the index was created, while, in $2011,82 \%$. It follows that the accuracy of classification of creditworthy companies has remained preserved and the bankruptcy explanatory power of IN05 has deteriorated. The results also showed that for some industries it is better than for others. However, the explanatory power is problematic in only two sectors: a) production and development of electricity, gas, heat and cold and b) real estate activities.

In addition to applicability of Altman Z-Score model in Slovakia, Delina, Packová (2013) and Mihalovič (2015) have tested also the applicability of the IN05. Delina and Packová came to a conclusion, that of the sample of 1560 companies (from which 103 actually went bankrupt) the index will mark 521 companies as at the brink of the bankruptcy. In comparison with the Z-score model, it is clear that the IN05 index predicted more bankruptcies, $85.41 \%$ incorrectly, consequently that index has a higher value return, but rightfully lower accuracy. The value of return is exactly $73.79 \%$, and the accuracy of the prediction is $14.59 \%$. In the study by Mihalovič, the prediction accuracy of index IN05 is $60 \%$ in $2009,93.4 \%$ in $2010,86.5 \%$ in $2011,89 \%$ in $2012,83.8 \%$ in $2013,85.7 \%$ in 2014 , the overall accuracy was $86.4 \%$. The predictive power of IN05 outperforms the predictive power of the Altman Z-Score in each observation year.

The IN05 index has been used for several years for forecasting financial conditions. Due to the similar conditions of the Czech and Slovak economic environments, its applicability for the classification of business entities in the Slovak Republic as bankrupt or non-bankrupt is considered to be higher than that of the Altman Z-score. This conclusion is supported by the fact, that the scope and the structure of financial statements of business entities in Czech republic and Slovakia are quite similar, which decreases the translation risks almost to a minimum. Though the Index IN05 is the revised version of the former index IN01 of 2005, (indicating that the model reflects current economic conditions and legislative changes in the reporting of financial statements) it is still 11 years old now. Furthermore, it has been tested primarily on data from medium and large industrial enterprises and for these businesses will have the highest explanatory power. And it is apparent that its relevance highly depends on the sample of enterprises on which the validity of index is verified, not only from the perspective of sample size, proportion of bankrupt and non-bankrupt within it, but also from the perspective of size and industrial structure (Neumaierová, Neumaier, 2013). This fact is confirmed by Hyránek, Fetisovová, Grell and Nagy (2014). In accordance with their opinion, there is no general prediction model that would be useful for predicting the financial health of all business entities. Each model is applicable only in a particular economic environment, at a certain time and only for a certain segment of companies. Thus, one can conclude that there is not a universal prediction model, which would be independent of time and economic environment. On the other side, compared to other models which were created and tested only on several dozen business entities, for the formation of the INOx indices, data form nearly 2,000 Czech companies were used, thus reducing the risks of the selections bias. 


\section{OHLSON AND ZMIJEWSKI MODELS}

Predictive ability of the Ohlson (1980) model is was (based on a sample of companies) determined to be equal to $96.12 \%$ (one year ahead) of bankruptcy, $95.55 \%$ for two years ahead of bankruptcy and $92.84 \%$ for three years ahead respectively. According to Ohlson, further improvement cannot be achieved by taking into account only accounting figures. Quite contrary, it is claimed, that better prediction accuracy of a model can be achieved by taking non-accounting variables (e. g. market based data, like the value of shares or change in their value) into the consideration. Ohlson also claims, that the predictive power of any model depends upon when the information (e. g. in the form of the financial report) is assumed to be available for the public. Jin (1993) published a study which was focused on testing the original parameters of the two most commonly used models in the American environment, the Altman Z-Score and Ohlson's probabilistic model. Though there is a considerable evidence that these models are still used today, given the extensive changes in bankruptcy laws in the late 70's and the increased use of financial leverage in the 80's it is also expected the at least the model parameters had changed. On examination he made used a sample from the time period of 1981 to 1990, which consisted from test of 99 bankrupt and 99 nonbankrupt companies (for the Z-score) and 99 bankrupt and 1980 non-bankrupt companies (in accordance with the Ohlson's underlying assumption, transportation and financial companies were not included in the sample). Jin have concluded that both models (Z-Score and Ohlson's $\mathrm{O}$-Score) have later a rather poorer predictive ability than at the time of their formation, but the Z-score model did not significantly changed its parameters. .Grice and Dugan (2001, 2003) published articles in which they focused on testing and newly-created Ohlson and Zmijewski models in another time period other than those the authors used for creating the models. According to the conclusion of their examination the predictive accuracy of the model, over time, generally decreases. The results of the predictive power of the Ohlson original model were on a sample from the period 1988 - 1991, 39.8\% and on a sample from the period 1992 - 1999, only $34.8 \%$. The original Zmijewski model had results significantly better: $81.3 \%$ - on the sample from the period 1988 - 1991, and $77.6 \%$ on a sample from the years 1992-1999. Grice and Dugan also pointed out that the models generally served better in the prediction of bad financial situations, and not directly in bankruptcy. Thus, analysts who use the models to predict the event of bankruptcy, not just the financial distress, should do so cautiously. Newly modified models should have better prediction accuracy than the original models, and this information has led authors to conclude, that the time period of sample on testing models is relevant. The results of the study also point to the fact that the modified models are not sensitive to the industrial classification of the examined companies.

Quite surprisingly, no study with sufficiently large sample deals with the relevance of the Zmijewski or Ohlson models in the Slovak Republic, though Kubičková (2015) tested the predictive exactness of the Ohlson model in the Czech Republic. In 2015 she published a study with a sample of companies including limited liability and joint stock companies, with a number of employees less than 250, the turnover less than 50 million EUR (or the balance sheet totals less than 43 million EUR) and location of the owner in the Czech Republic. Industrial companies with completely reliable financial data for the years 2012 and 2013 which in the end constituted the sample that was 2014. Of the surveyed sample the resulting value of Ohlson model was less than $0.1 \%$ for most $(1,042)$ of the companies. Values greater than $99.9 \%$ were the present for 63 companies. The model assesses the financial situation of most companies in the sample companies as good, the likelihood of financial distress is an average of $9 \%$. After clearing outliners (extremely low and extremely high values), the average value has been increased to $13 \%$. In addition to the Ohlson model, the author also examined the prediction accuracy of the Altman Z-Score and IN05. In the 
assessment of the financial situation of the given sample companies the Z-Score model appears to be the strictest, with the IN05 model being less strict, and the Ohlson model the least strict (Kubíčková, 2015). Neither the presumption of conformity in the evaluation of these models that come from a similar background (Ohlson vs. Z-Score), nor the difference of those coming from different backgrounds was confirmed (Ohlson vs. IN05, Z-Score vs. IN05).

The logistic regression is usually considered less difficult than a multivariate discriminant analysis (Vochozka, 2011). Moreover, in comparison with it has several significant advantages in the terms of their relevance and interpretation. But there are also evidences of the shortcomings of logistic regression when used for the forecasting a financial situation. Most of them are related to the fact that the model is best applicable in the country from which the parameters of the model have been estimated.

\section{NEURAL NETWORKS}

Several studies have been aimed at the aplicability of the neural networks for financial prediction. Many of these studies have concluded, that the neural networks provide a more accurate prediction of bankruptcy than a standard mathematical and statistical techniques. One of the first was a study Odom and Sharda (1990). The authors used Altman's financial ratios as the first layer of the neural network, with as a sample of the data of 129 US companies from for the periods 1975 - 1982 as the input. In reference to training for the neural network, the sample has been divided into two groups. First one, with 74 business entities (38 insolvent and 36 solvent) has been used for discovering the patterns among the inputs and financial conditions while the second one with remaining 55 subjects ( 27 insolvent and 28 solvent) was used for the validation of the the model. In addition, this data were examined through the use of discriminant analysis. Discriminant analysis correctly classified 33 of the 38 bankrupt companies, while the neural network classified all of them correctly.

The neural network was designed with three layers - input, one hidden and output. The input layer had five neurons. As we have already mentioned, each neuron contained one of the financial ratios from the original Altman model. The hidden layer was also composed of five neurons, and the output layer contains one. This has provided binary resulting values - 0 for the bankrupt company, 1 for the company in good financial condition. After the formation of the neural network model, the value were submitted for each of the ratio and for each company, and then the neural network provided the resulting values on a scale between 0 and 1. Companies with the result of less than 0.5 are classified as insolvent and entities with a final value of 0.5 as solvent. Construction of the network is shown in the following figure (1):

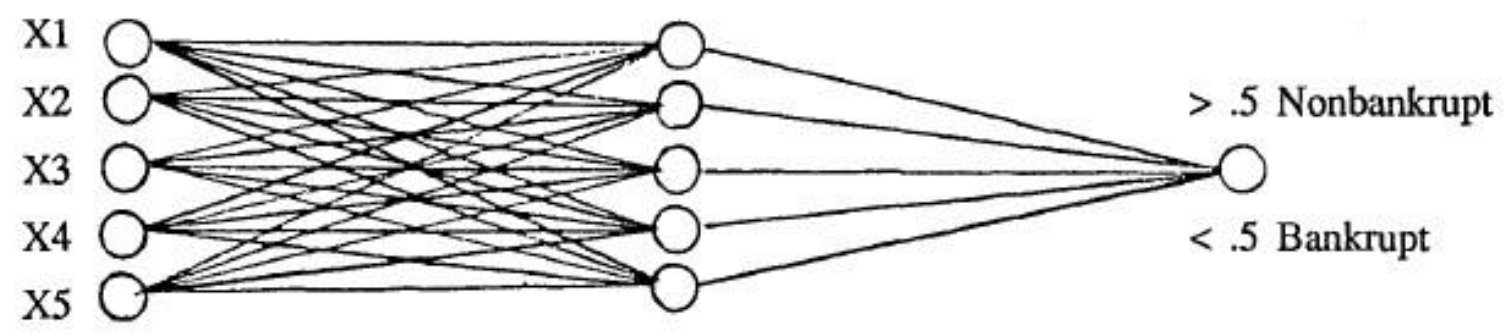

Figure 21 Construction of neural network. Source: Odom, Sharda (1990)

To test the model, part of the validation sample was divided into three different ratios: 50:50, 80:20, 90:10, in ratio to prosperous bankrupt: non-bankrupt. The results of discriminant 
analysis and neural network for the validation portion of the sample are given below in table 1:

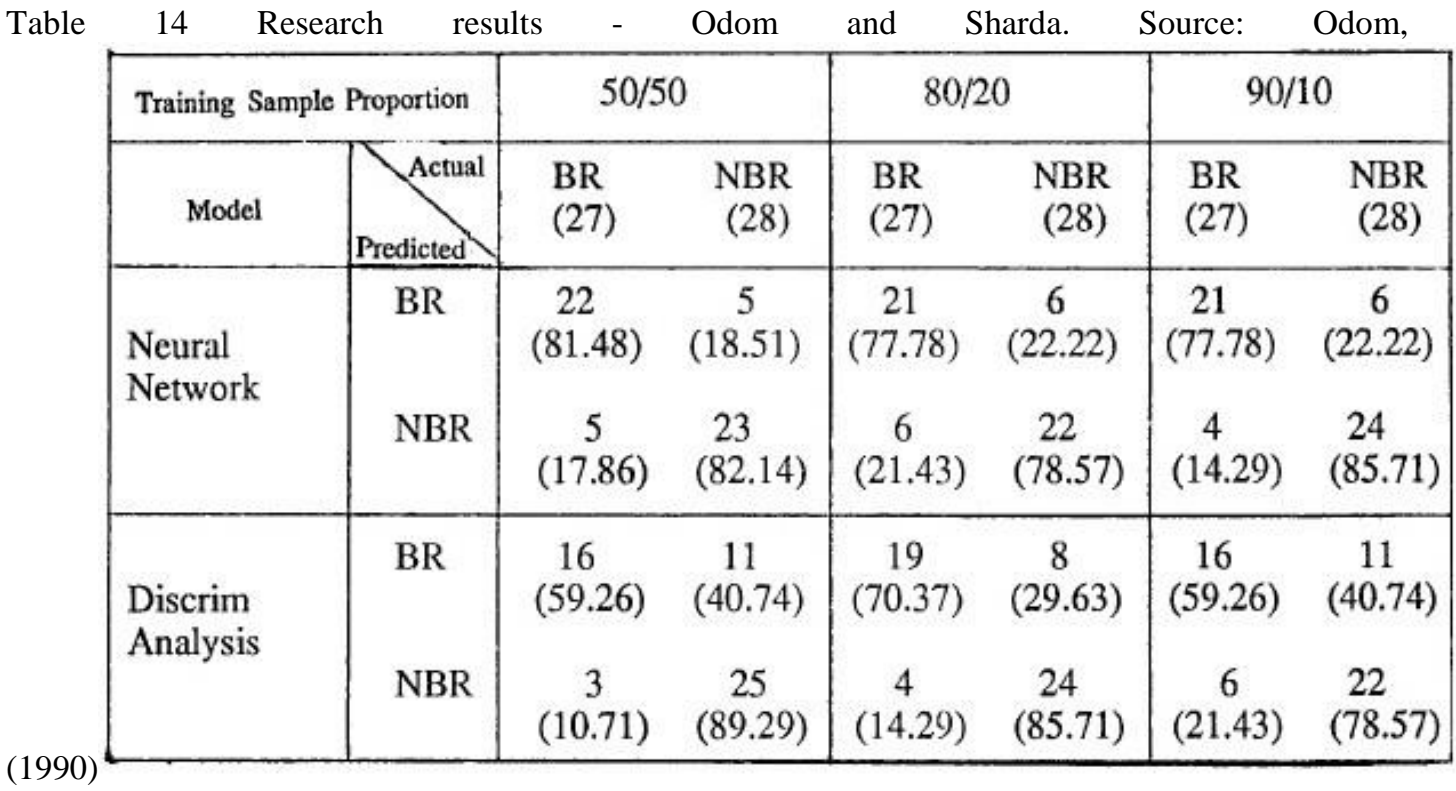

The Neural network achieved a significantly high classification accuracy in predicting the bankruptcy of a company from $77.8 \%$ to $81.5 \%$ (depending on the group being studied) and accuracy in classifying non-bankrupt firms ranging from $78.6 \%$ to $85.7 \%$. The corresponding results of the multivariate discriminant analysis ranged from $59.3 \%$ to $70.4 \%$ of the accuracy in the classification of a bankruptcy, and in a range from $78.6 \%$ to $89.3 \%$ of the accuracy in the classification of a non-bankrupt company. Another area for future research may be in applying different neural network architecture to this problem. Comparison of these other architecture may help to identify the best architecture for this type of problem (Odom, Sharda 1990).

Tam and Kiang (1992) made a comparison of different kinds of models for the prediction of bankruptcy: logit analysis, multivariate discriminant analysis, K-nearest neighbor, singlelayer neural networks, multilayer neural networks, and a classification algorithm decision tree. The result of their investigations was that multilayer neural networks are the best tool for predicting bankruptcy one year ahead of the bankruptcy, but in the time horizon of two years, logit analysis achieved rather better results. Salchenberger et al. (1992) analyzed bankruptcies of savings banks. Their results show that for the prediction of the bankruptcy, the backpropagation neural network had substantially better results than logit-analysis. The same result was achieved by Zhang et al. (1999). Other studies, which confirm a better predictive power for future financial conditions compared with traditional mathematical-statistical methods, are, for example Coats and Fant (1993), Boritz and Kennedy (1995), Bach et al. (1996), Lee et al. (1996), Atiya(2001), Lee et al. (2005).

\section{CONCLUSION}

Models of discriminant analysis and logistic regression are among the most widely used on forecasting the future of financial conditions in Slovakia. This is despite the fact that several studies made in Slovakia point to their disappointing results in the field. It is essential to find new ways of predicting the development and potential problems of individual businesses in the current unstable economic environment. In comparison to mathematical-statistical methods, on the basis of recent foreign studies, there seems to be to a much greater advantage 
in the models of neural networks in forecasting the future financial conditions of business. The Neural network is a means of imitating the capabilities of neurons of the human brain's ability to model the course of dependencies between individual indicators and results. They are popular mainly due to their simplicity, performance, and flexibility of use. However, for the purposes of forecasting in the Slovak Republic, to a greater extent, it is still not used. Their use in predicting the future financial development of Slovak businesses should be addressed further through research in this area.

\section{References}

Altman, E. I. (1968). Financial ratios, discriminant analysis and the prediction of corporate bankruptcy. Journal of Finance, 23 (4), 589-609. https://doi.org/10.1111/j.15406261.1968.tb00843.x

Altman, E. I. (1983). Corporate financial distress. New York : John Wiley \& Sons.

Altman, E. I. (2005). An emerging market credit scoring system for corporate bonds. Emerging Markets Review, 6 311-323. https://doi.org/10.1016/j.ememar.2005.09.007

Altman, E. I. (2006). Corporate financial distress and bankruptcy. Hoboken : John Wiley \& Sons. ISBN 978-0-471-69189-1.

Altman, E. I., Haldeman, R., \& Narayanan, P. (1977). Zeta analysis: A new model to identify bankruptcy risk of corporations. Journal of Banking and Finance, 1, 29-54. https://doi.org/10.1016/0378-4266(77)90017-6

Altman, E. I., Hartzell, J., \& Peck, M. (1998). Emerging market corporate bonds - a scoring system. Emerging Market Capital Flows, 341-400. https://doi.org/10.1007/978-14615-6197-2_25

Altman, E. I., \& Narayanan, P. (1997). An international survey of business failure classification models. Financial Markets, Institution \& Instruments, 6 (2), 1-57. https://doi.org/10.1111/1468-0416.00010

Atiya, A. (2001). Bankruptcy prediction for credit risk using neural networks: a survey and new results. IEEE Transactions on Neural Networks, 12 (4), 929-935. https://doi.org/10.1109/72.935101

Beaver, W. H. (1966). Empirical research in accounting: Selected studies. Journal of Accounting Research, 4, 71-111. https://doi.org/10.2307/2490171

Boritz, J., \& Kennedy, D. (1995). Effectiveness of neural networks types for prediction of business failure. Expert Systems with Applications, 9 (4), 503-512. https://doi.org/10.1016/0957-4174(95)00020-8

Cisko, Š., \& Vašanič, M. (2012). Predikcia rizika zlyhania podnikatel'ských subjektov pomocou logistickej regresie. Podniková ekonomika a manažment: elektronický vedecký časopis o ekonomike, manažmente, marketingu a logistike podniku, 2, 76-86.

Coats, P., \& Fant, L. (1993). Recognizing financial distress patterns using a neural network tool. Financial Management, 22 (3), 142-155. https://doi.org/10.2307/3665934

Delina, R., \& Packová, M. (2013). Validácia predikčných bankrotových modelov v podmienkach SR. E+M Ekonomie a Management, 16 (3), 101-112.

Grice, J. S., \& Dugan, M. T. (2001). The Limitations of Bankruptcy Prediction Models: Some Cautions for the Researcher. Review of Quantitative Finance and Accounting, 17, 151-166. https://doi.org/10.1023/A:1017973604789

Grice, J. S., \& Dugan, M. T. (2003). Re-estimations of the Zmijewski and Ohlson bankruptcy prediction models. Advances in Accounting, 20, 77-93. https://doi.org/10.1016/S08826110(03)20004-3

Hiadlovský, V., \& Gundová, P. (2014). Verifikácia vypovedacej schopnosti Altmanovho Zskóre na vzorke slovenských podnikov. Podniková ekonomika a manažment: 
elektronický odborný časopis o ekonomike, manažmente, marketingu a logistike podniku, 9(1), 25-30.

Hyránek, E., Fetisovová, E., Grell, M., \& Nagy, L. (2014). Vývoj modelov prognózovania finančnej situácie podnikov. Nové trendy $\mathrm{v}$ oblasti rozpočtovo-kapitálových a finančných rozhodnutí a ich vplyv na hodnotu podniku : zborník vedeckých statí, 922. ISBN 978-80-225-3955-5.

Jin, M. (1993). A re-examination of two major bankruptcy prediction models. Vancouver: The University of British Columbia.

Kubíčková, D. (2015). Komparace hodnocení finanční stability firem v segmentu zpracovatelského průmyslu na základě Ohlsonova modelu, modelu Z-Score a modelu IN05. Hradecké ekonomické dny 2015, 70-83.

Kumar, N., \& Rao, H. (2015). A New Methodology for Estimating Internal CreditRisk and Bankruptcy Prediction under Basel II Regime. Computation economics, 46(1), 83102. https://doi.org/10.1007/s10614-014-9452-9

Lee, K. C., Han, I. G., \& Kwon, Y. (1996). Hybrid neural network models for bankruptcy predictions. Decision Support Systems,18, 63-72. https://doi.org/10.1016/01679236(96)00018-8

Lee, S., \& Choi, W. S. (2013). A multi-industry bankruptcy prediction model using backpropagation neural network and multivariate discriminant analysis. Expert Systems with Applications, 40(8), 2941-2946. https://doi.org/10.1016/j.eswa.2012.12.009

Mihalovič, M. (2015). Are Altman Z-Score and IN05 Index able to predict financial difficulties of Slovak companies? European Union Knowledge Economy Review: scientific journal, 3 (1), 24-32.

Neumaier, I., \& Neumaierová, I. (2005). Index IN 05. Sborník př́spěvki̊ mezinárodní vědecké konference „,Evropské finančni systémy“, 143-148. ISBN 80-210-3753-9.

Neumaier, I., \& Neumaierová, I. (2013). Vypovídací schopnost indexu IN05. Sborník z mezinárodni védecké konference „Ekonomika v pohybu“, 169-176. ISBN 978-80245-1943-2.

Odom, M. D., \& Sharda, R. (1990). A neural network model for bankruptcy prediction. Proceedings from IJCNN International Joint Conference Neural Networks, 163-168. https://doi.org/10.1109/IJCNN.1990.137710

Ohlson, J. A. (1980). Financial ratios and probabilistic prediction of bankruptcy. Journal of Accounting Research, 18 (1), 109-131.

Salchenberger, L., Cinar, E., \& Lash, N. (1992). Neural networks: a new tool for predicting thrift failures. Decision Sciences, 23 (4), 899-916. https://doi.org/10.1111/j.15405915.1992.tb00425.xSherbo, A. J., \& Smith, A. J. (2013). The Altman Z-Score bankruptcy model at age 45: Standing the test of time? American Bankruptcy Institute Journal, 32 (11), 40-42.

Tam, K., \& Kiang, M. (1992). Managerial applications of neural networks: the case of bank failure prediction. Management Science, 38 (7), 926-947. https://doi.org/10.1287/mnsc.38.7.926

Vochozka, M. (2011). Metody komplexního hodnocení podniku. Grada Publishing. ISBN 978-80-247-3647-1.

Zmijewski, M. E. (1984). Methodological issues related to the estimation of financial distress prediction models. Journal of Accounting Research, 22, 59-82. https://doi.org/10.2307/2490859

\section{Contact information}

Miloš Tumpach.

Ekonomická univerzita v Bratislave, Fakulta hospodárskej informatiky 
Dolnozemská cesta 1, 85235 Bratislava

(421 2) 67295769

tumpach@euba.sk

Adriana Stanková

Ekonomická univerzita v Bratislave, Fakulta hospodárskej informatiky

Dolnozemská cesta 1,852 35 Bratislava

(421 2) 67295775

stankova@euba.sk

DOI: https://www.doi.org/10.7441/dokbat.2016.40 


\title{
LEAN HEALTHCARE: RESULTS OF MULTICENTER SURVEY OF CZECH MEDICAL STAFF
}

\author{
Veronika Vavrušová, Edita Vitásková
}

\begin{abstract}
There is a growing interest in applying lean in healthcare. Healthcare services around the world have adopted industrial engineering methods and process improvement methodologies from the manufacturing sector, known as lean production. The aim of this paper is to provide a review of the existing literature on lean healthcare and to publish basic results of survey focused on Czech medical staff's knowledge of lean healthcare philosophy. The article explores challenges and opportunities faced by organizations that intend incorporating lean management principles and presents the specific context of the healthcare industry. Though there seems to exist an agreement about the potential of lean healthcare, it remains a challenge for academics and practicioners to evaluate lean healthcare under a more critical perspective.
\end{abstract}

Keywords: Lean management, Lean healthcare, Lean methods, Ergonomics principles, Medical errore, Quality, Continuous improvement, Customer value.

\section{INTRODUCTION}

The idea of lean healthcare or lean services is not new. A concept which works well in industry has become a great example of using "best practises" to increase work efficiency. Therefore various attempts have been made since 70 s'to improve service performance in healthcare sector. Many of new studies talk about costs and non-value added activities reduction, increasing quality, reducing errors and increasing employee motivation and customer satisfaction. Public services all over the world are pressured to increase their efficiency and save money. This trend gives an opportunity to researchers to study this topic in detail and to assess which of the time-proven methods could be used in healthcare to make the health care efficient.

\section{INTRODUCTION OF LEAN}

Lean is a management model that was born in manufacturing and is now taking hold in health care. Focused on patient needs, it uses a bottom-up approach to identify and fix broken systems anywhere in an organization. Lean engages all staff as well as leaders in redesigning processes for greater efficiency and quality. (Mitchell, 2013)

High-performance work practices originated in the manufacturing sector in the early 1990s but have since spread to the health care and service sectors. (Harley, Allen, Sargent, 2007)

Healthcare systems are very costly and the inpatient treatment in hospitals is a major part of these costs. The question is, how can greater efficiency be effected without influencing the core business of a hospital - the cure of patients. Through improving the process flow of facility management (FM) processes, savings within these processes and less disturbance of primary processes should be accomplishable. (Kunibet, 2005)

Lean is an improvement approach that consists in eliminating waste (all steps that do not add value to the customer) to improve the flow of goods, information or e.g. patients. It is a multifaceted concept and requires organizations to exert effort along several dimensions simultaneously. (Teich, Faddoul, 2013) 
Lean emphasizes an array of tools and methods to help managers and workers in improvement, each designed for specific type of problems to illuminate and remove sources of waste through system redesign. (Sobek, Lang, 2010)

Although lean concepts were initially developed to improve car production, a study showed that the lean principles could be applied to virtually any manufacturing system. (Womack, 1996)

In minds of many, the health industry is different. This cannot be disclaimed. History, technology and culture of the healthcare industry is completely different. However, the decisive factors in what works and what does not are the managerial processes, which are alike for all industries. (Manos, Sattler, Alukal, 2006)

\subsection{History of Lean}

In 1990 James Womak published a comparative study of American, Europe and Japanese automotive production systems in which he used the phrase "lean manufacturing" but not its meaning. Lean manufacturing or industry engineering is strongly connected with TPS (Toyota Production System), but it is deeper rooted. TPS was developed from Henry Ford's production system, and Henry Ford developed F. W. Taylor's scientific management of manufacturing - thus "lean" has its beginnings at the turn of the twentieth century. Lean had its beginnings on the production floor at Toyota Production System, then migrated to other enterprises and these days is more and more producing benefits in services, including healthcare. (Souza, 2009)

The precise date of the first application of lean in healthcare is uncertain. In 1995 Heinbuch offered a lean solution in a particular case of just in time method. His work was dealing with physical inventory reduction in hospitals. A similar application regarding implementing lean approaches in healthcare was made by Jacobs and Pelfrey in 1995. Speculations about the potential use of lean in healthcare were put forth by the NHS Modernisation Agency in 2001. Bushell and Shelest described a pilot implementation of lean in a mid-sized hospital in the U.S.A. - this work was focused on patient flow improvement. Other similar publications of positive results of lean implementation in the area of medical facilities increased the interest about the topic. (Best, Neuhauser, 2006)

Joseph Juran, who linked manufacturing and the healthcare industry, wrote: “...as the health industry undertakes ... change, it is well advised to take into account the experience of other industries in order to understand what worked and what has not." (Bush, 2007)

Evidence presented in the literature indicates that lean has been embraced across the public services, including healthcare since 2005. This is the reasoning that allows the lean production principles to be applied in the healthcare industry, despite the principles was originally developed for application in other industries.

\subsection{Core of LEAN}

Lean solutions involve looking at processes, breaking them down into parts, and eliminating waste. Waste is an important concept in lean thinking, especially as it relates to time and motion. These wastes are common in all industries and are not unique to healthcare. The predefined wasteful activities are as follows (Bush, 2007, Aherne, 2007)

1. Overproduction 
Overproduction means producing something in excess, earlier, or faster than the next process needs it. In healthcare it can be e.g. printing clinical reports when they are not needed or reprinting labels "just in case" they are.

\section{Inventory}

The cost of managing a large supply inventory may not be obvious at first glance, however, beside consumption follow-up and space required to store, there is a need to follow expiration dates and to constantly ensure that the items in the inventory are not technologically obsolete. Moreover, it was already shown that the overall cost of smaller and more frequent shipment is lower than a large-volume discount purchases. Example in healthcare system: retaining unnecessary forms or obsolete items or keeping unused supply closets.

\section{Movement}

Moving or seeking patients, equipment, medication or charts unnecessarily far away or walking too far to find other staff members are the main examples of this type of waste. A lot of walking waste can arise from poor layout (or design of the working area).

\section{Transportation}

In healthcare the wasting transportation can be evident when moving patients, lab tests, information, etc.

\section{Over-processing}

There are times when material provided to the customers (patients) mandated by regulations can be confusing. Staff may be taking down unnecessary information from patients on admission, making multiple recordings and logs of data, writing by hand rather than by using a computer etc. Moreover, multiple insurance claim forms (mainly in the US), including ones that are not bills, can confuse the inexperienced "novice".

\section{Defects (errors)}

There are many examples for these defects that can be related to poor labeling of tests, incomplete information in patients 'charts, misfiling or making mistakes in documents that must be corrected later, making mistakes that lead to complaints about service quality, or in instructions provided to referrals.

\section{Waiting}

There is probably not much need to explain why waiting a few hours in line is a wasteful activity, as well as waiting for people to phone back, waiting for equipment to arrive from supplier departments etc.

\section{Under-utilizing staff}

Under-use is not only time-dependent but also involves deeper levels such as not sharing knowledge or not taking advantage of someone's skill and creativity. Under-use typically shows in hierarchical structures and not using teams.

Lean is not only about clinical care, but also about reducing inefficiencies in processes which are necessary for the health care. This is being done by transforming waste into value. Some authors report that up to $40 \%$ of time spent in hospitals is waste. (Berczuk, 2008)

When lean strategy eliminates wasted time and motion that means efficiency, productivity, employee satisfaction, and patient satisfaction all increase. "That's how hospitalists can use this - so much of what we do is about process," Dr. Kim explains. "Once a clinical encounter is finished, much of what we do to achieve our goal of treating patients is really about those 
processes." And processes are what lean seeks to optimize. Value is a crucial component of Lean care, and something that needs to be seriously discerned. Thinking Lean in a hospital setting involves considering the definition of value from a patient's perspective and putting in place efficient clinical changes to provide valuable care. It's essentially a shift in mindset, moving from viewing clinical care as a series of tasks to be completed as quickly as possible to a process that can be continuously improved on to achieve the goal of valuable outcomes for patients. (Berczuk, 2008)

\subsection{Alpha and Omega of Lean: Processes}

A process is a set of actions or steps, each of which must be accomplished properly in the proper sequence at the proper time to create value for a customer or patient.

Primary processes serve the external customer (in health care, patients and their families). Internal processes serve internal customers/staff in support of the primary process.

Primary processes are easier to see, but internal processes are necessary to create value in the primary process.

A crucial process in Lean is the identification of waste through root cause analysis. Root cause analysis in Lean involves a method called 5-Whys. This method rapidly identifies root causes and aides in determining the relationship between multiple root causes. It can be learned quickly and does not require statistical analysis. This method is especially effective for an implementation team in the initial stages of problem exploration. The application of this strategy involves asking a series of why-related questions to drill down into a problem area. Asking progressive questions about a perceived difficulty forces team members to think critically about the actual sources of waste and inefficiency. It is suggested that at least five questions

(5-Whys) are posed to arrive at the root cause, though a root cause may be discovered in more or less inquires. (Majdi, 2014)

Standard healthcare systems are not designed to make the process of care flow smoothly. Most are organized around functional departments such as pathology, radiology, radiotherapy etc., in which patients travel from one site to queue up at another. In such systems, a patient can typically spend a day in hospital for only 18 minutes of value-added-time: three minutes for a blood test and five for a radiograph (for example) and then ten minutes spent with a doctor. The focus of lean thinking in healthcare is on improving flow among activities of "core value" to organizations, and on individual patients and their journeys. The challenge is to revolutionize our expectations of healthcare: to design a continuous flow of work for clinicians and a seamless experience of care for patients. (Aherne, 2007)

\subsection{Why to implement Lean in hospitals?}

The main reason for implementing lean methods is the fact that lean leads to less disruptions and therefore to higher stability. According to Dennis, "STABILITY" is the main object of the lean. Archimedes motto: "Give me a place to stand, and I can move the earth", explains the importance of stability either in the production factors (man, machine, material, method) in the case of production or in other areas. Dennis argues that the stability starts with visual management, 5S workplace organization and TPM (Total Productive Maintenance). All of them support standardization and provide point-of-use information that eases decision making. (Dennis, 2002) 
Implementation of lean in healthcare, particularly in hospitals, should remove duplicate processes and unnecessary procedures and also eliminate disruptions which may cause fatal consequences. (Robinson, 2012)

With processes in the healthcare setting being as complex as they are today, it is important that they be properly managed. Any organization has its own long-term institutional culture. That culture also can lead to complacency, a "we've-always-done-it-this-way" attitude, which should have be avoided. The management of processes comprises planning, directing and monitoring. Planning is done before a process is carried out, directing during the execution of a process, and monitoring during the entire evolution of the process, from beginning to the end.

It is important to realize that there are many advantages that can be gained from a wellmanaged process, including reduced hospital costs due to reduced patient lengths of stay, increased rates of success of patient treatment due to greater coordination of activities amongst clinicians, and greater levels of clinician and patient satisfaction through the proper coordination and relaying of information regarding activities and outcomes. On the flip side, it is to be emphasized that poorly managed process can have negative effects.

One of the major causes that lead to poorly managed processes is the hectic of the clinical environment. There are several consequences that emerge as a result of this hectic, and of poorly managed processes in general. In particular, there are many problems that show up directly at the patient point of care. Tasks are often forgotten, or relationships between tasks not recognized. Poorly managed processes also result in physicians, nurses and other clinicians making diagnostic and therapeutic mistakes. (Reichert, 2000)

Many patient safety incidents are related to lack of attention to human factors and ergonomics in the design and implementation of technologies, processes, workflows, jobs, teams and sociotechnical systems. Human factors and ergonomics are now considered to be a key discipline to help reduce or mitigate medication errors, to improve quality of health services and to eliminate hazards that contribute to patient falls. (Carayon, Xie, Kainfar, 2013)

\subsection{Medical errors}

In 1999, the US Institute of Medicine (IOM) issued its landmark report, To Err Is Human, which stated that up to 98,000 Americans died as a result of preventable medical errors in US hospitals and up to 1 million more experienced some type of preventable error.

In 2008, medical errors cost the United States $\$ 19.5$ billion. About 87 percent or $\$ 17$ billion were directly associated with additional medical cost, including: ancillary services, prescription drug services, and inpatient and outpatient care, according to a study sponsored by the Society for Actuaries and conducted by Milliman in 2010. Additional costs of $\$ 1.4$ billion were attributed to increased mortality rates with $\$ 1.1$ billion or ten million days of lost productivity from missed workbased on short-term disability claims. (Shreve, 2010)

\section{RESEARCH IN SELECTED CZECH HOSPITALS}

In order to find out what is Czech medical staff's knowledge and perception of lean healthcare philosophy and tools, a survey was carried out with several not-for-profit Czech hospitals. In order to evaluate the knowledge, working attitude and behaviors of participants, it is important to use both quantitative and qualitative methods. Quantitative data provides 
numerical and statistical information, and qualitative data provides the deep narrative on the context. The design of the survey was done using standard instrument design methods.

The quantitative portion for this research comes from a survey of employees (doctors, nurses and paramedical staff) in various not-for-profit hospitals across the Czech Republic. The survey was administrated during spring 2014. At the end we collected a total of 279 completed surveys. Surveys were distributed to doctors, nurses and paramedical staff in selected Czech hospitals. The collected data was statistically proved using different statistic methods, mostly by ANOVA.

The basic characteristics are displayed in the table below.

Table 1 - Basic characteristics of sample

\begin{tabular}{|c|c|c|c|}
\hline & & Frequency (n) & Percent $(\%)$ \\
\hline \multirow[t]{2}{*}{ Gender } & Female & 42 & $15,05 \%$ \\
\hline & Male & 237 & $84,95 \%$ \\
\hline \multirow[t]{3}{*}{ Age } & 18 - 29 years & 87 & $31,18 \%$ \\
\hline & $30-49$ years & 129 & $46,24 \%$ \\
\hline & 50 and more & 63 & $22,58 \%$ \\
\hline \multirow[t]{3}{*}{ Practice } & Less than 5 years & 60 & $21,51 \%$ \\
\hline & $5-10$ years & 66 & $23,66 \%$ \\
\hline & 10 and more & 153 & $54,84 \%$ \\
\hline \multirow[t]{3}{*}{ Position } & Doctor & 42 & $15,05 \%$ \\
\hline & Nurse & 174 & $62,37 \%$ \\
\hline & Paramedical staff & 63 & $22,58 \%$ \\
\hline \multirow{4}{*}{$\begin{array}{l}\text { Interest in improvement activities } \\
\text { (kaizen) }\end{array}$} & Absolutely interested & 30 & $10,75 \%$ \\
\hline & Maybe interested & 135 & $48,39 \%$ \\
\hline & Not interested & 60 & $21,51 \%$ \\
\hline & Nothing to improve & 54 & $19,35 \%$ \\
\hline \multirow[t]{3}{*}{ Percieved influence on quality } & Absolutely influencing & 153 & $54,84 \%$ \\
\hline & Rather influencing & 90 & $32,26 \%$ \\
\hline & Rather not influencing & 30 & $10,75 \%$ \\
\hline
\end{tabular}




\begin{tabular}{|c|c|c|c|}
\hline & $\begin{array}{l}\text { Definitely } \\
\text { influencing }\end{array}$ & 6 & $2,15 \%$ \\
\hline Percieved rate of wasting & $\begin{array}{l}0-4(0=\text { rarely, } 4= \\
\text { permanently })\end{array}$ & & \\
\hline \multirow[t]{5}{*}{ Overproduction } & 0 & 15 & $5,38 \%$ \\
\hline & 1 & 78 & $27,96 \%$ \\
\hline & 2 & 99 & $35,48 \%$ \\
\hline & 3 & 54 & $19,35 \%$ \\
\hline & 4 & 33 & $11,83 \%$ \\
\hline \multirow[t]{5}{*}{ Wasteful movements } & 0 & 25 & $8,96 \%$ \\
\hline & 1 & 74 & $26,52 \%$ \\
\hline & 2 & 90 & $32,26 \%$ \\
\hline & 3 & 57 & $20,43 \%$ \\
\hline & 4 & 33 & $11,83 \%$ \\
\hline \multirow[t]{5}{*}{ Defects } & 0 & 48 & $17,20 \%$ \\
\hline & 1 & 93 & $33,33 \%$ \\
\hline & 2 & 78 & $27,96 \%$ \\
\hline & 3 & 30 & $10,75 \%$ \\
\hline & 4 & 30 & $10,75 \%$ \\
\hline
\end{tabular}

Below the perceived influence on quality depending on job position in hospital is displayed.

Table 2 - ANOVA: Perceived influence on quality dependig on job position

\begin{tabular}{|l|l|l|l|l|l|l|}
\hline \multicolumn{2}{|l}{ ANOVA } \\
\hline Source of Variation & SS & df & MS & F & P-value & F crit \\
\hline Between Groups & 10,4086022 & 1 & 10,40860 & 21,578870 & 0,00000645 & 3,8924943 \\
\hline Within Groups & 88,7526882 & 184 & 0,482351 & & & \\
\hline Total & 99,1612903 & 185 & & & & \\
\hline
\end{tabular}

According to the results, job position does not have an influence on how hospital employees do perceive their influence on quality of health care. A good message is, that regardless the 
job position, almost $88 \%$ of the participants believe that they can influence the quality of health care directly. If they do realize that, we can suppose that they should be more willing to work on increasing the quality.

Another good result was given by participants according to their willingness to get involved in improvement activities, which is also not conditional on a job position they have.

Table 3 - ANOVA: Influence of job position on willingness to get involved in kaizen activities

\begin{tabular}{|l|l|l|l|l|l|l|}
\hline \multicolumn{2}{|l|}{ ANOVA } \\
\hline Source of Variation & SS & df & MS & F & P-value & F crit \\
\hline Between Groups & 1,94086 & 1 & 1,94086 & 5,181279 & 0,023983346 & 3,892494 \\
\hline Within Groups & 68,92473 & 184 & 0,374591 & & & \\
\hline Total & 70,86559 & 185 & & & & \\
\hline
\end{tabular}

Regarding the improvement activities, we decided to analyze an influence of length of participants' practice on their attitude to improvement activities. As can be seen in the table below, length of practice has an impact on interest in improvement activities.

Table 4 - ANOVA: Influence of lenght of practice on the attitude to kaizen

\begin{tabular}{|l|l|l|l|l|l|l|}
\hline \multicolumn{2}{|l|}{ ANOVA } \\
\hline Source of Variation & SS & df & MS & F & P-value & F crit \\
\hline Between Groups & 1,209677 & 1 & 1,209677 & 1,590839 & 0,20880303 & 3,892494 \\
\hline Within Groups & 139,914 & 184 & 0,760402 & & & \\
\hline Total & 141,1237 & 185 & & & & \\
\hline
\end{tabular}

In order to prove the results above we have tested a correlation between the two factors.

Measurement units of the correlation values are set up as follows:

$0,00-0,14 \Rightarrow$ very weak correlation;

$0,15-0,24 \Rightarrow$ weak correlation

$0,25-0,39 \Rightarrow$ middle strong correlation

$0,40-0,50 \Rightarrow$ strong correlation

0,51 and above $\Rightarrow$ very strong correlation. (Ziebertz, 2005)

Correlation value between length of practice and interest in improvement activities is 0,5105 . It means very strong correlation between these factors.

Based on the previous results we were interested in how much is the involvement in improvements influenced by participants 'age. The correlation value between age and interest in improvement activities is 0,4715 , which proves a strong correlation. Therefore we can say that willingness to improve is strongly influenced by both age and length of practice. 
The analyses showed that the longer practice participants have, the lesser they are interested in any improvement activities. This is not really a good message. With increasing practice employees are losing appetite to think about possible improvements in their everyday work. This may be caused by a professional blindness (people are conditioned by their expertise and routine to only see what they are accustomed to seeing) or maybe by decreasing motivation. Whatever else might be said about it, the decreasing involvement in improvement activities should be perceived as a negative effect which should be reversed by trainings, workshops and positive motivation. This gives a huge opportunity to researchers, managers and practitioners to work with healthcare workers and to create an inspiring and supportive work environment.

\section{CONCLUSION}

As the cost of health care continues to rise, hospitals are put under increasing pressure to reduce costs while improving patient safety and care, and reducing errors. New discoveries in medicines are being made and new treatments are being developed, but these will be no more important to healthcare services in the future than the results of lean thinking. Medical devices and equipment are very costly and therefore it is necessary for hospitals to seek all possible ways of reducing them. One of those ways can consist of optimizing processes and a use of industrial engineering methods to make the processes more effective. Applying lean thinking to the healthcare sector can provide significant cost and process efficiencies. However, in order to realize and sustain these benefits fully, there is an urgent need to educate and empower healthcare staff in the Lean principles and methodologies. Education and training in lean thinking should be an inseparable part of organisations' competency frameworks to ensure consistency across all functions. Therefore there appears to be a significant need for the development of training materials and curricula that replace manufacturing jargon with healthcare terminology, contain healthcare-related examples. Much work remains to understand how to implement the lean model into healthcare.

\section{Acknowledgement}

This contribution was supported by the Internal Grant Agency of FaME TBU No. IGA/FaME/2013/023 "Optimization of management and processes of medical facilities and social services through Industrial Engineering methods"

\section{References}

Aherne, J., \& Whelton, J. (2010). Applying Lean in Healthcare. https://doi.org/10.1201/EBK1439827390

The Lean Hospital - The Hospitalist. (n.d.). Retrieved February 3, 2016, from http://www.the-hospitalist.org/article/the-lean-hospital/

Best, M., \& Neuhauser, D. (2006). Joseph Juran: Overcoming resistance to organisational change. Quality and Safety in Health Care, 15(5), 380-382. https://doi.org/10.1136/qshc.2006.020016

Souza, L. B. (2009). Trends and approaches in lean healthcare. Leadership in Health Services, 22(2), 121-139. https://doi.org/10.1108/17511870910953788

Bush, R. W. (2007). Reducing Waste in US Health Care Systems. Jama, 297(8), 871. https://doi.org/10.1001/jama.297.8.871

Carayon, P., Xie, A., \& Kianfar, S. (2013). Human factors and ergonomics as a patient safety practice. BMJ Quality \& Safety, 23(3), 196-205. https://doi.org/10.1136/bmjqs-2013001812 
Dennis, P. (2002). Lean production simplified: A plain language guide to the world's most powerful production system. New York: Productivity Press.

Harley, B., Allen, B. C., \& Sargent, L. D. (2007). High Performance Work Systems and Employee Experience of Work in the Service Sector: The Case of Aged Care. $B r J$ Industrial Relations British Journal of Industrial Relations, 45(3), 607-633. https://doi.org/10.1111/j.1467-8543.2007.00630.x

Lennerts, K., Abel, J., Pfründer, U., \& Sharma, V. (2005). Step-by-step process analysis for hospital facility management. Facilities, 23(3/4), 164-175. https://doi.org/10.1108/02632770510578539

Majdi, C. (n.d.). Lean methodology in health care quality improvement. Retrieved April 14, 2016, from http://transitionconsultants.com/articles/19-lean-methodology-in-healthcare-quality-improvement

Manos, A., Sattler, M., \& Alukal, G. (2006). Make Healthcare Lean. Journal for Healthcare Quality, 39(7). https://doi.org/10.1111/jhq.2006.28.issue-4Mitchell, R. (n.d.). Follow the Lean Journey. Retrieved February 12, 2016, from http://www.chcf.org/publications/2013/12/getting-lean

Reichert, M. (2000). Prozessmanagement im Krankenhaus: Nutzen, Anforderungen und Visionen. das Krankenhaus, 92(11), 903-909.

Robinson, S., Radnor, Z. J., Burgess, N., \& Worthington, C. (2012). SimLean: Utilising simulation in the implementation of lean in healthcare. European Journal of Operational Research, 219(1), 188-197. https://doi.org/10.1016/j.ejor.2011.12.029

Shreve, J., Van Den Bos, J., Gray, T., Halford, M., Rustagi, K., \& Ziemkiewicz, E. (2010). The economic measurement of medical errors sponsored by society of actuaries' health section. Milliman Inc.

Sobek II, D. K., \& Lang, M. (2010, January). Lean healthcare: Current state and future directions. In IIE Annual Conference. Proceedings (p. 1). Institute of Industrial Engineers-Publisher.

Teich, S. T., \& Faddoul, F. F. (2013). Lean Management - the Journey from Toyota to Healthcare. RMMJ Rambam Maimonides Medical Journal, 4(2). https://doi.org/10.5041/RMMJ.10107

Womack, J. P., \& Jones, D. T. (1997). Lean Thinking-Banish Waste and Create Wealth in your Corporation. J Oper Res Soc Journal of the Operational Research Society, 48(11), 1148-1148. https://doi.org/10.1038/sj.jors.2600967

Ziebertz, H. G., \& Kay, W. K. (2009). Youth in Europe: An international empirical study about life perspectives (Vol. 1). LIT Verlag Münster.

\section{Contact information}

Veronika Vavrušová

Univerzita Tomáše Bati ve Zlíně, Fakulta managementu a ekonomiky

Mostní 5139, Zlín 76001

+420721108509

vavru.ve@gmail.com

Edita Vitásková

Univerzita Tomáše Bati ve Zlíně, Fakulta managementu a ekonomiky

Mostní 5139, Zlín 76001

+420725703449

vitaskova.edita@gmail.com

DOI: https://www.doi.org/10.7441/dokbat.2016.41 


\title{
TECHNICAL EFFICIENCY OF FDI FIRMS IN THE VIETNAMESE MANUFACTURING SECTOR
}

\author{
Vu Hoang Duong
}

\begin{abstract}
The study examines technical efficiency of FDI firms in the manufacturing sector of Vietnam by applying stochastic production frontier model and making use of cross-sectional data in the period 2009- 2013. The average level of technical efficiency of FDI firms is about 60\% and it is higher than this of domestic firms (including private firms and state-owned firms). The result implies that FDI firms in Vietnam could improve their performance by $40 \%$ without changing level of technology.
\end{abstract}

Keywords: FDI, technical efficiency, stochastic production frontier, Vietnam.

\section{INTRODUCTION}

One of the most important impacts of FDI on economy of host countries is technological and managerial spill-over effects. Spillover effects are expected to happen in the cooperation between FDI firms and domestic firms. It is anticipated that the more efficient FDI firms operate, the better chance technological and managerial spill-over could happen. However, FDI spill-over effect will not be automatically converted into benefit of host countries but largely depends on FDI absorptive capacity of domestic firms (Ferragina \& Mazzotta 2014; Girma 2005; Marcin 2008; Tang \& Zhang 2015; Ghali \& Rezgui 2011). To absorb benefit from FDI, domestic firms must improve their capability first. If there is a big gap between FDI firms and domestic firms, spillover effect is unlikely to occur or it will occasionally occur. Consequently, domestic firms could be dominated by FDI ones via competition.

Eventually, there are two basic conditions to make sure that domestic firms will gain from FDI appearance: efficient operation of FDI firms and decent capability of domestic firms. Both of them are crucial, although, this study only draws attention on the first condition and leave the second one for further studies. Let temporarily ignore the condition of absorptive capacity and premise that if FDI firms operate efficiently in host countries, domestic firms will be benefited more from spillover effects.

It is becoming more importantly in case of Vietnam where impact of FDI is essential. FDI has not only contributed to economic growth and restructuring but also improved labour productivity, facilitated exporting activities and created new jobs. But the question is that could FDI firms have operated at their highest capability or could they have contributed more than what they have already done?

Therefore, this study will examine efficiency of FDI firms in comparison with domestic firms in the Vietnam manufacturing sector from 2009 to 2013 to answer these questions. It will be conducted by estimating technical efficiency of these firms. Basically, combining inputs and technology to produce output will create a potential production frontier of a specific firm. If real output of the firm is equal to potential output, this firm is technical efficiency. In other words, the firm could produce on production frontier. If real output of the firm is not equal to potential output, then this firm is technical inefficiency. However, when estimating production frontier, it is assumed that firms within one industry could use the same type of technology. Hence, it is insignificant to estimate the production frontier for the manufacturing sector as a whole because there are many sub-sectors. As a result, the study only chooses 04 sub-sectors which contribute importantly to growth of manufacturing sector to represent for it. They are: electronic, automobile, textiles and wearing apparel sub-sectors. 
The study includes five parts. The second part is background and literature review. The third part is a method to estimate efficiency of FDI firms. Next will be the main results and it is followed by conclusion.

\section{BACKGROUND}

There are several ways to examine performance of an organization. According to Porcelli (2009), performance of the organization should be assessed by effectiveness and efficiency (Figure 1). It is necessary to differentiate between efficiency and effectiveness. Worthington \& Dollery (2000) indicate that effectiveness could be measured by outcomes, quality, accessibility and appropriateness. Meanwhile, efficiency could be presented by effectiveness, allocative and productive efficiency. However, due to lack of data availability, effectiveness of firms is unlikely to measure, thus the study only focuses on efficiency of firms.

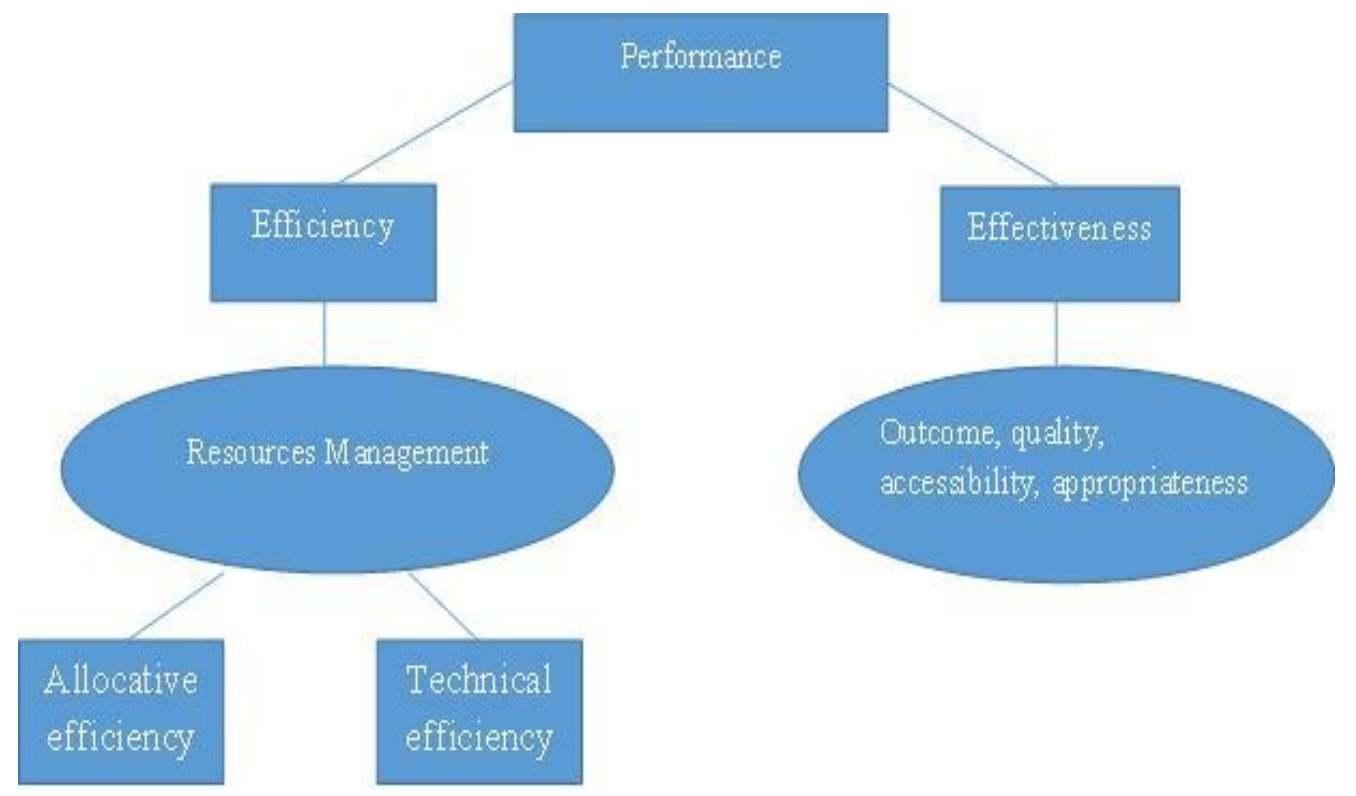

Figure 22 - Performance of firm. Source: Porcelli (2009)

As mentioned above, the theory of microeconomic about efficiency measurement has developed three types of efficiency. Technical efficiency refers to ability to combine inputs (such as labour and capital) in the most technological way to produce some certain level of output. Allocative efficiency mentions to capability of one establishment to combine inputs in the optimal option with some certain level of inputs' price and technology. In other words, allocative efficiency is to pick up technical efficiency choices to produce the largest amount of output. And finally, productive efficiency simply is a combination of technical efficiency and allocative efficiency (Worthington 2001). Because allocative efficiency and productive efficiency based on assumption of full technical efficiency of an organization, thus the study only attempts to estimate technical efficiency as a background.

The first author mentions to efficiency measurement is Farrell (1957). Farrell states that efficiency measurement must base on assumption that efficient production function is wellknown. However, this function is unlikely to be defined in reality; hence it is necessary to estimate it by applying parametric or non-parametric approach.

There are a substantial part of researches estimating technical efficiency by using parametric, non-parametric approach or both of them. Badunenko, Fritsch, \& Stephan, (2006) examines determinants of technical efficiency of Germany manufacturing firms by exploiting a database of Germany cost structure Census from 1992 to 2004 including 35.000 firms within 
252 industries. Technical efficiency depends on firm-industry effect, location of firm headquarters, firm's size and R\&D intensity. Burki and Dek (1998) examine technical efficiency and economy of scale of Pakistan firms in the 09 manufacturing industries by applying Data Envelop Analysis (DEA - non-parametric approach). The result is that surveyed firms could increase output by $6 \%$ to $29 \%$ by improving technical efficiency. Lundvall and Battese (2000) exploit unbalanced panel data to calculate technical efficiency of Kenyan manufacturing firms by applying stochastic frontier production method (SFPparametric approach). The authors find that technical efficiency could be affected significantly by firm's size. In addition, Mahadeven (2000) estimates technical efficiency of 28 the Singapore manufacturing industries from 1975 to 1994 by applying SFP method. The result is that technical efficiency of observed firms is $73 \%$ in average. Moreover, there are two important determinants of technical efficiency: capital intensity and labour quality. Interestingly, $\mathrm{Wu}$ (2000) uses input-oriented distance function approach to calculate technical efficiency of FDI firms in China between 1983 and 1995. In that time, FDI performance has inverted J-shape form.

In case of Vietnam, there are also various studies on technical efficiency of Vietnamese firms. $\mathrm{Vu}$ (2003) estimates technical efficiency of state-owned firms and non-state firms in Vietnam by using SFP method and exploiting a surveyed data of 164 firms in 1996, 1997, 1998 across Hanoi, Hai Phong and Ho Chi Minh city. The author shows that stat-owned firms are more technically efficient than other firms. Besides, the study also figures out determinants of technical efficiency including human capital, location and exports activities. Minh, Long and Thang (2007) calculate technical efficiency of small and medium-sized enterprises in the Vietnamese manufacturing sector by using both DEA and SFP method. The authors exploit a panel data from 2000 to 2003 and indicate some key findings. Technical efficiency of SME estimated by SPF and DEA is 50\% and 40\% respectively. Tran (2007) studies technical efficiency of Vietnamese pharmacy firms by using cross-sectional data in 2002 and SFP method. Tran concludes that cost efficiency of these firms is $50 \%$ higher than the frontier and influential factors are debt ratio, ownership and firm's location. Similarly, Le and Harvie (2010) estimate technical efficiency of SME in the Vietnamese manufacturing sector in the period 2000-2007. The authors make use of a panel data of 5,204 SME and apply SFP method to conclude that technical efficiency of these firms is $89.71 \%$ in average. Khai and Yabe (2011) apply SFP method to analyse technical efficiency of Vietnam agricultural production household in 2005 and 2006. The authors take advantage of a panel data of 3,733 household and find that technical efficiency of these household is $81.6 \%$. Vu (2012) also applies SFP method to estimate technical efficiency of Vietnamese manufacturing firms from 2000 to 2009. He concludes that private firms are the most efficient one and they are benefited from cooperating with foreigners.

In general, majority of researches in Vietnam pay attention on technical efficiency of SME or state-owned enterprises and lack of researches on technical efficiency of FDI firms specifically. Therefore, this study will fill the gap by estimating technical efficiency of FDI firms in the manufacturing sector. Moreover, the study also takes a further step by exploiting 3-digit sub-sectors including textiles, wearing apparel, electronic and automobile industry to represent for the manufacturing sector. In 2013, value added created by these four sub-sectors ranked the $23^{\text {rd }}, 14^{\text {th }}, 3^{\text {rd }}$ and $20^{\text {th }}$ over 99 sub-sectors of the manufacturing sectors. In addition, the numbers of employment in these sub-sectors are also quite big.

\section{METHOD}

The study will make use of stochastic frontier production function method. 
According to Kumbhkar and Lovell (2004), assume that there are $\mathrm{n}$ inputs to produce one single output, and then stochastic frontier production model will be:

$$
y_{i}=f\left(x_{i}, \beta\right) \cdot \exp \left\{v_{i}\right\} . T E_{i}
$$

Where $y_{i}$ is output of firm i, $x_{i}$ is a vector of $\mathrm{n}$ inputs used by firm $\mathrm{i}, f\left(x_{i}, \beta\right) \cdot \exp \left\{v_{i}\right\}$ is stochastic frontier production, $\beta$ is a vector of technology coefficient, $\exp \left\{v_{i}\right\}$ is random factors that firm $I$ is unlikely to control and $T E_{i}$ is technical efficiency of firm i.

From equation (1), technical efficiency of firm i will be:

$$
T E_{i}=\frac{y_{i}}{f\left(x_{i}, \beta\right) \cdot \exp \left\{v_{i}\right\}}
$$

In which, technical efficiency is a ratio of real output that firm i produce to potential output that firm i could produce, conditional on stochastic factor $\exp \left\{v_{i}\right\}$. If TE equals to 1 , firm $\mathrm{i}$ is full technical efficient and if TE is smaller than 1, firm $i$ is technical inefficient.

Equation (1) could be transformed into:

$$
y_{i}=f\left(x_{i}, \beta\right) \cdot \exp \left\{v_{i}\right\} \cdot \exp \left\{u_{i}\right\}
$$

Where $T E_{i}=\exp \left\{-u_{i}\right\}$. Technical efficiency is always smaller or equal to 1 , thus $u_{i}$ is always bigger or equal to 0 . Assume that $f\left(x_{i}, \beta\right)$ if formed in log-linear Cobb-Douglas function, then the stochastic production function will be:

$$
\ln y_{i}=\beta_{0}+\sum_{n} \beta_{n} \ln x_{n i}+v_{i}-u_{i}
$$

$v_{i}$ and $u_{i}$ is two components of error term, in which $v_{i}$ could understood as "noise" component and $u_{i}$ is a positive component of technical inefficiency. $v_{i}$ is independent and identical distributed $N\left(0, \sigma_{v}^{2}\right), u_{i}$ independent and exponential distributed and $v_{i}$ and $u_{i}$ are independent to each other and input variables.

Equation (4) will be estimated by applying maximum likelihood (ML). Thus, maximum likelihood function is presented in standard deviations of frontier function as follow:

$$
\sigma^{2}=\sigma_{v}^{2}+\sigma_{u}^{2} \text { và } \gamma=\frac{\sigma_{u}^{2}}{\sigma^{2}}
$$

$\sigma_{v}^{2}$ is variance of "noise" component $\mathrm{v}$ and $\sigma_{u}^{2}$ is variance of technical inefficiency component. If total error variance $\sigma^{2}=0$ and $u_{i}=0$ then the firm is full technical efficient. $\gamma$ is ratio between variance of technical efficiency component and total error variance and has a value from 0 to 1 . If $\gamma$ equals to 0 , it means bias of production function is created by "noise" component or uncontrolled factors. In other words, the smaller value of $\gamma$ is, the lower effect of technical inefficiency component is.

It is necessary to test the model. The first one is to test whether technical inefficiency exists. The null hypothesis is $H_{0}: \sigma_{u}^{2}=0$ and the alternative hypothesis is $H_{1}: \sigma_{u}^{2} \neq 0$. If technical inefficiency does not exist, firm is full technical efficient and the stochastic frontier model 
will be no longer significant and it is reduced to OLS model. The hypothesis will be tested by one-side generalized likelihood ratio test.

Then, if the technical inefficiency exists, it is necessary to test functional form of the stochastic frontier model. There are two possibilities: Cobb-Douglas function and trans-log Cobb- Douglas function will be presented in the equation (5) and (6) respectively:

$$
\begin{gathered}
\ln Y_{i}=\beta_{0}+\beta_{1} \ln K_{i}+\beta_{2} \ln L_{i}+v_{i}-u_{i} \\
\ln Y_{i}=\beta_{0}+\beta_{1} \ln K_{i}+\beta_{2} \ln L_{i}+\beta_{3} \ln L_{i}^{2}+\beta_{4} \ln K_{i}^{2}+\beta_{5} \ln L_{i} * \ln K_{i}+v_{i}-u_{i}
\end{gathered}
$$

Assume that there only two inputs to produce output including capital and labour. Then, $Y_{i}$ is output of firm i, $K_{i}$ is stock capital of firm i used to produce output $\mathrm{Y}$ and $L_{i}$ is number of employment used to produce output Y. The null hypothesis is $H_{0}: \beta_{3}=\beta_{4}=\beta_{5}=0$. If the hypothesis is rejected, production function will be in trans-log form, otherwise, it will be Cobb-Douglas production function.

\section{Data}

The study exploits cross-sectional data from 2009 to 2013 from Vietnam Annual Enterprises Survey which contains information about type of firms, number of employment, fixed capital, investment, export activities, economic activity, location and net turnover of firms in specific years. It is expected to estimate technical efficiency of firms year by year from 2009 to 2013 to make a comparison.

In this survey, one firm could operate in more than one economic activity and these activities could be separated. The study only focuses on 04 sub-sectors of the manufacturing sector: wearing apparel, textiles, automobile and electronic. Therefore, it is necessary to split economic activities of firms into specific ones. For example, if the firm i operates in two economic activities such as: processing and preserving of meat and manufacturing of textiles, the study will split information about textiles, not firm i as a whole.

More specifically, $\mathrm{K}$ is capital of firm proxied by fixed assets of firms at the end of the year. $\mathrm{L}$ is employment of firms at the end of the year. $\mathrm{Y}$ is net returns of firms. It will be ideal to proxy Y by gross output of firm. However, information about output of specific economic activity of each firm is not available; hence net return of specific economic activity is used. In addition, the study also filters the database by ignoring firms with negative net returns and non-positive employment and fixed assets. Duplicate firms also are ignored. (Summary of variables is described in the Table 4 Appendix).

Study uses STATA 14 software to conduct estimating stochastic frontier production function and technical efficiency of firms.

\section{RESULTS AND DISCUSSION}

First of all, the study tests existence of technical inefficiency. The results from one-sided generalized likelihood-ratio test show that all of FDI firms within 04 sub-sectors from 2009 to 2013 are technical inefficient (Table 5 in Appendix). The results show that applying stochastic frontier production function is appropriate. After that, it is necessary to conduct a test on functional form of stochastic frontier production function. Results from tests indicate that majority of FDI stochastic frontier production function should be trans-log form while results of domestic ones are mixed (Table 6 in Appendix). 
Interestingly, if comparing between 2009 and 2013, $\gamma$ of FDI firms shows an improvement, particularly in the wearing apparel when $\gamma$ decreases from 0.7 to 0.41 . It indicates that in 2009 , bias of production function $70 \%$ created by technical inefficiency component and in 2013 , it is only about $40 \%$. In other words, in $2013,60 \%$ of production function bias is due to "noise" component (such as weather condition) that the firm is unlikely to control. Similarly is the case of textiles with a decrease of $\gamma$ from 0.53 in 2009 to 0.48 in 2013. FDI firms in automobile and electronic industries have insignificant improvement, although $\gamma$ of them are pretty low (0.33 and 0.44 respectively) (Table 1$)$.

Table 15: $y$ of FDI firms in 2009 and 2013. Source: Author's calculation

\begin{tabular}{|c|c|c|c|c|}
\hline & Textiles & Wearing apparel & Electronic & Automobile \\
\hline 2009 & 0.5250 & 0.7046 & 0.3255 & 0.4143 \\
\hline 2013 & 0.4824 & 0.4193 & 0.3366 & 0.4020 \\
\hline
\end{tabular}

The study based to functional form test to estimate stochastic production function of FDI (in comparison with domestic firms including state and private firms) and technical efficiency of them. Due to word limitation, the table of results of estimated stochastic production function cannot present here, but will be provided in request. This paper only shows estimated technical efficiency of FDI firms and domestics firms from 2009 to 2013.

Table 16: Technical efficiency of firms 2009-2013. Source: Author's calculation

\begin{tabular}{|c|c|c|c|c|c|c|c|}
\hline & & 2009 & 2010 & 2011 & 2012 & 2013 & Average \\
\hline \multirow{2}{*}{ 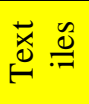 } & Domestic & 0.4911 & 0.4706 & 0.5298 & 0.5058 & 0.5441 & 0.508289 \\
\hline & FDI & 0.5799 & 0.5640 & 0.5798 & 0.5769 & 0.6038 & 0.5809 \\
\hline \multirow{2}{*}{$\sum^{\mathbb{D}} \cdot \stackrel{\infty}{\Xi}$} & Domestic & 0.5228 & 0.5162 & 0.5813 & 0.5339 & 0.5685 & 0.544564 \\
\hline & FDI & 0.5167 & 0.6019 & 0.5409 & 0.5734 & 0.6679 & 0.580151 \\
\hline \multirow{2}{*}{$\frac{\circlearrowright}{\square}$ ฮี } & Domestic & 0.4472 & 0.4471 & 0.4876 & 0.5077 & 0.5083 & $\mathbf{0 . 4 7 9 5 7}$ \\
\hline & FDI & 0.5645 & 0.5174 & 0.5922 & 0.6568 & 0.6115 & 0.588485 \\
\hline \multirow{2}{*}{$\vec{z} 0$} & Domestic & 0.5802 & 0.5159 & 0.5775 & 0.5458 & 0.7134 & 0.586575 \\
\hline & FDI & 0.5967 & 0.5965 & 0.5964 & 0.5471 & 0.6162 & 0.590609 \\
\hline
\end{tabular}

From the result table 2, we can see an improvement in technical efficiency of majority of firms in the observed time. Generally, technical efficiency of FDI firms across four subsectors seems to be higher than this of domestic firms. It could be explained that capability of combining inputs and technology of FDI firms is better than domestic ones.

In 2013, technical efficiency of FDI firms in the observed sub-sectors is somewhat higher than 0.6. The sub-sector with highest level of technical efficiency is wearing apparel (0.667), while the others are approximately 0.6. However, the average levels of technical efficiency of FDI firms in four sub-sectors from 2009 to 2013 are quite similar (Table 2), about 0.59 approximately. This means FDI firms in these sub-sectors are only $59 \%$ technical efficient. The capability to combine input, especially is labour with level of technology of FDI firms is $59 \%$. In other words, FDI firms only operate at about $60 \%$ of their full potential capability. It raises a concern about level of Vietnam labour force quality. Given this certain level of technology, workers in such FDI firms only make use of $60 \%$. Therefore, there is still room to increase efficiency without changing technology level by improving workers' skills. 


\section{CONCLUSION}

It is noteworthy that there are two necessary conditions to convert FDI spillover effects into benefit of a host country: efficient operation of FDI firms and decent absorptive capacity of domestic firms. This study only focuses on the former condition premising that if FDI firms operate more efficiency, they could bring more positive spillover effects to domestic ones.

The study examines efficiency of FDI firms by estimating technical efficiency from stochastic frontier production model. In order to estimate technical efficiency of firm, it is assumed that all firms could use the same type of technology. Therefore, it will not make sense to estimate production function of the Vietnam manufacturing sector as a whole because there are many sub-sectors within it. Hence, the study only chooses 04 sub-sectors that have contributed significantly to growth of manufacturing sector over time, they are: textiles, wearing apparel, electronic and automobile. The study also compares technical efficiency of FDI firms to domestic firms. There are some main remarks as follow. In general, technical efficiency of all type of firms increases from 2009 to 2013 and as expected, FDI firms have higher level of technical efficiency than domestic ones. However, average technical efficiency of FDI firms in four sub-sectors is only smaller than $60 \%$. In other words, FDI firms could improve their efficiency by $40 \%$ without upgrading technology level. It could also be understood that workers in these FDI firms are only making use of $60 \%$ of technology level.

\section{APPENDICES}

Table 3: Foreign direct investment projects licensed by kinds of economic activity (Accumulation of projects having effect as of 31/12/2013). Source: Vietnam General Statistic Office, 2014

\begin{tabular}{|c|c|c|}
\hline Kinds of economic activity & \begin{tabular}{|l|l}
$\begin{array}{l}\text { Number } \\
\text { projects }\end{array}$ & of \\
\end{tabular} & $\begin{array}{l}\text { Total registered capital } \\
(\text { Mill. USD) }(*)\end{array}$ \\
\hline TOTAL & 17768 & 252716 \\
\hline Agriculture, forestry and fishing & 528 & 3721.8 \\
\hline Mining and quarrying & 87 & 3375.3 \\
\hline Manufacturing & 9600 & 141406.7 \\
\hline Electricity, gas, stream and air conditioning supply & 98 & 9774.8 \\
\hline $\begin{array}{l}\text { Water supply, sewerage, waste management and } \\
\text { remediation activities }\end{array}$ & 38 & 1348.5 \\
\hline Construction & 1166 & 11400.4 \\
\hline $\begin{array}{l}\text { Wholesale and retail trade; Repair of motor } \\
\text { vehicles and motorcycles }\end{array}$ & 1383 & 4030.7 \\
\hline Transporation and storage & 448 & 3755.3 \\
\hline Accommodation and food service activities & 371 & 11193.6 \\
\hline Information and communication & 1095 & 4124.9 \\
\hline Fiancial, banking and insurance activities & 82 & 1332.4 \\
\hline Real estate activities & 453 & 48279.8 \\
\hline Professional, scientific and technical activities & 1698 & 1797.4 \\
\hline Administrative and support service activities & 131 & 211.6 \\
\hline Education and trainning & 204 & 819.9 \\
\hline Human health and social work activities & 97 & 1754.6 \\
\hline Arts, entertainment and recreation & 148 & 3634.2 \\
\hline Other service activities & 141 & 754.1 \\
\hline
\end{tabular}


Table 4: Summary of variables (million VND). Source: Author's calculation

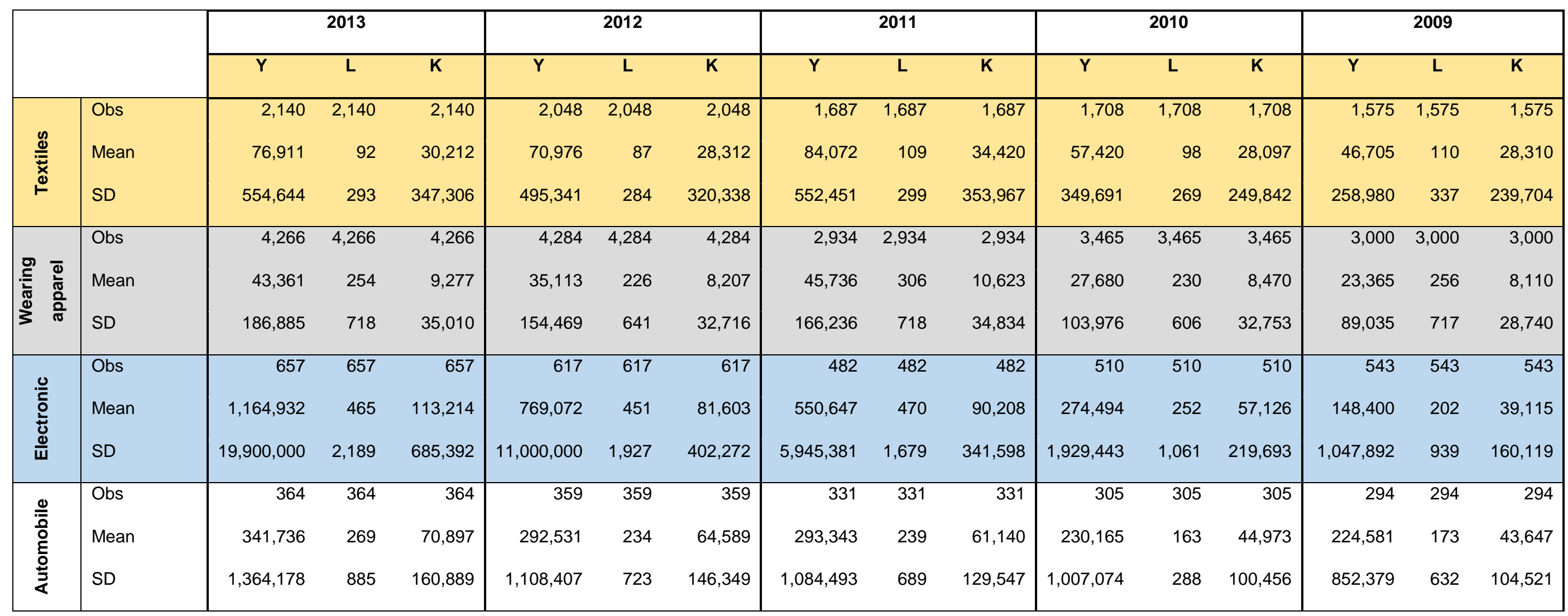

Table 5: One-sided generalized likelihood-ratio test. Source: Author's calculation

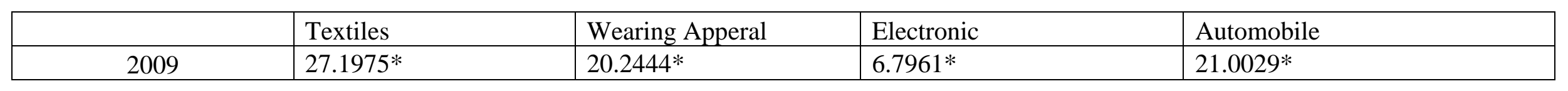




\begin{tabular}{|l|l|l|l|l|}
\hline 2010 & $60.9689^{*}$ & $8.1536^{*}$ & $9.40^{*}$ & $20.0506^{*}$ \\
\hline 2011 & $34.9087^{*}$ & $21.9616^{*}$ & $20.4537^{*}$ & $12.4062^{*}$ \\
\hline 2012 & $23.0765^{*}$ & $22.9790^{*}$ & $5.5482^{*}$ & $75.1633^{*}$ \\
\hline 2013 & $22.7723^{*}$ & $5.3610^{*}$ & $9.4412^{*}$ & $30.2832^{*}$ \\
\hline
\end{tabular}

*statistically significant at $1 \%, * *$ statistically significant at $5 \%$

Table 6: Test for functional form. Source: Author's calculation

\begin{tabular}{|c|c|c|c|c|c|c|c|c|c|c|c|c|c|c|c|c|}
\hline & & \multicolumn{3}{|c|}{2013} & \multicolumn{3}{|c|}{2012} & \multicolumn{3}{|c|}{2011} & \multicolumn{3}{|c|}{2010} & \multicolumn{3}{|c|}{2009} \\
\hline & & Chi2 & $\mathrm{P}>$ chi2 & Function & Chi2 & $\mathrm{P}>$ chi2 & Function & Chi2 & $\mathrm{P}>$ chi2 & Function & Chi2 & $\mathrm{P}>\mathrm{chi} 2$ & Function & Chi2 & $\mathrm{P}>$ chi2 & Function \\
\hline 岂 & $\begin{array}{l}\text { DE } \\
\text { FDI }\end{array}$ & $\begin{array}{r}1.41 \\
19.07\end{array}$ & $\begin{array}{l}0.7020 \\
0.0003\end{array}$ & $\begin{array}{l}\text { Cobb-Douglas } \\
\text { translog }\end{array}$ & $\begin{array}{r}9.73 \\
15.67\end{array}$ & $\begin{array}{l}0.0210 \\
0.0013\end{array}$ & $\begin{array}{l}\text { translog } \\
\text { translog }\end{array}$ & $\begin{array}{l}21.65 \\
25.66\end{array}$ & $\begin{array}{l}0.0001 \\
0.0000\end{array}$ & $\begin{array}{l}\text { translog } \\
\text { translog }\end{array}$ & $\begin{array}{r}7.23 \\
18.68\end{array}$ & $\begin{array}{l}0.0650 \\
0.0003\end{array}$ & $\begin{array}{l}\text { Cobb-Douglas } \\
\text { translog }\end{array}$ & $\begin{array}{r}14.97 \\
27.9\end{array}$ & $\begin{array}{l}0.0018 \\
0.0000\end{array}$ & $\begin{array}{l}\text { translog } \\
\text { translog }\end{array}$ \\
\hline 离 & $\begin{array}{l}\text { DE } \\
\text { FDI }\end{array}$ & $\begin{array}{r}11.44 \\
5.53\end{array}$ & $\begin{array}{l}0.0096 \\
0.1368\end{array}$ & $\begin{array}{l}\text { translog } \\
\text { Cobb-Douglas }\end{array}$ & $\begin{array}{r}6.24 \\
9.5\end{array}$ & $\begin{array}{l}0.1006 \\
0.0233\end{array}$ & $\begin{array}{l}\text { Cobb-Douglas } \\
\text { translog }\end{array}$ & $\begin{array}{r}43 \\
16.55\end{array}$ & $\begin{array}{l}0.0000 \\
0.0009\end{array}$ & $\begin{array}{l}\text { translog } \\
\text { translog }\end{array}$ & $\begin{array}{l}7.32 \\
5.12\end{array}$ & $\begin{array}{l}0.0624 \\
0.1633\end{array}$ & $\begin{array}{l}\text { Cobb-Douglas } \\
\text { Cobb-Douglas }\end{array}$ & $\begin{array}{l}10.86 \\
11.09\end{array}$ & $\begin{array}{l}0.0125 \\
0.0113\end{array}$ & $\begin{array}{l}\text { translog } \\
\text { translog }\end{array}$ \\
\hline 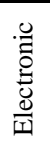 & $\begin{array}{l}\mathrm{DE} \\
\text { FDI }\end{array}$ & $\begin{array}{r}14.69 \\
18.19\end{array}$ & $\begin{array}{l}0.0021 \\
0.0004\end{array}$ & $\begin{array}{l}\text { translog } \\
\text { translog }\end{array}$ & $\begin{array}{r}18.19 \\
6.76\end{array}$ & $\begin{array}{l}0.0004 \\
0.0801\end{array}$ & $\begin{array}{l}\text { translog } \\
\text { Cobb-Douglas }\end{array}$ & $\begin{array}{r}3.75 \\
21.09\end{array}$ & $\begin{array}{l}0.2902 \\
0.0001\end{array}$ & $\begin{array}{l}\text { Cobb-Douglas } \\
\text { translog }\end{array}$ & $\begin{array}{l}0.65 \\
7.78\end{array}$ & $\begin{array}{l}0.0507 \\
0.0001\end{array}$ & $\begin{array}{l}\text { Cobb-Douglas } \\
\text { translog }\end{array}$ & $\begin{array}{r}4.3 \\
7.78\end{array}$ & $\begin{array}{l}0.2313 \\
0.0001\end{array}$ & $\begin{array}{l}\text { Cobb-Douglas } \\
\text { translog }\end{array}$ \\
\hline 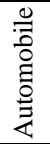 & $\begin{array}{l}\text { DE } \\
\text { FDI }\end{array}$ & $\begin{array}{l}6.43 \\
7.19\end{array}$ & $\begin{array}{l}0.0925 \\
0.0662\end{array}$ & $\begin{array}{l}\text { Cobb-Douglas } \\
\text { Cobb-Douglas }\end{array}$ & $\begin{array}{r}8.31 \\
23.47\end{array}$ & $\begin{array}{l}0.0401 \\
0.0000\end{array}$ & $\begin{array}{l}\text { translog } \\
\text { translog }\end{array}$ & $\begin{array}{r}8.88 \\
27.25\end{array}$ & $\begin{array}{l}0.0309 \\
0.0000\end{array}$ & $\begin{array}{l}\text { translog } \\
\text { translog }\end{array}$ & 1.41 & $\begin{array}{l}0.2433 \\
0.0000\end{array}$ & $\begin{array}{l}\text { Cobb-Douglas } \\
\text { translog }\end{array}$ & $\begin{array}{r}13.7 \\
11.69\end{array}$ & $\begin{array}{l}0.0033 \\
0.0085\end{array}$ & $\begin{array}{l}\text { translog } \\
\text { translog }\end{array}$ \\
\hline
\end{tabular}

\section{Contac information}

\section{Vu Hoang Duong}

DOI: https://www.doi.org/10.7441/dokbat.2016.42 


\section{References}

Aw Bee-Yan, Sukkyn Chung and Mark J. Roberts. (2000). Productivity and Turnover in the Export Market: Micro-level Evidence from the Republic of Korea and Taiwan. The World Bank Economic Review, 14(1), 65-90. /https://doi.org/10.1093/wber/14.1.65

Badunenko, O., Fritsch, M. \& Stephan, A., (2006). What Determines the Technical Efficiency of a Firm? The Importance of Industry, Location, and Size, Available at: http://econpapers.repec.org/RePEc:jen:jenasw:2006-33.

Bernard, Andrew B. and J. Bradford Jensen. (1999). Exceptional Exporter Performance: Cause, Effect, or Both?. Journal of International Economics, Vol. 47(1), 1-25. https://doi.org/10.1016/S0022-1996(98)00027-0

Burki, A. and T. Dek. (1998). Measuring Production Efficiency of Small Firms in Pakistan. World Development 26(1), 155-169. https://doi.org/10.1016/S0305-750X(97)00122-8

Caves, R. (1992). Determinants of Technical Efficiency in Australia", in Caves, R (ed.) Industrial Efficiency in Six Nations. MIT Press, 241-272.

Clerides, K. Sofronis, Saul Lach and James R. Tybout. (1998). Is Learning by Exporting Important? Micro-Dynamic Evidence from Colombia, Mexico, and Morocco. Quarterly Journal of Economics, Aug: 903-947. https://doi.org/10.1162/003355398555784

Farrell, M.J., (1957). The Measurement of Productive Efficiency. Journal of the Royal Statistical Society. Series A (General), 120(3), pp.253-290. Available at: http://www.jstor.org/stable/2343100. https://doi.org/10.2307/2343100

Ferragina, A.M. \& Mazzotta, F., (2014). FDI spillovers on firm survival in Italy: absorptive capacity matters! Journal of Technology Transfer, 39(6), pp.859-897. Available at: https://doi.org/10.1007/s10961-013-9321-z

Ghali, S. \& Rezgui, S., (2011). FDI Contribution to Technical Efficiency in the Tunisian Manufacturing Sector: Evidence from Micro-panel Data. International Economic Journal, 25(2), pp.319-339. https://doi.org/10.1080/10168737.2010.504215

Girma, S., (2005). Absorptive Capacity and Productivity Spillovers from FDI : A Threshold Regression. Oxford Bulletin of Economics and Statistics, 67(3), pp.281 - 306. https://doi.org/10.1111/j.1468-0084.2005.00120.x

Gorg, H. and D. Greenaway, (2004). Much Ado about Nothing? do Domestic Firms really Benefit from Foreign Direct Investment? The World Bank Research Observer 19(2): 171-197. https://doi.org/10.1093/wbro/lkh019

Gumbau-Albert M. và J. Maudos.(2002). Determinants of efficiency: the case of the Spanish $\begin{array}{llllll}\text { industry. } \quad \text { Applied } & \text { Economics. } & \text { Pol } & \text { Pp. } & \text { 1941-1948 }\end{array}$ https://doi.org/10.1080/00036840210127213

Ishita G. Tripathi, Yadav S.S., Sharma S., (2009). Measuring the Efficiency of Pharmaceutical Firms in India: An Application of Data Envelopment Analysis and Tobit Estimation. Proceedings of the 9th Comparative Analysis of Enterprise (Micro) Data Conference Oct 2-4, 2009, Tokyo.

Khai, H. V., \& Yabe, M., (2011). Technical Efficiency Analysis Of Rice Production. ISSAAS, 17(1), 135-146.

Kumbhakar C.S \&C.A. Knox Lovell, (2004). Stochastic Frontier Analysis. Cambrigde University Press, United Kingdom

Le, V., \& Harvie, C. (2010). How do Vietnamese SMEs perform? Technical efficiency of SMEs in the manufacturing sector and its sub-sectors. How do Vietnamese SMEs perform? Technical efficiency of SMEs in the. Korea and the World Economy, IX, 137. 
Lundvall, K. and E. Battese. (2000). Firm size, age and efficiency: Evidence from Kenyan Manufacturing firms. Journal of Development Studies, 36(3), 146-163 https://doi.org/10.1080/00220380008422632

Mahadeven, R. (2000). How Technically Efficient are Singapore's Manufacturing Industries. Applied Economics 32, 2007-20014 https://doi.org/10.1080/00036840050155931

Marcin, K., (2008). How does FDI inflow affect productivity of domestic firms? The role of horizontal and vertical spillovers, absorptive capacity and competition. The Journal of International Trade \& Economic Development, 17(1), pp.155-173. https://doi.org/10.1080/09638190701728131

Minh, N. K., Long, G. T., \& Thang, B. N., (2007). Technical Efficiency Of Small And Medium Manufacturing Firms In Vietnam: Parametric And Non-Parametric Approaches . The Korean Economic Review, 23(1), 187-221.

Mitra, A., Sharma, C. \& Veganzones, M.-A., (2011). Total Factor Productivity and Technical Efficiency of Indian Manufacturing: The Role of Infrastructure and Information \& Communication Technology, Available at: https://halshs.archives-ouvertes.fr/halshs00597656.

Porcelli, F. (2009). Measurement of Technical Efficiency. A brief survey on parametric and non-parametric techniques. http://www.warwick.ac.uk/fac/soc/economics/staff/phd_students/porcelli/porcelli_dea _sfm.pdf.

Sinani E., Jones D.C. and Mygind N.(2007). Determinants of firm level Technical efficiency: A stochastic frontier approach. Proceedings of the $29^{\text {th }}$ European International Business Association Annual Conference. Copenhagen 2003

Tang, Y. \& Zhang, K.H., (2015). Absorptive capacity and benefits from FDI: Evidence from Chinese manufactured exports. International Review of Economics \& Finance. Available at: http://www.sciencedirect.com/science/article/pii/S105905601500163X.

Tingum N.E. (2014). Technical efficiency and manufacturing export performance in Cameroon, A firm Level analysis. PhD. Dissertation. University of Dares Salaam.

Torii, S. (1992). Technical Efficiency in Japanese Industries, in Caves, R (ed.) Industrial Efficiency in Six Nations. MIT Press, 31-120.

Tran, N. T. M. T. (2007). Technical Efficiency of The Vietnam's Manufacture of Chemical and Chemical Products: A Dual Approach. DEPOCEN working paper 2007/17.

Vu Hung Cuong \& Bui Trinh. (2014). Doanh nghiệp ngoài nhà nước: vai trò và thực trạng. Tạp chí Nghiên cứu kinh tế (10). Trang 38-44

$\mathrm{Vu}$, Q.N., (2003) Technical Efficiency of Industrial State-Owned Enterprises in Vietnam. Asian Economic Journal, 17(1), 87-101. https://doi.org/10.1111/1351-3958.00163

$\mathrm{Vu}, \mathrm{T}$. B. L. (2012). Technical Efficiency of Vietnamese Manufacturing Firms and Its Determinants: A Preliminary Analysis. Proceedings of International conference: Sustainable Manufacturing and Evironment Management, 2012.

Worthington, A.C., (2001). An Empirical Survey of Frontier Efficiency Measurement Techniques in Education. Education Economics, 9(3), pp.245-268. https://doi.org/10.1080/09645290110086126

Wu, Y., (2000). Measuring the performance of foreign direct investment: a case study of China. Economics Letters, 66(2), pp.143-150. Available at: http://www.sciencedirect.com/science/article/pii/S0165176599002256 [Accessed February 2, 2016]. https://doi.org/10.1016/S0165-1765(99)00225-6

Zhang, C., Guo, B. \& Wang, J., (2014). The different impacts of home countries characteristics in FDI on Chinese spillover effects: Based on one-stage SFA. Economic Modelling, 38, pp.572-580. Available at: https://doi.org/10.1016/j.econmod.2014.02.007 


\title{
THE RELATIONSHIPS BETWEEN SERVICE QUALITY, CUSTOMER SATISFACTION AND CUSTOMER LOYALTY: AN INVESTIGATION IN VIETNAMESE RETAIL BANKING SECTOR
}

\author{
$\mathrm{Vu}$ Minh Ngo
}

\begin{abstract}
This paper develops and empirically tests the interrelationships between service quality, customer satisfaction and customer loyalty in a retail banking context. A research model about the interrelationships between service quality, customer satisfaction and customer loyalty is developed. Based on this model, a survey is conducted with retail banking customers, with and 261 valid respondents. The hypotheses are then proposed and tested using confirmatory factor analysis (CFA) and structural equation modeling technique (SME). The analysis reveals that service quality and customer satisfaction are important antecedents of customer loyalty and customer satisfaction mediates the effects of service quality on customer loyalty. These findings suggest the non-linearity relationships between three constructs and emphasize the need of treating customer loyalty management as the process which includes plenty of factors interactions to each other.
\end{abstract}

Key words: service quality, customer satisfaction, customer loyalty, and mediators.

\section{INTRODUCTION}

It might be well accepted nowadays that intensive competitiveness, dynamic business environments and the increasing of customer powers have pushed firms toward the customerfocused strategy (Teece, 2007; Wang \& Ahmed, 2007). As a result, excellent business process and intangible assets such as brands, customer satisfactions and powerful human resources might become the most essential sources for sustainable competitive advantages (Chien \& Tsai, 2012; Roos \& Roos, 1997). These fundamental trends together with the invisible and hard-to-observe characteristics of qualitative/nonfinancial measures have raised the questions of whether nonfinancial measures such as customer satisfaction, job satisfaction do have the real and significant effects on firm performance and how they do it. Among them, customer loyalty has been considered as one of the most important competitive edges in today business environment, in which the purchasing power of the customer is increasing while companies have to encounter limitless challenges from their competitors (Heskett, Sasser Jr, \& Schlesinger, 1997; Woodruff, 1997). Therefore, for cost reduction and profit improvement reasons, maintaining long-term customer loyalty is a mandatory task. In this context, both practitioners and researchers have searched for the most important antecedents of customer loyalty. Many studies in relationship marketing literatures have demonstrated that customer satisfaction is one of the most popular determinants of customer loyalty (Anderson, Fornell, \& Lehmann, 1994; Mittal \& Kamakura, 2001; Oliver, 1999). Although there is a consensus among researchers that satisfaction can be a basis ground for achieving loyalty, researchers also agree that the satisfaction-loyalty relationship should have more ingredients. In this stream of research, previous studies have developed and applied some theoretical and conceptual frameworks which can extent and elaborate the satisfaction-loyalty relationship such as the Balanced Scorecard (BSC) and the Service-profit chain frameworks (Heskett, Jones, Loveman, Sasser Jr., \& Schlesinger, 2008; Kaplan \& Norton, 1992). Theses frameworks view the customer loyalty and financial sequences as the top and final sequences of a system and proposed completed set of cause-and-effects relationships between different organizational factors such as learning organization, excellent internal service, employee 
satisfaction and excellent business processes to achieve them. Among these factors, the excellent business processes which lead to the product/service quality can be seen as the direct factors impacting customer satisfaction and customer loyalty (Brady, Cronin, \& Brand, 2002). If these relationships are valid, managers can understand more clearly the sources of customer satisfaction and customer loyalty for better serving customer and improve firm's financial performance. Therefore, using a new banking service contexts, this study develops and empirically tests the interrelationships between service quality, customer satisfaction and customer loyalty. The main objective of this study is to confirm and provide new empirical evidences about the interrelationships between service quality, customer satisfaction and customer loyalty which suggested in the mentioned conceptual frameworks.

The rest of this study is divided into sections as following. First, the next section provides the theoretical background and develops the hypotheses for this study. Second, the research methodology is developed and executed. Third, in order to test the hypotheses, data analysis and results are presented. Finally, the findings of this study are concluded and managerial implications, and limitations are discussed.

\section{THEORETICAL BACKGROUND AND HYPOTHESES DEVELOPMENT}

\subsection{Customer loyalty}

Customer loyalty can be defined as the closest step to the repurchase behavior of customer. Customer loyalty has been usually referred as the consequence for all the experiences which customer has with a service/product provider (Mascarenhas, Kesavan, \& Bernacchi, 2006). The experiences might include the physical interactions, emotional involvements and value chain moments according to Mascarenhas et al. (2006). According to Oliver (1999), the shift to loyalty strategy from only satisfaction strategy can substantially increase customer retention and reduce marketing cost. In other study, Camarero and colleagues (2005) found on a Spanish case that customer loyalty have both positive impacts on firm's market performance and economic performance. Generally, customer loyalty has been referred as the link between customer attitude, repeat purchase and financial performance (J. L. Heskett et al., 2008; T. O. Jones \& Sasser, 1995). Moreover, by including the psychological meaning of loyalty, Oliver (1999) define customer loyalty as:

"a deeply held commitment to rebuy or re-patronize a preferred product/service consistently in the future, thereby causing repetitive same-brand or same brandset purchasing, despite situational incidences and marketing efforts having the potential to cause switching behavior."

In addition, according to Oliver (1999), loyalty can be developed through different phase which are cognitive sense, affective sense, conative manner and finally behavioral manner. The first three phases are usually referred as attitudinal loyalty which are dependent on the experiences that customers have with service providers (overall satisfaction). Completing these three stages can lead to the behavioral loyalty as the final stage (Oliver, 1999). This evolvement process of customer loyalty is confirmed by a meta-analysis about the antecedents of customer loyalty by Pan, Sheng and Xie (2012).

\subsection{Service quality and customer satisfaction}

One of the main element determining customer satisfaction is the customer's perception of service quality. Customer satisfaction is described as the result of a comparison of the 
customers' expectations and his or her subsequent perceived performance of service quality (Zeithaml, Berry, \& Parasuraman, 1996). According to this conceptualization, perceived service quality is the antecedents to overall customer satisfaction. Other studies also showed the evidence support this relationship between customer satisfaction and service quality (Crosby \& Stephens, 1987; Parasuraman, Zeithaml, \& Berry, 1985). But there are also debates about the causal relationship between customer satisfaction and service quality. Specifically, there are three major positions about this relationship in the literature (Brady et al., 2002). First, as indicated above, service quality is described as an antecedents to customer satisfaction (Anderson et al., 1994; E. W. Anderson \& Sullivan, 1993; Cronin \& Taylor, 1992). Second, some researchers suggest that customer satisfaction is the cause of service quality (Bitner, 1990). The third position of the service quality- satisfaction relationship argues that neither satisfaction nor service quality may be antecedent to the others (Dabbolkar, 1995; McAlexander, Kaldenberg, \& Koenig, 1994). In general, although there is the lack of consensus about the conceptualization of the service quality- satisfaction relationship, service quality is an antecedent to customer satisfaction is considered as dominant position (Chodzaza \& Gombachika, 2013; Chu, Lee, \& Chao, 2012). In this study, one of the objectives is to empirically test this relationship. Therefore, the following hypothesis is offered:

$\mathrm{H}_{1}$ : In banking industry context, overall service quality positively influences customer satisfaction

\subsection{Customer satisfaction and customer loyalty}

Although customer satisfaction and customer loyalty are distinct constructs, they are highly correlated (Hallowell, 1996; Silvestro \& Cross, 2000). It can be assume that customer satisfaction can lead to customer loyalty because people tend to be rational and risk-adverse so that they might have a tendency to reduce risk and stay with the service providers which they already had good experience with. Actually, customer satisfaction has been suggested to be an antecedent of loyalty in service context in previous studies (Bolton, 1998; Mittal \& Kamakura, 2001). Fornell (1992) and Reichheld (1996) also support this conceptualization by arguing that customer satisfaction can prevent customer churn and lowering customer's price sensitivity. There are also many type of relationship between customer satisfaction and customer loyalty suggested such as satisfaction is the core of loyalty, satisfaction is one of the necessary components of loyalty, satisfaction and loyalty are the components of ultimate loyalty and satisfaction as the starting point of loyalty (Oliver, 1999). In addition, the relationship between customer satisfaction and customer loyalty might be nonlinear. Heskett et al. (1997) suggested that customer loyalty should improve dramatically when customer satisfaction overcome a certain level. In sum, the dominant proposition is that satisfaction is an essential necessary parts to achieve customer loyalty. In addition, as it presented here in early part, service quality is assumed to be an antecedent of customer satisfaction. Therefore, it can be interesting to test the relationship between service quality and customer loyalty with customer satisfaction as the mediator of this relationship. In this stream of research, most of the studies confirm that there is positive relationship between service quality and customer loyalty and customer satisfaction is usually the mediator between them (Chodzaza \& Gombachika, 2013; Chu et al., 2012). In addition, in a meta-analysis about customer loyalty antecedents, the results show that the effect of quality on loyalty become stronger over time (Pan et al., 2012). As a result of the analysis, the following hypothesis is offered:

$\mathrm{H}_{2}$ : In banking industry context, Customer satisfaction positively influences customer loyalty 
$\mathrm{H}_{3}$ : In service banking context, overall service quality positively influences customer loyalty

$\mathrm{H}_{4}$ : In service banking context, customer satisfaction mediate the relationship between service quality and customer loyalty.

\section{RESEARCH METHODOLOGY}

\subsection{Data collection and sample}

A questionnaire is developed by the author for collection data from retail banking customers in Vietnam. Retail banking customers have to use at least one service from one bank in Vietnam. The sample of retail banking customers was collected on the basis of convenience sampling. Emails with a survey instrument were sent by author to a total 850 customers of 11 retail banks in Vietnam. There were 273 customers participated in the research. Among responds returned, there were 12 responses were eliminated because of uncompleted answers. Finally, there are usable 261 responses were collected and used, which make $30 \%$ successful response rate.

The main demographic features of the respondents are described as followed. There are 102 respondents are males (39\%) and 159 are female (61\%). Respondents whose age are from 20 to 30 and 30 to 45 constitute $46.2 \%$ and $51.4 \%$ of the sample population. The average income per month of respondents varied widely from \$ 200 to more than $\$ 1500$. Almost half of the respondents have the average income per month around $\$ 400$ to $\$ 800(46 \%)$, only small portion of respondents have average income per month from $\$ 800$ to more than $\$ 1500$ $(16 \%)$. Most of the respondents have college or university degree $(80 \%)$ or have postgraduate degrees $(14.5 \%)$. In addition, regarding the services that respondents use the most from their banks, most of the respondents use the debit/credit card and payment services (50\%), transferring money services (25\%), or deposit and saving service (15\%).

\subsection{Measures}

For this study, the measurement scales and the indicators are adopted from previous studies. These measurements scales are validated in prior researches, especially in the context of financial service (Brady et al., 2002; Colgate \& Lang, 2001; Cronin Jr., Brady, \& Hult, 2000a; M. A. Jones, Mothersbaugh, \& Beatty, 2000). Modifications and translations are made to transform the measurement scale to be readable for average retail banking customer in Vietnam and reflect the context of the retail banking industry in Vietnam. In general, the respondents are asked to give their agreement or disagreement with the statement. Respondents give their opinion for each statement through 7-point Likert scale with 1 to indicate "strongly disagree" and 7 to indicate "strongly agree".

In order to investigate the mediating role of customer satisfaction in the service qualityloyalty relationship, the service quality is approached as an overall construct. Therefore, four items for measuring overall service quality construct adopted from Brady et al. (2002) are used. Three items which are adopted from Cronin et al. (2000) are used to measure the overall customer satisfaction. There items are used to measure the customer loyalty including 1 item about the word-of-mouth intention and 2 items about repurchase intention. These three items are also adopted from Cronin et al. (2000). 


\section{DATA ANALYSIS AND RESULT}

The proposed mediating relationship between overall service quality, customer satisfaction, and customer loyalty are tested by structure equation modeling using Amos 22.0. The confirmatory factor analysis (CFA), reliability and validity analysis are performed to assess the adequacy of the measurement model. Then, the structural model is tested to assess the relationships within proposed research model in Figure 1, especially for the mediating effects of customer satisfaction.

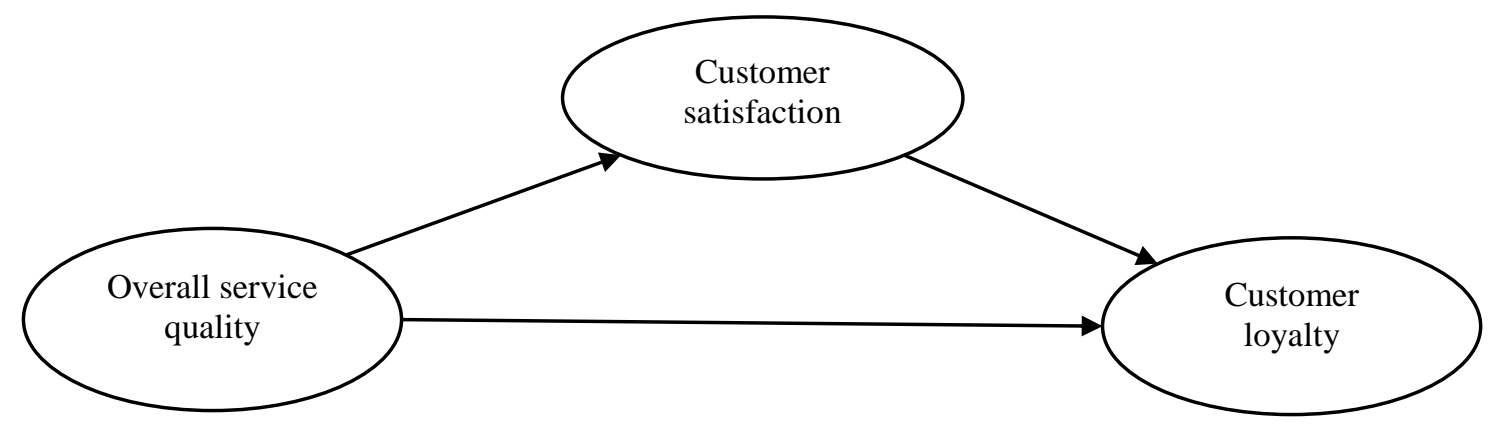

Fig. 1 Research model (Source: Own research)

\subsection{Testing of the measurement model}

CFA is executed to see how the research model in the Figure 1 fit with the data collected from the samples (J. C. Anderson \& Gerbing, 1988). Previous studies suggests to use more than one goodness-of-fit index to evaluate the model fit of the proposed model. Therefore, in this study set of goodness-of-fit indices are used. Specifically, the Chi-square is significant at 0.05 level $\chi^{2}=48.345(p=0.03)$ and the relative Chi-square $\left(\chi^{2} / d f=1.511\right)$ (smaller than 2$)$ show the acceptable fit with large data analysis. Other indices show the good fit for the research model. The normed fit index $(\mathrm{NFI})=0.98$, the comparative fit index $(\mathrm{CFI})=0.993$, the Tucker-Lewis coefficient index (TLI) $=0.99$ (NFI, CFI, TLI all > 0.95); the root mean square residual $(\mathrm{RMR})=0.033$ and root mean square error of approximation (RMSEA) $=0.044$ (both < 0.08). In sum, the data collected from the sample of retail banking customers are fit well with the proposed research model.

\subsection{Construct reliability and validity}

Construct reliability refers to the degree to which a set of indicators consistently and stability reflect a given constructs. Cronbach's alpha is the most commonly used for assessing the reliability of a construct. The Cronbach's alpha of each construct in the research model is presented in Table 1. As indicated in Table 1, all the Cronbach's alpha for all constructs exceeds 0.80 , satisfying the general recommended level of 0.70 for the research indicators (Cronbach, 1951).

Convergence validity refers to how well different indicators for measuring constructs converge, indicating that a single dimension of meaning is being measured. Convergent validity can be assessed by examining the factor loading and the average variance extracted (AVE) of the constructs (Fornell \& Larcker, 1981). All the indicators had significant loading onto the constructs which they expected to measure $(p<0.01)$. Moreover, as presented in Table 1, the AVE for each construct is greater than 0.50, which indicate the convergence validity of the constructs. 
Discriminant validity refers to the fact that indicators for different constructs should not be so highly correlated across constructs which can be lead to the constructs overlap. Discriminant can be examined by comparing the construct's square root of AVE with its square correlation with other constructs (Fornell \& Larcker, 1981). As presented in Table 2, the square root AVE value of each construct are greater than its square correlation with other constructs, which support the discriminant validity of the constructs.

Table.1 Convergent Validity (Source: Own research)

\begin{tabular}{|c|c|c|c|c|c|}
\hline Constructs & Indicator & $\begin{array}{l}\text { Standardize } \\
\text { estimates }\end{array}$ & $P$ value & $\begin{array}{l}\text { Cronbach' } \\
\text { s alpha }\end{array}$ & AVE \\
\hline \multirow[t]{4}{*}{ Service Quality } & $\mathrm{SQ}_{1}$ & 0.872 & $*$ & & \\
\hline & $\mathrm{SQ}_{2}$ & 0.835 & $*$ & 0.890 & 0.683 \\
\hline & $\mathrm{SQ}_{3}$ & 0.764 & $*$ & & \\
\hline & $\mathrm{SQ}_{4}$ & 0.832 & $*$ & & \\
\hline \multirow[t]{3}{*}{ Customer satisfaction } & $\mathrm{CS}_{1}$ & 0.862 & $*$ & & \\
\hline & $\mathrm{CS}_{2}$ & 0.906 & $*$ & 0.923 & 0.779 \\
\hline & $\mathrm{CS}_{3}$ & 0.880 & $*$ & & \\
\hline \multirow[t]{3}{*}{ Customer loyalty } & $\mathrm{CL}_{1}$ & 0.916 & $*$ & & \\
\hline & $\mathrm{CL}_{2}$ & 0.888 & $*$ & 0.930 & 0.817 \\
\hline & $\mathrm{CL}_{3}$ & 0.909 & $*$ & & \\
\hline
\end{tabular}

Table. 2 Discriminant Validity (Source: Own research)

\begin{tabular}{llll}
\hline & $\begin{array}{l}\text { Service } \\
\text { quality }\end{array}$ & $\begin{array}{l}\text { Customer } \\
\text { satisfaction }\end{array}$ & $\begin{array}{l}\text { Customer } \\
\text { loyalty }\end{array}$ \\
Service quality & 0.827 & & \\
$\begin{array}{l}\text { Customer } \\
\text { satisfaction }\end{array}$ & 0.812 & 0.883 & \\
\hline
\end{tabular}




$$
\begin{array}{llll}
\text { Customer loyalty } \quad 0.811 & 0.867 & 0.904
\end{array}
$$

\subsection{Testing the hypothesis}

Path analysis of structural equation modeling is used to test the hypotheses about the relationship between service quality, customer satisfaction, and customer loyalty. The research model as shown Figure 1 is used to test the customer satisfaction mediating role in the service quality- loyalty relationships. Model fit indices for base model show a good fit $\left(\chi^{2}=54.6, \mathrm{p}\right.$-value $=0.14, \chi^{2} / \mathrm{df}=1.606 ; \mathrm{NFI}=0.977 ; \mathrm{CFI}=0.991 ; \mathrm{RMR}=0.05 ; \mathrm{RMSEA}=$ 0.048). The result of path analyses for the reseach model are shown in Table 3. As presented in Table 3, hypotheses $\mathrm{H}_{1}, \mathrm{H}_{2}$ and $\mathrm{H}_{3}$ are supported in the base model when all the paths, service quality to customer satisfaction, customer satisfaction to customer loyalty, service quality to customer loyalty, are statistically significant (all p-values < 0.001). For investigating the statistical significant mediation effect of customer satisfaction, the bootstrapping approach is used because it does not impose distributional assumptions (Preacher \& Hayes, 2004). The bootstrapping analyses are shown in Table 4. The indirect effect of service quality to customer loyalty is statistically significant ( $\mathrm{p}$-value < 0.001 ). Hypothesis $\mathrm{H}_{4}$ is supported.

Table. 3 Standardized path coefficients of the structural model (Source: Own research)

$\begin{array}{lll}\text { Relationships } & \text { Estimation } & \text { Hypotheses testing } \\ \text { SQ -> CS } & 0.900 * * * & \text { Support } \mathrm{H}_{1}, \mathrm{H}_{4} \\ \text { CS -> CL } & 0.744 * * * & \text { Support } \mathrm{H}_{2}, \mathrm{H}_{4} \\ \text { SQ -> CL } & 0.400 * * * & \text { Support } \mathrm{H}_{3}, \mathrm{H}_{4}\end{array}$

Note. SQ: Service quality; CS: Customer satisfaction; CL: Customer loyalty;. $* * *=p$-value $<0.01$; ns $=$ not significant.

Table. 4 Bootstrapping results for testing mediation effects (Source: Own research)

\begin{tabular}{lllll}
$\begin{array}{l}\text { Hypotheses } \\
\text { mediations }\end{array}$ & Direct effect & Indirect effect & \multicolumn{2}{l}{ Result } \\
SQ -> CS -> CL & $0.400 * * *$ & $0.528 * * *$ & $\begin{array}{l}\text { Partial } \\
\text { supported }\end{array}$ & mediation.
\end{tabular}

$* * *=$ p-value $<0.01$

\section{DISCUSSION}

Our findings contribute to the discussion about the complex interrelationship between service quality, customer satisfaction, and customer loyalty. This study provides the empirical evidences of their relations to each other as proposed in the research model in banking industry context. This study adopts the view that the relationship between service quality, 
customer satisfaction, and customer loyalty are complex and contribute the new empirical evidences for these interrelationships. The major contribution of this study is to bring up some of the most popular constructs in the relationship marketing literature, namely, service quality, customer satisfaction, and customer loyalty together for testing their interrelation relationships in retail banking context. Most of the previous researches about their interrelation relationships has been done in the Western developed countries which are generally recognized to have many differences to the Eastern and developing countries in term of cultures and customers' needs which form the basis for the relationship between customers and service providers. Although in different context, this study's results also support some popular findings in previous researches in relationship marketing field. Service quality is the antecedents of customer satisfaction hypothesis is confirmed in this study which is in line with results from previous studies (Cronin Jr., Brady, \& Hult, 2000b; Cronin, Brady, Brand, Hightower, \& Shemwell, 1997). Customer satisfaction are also validated as an antecedents of customer loyalty which are proposed in research in both marketing literature and management (Fornell, Johnson, Anderson, Cha, \& Bryant, 1996; Gillani \& Awan, 2014; Hall, 2011; Mithas, Krishnan, \& Fornell, 2005). Moreover, service quality are also significantly and positively related customer loyalty which make them one of the sources for improving customer loyalty. This finding is consistent with the results of previous research (Brady \& Robertson, 2001; Caceres \& Paparoidamis, 2007). Especially, customer satisfaction is confirmed to partially mediate the relationship between service quality and customer loyalty which highlights the role of customer satisfaction as a fundamental foundation for achieving customer loyalty. This finding is also consistent with studies which view customer satisfaction as the mediators for the relationship of customer loyalty and other constructs such as customer knowledge management, relationship quality, customer customization (Caceres \& Paparoidamis, 2007; Hu, Kandampully, \& Juwaheer, 2009).

The findings of the current study have some implications for service providers and managers. Frist, customer-related measures such as customer perceive of service quality and customer satisfactions should be the primary objectives for firm's business strategy. In other words, firms should follow the customer-orientation strategy to cope with the challenges in nowadays business since it can improve customer retention then help firm to reduce cost of marketing, improve and stabilize revenues and adapt timely and adequately with changes in customers profile or preferences. In addition, regularly monitor and evaluate the customer-related measures can help managers to deliver the product/services which customers value the most then also attracted new customers. Second, this study emphasize the need for managers to view their organizations as a completed system which consists of a lot of components and more importantly managers should put their efforts into the tasks of linking all these components together serving for an common objective. Manager can use the conceptual frameworks such as Balanced Scorecard or Service-Profit Chain as the reference point for starting connecting all the activities in the organizations. This study confirms the link from excellent business processes resulted in high service quality in banking sector with customer satisfaction and customer loyalty. This finding suggest managers that if they can direct and align all the business process in their bank toward creating higher customer perceive of service quality, customer tend to be more satisfaction and their loyalties also improve. However, for improving business processes, managers should also considers to align other important factors in the organizations such as human resources or employee satisfaction.

\section{Limitations and future researches}

As is the case of most of research project, this study also represents some limitations should be considered. First, the measurement scales which is used for measuring service quality, 
customer satisfaction are not so optimal for the purpose of the research. Service quality and customer satisfaction should be measured with more complex modes which are suggested in the literature such as SERVQUAL or National Customer Satisfaction Index methods. Unfortunately, because of the limited resources and such data are often difficult and costly to collect, this study use the direct scale to measure service quality and customer satisfaction. Second, the results presented in this study are based on the analysis of causal model with cross-sectional data. It is not optimal because the time orders of the constructs are ignored which are one of the important elements for causal model analysis. Therefore, definite evidence of causal effect cannot be inferred. Future research should attempt to collect pooled time series and cross-sectional data for investigating the objectives of this study.

\section{Acknowledgements}

The research for this paper was financially supported by the Internal Grant Agency of Faculty of Management and Economics, Tomas Bata University in Zlín, grant No. IGA/FaME/2016/020.

\section{References}

Anderson, E. W., Fornell, C., \& Lehmann, D. R. (1994). Customer satisfaction, market share, and profitability: Findings from Sweden. Journal of Marketing, 58(3), 53. https://doi.org/10.2307/1252310

Anderson, E. W., \& Sullivan, M. W. (1993). The antecedents and consequences of customer satisfaction for firms. Marketing Science (1986-1998), 12(2), 125. https://doi.org/10.1287/mksc.12.2.125

Anderson, J. C., \& Gerbing, D. W. (1988). Structural equation modeling in practice: A review and recommended two-step approach. Psychological Bulletin, 103(3), 411-423. https://doi.org/10.1037/0033-2909.103.3.411

Bitner, M. J. (1990). Evaluating service encounters: The effects of physical surroundings and employee responses. Journal of Marketing, 54(2), 69-82. https://doi.org/10.2307/1251871

Bolton, R. N. (1998). A dynamic model of the duration of the customer's relationship with a continuous service provider: The role of satisfaction. Marketing Science, 17(1), 45-65. https://doi.org/10.1287/mksc.17.1.45

Brady, M. K., Cronin, J. J., \& Brand, R. R. (2002). Performance-only measurement of service quality: A replication and extension. Journal of Business Research, 55(1), 17-31. https://doi.org/10.1016/S0148-2963(00)00171-5

Brady, M. K., \& Robertson, C. J. (2001). Searching for a consensus on the antecedent role of service quality and satisfaction: An exploratory cross-national study. Journal of Business Research, 51(1), 53-60. https://doi.org/10.1016/S0148-2963(99)00041-7

Caceres, R. C., \& Paparoidamis, N. G. (2007). Service quality, relationship satisfaction, trust, commitment and business-to-business loyalty. European Journal of Marketing, 41(78), 836-867. https://doi.org/10.1108/03090560710752429

Camarero Izquierdo, C., Gutiérrez Cillán, J., \& San Martín Gutiérrez, S. (2005). The impact of customer relationship marketing on the firm performance: A Spanish case. Journal of Services Marketing, 19(4), 234-244. https://doi.org/10.1108/08876040510605262

Chien, S. \& Tsai, C. (2012). Dynamic capability, knowledge, learning, and firm performance. Journal of Organizational Change Management, 25(3), 434-444. https://doi.org/10.1108/09534811211228148 
Chodzaza, G. E., \& Gombachika, H. S. H. (2013). Service quality, customer satisfaction and loyalty among industrial customers of a public electricity utility in Malawi. International Journal of Energy Sector Management, 7(2), 269-282. https://doi.org/10.1108/IJESM-02-2013-0003

Chu, P. -., Lee, G. -., \& Chao, Y. (2012). Service quality, customer satisfaction, customer trust, and loyalty in an e-banking context. Social Behavior and Personality, 40(8), 1271-1284. https://doi.org/10.2224/sbp.2012.40.8.1271

Colgate, M., \& Lang, B. (2001). Switching barriers in consumer markets: An investigation of the financial services industry. Journal of Consumer Marketing, 18(4), 332-347. https://doi.org/10.2224/sbp.2012.40.8.1271

Cronbach, L. J. (1951). Coefficient alpha and the internal structure of tests. Psychometrika, 16(3), 297-334. https://doi.org/10.1007/BF02310555

Cronin Jr., J. J., Brady, M. K., \& Hult, G. T. M. (2000a). Assessing the effects of quality, value, and customer satisfaction on consumer behavioral intentions in service environments. Journal of Retailing, 76(2), 193-218. https://doi.org/10.1016/S00224359(00)00028-2

Cronin Jr., J. J., Brady, M. K., \& Hult, G. T. M. (2000b). Assessing the effects of quality, value, and customer satisfaction on consumer behavioral intentions in service $\begin{array}{llll}\text { environments. Journal of } & \text { Retailing, }\end{array}$ doi:http://dx.doi.org.proxy.k.utb.cz/10.1016/S0022-4359(00)00028-2

Cronin, J. J., Brady, M. K., Brand, R. R., Hightower, R. J., \& Shemwell, D. J. (1997). A cross-sectional test of the effect and conceptualization of service value. The Journal of Services Marketing, 11(6), 375-391. https://doi.org/10.1108/08876049710187482

Cronin, J. J., \& Taylor, S. A. (1992). Measuring service quality: A reexamination and extension. Journal of Marketing, 56(3), 55-68. https://doi.org/10.2307/1252296

Crosby, L. A., \& Stephens, N. (1987). Effects of relationship marketing on satisfaction, retention, and prices in the life insurance industry. Journal of Marketing Research, 24(4), 404-411. https://doi.org/10.2307/3151388

Dabbolkar, P. A. (1995). A contingency framework for predicting causality between customer satisfaction and service quality. Advances in Consumer Research, 22(1), 101-108.

Fornell, C., Johnson, M. D., Anderson, E. W., Cha, J., \& Bryant, B. E. (1996). The American customer satisfaction index: Nature, purpose, and findings. Journal of Marketing, 60(4), 7-18. https://doi.org/10.2307/1251898

Fornell, C. (1992). A national customer satisfaction barometer: The Swedish experience. Journal of Marketing, 56(1), 6. https://doi.org/10.2307/1252129

Fornell, C., \& Larcker, D. F. (1981). Evaluating structural equation models with unobservable variables and measurement error. Journal of Marketing Research, 18(1), 39-50. https://doi.org/10.2307/3151312

Gillani, S. U. A., \& Awan, A. G. (2014). Customer loyalty in financial sector: A case study of commercial banks in southern Punjab. International Journal of Accounting and Financial Reporting, 4(2), 587-606. https://doi.org/10.5296/ijafr.v4i2.6870

Hall, A. (2011). Antecedents and outcomes of customer loyalty in the financial services industry (Ph.D.). Available from ProQuest Central. (900575932).

Hallowell, R. (1996). The relationships of customer satisfaction, customer loyalty, and profitability: An empirical study. Int J of Service Industry Mgmt, 7(4), 27-42. /https://doi.org/10.1108/09564239610129931

Heskett, J., Sasser Jr, W. E., \& Schlesinger, L. (1997). The service profit chain. New York: Free Press. 
Heskett, J. L., Jones, T. O., Loveman, G. W., Sasser Jr., W. E., \& Schlesinger, L. A. (2008). Putting the service-profit chain to work. Harvard Business Review, 86(7-8), 118$129+162$.

Hu, H. , Kandampully, J., \& Juwaheer, D. D. (2009). Relationships and impacts of service quality, perceived value, customer satisfaction, and image: An empirical study. Service Industries Journal, 29(2), 111-125. https://doi.org/10.1080/02642060802292932

Jones, T. O., \& Sasser, W. E. (1995). Why satisfied customers defect. Harvard Business Review, 73(6), 88-91.

Jones, M. A., Mothersbaugh, D. L., \& Beatty, S. E. (2000). Switching barriers and repurchase intentions in services. Journal of Retailing, 76(2), 259-274. https://doi.org/10.1016/S0022-4359(00)00024-5

Kaplan, R. S., \& Norton, D. P. (1992, Jan/Feb 1992). The balanced scorecard - measures that drive performance. Harvard Business Review, 70, 71.

Mascarenhas, O. A., Kesavan, R., \& Bernacchi, M. (2006). Lasting customer loyalty: A total customer experience approach. Journal of Consumer Marketing, 23(7), 397-405. https://doi.org/10.1108/07363760610712939

McAlexander, J. H., Kaldenberg, D. O., \& Koenig, H. F. (1994). Service quality measurement. Journal of Health Care Marketing, 14(3), 34-40.

Mithas, S., Krishnan, M., \& Fornell, C. (2005). Why do customer relationship management applications affect customer satisfaction? Journal of Marketing, 69(4), 201-209. https://doi.org/10.1509/jmkg.2005.69.4.201

Mittal, V., \& Kamakura, W. A. (2001). Satisfaction, repurchase intent, and repurchase behavior: Investigating the moderating effect of customer characteristics. Journal of Marketing Research, 38(1), 131-142. https://doi.org/10.1509/jmkr.38.1.131.18832

Oliver, R. L. (1999). Whence consumer loyalty? Journal of Marketing, 63(SUPPL.), 33-44. https://doi.org/10.2307/1252099

Pan, Y., Sheng, S., \& Xie, F. T. (2012). Antecedents of customer loyalty: An empirical synthesis and reexamination. Journal of Retailing and Consumer Services, 19(1), 150158. https://doi.org/10.1016/j.jretconser.2011.11.004

Parasuraman, A., Zeithaml, V. A., \& Berry, L. L. (1985). A conceptual model of service quality and its implications for future research. Journal of Marketing, 49(4), 41-50. https://doi.org/10.2307/1251430

Preacher, K. J., \& Hayes, A. F. (2004). SPSS and SAS procedures for estimating indirect effects in simple mediation models. Behavior Research Methods, Instruments, and Computers, 36, 717-731. https://doi.org/10.3758/BF03206553

Roos, G., \& Roos, J. (1997). Measuring your company's intellectual performance. Long Range Planning, 30(3), 413-426+325. https://doi.org/10.1016/S0024-6301(97)902600

Silvestro, R., \& Cross, S. (2000). Applying the service profit chain in a retail environment: Challenging the "satisfaction mirror". Int J of Service Industry Mgmt, 11(3), 244-268. https://doi.org/10.1108/09564230010340760

Teece, D. J. (2007). Explicating dynamic capabilities: The nature and micro-foundations of (sustainable) enterprise performance. Strategic Management Journal, 28(13), 13191350. https://doi.org/10.1002/smj.640

Wang, C. L., \& Ahmed, P. K. (2007). Dynamic capabilities: A review and research agenda. International Journal of Management Reviews, 9(1), 31-51. https://doi.org/10.1111/j.1468-2370.2007.00201.x

Woodruff, R. B. (1997). Customer value: The next source for competitive advantage? Journal of the Academy of Marketing Science, 25(2), 139-153. https://doi.org/10.1007/BF02894350 
Zeithaml, V. A., Berry, L. L., \& Parasuraman, A. (1996). The behavioral consequences of service quality. Journal of Marketing, 60(2), 31. https://doi.org/10.2307/1251929

\section{Contact information}

Vu Minh Ngo

Tomas Bata University in Zlín, Faculty of Management and Economic

Mostní 5139 - Zlín - Czech Republic.

Phone: +420775204759

ngominhvu@gmail.com

DOI: https://www.doi.org/10.7441/dokbat.2016.43 


\title{
CROSS-CULTURE STUDY FOCUSING ON ARGENTINE, CZECH AND AMERICAN BUSINESS PRACTICES WHAT DIFFERENT MANAGERIAL SKILL-SETS TEACH US
}

\author{
Mariela Farhi-Zimmerman
}

\begin{abstract}
The dissertation compares attendees of Americans, Argentines, and Czechs executives and employees based on the responses taken from a survey of these groups. The paper conclusions are highlighted by case studies involving corporate culture and problem-solving. Goal: How three ethnic groups maintain vary management styles. The goal of the paper is to demonstrate how distinct styles can potentially complement one another. The paper analyzes how groups representing different cultures can work together to make strategic decisions to ramp up sales and improve firms strategic positions.
\end{abstract}

Objectives: To analyze, describe and match particular ethnic groups and to show how cultures and historical contexts affect their business practices.

Research Methods: Qualitative Research methods used to compile this paper included surveys, interviews and case studies. These methods are less structured and more intense than quantitative methods. There is a longer and more flexible relationship with the interviewee, so the resulting data have more depth and richness of context, which also means a greater potential for new knowledge and perspectives.

Sample: Sampling included 10 surveys and 5 interviews for each of the three ethnic groups studied in this project. These primary data has been analyzed, compiled, and summarized. Estimated time for the project: Five months took the researcher to collect the presented information in this paper. Overseas survey often subjects were often unwilling to respond. While resident in the Czech Republic. The author was able to interview a number of respondents from all three countries. A visit to Argentine allowed to interview Czechs and Argentines, and while currently living in the U.S. permitted access to Americans and Argentines.

\section{INTRODUCTION}

The research focuses on managerial styles as perceived by the managers and employees who worked in the Czech Republic, Argentina and United States, and responded to the presented surveys. In 2015 and 2016, the author surveyed these three groups. Conclusions appear below.

\subsection{Brief description on the Americans, Czechs and Argentines business' styles}

Employment is central to the identities of the Americans that were surveyed. They seem more results oriented; view themselves as hard working; and are less desirous of social interaction. Their confidence level is more tied to achievements in the workplace.

The Czechs who responded to my surveys described themselves as cautious on the job. When compared with their American counterparts, they are less inclined to take risks. Most seek stable, long-term employment in large firms, whereas many Americans often aspired to be entrepreneurs or were amenable to changing jobs every two years. As for the Argentines I surveyed, they value relationships. Without trust in their coworkers or supervisors, they refuse to move forward. 
Argentines also value innovation and improvisation. The surveys show their predilection for "lighter" fields of employment, such as design and architecture, in lieu of positions tied to heavy industry. As for the abstract this is a brief summary that will be explained in detailed in the paper, including the potential areas of conflicts when members of these groups interact, and their areas for improvement.

\subsection{Historic and Geographic influence on managerial style}

These differences in managerial style have a basis in the histories and geographies of the respective countries, and the development of their national institutions. For example, from the nineteenth century to the present, the United States leads the world's information/technological. In the U.S., the free market system has fostered a highly innovative and entrepreneurial country that enables small business and large corporations alike to innovate and take risks, continually delivering better products and smarter services. This evolution of creations and patents led the way to the information age of our time. According to the authors D. Acemoglu, D. and Robinson J. (2012) in "Why Nations Fail", between 1820 and 1845, only 19 percent of patent recipients in the United States were either professionals or the offspring of recognizable major landowning families. During the same period, 40 percent of those who obtained patents had only primary schooling or less, including none other than iconic inventor Thomas Edison. Moreover, they often started a firm, to exploit their patents, as Edison did. Just as the United States in the nineteenth century was more democratic politically than almost any other nation in the world at the time, it was also more democratic than others when it came to innovation. This was critical to its path the United States took to become the world's most economically innovative nation.

We can see how national cultural trends apply to the types of industries a country has developed. There is a correlation between the culture of a nation; the most important industries they have; and their macroeconomic performance, as measured by their GDP and Public and Private Investments.

\section{$1.4 \quad$ American G.D.P.}

The American managerial modus values risk taking and entrepreneurships. Services constitute 80 percent of its GDP sector and industry (manufacturing, etc.) 19 percent. Once an agricultural country, this sector now constitutes only 1.2 of the American economy.

\subsection{Case Study - Starbucks and American customer service culture}

This reflects that there is a strong emphasis on customer service and training nationwide, and explains how Starbucks, an iconic café franchise, has become a multi-billion dollar company. Case studies analyzed by Duhigg, C. (2012) in "The Power of Habits" discussed how the firm needed to train its employees to offer a positive atmosphere to its customers, along with lattes and scones. Early in its history, Starbucks researched how it could teach employees to regulate their emotions and marshal their self-discipline to offer service with enthusiasm. The company spent millions of dollars developing curricula about training employees to exercise self-discipline. Executives wrote workbooks that serve as guides to how to make willpower a habit in workers' lives. Those curriculums explain, in part, why Starbucks has grown from a small Seattle company into a global behemoth with more than seventeen thousand stores and revenues totaling over $\$ 10$ billion annually.

$1.6 \quad$ Czech G.D.P. 
On the subject of the Czech Republic's workers and management, the country's GDP industrial sector is distributed along the following: pattern: 39.6 percent represent industries, such as motor vehicles, metallurgy, machinery and equipment; 58.6 percent represent services industries, such as tourism; and agriculture accounts for a mere1.8 percent. Czechs highly value technical and engineering knowledge and appear to think of marketing and sales as a shallow discipline. The Czech Republic, once part of the Austro-Hungarian Empire, was its workshop for heavy industry and machinery, motor vehicles and equipment.

\subsection{Case Study - Pharmaceutical company- Engineering corporate culture}

A case study in Schein's book "Corporate Culture, written about the U.S. company - contains insights from an employee identified by the initials "CG," who asked that his identity be concealed,." Prominent in this work is the conflict between the organization's engineers and marketers. The study shows that to improve marketing skills, CG empowered its U.S subsidiary "Airwick" to purchase a consumer goods subsidiary to learn how to apply sophisticated marketing. The president of the U.S. subsidiary showed what he thought to be a successful advertising campaign: a housewife sprinkling Airwick's Carpet Fresh brand powder on her rugs. A minute later she would be seen vacuuming to illustrate ease of use. That triggered one of the top engineers to comment "You know, those aren't even products!" He opined that he was working for a company producing "important products" that combated starvation (industrial pesticides) and saved lives (pharmaceutical products to cure major diseases), and viewed as undignified working for a firm that made carpet-cleaning products, even though they played a big role in the growth of the company's asset balance sheet.. Strategic thinking is sometimes colored by tacit assumptions about a firm and its mission, with some mistakenly thinking they can separate strategy from culture.

\subsection{Argentine G.D.P.}

Argentine managerial practices, encompassing the third group I researched, show that their principal economic sector is represented by the following percentages: business, social and other services, 35.1\%; manufacturing 14 percent; commerce and tourism, 13 percent; and

agriculture total eight percent. Argentina has a long tradition of agricultural exporter, and also focuses on design, architecture and the arts, which are reflected in its more successful industries.

In order to minimize potential areas of conflicts for each of the three groups surveyed, it is necessary to sense of threat, crisis, or dissatisfaction in a mature system, for things to be unlearned before new things can be learned. The Transformational Process developed by the author Schein in his book "Corporate Culture" will be presented in detailed along the paper, explaining the three stages he highlights.

\subsection{Case Study- Department Stores- Overcoming prejudices}

In a case study by Charles Duhigg about Target, a national American department store similar to Europe's Tesco, presents two different subsets: marketing and science which work together to boost the firm's sales. They proudly and markedly maximized math and marketing tools. Target's marketing team challenged an in-house statistician by asking him if his: "Computers (could) figure our which customers are pregnant, even if they don't want us to know?" In the firm's view, "new parents and pregnant women constituted the most profitable, product-hungry, and price-insensitive market in existence". The statistician's marching orders mandated that he become a mathematical mind reader, deciphering shoppers' habits in order to convince them to increase their spending. Figuring out who was pregnant could earn Target millions of dollars in revenue. 
Target addressed this challenge by creating a "Guest ID:" a Target-brand Visa debit card identifying the user's purchases. The company was able to link about half of all in-store sales, a quarter of all online browsing, and almost all online sales to a specific customer or would-be purchaser. Target's "Mom and Baby" sales grew exponentially from $\$ 44$ billion to $\$ 65$ billion. In 2005, the company's president boasted to investors about Target's "heightened focus on items and categories that appeal to specific segments such as mom and baby.

Culture has a powerful influence on the economic development. Innovation, training and developing psychological safety for change to happen is essential for growing as individuals, as an organization and as a nation.

\section{QUALITATIVE RESEARCH}

\section{Results from Survey:}

This paper contains a summary of the questionnaire and its responses, divided in two groups, modeled after how I conducted the survey. First I will compare the Argentines, versus Americans, followed by Argentines versus Czechs. Afterwards will present the results for Czech managerial procedures versus the American one. At the end, I will present major characteristics of the 3 groups.

\subsection{Describe characteristics of the Argentine the Americans Managerial styles.}

\subsubsection{ARGENTINA (AR)}

Has a more vertical system in which. directors take the decisions most of the time without consultation. In AR, usually the Director is a friend of the company president or owner. Social relationships in AR are more diverse and profound. These are expected and fostered, allowing for an easier social relationship between managers and employees.

Some respondents consider Argentine managers (including Argentines!) to be arrogant, biased, and that achieve results primarily through contacts. Others are seen as selfish though "street smart". Most of the respondents recognize that friendships play a key role.

The system overall is more informal, unstructured, spontaneous, and ambiguous.

\subsubsection{AMERICAN (US)}

Has a more horizontal style. In the US the supervisor versus subordinate hierarchy is absolutely necessary. In the US usually the director is considered the most capable officer available. Social relationships between managers and employees are rare.

Americans consider training to be an important investment with high impact on the employee and firm productivity. Salaries and benefits of the top managers are usually much higher than rank-and-file compensation. If the corporation and manager values subordinate they will try to keep him/her, upgrade the employee, and increase his/her salary. Loyalty it is also very valuable.

Americans tend to find managers focused on profit more than on people; micromanagers; and direct, formal, cold, and professional.

They system is structured, formal with clear roles, and job descriptions.

\subsubsection{Describe three characteristics of employees from each of the groups}

(AR): They experience a more relaxed work environment. Thought some are considered lazy, many are hard workers. They enjoy have relationships with fellow employees. Much of the 
workforce may have more than one job at any one time. Argentines work long hours, , are committed and helpful, and can be very loyal and warm. Punctuality is not common.

They are open to personal relations, can work in unclear environments, used to change, due to political and economical instability; therefore they can improvise and be more adaptive. Reality that can sharpen people's ingenuity and their the problem-solving approach.

(US) American employees take their job more seriously. Provide new ideas. Negotiate salary and benefits constantly. Take the job as career, and pretend to be at the top as soon as possible. They are ambitious and competitive I their jobs. They commit themselves to the corporation though at the same time they don't foresee to stay in the same job as a life-long job. They will change jobs when they find a better opportunity, therefore they could also be more unreliable. They usually maintain a strictly professional relation, being perceived as cold, and work fixed number of hours. " $9 / 5$ ". Though some organizations offer flexible schedules or they are even introducing teleworking. Hard-worker. Tend to be limited to their role. Praise efficiency. Are organized, logical, and result oriented.

Tend to follow orders.

\subsubsection{Which skills or set of skills, the company values the most for an employee to be promoted?}

(AR) Initiative, Innovation, Loyalty. Verbal and social skills. Management skills, communication skills Dedication, and respect by fellow workers. Friendship. Flexible

Loyalty and hard working.

Also, technical skills ascribed to the position to which they are assigned. Years of experience/level of education. In general they said they I believe than management skills are more valuable to be promoted rather than technical skills.

(AR-US) Whereas the Argentine respondents highlighted friendship and people skills, the Americans stressed ability and accomplishments. Knowledge, self-starter, drive/initiative

Both groups said that it depends on company.

\subsubsection{Does the manager have the willingness to accept and ability to manage change?}

While a group said that it happens more in the USA than in Argentina, another group said that managers in the US tend to be more rigid.

Here answers varied from, "not so much," to "yes, absolutely."

\subsubsection{Ability to create a climate of innovation}

(AR) Most of the respondents think innovation is lagging in Argentina., It comes to many corporations years later after it has been tried in the U.S.A. but there are exceptions, such as, agriculture, in which the level of innovation is very high.

Considered important.

In some American industry sectors, such as the software industry, yes it is one of the priorities of the organization. In other type of organizations also new ideas are welcome and encouraged. Innovation is key.

(US) In the US instead, innovation is essential, especially in the technological field. Innovation allows adjustments to the changing markets and keeping up with their profits high. 


\subsubsection{Potential areas of conflicts.}

(AR) Has a more relaxed type of work, a style suggestion work that may need to be done today can be completed at some unspecified point in the future. They share their personal lives so they consider appropriate discussing their personal issues at work.

Uncertainty, when things are not clear, could lead unproductive and inefficient results.

Uncertainty about effort to clarify the problem.

Dealing with informality.

"Cheaters" vs. "abide by the rule"

(US) Given the different characteristics there may be conflict in execution of projects. Trying to find a balance for the US may need to plan and quickness in execution for achievements. For US individuals surveyed, successful performance is expected and is prioritized over relationships.

Some responded that an un friendly environment, which is a common experience in the US, can create social conflicts; jokes at the workplace are not acceptable. "However, I believe one can have fun and be productive."

"Cut and dry" style often find in many managers is seen as not considerate and sensitive by argentines.

\subsubsection{In your opinion, which areas in Argentina and in the American style, need improvement?}

(AR) For the Argentine side: A mid point of the leadership styles would be ideal.

Need for more formality, better planning, willing to follow process. Professionalism

(US) Needs to be: Friendlier. More coaching. Think "outside the box". Warmer with client and more loyal to their managers and colleagues.

\subsection{Argentines \& Czechs}

\subsubsection{Describe characteristics of the Argentines and 4 of the Czech Managerial style.}

2.2.2 (AR) Managerial Style: Are more informal. They improvise and achieve good quality standards. They have a lot of initiative, creativity and attitude of "we can do" many things. Flexibility. Adaptability to change and new demands from the market, and from the clients.

"We look for gray areas, and avoid extremes." "From white to gray you can be reached" we are flexible. "We fight all even before birth" said one interviewer.

The travel agent I interview told me that she has many Russians clients/travelers who book trips at the last minute and can accommodate their needs. In her opinion, a German firm would need much more time in advance to do the same "on the fly."

2.2.3 (CZ) Managerial Style: Formal, concise. Resolve personnel problems without participating the employee. Prefer to avoid making hard decisions, or take risks. Preferable method is to follow procedures.

Few Czechs are studying MBAs in the US or UK and are not in key or directive positions in the corporation located in their country. The foreign corporation in the Czech Republic sends $80 \%$ of their profits to their headquarters. The situation in Argentina is similar.

\subsubsection{Employees:}


(CZ) Productive, formal, more controlled. At times uneasy about innovating or proposing new ideas. They prefer to follow orders rather than be proactive. Need to follow manuals such as "1 to $10 "$ make it perfect, but it is hard if the number 11 comes up. Hard to adapt.

While Argentines are better at improvising.

Czechs need to better understand customer service as a concept. The AR manager of an international hotel chain in Prague said that if the customer pays 800 euros and wants a room with a scenic view, the employee who assigns quarters has to do whatever is necessary to give the client the room s/he desires, and not to expect that person to pay anything additional. The manager insists and says: "You need to satisfy the client," explaining that the room costs only 100 euros and since they charge 800 euros, there is 700 euros for profit for the hotel.

This individual supervises 25 employees and states that The important thing in an employees is the attitude. Technical things always can be taught. The attitude comes from within. He values a positive attitude, the desire to help others, and have driven-energy.

Also Czechs are seen as educated, that have sense of self and community, streets are clean and usually tide. Thanks to Prague's outstanding public transportation system, Czech employees are expected to be punctual, whereas Argentines who work in their country's capital, Buenos Aires, can expect leeway, owing to the chaotic conditions of their daily commute to work.

The survey showed Czech employees receive less training when compared to their American and Argentine counterparts.

Leaders in the hotel industry say they prefer, exhibited by Argentines and other Latins. For this reason, they employ more managers of Latin heritage in the Four Seasons Hotel Chain.

Sometimes there is miscommunication because Latinos do not pass the information the way the Czech would expect, that engenders a conflict. Czechs expect language to follow a linear structure, whereas the Argentinean may be cyclical, going back and forth in time. AR.. The Czechs have difficulty understanding, seeing that style as disorganized. Takes more time to be understood, and then conflict grow bigger.

\subsection{Czech compare to Americans}

\subsubsection{Describe characteristics of the Czechs and 4 of the Americans Managerial style.}

2.3.2 (CZ) Technical knowledge. Hierarchy and bossy. Less formal in communication. Less strict. diplomacy, non-conflict, high-risk aversion, flexibility. Less politically correct. Less rely on rules often more bureaucratic and implicit, an element left over from the old days. Everything must be stamped. Hence, a simple decision will be considered by lower managers for a long time before they have collected enough consensuses and properly prepared it for senior review.

Czechs respect titles, age, and experience too. A manager should have all of these things in greater supply than his/her employees. This creates stratification; ensuring qualified individuals with institutional endurance hold leadership positions.

Rewarding the young, energetic employees who have new ideas is still novel. Young employees are quickly molded into the normal Czech management style through extra criticism until respect for their opinions is earned over a long period.

Czech managers protect their territory in the company by controlling knowledge about their department's operations. 
2.3.3 (US) Transparency, Collaborative and at the same time aggressive

Planning a priority, Feedback very important. Energetic. Rules maters, more formal.

Political correction, not as close relations

Deeper HR evaluations by standards, less day-to-day emotional interaction

Friendship matters less.

Initiatives focused with long term objectives set by upper management, and short-term goals established by the department teams closer to the task. Everyone expects the lowest level workers to at least be sampled before decisions are made.

American managers often have an up-or-out attitude, and assume people not promoting or improving their function are non-starters and a drag on progress.

American managers often respect employee independence and encourage confident decision makers a level beneath theirs.

\subsubsection{Describe three characteristics of employees from each of the groups}

(CZ) Non-conflict, flexibility, putting own interest above that of the company. Recommendations matters. Free time matters. Hard-worker.

(US) Result oriented, hard working, lower level of diplomacy and social intelligence.

Resume and qualifications matters. Not mixing private and work relations. Career oriented

Not associated with place and people

Openly discuss issues with managers. Issues must be brought to the forefront sooner or later. The sooner it is discussed, the better. This can lead to incompatibility between manager and employee, causing the manger to change styles, or the employee to leave. Employees expect to be consulted for changes, and if not, they will not 'buy in' to a change initiative. American employees also expect incremental rewards for there better than expected contributions. Incentives are a great topic of debate, and discovering who was rewarded more without a real impact to the company is the target irony.

The individual takes the glory. Employees want to invent something new and better. Sometimes this can improve things, and other times it can over engineer and lead to set in stone processes hard to functionally change later.

\subsubsection{Which skills or set of skills, the company values the most for an employee to be promoted?}

(CZ) Mainly (Technical skills. "They excel in those skills."

(US) Managerial skills, communication, collaboration.

Skills demanded are the same for both groups, but approach to achieve them may differ. Training in Czech is more seen as an opportunity for team building, Czechs don't care too much about the certificates and don't like to evaluate trainings.

\subsubsection{Does the manager has the willingness to accept and ability to manage change?}

(CZ) It depends on who is the boss, if he is the same nationality as his boss, its easier, if Czech people don't like the change, it take longer to implement, but ones it is implemented and they get used to it they realize the benefit of it. 
Will manage change if his/her superiors have confirmed the ability to do so at that level. Responsibility will lay solely with this manager at first, so the stakes are high and are often deflected to a subordinate if possible.

(US) Most accept the ability to manage change and understand it is part of their implicit or explicit job description. Sometimes faking innovative spirit is the way for a non-starter to survive.

\subsubsection{Ability to create a climate of innovation}

(CZ) Czech people don't like systems to achieve evaluation, they like informal communication with their boss, motivation by common goal etc.

(US) Innovation is essential. Employees are expected to propose new ideas and new procedures.

\subsubsection{Potential areas on conflicts.}

(CZ) When job needs to be done American employee stays at work till $4 \mathrm{am}$, Czechs want to go home at $6 \mathrm{pm}$ at the latest

In your opinion, which areas in the American and in the Czech style need improvement?

Not understanding what is important for each group. Different accents and priorities. Different understanding of goals, private-business interference. Czechs are not as proud of their country; use more politically incorrect humor and way to interact.

One of the respondents said: Having worked under the Czech style as an American, and also seeing Americans in charge of Czechs, I hope I can provide some good advice.

American Managers to Czech Employees - The American managers leave the Czechs with decision autonomy and it leads to process stagnation. The Czechs want directed initiatives to innovate beneath, and the Americans want bottom up advice. Also, if the American managers request a special deliverable, the Czechs over deliver. Additionally, Americans will be surprised that someone will hold a position for a long period of time and come to assume that this is just part of Czech bureaucracy. The American ideal of promoting the new and smart ideas languishes in order to respect Czech business culture. After all, the Czech bosses will make sure to be the only ones to actually deal with the Americans. It is manageable, but with pitfalls to avoid. Hiring a younger staff from the start can help to avert many adverse norms."

Czech Manager to American Employees. Americans believe in bottom up innovation, while Czechs focus on the opposite. Americans also do not believe in formal stratifications between business groups and between managers/employees, so the silent Czech formalities are hard to navigate. For the American employee, the Czech manager will seem micromanaging and change averse. The American will also try to pragmatically approach problems assuming processes and outcomes, while the Czech manager will have to play damage control as other business units complain directly to management rather than being overt with the American employee from the start.

\subsubsection{In your opinion, which areas in the Czech and in the American style need improvement?}

In brief, for (CZ) more risk-taken attitude, and for (US) more social skills. 
Czechs have to know how to accept the rules for the company profit and lessened informal style. At the same time they have to keep their intuition and personal experience.

Americans have to be less formal and listen the people's needs and not solve problems for Czechs. The often more strict hierarchies need to level more and job descriptions be written more loosely to promote less risk aversion. Could worked as a motivation to encourage risktaking that employees could be fired if they avoid too much any innovation, decision making or risk taking. Turnover in the Czech Republic is hard to orchestrate due to legal protection of employees though.

Americans need to work more collaboratively instead of focusing on the 'baby boomer' ideal of the strong, iconic individualist. The individualistic approach can lead to small changes, but in many divergent directions, or large changes in one direction. Instead a holistic, integrative, collaborative approach has a longer spam impact and becomes more sustainable.

\section{SURVEY RESULTS}

The author surveyed employees and managers from the Czech Republic; the United States; and Argentina. Of these, the majority were nationals of one of these three countries and was either working in one of the other countries indicated here, or worked for organizations in which nationalities other than their own predominated. The survey suggested that those queried had expectations that could be placed into three categories: those who are: a) results oriented; b) analytical; or c) foster business success through relationship-building.

3.1 Generalizations in order to come up a group typology.

\begin{tabular}{|c|c|c|c|}
\hline & American (AM) & Argentina (AR) & Czech (CZ) \\
\hline \multirow[t]{4}{*}{ American } & $\begin{array}{l}\text { AMs about AMs. 1- } \\
\text { Management style: } \\
\text { Organized, logical and } \\
\text { result-oriented. } \\
\text { Transparency and } \\
\text { allocating priorities. } \\
\text { Taking feedback, whether } \\
\text { positive or negative. } \\
\text { Forced Relationships, } \\
\text { Commitment and } \\
\text { competency. Risk takers } \\
\text { and aggressive. } \\
\text { Invest in training. }\end{array}$ & $\begin{array}{l}\text { ARs thinking of AMs. } \\
\text { Committed. Smart. Goal- } \\
\text { driven, aggressive, } \\
\text { accountable. Limited to } \\
\text { their role. Structured. }\end{array}$ & $\begin{array}{l}\text { CZs thinking about AMs } \\
\text { Simultaneously } \\
\text { collaborative } \\
\text { aggressive. Rules matter. } \\
\text { Formal. } \\
\text { Politically correct. HR } \\
\text { evaluations by standards. } \\
\text { Less day-to-day emotional } \\
\text { interaction. Friendship less } \\
\text { key. }\end{array}$ \\
\hline & $\begin{array}{l}\text { 2- Skills most valued: The } \\
\text { appearance of hard work } \\
\text { and motivation to succeed. }\end{array}$ & $\begin{array}{l}\text { 2- Skills most valued: } \\
\text { Effectiveness, Innovation, } \\
\text { self-promotion. }\end{array}$ & $\begin{array}{l}\text { 2- Skills most valued: For } \\
\text { Americans, getting the job } \\
\text { done is important, even if } \\
\text { they have to work extra } \\
\text { hours. }\end{array}$ \\
\hline & $\begin{array}{lrl}3- & \text { Areas } & \text { from } \\
\text { improvement: } & \end{array}$ & $\begin{array}{lrl}3- & \text { Areas } & \text { from } \\
\text { improvement: } & \end{array}$ & $\begin{array}{lll}3- & \text { Areas } & \text { from } \\
\text { improvement: } & \end{array}$ \\
\hline & $\begin{array}{l}\text { Need to work more } \\
\text { collaboratively instead of } \\
\text { seeking for the ultimately }\end{array}$ & $\begin{array}{l}\text { More flexible. Think } \\
\text { outside of the box. }\end{array}$ & $\begin{array}{l}\text { More coaching over } \\
\text { decision } \\
\text { throughout the work in }\end{array}$ \\
\hline
\end{tabular}




\begin{tabular}{|c|c|c|c|}
\hline & $\begin{array}{l}\text { individual recognition. } \\
\text { Enhance personal } \\
\text { relationships at work. }\end{array}$ & Coaching. More friendly. & $\begin{array}{l}\text { progress. More directives } \\
\text { procedures on how to } \\
\text { innovate or accomplish a } \\
\text { new/different task. } \\
\text { Allocate more time for } \\
\text { research and analysis each } \\
\text { phase of a project. }\end{array}$ \\
\hline \multirow[t]{3}{*}{ Argentina } & $\begin{array}{l}\text { 1- Management style: } \\
\text { AM about AR: } \\
\text { Creative, unstructured, } \\
\text { unpunctual. Not } \\
\text { compliance with deadlines, } \\
\text { though hard-workers. }\end{array}$ & $\begin{array}{l}\text { Creative, hard-working, } \\
\text { unorganized. } \\
\text { Unstructured, Informal. } \\
\text { Flexible, easily adaptable } \\
\text { to changes and crises. } \\
\text { Friendship and personal } \\
\text { relations play a key role. } \\
\text { Resilient. Sometimes } \\
\text { corrupt. }\end{array}$ & $\begin{array}{l}\text { CZs on ARs: } \\
\text { Informal, creative, adaptive, } \\
\text { unpunctual and relations } \\
\text { oriented. }\end{array}$ \\
\hline & $\begin{array}{l}\text { 2- Skills most valued: } \\
\text { Peoples's skills, capacity } \\
\text { to build long-lasting } \\
\text { relationships. } \\
\text { Communication skills. } \\
\text { Creativity, capacity to find } \\
\text { solutions within crises or } \\
\text { new situations. Good at } \\
\text { improvising. }\end{array}$ & $\begin{array}{l}\text { 2- Knowledge, self-starter, } \\
\text { drive, initiative. }\end{array}$ & $\begin{array}{l}\text { Intellectual and artistic and } \\
\text { communication skills. } \\
\text { Adaptability and creativity. }\end{array}$ \\
\hline & $\begin{array}{l}\text { 3- Areas for improvement: } \\
\text { More structured, more } \\
\text { planning. More committed } \\
\text { to deadlines. Less } \\
\text { emotions and chatting at } \\
\text { work. }\end{array}$ & $\begin{array}{l}\text { 3- Areas for } \\
\text { improvement: } \\
\text { Follow process, better } \\
\text { planning, drive } \\
\text { efficiencies. Formality. }\end{array}$ & $\begin{array}{l}\text { 3-Areas for improvement: } \\
\text { More formal. More planning } \\
\text { and specific steps for each } \\
\text { phase of the project or work. } \\
\text { More lineal thinking and } \\
\text { communication skills. }\end{array}$ \\
\hline \multirow[t]{3}{*}{ Czech } & $\begin{array}{l}\text { AM about Czech } \\
\text { Formal, hierarchical. } \\
\text { Prefer to avoid making } \\
\text { hard decisions. }\end{array}$ & $\begin{array}{l}\text { AR about Czech } \\
\text { Higher positions gained by } \\
\text { good contacts. }\end{array}$ & $\begin{array}{l}\text { Good at technical skills. } \\
\text { Analytical. Process and } \\
\text { research oriented. Formal } \\
\text { and hierarchical. Detail- } \\
\text { oriented. } \\
\text { Risk avoidance. }\end{array}$ \\
\hline & $\begin{array}{l}\text { 2- Skills most valued: } \\
\text { Technical skills. Hard- } \\
\text { working. Loyalty. }\end{array}$ & $\begin{array}{l}\text { 2- Skills most valued: } \\
\text { Technical skills. Follow } \\
\text { procedures and manuals. }\end{array}$ & $\begin{array}{l}\text { 2- Skills most valued: } \\
\text { Technical and analytical } \\
\text { skills. }\end{array}$ \\
\hline & $\begin{array}{l}\text { 3-Areas for improvement: } \\
\text { Risk-taking, autonomy to } \\
\text { make decisions; initiative } \\
\text { to innovate and find new or } \\
\text { different processes or } \\
\text { solutions. }\end{array}$ & $\begin{array}{lr}\text { 3- } \quad \text { Areas } & \text { for } \\
\text { improvement: } & \\
\text { Risk-taking. } & \text { More } \\
\text { flexibility. } & \text { Improve } \\
\text { customer service concept. }\end{array}$ & $\begin{array}{l}\text { 3-Areas for improvement: } \\
\text { More risk-taken. Better } \\
\text { advocate for oneself. }\end{array}$ \\
\hline
\end{tabular}


3.2 American managers, in general, could be associated with the "Results oriented" with the main following traits: they are directive and outcome oriented with quickest route to a desirable result. They are persuasive; organizing people and resources to accomplish organization goals. May over-burden individuals or reduce research time in pursuit of results. Generally competitive, sometimes they have a big picture vision overlooking details and possibly others. Ambitious, energetic, igniters, risk takers and could be impatient.

\subsubsection{Suggestions to avoid problems with the result-oriented type:}

Need to state achievement and action. Avoid the process and be brief, conversation may be made standing up or walking with them. They may make a snap decision based on your content, then course-correct later. Stay on issue. Depersonalized and be task centered.

3.3 Czech managers, in general, could be associated with the "Analytical type" who has the following traits: Procedural and concerned about processes, fairness, and order. They may prioritize standards, focus on accuracy and thoroughness, and recognize inconsistencies. They are "by the book" and may experience analysis paralysis, thinking through details. They are calm, organized, detail-oriented, and methodical; create order out of chaos, like structure, process in writing and consistent. Avoid risk, practical, cautious, stubborn, content-based and process in writing.

\subsubsection{Suggestions to avoid problems with the analytical-oriented type:}

Avoid emotions, no tangents allowed - only orderly, correct, detailed, structured. Be precise, concise, use bullet points, organized thoughts $\mathrm{A}$ to $\mathrm{Z}$ with an end result.

Come fully prepared with well-thought-out plans and supporting data in writing

Be patient as they process all the data to make a decision. Allow mental and/or physical distance. Focus on the issue and facts and diminish emotion. Give specific reasons and solutions.

3.4 The Argentinian managers, in general can be associated with the "relationship type" people, that has the following traits:

Supportive with heartfelt concern for the people they lead and willing to bend a rule for better morale. They feel that a positive, nurturing work environment will ultimately lead to better results. They value relationships, trust, harmony, devotion, loyalty, and avoid conflict. Good Listeners, team builder, talkative, pushover, emotional, feelings over tasks, process.

\subsubsection{Suggestions to avoid problems with the relationship-oriented type:}

Use social pleasantries before discussing issues, because they are process oriented. Show how your idea would benefit the people involved in it - let them know that you have solicited input from those involved and affected. Be sincere, don't patronize.

Relationships are key factors - let them know who else is on board with your idea.

\subsection{Is one style better than other?}


The answer is negative. Ideally is to apply an integrative approach, a balance approach that encompasses the three different styles, where negotiation is a key part of the process, so as to be open to options and stay flexible.

This approach is concerned about incorporating input from multiple sources to produce a result acceptable to all parties. They are not mainly result-oriented but also process-oriented and understanding about other people's needs. They value social skills and are good mediators. Collect data from all sides and consider how it will affect others, the organization, people, bottom line and results.

\subsection{Integrative approach}

Acknowledging the differences in managerial strategies can let us know their different perspectives and therefore anticipate their behavior. We can try to prevent a conflict by demonstrating understanding and expected behavior. In this case we would be managing ourselves and the relationship we are involved in. Then, we can move forward to a resolution. The integrative approach goes together with the compromising approach presented by the respected Thomas and Kilmann Conflict Management Mode..

\section{Ken Thomas-Ralph Kilmann Conflict Management Model}

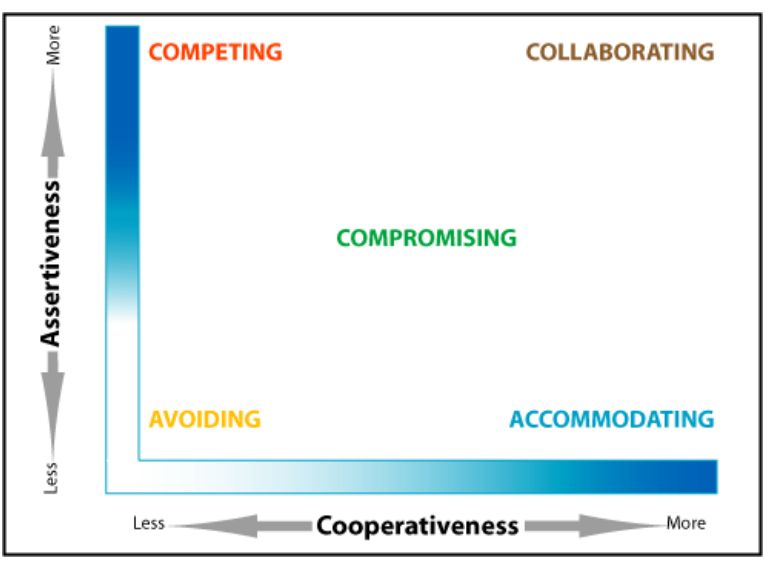

This "more integrative approach", the one guided by compromising our opinion with others, the one that includes results, process and emotions is aligned with the latest discoveries by the Google company on how to create the best team, "What Google Learned From Its Quest to Build the Perfect Team", the article was written by Charles Duhigg. Google's data indicated that psychological safety, more than anything else, was critical to making a teamwork.

\section{Case Study- Integrative approach}

The research was named: "Project Aristotle". For Project Aristotle, research on psychological safety pointed to particular norms that are vital to success. There were other behaviors that seemed important as well, like making sure teams had clear goals and creating a culture of dependability.

What Project Aristotle has taught people within Google is that no one wants to put on a "work face" when they get to the office. "No one wants to leave part of their personality and inner life at home. But to be fully present at work, to feel "psychologically safe," we must know that we can be free enough, sometimes, to share the things that scare us without fear of 
recriminations. "We must be able to talk about what is messy or sad, to have hard conversations with colleagues who are driving us crazy. We can't be focused just on efficiency. Rather, when we start the morning by collaborating with a team of engineers and then send emails to our marketing colleagues and then jump on a conference call, we want to know that those people really hear us. We want to know that work is more than just labor."

Five years ago, Google — one of the most public proselytizers of how studying workers can transform productivity - became focused on building the perfect team. In the last decade, the tech giant has spent untold millions of dollars measuring nearly every aspect of its employees' lives. Google's People Operations department has scrutinized everything from how frequently particular people eat together (the most productive employees tend to build larger networks by rotating dining companions) to which traits the best managers share (unsurprisingly, good communication and avoiding micromanaging is critical; more shocking, this was news to many Google managers).

Project Aristotle's researchers began by reviewing a half-century of academic studies looking at how teams worked. Were the best teams made up of people with similar interests? Or did it matter more whether everyone was motivated by the same kinds of rewards? Based on those studies, the researchers scrutinized the composition of groups inside Google.

Project Aristotle is a reminder that when companies try to optimize everything, it's sometimes easy to forget that success is often built on experiences - like emotional interactions and complicated conversations and discussions of who we want to be and how our teammates make us feel — that can't really be optimized.

\section{Strengthening nations opportunities and learning from other nations.}

It is important to find common grounds among employees and managers, and between different nations.

Transportation is a promising industry in which Czechs lead. They have an expansive, highquality, integrated public transportation that can inspire Americans and all nations within the "New world". In fact, in Washington DC, the U.S. Top Universities are offering Ph.D. programs in transportation planning. The metro system is expanding and the city of Washington bought from a Czech company streetcars back in 2009 that are just now starting to function in D.C. area. Ms. Hamre, an American student claimed that after traveling to Europe she was inspired to study transportation planning and improve America's public transit.

Argentines had been updating their subway system recently, buying cars from China. Acknowledging that a modern transportation system is key for better quality of life and better business transactions. They could also benefit from the Czech know-how and expertise in the field.

On the other side, Czechs want to attract more software companies to their Moravian-Silesian Region, such as the IT company Tieto, originally from Finland and Sweden. Now, the Czech's operation is the largest brand in the world, with more than 1,900 employees in the Czech Republic and in Moravia-Silesia. The region could also attract more American and South American software companies.

Argentina, on her side, has a highly competitive and well-consolidated food industry. Sector growth in Argentina is driven by innovative developments and the implementation of new 
technologies. The country is a leader producer and exporter of foodstuff because of the vast expanse of fertile land and the application of biotechnology.

Each county has to "sell" their products, services and sharpen their managerial and negotiation skills to maximize benefits and achieve win-win deals. Therefore, knowing "owns" culture first and then the business negotiator culture, can paved the way to success.

\subsection{Nation Branding}

The U.S. had been the biggest marketer of their nations brand. In fact, International brand consultancy Interbrand and Business Week publish an annual report on the world's top 100 brands, and America dominates the table every year, producing ten times more billion-dollar brands than any other country. Out of the most valuable global brands, 64 are American owned.

Today, commercial practices influences many other areas of life, so the American inspired commercial models have a very broad impact. In fact, the idea of nation branding itself, which stems from a very American mixture of marketing, politics and international relations, is a good example of this.

\subsubsection{The Hexagon Model}

Most countries send out messages about themselves most of the time, via a "hexagon" of communication channels and actions and behaviors and it's the cumulative effect of these which, over the years, creates their brands.

The points of the Hexagon

1-Tourism, 2- Export Brands, 3- People, 4- Foreign and domestic policy, 5- Culture and heritage, and 6- Investment and immigration.

- Country's tourism promotion, and people's experience of visiting the country as tourists or business travellers.

- Country's exports, which are powerful ambassadors of the country's image abroad.

- Policy decisions of the country's government, traditionally communicated through diplomatic channels.

- To business audiences, the way the country attracts inward investment, foreign talent and foreign companies.

- Country's cultural activities and exports: a world tour by a national opera company, the works of a famous author, the national sports team.

- People of the country: high-profile leaders, media, sports stars and general population.

Strengthening the six points of the model, can lead to a powerful and positive national brand that benefits exporters, importers, government, the culture sector, tourism, immigration and pretty much every aspect of international relations.

\subsubsection{In synthesis, Culture-The soft power that turns into high, tangible results.}

Joseph Nye, a political scientist and dean of Harvard University's Kennedy School of Government, draws a distinction between the "soft" and "hard" powers of nations. The second one, concept is self-explanatory while the soft power can be attained only through the exercise of cultural, intellectual or spiritual influence. Soft power is making people want to do what you want them to do, which is fundamental to the idea of branding, and fundamental to the idea of America. 


\section{CONCLUSIONS}

\subsection{From the macro-perspective}

American Economy: The service sector is the largest component of the American economy. The United States has established itself as a world leader in telecommunications, financial services, and information technology or IT (computer-based information systems and communications). The growth of IT has propelled the "new economy" of the United States, based less on manufacturing and more on information products and services. In fact, Services employ 77 percent of American workers

Czech Economy: In contrast, industry and external sector have been the traditional engines of Czech growth. Proximity to west European markets and strong competitiveness facilitated a rapid rise in export capacity. Exports now comprise more than $80 \%$ of GDP.

Under communism, industry was the priority sector and service-oriented industries were neglected; heavy industry's share of output was larger than that in developed capitalist economies.

Argentine Economy: Argentina, on her side, had been traditionally an agriculture country, major exports are cereals, animal feed, motor vehicles (trucks, buses, and tractors), crude petroleum, steel, and manufactured goods. In the last decades it had been sharpening its skills domestic appliances, printing, electronics, medical equipment, cars and utility vehicles, furniture, chemicals and petrochemicals.

\subsection{Historical Influence}

Among these three countries, the only one who was affected by a communist regime, was the Czech Republic, as macroeconomic figures had been showing the industrial, heavy industry had high numbers, whereas consumer goods and services where low. Very different from the U.S. and Argentina economic components. This reflects that historical trends have a profound impact in the development of the country, in the macroeconomic and microeconomic measures.

\subsection{Culture impacts microeconomic development which influences macroeconomic growth.}

The analysis and research of this paper, enable us to understand values, perceptions and behaviors from the three different cultures presented, so as to cross bridges and build better agreements and achieve better deals within a more profound understanding. Case studies, such as the Target hypermarket implementing statistician, mathematical formulas for maximizing their sales and capturing and predicting their clients' needs and aspirations; so as the Starbucks training courses for strengthening will-power among their workforce enabling them to provide better customer services are inspirational ideas. Combining top scientist, such as mathematicians with sales, is a good idea that the engineering department in some of the Czech firms can keep in mind so as to bring marketers and make the promotion of the company a challenging and dignifying endeavor.

\subsection{Analogy between a palette of colors and cultural traits}


There can be an analogy between a palette of colors, the board painters use to hold and mix their colors to create a painting, and the different cultural traits that managers and employees appeal to to accomplish a project. The artist choose colors based on what he/she wants to communicate, an d open blues sky or deep ocean; the manager can also "choose" among different managerial practices. The artist can be subject to an artistic movement, therefore will be more incline for one type of colors, tones over others. The manager, and employee is more influenced by his/hers history and her nations common practice that had been embedded in the persons' mindset.

By extension, it sometimes denotes the range of colors used in a design or work of art. The combination of different cultural traits By acknowledging our own preconceptions and the ones of our counterparts or business partners, by putting them on the surface, as real , tangible practices, we can be more conscious about them, and then decide more freely which would be the best path to take, the best "combination of colors" for achieving certain goal, or certain project.

\section{References}

Acemoglu, D. and Robinson, J. (2012). Why Nations Fail: The origins of power, prosperity, and poverty. 1ed. London. Profile Books Ltd. $2^{\text {nd }}$. New York, NY. Crown Business. (33/34) https://doi.org/10.1355/ae29-2j

Duhigg, C. (2016). Group Study. Project Aristotle. New York. New York Magazine.

Duhigg, C. (2012). The Power of Habit. Why we do what we do in life and in business. New York, NY. Random House LLC. Chapter 5: Starbucks and the habit for success; Chapter 7: How Target Knows What You Want Before You Do. (182/214).

Food Industry in Argentina. Argentine Agrifood Promotion for Export Projects (PROARGEX) Retrieved from www.proargex.gob.ar

Kratochvilova, L. (1/2013) Moravia-Silesia: Time Proven traditions and brand new opportunities. Czech Focus. The magazine of the Association for Foreign Investment and CzechInvest. (p.15). Retrieved from http://www.tradingeconomics.com

Schein, E. H. (1999). The Corporate Culture. Survival Guide. San Francisco (CA). Jossey Bass Books.. Chapter 3: What is Corporate Culture Built On. (27/58).

Thomas, K., Kilmann, R. Retrieved from: www.kilmanndiagnostics.com

"You Will Make Tracks on This Path" (03/14/2016) Express Newspaper. Washington D.C. Retrieved from: https://issuu.com/expressnightout/docs/express_03142016

\section{Contact information}

Mariela Farhi-Zimmerman

International Management and Relations

University of Economics, VSE, Prague

DOI: https://www.doi.org/10.7441/dokbat.2016.44 


\section{Contact information DOKBAT 2016:}

Martin Horák

Tomas Bata University in Zlín

Faculty of Management and Economics

Mostní 5139, 76001 Zlín

Telephone number: 728483184

E-mail:mhorak@fame.utb.cz

\section{Conference proceedings}

DOKBAT 2016 - 12th International Conference for Ph.D. Students and Young Researchers

Edited by: Ing. Markéta Slováková, Ing. Lukáš Danko

Published by: Tomas Bata University in Zlín, Faculty of Management and Economics

1st edition

2016

Cover by: Ing. Tomáš Janů

Published electronically

The conference proceedings have not undergone language correction.

ISBN: 978-80-7454-592-4

DOI: 10.7441/dokbat.2016 